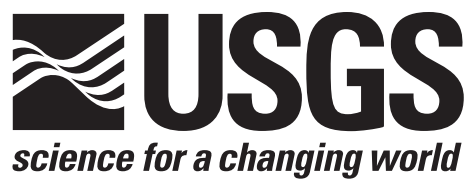

\title{
Public Review Draft: A Method for Assessing Carbon Stocks, Carbon Sequestration, and Greenhouse-Gas Fluxes in Ecosystems of the United States Under Present Conditions and Future Scenarios
}

By Zhiliang Zhu (editor), Brian Bergamaschi, Richard Bernknopf, David Clow, Dennis Dye, Stephen Faulkner, William Forney, Robert Gleason, Todd Hawbaker, Jinxun Liu, Shuguang Liu, Stephen Prisley, Bradley Reed, Matthew Reeves, Matthew Rollins, Benjamin Sleeter, Terry Sohl, Sarah Stackpoole, Stephen Stehman, Robert Striegl, Anne Wein, and Zhiliang Zhu

Open-File Report 2010-1144 


\section{U.S. Department of the Interior \\ KEN SALAZAR, Secretary \\ U.S. Geological Survey \\ Marcia K. McNutt, Director}

\section{U.S. Geological Survey, Reston, Virginia: 2010}

For more information on the USGS - the Federal source for science about the Earth, its natural and living resources, natural hazards, and the environment, visit http://www.usgs.gov or call 1-888-ASK-USGS

For an overview of USGS information products, including maps, imagery, and publications, visit http://www.usgs.gov/pubprod

To order this and other USGS information products, visit http://store.usgs.gov

Any use of trade, product, or firm names is for descriptive purposes only and does not imply endorsement by the U.S. Government.

Although this report is in the public domain, permission must be secured from the individual copyright owners to reproduce any copyrighted materials contained within this report.

Suggested citation:

Zhu, Zhiliang, ed., Bergamaschi, Brian, Bernknopf, Richard, Clow, David, Dye, Dennis, Faulkner, Stephen, Forney, William, Gleason, Robert, Hawbaker, Todd, Liu, Jinxun, Liu, Shuguang, Prisley, Stephen, Reed, Bradley, Reeves, Matthew, Rollins, Matthew, Sleeter, Benjamin, Sohl, Terry, Stackpoole, Sarah, Stehman, Stephen, Striegl, Robert, Wein, Anne, and Zhu, Zhiliang, 2010, Public review draft; A method for assessing carbon stocks, carbon sequestration, and greenhouse-gas fluxes in ecosystems of the United States under present conditions and future scenarios: U.S. Geological Survey Open-File Report 2010-1144, 195 p., available online at http://pubs.usgs.gov/of/2010/1144/ 


\section{Acknowledgments}

The authors express their gratitude towards the following individuals for their invaluable contributions to this manuscript: Members of an interagency science panel (Richard Birdsey, U.S. Forest Service (USFS); Jennifer Jenkins, U.S. Environmental Protection Agency (EPA); Linda Langner, USFS; Thomas Loveland, U.S. Geological Survey (USGS); David McGuire, USGS; Tilden Meyers, National Oceanic and Atmospheric Administration; Ramakrishna Nemani, National Aeronautics and Space Administration; Donald Reicosky, U.S. Department of Agriculture (USDA) Agricultural Research Service; Benjamin Simon, U.S. Department of the Interior; and Susan Southard, USDA, Natural Resources Conservation Service) for their technical and science guidance; Eric Sundquist, Jennifer Harden and Stephen Perakis, all of the U.S. Geological Survey, for their review and coordination; and the twelve peer reviewers (Sandra Brown, Winrock International; Richard Conant, Colorado State University; John Downing, Iowa State University; Thomas Huntington, USGS; Robert Keane, USFS; James McClelland, University of Texas at Austin; Karen Murphy, U.S. Fish and Wildlife Service; Emilio Mayorga, University of Washington; Sarah Bushey Ohrel, U.S. Environmental Protection Agency; David Schimel, National Ecological Observatory Network; Bill Sommers, George Mason University; and Michael Wimberly, South Dakota State University) for their careful, constructive, and critical reviews. June Thormodsgard (USGS) and Beatrice Van Horne (USFS, formerly with USGS) were instrumental in leading communication with our Federal partners and providing technical advice, as well as leading coordination of science support. The authors especially thank William Werkheiser of the USGS for his active leadership in guiding the overall methodology development process. 


\section{Contents}

Acknowledgments ....................................................................................................................ii

Energy Independence and Security Act of 2007 .......................................................................

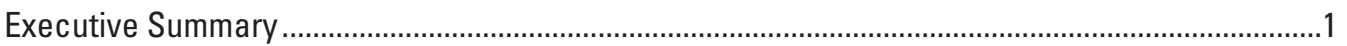

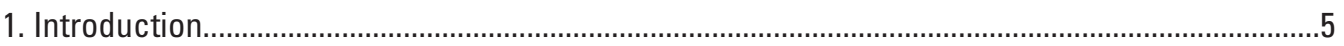

1.1. Requirements of Section 712 of the Energy Independence and Security Act

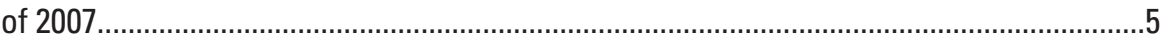

1.2. Understanding the Concepts and Requirements of the Energy Independence

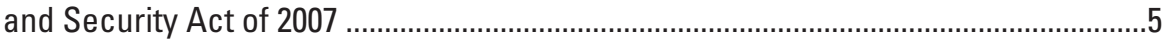

1.2.1. Assessment.

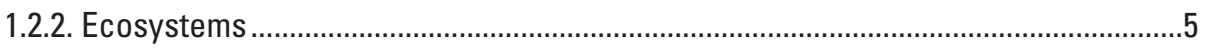

1.2.3. Adaptation and Mitigation Strategies ...............................................................

1.2.4. Carbon-Sequestration Capacity ......................................................................

1.2.5. Processes That Control the Flux of Covered Greenhouse Gases.............................

1.2.6. Management Activities and Restoration Activities .................................................6

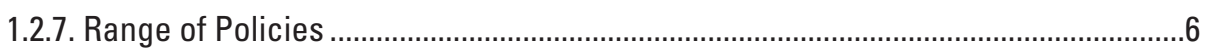

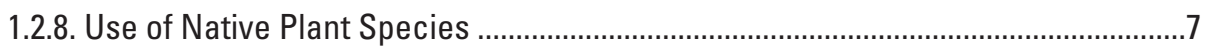

1.2.9. Measuring, Monitoring, and Quantifying ............................................................

1.2.10. Use of Economic and Other Systems Models, Analyses, and Estimates ...............7

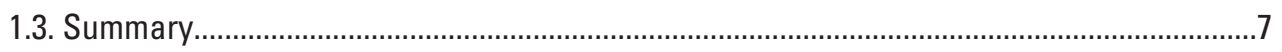

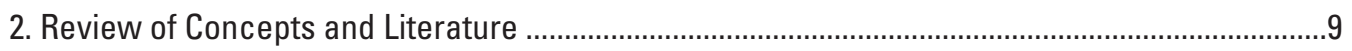

2.1. Major Carbon-Cycle Processes and Pools ....................................................................

2.2. Current Knowledge of the Carbon Cycle and Greenhouse-Gas Fluxes in the

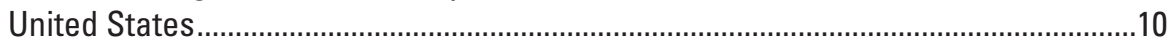

2.3. Effects of Major Controlling Processes .........................................................................13

2.3.1. Effects of Land-Use and Land-Cover Change and Land-Management

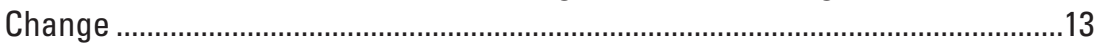

2.3.2. Effects of Ecosystem Disturbances ......................................................................14

2.3.3. Effects of Climate Change, Elevated Carbon Dioxide, and Nitrogen

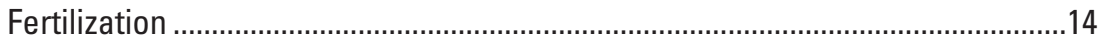

2.4. Carbon Sequestration and Ecosystem Services .......................................................15

2.5. Ongoing Global and National Carbon and Greenhouse-Gas Inventories and

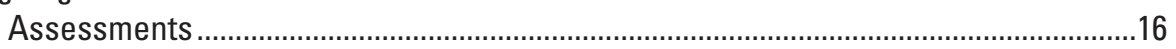

2.5.1. Intergovernmental Panel on Climate Change Scenarios and Guidelines ..............17

2.5.2. Examples of Continental-Scale Greenhouse-Gas Inventories and Assessments ............................................................................................17

2.5.3. Existing National-Scale Inventories and Assessments in the United States ........18

2.5.4. Uncertainty Assessment and Reporting in Existing National Assessments..........19

2.5.5. Economic Analysis and Its Use in Existing National Assessments.......................20

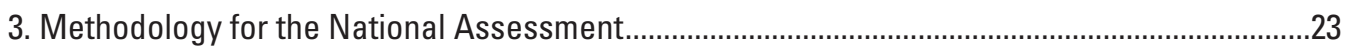

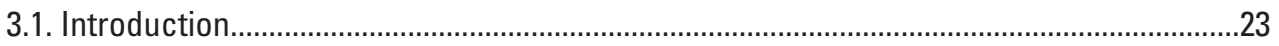

3.1.1. Design Requirements and Goals for Assessment.............................................23

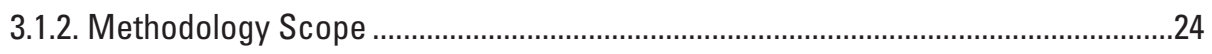

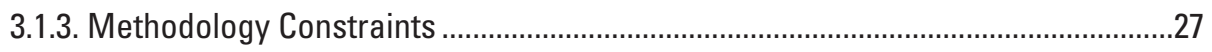




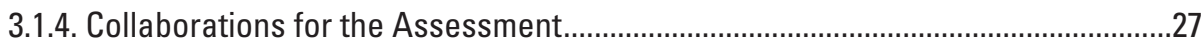

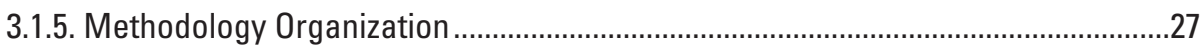

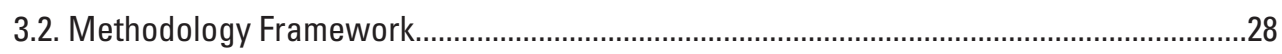

3.2.1. Framework for Assessing Current Carbon Stocks, Carbon Sequestration, and Greenhouse-Gas Fluxes ........................................................................28

3.2.2. Framework for Assessing Future Potential Carbon Stocks, Carbon Sequestration, and Greenhouse-Gas Fluxes ....................................................29

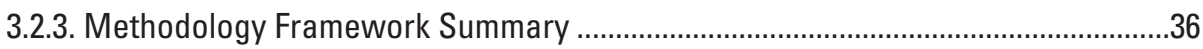

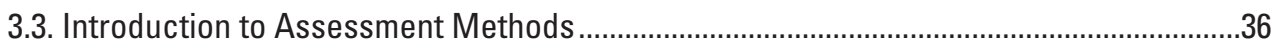

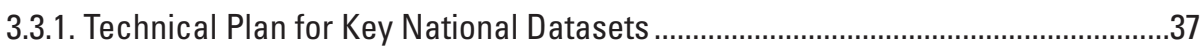

3.3.2. Land-Use and Land-Cover Change ..................................................................4

3.3.3. Ecosystem Disturbances ..................................................................................43

3.3.4. Carbon Stocks, Carbon Sequestration, and Greenhouse-Gas Fluxes in Terrestrial Ecosystems ....................................................................................4

3.3.5. Carbon Sequestration and Greenhouse-Gas Fluxes of Aquatic Ecosystems ................................................................................................57

3.3.6. Analyses of Assessment Results-Mitigation Activities, Ecosystem Services, Costs, and Benefits .......................................................................58

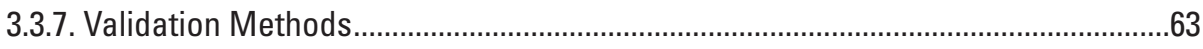

3.3.8. Methods for Assessing and Reporting Uncertainty..............................................64

3.3.9. Requirements of Section 712 of the Energy Independence and Security Act for Measuring and Monitoring.......................................................................64

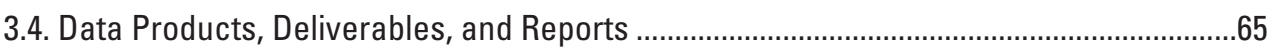

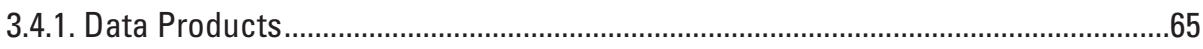

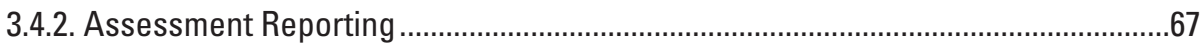

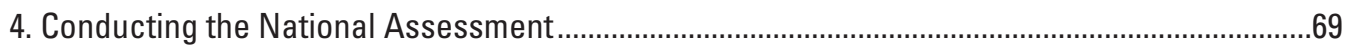

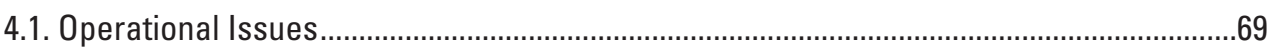

4.2. Major Scientific Research and Development Needs .....................................................69

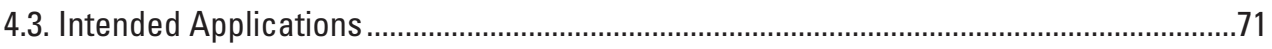

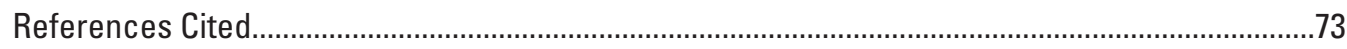

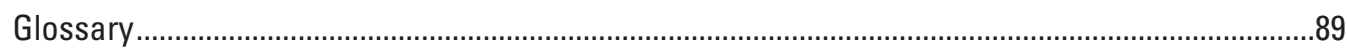

Appendix A. Reference and Alternative Mitigation Scenarios ....................................................91

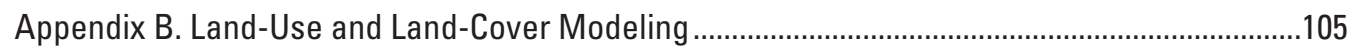

Appendix C. Characterization and Modeling of Major Ecosystem Disturbances...........................113

Appendix D. Methods for Assessing Carbon Stocks, Carbon Sequestration, and Greenhouse-Gas Fluxes of Terrestrial Ecosystems........................................................123

Appendix E. Methods for Assessing Carbon Stocks, Carbon Sequestration, and

Appendix F. Methods for Analyzing Ecosystem Services and Benefits and Costs of

Appendix G. Methods for Validation and Uncertainty Assessment ............................................177

Appendix H. Methods for Energy Independence and Security Act Measuring and

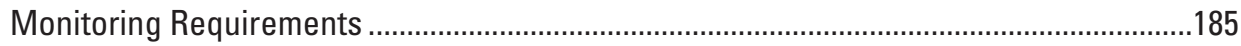

Appendix I. Data Management Technical Plan .............................................................................. 


\section{Figures}

2.1. Diagram showing primary ecosystem carbon pools

2.2. Diagrams showing the main carbon and nitrogen cycling processes associated with five major ecosystems in the United States

2.3. Conceptual diagram of the relations among ecosystem structure, function, and services.

3.1. Map showing Level II ecoregions of the U.S. Environmental Protection Agency for this report and for the assessment.

3.2. Diagram showing fluxes of carbon and nitrogen and exchanges among the seven primary carbon pools

3.3. Graph showing hypothetical emission ranges for each of three scenarios .................31

3.4. Diagram showing the assessment framework for each IPCC SRES storyline, using storyline A1B as an example

3.5. Diagram showing relations among major methods that are designed to run scenarios and produce assessment deliverables

3.6. Graphs showing the net change for the modeled land-use and land-cover types in the two U.S. Environmental Protection Agency Level III ecoregions scenarios.......44

3.7. Maps showing the results of a land-use-modeling test for the A1B scenario

3.8. Graphs showing the observed and simulated number of wildfires per year, and the observed and simulated number of hectares of area burned by wildfire per year

3.9. Map of the test area showing locations of simulated wildfires in two EPA Level III ecoregions for 2001 through 2050, using the A1B storyline...

3.10. Map showing results of a test using terrestrial methods to assess carbon stocks, carbon sequestration and greenhouse-gas fluxes...

3.11. Graph showing comparisons of annual carbon-sequestration rates of biomass carbon stock among the three methods using the "enhanced land use and land cover with reference land management" (L) scenario for the whole test area from 2001 to 2050

3.12. Graphs showing comparisons of annual methane emission from wetlands and the total nitrous-oxide emission from all land between the GEMS-spreadsheet model and the GEMS-EDCM model, showing the difference between the "reference land use, land cover, and land management" (R) scenario and the "enhanced land use and land cover with reference land management" (L) scenario, from 2001 to 2050.

3.13. Chart showing a comparison of ecosystem service changes using the ecosystem service change indicator 


\section{Tables}

2.1. Carbon stocks in the conterminous United States and Alaska, and greenhouse-gas emissions from major ecosystems in the conterminous United States only, as reported by recent studies.

2.2 Comparison of forest stocks and net forest-stock changes from three continentalscale studies of temperate forest zones....................................................................18

2.3. Selected estimates and uncertainties reported from recent national-scale assessments of carbon sequestration ............................................................................20

3.1. Ecosystems, descriptions, and thematic components of source datasets ......................25

3.2. Broad-level definitions of relevant carbon pools to be included for carbonassessment products.

3.3. Time periods, land use and land cover, ecosystem disturbances, and landmanagement activities used for assessments of current and future potential carbon stocks, carbon sequestration, and greenhouse-gas fluxes

3.4. Thematic land-cover classes used to describe current conditions .................................30

3.5. Candidate mitigation activities to be considered for the assessment...............................33

3.6. Summary of the assessment framework for linking climate-change mitigation scenarios to changes in ecosystem capacities for carbon stocks and carbon sequestration and to changes in greenhouse-gas fluxes .

3.7. Data needs, sources, variables, spatial and temporal resolution, and uses in the

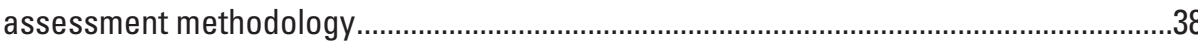

3.8. General circulation models used to project future climate scenarios .............................41

3.9. Major natural and anthropogenic ecosystem disturbances, selected attributes, and data sources.

3.10. Preliminary methods or models, quantifying parameters, technical processes, target ecosystems, and data needs or sources that will be used to assess parameters of carbon stocks, carbon sequestration, and greenhouse-gas flux

3.11. Total carbon stocks and cumulative and additional carbon sequestration within the test area (Tensas Parish, La., and Claiborne County, Miss.), calculated using the specified method, and using the "reference land use, land cover, and land management" (R) and "enhanced land use and land cover with reference land management" (L) scenarios.....

3.12. Annual emission rates of methane and nitrous oxide and their total differences (between 2001 and 2050), for the "reference land use, land cover, and land management" (R) and the "enhanced land use and land cover with reference land management" (L) scenarios.

3.13. Example of a table format for reporting the effectiveness of mitigation activities for sequestering carbon, by the duration (years) of the implementation.

3.14. Ecosystem services that are likely to be affected by mitigation activities and will be analyzed, their functions, and the assessment data products that will be used to analyze the effects of mitigation activities

3.15. Preliminary ecosystem service estimates for a test in Tensas Parish, La., and Claiborne County, Miss., using the A1B storyline.

3.16. Partial list of deliverable and intermediate data products targeted for validation, and the corresponding reference data sources and needs.

3.17. A subset of primary deliverables for the national assessment, by deliverable type.......66 
3.18. Example of a table format for reporting the results of the assessment of carbon stocks, carbon sequestration, and greenhouse gases, including uncertainties, for current or future scenarios depicted in table 3.6.

3.19. Example of a table format for reporting the effects of wildfires and manmade fires on carbon stocks for a given assessment unit, for all ecosystems

3.20. Example of a table format for reporting validation results of comparing the reference data with the 2010 assessment estimates (present conditions) for selected assessment parameters, for a given assessment unit 


\section{Conversion Factors}

\begin{tabular}{lcl}
\hline \multicolumn{1}{c}{ Multiply } & By & \multicolumn{1}{c}{ To obtain } \\
\hline millimeter $(\mathrm{mm})$ & Length & inch (in.) \\
centimeter $(\mathrm{cm})$ & 0.03937 & inch (in.) \\
meter $(\mathrm{m})$ & 0.3937 & foot $(\mathrm{ft})$ \\
\hline & 3.281 & \\
\hline square meter $\left(\mathrm{m}^{2}\right)$ & Area & square foot $\left(\mathrm{ft}^{2}\right)$ \\
hectare $($ ha) & 10.76 & acre \\
square kilometer $\left(\mathrm{km}^{2}\right)$ & 2.471 & square miles $\left(\mathrm{mi}^{2}\right)$ \\
megahectare $(\mathrm{Mha})$ & 0.3861 & square mile $\left(\mathrm{mi}^{2}\right)$ \\
\hline & 3,861 & \\
\hline cubic meter $\left(\mathrm{m}^{3}\right)$ & Volume & cubic foot $\left(\mathrm{ft}^{3}\right)$ \\
\hline & 35.31 & \\
\hline gram $(\mathrm{g})$ & Mass & ounce, avoirdupois $(\mathrm{oz})$ \\
kilogram $(\mathrm{kg})$ & 0.03527 & pound avoirdupois $(\mathrm{lb})$ \\
megagram $(\mathrm{Mg})[\mathrm{metric}$ ton $(\mathrm{t})]$ & 2.205 & ton, short $(2,000 \mathrm{lb})$ \\
gigagram $(\mathrm{Gg})$ & 1.102 & ton, short $(2,000 \mathrm{lb})$ \\
teragram $(\mathrm{Tg})$ & $1.102 \times 10^{3}$ & ton, short $(2,000 \mathrm{lb})$ \\
petagram $(\mathrm{Pg})$ & $1.102 \times 10^{6}$ & ton, short $(2,000 \mathrm{lb})$ \\
\hline & $1.102 \times 10^{9}$ & watts per square foot $\left(\mathrm{W} / \mathrm{ft}^{2}\right)$ \\
\hline watts per square meter $\left(\mathrm{W} / \mathrm{m}^{2}\right)$ & Irradiance &
\end{tabular}

Temperature in degrees Celsius $\left({ }^{\circ} \mathrm{C}\right)$ may be converted to degrees Fahrenheit $\left({ }^{\circ} \mathrm{F}\right)$ as follows:

${ }^{\circ} \mathrm{F}=\left(1.8 \times^{\circ} \mathrm{C}\right)+32$.

Temperature in degrees Fahrenheit $\left({ }^{\circ} \mathrm{F}\right)$ may be converted to degrees Celsius $\left({ }^{\circ} \mathrm{C}\right)$ as follows:

${ }^{\circ} \mathrm{C}=\left({ }^{\circ} \mathrm{F}-32\right) / 1.8$.

The resolution of pixels in spatial datasets follows the conventions used in the spatial data and modeling communities. The format is " $n$-meter resolution," where $n$ is a numerical value for the length. The usage translates into a pixel with a length of $n$ on all sides that covers an area of $n$ meters $\times n$ meters.

\section{How Megagrams, Gigagrams, Teragrams, and Petagrams Relate to Metric Tons}

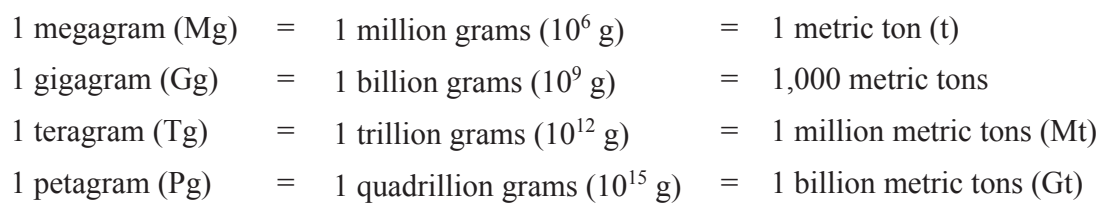




\section{Abbreviations, Acronyms, and Chemical Symbols}

\begin{tabular}{|c|c|}
\hline ADAGE & Applied Dynamic Analysis of the Global Economy \\
\hline AFOLU & agriculture, forestry, and other land uses \\
\hline AmeriFlux & American flux network \\
\hline AR4 & IPCC fourth assessment report \\
\hline AR5 & IPCC fifth assessment report \\
\hline ArcFVS & ArcInfo's Forest Vegetation Simulator \\
\hline ArcSDE & Arclnfo's Spatial Database Engine \\
\hline ARMS & Agricultural Resource Management Survey \\
\hline ARS & USDA Agricultural Research Service \\
\hline AVHRR & Advanced Very High Resolution Radiometer \\
\hline BAER & Burned Area Emergency Recovery \\
\hline BCC-BCM2.0 & Bjerknes Centre for Climate Research, Bergen Climate Model 2.0 \\
\hline BGC & biogeochemical \\
\hline BMPs & best management practices \\
\hline BPS & biophysical settings \\
\hline C & carbon \\
\hline $\mathbf{C}_{\text {ed }}$ & carbon erosion and deposition \\
\hline $\mathbf{C}_{\mathrm{s}}$ & carbon stock \\
\hline $\mathrm{C}_{\mathrm{sr}}$ & carbon sequestration \\
\hline CASA & Carnegie-Ames-Stanford Approach model \\
\hline CBI & Conservation Biology Institute \\
\hline CCSP & U.S. Climate Change Science Program \\
\hline CEAP & Conservation Effects Assessment Project \\
\hline $\mathrm{CH}_{4}$ & methane \\
\hline CLUE & Conversion of Land Use and Its Effects \\
\hline CMIP3 & $\begin{array}{l}\text { World Climate Research Programme's Coupled Model Intercomparison } \\
\text { Project (phase 3) }\end{array}$ \\
\hline $\mathrm{CO}_{2}$ & carbon dioxide \\
\hline COLE & carbon online estimator \\
\hline COMET-VR & $\begin{array}{l}\text { Voluntary Reporting of Greenhouse Gases-Carbon Management Evaluation } \\
\text { Tool }\end{array}$ \\
\hline CONUS & conterminous United States \\
\hline CRP & Conservation Reserve Program \\
\hline CSIRO-Mk3.0 & $\begin{array}{l}\text { Australia's Commonwealth Scientific and Industrial Research Organisation } \\
\text { Mark 3.0 }\end{array}$ \\
\hline CSP & Conservation Security Program \\
\hline CSW & Catalogue Service for Web \\
\hline DCF & discounted cash flow \\
\hline DED & duck energy day \\
\hline DEM & digital elevation model \\
\hline DIC & dissolved inorganic carbon \\
\hline DLG & digital line graph \\
\hline DNDC & denitrification-decomposition model \\
\hline
\end{tabular}




\begin{tabular}{|c|c|}
\hline DOC & dissolved organic carbon \\
\hline DOI & U.S. Department of the Interior \\
\hline DON & dissolved organic nitrogen \\
\hline EAC & equivalent annual cost \\
\hline EcoServ & ecosystem services model \\
\hline EDCM & Erosion-Deposition-Carbon Model \\
\hline EDNA & Elevation Derivatives for National Applications \\
\hline EF & emission factor \\
\hline EISA & Energy Independence and Security Act of 2007 \\
\hline EnKF & Ensemble Kalman Filter \\
\hline EPA & U.S. Environmental Protection Agency \\
\hline EOIP & Environmental Quality Incentives Program \\
\hline ER & ecosystem respiration \\
\hline ERF1 & Enhanced River Reach File (USGS) \\
\hline EROS & USGS Center for Earth Resources Observation and Science \\
\hline ERS & Economic Research \\
\hline ESCI & ecosystem services change indicator \\
\hline FACE & Free-Air $\mathrm{CO}_{2}$ Enrichment \\
\hline FARSITE & Fire Area Simulator \\
\hline FASOM-GHG & Forest and Agriculture Sector Optimization Model with Greenhouse Gases \\
\hline FCCS & fuel characteristic classification system \\
\hline FGDC & Federal Geographic Data Committee \\
\hline FIA & U.S. Forest Service Forest Inventory and Analysis Program \\
\hline FlamMap & fire behavior mapping and analysis program (USFS) \\
\hline FLM & fuel loading model \\
\hline FLUXNET & flux network \\
\hline FOFEM & First Order Fire Effects Model \\
\hline FORE-SCE & "forecasting scenarios of land cover change" model \\
\hline FPA & fire program analysis \\
\hline FPAR & Fraction of Photosynthetically Active Radiation \\
\hline FRLPP & Farm and Ranch Lands Protection Program \\
\hline FSPro & Fire Spread Probability model \\
\hline FVS & Forest Vegetation Simulator \\
\hline FWS & U.S. Fish and Wildlife Service \\
\hline GAP & Gap Analysis Program \\
\hline GCM & Global Circulation Model \\
\hline GCP & Global Carbon Project \\
\hline GDP & Gross Domestic Product \\
\hline GEMS & General Ensemble Modeling System \\
\hline GeoEye & commercial Earth-observation satellite \\
\hline GeoMPI & Geospatial Model Programming Interface \\
\hline GeoMSI & Geospatial Model Sharing Interface \\
\hline GHG & greenhouse gases \\
\hline GIS & geographic information system \\
\hline GPP & gross primary productivity \\
\hline
\end{tabular}




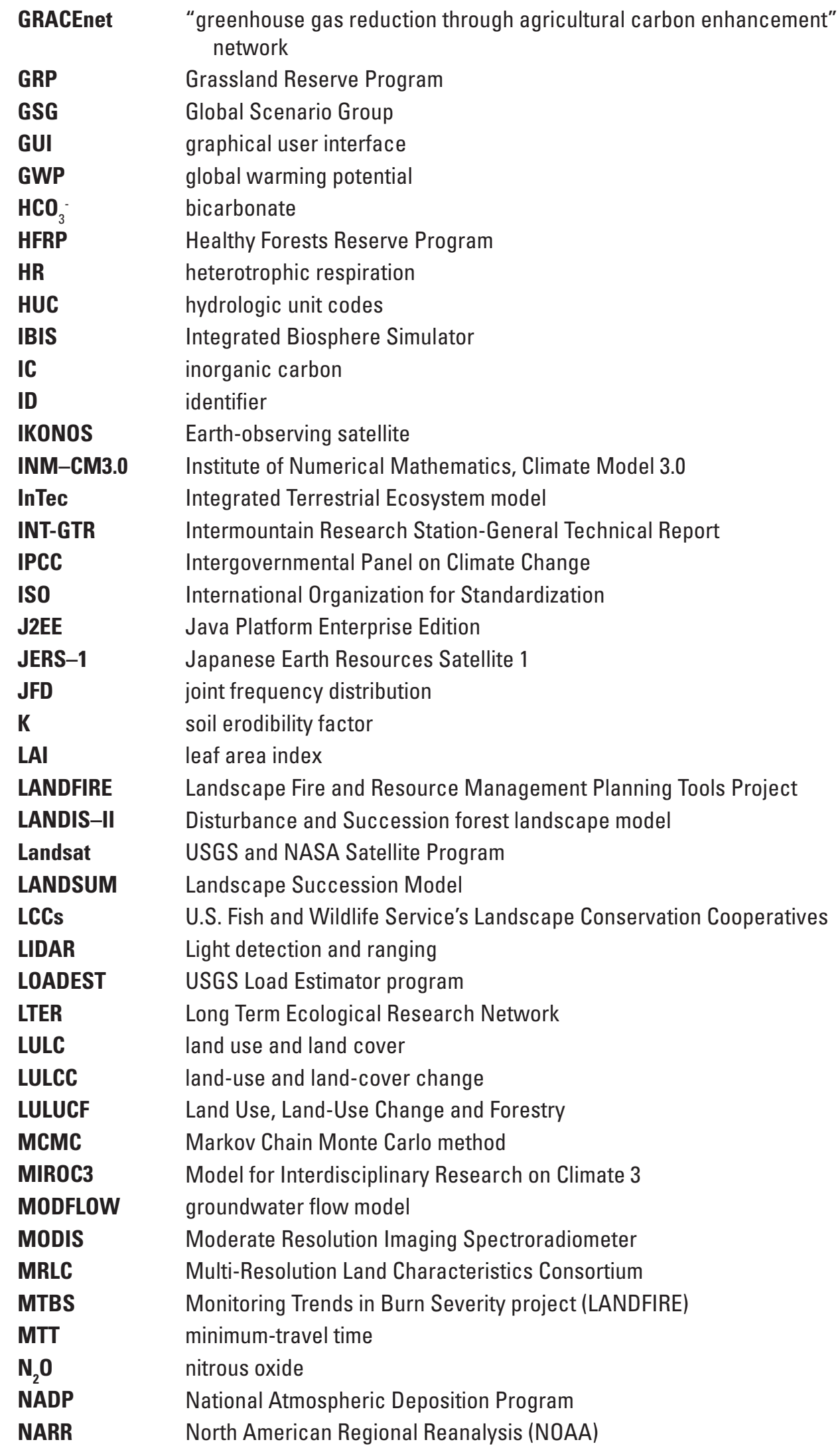




\begin{tabular}{|c|c|}
\hline NASA & National Aeronautics and Space Administration \\
\hline NASS & National Agricultural Statistics Service \\
\hline NASQAN & USGS National Stream Quality Accounting Network \\
\hline NBP & net biome productivity \\
\hline NCAS & National Carbon Accounting System \\
\hline NCDC & National Climatic Data Center (NOAA) \\
\hline NCEP & National Centers for Environmental Prediction \\
\hline NCWin & NetCDF program for processing and visualizing NetCDF data \\
\hline NDVI & Normalized Difference Vegetation Index \\
\hline NECB & net ecosystem carbon balance \\
\hline NED & National Elevation Dataset \\
\hline NEE & net ecosystem exchange \\
\hline NEON & National Ecological Observatory Network \\
\hline NEP & net ecosystem production \\
\hline NetCDF & network Common Data Form \\
\hline NEWS & Nutrient Export from Watersheds model \\
\hline NFPORS & National Fire Plan Operations and Reporting System \\
\hline NHD & National Hydrography Dataset \\
\hline NID & National Inventory of Dams \\
\hline NLCD & National Land Cover Database \\
\hline NLM & Nitrogen Loading Model \\
\hline $\mathrm{NO}_{3}^{-}$ & nitrate \\
\hline NOAA & National Oceanic and Atmospheric Administration \\
\hline NPP & net primary productivity \\
\hline NPCDI & National Coastal Pollutant Discharge Inventory \\
\hline NPDES & National Pollutant Discharge Elimination System \\
\hline $\mathbf{N r}$ & reactive nitrogen \\
\hline NRCS & Natural Resources Conservation Service \\
\hline NRI & National Resources Inventory (USDA) \\
\hline NSDI & National Spatial Data Infrastructure \\
\hline NSF & National Science Foundation \\
\hline NWI & National Wetlands Inventory \\
\hline NWIS & National Water Information System \\
\hline OC & organic carbon \\
\hline OGC & Open Geospatial Consortium \\
\hline $\mathbf{O M}$ & organic matter \\
\hline OSU & Oregon State University \\
\hline $\mathbf{P}$ & phosphorus \\
\hline PAD-US (CBI) & $\begin{array}{l}\text { Protected Areas Database of the United States (maintained by the } \\
\text { Conservation Biology Institute of Oregon) }\end{array}$ \\
\hline PAO & proportion of area occupied \\
\hline PDF & probability distribution function \\
\hline PEST & model-independent parameter estimation application (EPA) \\
\hline PIC & particulate inorganic carbon \\
\hline PNV & potential natural vegetation \\
\hline
\end{tabular}




\begin{tabular}{|c|c|}
\hline POC & particulate organic carbon \\
\hline PPR & Prairie Pothole region \\
\hline PRISM & parameter-elevation regressions on independent slopes model \\
\hline PRMS & Precipitation-Runoff Modeling System \\
\hline PVB & present value of the benefits \\
\hline PVC & present value of the costs \\
\hline $\mathbf{Q C} / \mathbf{Q A}$ & quality control and quality assurance \\
\hline $\mathbf{r}_{2}$ & coefficient of determination \\
\hline RAC & Oracle's Real Application Clusters database \\
\hline RDBMS & Oracle's Enterprise Edition Relational Database Management System \\
\hline RCP & representative concentration pathways \\
\hline REDD & reducing emissions from deforestation and forest degradation \\
\hline redox & reduction-oxidation \\
\hline RESIS-II & Reservoir Sedimentation Survey Information System (updated version) \\
\hline RESSED & Reservoir Sedimentation Database \\
\hline RPA & $\begin{array}{l}\text { U.S. Forest Service Forest and Rangeland Renewable Resources Planning } \\
\text { Act of } 1974\end{array}$ \\
\hline RSLC & remote sensing of landscape change activities at U.S. Geological Survey \\
\hline SAR & synthetic aperture radar \\
\hline SEnKF & Smoothed Ensemble Kalman Filter \\
\hline SIC & soil inorganic carbon \\
\hline SOC & soil organic carbon \\
\hline SOCCR & State of the Carbon Cycle Report \\
\hline SOM & soil organic matter \\
\hline SPARROW & $\begin{array}{l}\text { "spatially referenced regressions on watershed attributes" water-quality } \\
\text { model }\end{array}$ \\
\hline SRES & IPCC's Special Report on Emission Scenarios \\
\hline SRTM & Shuttle Radar Topography Mission \\
\hline SSURGO & Soil Survey Geographic database (NRCS) \\
\hline STATSG02 & U.S. General Soil Map (formerly STATSGO) \\
\hline STORET & EPA's Storage and Retrieval Data Warehouse \\
\hline SWAT & Soil and Water Assessment Tool (USDA) \\
\hline TDN & total dissolved nitrogen \\
\hline TIGER $^{\circledR}$ & $\begin{array}{l}\text { Topologically Integrated Geographic Encoding and Referencing system of the } \\
\text { U.S. Census Bureau }\end{array}$ \\
\hline TM & Landsat Thematic Mapper \\
\hline TN & total nitrogen \\
\hline TOC & total organic carbon \\
\hline TP & total phosphorous \\
\hline TRIPLEX & $\begin{array}{l}\text { monthly time-step model of forest growth and carbon dynamics that } \\
\text { integrates three BGC models }\end{array}$ \\
\hline TSS & total suspended sediments \\
\hline UMD & University of Maryland \\
\hline UMCES & University of Maryland, Center for Environmental Science \\
\hline UNEP & United Nations Environment Programme \\
\hline
\end{tabular}




$\begin{array}{ll}\text { USDA } & \text { U.S. Department of Agriculture } \\ \text { USDC } & \text { U.S. Department of Commerce } \\ \text { USFS } & \text { U.S. Forest Service } \\ \text { USGS } & \text { U.S. Geological Survey } \\ \text { USLE } & \text { Universal Soil Loss Equation } \\ \text { USPED } & \text { Unit Stream Power Erosion and Deposition } \\ \text { VCT } & \text { vegetation change tracker (a product of LANDFIRE) } \\ \text { VDDT } & \text { Vegetation Dynamics Development Tool } \\ \text { WHIP } & \text { Wildlife Habitats Incentives Program } \\ \text { WRP } & \text { Wetland Reserve Program } \\ \text { WUE } & \text { water-use efficiency }\end{array}$




\title{
Energy Independence and Security Act of 2007
}

\author{
H. R. $6-222$
}

SEC. 712. ASSESSMENT OF CARBON SEQUESTRATION AND METHANE AND NITROUS OXIDE EMISSIONS FROM ECOSYSTEMS.

(a) DEFINITIONS.-In this section:

(1) ADAPTATION STRATEGY.-The term "adaptation strategy" means a land use and management strategy that can be used-

(A) to increase the sequestration capabilities of covered greenhouse gases of any ecosystem; or

(B) to reduce the emissions of covered greenhouse gases from any ecosystem.

(2) Assessment-The term "assessment" means the national assessment authorized under subsection (b).

(3) COVERED GREENHOUSE GAS.-The term "covered greenhouse gas" means carbon dioxide, nitrous oxide, and methane gas.

(4) ECOSYSTEM.-The term "ecosystem" means any terrestrial, freshwater aquatic, or coastal ecosystem, including an estuary

(5) NATIVE PLANT SPECIES.-The term "native plant species" means any noninvasive, naturally occurring plant species within an ecosystem.

(6) SECRETARY.- The term "Secretary" means the Secretary of the Interior.

(b) AUTHORIZATION OF ASSESSMENT,-Not later than 2 years after the date on which the final methodology is published under subsection $(f)(3)(D)$, the Secretary shall complete a national assessment of-

(1) the quantity of carbon stored in and released from ecosystems, including from man-caused and natural fires; and

(2) the annual flux of covered greenhouse gases in and out of ecosystems.

(c) COMPONENTS.-In conducting the assessment under subsection (b), the Secretary shall-

(1) determine the processes that control the flux of covered greenhouse gases in and out of each ecosystem;

(2) estimate the potential for increasing carbon sequestration in natural and managed ecosystems through management activities or restoration activities in each ecosystem;

(3) develop near-term and long-term adaptation strategies or mitigation strategies that can be employed-

(A) to enhance the sequestration of carbon in each ecosystem;

(B) to reduce emissions of covered greenhouse gases from ecosystems; and

(C) to adapt to climate change; and

(4) estimate the annual carbon sequestration capacity of ecosystems under a range of policies in support of management activities to optimize sequestration.

(d) USE OF NATIVE PLANT SPECIES.-In developing restoration activities under subsection (c)(2) and management strategies and adaptation strategies under subsection (c)(3), the Secretary shall emphasize the use of native plant species (including mixtures of many native plant species) for sequestering covered greenhouse gas in each ecosystem.

(e) CONSUltation.-

(1) IN GENERAL, - In conducting the assessment under subsection (b) and developing the methodology under subsection (f), the Secretary shall consult with- 
H. R. $6-223$

(A) the Secretary of Energy;

(B) the Secretary of Agriculture;

(C) the Administrator of the Environmental Protection Agency:

(D) the Secretary of Commerce, acting through the

Under Secretary for Oceans and Atmosphere; and

(E) the heads of other relevant agencies.

(2) OCEAN AND COASTAL ECOSYSTEMS.-In carrying out this section with respect to ocean and coastal ecosystems (including estuaries), the Secretary shall work jointly with the Secretary of Commerce, acting through the Under Secretary for Oceans and Atmosphere.

(f) METHODOLOGY.-

(1) IN GENERAL.-Not later than 1 year after the date of enactment of this Act, the Secretary shall develop a methodology for conducting the assessment.

(2) REQUIREMENTS,-The methodology developed under paragraph (1) -

(A) shall-

(i) determine the method for measuring, monitoring, and quantifying covered greenhouse gas emissions and reductions;

(ii) estimate the total capacity of each ecosystem to sequester carbon; and

(iii) estimate the ability of each ecosystem to reduce emissions of covered greenhouse gases through management practices; and

(B) may employ economic and other systems models, analyses, and estimates, to be developed in consultation with each of the individuals described in subsection (e).

(3) EXTERNAL REVIEW AND PUBLICATION, - On completion of a proposed methodology, the Secretary shall-

(A) publish the proposed methodology;

(B) at least 60 days before the date on which the final methodology is published, solicit comments from-

(i) the public; and

(ii) heads of affected Federal and State agencies;

(C) establish a panel to review the proposed methodology published under subparagraph (A) and any comments received under subparagraph (B), to be composed of members-

(i) with expertise in the matters described in subsections (c) and (d); and

(ii) that are, as appropriate, representatives of Federal agencies, institutions of higher education, nongovernmental organizations, State organizations, industry, and international organizations; and

(D) on completion of the review under subparagraph (C), publish in the Federal Register the revised final methodology.

(g) EsTIMATE; REviEW.-The Secretary shall-

(1) based on the assessment, prescribe the data, information, and analysis needed to establish a scientifically sound estimate of the carbon sequestration capacity of relevant ecosystems; and

(2) not later than 180 days after the date on which the assessment is completed, submit to the heads of applicable 


\section{H.R. $6-224$}

Federal agencies and the appropriate committees of Congress a report that describes the results of the assessment.

(h) DATA AND REPORT AVAILABILITY.-On completion of the assessment, the Secretary shall incorporate the results of the assessment into a web-accessible database for public use.

(i) AUTHORIZATION.-There is authorized to be appropriated to carry out this section $\$ 20,000,000$ for the period of fiscal years 2008 through 2012. 


\title{
Public Review Draft: A Method for Assessing Carbon Stocks, Carbon Sequestration, and Greenhouse-Gas Fluxes in Ecosystems of the United States Under Present Conditions and Future Scenarios
}

\author{
By Zhiliang Zhu' (editor), Brian Bergamaschi², Richard Bernknopf ${ }^{3}$, David Clow ${ }^{4}$, Dennis Dye ${ }^{5}$, Stephen \\ Faulkner ${ }^{6}$, William Forney ${ }^{3}$, Robert Gleason ${ }^{7}$, Todd Hawbaker $^{4}$, Jinxun Liu ${ }^{8}$, Shuguang Liu ${ }^{9}$, Stephen Prisley ${ }^{10}$, \\ Bradley Reed ${ }^{1}$, Matthew Reeves ${ }^{11}$, Matthew Rollins ${ }^{9}$, Benjamin Sleeter ${ }^{3}$, Terry Sohl ${ }^{9}$, Sarah Stackpoole ${ }^{4}$, \\ Stephen Stehman ${ }^{12}$, Robert Striegl ${ }^{13}$, Anne Wein ${ }^{1}$, and Zhiliang Zhu ${ }^{1}$
}

\section{Executive Summary}

This methodology was developed to fulfill a requirement by the Energy Independence and Security Act of 2007 (EISA). The EISA legislation mandates the U.S. Department of the Interior (DOI) to develop a methodology and conduct an assessment of carbon storage, carbon sequestration, and fluxes of three principal greenhouse gases (GHG) for the Nation's ecosystems. The three principal GHG are carbon dioxide $\left(\mathrm{CO}_{2}\right)$, methane $\left(\mathrm{CH}_{4}\right)$, and nitrous oxide $\left(\mathrm{N}_{2} \mathrm{O}\right)$. Section 712 of this legislation (provided in the front of this report) asks DOI to develop the following:

- A methodology that includes quantifying, measuring, and monitoring carbon sequestration and GHG fluxes using current science and available, suitable national datasets

- A resource assessment of the Nation's ecosystemsterrestrial (forests, croplands, wetlands, and others) and aquatic (freshwater systems, estuaries, coastal waters) - focusing on the evaluation of the following:

- A range of mitigation activities for a potential increase in carbon-sequestration capacity and reduction of GHG fluxes to inform policy analysis
- Climate-change effects and other controlling processes (including wildland fires) on carbon and GHG uptake and emissions from ecosystems

The legislation requires that an assessment of carbon storage and GHG fluxes in the Nation's ecosystems be performed, including an evaluation of potential policies for climate-change mitigation. Such an assessment is as complex as it is geographically broad, encompassing high ecological diversity and influenced by many present and future potential consequences of climate change, population change, landcover change, ecosystem disturbances, and land-management activities. This document defines the scope and methods of the assessment in terms of the ecosystems, pools, assessment units, and scale of applications; and explains the interdisciplinary framework and the individual methods and models used to develop assessment reports.

The concepts of ecosystems, carbon pools, and GHG fluxes used for the assessment follow conventional definitions in use by major national and international assessment or inventory efforts such as the Intergovernmental Panel on Climate Change (IPCC), U.S. Global Change Research Program's State of the Carbon Cycle Report, and the U.S. Environmental Protection Agency (EPA) Greenhouse Gas Inventory Report. Ecosystems defined in the methodology are

\footnotetext{
${ }^{8}$ Stinger Ghaffarian Technologies, Inc., Sioux Falls, S.D.

${ }^{9}$ U.S. Geological Survey, Sioux Falls, S.D.

${ }^{10}$ Virginia Polytechnic Institute and State University, Blacksburg, Va.

${ }^{11}$ U.S. Forest Service, Missoula, Mont.

${ }^{12}$ State University of New York, College of Environmental Science and Forestry, Syracuse, N.Y.

${ }^{13}$ U.S. Geological Survey, Boulder, Colo.
} 
forests, grassland/shrublands, croplands, wetlands, and aquatic habitats (which include inland impoundments, estuaries, and coastal waters). Terrestrial carbon pools include aboveground and belowground biomass, nonliving woody debris and litter, soil organic matter, and harvested wood. Aquatic pools include dissolved organic and inorganic carbon as well as particulate and sedimentary organic carbon. Across the Nation, the EPA's Level II ecoregions map (which delineates 24 ecoregions for the Nation) is the practical instrument for developing and delivering assessment results. Consequently, the ecoregion is the scale of the assessment because the mitigation scenarios, assessment results, validation, and uncertainty analysis are produced at this scale.

For a given landscape, an ecosystem's capacity to increase carbon stocks and reduce GHG flux can be enhanced through changes in land use and land cover (LULC) (such as converting marginal cropland to forest or wetland) and changes in land management (such as increased use of prescribed burning to manage wildland fires). In order to estimate current ecosystem carbon stocks and GHG fluxes and to understand the potential capacity and effects of mitigation strategies, two time periods are used for the assessment: 2001 through 2010, which is used to establish a current ecosystem GHG baseline and validate models; and 2011 through 2050, which is used to assess future potential conditions.

The method for conducting the assessment of future potential conditions uses IPCC storylines and climate scenarios. A reference and three mitigation scenarios are constructed for each storyline. The reference scenario projects LULC and land-management change in the absence of climate-mitigation policy. Alternative mitigation scenarios apply combinations of LULC changes and management activities to enhance carbon sequestration and reduce GHG emissions. In addition, the assessment also will consider the concept of potential natural vegetation as a scenario. Input from regional experts and stakeholders will be solicited to construct realistic and meaningful scenarios.

The methods used in the assessment include a current (2010) baseline component and a future potential component. The baseline component uses existing inventory and remotesensing data to measure and analyze spatial and temporal distributions of carbon stocks and GHG fluxes. The future potential component starts with the IPCC scenarios and examines the underlying economic and policy assumptions. The economic and policy assumptions are then translated into spatially and temporally resolved projections of future LULC in annual steps. Projections of future climate under different scenarios are obtained by downscaling data from global climate models. Future potential ecosystem disturbances, such as wildfires, are modeled in a similar manner. Using a geographic information system (GIS), data on the projected climate, LULC, and ecosystem disturbances are integrated to generate georeferenced layers of information that describe the future distribution of ecosystems and vegetation. The product of these analyses is a map of future ecosystems and ecosystem conditions for each future year and each scenario. These annual maps form the basis for calculating carbon storage and GHG emissions.

The carbon storage, carbon-sequestration capacities, and GHG emissions from terrestrial and wetland ecosystems under projected future conditions are assessed quantitatively from these GIS-produced maps using a spatially explicit biogeochemical ensemble modeling system that incorporates properties of management activities (such as tillage or harvesting) and properties of individual ecosystems (such as elevation, vegetation characteristics, and soil attributes) and integrates them with the LULC and climate data. In addition to carbon storage and GHG fluxes, this model also provides important ancillary information about water use and other ecosystem services. Assessment of aquatic habitats also is based on the maps, but uses empirical models. The export of carbon in rivers, the flux of carbon and GHG into or out of inland basins (such as ponds, lakes, and reservoirs), and the impact of modified nutrient and sediment loads on carbon storage and GHG flux into or out of estuarine and coastal waters are assessed for the projected future conditions. Validation and uncertainty analysis of the assessment results follows established technical protocols, such as IPCC guidelines on assessing and reporting uncertainties. The assessment results (for each annual map of projected future ecosystem conditions and associated uncertainties) (1) permit the reporting of probability distributions of effects and the effectiveness of controlling processes and potential mitigation activities, and (2) support an analysis of potential policy applications.

The success of the assessment will depend on the methods and models used and the availability of suitable observational data. A wide variety of datasets for input are needed: carbon and GHG measurements (such as forest inventory or flux-tower data), streamgage data, remote-sensing data (such as precipitation, land-cover maps, and wildfires), soil attributes, current and future projected climates, agriculture and forestry production data, and a host of other input data. In addition, an approach for ecosystem GHG-flux monitoring is outlined in the methodology.

Implementation of the methods and access to datasets requires collaborations among various Federal agencies, State agencies, nongovernmental organizations, and the science community. For example, sharing or developing input data will be critical to the assessment, thereby ensuring a common basis to produce consistent assessment results, which then becomes important when making comparisons to other existing inventory or assessment efforts. Participation by experts or stakeholders in understanding the needs of policymakers and developing realistic mitigation scenarios will lead to improved accuracy in assessment results. Collaborative research on carbon cycling, GHG fluxes, ecosystem services, and model or method comparisons will help improve the methodology and enhance user confidence in assessment results. Applications of the assessment for mitigation planning or creating other land-management policies also will provide opportunities for validating the assessment results and for monitoring future 
mitigation performances. Not all data and information needs can be met adequately. Further research and development will be needed as described in the document.

Using the method described in this document, the assessment can be completed in approximately three years. The primary deliverables will be assessment reports that present the results in the form of tables, charts, and maps. Changes in carbon stocks, net ecosystem carbon balance, GHG fluxes, and other services in ecoregions will be reported annually for 2001 through 2050 by ecosystem, pool, and scenario. These results will be used to examine policy- or research-relevant questions, such as the following:

- What are estimates of the ecological carbon-sequestration capacity and GHG flux of the Nation's ecosystems under different future climate scenarios, and how do these estimates vary geographically and temporally?

- How effective are management practices, such as notill agriculture or fire suppression, on short- and longterm carbon sequestration and GHG fluxes?

- How effective are deliberate changes in land use, such as reforestation or wetland restoration, on carbonsequestration capacity and GHG emissions?
- What might be the most effective and economically feasible regional mitigation strategies?

- How might other ecosystem services, such as water yield or wildlife habitat conditions, be affected by mitigation strategies to enhance carbon sequestration?

- How will changes in the terrestrial supply of carbon, nutrients, and sediments to inland basins, estuaries, and coastal oceans affect carbon sequestration and GHG production, including potential effects on natural processes and mitigation actions such as enhanced algal production and wetland restoration?

In short, the methods described in this document represent a nationally consistent, comprehensive effort to assess carbon storage and GHG fluxes covering the ecosystems of all 50 States. The assessment will rely on the contribution of agencies and scientists for expert evaluation of data, models, and validation, thereby linking to the best available approaches at each phase of the assessment. The results will permit (1) an evaluation of a range of policies and mitigation options, and (2) an evaluation of the effects that changes in demography, LULC, and climate will have on carbon stocks and GHG fluxes in ecosystems. 
This page intentionally left blank. 


\section{Introduction}

This chapter briefly summarizes DOI's responsibilities and explains the concepts and requirements contained in Section 712 of the Energy Independence and Security Act of 2007 (U.S. Congress, 2007). A firm understanding of these concepts and requirements is necessary because they form the foundation upon which to construct the methodology for carrying out the assessment.

\subsection{Requirements of Section 712 of the Energy Independence and Security Act of 2007}

In 2007, the U.S. Congress passed Public Law 110-140, the Energy Independence and Security Act (EISA). Section 712 of the EISA (provided in the front of this report; U.S. Congress, 2007) authorizes the U.S. Department of the Interior (DOI) to develop a methodology and conduct an assessment of the Nation's ecosystems for (1) carbon storage and sequestration, and (2) the fluxes of three greenhouse gases (GHG) - carbon dioxide $\left(\mathrm{CO}_{2}\right)$, methane $\left(\mathrm{CH}_{4}\right)$, and nitrous oxide $\left(\mathrm{N}_{2} \mathrm{O}\right)$. Ecosystems (such as forests, wetlands, croplands, grassland/ shrublands, and aquatic habitats) both sequester and emit greenhouse gases and, to certain extent, can be managed in order to increase carbon sequestration or decrease emissions to help mitigate the effects of burning fossil fuels. The EISA also states that a purpose of the assessment is "to promote research on and deploy greenhouse gas capture and storage options."

Section 712 begins with the definition of terms used in the law. Some of these terms, as well as others used in this report, are included in the glossary found at the end of this report. Section 712 also contains specific requirements - mainly that DOI must develop a methodology, complete a national assessment, and report on that assessment; in the process, DOI must use native plant species and consult with other government agencies. Within the sections entitled "Authorization of Assessment," "Components," and "Methodology," the law specifies the information that the methodology and assessment must include.

To understand the requirements of section 712 of the EISA and maintain the usage and intent of the terminology, key concepts in the legislative language are defined below. These concepts and requirements include assessment, ecosystems, mitigation and adaptation strategies, carbon-sequestration capacity, major processes that control greenhouse-gas fluxes, management and restoration activities, range of policies, the use of native plant species, and components of the methodology.

\subsection{Understanding the Concepts and Requirements of the Energy Independence and Security Act of 2007}

\subsubsection{Assessment}

The EISA requires an assessment of resources. In this assessment, the resources are the three greenhouse gases covered by the EISA: carbon dioxide, methane, and nitrous oxide. A resource assessment is a measurement or an estimate that determines the amount of a resource. The requirement for an ecosystem-based assessment by the legislation suggests, accordingly, a quantitative evaluation of the ecological processes and ecosystem capacities of carbon sequestration and GHG fluxes. The assessment needs to establish baseline conditions and therefore overlaps with existing resource (such as forest and rangeland) inventories; however, the focus of the assessment is on the estimates of future potential ecosystem capacities for fluxes of the three gases.

\subsubsection{Ecosystems}

An ecosystem is generally defined as a functional unit of the environment consisting of physical and biological components (Heal and others, 2005). Examples of ecosystems are provided in the EISA in terms of terrestrial systems, freshwater systems, and coastal aquatic systems (including estuaries). This context is consistent with the definitions of the ecosystems that are used in other global and national studies, which are reviewed in chapter 2 of this report; those studies consistently used forests, wetlands, croplands, grassland/ shrublands, and aquatic habitats as ecosystems for assessment and reporting purposes. The specific definitions, boundaries, and scale of ecosystems for this assessment are discussed in chapter 3 of this report.

Among the major functions of ecosystems is land cover and land use. Land use is generally defined as the anthropogenic use of land resources, typically in terms of economic decisions for the land. Land use can be referred to in terms of types of land use (such as agricultural or forest land) and management conducted within a type of land use (such as fertilization of agricultural land or controlled burning of forest land). Land cover refers to the actual vegetative or other surface cover at any given time. Land cover is related to land use in that it is often the result of economic land-use decisions. The effects of changes in both land use and land cover often need examination. Given the inextricable relationship between land use and land cover (LULC), changes in LULC often are considered simultaneously.

\subsubsection{Adaptation and Mitigation Strategies}

The EISA requires the development of "near-term and long-term adaptation strategies and mitigation strategies;" however, the law only defines adaptation strategy, not mitigation strategy. Adaptation strategy is defined as "a land use and management strategy that can be used (A) to increase the sequestration capabilities of covered greenhouse gases of any ecosystem, or (B) to reduce the emissions of covered greenhouse gases from any ecosystem."

This definition, however, is more consistent with the standard definition of mitigation, which is the taking of action to avoid, reduce, minimize, rectify, or compensate for adverse 
impacts (see National Environmental Policy Act of 1970; U.S. Congress, 1970). In contrast, adaptation refers to changes in natural systems or "actions taken to enhance the resilience of vulnerable systems, thereby reducing damages to human and natural systems from climate change and variability" (Scheraga and Grambsch, 1998, p. 85). Therefore, it is reasonable to consider mitigation strategies as portfolios of land-use change and land-management activities that are implemented over time and across landscapes to enhance carbon sequestration and reduce GHG emissions. Estimation of carbon sequestration and GHG fluxes for various climates scenarios should inform the development of strategies to adapt to climate change.

\subsubsection{Carbon-Sequestration Capacity}

EISA requires that the assessment shall "estimate the annual carbon sequestration capacity of ecosystems." The term "carbon sequestration" is defined in this methodology as the removal of $\mathrm{CO}_{2}$ from the atmosphere and its storage in ecological sinks (terrestrial and aquatic ecosystems). Carbon sequestration can be quantified as a change in the amount of carbon stocks either in an ecosystem or between ecosystems. The term "carbon-sequestration capacity" can refer to both the maximum rate of carbon storage (such as the rate of growth measured for an actively managed forest) and the maximum amount of carbon that can be stored (such as in an old-growth forest or a boreal soil pool).

The reporting of annual rates of carbon storage and changes in carbon stocks is questionable given the amount of annual variance in climate and in vegetation productivity. All ecosystems have a finite storage capacity for a given climate that is limited by ecophysiological constraints on primary productivity, respiration, and decomposition, resulting in a net carbon balance (Chapin and others, 2006). The storage capacity for a given landscape or region can be determined by the extent of specific factors or processes, including changes in LULC and changes in land management within the defined area.

\subsubsection{Processes That Control the Flux of Covered Greenhouse Gases}

The EISA requirement to "determine the processes that control the flux of covered greenhouse gases" is understood as a requirement to determine the effects of the processes rather than to conduct experiments to identify the processes; these processes (such as photosynthesis, respiration and decomposition, LULC, land management, and ecosystem disturbance) are generally well understood and have been extensively documented in the scientific literature. A general review of the processes and their effects is provided in chapter 2. A key controlling process for GHG fluxes in ecosystems is fire caused by natural and human processes, which is generally considered as either a function of ecosystems or a disturbance. The legislation requires that wildland fire be assessed for its effect on carbon storage and releases. The methodology thus will incorporate existing scientific knowledge to quantify the effects of the relevant controlling processes on carbon sequestration and GHG flux.

\subsubsection{Management Activities and Restoration Activities}

The EISA requires that the assessment shall "estimate the annual carbon sequestration capacity of ecosystems under a range of policies in support of management activities to optimize sequestration." As defined above for mitigation strategies, management and restoration activities are considered components of mitigation strategic portfolios that are developed in order to increase ecological carbon sequestration and (or) reduce GHG emissions. Changes in management or restoration activities occur within a LULC class (for example, reduced tillage on croplands, wildland fuel treatments, rice-paddy management, or controlled water flow in freshwater systems). For the purpose of assessing ecological carbon-sequestration capacity, land-use change and land-management activities are limited to those that directly increase carbon sequestration in soils, vegetation, wood products, and sediments. Not included are (1) the indirect effects on climate mitigation from the generation of energy from biomass; (2) technological actions that can aid in ecologically sequestering carbon but are not explicitly a land-use or management change (for example, growing algae in industrial fluxes); (3) activities to reduce downstream or life-cycle GHG fluxes (for example, GHG emissions from hauling and processing of timber are not assessed even though they are the result of harvest rotation changes); and (4) GHG emissions from livestock. To address these broader implications, it will be necessary to use results of the assessment in other life-cycle analyses, such as the various ongoing efforts that analyze biomass for energy applications.

The consideration of mitigation activities will require information on potential ancillary effects for other ecosystem services because these services may either limit or enhance the implementation of a particular land-use change or management activity, thus changing the potential for increasing carbon sequestration. In addition, losses and gains to ecosystem services can be expressed as (nonmarket) social values (Brookshire and others, 2010; Jenkins and others, 2010). Evaluating indirect or ancillary effects of mitigation strategies on ecosystem services is a necessary and critical part of the assessment and is directly relevant to informing the policy process, particularly because of the environmental impact review requirements by the National Environmental Policy Act of 1970 (U.S. Congress, 1970).

\subsubsection{Range of Policies}

The EISA requirement "to estimate the annual carbon sequestration capacity of ecosystems under a range of policies in support of management activities to optimize sequestration" is understood as estimating the carbon-sequestration capacity of ecosystems for a range of land-use change and management 
activities which will in turn inform policy analyses. Policy analyses of management activities and land-use change alone would be suboptimal; the results of this assessment should be considered together with climate-mitigation-policy analyses that include other mitigation options besides ecological carbon sequestration (for example, Creyts and others, 2007) that pertain to other sectors (such as energy) for informing policymaking. These broader analyses accommodate (1) multiple and competing uses of land for carbon sequestration, food, fiber, and energy; (2) interactions between multiple sectors; and (3) international impacts (for example, Lewandrowski and others, 2004; Murray and others, 2005; U.S. Environmental Protection Agency, 2008; Larsen, 2009; Ross and others, 2009). This national assessment can evaluate mitigation activities and strategies for carbon-sequestration capacity and effects on GHG emissions, and ancillary ramifications on cost and ecosystem services, but otherwise needs to link to the other policy analyses, such as the three examples given above.

\subsubsection{Use of Native Plant Species}

The EISA requires that the assessment should "emphasize the use of native plant species." The assessment requires that the plants will be used in the restoration, management, and mitigation activities. In this methodology, when plant species are evaluated as part of assessing management activities, only native plant species are considered.

\subsubsection{Measuring, Monitoring, and Quantifying}

The EISA stipulates that the methodology for the national assessment shall include methods for "measuring, monitoring, and quantifying covered greenhouse gases emissions and reductions." In the context of the national assessment, these three closely related activities are defined as follows:

"Measuring" is applying effective tools and techniques for collecting primary data that address information requirements of the national assessment. Measurement can be subsidiary to the quantification task defined below (for example, providing data for input into a model) or independent of it (for example, providing data for validation or monitoring). Measurement products to be used by the national assessment include past (archived), current, and future data records. Measurement products may be provided by ongoing national inventory programs (such as plot-based biomass measurements by the U.S. Forest Service's Forest Inventory and Analysis Program) or by the use of remote-sensing methods (such as fire perimeters defined by using satellite imagery).

"Monitoring" is the continual, systematic repetition of measurement defined above. The objectives of monitoring for this assessment are to enable the following:

- Quantification through time of carbon stocks, carbon sequestration, GHG emissions, and related ecological processes by providing the data required for calibrat- ing, updating, and improving the accuracy of methods and assessment results

- Validation or assessment of the accuracy and precision of assessment results

- Evaluation of the effectiveness of applied LULC changes, management activities, and mitigation strategies for increasing carbon sequestration, reducing GHG emission, and related goals

"Quantification" is the determination of numerical values for variables specified in the national assessment for specific ecosystems, including current and projected future potential carbon sequestration, GHG emissions, and reductions in those emissions due to LULC change and management activities. Quantification in the national assessment is achieved primarily through the methods described in chapter 3.

\subsubsection{Use of Economic and Other Systems Models, Analyses, and Estimates}

The EISA notes that the methodology may involve the use of "economic and other systems models, analyses, and estimates." In order to select appropriate models, certain factors will be considered, such as (1) a consensus by the scientific community that the model is of a high enough quality, (2) technical practicality or operational considerations, (3) availability of input data to support the particular method, and (4) whether the models can be integrated with each other and produce results that are consistent with other similar ongoing assessment efforts.

\subsection{Summary}

In summary, the components of the assessment required by section 712 of the EISA represent a progression from science to policy: (1) existing scientific knowledge is incorporated in order to quantify the effects of the relevant controlling processes on carbon sequestration and GHG flux, (2) increased carbon sequestration and reduced GHG emissions in ecosystems from LULC change and land-management activities are estimated, (3) mitigation strategies under a range of climate-change projections are examined, and (4) activities to enhance sequestration capacity are identified and their costs and effects on ecosystem services are examined as contributions to the policymaking process. The methodology criteria require the preparation of data products to support the informational needs of the assessment (measuring); an estimation of the current and projected future potential carbon sequestration, GHG emissions, and reductions in those emissions due to LULC change and management activities (quantifying); and the calibration, validation, and updating of results (monitoring). Consultation with other agencies is integral to the assessment, as are productive partnerships for implementing the methodology. 
This page intentionally left blank. 


\section{Review of Concepts and Literature}

The intent of this chapter is to summarize current knowledge about the carbon cycle and GHG fluxes in the Nation's ecosystems and associated controlling processes. A review of large-scale (continental or national-scale) inventories and assessments also is provided.

\subsection{Major Carbon-Cycle Processes and Pools}

Carbon research, covering global to local scales, informs our understanding of the potential role of ecological sequestration in offsetting carbon emissions. Observations and modeling indicate that annual rates of $\mathrm{CO}_{2}$ accumulation in the atmosphere are far larger than can be balanced by natural ecological processes that remove $\mathrm{CO}_{2}$ from the atmosphere (U.S. Climate Change Science Program (CCSP), 2007; Le Quéré and others, 2009). Global carbon sinks vary annually, but from 1990 to 2000, on average the land sink accumulated $2.6 \pm 0.7$ petagrams of carbon per year $(\mathrm{PgC} / \mathrm{yr})$ and the ocean sink accumulated $2.2 \pm 0.4 \mathrm{PgC} / \mathrm{yr}$. In 2008, the global average uptake rate for land was $4.7 \pm 1.2 \mathrm{PgC} / \mathrm{yr}$ and for oceans was $2.3 \pm 0.4 \mathrm{PgC} / \mathrm{yr}$, but annual $\mathrm{CO}_{2}$ emissions from fossil-fuel combustion for the same year were estimated to be $8.7 \mathrm{PgC}$ (Global Carbon Project (GCP), 2009; Le Quéré and others, 2009). Therefore, mitigation of net global carbon emissions ultimately will require both a reduction in the sources of $\mathrm{CO}_{2}$ to the atmosphere as well as maintaining and increasing terrestrial and aquatic sinks (CCSP, 2007).
Although biological and anthropogenic controls over carbon cycling and GHG flux vary among major ecosystems, the basic ecophysiological processes controlling the accumulation and loss of carbon to and from ecosystems are similar. The primary $\mathrm{CO}_{2}$ fluxes between the atmosphere and ecosystems are uptake through plant photosynthesis and release by respiration, decomposition, and combustion of organic matter (Paustian, Ravindranath, van Amstel, and others, 2006). Carbon fluxes associated with aquatic ecosystems occur through lateral transfer via rivers and streams, sedimentation and burial in inland and coastal waters, and emission of GHGs from water bodies (CCSP, 2007; Tranvik and others, 2009). Both $\mathrm{CH}_{4}$ and $\mathrm{N}_{2} \mathrm{O}$ emissions are largely caused by microbial processes and combustion of organic materials in fires. For example, $\mathrm{CH}_{4}$ is released through methanogenesis under anaerobic conditions in soils and during incomplete combustion of organic matter, and $\mathrm{N}_{2} \mathrm{O}$ is a byproduct of nitrification and denitrification (Faulkner, 2004; Wiedinmyer and Neff, 2007). These GHGs $\left(\mathrm{CO}_{2}, \mathrm{CH}_{4}\right.$, and $\left.\mathrm{N}_{2} \mathrm{O}\right)$ have atmospheric consequences and the IPCC developed the global warming potential (GWP) concept to compare their climate impact. The GWP is a measure that combines the effects of the radiative influence of a gas into the atmosphere relative to $\mathrm{CO}_{2}$ as well as the residence time of the gas in the atmosphere (Ramaswamy and others, 2001). Carbon dioxide is the standard to which other gases are compared, so it has a GWP of 1. Methane has a GWP of 21, and nitrous oxide is the most potent greenhouse gas with a GWP of 310 (U.S. Environmental Protection Agency, 2010).

Terrestrial and aquatic ecosystems play an important role in the carbon cycle (fig. 2.1). Major ecosystems that are

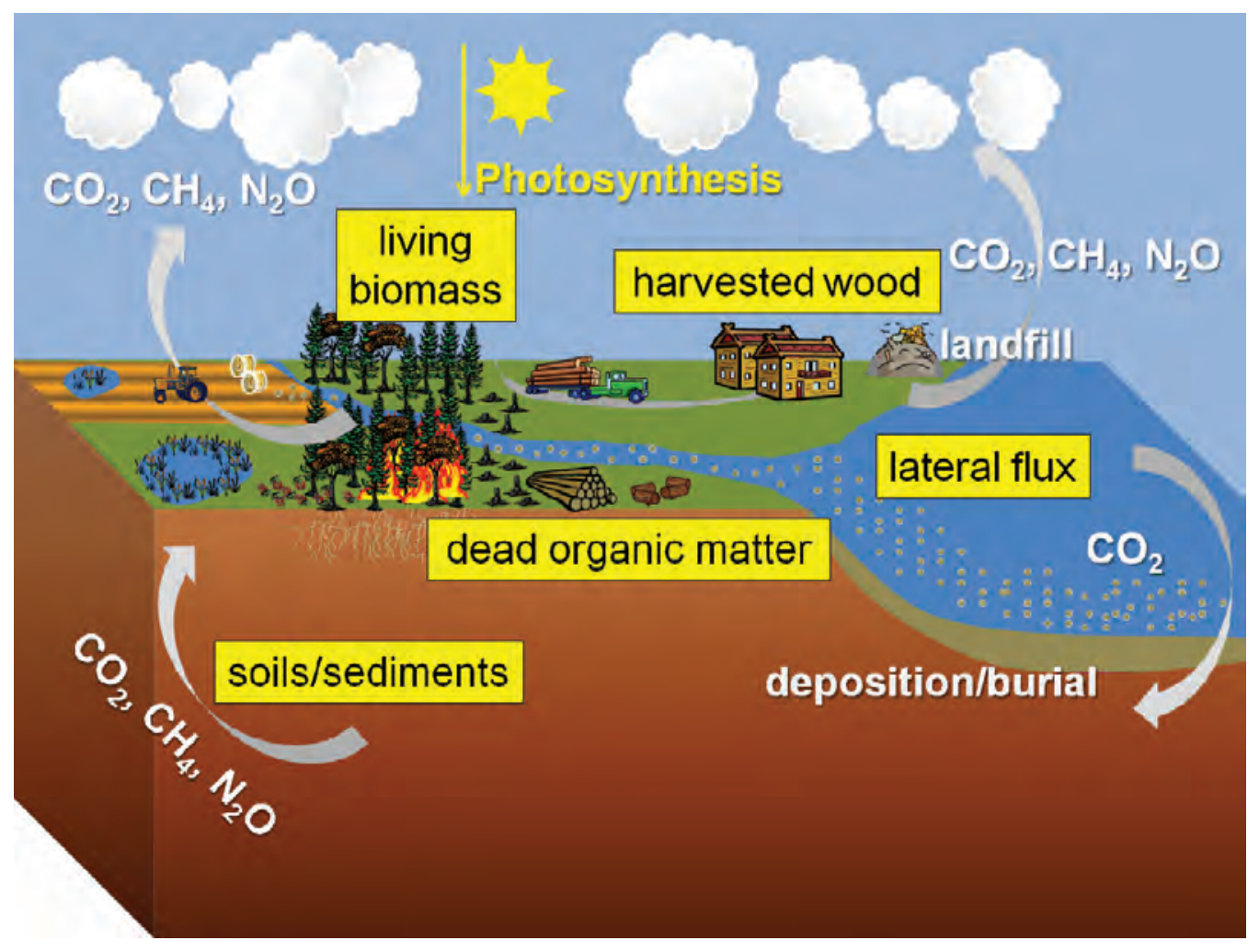

Figure 2.1. Diagram showing primary ecosystem carbon pools. These pools (yellow boxes) include the following: living biomass (above and below the ground), dead wood, litter, soil organic matter, harvested wood, and lateral flux (dissolved organic and inorganic carbon; particulate organic carbon). Abbreviations are as follows: $\mathrm{CH}_{4}$, methane; $\mathrm{CO}_{2^{\prime}}$ carbon dioxide, $\mathrm{N}_{2} \mathrm{O}$, nitrous oxide. 
commonly considered in both global and national carbon assessments and in inventories include forests, croplands, grassland/shrublands, and wetlands. Carbon cycling in aquatic ecosystems (such as rivers, lakes, and coastal waters) has not received as much attention, particularly in inventories at the national level (Cole and others, 2007; Battin and others, 2009). Plant biomass, both aboveground and belowground, is a main pool of carbon. The amount of carbon stored in plant biomass is influenced by land use. For example, forest clearing for cropland greatly reduces the amount of carbon stored in the vegetative biomass. In a natural system, most of the biomass production contained in living plant material is eventually transferred to dead organic matter pools, such as dead wood and litter. Dead organic matter on the ground and plant biomass below the ground decompose and transform into soil organic matter (SOM), which is another primary pool and can have varying residence times in the soil. Decomposition of SOM releases $\mathrm{CO}_{2}$ back into the atmosphere (Chapin and others, 2006; Paustian, Ravindranath, van Amstel and others, 2006). Rivers receive dissolved particulate inorganic carbon (PIC), particulate organic carbon (POC), dissolved inorganic carbon (DIC), and dissolved organic carbon (DOC) from terrestrial ecosystems and transport it downstream. A fraction of this carbon is emitted as GHGs during transport and most of the remainder is buried in aquatic sediments in inland basins, waterways, coastal areas, and oceans (Cole and others, 2007; Tranvik and others, 2009).

By assessing carbon fluxes among all major pools, it is possible to summarize all resulting quantities as the net ecosystem carbon balance (NECB) for each ecosystem (Chapin, and others, 2006). This value accounts for net ecosystem production (NEP), which is calculated by subtracting ecosystem respiration (ER) from gross primary productivity (GPP). Net biome productivity (NBP) is based on NEP, but further accounts for ecosystem disturbances. The NECB integrates all carbon flux terms, including lateral runoff and river transport of carbon (Chapin and others, 2006).

\subsection{Current Knowledge of the Carbon Cycle and Greenhouse-Gas Fluxes in the United States}

Recent studies indicate that terrestrial ecosystems in the United States represent a sizeable and globally important carbon sink (Potter and others, 2007). Forests are a large carbon sink, but they are ecosystems that gain and lose carbon continually (fig. 2.2A). Photosynthesis is the driving process behind carbon storage in biomass, and the stored biomass eventually ends up in soils and dead organic matter pools. Respiration, decomposition, and combustion (fire) release $\mathrm{CO}_{2}$ and $\mathrm{CH}_{4}$ back into the atmosphere (see section 2.3.2 for more information on the impacts of ecosystem disturbances on forests). A forest will show a net gain or loss of carbon based on the balance of these processes. One forest may be highly variable in its carbon-storage capacity if it is measured over a long time period, in part because of natural disturbances and harvest events; however, when considering many different forests in a large region, such variability in carbon storage will not be as apparent because the region is composed of forests that are in different stages of recovery and regrowth. In the conterminous United States, forests cover about 246 million hectares, with an additional 52 million hectares in Alaska (Goodale and others, 2002). The forest carbon stock in the conterminous United States is $41 \mathrm{Pg}$ and Alaska has an additional $16 \mathrm{Pg}$, as estimated by forest inventories (Birdsey and Heath, 1995; Goodale and others, 2002). The forest product pool is a considerable carbon sink that sequesters 57 teragrams of carbon per year ( $\mathrm{TgC} / \mathrm{yr}$ ) (CCSP, 2007, also known as the first State of the Carbon Cycle Report, or SOCCR, throughout this report), but individual wood products can have widely varying decomposition rates (Ryan and others, 2010).

Croplands can be very productive ecosystems, and often this productivity is measured in terms of crop yield; however, the accumulation of carbon in plant material is transient, as the plants are mostly herbaceous, and often the plants have an annual life cycle and a constrained growing season. Therefore, the majority of carbon in croplands actually is held in the soil as annual litter additions slowly decompose and become part of the soil organic matter (CCSP, 2007). To some extent, fire plays a role in the combustion of carbon from these lands because farmers sometimes burn plant residues on the soil surface to release nutrients back into the soil. In croplands, $\mathrm{N}_{2} \mathrm{O}$ emissions are driven by a combination of factors including fertilization levels, crop type, and soil-drainage capacity (Del Grosso and others, 2005). In the conterminous United States and Alaska, croplands cover about 134 million hectares, and the cropland carbon stock for these regions is about $16 \mathrm{Pg}$ (Bliss, 2003).

Grassland/shrubland ecosystems are similar to croplands in that most of the carbon stock is stored in the soil. Plant roots provide the primary input of carbon into grassland soils, but some of the carbon is oxidized by soil microbes and is released back into the atmosphere. Grassland/shrublands can be net sinks for carbon, although the capacity of these ecosystems to store carbon is variable across the landscape (Reeder and others, 2000). Grasslands/shrublands are subject to woody encroachment, which is the invasion of woody species into grasslands, or of trees into shrublands. In the conterminous United States and Alaska, grasslands/shrublands cover about 345 million hectares, and the grassland/shrubland carbon stock for these regions is about $20 \mathrm{Pg}$ (Bliss, 2003). Many grassland/ shrubland ecosystems are used as rangelands or pasturelands in the United States. Rangelands, which are dominant in the Western United States, have native grasses, forbs, or shrubs. Pasturelands, which are more dominant in the eastern part of the United States, contain introduced forage plant species rather than native plants. On rangelands and pasturelands, $\mathrm{N}_{2} \mathrm{O}$ emissions are largely influenced by the presence of livestock (Follett and others, 2010).

Wetlands are transitional areas between uplands and aquatic ecosystems and generally can be defined as lands that are inundated periodically or permanently with water, or have 

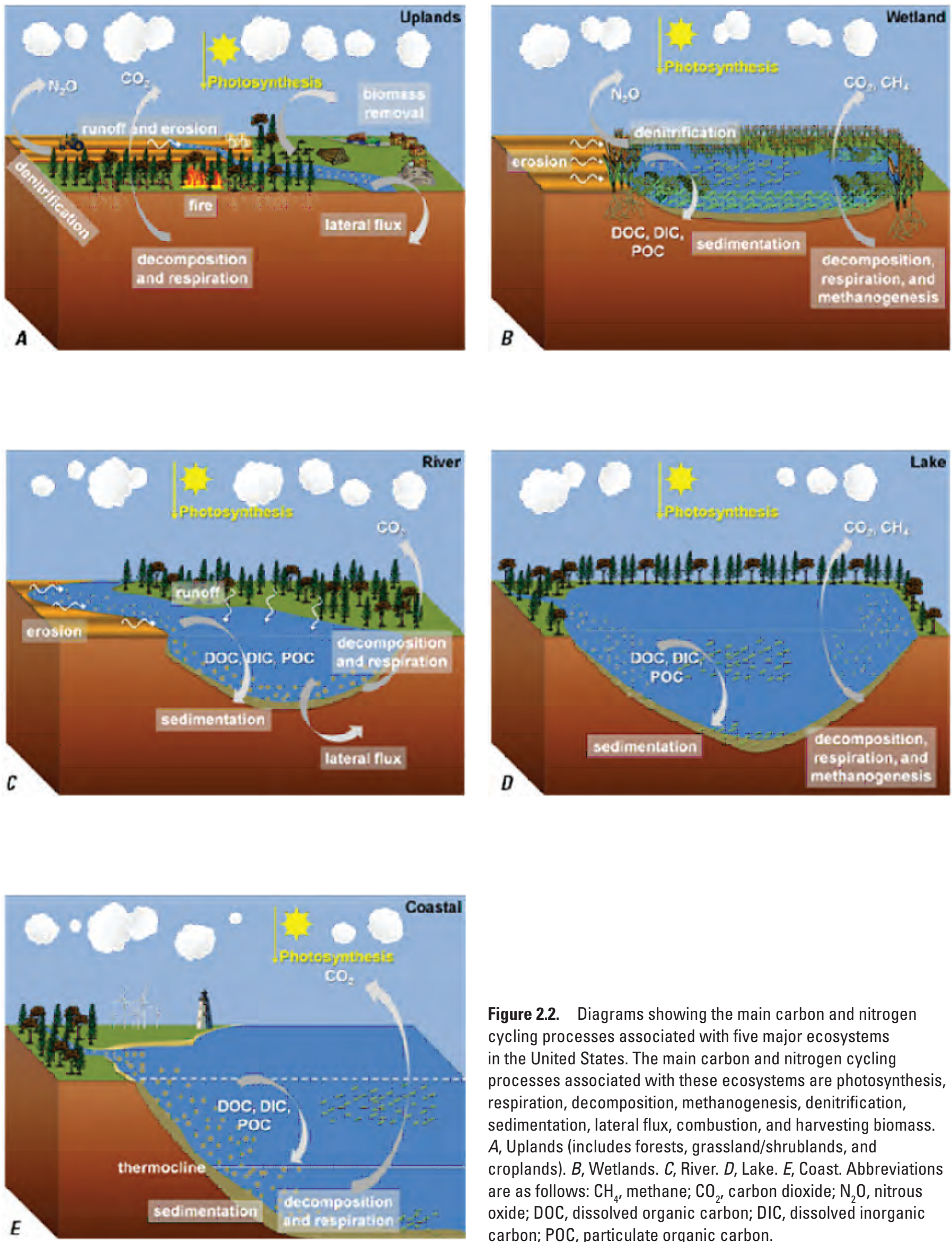

Figure 2.2. Diagrams showing the main carbon and nitrogen cycling processes associated with five major ecosystems in the United States. The main carbon and nitrogen cycling processes associated with these ecosystems are photosynthesis, respiration, decomposition, methanogenesis, denitrification, sedimentation, lateral flux, combustion, and harvesting biomass. $A$, Uplands (includes forests, grassland/shrublands, and croplands). $B$, Wetlands. $C$, River. $D$, Lake. E, Coast. Abbreviations are as follows: $\mathrm{CH}_{4}$, methane; $\mathrm{CO}_{2}$, carbon dioxide; $\mathrm{N}_{2} \mathrm{O}$, nitrous oxide; DOC, dissolved organic carbon; DIC, dissolved inorganic carbon; POC, particulate organic carbon. 
saturated soils, and support vegetation adapted to anaerobic conditions (fig. 2.2B). Carbon is stored mainly in the soil carbon pool, which is the result of saturated, anaerobic soils that slow the decomposition of biomass production; however, both woody and nonwoody vegetation and sediments also contribute to sequestered carbon in wetlands. The primary productivity in wetlands can be highly variable; wetlands that receive most of their water from precipitation have low primary productivity, but wetlands (such as river floodplains) that receive pulses of nutrients typically are very productive (Reddy and DeLaune, 2008). Carbon is lost from wetlands through methanogenesis in anaerobic soils and through oxidation of organic matter when wetlands are drained. Therefore, wetland carbon sequestration is a balance of soil and plant carbon sequestration, loss of carbon through methanogenesis, and loss of carbon due to drainage of wetlands. Only 48 percent of the original wetland area in the conterminous United States still exists (CCSP, 2007). The current wetland acreage in the conterminous United States is 70 million hectares with 43 million hectares more in Alaska. Wetlands in the conterminous United States store $20 \mathrm{PgC}$. An additional $42 \mathrm{PgC}$ are stored in Alaskan wetlands (Bridgham and others, 2006).

Global estimates exist for GHG fluxes from inland waters (Tranvik and others, 2009), and national estimates exist for the export of carbon from rivers to oceans (Pacala and others, 2001); however, national estimates of GHG fluxes from inland waters (for example, lakes and impoundments), coastal systems, and estuarine systems are lacking. Rivers (fig. 2.2C) in the conterminous United States export an estimated 30 to $40 \mathrm{TgC} / \mathrm{yr}$ to the oceans (Pacala and others, 2001) and global exports have been estimated at $0.9 \mathrm{PgC} / \mathrm{yr}$ (Tranvik and others, 2009). Exports are the sum of four carbon fractions: PIC, POC, DIC, and DOC. Globally, approximately 46 percent of riverine carbon is in organic form ( $25 \%$ dissolved and $21 \%$ particulate) and 38 percent is transported as dissolved $\mathrm{CO}_{2}$ (CCSP, 2007).

Considerable amounts of dissolved carbon and sediment are transported and then stored in inland water bodies, estuaries, and coastal waters (fig. 2.2D). For example, global estimates state that lakes stored $820 \mathrm{Pg}$ of carbon during the Holocene Epoch (Einsele and others, 2001), which is comparable to the global estimates of carbon currently stored in the soil surface layer $(1,350$ to $1,576 \mathrm{Pg})$ and in terrestrial biomass (460 Pg) (Post and others, 1982; Raich and Schlesinger, 1992; Eswaran and others, 1993). Thus, quantification of inland aquatic processes related to carbon, nutrient, and sediment transport is critical for accurately quantifying regional and national carbon budgets and assessing aquatic carbon cycling. Lakes and impoundments (reservoirs and farm ponds) sequester carbon through burial of organic matter in sediments (Cole and others, 2007; Tranvik and others, 2009). Tranvik and others (2009) estimated that global burial of organic carbon in lakes and impoundments may account for $0.6 \mathrm{PgC} / \mathrm{yr}$. Global emissions of $\mathrm{CO}_{2}$ from lakes and reservoirs have been estimated at approximately $0.8 \mathrm{PgC} / \mathrm{yr}$ (Tranvik and others, 2009). Methane emissions from lakes and impoundments could be even more important than $\mathrm{CO}_{2}$ in terms of GWP. The magnitude of GHG emissions from lakes, ponds, and reservoirs in the United States alone is unknown.

The transport of carbon, sediment, and nutrients to coastal waters stimulates primary productivity and leads to carbon burial in coastal sediments and sequestration in the deep ocean (fig. 2.2E). Nutrient additions to coastal systems cause an increase in the $\mathrm{CO}_{2}$ uptake in coastal systems (van Geen and others, 2000; Hales and others, 2005). Seitzinger and Mayorga (2008) estimated that the carbon production in coastal waters that are specifically fueled by nitrogen loading had a total global estimate of $20 \mathrm{TgC} / \mathrm{yr}$. The fate of this new coastal primary production of carbon and the terrestrial organic carbon exported by rivers is related to both its composition and the rate of sediment supply by rivers (Boudreau and Ruddick, 1991; Hedges and Keil, 1995; Dagg and others, 2004). Finally, this influx of nutrients and coastal productivity can result in the production of significant amounts of $\mathrm{CH}_{4}$ and $\mathrm{N}_{2} \mathrm{O}$ (Bange, 2006; Hirota and others, 2007). The estimates of current carbon stocks and GHG emissions for each ecosystem described above are shown in table 2.1.

Table 2.1. Carbon stocks in the conterminous United States and Alaska, and greenhouse-gas emissions from major ecosystems in the conterminous United States only, as reported by recent studies.

[For each carbon, methane, and nitrous-oxide flux value, a carbon source is indicated by a positive value and a sink is indicated by a negative value. Abbreviations and symbols are as follows: LULUCF, land use, land-use change, and forestry; $\mathrm{TgC}$, teragrams of carbon; $\mathrm{TgC} / \mathrm{yr}$, teragrams of carbon per year; $\mathrm{TgCH}_{4} / \mathrm{yr}$, teragrams of methane per year; $\mathrm{TgN}_{2} \mathrm{O} / \mathrm{yr}$, teragrams of nitrous oxide per year; -, negligible value; NA, data not currently available]

\begin{tabular}{|c|c|c|c|c|}
\hline Ecosystem & $\begin{array}{c}\text { Carbon } \\
\text { stock } \\
\text { TgC }\end{array}$ & $\begin{array}{c}\text { Carbon } \\
\text { flux } \\
\mathrm{TgC} / \mathrm{yr}\end{array}$ & $\begin{array}{c}\text { Methane } \\
\text { flux } \\
\mathrm{TgCH}_{4} / \mathrm{yr}\end{array}$ & $\begin{array}{c}\text { Nitrous } \\
\text { oxide flux } \\
\mathrm{TgN}_{2} \mathrm{O} / \mathrm{yr}\end{array}$ \\
\hline Forests & $57,000^{\mathrm{a}}$ & $-162^{\mathrm{d}}$ & - & - \\
\hline $\begin{array}{l}\text { Grassland/shrub- } \\
\text { lands }\end{array}$ & $16,000^{\mathrm{b}}$ & $-0.05^{\mathrm{d}}$ & $0.03^{\mathrm{d}}$ & $0.09^{\mathrm{d}}$ \\
\hline Croplands & $20,000^{\mathrm{b}}$ & $-8.8^{\mathrm{d}}$ & $0.1^{\mathrm{d}}$ & $0.16^{\mathrm{d}}$ \\
\hline Wetlands & $62,000^{c}$ & $-9.5^{\mathrm{e}}$ & $3.1^{\mathrm{e}}$ & NA \\
\hline Aquatic habitat ${ }^{\mathrm{f}}$ & NA & -30 to $-40^{\mathrm{g}}$ & NA & NA \\
\hline
\end{tabular}

${ }^{a}$ Source: Goodale and others (2002). Forest and woodland pools include aboveground and belowground live vegetation for trees and understory vegetation, dead wood, litter, and soil organic matter below the litter layer to a depth of 1 meter.

${ }^{\mathrm{b}}$ Source: Bliss (2003).

${ }^{\mathrm{c}}$ Source: Bridgham and others (2006). This estimate accounts for vegetation and soil organic carbon pools.

${ }^{\mathrm{d} S}$ Source: U.S. Department of Agriculture (USDA, 2008).

${ }^{\mathrm{e}}$ Source: CCSP (2007).

fincludes rivers, lakes, and coastal areas. Currently, only carbon-flux estimates from rivers are available at a national level.

${ }^{g}$ Source: Pacala and others (2001). Refers only to lateral flux via rivers. 


\subsection{Effects of Major Controlling Processes}

\subsubsection{Effects of Land-Use and Land-Cover Change and Land-Management Change}

The examination of carbon sequestration and emissions requires an analysis of changes in both land use (for example, conversion of agricultural land to urban development) and land cover (for example, harvesting trees on a parcel used for forestry). Changes in LULC influence biogeochemical cycles and the carbon and GHG status of an ecosystem (Meyer and Turner, 1992; Houghton and others, 1999). Changes to the Earth's surface that are caused by human activity can have significant effects on ecosystem composition, structure, and function. For example, current global-change studies estimate that approximately 50 percent of the Earth's ice-free land surface has been transformed. This land transformation was caused by major changes in land use and land cover, such as clearing forests for agriculture. If this estimate also included land that was in its "wild" state before being altered by human activity, this number would be much larger (B.L. Turner and others, 2007). When forests or other ecosystems are degraded or cleared, stored carbon is released into the atmosphere.

Tropical deforestation alone released roughly 15 to 25 percent of annual global GHG emissions during the 1990s (Gibbs and others, 2007). Changes in LULC generally take two forms: (1) conversion from one land-cover type to another (for example, forest to agricultural use) or (2) modification of a condition within a type (for example, timber harvest with subsequent regeneration of forest).

During the period from 1700 to the 1930s, major LULC changes in the United States occurred when native forests and prairies were converted to agricultural lands. In the 20th century, the trend reversed due to the following: (1) as farms were abandoned, both managed and unmanaged forests were regenerated; (2) the demand for harvested wood for fuel decreased; and (3) fire-suppression methods increased the forest biomass (Houghton and others, 1999; CCSP, 2007). These historical LULC changes were identified mainly by inventory or survey methods, but more current large-scale LULC change studies have been based on a combination of inventories, surveys, and remote-sensing techniques (Meyer and Turner, 1992; Sleeter and others, 2010). Using these methods, studies have shown that there are strong regional differences driving LULC change in the United States. For example, apart from ecosystem disturbance, both agricultural intensification and urbanization have been the major land-use changes in regions such as California during recent decades (Sleeter and others, 2010). In contrast, economic gain fostered an increase in agricultural land cover at the expense of native grasslands in the western Great Plains between 1973 and 1986; however, between 1986 and 2000, public policy, which encouraged native grassland restoration, drove a conversion from agriculture back to grassland (Drummond, 2007). In the Eastern United States, trends, causes, and consequences for LULC change were far more complex. A recent study found that recent LULC changes were associated with forest harvesting and regrowth, agricultural abandonment, and development (Drummond and Loveland, 2010). These findings in LULC changes have significant implications on the capacities of ecosystems to sequester carbon in these regions.

A contemporary driver of LULC change is land management. By applying changes in the types of land management (for example, change in cropland tillage) or in the intensity of land-management activities (for example, active use of prescribed burning), it is possible to manage forests and other ecosystems to enhance carbon sequestration. Recent studies showed that the active use of prescribed burning in fire-dependent forest ecosystems helps to increase the rate of carbon sequestration (Wiedinmyer and Hurteau, 2010). In the Pacific Northwest, increasing the time between harvests and reducing the total number of acres to be harvested are two management activities that would enable forests to store theoretically up to 40 percent more carbon (Hudiburg and others, 2009).

Grassland/shrublands in the Western United States are frequently used for livestock grazing, and the lands store and process far less carbon than forests (Negra and others, 2008); however, with sustainable grazing intensity, grassland/shrublands cumulatively have the potential to sequester a significant quantity of carbon when integrated over approximately 350 million hectares in the United States (Joyce, 1989; Baron and others, 2002; Elmore and Asner, 2006). Reducing grazing intensity also contributes to a reduction in the emissions of $\mathrm{N}_{2} \mathrm{O}$ and $\mathrm{CH}_{4}$ (Baron and others, 2002). Two-thirds of the grassland/shrublands in the United States are identified as having some limits on productivity and carbon storage; therefore, increases in potential soil carbon pools on these lands would be variable and possibly slow (Bruce and others, 1999).

Changes in crop-management practices, such as implementing crop rotation, planting winter cover crops, and setting aside land according to the Conservation Reserve Program (CRP) and Wetland Reserve Program (WRP) agreements, have great potential to increase carbon stock in croplands (McLachlan and Knispel, 2005; Rees and others, 2005; Lal and others, 2007). The CRP offers incentives to encourage the reclamation of former agricultural lands by converting it to other vegetation (often grasses), and this change has resulted in increased carbon storage of approximately 0.6 megagrams of carbon per hectare per year in the United States (Schuman and others, 2002). Additionally, implementation of conservation practices, such as residue management and reductions of summer fallow lands coupled with no-till and reduced-tillage, may be possible land-management activities that may help enhance carbon sequestration and reduce GHG emission in croplands (Tan and others, 2006, 2007). These activities also may help improve soil quality and crop productivity (Causarano and others, 2006).

Land-management activities that affect carbon cycling in terrestrial ecosystems also influence carbon processes in aquatic ecosystems. For example, reservoirs and farm ponds can sequester carbon through the burial of organic matter in 
aquatic sediments (Cole and others, 2007; Tranvik and others, 2009); the number of farm ponds in agricultural areas of the United States has been increasing 1 to 2 percent annually (Downing and others, 2006). Carbon burial is influenced by rates of erosion and carbon concentration in upland soils, which in turn are influenced by land use. For example, tillage increases the erosion of agricultural land, and sediment resulting from the erosion is deposited in downstream water bodies. Farm ponds can be created to capture sediment that otherwise would enter streams and rivers; however, the utility of farm ponds as carbon-sequestration tools depends on their longevity. Numerous future land-management activities may intentionally or unintentionally alter sediment loads to coastal systems as well. Land-management activities that may positively or negatively affect sediment flux to coastal areas include building new reservoirs, fortifying river channels and banks, and trapping farm sediment (Syvitski and others, 2003). Sediment diverted for inland wetland or floodplain restoration or coastal wetland creation will lower sediment supply to the ocean (Khalil and Finkl, 2009).

\subsubsection{Effects of Ecosystem Disturbances}

Ecosystem disturbances are episodic events that may affect the composition, structure, and (or) function of an ecosystem (Pickett and White, 1985; E.A. Johnson and Miyanishi, 2001; M.G. Turner and others, 2001). The effects of ecosystem disturbances are treated differently from the effects of global environmental change, which includes sustained alterations in climate that may arise from increasing $\mathrm{CO}_{2}$ in the atmosphere or nitrogen deposition (B.L.I. Turner and others, 1990). The effects of ecosystem disturbances also are separate from the effects of LULC changes, such as the conversion of forest to cropland. Major ecosystem disturbances are one of the primary mechanisms that have the potential to reset carbonsequestration pathways and change ecosystems from carbon sinks to sources (Baldocchi, 2008; Running, 2008). Examples of such disturbances include wildland or prescribed fires, hurricanes and storms, and insect or disease outbreaks.

Wildland fire contributes to the loss of stored carbon in terrestrial ecosystems and the release of both $\mathrm{CO}_{2}$ and $\mathrm{CH}_{4}$ emissions into the atmosphere (Simpson and others, 2006; Wiedinmyer and Neff, 2007). A study using a global airsample dataset indicated that burning biomass has contributed to an increase in atmospheric methane levels (Simpson and others, 2006). A study using satellite imagery showed that, between 2002 and 2006, the average annual $\mathrm{CO}_{2}$ emissions were estimated at $213 \pm 50 \mathrm{Tg} / \mathrm{yr}$ for the conterminous United States and $80 \pm 89 \mathrm{Tg} / \mathrm{yr}$ for Alaska (Wiedinmyer and Neff, 2007). The EPA estimated that total $\mathrm{CO}_{2}$ emissions in the United States from forest fires amounted to $318 \mathrm{Tg} / \mathrm{yr}$ in 2007 and $189.7 \mathrm{Tg} / \mathrm{yr}$ in 2008 (EPA, 2010). These current estimates of carbon emissions actually may underestimate the amount of carbon historically emitted by fires because fire-return intervals (the number of years between two successive fire events at a specific site or an area of a specified size) actually have increased by an order of magnitude in many areas relative to historic fire regimes (Rollins and others, 2001; Cleland and others, 2004; Grissino-Mayer and others, 2004).

Greenhouse-gas emissions from wildland fires are difficult to estimate because of the temporal and spatial variability of their occurrences, the long-term effects of fires of mixed severity, and the differing degrees of combustion of aboveground biomass and soil organic matter stocks (Neff and others, 2005; Wiedinmyer and Neff, 2007). In the Western United States, an increase in fire-suppression activities during the 20th century is partially responsible for the increase in forest biomass in fire-dependent ecosystems (McKelvey and Busse, 1996; Houghton and Hackler, 2000; Canadell and Raupach, 2008); however, shifts in climate have been correlated with longer wildfire seasons and an increase in the frequency of large fires (those that cover more than 9,400 ha) (Westerling and others, 2006). One result of very large wildfires is that a severe fire season lasting only one or two months can release a considerable amount of carbon dioxide and possibly cancel out the effects of carbon sequestration in forests (Wiedinmyer and Neff, 2007). Because many of these ecosystems are adapted to fire, suppression of wildfires to reduce GHG emissions may not yield greater long-term emissions reductions when compared with GHG emissions from areas where fire is retained or is re-established in its functional ecosystem role.

Other disturbances, such as windstorms or insect outbreaks, do not cause the same direct and rapid emissions of $\mathrm{CO}_{2}$ as fires, but they do change trees from live carbon sinks to dead and slowly decaying carbon sources over large areas (Running, 2008). In the Eastern United States, strong hurricanes usually occur in two out of every three years. Just one storm can change the equivalent of 10 percent of the total annual carbon sequestrated by forests in the United States into dead and downed biomass (McNulty, 2002). Generally, limited amounts of destroyed timber are salvaged following a major hurricane, and eventually the carbon stored in the trees returns to the atmosphere (McNulty, 2002). Insect outbreaks, such as the mountain pine beetle epidemic in forest ecosystems of the Rocky Mountains, have the same effect. Large amounts of carbon emissions from forests are lost either directly (because live biomass has been converted to dead organic matter) or indirectly (because the death of the forest leads to lost carbonsequestration capacity). Because of the changing climate regime, these types of insect outbreaks, together with highseverity fires and storm damage, could put forest carbon sinks at risk.

\subsubsection{Effects of Climate Change, Elevated Carbon Dioxide, and Nitrogen Fertilization}

Climate change, increasing atmospheric $\mathrm{CO}_{2}$ concentrations, and increasing reactive nitrogen deposition have a strong potential to influence carbon-cycling processes in terrestrial and aquatic environments (Canadell and others, 2007; Reay and others, 2008; McMahon and others, 2010). 
The fourth assessment report (AR4) by the IPCC (2007) stated that the best estimates of likely increases in the mean global surface-air temperature by the end of the 21 st century are between $1.1^{\circ} \mathrm{C}$ and $2.9^{\circ} \mathrm{C}$ for the "low scenario" and $2.4^{\circ} \mathrm{C}$ and $6.4^{\circ} \mathrm{C}$ for the "high scenario," and that the major cause of global warming is the human-induced increase of GHG in the atmosphere. Climate change may influence the frequency of extreme events, such as droughts, fires, heat waves, flooding, and hurricanes, thereby releasing additional carbon into the atmosphere. One of the most profound effects of increasing temperatures may be a thaw of permafrost in the northern latitudes (Camill, 2005; Lawrence and Slater, 2005). Climate change can also bring gradual changes to the length of the growing season and shifts in the geographical ranges for some plants (IPCC, 2007). Studies of the effects of climate change on both permafrost and the growing seasons and geographical ranges of plants contain large uncertainties. An increase in the length of the growing season may promote more crop and tree growth, especially of plants in northern regions and higher elevations that act as carbon sinks (Euskirchen and others, 2006; IPCC, 2007); however, many studies indicate that ecosystem respiration has increased due to warming (Bond-Lamberty and Thomson, 2010). Therefore, the carbon loss from ecosystem respiration may substantially reduce or even outweigh the gain from the increase in the length of the growing season (Piao and others, 2008).

Increases in atmospheric $\mathrm{CO}_{2}$ may enhance crop production and water-use efficiency (WUE; the ratio of $\mathrm{CO}_{2}$ uptake to evapotranspiration) (Allen and others, 1996). For forests, the Free-Air $\mathrm{CO}_{2}$ Enrichment (FACE) experiments by Norby and others (2005), tree-ring studies by Soulé and Knapp (2006), and improved field-data analysis by McMahon and others (2010) all suggest that the growth rates for trees may increase with increasing atmospheric $\mathrm{CO}_{2}$; however, other studies have shown that the magnitude of growth enhancement can vary from 0 to 60 percent when atmospheric $\mathrm{CO}_{2}$ is doubled (Running, 2008).

Reay and others (2008) studied the possible effects of nitrogen deposition on global carbon sinks; they noted that emissions of reactive nitrogen $(\mathrm{Nr}$; for example, nitric oxide (NO) and nitrogen dioxide $\left(\mathrm{NO}_{2}\right)$ ) currently are three to five times the global preindustrial levels (mid-1800s) due to fossilfuel combustion and agricultural activities (Galloway and others, 2004). Under the SRES A2 storyline, worldwide Nr deposition will increase by between 50 and 100 percent by 2030 relative to 2000 (Dentener and others, 2006; Reay and others, 2008). When deposited on land and water, $\mathrm{Nr}$ has a stimulating effect on primary productivity in ecosystems that are nitrogenlimited (Vitousek and Howarth, 1991; Elser and others, 2007). On land, an increase in $\mathrm{Nr}$ can result in a net increase in forest biomass (and hence, carbon sequestration), except in areas that already receive high levels of atmospheric nitrogen. Similarly, agricultural lands, which often are heavily fertilized, are not expected to see an increase in crop biomass. Increases in primary productivity in oceans can lead to increased burial of organic matter; however, increasing greenhouse-gas emissions from the ocean into the atmosphere may largely offset the carbon-sequestration effect. Reay and others (2008) concluded that carbon uptake by both northern and tropical forests might increase by up to $0.67 \mathrm{Pg} / \mathrm{yr}$ and $0.14 \mathrm{Pg} / \mathrm{yr}$, respectively, by 2030 . This would amount to an additional 10 percent of projected $\mathrm{CO}_{2}$ emissions, but the increase was considered to be an upper limit; an increased uptake of 1 to 2 percent of $\mathrm{CO}_{2}$ emissions was considered more likely (Reay and others, 2008). The enhancement of $\mathrm{CO}_{2}$ uptake in oceans by nitrogen deposition was estimated to be less than $0.3 \mathrm{PgC} / \mathrm{yr}$ (Reay and others, 2008). The potential for increased carbon sequestration in freshwater systems (lakes, impoundments, and wetlands) due to the addition of nutrients was thought to be potentially significant but required further investigation (Elser and others, 2007; Reay and others, 2008).

Complicated interactions exist among climatic and atmospheric factors and among carbon-nitrogen-water cycles. The combined effect (synergies and tradeoffs) of driving forces on an ecosystem biogeochemical cycle and productivity needs detailed analysis. For example, research results based on measurements made at hundreds of European forest-monitoring plots indicate that an increase in carbon-sequestration rates in response to increased $\mathrm{Nr}$ deposition will only occur if the site already is nitrogen-limited (de Vries and others, 2009). The AR4 (IPCC, 2007) also indicated that all regions of the world show an overall net negative impact of climate change on water resources and freshwater ecosystems and that water resources will depend on trends in both climatic and nonclimatic factors. Because an increase in carbon sequestration may require more water supplies, tradeoffs between carbon and water resources must also be assessed.

\subsection{Carbon Sequestration and Ecosystem Services}

In order to properly evaluate appropriate management actions to enhance carbon sequestration, it is important to consider the effects of these actions on ecosystem services. Ecosystem services are the benefits that people and societies derive from the natural processes that sustain ecosystems (Daily, 1997), and they can be generally cataloged into four broad areas: supporting, regulating, provisioning, and cultural (Millennium Ecosystem Assessment, 2003). Supporting services include basic ecosystem functions such as soil formation, whereas provisioning services are important sources of food and fiber. Regulating services help control climate change through carbon sequestration. Cultural services include recreation and education. The concept of ecosystem services is inherently based on the value or importance to humans, but the expression of those services is controlled by the underlying complex ecological structure and processes. (Daily and Matson, 2008; Fisher and others, 2008) (fig. 2.3). In some cases, the links between structure, processes, and resulting services is fairly straightforward. For example, the degree to which a specific plant community can support a given wildlife 
population can be determined directly by measuring community attributes, such as species composition, height, and age. Other services, such as improving water quality by converting nitrate to nitrogen gas through denitrification, are controlled by more complex interactions between multiple ecosystem attributes (for example, carbon, reduction-oxidation (or redox) status, soil microbial population, and temperature) that are more difficult to measure. These relations also are altered by temporal and condition gradients (fig. 2.3), which result in dynamic processes and significant variability across and within different ecosystems. This makes the relations difficult to measure and quantify at large spatial scales. Ecological production function models based on biophysical inputs are often used to produce spatial estimates of specific services (Nelson and others, 2009).

An explicit recognition of the complex relations among ecosystem structure, processes, and services is critical to understanding the potential ancillary effects of carbon-sequestration strategies. Any change, either anthropogenic or naturally occurring, that affects structural components (such as plant-community composition) or processes (such as nutrient cycling) may affect the quality, quantity, and types of services produced from that ecosystem. The quantification of the effect is a difficult task because some services, such as biodiversity, can be both a cause of the way an ecosystem functions and a response that varies with changing management activities (Hooper and others, 2005;
Costanza and others, 2007); therefore, the effects of carbonspecific components may be hard to separate.

Another problem is that the responses of multiple services to specific carbon-related land-management activities are not well studied. Nelson and others (2008) concluded that policies aimed at increasing carbon sequestration did not necessarily increase species conservation and that highly targeted policies were not necessarily better than more general policies. The study by Nelson and others (2008) demonstrates the likelihood that many of the possible management activities and sequestration strategies may affect those ecosystem services that are of direct importance to landowners and land managers. For example, an afforestation plan that is designed to increase carbon sequestration may alter migratory bird habitat depending on the location and the variety of species chosen for that forest (Hamilton and others, 2005; Twedt and others, 2006); therefore, ecological tradeoffs may be necessary when planning land-management activities.

\subsection{Ongoing Global and National Carbon and Greenhouse-Gas Inventories and Assessments}

Currently, there are many ongoing national and international carbon inventories and assessments. This section describes some of the objectives and methods of these

\section{Sustaining and Restoring Ecosystems: Structure to Function to Services}

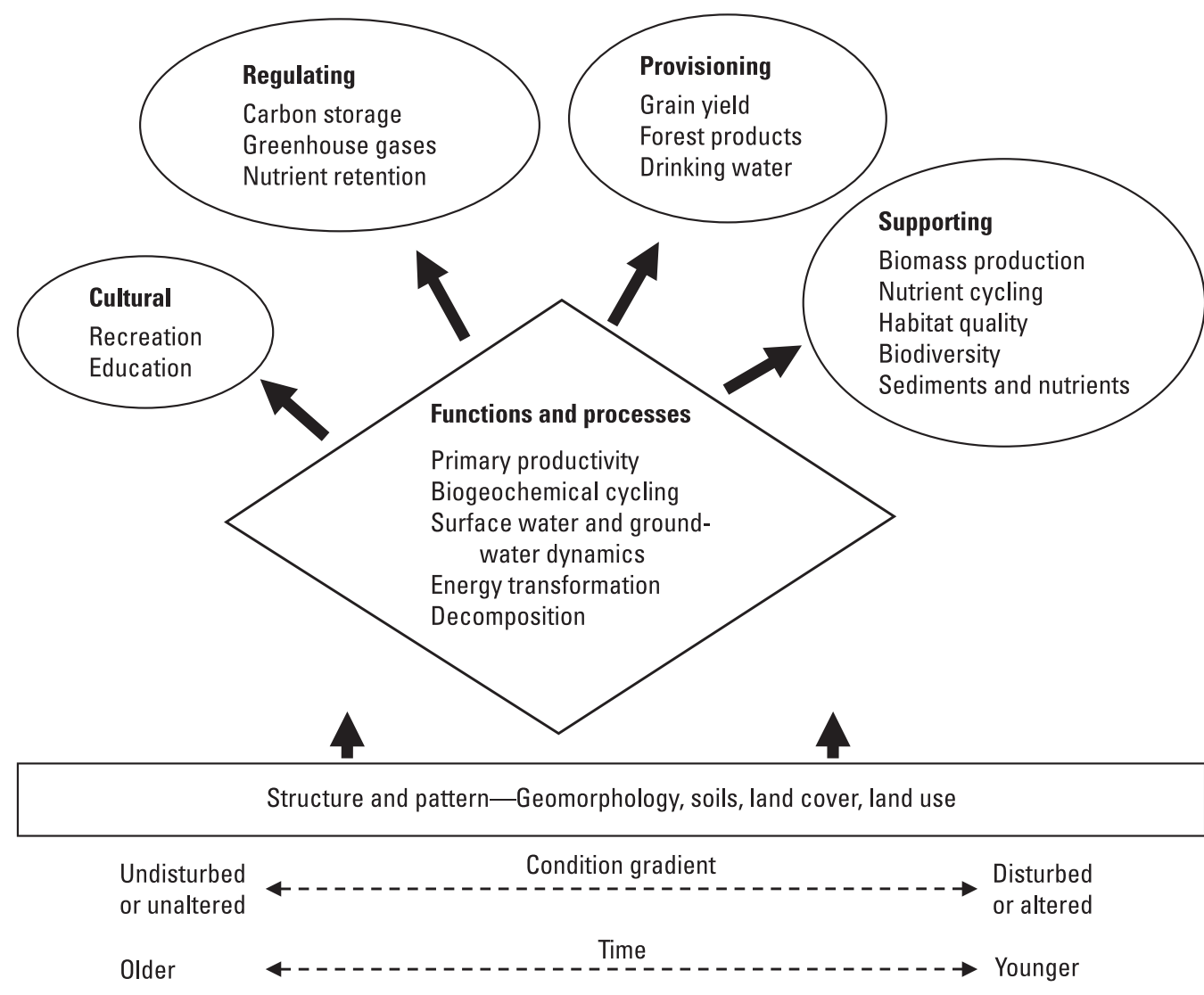

Figure 2.3. Conceptual diagram of the relations among ecosystem structure, function, and services. 
large-scale projects. The terms "inventory" and "assessment" are similar in that they both provide estimates of resource conditions; however, the inventory methods focus on measurements of present resource conditions rather than providing an estimate of future carbon-sequestration capacity and $\mathrm{GHG}$ fluxes.

\subsubsection{Intergovernmental Panel on Climate Change Scenarios and Guidelines}

The Intergovernmental Panel on Climate Change (IPCC) is an international scientific body charged with conducting global assessments related to climate change. Since 1990, the IPCC has produced four comprehensive assessment reports (IPCC, 1990, 1992, 2001, 2007). In 2000, a special report on emission scenarios (SRES) was produced by the IPCC (Nakicenovic and others, 2000). The SRES framework provides assumptions about future potential socioeconomic, demographic, and technological changes that serve as storylines or pathways to project future potential GHG emissions and changes in climate. The SRES does not set forth policies that explicitly address climate change; it provides a reference for the evaluation of potential mitigation activities. The SRES includes four main storylines that produce four families of scenarios: A1, A2, B1, and B2. In brief, the A1 family describes a future with fast economic growth, a population increase that peaks in mid- $20^{\text {th }}$ century and then declines, and a rapid introduction of new technologies until the middle of the 21st century, after which there is a decline. The A2 family describes a future with economic growth that is tied to regional interests, a slow and steady change in population, and technological adaptation that is not as consistent and widespread as that described in A1. The B1 family describes a future where the economy is focused on the service and information sectors of society; there is a peak in the population with a drop in the middle of the 21 st century, as in A1, but this population uses fewer material goods and strives to introduce more environmentally sustainable technologies. Finally, the B2 family describes a world in which there is a focus on developing local economies and promoting environmental sustainability; the population growth is slow, and the development and acceptance of new technologies also are slow. The IPCC projected future emissions and climate change on the basis of the four scenarios in order to allow adequate representation of the inherent uncertainties associated with predicting future climate change.

In 2006, the IPCC published guidelines for agriculture, forestry, and other land uses (AFOLU) that defined three tiers, three different approaches, and two methods for assessing and reporting GHG emissions (IPCC, 2006). The tier 1 method is a basic method that uses default values by LULC type and is most suitable for nations with limited inventory and remotesensing capabilities. The tier 2 (inventory and bookkeeping) and tier 3 (inventory and process-based models) methods represent more demanding technical capabilities, accuracy, and data requirements. Three different IPCC approaches were described in the guidelines for handling LULC and changes, ranging from simple to more complex treatment of those changes. In describing the approaches, the IPCC recommended six standard AFOLU categories for consistent and comparable reporting: forest land, cropland, grassland, wetlands, settlements, and other land. Finally, the IPCC elaborated on two different methods for GHG emission accounting: the gain-loss method and the stock-difference method.

\subsubsection{Examples of Continental-Scale Greenhouse-Gas Inventories and Assessments}

Continental-scale inventories and assessments of carbon and GHG have been conducted for various countries and regions in the world; a few examples reported in recent literature are summarized below for Australia, the European Union, and China. In the Australian inventory, carbon storage and GHG emissions $\left(\mathrm{CO}_{2}, \mathrm{CH}_{4}\right.$, and $\left.\mathrm{N}_{2} \mathrm{O}\right)$ have been assessed for terrestrial ecosystems by using a prototype National Carbon Accounting System (NCAS; Richards and Brack, 2004). Carbon stocks and GHG fluxes are inventoried and forecasted in spatially and temporally explicit fashions for major ecosystems (such as forests, grasslands, and croplands) by considering major controlling processes, including climate change, soil productivity, land-cover change, soil decomposition, and landmanagement activities. The NCAS methodology is based on the combined use of Landsat remote-sensing imagery, current and future potential climate-model estimates, soil, inventory, and land-management databases. At the core of the NCAS methodology is an ecosystem biogeochemical (BGC) model that uses accounting algorithms implemented for both nonspatial and spatial applications (Richards and Evans, 2000). Although the prototype NCAS will be enhanced during the next several years, the assessment results have been incrementally reported. In 2007, the most recent year for which reporting was conducted, the net GHG emissions for Australia from agricultural land use, deforestation, and net uptake from forest plantation accounted for 24,21 , and $-5.8 \mathrm{TgC}$, respectively (Australian Government, Department of Climate Change, 2009). The development of a new phase of the NCAS is based on the use of remote sensing for tracking LULC changes and a process-based ecosystem biogeochemical model to estimate GHG emissions (IPCC tier 3 and approach 3 in IPCC (2006)). It is worth noting that the NCAS methodology is used in Australia for both GHG accounting and monitoring purposes.

A recent European Union-wide assessment was conducted for terrestrial ecosystems to assess carbon and GHG $\left(\mathrm{N}_{2} \mathrm{O}, \mathrm{CH}_{4}\right)$ fluxes into and out of forest and cropland ecosystems. A compilation approach for the assessment used different methods (inventory accounting, process-based ecosystem models, and direct remote sensing) and source datasets (national forest or soil inventory, flux tower, and remote-sensing sources, all of which were collected over a five-year period between 2003 and 2009) (Ciais and others, 2010; Luyssaert and others, 2010). For both forest and cropland ecosystems 
of the European Union's 25 nations, different carbon pools, fluxes, and processes (such as harvesting, decomposition, and wildfire) were analyzed using the approach. Uncertainties were quantified (where feasible) and communicated following IPCC guidelines. Results from the different methods and datasets then were analyzed and compared, and average values were derived. Results showed that, overall, forest ecosystems in the European Union had an average net primary productivity (NPP) of $520 \pm 75$ grams of carbon per square meter per year. The total forested area included in this estimate was $1.32 \times 10^{6}$ square kilometers $\left(\mathrm{km}^{2}\right)$ to $1.55 \times 10^{6} \mathrm{~km}^{2}$. The net biome productivity (NBP) was $75 \pm 20$ grams of carbon per square meter per year. For cropland systems, the average NPP ranged between 490 to 846 grams of carbon per square meter per year, and the NBP (estimated by using flux-tower or soilinventory data) averaged a net loss of 23 grams of carbon per square meter per year. Cropland assessment also considered the $\mathrm{N}_{2} \mathrm{O}$ and $\mathrm{CH}_{4}$ fluxes, which resulted in a combined global warming potential (GWP) range of 42 to 47 grams carbon equivalents per square meter per year (Ciais and others, 2010; Luyssaert and others, 2010). As a result, the study showed that European Union forests and croplands ecosystems are a net carbon sink of 52 grams of carbon per square meter per year.

A recent study on China's carbon balance found that China's terrestrial ecosystems (forests, grasslands/shrublands, and croplands) also were a net carbon sink and averaged between 0.19 and $0.26 \mathrm{PgC} / \mathrm{yr}$ (Piao and others, 2009). The study evaluated aboveground vegetation and soil organic carbon by using a methodology in which forest inventory data were (1) analyzed and interpolated together with satellite imagery, (2) calibrated with an atmospheric $\mathrm{CO}_{2}$ inversion method, and (3) attributed with the use of five process-based models. Because soil data were very limited, the amount of carbon in the soil was estimated by using a regression approach. In addition to estimating the overall carbon-sequestration capacity, the study also reported per-ecosystem estimates of carbon-sequestration capacity and compared those estimates with estimates for the United States, by ecosystem. For example, the study found that aboveground biomass accumulation in forests, on a perarea basis, was $57 \pm 26$ grams of carbon per square meter per year for China; the same type of accumulation in forests in the United States is reported to be 52 to 71 grams of carbon per square meter per year. Woody encroachment (the invasion of woody plants into grasslands and trees into shrublands) in China was estimated at approximately 30 percent of total forest biomass accumulation. In the United States, woody encroachment represents about 30 percent of the total terrestrial carbon sink (CCSP, 2007). Overall, the study noted that the total terrestrial carbon sink of China is comparable to that of continental Europe but is about half the size of the sink in the United States. One significant weakness, as noted in the report, was that the study did not account for land-use change, which is a significant factor for China (Piao and others, 2009). These studies indicate the global-scale impact from biological carbon sequestration and possible methods and techniques to follow to produce a successful assessment. Additionally, it is useful to compare carbon stock numbers from ecosystems in different parts of the world. Table 2.2 compares the forest stocks from studies in China and the European Union to forest stocks from the United States.

Table 2.2 Comparison of forest stocks and net forest-stock changes from three continental-scale studies of temperate forest zones.

[Abbreviations are as follows: $\mathrm{M} \mathrm{km}^{2}$, millions of square kilometers; $\mathrm{PgC}$, petagrams of carbon; $\mathrm{TgC} / \mathrm{yr}$, teragrams of carbon per year]

\begin{tabular}{lcccc}
\hline Study regions & $\begin{array}{c}\text { Forest } \\
\text { area } \\
\left(\mathbf{M ~ k m}^{2}\right)\end{array}$ & $\begin{array}{c}\text { Stocks } \\
\mathbf{( P g C )}\end{array}$ & $\begin{array}{c}\text { Net forest } \\
\text { stock } \\
\text { change } \\
(\mathbf{T g C} / \mathbf{y r})\end{array}$ & $\begin{array}{c}\text { Uncertainty } \\
\text { (percent) }\end{array}$ \\
\hline China & 1.75 & $27.1^{\mathrm{a}}$ & $-92^{\mathrm{b}}$ & $47^{\mathrm{b}}$ \\
European Union & 1.46 & $23.1^{\mathrm{a}}$ & $-110^{\mathrm{c}}$ & $27^{\mathrm{c}}$ \\
Conterminous & 2.69 & $41.3^{\mathrm{a}}$ & $-162^{\mathrm{d}}$ & $18^{\mathrm{d}}$ \\
$\quad$ United States & & & & \\
\hline
\end{tabular}

${ }^{\text {a }}$ Source: Goodale and others (2002). Forest and woodland pools include aboveground and belowground live vegetation for trees and understory vegetation, dead wood, litter, and soil organic matter below the litter layer to a depth of 1 meter.

${ }^{\mathrm{b}}$ Source: Piao and others (2009). Pools included in their stock change estimate are not clear.

${ }^{\mathrm{c}}$ Source: Luyssaert and others (2010). Pools included in their stock change estimate are not clear

${ }^{\mathrm{d} S}$ Source: U.S. Environmental Protection Agency (EPA) (2010). Pools included in the stock change estimate are aboveground and belowground biomass, litter, and soil organic carbon.

\subsubsection{Existing National-Scale Inventories and Assessments in the United States}

As of 2006, the United States has been identified as the world's second largest cumulative national source of fossilfuel-related $\mathrm{CO}_{2}$ emissions with a source of $1.6 \mathrm{Pg}$ of carbon (Marland and others, 2009). A considerable amount of work already has been done within the United States to account for the potential effect of ecological carbon sequestration in offsetting these emissions. The most comprehensive assessment related to the carbon cycle and budget is that of the first State of the Carbon Cycle Report (SOCCR) (CCSP, 2007), which is discussed above in section 2.2. Two other ongoing nationalscale studies also contribute to the state of knowledge about the Nation's carbon and GHG in ecosystems: the EPA's annual U.S. Greenhouse Gas Inventory Report (EPA, 2009, 2010), and the U.S. Forest Service's Forest and Rangeland Renewable Resources Planning Act (RPA) assessment (U.S. Department of Agriculture (USDA) Forest Service, 2000), which is conducted on a 10 -year cycle.

In the EPA's annual GHG inventory reports (EPA, 2009, 2010), GHG emission estimates are reported from a range of 
sectors including energy, industry, waste, LULC, forestry, and agriculture. The primary data sources for the annual emission reports related to LULC, forestry, and agriculture are the Forest Inventory and Analysis (FIA) program of the U.S. Forest Service (USFS) and the National Resources Inventory (NRI) of the National Resource Conservation Service (both within the USDA); these databases are augmented by the National Land Cover Database (NLCD) produced by the Multi-Resolution Land Characteristics Consortium (MRLC) (Homer and others, 2004). Because of the source data used, the annual GHG inventory reports were compiled using a tier 3 and approach 2 methodology, according to the IPCC (2006) terminology. The estimates in the GHG inventory reports address land-use change, as well as carbon emissions from agricultural and forest fires on managed lands. Alaska and Federal lands in Hawaii are not included in the current reports.

The USDA also produces periodic GHG inventory reports, which are incorporated into the EPA's annual inventories. The most recent agriculture and forestry greenhouse gas inventory (USDA, 2008) spans the time period from 1990 to 2005, and it complements EPA's Inventory of U.S. Greenhouse Gas Emissions and Sinks (EPA, 2007). The USDA report provides a more in-depth review of emissions from forestry and agricultural lands in the United States than what is presented in the EPA reports. The USDA relies on the Century (Parton and others, 1993) and Daycent (Parton and others, 1998) ecosystem models to estimate direct and indirect GHG emissions for major croplands in the United States. These models simulate fluxes of carbon and nitrogen between the atmosphere, vegetation, and soil for croplands and grazing lands. Carbon emissions from forests are estimated using the FORCARB2 model. The NRI (USDA, 2009) is an important data source for USDA's greenhouse-gas-emission inventory for the United States.

The annual FIA program conducted by the USFS provides the Nation with the most extensive and intensive in situ data about forest, species composition, timber volume, aboveground biomass, LULC classes, various ecosystem services (for example, water supply and wildlife habitat conditions), and other variables (W.B. Smith, 2002; Birdsey, 2004; W.B. Smith and others, 2009). The FIA visits between 15,000 and 60,000 plots annually across the Nation. Soil and forest health data also are collected in the FIA database, but are not as extensive as some of the other data variables. Using the FIA database as the primary data source, the USFS conducts an assessment of forest and rangelands resources every 10 years, as required by the Forest and Rangeland Renewable Resources Planning Act of 1974 (RPA) (U.S. Congress, 1974). The two most recent RPA-mandated assessments (1990 and 2000) focused on present and future resource conditions, productivity (including forest carbon), sustainability, and economic demand of forest and rangeland ecosystems (Powell and others, 1993; Langner and Flather, 1994; Joyce, 1995; Dwyer and others, 2000; Joyce and Birdsey, 2000; W.B. Smith and others, 2001, 2009; Alig and others, 2003). The upcoming 2010 RPA-mandated assessment will continue to assess resources and impacts and pressure on resources from climate change, LULC change, and global supply and demand. Although reports are not yet available, several distinct characteristics of the 2010 RPA assessment have been provided as below:

- Global effects on U.S. forest resources and trends will be considered by integrating forest-product models within a larger global forest model.

- Effects of climate change will be addressed in resource analyses, including projections of forest resources, wildlife habitat effects, and water supply.

- Analysis of forest resources will incorporate three future IPCC scenarios to address the climate change, LULC change, and uncertainty associated with the assessment.

\subsubsection{Uncertainty Assessment and Reporting in Existing National Assessments}

An evaluation of uncertainty is a critical component of resource assessments and is necessary in order for an assessment to be translated into information that is useful for formulating policy. In addition, when complex models are used as a basis for evaluating policy or management alternatives, it is important that the models are consistent, accurate, verifiable, and transparent (Prisley and Mortimer, 2004). Therefore, model validation and verification approaches, such as sensitivity analysis and expert review, are recommended.

The IPCC (2006) recommended techniques to develop estimates of uncertainty for GHG reporting and guidance for incorporating these techniques These estimates may be developed from measured data, published information, modeling approaches, and expert judgment. One widely used modeling approach is Monte Carlo simulation. Here, variables in a model are assumed to have probability distributions rather than single deterministic values; models are run multiple times and draw parameters from distributions of possible values. For example, IPCC (2006) identified a range of popular distribution functions that might be used in a simulation. The outcomes from multiple runs of the model provide a distribution of results, thereby allowing the variability of results to be quantified. In an example of this type of evaluation, Heath and Smith (2000) conducted a Monte Carlo simulation of the national forest carbon budget and reported that carbon stocks had uncertainty levels of \pm 10 percent, although fluxes had confidence intervals of 50 to 100 percent. Because many biophysical parameters (such as soil characteristics and forest growth) are not independent, but rather are strongly related, it is important to account for covariability among parameters as well. J.E. Smith and Heath (2001) found that distributional forms for variables were less important than covariability between parameters.

Several recent assessments of different aspects of GHG flux serve to illustrate viable techniques for uncertainty assessment and provide the results from similar efforts. Table 2.3 summarizes some of the carbon-sequestration quantities and uncertainties from recent studies. 
Some general lessons can be learned from these and other assessments. Uncertainties expressed as relative terms (as a percentage of a mean estimate) tend to be higher for small pools and fluxes (as noted above). Fluxes tend to have higher relative uncertainties than stocks, and estimates for detailed subcategories (for example, specific pools or components) have higher relative uncertainties than broadly aggregated categories. Similarly, geographic aggregation serves to lower relative uncertainties. As an example, in the spatial aggregation of forest-inventory data, an estimate for a State has a lower uncertainty than the collective estimate for the survey units (regions that make up the State) (Reams and others, 2005). For example, Kim and McCarl (2009) described the use of the reduction in the coefficient of variation (an uncertainty measure related to confidence interval) when conducting an assessment, because estimates were aggregated progressively from a county to a region to a State.

In the examples described above, uncertainty of carbon stocks and flux estimates is characterized by the use of confidence intervals. Spatially explicit modeling approaches also can characterize uncertainty in a spatial model or a map. In such cases, spatial patterns and relationships in uncertainty can be examined, which could lead to insights in model validation and improvement. For example, Blackard and others (2008) developed percent-error maps to graphically depict the spatial distributions of the variability of estimated biomass.

\subsubsection{Economic Analysis and Its Use in Existing National Assessments}

Climate-change mitigation assessments focus on the future ability of a system to sequester carbon and reduce $\mathrm{GHG}$ emission. Climate-change mitigation policy analyses often estimate a sector of society's capacity to abate climate change. Some approaches include the specific analyses of proposed legislation (for example, EPA, 2009; Larsen, 2009; Ross and others, 2009) or approximations of national levels of commitment to incentives, investments, regulatory reforms, and urgency for action (Creyts and others, 2007). From a policy perspective, carbon sequestration by ecosystems is one of many types of climate-change mitigation.

Economic analyses, including those that concern climatechange mitigation assessment, can be differentiated in terms of scope. The narrowest and generally more detailed analyses are those of a single sector or a single market. Conversely, the most comprehensive analyses attempt to capture economywide effects, but this often comes with a loss of detail. The following studies exemplify this compromise between scope and detail. An econometric model (Lubowski, 2006) operates at the unit of private parcel of land. It accounts for land-use decisions; for example, the incentive for land conversion to forest based on a carbon subsidy for growing trees. The model assumes that landowners choose to maximize the present value of expected net benefits from the land and base their expectations of future land-use profits on historical and current subsidy levels. Looking at the agricultural sector, Lewandrowski and others (2004) adapted the U.S. Mathematical Programming Regional Agricultural Sector Model to analyze the performance of alternative incentive designs (for example, cost shares) and payment levels (for example, carbon price) paid to farmers for adopting land uses and management practices that increase the storage of carbon in soil.

In order to capture sector details, yet retain economywide scope, the EPA applies a set of interactive tools to analyze climate-change mitigation strategies and the ensuing effects. These models include the Forest and Agriculture

Table 2.3. Selected estimates and uncertainties reported from recent national-scale assessments of carbon sequestration.

[SOCCR, first State of the Carbon Cycle Report (U.S. Climate Change Science Program (CCSP), 2007); Pg, petagram (1 billon metric tons); $\mathrm{CO}_{2}$, carbon dioxide]

\begin{tabular}{|c|c|c|c|c|}
\hline Assessment and source & Assessment components & Geographic scope & $\begin{array}{c}\text { Quantity } \\
\text { (stock or flux) }\end{array}$ & $\begin{array}{l}\text { Uncertainty } \\
\text { (95 percent } \\
\text { confidence } \\
\text { level) }\end{array}$ \\
\hline EPA (2010) & $\begin{array}{l}\text { Forests and harvested } \\
\text { wood }\end{array}$ & $\begin{array}{l}\text { Conterminous United } \\
\text { States }\end{array}$ & $\begin{array}{l}0.8 \mathrm{Pg} \mathrm{CO}_{2} \text { equivalent } \\
\quad \text { (annual sequestration) }\end{array}$ & \pm 18 percent \\
\hline $\begin{array}{l}\text { Sundquist and others (2009), a rapid } \\
\text { assessment of carbon sequestration }\end{array}$ & Soil organic carbon & $\begin{array}{l}\text { Conterminous United } \\
\text { States }\end{array}$ & 73.4 Pg carbon (storage) & \pm 30 percent \\
\hline $\begin{array}{l}\text { Sundquist and others (2009), a rapid } \\
\text { assessment of carbon sequestration }\end{array}$ & Forest biomass carbon & $\begin{array}{l}\text { Conterminous United } \\
\text { States }\end{array}$ & 17.0 Pg carbon (storage) & \pm 20 percent \\
\hline CCSP (2007), SOCCR & Forest carbon & United States & $\begin{array}{l}0.3 \text { Pg carbon (annual } \\
\text { sequestration) }\end{array}$ & \pm 50 percent \\
\hline CCSP (2007), SOCCR & Wood products & United States & $\begin{array}{l}0.06 \text { Pg carbon (annual } \\
\text { sequestration) }\end{array}$ & \pm 50 percent \\
\hline CCSP (2007), SOCCR & Wetlands & United States & $\begin{array}{l}0.02 \text { Pg carbon (annual } \\
\text { sequestration) }\end{array}$ & $\pm>100$ percent \\
\hline
\end{tabular}


Sector Optimization Model with Greenhouse Gases (FASOMGHG; Murray and others, 2005), which is a partial equilibrium model that can evaluate joint economic and biophysical effects of GHG mitigation scenarios in the U.S. forestry and agricultural sectors. The Applied Dynamic Analysis of the Global Economy Model (ADAGE; Ross and others, 2009) is a computable general equilibrium model that can estimate policy effects while accounting for all interactions between businesses and consumers. Such economy-wide models generally seek to explain the behavior of supply, demand, and prices in a whole economy that has several or many interconnected markets. As an example, the FASOM-GHG model indicates that increasing the quantity of forest acreage dedicated to carbon sequestration has implications for current and future industrial forest production and prices, and for agricultural production and prices. Next, the ADAGE model indicates that these price and production changes generate feedback through the broader market. Finally, the FASOM-GHG model indicates that this feedback affects the forest and agricultural sectors.

The above-mentioned policy models capture (to varying degrees) the competing land uses for carbon sequestration, food, timber, and biofuel-energy-crop production. Although the policy models help decisionmakers understand the economic influences on resource capacity, they currently are not adequate for an understanding of the biophysical capacities of carbon sequestration in all disturbed ecosystems under a range of climate scenarios. Also, the policy models tend to be concerned with resources on private lands, although a publiclands policy model for forests recently has been developed that can be coupled with FASOM-GHG (Darius Adams, Oregon State University, written commun., 2009). 
This page intentionally left blank. 


\section{Methodology for the National Assessment}

\subsection{Introduction}

This chapter introduces the scope of the methodology, a framework for assessing carbon and other GHG fluxes, and specific methods for the assessment. Detailed discussions about the framework and specific methods are provided in the appendixes.

\subsubsection{Design Requirements and Goals for Assessment}

This section describes the integrated suite of methods necessary to conduct an assessment of carbon stocks, carbonsequestration capacity, and fluxes of GHGs $\left(\mathrm{CO}_{2}, \mathrm{CH}_{4}\right.$, and $\mathrm{N}_{2} \mathrm{O}$ ) in the Nation's ecosystems, as mandated by the EISA (U.S. Congress, 2007) (see chap. 1). In assessing these GHGs, the EISA requires an examination of the effects of controlling processes (land-use and land-cover changes and ecosystem disturbances are two major controlling processes for GHG fluxes), and the potential for land-mitigation activities to increase carbon sequestration and reduce GHG emission over time. Carbon sequestration and GHG emissions in natural and managed ecosystems are the result of complex interactions among land use, land cover, management activities, ecosystem compositions and structure, natural and anthropogenic disturbances, and biogeochemical processes. Thus, to perform the assessment and meet the requirements of the EISA, an integrated multidisciplinary methodology is needed based on the following design considerations:

- Assess GHG fluxes and carbon-sequestration capacities comprehensively by considering all major pools, stocks, flux types, and controlling processes for all national lands and aquatic ecosystems of the 50 States. Incorporate key processes or factors that affect carbon cycling and GHG emissions, such as land-use and land-cover changes, ecosystem disturbances (for example, fire), lateral fluxes, and management activities. The comprehensive nature of the assessment should lead to an improvement in the quality of the assessment and a characterization of the uncertainties in the assessment results (Loveland and DeFries, 2004; Running, 2008).

- Assess both present and future GHG fluxes and carbon-sequestration capacities and produce annual estimates for 50 years, from 2001 to 2050. An evaluation of future potential ecosystem carbon and GHG conditions will be based on a framework of reference and alternative enhanced land-cover and management scenarios that are calibrated and reported at the regional scale. The first 10 years of the assessment
(2001-2010) will provide current carbon storage and GHG production conditions, while also enabling calibration, validation, and estimation of uncertainties. The next 40 years will be used to project future potential changes in carbon storage, carbon sequestration, and GHG fluxes. Assessment over the 50 years will permit an examination of complex interactions among climate change, land cover, land management, and other controlling processes.

- Conduct the assessment at a spatial resolution sufficient to evaluate process-level connections between land use, land cover, management, climate, and site-specific properties such as soil type, hydrology, and topographic setting. Thus, the assessment will be spatially explicit for the purpose of capturing the variety of processes that exist in heterogeneous landscapes and thereby will provide GHG flux and carbon-storage results that are meaningful when aggregated and compared over broad areas, such as a region or a State. The spatially explicit methods also will provide a greater understanding of geographic distributions of ecological carbon sequestration by pools and flux types.

- Investigate links between (1) potential land-use and land-cover change and land-management activities, and (2) future carbon storage and GHG fluxes in ecosystem and ancillary effects (for example, ecosystem services and costs). This analysis will permit decisionmakers and other stakeholders to evaluate the effects of mitigation strategies on future potential ecological capacities for carbon sequestration and GHG flux while also considering the potential unintended consequences within or between other ecosystems.

- Identify and collaborate with other existing national programs that evaluate carbon storage and GHG fluxes. Use common data, assumptions, and scenarios as much as possible for this assessment in an effort to minimize inconsistent or conflicting results. Portions of existing national programs, such as the U.S. Environmental Protection Agency (EPA) national emissions inventory and the U.S. Forest Service's RPA-mandated assessment, overlap with parts of this assessment, thus creating an opportunity to enhance consistency between this assessment and other, more specific programs.

- Assimilate appropriate in situ and observational data to constrain methods and models and to evaluate uncertainty. Efforts will be made to include suitable data or models in order to further reduce uncertainty. In situ data (for example, the FLUXNET database; Running and others, 1999; Baldocchi and others, 2001) are commonly used for resource and GHG-flux assessments. To the extent possible, these and any other appropriate datasets will be incorporated, such as those containing biophysical data (for example, soils, climate) and data derived from remote-sensing methods (such as landcover change, wildland fires, or vegetation indices). 
Judgments as to the suitability and use of input data will be made on a case-by-case basis as the assessment proceeds.

\subsubsection{Methodology Scope}

This section describes the scope of the assessment, including definitions of pools and flux types, assessment units, ecosystems, temporal scales, and spatial scales.

Scale of Assessment and Reporting: Assessment Units.Operational logistics require that the assessment be separated into several individual units to stratify data collection and modeling efforts, plan and prioritize the assessment, and report results. The assessment and reporting units will correspond to Level II EPA ecoregions (Omernik, 1987, 2004). The Nation includes 24 large Level II EPA ecoregions (fig. 3.1), and assessment results will be provided for each ecoregion. Components of the aquatic assessment will be stratified using watersheds that are aligned, to the extent possible, with the boundaries of the ecoregions.

The use of the EPA Level II ecoregions as units of the assessment defines the scale for reporting the assessment results because it is within each of these ecoregions that the scenarios will be developed and the results will be analyzed (including validation and uncertainty analysis) and reported. Below this scale, data products may still be useful because many data products are geographic information system (GIS) maps that are generated at a pixel size (map resolution) of 250 meters (m) using spatially explicit models. However, the map resolution does not designate a scale of the assessment. The scale of the methodology is set as assessment units. Users are encouraged to explore further validation and uncertainty measures in order to address scaling and other effects when using GIS map data.

Ecosystems.-The EISA requires the assessment of carbon storage, carbon sequestration, and GHG fluxes in and out of the Nation's ecosystems. For the purpose of this

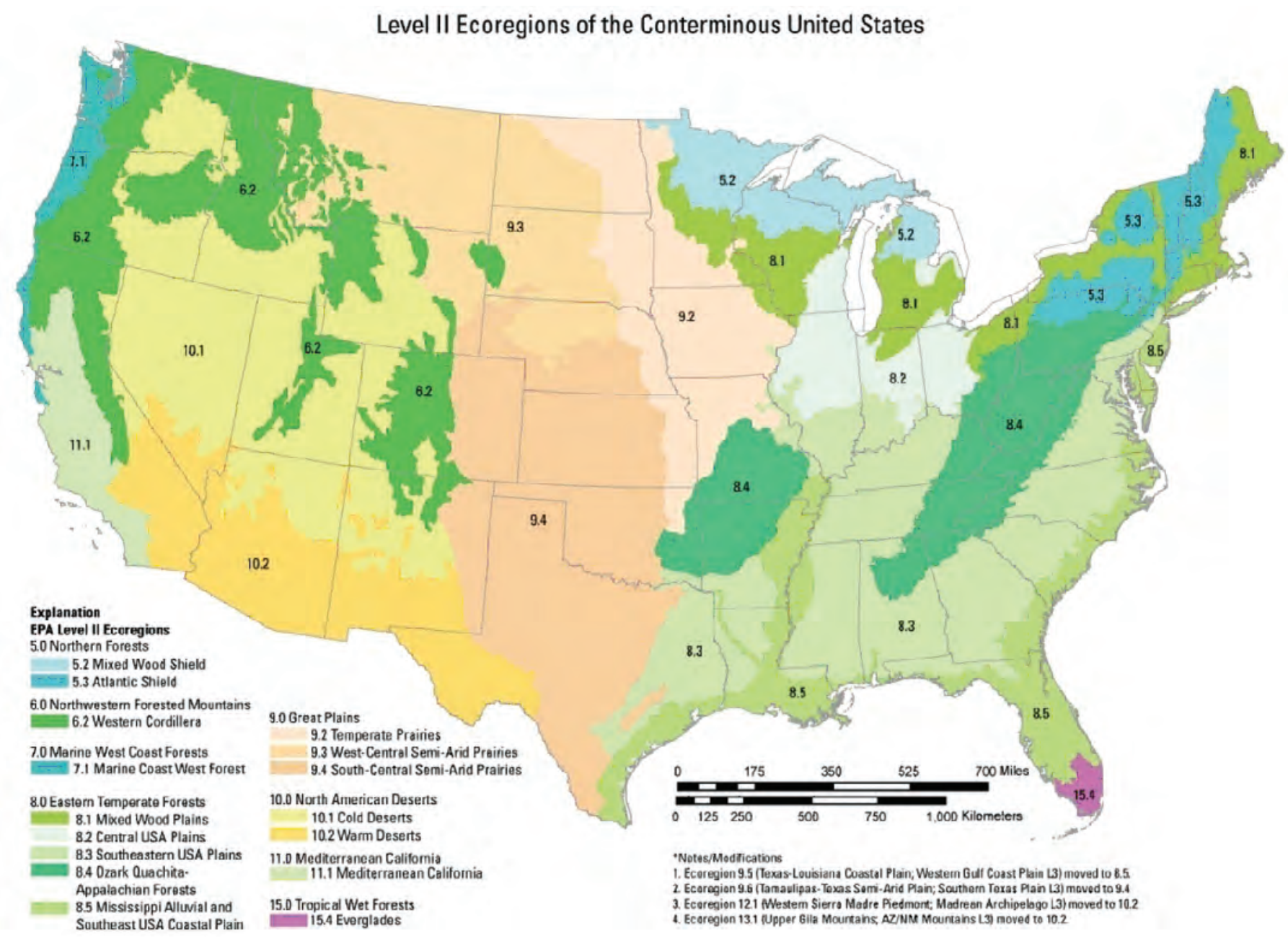

Figure 3.1. Map showing Level II ecoregions of the U.S. Environmental Protection Agency, modified from Omernik (1987) for this report and for the assessment. Only the conterminous United States is shown. This ecoregion framework will be used as the basis for the assessment units, and the ecoregions will be used as assessment units for purposes of planning, prioritization, analysis, and reporting. 
methodology for the assessment, the ecosystem terms used in this report are defined as broad types of forests, grassland/ shrublands, croplands, wetlands, and aquatic habitats (table 3.1 ). The use of these broad biome types for ecosystem classification follows the intent (but not the actual terminology) of the U.S. Climate Change Science Program (now U.S. Global Change Research Program) "State of the Carbon Cycle Report," Part III, Land and Water Systems (U.S. Climate Change Science Program, 2007). Because this assessment is conducted at the ecoregion scale, the ecosystems defined above will be assessed and analyzed on the basis of their unique regional characteristics.

Within each assessment unit, ecosystem boundaries will be determined by using the 2001 National Land Cover Dataset (NLCD, Homer and others, 2004) and other datasets such as the National Wetland Inventory (NWI, Cowardin and others, 1979). These datasets, which have comparable definitions for various ecosystems, will be crosschecked and used in the assessment to help define the spatial boundaries of the ecosystems (table 3.1). Further discussion about spatial boundaries for the ecosystems may be found below in section 3.2, "Methodology Framework."

Pools and Flux Types.-Production, consumption, and transitions of carbon among seven pools (table 3.2) will be assessed in order to account for carbon stocks and GHG fluxes. The methodology includes the five primary carbon pools and a harvested wood pool that are defined and recognized by the IPCC (Penman and others, 2003; IPCC, 2006) and are most commonly used for other national GHG inventories (for example, U.S. Climate Change Science Program, 2007; U.S. Environmental Protection Agency, 2009). Unique to the methodology for this assessment is the inclusion of a lateral flux pool, which accounts for carbon that is exported by rivers and streams and is used to evaluate the effects of terrestrial management on carbon storage and GHG production in inland and coastal waters. The relations between the carbon pools and the fluxes of carbon and nitrogen to be assessed are illustrated in figure 3.2 .

The net ecosystem exchange (NEE) is the net flux or uptake of carbon $\left(\mathrm{CO}_{2}\right.$ and $\left.\mathrm{CH}_{4}\right)$ or nitrogen $\left(\mathrm{N}_{2} \mathrm{O}\right)$ between the ecosystem and the atmosphere. The primary processes in determining NEE are (1) net primary productivity (NPP, which is calculated by subtracting autotrophic respiration from photosynthesis), (2) fluxes from heterotrophic respiration (HR), (3) fire, and (4) the production of biomass commodities (for example, wood products). The net ecosystem carbon balance (NECB) accounts for all physical, biological, and anthropogenic sources and sinks (for example, photosynthesis and the lateral movement of dissolved organic carbon (DOC), inorganic carbon (DIC), and particulate organic carbon (POC)) (fig. 3.2).

Mitigation Activities. - Changes in carbon stocks and fluxes in the seven pools are affected by mitigation activities of two types: land-use change and land-management change. Mitigation activities within this scope directly increase carbon sequestration in soils, vegetation, wood products, and sediments. The following items are not included when considering mitigation activities: (1) indirect effects from the generation of energy from biomass; (2) technological actions that can aid in ecologically sequestering carbon, but that are not explicitly land-use or land-management changes (for example, growing algae in industrial fluxes); (3) activities to reduce downstream or life-cycle GHG fluxes (for example, GHG emissions from hauling and processing of timber are not assessed for harvest rotation changes); and (4) GHG emissions from livestock.

Assessment Timeframe.-The assessment will be conducted in annual time steps from 2001 to 2050 . This timeframe meets the legislative requirements for assessing annual present and future ecosystems capacities and addresses the following considerations. The 2001 starting year was selected because the National Land Cover Database (NCLD) 2001 (which describes the general land cover of the Nation) and the Landscape Fire and Resource Management Planning Tools Project (LANDFIRE) dataset (which describes vegetated ecosystem composition, structure, succession state, and wildland fire disturbances) were both available during that year. The two datasets will provide the starting point for modeling future land changes, disturbances, and GHG fluxes into and out of ecosystems. The data for years between 2001

Table 3.1. Ecosystems, descriptions, and thematic components of source datasets.

[The use of the 2001 National Land Cover Dataset (NLCD) and other datasets helps to define spatial boundaries of the ecosystems at a regional scale. Other abbreviations are as follows: NHD, National Hydrography Dataset; NID, National Inventory of Dams; DLG, digital line graph; NWI, National Wetland Inventory]

\begin{tabular}{ll}
\hline \multicolumn{1}{c}{ Ecosystem } & \multicolumn{1}{c}{ Included land-cover type (and dataset source) } \\
\hline $\begin{array}{l}\text { Forests } \\
\text { Grassland/shrublands }\end{array}$ & $\begin{array}{l}\text { Deciduous, evergreen, mixed, and disturbed forests (NLCD). } \\
\text { Shrub/scrub and grassland/herbaceous classes, as well as Alaska-specific areas mapped as sedge/herbaceous, } \\
\text { lichens, and moss (NLCD). } \\
\text { Cultivated cropland, irrigated land, and pasture/hay classes (NLCD). } \\
\text { Wetlands }\end{array}$ \\
Combinations of NLCD wetland classes and NWI wetland classes (for example, palustrine wetland). \\
Lakes, impoundments, estuaries, coastal waters, ponds, rivers, and other inland water bodies (combined use of \\
NLCD, NHD, NID, DLG, and NWI).
\end{tabular}


Table 3.2. Broad-level definitions of relevant carbon pools to be included for carbon-assessment products.

[Definitions for all but harvested wood and lateral flux are adapted from Intergovernmental Panel on Climate Change (IPCC) (2006). Abbreviations are as follows: mm, millimeter; cm, centimeter; DOC, dissolved organic carbon; DIC, dissolved inorganic carbon; POC, particulate organic carbon]
Pool
Description

Living biomass

Aboveground biomass

All biomass of living vegetation, both woody and herbaceous, above the soil, including stem, stump, branches, bark, seeds, and foliage.

Belowground biomass

All biomass of live roots. Fine roots of less than 2-mm diameter often are excluded because often they cannot be distinguished empirically from soil organic matter or litter.

Dead organic matter

Dead wood

All nonliving woody biomass not contained in the litter, either standing, lying on the ground, or in the soil or sediments. Dead wood includes wood lying on the surface, dead roots, and stumps larger than or equal to $10 \mathrm{~cm}$ in diameter.

Soils/sediments ${ }^{1}$

Litter and deadwood

All nonliving biomass with a diameter less than the minimum diameter chosen for dead wood (10 $\mathrm{cm})$, lying dead, in various states of decomposition above mineral or organic soil or sediments. Includes the litter layer as usually defined by soil typologies. Live fine roots less than $2 \mathrm{~mm}$ in diameter where they cannot be distinguished from it empirically.

Soil organic matter

Organic carbon in mineral and organic soils and sediments to a specified depth chosen for the assessment and applied consistently through the time series. Includes live fine roots less than 2 $\mathrm{mm}$ in diameter where they cannot be distinguished from it empirically.

Harvested wood

Wood

Harvested wood from forests.

Lateral flux

Dissolved organic and inorganic

carbon; particulate organic carbon

DOC, DIC, and POC that are exported by surface waters, and POC that is stored in inland and coastal waters.

${ }^{1}$ Inorganic carbon stocks (such as calcium carbonate) in mineral soils and sediments will be estimated using the Soil Survey Geographic (SSURGO) database (http://soils.usda.gov/survey/geography/ssurgo/) (see section 3.3.1 of this report); however, given the uncertainty in modeling formative processes in relation to land use as well as tracking vertical and lateral leakage processes, future potential changes in inorganic carbon stocks will not be modeled.

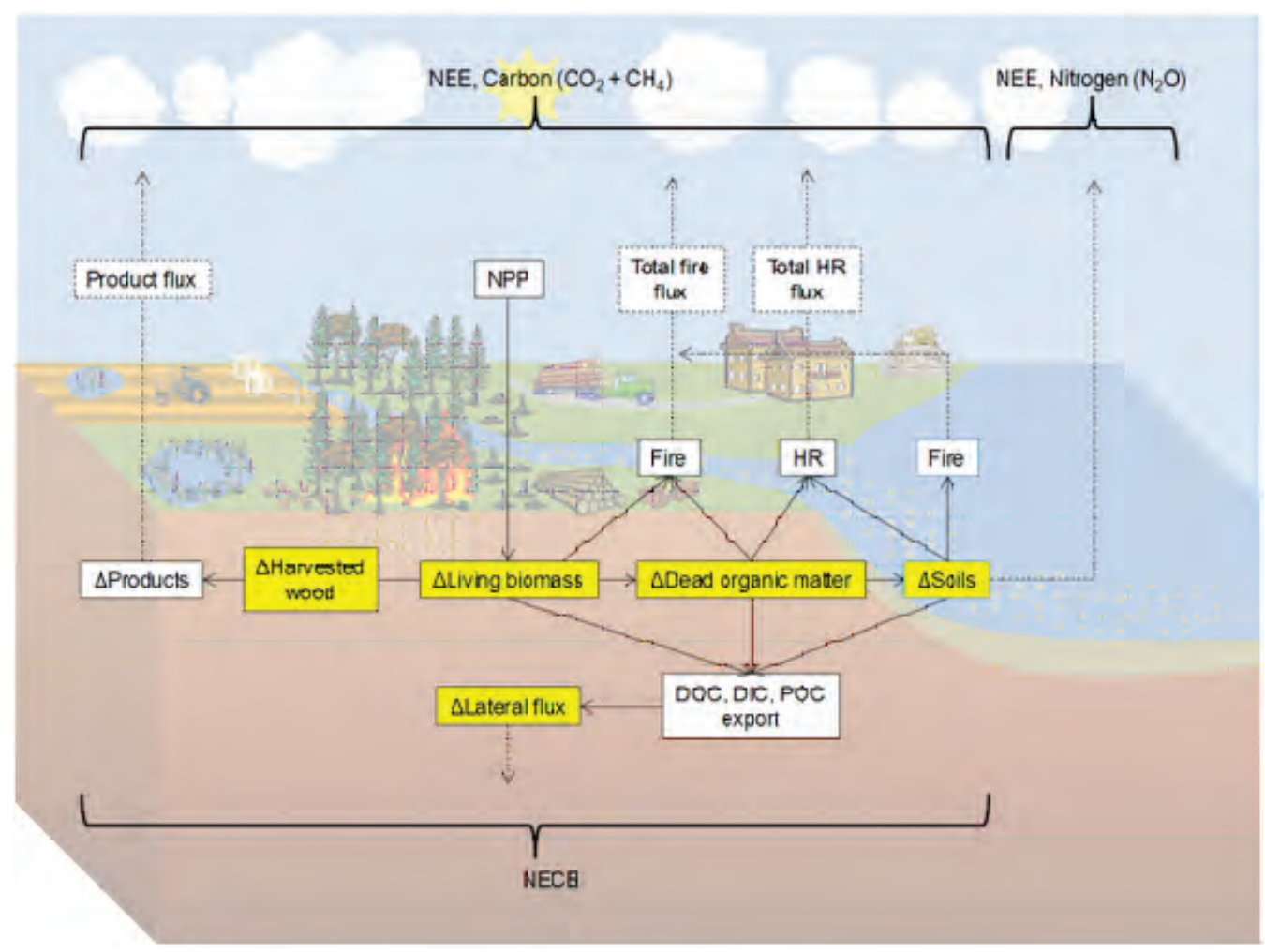

Figure 3.2. Diagram showing fluxes of carbon (as carbon dioxide and methane) and nitrogen (as nitrous oxide) and exchanges among the seven primary carbon pools (yellow boxes). Abbreviations are as follows: $\mathrm{CH}_{4^{\prime}}$ methane; $\mathrm{CO}_{2^{\prime}}$ carbon dioxide; DIC, dissolved inorganic carbon; DOC, dissolved organic carbon; POC, particulate organic carbon; $H R$, heterotrophic respiration; NECB, net ecosystem carbon exchange; NEE, net ecosystem exchange; $\mathrm{N}_{2} \mathrm{O}$, nitrous oxide; NPP, net primary productivity. Small triangles in yellow boxes are deltas, which indicate "change in." For more information about these terms, see Chapin and others (2006). 
and 2010 will offer opportunities to assess current ecosystem carbon stocks, sequestration rates, and GHG fluxes and will be used for the model design and the calibration and validation of results. The selection of 2050 as the endpoint was influenced by two considerations: (1) Uncertainties associated with scenarios, data, and methods will increase with time. Limiting the assessment to 2050 will help constrain such uncertainties. (2) The EISA does not specifically define a time horizon for the assessment, but an assessment over a 50-year time frame should provide adequate information for policy and management applications.

\subsubsection{Methodology Constraints}

Comprehensive national-resource assessments are usually limited by many constraints, including the scope of the assessment, data availability, technological developments, established scientific concepts and methods, available project time, and resources. These limitations apply to this assessment as well. Given that this methodology has been developed to fulfill the EISA's legislative requirements, the limitations inherent in this process need to be discussed:

- The scope of the methodology and assessment will be limited to the requirements set forth by section 712 of the EISA, as detailed in chapter 1.

- Consistency at the national level is needed, such that quality, inherent variability, and uncertainty of results are comparable among regions and contain minimum biases when compared with known reference data (such as national inventory programs). Scenario construction and methods for assessment also must be transparent in order to maintain consistency in interpretation.

- Established and simplified methods and models that incorporate datasets of national coverage will be used in the assessment. The assessment needs simplified dependencies between technical components to permit effective coupling of methods and models. Areas where established methods or models are limiting will be prioritized for research treatment by others.

- Availability of in situ, mapped, and remotely sensed data is uneven for the national assessment. The GHG flux data are especially uneven. The methodology is designed to circumvent, where necessary, issues of poor data availability or quality by using surrogate data and appropriate available techniques for calculation. Ultimately, the quality and availability of input data will affect the quality and uncertainty of the assessment.

\subsubsection{Collaborations for the Assessment}

Many Federal agencies, nongovernmental organizations, and international entities already have developed unique inventory, assessment, and research programs in support of their policy and science needs for understanding the carbon cycle and processes and for mitigating GHG fluxes. Where appropriate, these ongoing programs will play important roles for this assessment, including (1) active collaborations for conducting the assessment, and (2) review, feedback, and use of results of the assessment. As discussed below in the methodology descriptions, a successful implementation of the methodology will depend on the extent to which this assessment is developed collaboratively. Important areas of collaboration for the assessment are described below:

- Data sharing - In situ reference data (such as national inventory programs, flux-tower data, informal networks, and location- or ecosystem-specific GHG-flux data) are critical in order to constrain methods and models for estimating current and future potential carbon and GHG fluxes. Data about land management and their associated costs are required in order to construct potential mitigation actions and to analyze tradeoffs between the management of carbon and other ecosystem services.

- Review of methods and results - A rigorous scientific review process will set the foundation for the assessment. Throughout the methodology development process and the assessment, the science community (such as the North America Carbon Program) and agency research programs will be engaged both for the review of this method and the assessment, and for the opportunity to compare methods and models.

- Participation-The quality and usefulness of the assessment will benefit greatly from participation by individual investigators, agency programs, and stakeholders. For various methods and data needs, agencies and organizations have roles to play, including that of providing assessment components, models, and data. In addition, stakeholders, such as land managers in various regions, may find that participation in regional consultation processes for constructing mitigation scenarios will benefit their organization's missions. Encouraging broad participation by stakeholders in the use of assessment results is critical to the ultimate value of this assessment effort.

- Enhancing consistency-Agencies or organizations that play active roles in resource assessment will be actively consulted throughout development of the methodology and the assessment. Consistency between this assessment and other national programs will be enhanced by (1) using the same high-quality in situ data, and (2) using comparable scenarios or assumptions.

\subsubsection{Methodology Organization}

As discussed above, the EISA requires the national assessment to consider carbon-sequestration capacities and GHG fluxes for both terrestrial and aquatic ecosystems. The assessment also will address major controlling processes that 
affect present and future carbon storage and GHG fluxes in order to support a range of policy and management applications. The organization of this methodology document addresses each of these issues in turn:

- An approach for assessing present carbon storage in ecosystems and GHG fluxes that is consistent with both existing accounting guidelines and the subsequent methods presented.-Years 2001 through 2010 are considered in order to determine the current carbon storage and rates of flux and carbon sequestration.

- An approach for assessing future carbon storage in ecosystems and GHG fluxes.-The scenario framework for years 2011 through 2050 will link future potential climate and socioeconomic projections with the design of future potential mitigation activities (for example, potential land-use and land-management changes to enhance carbon-sequestration capacity).

- A set of methods that supports the assessment of both present and future potential conditions. - The methods are (1) mapping and modeling of current and future land use and land cover, (2) characterizing and modeling present and future ecosystem disturbances, (3) estimating and modeling carbon storage and GHG fluxes from terrestrial and aquatic ecosystems, (4) syntheses of mitigation scenarios (including ecosystem services and cost), and (5) validation, uncertainty analysis, and monitoring.

\subsection{Methodology Framework}

This methodology is designed for a comprehensive assessment of current and future potential carbon stock, carbon sequestration, and GHG fluxes. Assessment results will be produced for the years 2001 through 2050 . The results for years 2001 through 2010, which are based on past and current input data, will be used to estimate the current carbon and GHG conditions. Future potential carbon stocks, carbon sequestration, and GHG fluxes will be modeled and estimated for 2001 through 2050 for a range of future mitigation scenarios aligned within three IPCC scenarios (discussed later in this section).

The framework incorporates recommendations of IPCC's good practice guidelines for the assessment of carbon and GHG for land use, agriculture, and forestry (Penman and others, 2003). The methods to be used for the assessment are based on extensive observational data, as well as on tested empirical or process-based models. A common set of input data and controlling processes will be analyzed and used in the assessment of both current and future potential carbon stocks, carbon storage, and GHG fluxes. Table 3.3 specifies the common characteristics and the differences between assessments of current and future potential carbon sequestration and GHG fluxes. In this section, methods and models supporting the assessment are introduced; specific technical information is discussed in more detail in the appendixes.

\subsubsection{Framework for Assessing Current Carbon Stocks, Carbon Sequestration, and Greenhouse- Gas Fluxes}

Relationship to Existing Inventory and Accounting

Methods.-This methodology must be designed to maintain consistency with other existing (1) inventory and assessment guidelines and (2) methods for assessing current carbon stocks, carbon sequestration, and GHG fluxes. This concern involves both U.S. and international efforts developed under the IPCC guidance for land-use change and forestry (Penman and others, 2003; IPCC, 2006). The primary nationalscale efforts in the United States include (1) the State of the Carbon Cycle Report (U.S. Climate Change Science Program, 2007); (2) the EPA Inventory of U.S. Greenhouse Gas Emissions and Sinks (U.S. Environmental Protection Agency, 2009); (3) U.S. Department of Agriculture (USDA) Forest Service (2007), and (4) a report on the economics of sequestering carbon in the U.S. agricultural sector (Lewandrowski and others, 2004). These national assessments follow

Table 3.3. Time periods, land use and land cover, ecosystem disturbances, and land-management activities used for assessments of current and future potential carbon stocks, carbon sequestration, and greenhouse-gas fluxes.

[Abbreviations are as follows: LULC, land use and land cover; GHG, greenhouse gas]

\begin{tabular}{cccc}
\hline $\begin{array}{c}\text { Time period of } \\
\text { assessment }\end{array}$ & $\begin{array}{c}\text { LULC, ecosystem } \\
\text { disturbances }\end{array}$ & Land management & Major input data and uses \\
\hline $\begin{array}{c}\text { Current assessment } \\
(2001-2010)\end{array}$ & $\begin{array}{c}\text { Current LULC, } \\
\text { changes in LULC, } \\
\text { and ecosystem } \\
\text { disturbances }\end{array}$ & $\begin{array}{c}\text { Current land man- } \\
\text { agement }\end{array}$ & $\begin{array}{c}\text { In situ data, soil data, current climate data, and other input data together } \\
\text { with current LULC and disturbances data are used to create empirical } \\
\text { and process models to estimate current carbon stocks, carbon seques- } \\
\text { tration, and GHG fluxes. }\end{array}$ \\
$\begin{array}{c}\text { Future potential } \\
\text { assessment } \\
(2011-2050)\end{array}$ & $\begin{array}{c}\text { Projected future } \\
\text { LULC and distur- } \\
\text { bances for each } \\
\text { future scenario }\end{array}$ & $\begin{array}{c}\text { Projected land man- } \\
\text { agement for each } \\
\text { future scenario }\end{array}$ & $\begin{array}{c}\text { Input data (above) combined with projections of climate, LULC, and } \\
\text { disturbances to create parameters for simulation models and estimate } \\
\text { future potential carbon stocks, carbon sequestration, and GHG fluxes. }\end{array}$ \\
\hline
\end{tabular}


the three-tiered approach recommended by IPCC (2006), as reviewed in chapter 2 .

The primary methods and models used in this methodology for regional-scale assessment are a tier 3 effort in the IPCC (2006) hierarchy. Where appropriate data are unavailable, tier 2 approaches involving simple algorithms will be incorporated into the methodology. In addition, by assessing similarly defined ecosystems and pools and by using the same nationallevel datasets for land cover, vegetation, soils, and ecosystem disturbances that are maintained by the USDA, DOI, and other agencies, the methodology should yield consistent results at the national level. All of these approaches will maintain a relationship and consistency with other national efforts.

Carbon stocks, carbon sequestration, and GHG fluxes assessed for the period from 2001 through 2010 will be compared with those of other existing inventories. If conflicting results are found, efforts will be made to consult with appropriate agency programs, identify the source of discrepancies, capture and correct any errors, and notify the climate-change community about the differences.

Ecosystems and Current Land Use and Land Cover--The ecosystem terms that have been chosen for this methodology and for the assessment of ecosystems are provided in section 3.1.2 and are described in table 3.1. To better represent carbon stocks, carbon storage, and GHG fluxes associated with LULC change, the national assessment will use a spatially explicit representation of the defined ecosystems and the thematic components or classes within each ecosystem, as listed in table 3.1. The NLCD 2001 land-cover classes can be easily aggregated and keyed to the ecosystems described in table 3.1; they also contain enough thematic classes that they can be aggregated to the six LULC categories used in IPCC (2006) for reporting purposes. The LULC classifications initially will be based on NLCD 2001 classes and will be modified to meet the needs of the project (table 3.4). Specifically, the following modifications will be made:

Forests.-The U.S. Forest Service Forest Inventory and Analysis (FIA) program defines forested land as "any plot that is 10 percent stocked, except woodland, can be forest if it's 5 percent stocked, with a minimum area of 1 acre [0.4 hectare] and width of $120 \mathrm{ft}$ [37 m]" (Smith and others, 2009). The Multi-Resolution Land Characteristics Consortium (MRLC), which sponsors the development of the NLCD datasets, defines a forest class in the NLCD in terms of pixels with tree cover of greater than 20 percent. Differences in the definitions of "forest" can result in differences in forest biomass, especially in regions where woodland habitats (such as pinion-juniper and black spruce) are common. For forested areas, a solution by the MRLC, of which the Forest Service is a member, will be followed that uses remote-sensing-derived continuous forest-canopy estimates to interactively adjust spatial boundaries to match FIA in situ data (Huang and others, 2001; Hansen and others, 2003)

For forest cover in urban areas, the NLCD 2001 forestcanopy dataset that characterizes the percentage of forest canopy will be intersected with classes of developed lands in the NLCD 2001 land-cover dataset to provide regional (EPA Level II ecoregion) proportional distributions and averages of forest-canopy percentage in urban areas. The resulting urban forest cover will allow the biogeochemical model to quantify regional impacts of urban forestry on carbon stocks, carbon sequestration, and GHG fluxes.

Wetlands and Aquatic Habitats. - Wetlands include a variety of systems such as prairie potholes, coastal-plain woody swamps, boreal peat lands, and salt marshes (for example, palustrine habitats consistent with the U.S. Fish and Wildlife Service (FWS) definitions by Cowardin and others (1979)). Wetlands will be assessed using the same methods as for terrestrial ecosystems. Aquatic habitats in this assessment include coastal waters, estuaries, streams, rivers, lakes, impoundments, and other inland water bodies. Aquatic habitats will be assessed using models developed for this purpose. The boundaries for wetlands will be mapped by using NWI data that are supplemented with data about two NLCD wetland classes: woody wetland (class 90) and emergent herbaceous wetlands (class 95) (Homer and others, 2004). Aquatic habitats will be mapped by using a combination of datasets, including the National Wetland Inventory (NWI), the National Water Information System (NWIS) of the U.S. Geological Survey (USGS), the National Hydrography Dataset (NHD), the National Inventory of Dams (NID), digital line graphs (DLGs), and the NLCD. Open-water bodies such as rivers, lakes, and other aquatic systems will be similarly mapped. The initial land-cover map will be based on the revised NLCD 2001, as discussed above (table 3.4). To represent land-cover conditions for 2001 through 2010, the LANDFIRE ecosystemdisturbance data (Rollins, 2009) will be used along with a 2006 update to the 2001 NLCD by Xian and others (2009) to quantify contemporary LULC change. These data will inform a land-change model (section 3.3.2, "Land-Use and Land-Cover Change") that will be used to produce spatially explicit LULC maps for the period of 2001 through 2050. Reference datasets (such as LANDFIRE disturbance data) from the period of 2001 through 2010 will be used to calibrate and validate results of the LULC-change model for the same period of time.

Major current ecosystem disturbances caused by both natural and anthropogenic events (for example, wildland fires, forest cuts, insect and disease outbreaks, and storm damages) for 2001 through 2010 will be summarized by assessment units. Technical details for generating present LULC and ecosystem disturbances are provided in section 3.3 and in appendixes B and $\mathrm{C}$.

\subsubsection{Framework for Assessing Future Potential Carbon Stocks, Carbon Sequestration, and Greenhouse-Gas Fluxes}

Scenario Framework.-Annual carbon stocks, carbon sequestration, and GHG fluxes for ecosystems of the United States will be analyzed within the context of a range of LULC and land-management projections (scenarios). The results will generate a rich set of spatial and temporal data products 
Table 3.4. Thematic land-cover classes used to describe current conditions.

[The same classes will be used to parameterize modeling for future land-cover changes. Classes are modified from NLCD 2001 (National Land Cover Database; Homer and others, 2004). Abbreviations are as follows: m, meters; cm, centimeters]

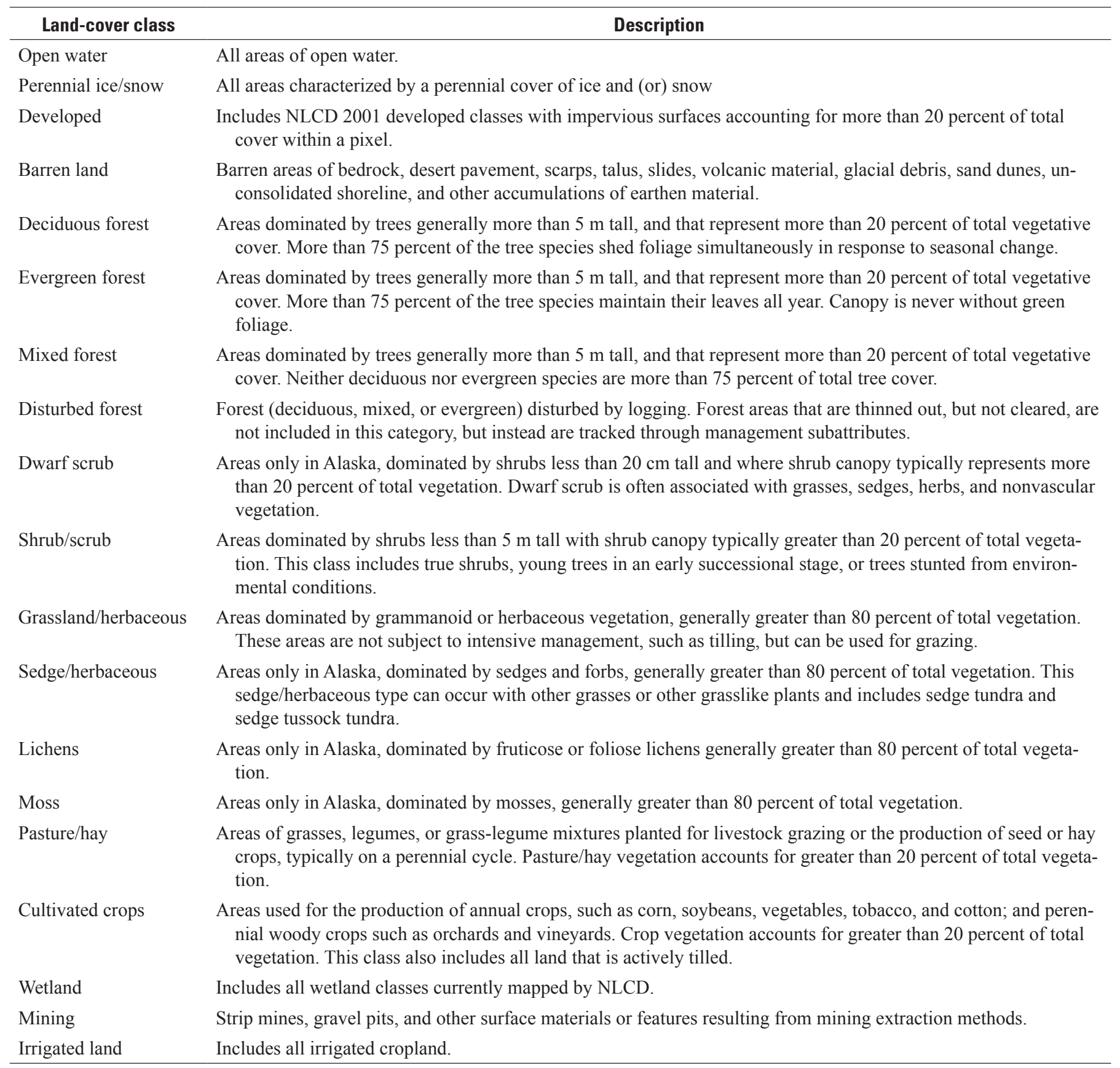


that will be used for assessing the effectiveness of mitigation activities to sequester carbon. Although scenarios will be constructed for assessment units, national-level consultation will be needed in order to establish construction guidelines for them that will ensure consistency across regional assessments. The use of a scenario framework will allow scientists to employ the methodology to provide a range of data products and bound overall uncertainties (fig. 3.3) of carbon stock capacity, carbon-sequestration capacity, and GHG fluxes.

Scenarios are neither predictions nor forecasts of the future; rather, they are ways of showing how the future may unfold under a set of assumptions. Scenarios are a useful tool for exploring the uncertainty associated with projecting potential resources in the future. Raskin (2005, p. 134) described scenarios as "drawing from the human imagination as well as science to provide an account of the flow of events leading to a vision of the future... using both words and numbers." He continued by stating (p. 134) that, "the great strength of scenario research lies in its blending of the richness, texture, and imaginative qualities of narrative with the structure, replicability, and rigor offered by modeling."

Scenarios combining both qualitative and quantitative elements have been used in several global assessments, including the Global Scenario Group (GSG) (Raskin and others, 1998), the World Water Commission scenarios (Alcamo and others, 2000;

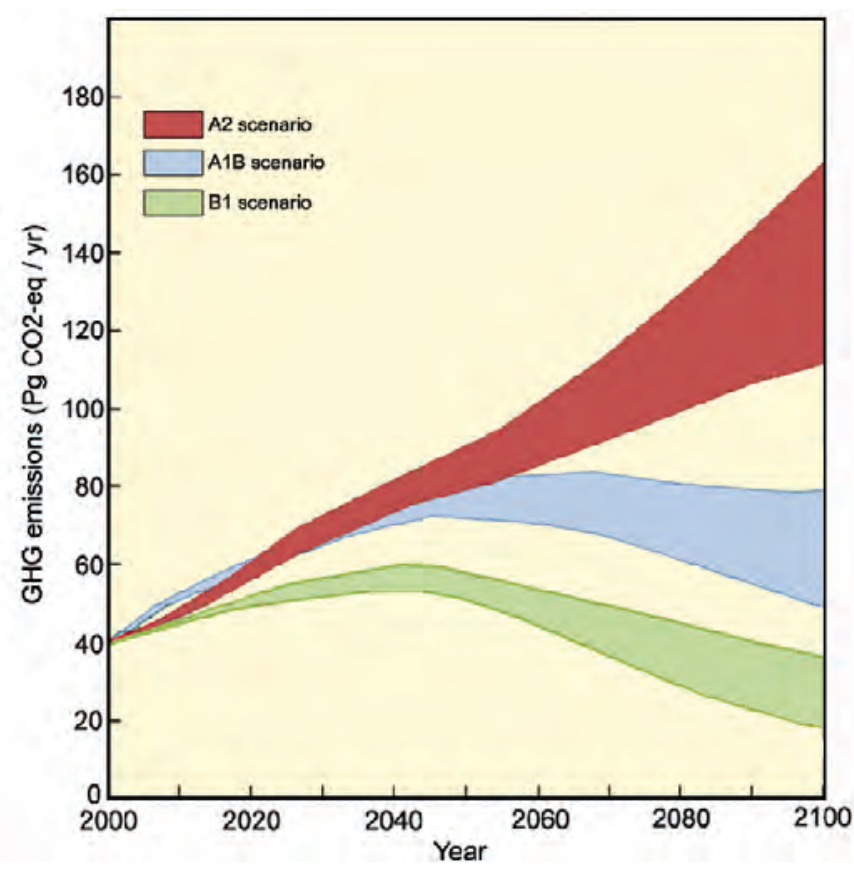

Figure 3.3. Graph showing hypothetical emission ranges for each of three scenarios defined by Nakicenovic and others (2000). The scenario framework will allow assessment of potential carbon sequestration capacities and associated uncertainties within each scenario and mitigation potential of GHG fluxes across the scenarios. Emissions are in petagrams of carbon dioxide equivalent per year $\left(\mathrm{PgCO}_{2} \mathrm{eq} / \mathrm{yr}\right)$.
Cosgrove and Rijsberman, 2000), the IPCC "Special Report on Emission Scenarios" (SRES; Nakicenovic and others, 2000), the United Nations Environment Programme's (UNEP) third Global Environmental Outlook (UNEP, 2002), and the Millennium Ecosystem Assessment (Carpenter and others, eds., 2005). Within the global change community, an increased emphasis has been placed on integrated assessment scenarios that promote scaling from regional to global scales. One such effort was that of the UNEP third Global Environmental Outlook (UNEP, 2002) where, through a collaborative process, four GSG scenarios were refined with input from SRES and with an emphasis on giving the global scenarios a "regional texture" (Carpenter and others, eds., 2005). The use of similar scenarios as a methodology framework is proposed for the national assessment. The selection of the scenario framework should meet the following criteria:

- Scenarios for the assessment should be based on socioeconomic conditions, such as trends in demographics, changes, and patterns of economic growth, and rates of energy consumption.--Socioeconomic scenarios, as opposed to climate scenarios, provide the means to explore the interaction of LULC change and the primary factors that drive that change, which ultimately affect the flux of GHG from ecosystems.

- The scenarios should consist of both qualitative and quantitative components.-(1) Qualitative components include "storylines," which describe elements of alternative futures. Storylines, or narratives, are scalable and can be interpreted to result in certain conditions based on regional landscape characteristics. Qualitative components also are highly useful for communicating scenario characteristics to a nonscientific audience, which is an important component of this research. (2) Quantitative components include modeling and projections of LULC and land management based on scenario assumptions about the interactions among the driving forces of change. Within the SRES process, there are 40 quantified scenarios based on 4 scenario families produced by 6 modeling teams (Nakicenovic and others, 2000).

- Links to associated projections of climate conditions.- These data are available from both the IPCC third assessment (IPCC, 2001) and fourth assessment (IPCC, 2007) reports and are based on the projections of emissions and changes in LULC associated with SRES scenario assumptions.

- Use of only current mitigation policies in order to provide a reference for the evaluation of potential mitigation activities.

- Scalability.-Data must be scalable from global down to regional scales. The chosen scenario framework must also be portable across regions (that is, the methods can be applied to different regions with consistent input parameters).

- Review by the scientific and policymaking communities.-For example, the SRES scenarios were produced 
in an open process with broad scientific participation. Where possible, scenarios will incorporate robust projections of LULC drivers (for example, population projections) that are accepted by the scientific community.

- Transparency and easy communication to stakeholders and decisionmakers.- Scenarios should avoid depending on "black box" model outputs that cannot be modified or reproduced.

A set of regional LULC scenarios based on the IPCC SRES scenario structure (Nakicenovic and others, 2000) will satisfy the criteria listed above. A new set of scenarios, however, is being developed for the IPCC's fifth assessment (AR5) (Moss and others, 2010). The new process, representative concentration pathways (RCP), will begin with radiative forcing targets (measured in watts $/ \mathrm{m}^{2}$ ), and will allow modeling teams to explore various ways to achieve the forcing goal, including the imposition of various climate-change mitigation policies. Unlike SRES, which begins with a fixed set of socioeconomic conditions, the RCP process will provide a framework to allow modeling teams the ability to explore different and perhaps diverging LULC conditions to reach the same radiative forcing target. The first set of RCP scenarios already has been developed and analyzed (Wise and others, 2009); however, reference scenarios (those devoid of any climate-mitigation action) are still under development. Although the RCP approach is not the ideal framework for the reference scenarios for this methodology (see criteria above), they may provide insight for understanding the role of specific mitigation activities. As the RCP scenarios become more widely available, their use within the methodology framework will be considered, specifically to explore comprehensive climate-mitigation scenarios.

The IPCC SRES storylines (Nakicenovic and others, 2000) will serve as the primary basis of the framework for the assessment. Reference and mitigation (that is, enhanced for carbon sequestration) scenarios will be constructed for each of three major storylines found in the SRES. The storylines themselves are broad in scope, focus on global-level driving forces, and will need to be downscaled to the national and regional level for the United States. For this assessment, three IPCC SRES storylines from the IPCC Fourth Assessment (IPCC, 2007) will be used to guide the development of the specific LULC and management scenarios: A1B, A2, and B1 (Nakicenovic and others, 2000). The choice of three SRES storylines is dictated by the availability of the downscaled regional-climate data described in section 3.3 of this report. To date, the General Circulation Model (GCM) data for the B2 scenario that meet climate downscaling methods adopted for the methodology are not available. Should B2 climate data become available, or should an alternate source of climate data be found, then the B2 storyline may be included in the analysis.

For each assessment unit, regional LULC scenarios will be constructed based on experiences and results of ongoing LULC studies and regional expert knowledge. The SRES narratives and storylines and the existing knowledge of regional LULC changes provide a basis for constructing both the reference and mitigation scenarios, which will allow for opportunities to explore a wide range of regional LULC scenarios while remaining consistent with overall SRES assumptions.

Within each SRES storyline (Nakicenovic and others, 2000), there will be an opportunity to assess carbon stocks, carbon sequestration, and GHG fluxes under both a "reference" and an "enhanced" LULC and land-management scenarios. The framework will be designed to first identify a "reference" scenario of carbon stocks, carbon sequestration and GHG fluxes under the varied socioeconomic and climate conditions represented within the SRES storylines. Because the SRES storylines are inherently devoid of specific policies for sequestering carbon or mitigating GHGs, the use of reference assessments will provide a baseline against which effectiveness of various mitigation activities can be estimated. The "enhanced" scenarios will allow for both independent and joint evaluation of the LULC and land-management activities to enhance carbon sequestration and reduce GHG emissions within the assumptions of the IPCC SRES storylines.

The following sections introduce methods of constructing mitigation activities and scenarios that will be prioritized for the national assessment, evaluated within each assessment unit, and combined into the LULC and land-management scenarios. A summary of the reference and alternative scenarios also is provided. Further details are available in appendix A.

Mitigation Activities. - In the context of this assessment, mitigation activities refer to an ecological means of sequestering carbon or mitigating GHG gases (see table 3.5). The assessment includes two types of mitigation activities: land-management change (such as increased use of prescribed burning in the interior Western United States) and LULC change (for example, afforestation of agricultural land). See table 3.5 for candidate mitigation activities and chapter 2 for a more detailed description of current knowledge about these activities. Candidate mitigation activities will be presented to agencies that have land-management responsibilities and to other stakeholders for review and prioritization. The following criteria will be important for selecting mitigation activities to enhance carbon sequestration capacity:

- Sequestration capacity per hectare of mitigationactivity change

- Hectares of suitable lands for mitigation-activity change to identify applicable upper bounds on mitigation-activity change

- Time-effectiveness of sequestration to address how quickly the mitigation activity provides climate-change mitigation and duration of the effect of the mitigation activity on the sequestration rate (for example, five decades for management activities affecting forest and soil pools, one decade for cropland management changes, and two decades for LULC conversion)

- Permanence of sequestration to address differences in how much carbon remains sequestered over time for each mitigation activity 
In addition to those criteria, the interests of consulting agencies and needs of policy makers will be considered in the prioritization of mitigation activities for the national assessment, but the final selection of activities will be subject to data availability, acceptance of assumptions, and (or) model capabilities.

Mitigation activities will be evaluated for their potential (the possible capacity in terms of amount and longevity) to sequester carbon and reduce GHG emissions in each assessment unit and to identify the effectiveness of these activities. For example, the conversion of grasslands to woodlands may not increase carbon-sequestration capacity in all regions.
These evaluations will be conducted with an awareness of the tradeoffs within a management activity. For example, although reducing grazing may enhance carbon sequestration on rangelands, it also increases wildland fuel availability and flammability. The evaluation of mitigation activities for each assessment unit will be accomplished by (1) reviewing and synthesizing regional studies of carbon-sequestration mitigation activities, (2) estimating areas of land that are ecologically suitable and economically available for the mitigation activity, (3) consulting with regional experts (for example, participants in the "greenhouse gas reduction through agricultural carbon enhancement" network (GRACEnet) or the U.S. Fish and

Table 3.5. Candidate mitigation activities to be considered for the assessment.

[Abbreviations are as follows: $\mathrm{CH}_{4}$, methane; $\mathrm{N}_{2} \mathrm{O}$, nitrous oxide; $\mathrm{GHG}$, greenhouse gases]

\begin{tabular}{|c|c|c|c|}
\hline Ecosystem & Strategy & Potential land-management change & $\begin{array}{c}\text { Potential land-use or land-cover } \\
\text { change }\end{array}$ \\
\hline \multirow[t]{3}{*}{ Forests } & Carbon sequestration & $\begin{array}{l}\text { Lengthen timber harvest-regeneration rotation } \\
\text { Increase forest management intensity (increase in } \\
\text { forest density, forest fertilization, thinning, reduc- } \\
\text { tion in fire fuel to reduce severe fires, manage- } \\
\text { ment of insects and diseases) }\end{array}$ & $\begin{array}{l}\text { Reduce logging frequency. } \\
\text { Convert lands to forest (afforestation). } \\
\text { Preserve forest, avoid deforestation. }\end{array}$ \\
\hline & $\begin{array}{l}\text { Mitigation of net GHG } \\
\text { emissions }\end{array}$ & Reduce logging impacts & Reduce deforestation. \\
\hline & $\begin{array}{l}\text { Offsite wood product } \\
\text { sequestration }\end{array}$ & $\begin{array}{l}\text { Improve mill waste recovery } \\
\text { Increase wood-product production } \\
\text { Extend wood-product life } \\
\text { Increase paper and wood recycling }\end{array}$ & \\
\hline Croplands & $\begin{array}{l}\mathrm{CH}_{4} \text { and } \mathrm{N}_{2} \mathrm{O} \text { emission } \\
\text { mitigation }\end{array}$ & $\begin{array}{l}\text { Improve crop tillage } \\
\text { Improve crop mix } \\
\text { Increase efficiency of crop fertilization } \\
\text { Expand irrigation }\end{array}$ & Reduce rice acreage. \\
\hline $\begin{array}{l}\text { Grassland/ } \\
\text { shrublands }\end{array}$ & Soil carbon sequestration & $\begin{array}{l}\text { Modify grazing management practices } \\
\text { Improve efficiency of fertilizer } \\
\text { Allow natural succession towards native shrub and } \\
\quad \text { forest } \\
\text { Restore degraded rangelands }\end{array}$ & \\
\hline Wetlands & $\begin{array}{l}\text { Mitigation of net GHG } \\
\text { emissions }\end{array}$ & Unknown & Preserve wetlands. \\
\hline $\begin{array}{l}\text { Aquatic habi- } \\
\text { tats }\end{array}$ & $\begin{array}{l}\text { Mitigation of net GHG } \\
\text { emissions }\end{array}$ & $\begin{array}{l}\text { Reduce nutrient export from urban and agricultural } \\
\text { lands } \\
\text { Alter withdrawal from deep reservoirs }\end{array}$ & \\
\hline
\end{tabular}


Wildlife Service's (FWS) Landscape Conservation Cooperatives (LCCs)) for likely amounts and intensities of mitigation activities, and (4) developing a spreadsheet tool to quantitatively evaluate and summarize attributes of candidate mitigation activities. An evaluation of mitigation activities to enhance carbon sequestration (both the intensities and the amounts) will enable a more informed construction of alternative mitigation scenarios, which is pertinent to the limited number of scenario simulations that will be run. Refer to appendix A for more information on the methodologies used to evaluate mitigation activities.

Summary of LULC and Land-Management Scenarios.-A scenario is a combination of future potential LULC and landmanagement changes ("mitigation activities") associated with vetted climate and socioeconomic conditions. Scenarios will be used to help identify possible GHG mitigation activities under various assumptions. Figure 3.4 illustrates how one of the scenarios (A1B in Nakicenovic and others, 2000) will be used in the assessment framework and will be used to help illustrate the sections below. Appendix A provides the details of scenario development methods.

Reference Land Use, Land Cover, and Land Management (R).- The "reference land use, land cover, and land management" (R) scenario will be designed to provide reference LULC and land-management scenarios that are consistent with SRES storylines (Nakicenovic and others, 2000). Because of the use of SRES storylines in the methodology, the R scenario will be devoid of any direct carbon-sequestration or GHG mitigation policies or actions and thus serves as a baseline against which to compare alternative ecological carbon sequestration or GHG mitigation activities.

The first step toward creating a set of regional LULC and land-management scenarios will be to develop a set of national narratives that are consistent with the SRES storylines and the related three scenarios (Nakicenovic and others, 2000). This step will be done primarily through a national workshop. Using existing LULC projections associated with SRES storylines and other supporting data, expert opinions will be solicited in order to describe plausible pathways of LULC and land management based on the underlying assumptions of the SRES storylines. The "downscaled" national storylines will be viewed as geographically meaningful sets of SRES storylines with characteristics that are specific to LULC and land management in the United States. The primary outcome of the national workshop will be expanded LULC narratives and national-scale LULC trajectories. Nested within the national narratives will be assumptions about the regional variability of LULC and land management, where available. For example, a national-scale narrative might include assumptions on forest use while also highlighting certain regions as likely places for changes in forestry activities.

Regional reference scenarios will be based on the national scenarios discussed above. The foundations of regional scenarios will be LULC and land-management histories that will be developed through review of existing

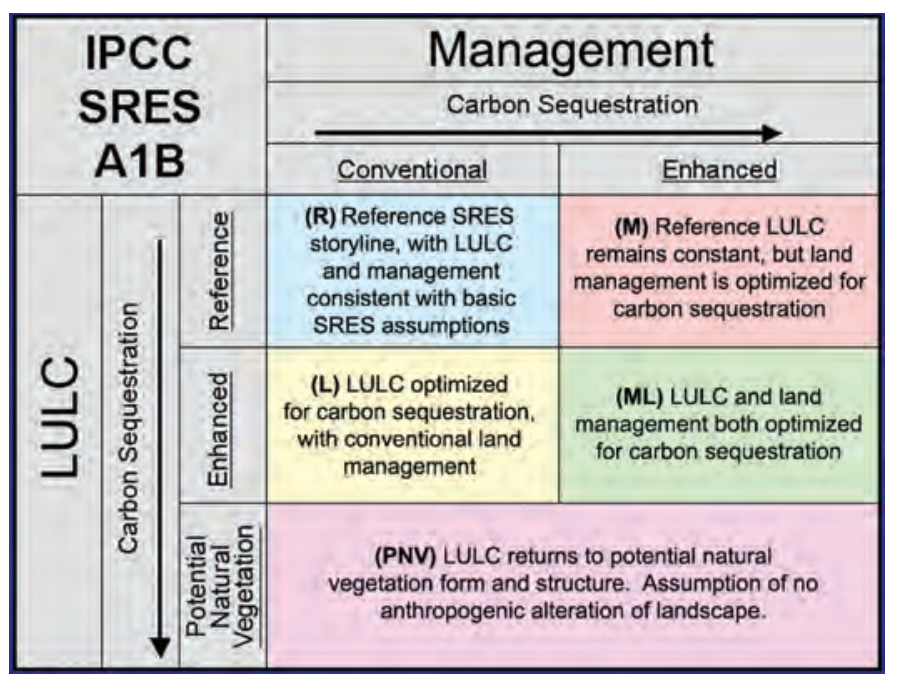

Figure 3.4. Diagram showing the assessment framework for each IPCC SRES storyline (Nakicenovic and others, 2000), using storyline $A 1 B$ as an example. $R$ represents the reference scenario with conventional (existing) land-management activities and will be used to generate spatially explicit land-use and land-cover forecasts for analyzing reference carbons stocks, carbon sequestration, and $\mathrm{GHG}$ fluxes. The enhanced land management (M), enhanced land use and land cover (L), or enhanced land use, land cover, and land management $(\mathrm{ML})$ scenarios will be used to represent increases in carbon sequestration and (or) to mitigate $\mathrm{GHG}$ emissions. Future potential land-use and land-cover projections associated with the $M, L$, and $M L$ scenarios will be produced in order to analyze how land-cover or land-management changes affect carbon stocks, carbon sequestration, and greenhouse gas fluxes. Finally, a potential natural vegetation (PNV) is introduced as a separate scenario. LULC, land use and land cover.

historical data sources and will include the comprehensive analysis of recent historical LULC change reported by the U.S. Geological Survey (USGS) Land Cover Trends project (Loveland and others, 2002). Consultations with regional experts will be used to project recent LULC into the future based on our understanding of the interactions among the drivers of LULC change. Regional experts will link both the SRES storylines and the national storylines with the biophysical and socioeconomic characteristics of the assessment units (ecoregions) in order to provide a range of LULC scenarios that will be consistent with recent historical observations.

The scenario construction process may incorporate exogenous projections of particular LULC types or management that are not covered by the SRES storylines. Examples may be projections of population from the U.S. Census Bureau or LULC projections from the U.S. Forest Service's RPA-mandated assessment. Maintaining fidelity to SRES storylines will be desirable, however, and the regional expert consultation process will determine the degree to which these exogenous projections will be used, if at all. 
Reference Land Use and Land Cover With Enhanced Land Management (M).-The "reference land use and land cover with enhanced land management" (M) scenario will examine the potential for land-management activities to increase carbon sequestration and mitigate GHG emissions with land use unaltered from the reference conditions (that is, land use and land cover are unchanged). The M scenario will be constructed to enhance carbon sequestration by enhancing land-management activities (such as increased timber rotation age) from the reference point of the $\mathrm{R}$ scenario. Like the $\mathrm{R}$ scenario, the mitigation scenarios will be influenced by the national storyline in order to encourage regional experts to reflect beyond the current range of thinking and to create a diverse set of $\mathrm{M}$ scenarios. The national storyline will inspire different emphases on mitigation activities, different amounts of change, and different concerns for the temporal aspects of carbon sequestration, including timeliness and permanence of sequestration. The national consultation process will be relied upon to provide guidelines for mitigation scenarios, including setting realistic bounds on increases in mitigation activities. The aforementioned evaluations of mitigation activities at the ecoregion level are used to regionalize the $\mathrm{M}$ assessment. The result is an altered land-management prescription for the $\mathrm{M}$ assessment.

The modeling of the $\mathrm{M}$ scenario will be conducted using the same 2011 through 2050 LULC forecast data from the R scenario, but it will use the altered regional land-management prescription. The enhanced land-management prescription will be assessed using the ecosystem-level carbon and GHG modeling methods (discussed below in this chapter) to analyze the impacts of land-management change on carbon sequestration and mitigation of other GHG emissions.

Enhanced Land Use and Land Cover With Reference Land Management (L).-The "enhanced land use and land cover with reference land management" (L) scenario will examine the potential for land-use change to increase carbon sequestration and to mitigate GHG emissions but with land-management activities unchanged from the $\mathrm{R}$ scenario. The approach outlined in the section on the M scenario (above) will be used to inform construction of the L scenario. The SRES storylines will influence a range of LULC changes. For example, the emphasis of storyline A1B on managed solutions may be associated with evergreen plantations, whereas the emphasis of storyline B1 on more sustainable forestry may favor restoration of natural, unevenly aged forests. In addition, national programs for ecological carbon sequestration will be elicited from consulting agencies and applied to varying degrees (for example, high, medium, and low levels of national commitment) across the storylines. Maintaining the integrity of the SRES storylines (Nakicenovic and others, 2000) will become more difficult when land use is being altered because of the competing uses of the land for food, fiber, and energy; and the potential effects of large regional changes in agricultural or forest land use on potential displacement and leakage of carbon credits. Again, "reasonable" fluctuations in land-use proportions will maintain a general fidelity to the SRES storylines. The result will be an altered land-use prescription for the $\mathrm{L}$ assessment.
The modeling of the L scenario will be conducted by using the altered land-use prescription for a given SRES storyline and by using the LULC model to produce a spatially explicit LULC projection for 2001 through 2050. Without changing the land-management assumptions from the $\mathrm{R}$ scenario, an ecosystem biogeochemical method (discussed in section 3.3.4) will be used to analyze the impacts of the land-use changes in the $\mathrm{L}$ scenario on carbon sequestration and mitigation of other GHG emissions

Enhanced Land Use and Land Cover With Enhanced Land Management (ML).- The "enhanced land use and land cover with enhanced land management" (ML) scenario will examine the potential for both land-use, land-cover, and landmanagement changes to increase carbon sequestration and mitigate GHG emissions. Of all of the reference and enhanced assessment groups, the ML scenario will be designed to maximize carbon sequestration and GHG emissions mitigation, while staying within the context of the SRES storylines (Nakicenovic and others, 2000). Land-management activities related to enhanced carbon sequestration have been shown to be effective in significantly increasing landscape carbon stocks (Hudiburg and others, 2009). Methodologies for providing land-management and LULC prescriptions will be consistent with the $\mathrm{M}$ and $\mathrm{L}$ scenarios described above. The land-management activities of the $\mathrm{M}$ scenario will be distributed across the LULC data from the L scenario and used as input to the biogeochemical model. The resulting scenario will be used to analyze carbon sequestration and GHG-flux mitigation from land-use, land-cover, and land-management change.

Potential Natural Vegetation (PNV). - Potential natural vegetation is defined as the native vegetation that would grow on any given parcel of land given a set of environmental (climate and site) conditions, but without land-use or landmanagement practices. The potential natural vegetation (PNV) scenario will be designed to analyze each assessment unit's carbon-sequestration potential in a scenario where the land is allowed to revert to the biophysical potential vegetation type, without anthropogenic alteration or management of the landscape, but with an approximation of present disturbance regimes ("current"). The use of PNV in the methodology will provide a basis for comparison with the other four scenarios (R, M, L, and ML). Given the persistence of urban and developed lands (that is, that a parcel of land rarely reverts to another land use once it is developed), the current urban and developed lands will be kept constant, but all other land-cover types will be allowed to revert to their potential vegetation types (native forests, shrub and grasslands). Therefore, the use of PNV as a scenario will have no LULC or land-management implications. Instead, it will be an exercise in modeling potential natural vegetation succession under overall influences of the biophysical environment as maintained by natural disturbances (Sundquist and others, 2009).

Development of potential natural vegetation will begin with a modeling of LANDFIRE's biophysical settings (BPS) data layer. The BPS layer represents vegetation that may have been dominant on the landscape before European settlement 
and is based on both the current biophysical environment and an approximation of the historical disturbance regime (Dillon and others, 2005), a concept similar to that of the potential natural vegetation of Kuchler (1964). To bring the LANDFIRE BPS layer to "current" time, a vegetation succession-modeling tool will be used to model the biophysical potential of vegetation succession in the context of current and future climate and natural disturbances (disturbance modeling is discussed in detail in appendix C). The BPS map units will be aggregated to approximate the common NLCD classes that are used with the other LULC and land-management assessments (reference and enhanced). The translated maps will represent potential natural vegetation succession from 2010 to 2050, and they will be used to examine resultant carbon sequestration and changes in GHG flux for the PNV scenario.

\subsubsection{Methodology Framework Summary}

A comprehensive set of data products (table 3.6) will be produced for both the current and future potential assessment. The results of the assessment will provide opportunities to examine the implications of the EISA requirements (U.S. Congress, 2007) as described below:

- For a given assessment unit, ecosystem capacities for carbon stocks, carbon sequestration, and GHG fluxes will be reported by pools and flux types. For estimating the current carbon sequestration and GHG conditions, results will be averaged values for the years 2001 through 2010. Results will be constrained by available in situ data about carbon stocks, carbon sequestrations, and GHG fluxes, and will be supplemented by LULC change data, ecosystem disturbance data, and other biophysical data.

- For estimating the future potential carbon sequestration and GHG conditions from 2011 through 2050, regionally specific ecosystem capacities for increased carbon sequestration and GHG-flux mitigation will be estimated within each IPCC SRES scenario. The M, L, and ML scenarios (fig. 3.4) will provide information on the effects of specific land-use, land-cover, and land-management mitigation actions within a given assessment unit. This information also will inform the analyses of the most economically feasible regional mitigation actions.

- Regionally specific ecosystem capacities for increased carbon sequestration and GHG flux mitigation will be estimated in order to compare results across multiple SRES storylines (Nakicenovic and others, 2000). The variability in results across the SRES storylines will frame the uncertainties in carbon sequestration and GHG-flux mitigation that result from uncertain future demographic, socioeconomic, energy, and climate projections.

- The regionally significant effects on ecosystem services that will result from the potential increased carbon sequestration and mitigation activities will be identified. An analysis of such ancillary effects on ecosystem services can be conducted across different SRES storylines and climate projections, across different mitigation scenarios within an SRES storyline, across temporal projections, and across geographic landscapes.

Table 3.6. Summary of the assessment framework for linking climate-change mitigation scenarios to changes in ecosystem capacities for carbon stocks and carbon sequestration and to changes in greenhouse-gas fluxes.

[Covers current (2001-2010) and future potential (2011-2050) assessments. Abbreviations are as follows: SRES, Special Report on Emission Scenarios of the Intergovernmental Panel on Climate Change (Nakicenovich and others (2000); NA, not applicable; R, "Reference land use, land cover, and land management" scenario; M, "Reference land use and land cover with enhance land management" scenario; L, "Enhanced land use and land cover with reference land management" scenario; ML, "Enhanced land use and land cover with enhanced land management" scenario]

\begin{tabular}{llll}
\hline $\begin{array}{c}\text { SRES } \\
\text { storyline }\end{array}$ & $\begin{array}{c}\text { Land use and land } \\
\text { cover }\end{array}$ & Land management & $\begin{array}{c}\text { Scenario } \\
\text { code }\end{array}$ \\
\hline NA & Current & Current & \\
\hline A1B & Reference & Future potential & Current \\
& & Reference & A1B-R \\
& Enhanced & Enhanced & A1B-M \\
& & Reference & A1B-L \\
& Potential natural & NA & A1B-ML \\
A2 & Regetation & A1B-PNV & \\
& & Reference & A2-R \\
& & Enhanced & A2-M \\
& Enhanced & Reference & A2-L \\
& & Enhanced & A2-ML \\
& Reference & Reference & B1-R \\
& & Enhanced & B1-M \\
& & Reference & B2-L \\
& Enhanced & Enhanced & B-ML \\
& & NA & B1-PNV \\
& & & \\
& & &
\end{tabular}

\subsection{Introduction to Assessment Methods}

The scenarios and storylines described in the previous section outline an overall framework and describe data products that will be generated by the national assessment. Integrated assessment methods or models are required to assess current and future potential ecosystem conditions for carbon stocks, carbon sequestration, and GHG fluxes and produce the 
desired information products. In designing and developing the methods, choices were made based on technical merits, data availability, and the consensus of the underlying science for components of the assessment. The methods introduced here represent a hybrid methodology involving in situ and remotesensing data, process-based ecosystem models, empirical models, statistical methods, and expert knowledge. The overall approach follows guidelines by the IPCC for agriculture, forestry, and other land uses in designing a combined tier 2 and tier 3 and approach 3 methodology (IPCC, 2006) to investigate LULC transitions, ecosystem disturbances, and changes in carbon stocks and GHG fluxes. Figure 3.5 illustrates relations and data flows among the major components of the methodology. The methods are briefly introduced in this section with detailed descriptions and discussions provided in appendixes A through I.

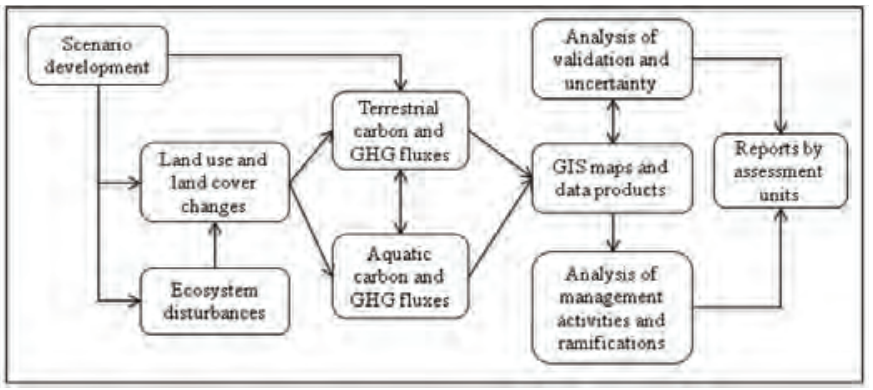

Figure 3.5. Diagram showing relations among major methods that are designed to run scenarios and produce assessment deliverables. These methods (statistical models, analyses, process models, or simple algorithms) are introduced in sections below. Abbreviations are as follows: GIS, geographic information system; GHG, greenhouse gas.

\subsubsection{Technical Plan for Key National Datasets}

Data Needs and Sources.-Various types of data will need to be assembled in order to complete a national assessment. The methodology will rely on existing data sets, promote collaborations to improve data availability, and use remotely sensed data to monitor key geospatial processes. Reference and observation data (in situ data, mapped biophysical data, remote-sensing data, and management- and policy-oriented data) will be used as the initial input data for (1) assessing present carbon stocks, carbon sequestration, and GHG fluxes, and (2) to parameterizing and constraining the methods and models that will be used for estimating future potential conditions. A critical deciding factor for the quality of the assessment will be the availability and quality of reference input data. Input data used for the national assessment will include the following:
- In situ, mapped, or remotely sensed (for example, light detection and ranging, or LIDAR) data about carbon stocks, rates of sequestration, or GHG fluxes in different pools and flux types

- In situ and remotely sensed data or studies that document the effects of controlling processes, such as ecosystem disturbances and land-use and land-cover change

- Up-to-date mapped biophysical data that has regional to national coverage, including current weather and climate, future climate projections, soil, permafrost, topography, land cover, vegetation types and structure, wetlands, and ecosystem disturbances (for example, areas affected by insect outbreaks, storms, and fires)

- In situ, mapped, or remotely sensed data that document temporally relevant ecological relations, such as information about the intra- and inter-annual variations for carbon stocks and GHG fluxes that can be measured in different pools and for different flux types, or information about the behavior of vegetation growth along different climate trajectories

A general summary of the assessment's input data needs, data sources and time span, essential attributes, and uses in the assessment methodology are provided in table 3.7.

Data Gaps and Plans. - The needs of the national assessment will not be met completely by existing data sources. Although some data development efforts may be necessary, the assessment largely will rely on existing suitable datasets for practical reasons. Other data gaps may be filled partially with surrogate data (for example, remote-sensing-based biomass data for ground biomass measurements); however, uncertainty caused by data gaps will be reported as part of the overall uncertainty assessment. Major data gaps are summarized below:

- A well-distributed, national spatiotemporal dataset of fluxes specifically for $\mathrm{CH}_{4}$ and $\mathrm{N}_{2} \mathrm{O}$ does not exist to support the national assessment and help constrain estimates of GHG modeling. Although the assessment will rely on all available flux data from sources such as FLUXNET, GRACEnet, and other available sources for parameterization and calibration purposes, the primary method for producing GHG-flux estimates for different ecosystems will rely on ecosystem simulation models (discussed in section 3.3.4). Uncertainties related to GHG-flux estimates will be provided at the regional scale. Data from other researchers or programs will be needed in order to increase the availability of GHG-flux data.

- The availability of many types of data, including data on GHG fluxes, is limited for Alaska; however, mapping efforts by the National Land Cover Database and the LANDIFRE database have improved the availability of data on land cover and vegetation as well as wildland fires. Forest, soil, and stream inventory data are undersampled and digital maps of vegeta- 
Table 3.7. Data needs, sources, variables, spatial and temporal resolution, and uses in the assessment methodology.

[Datasets and sources represent only the major data needs. There are other data needs that are met by miscellaneous individual datasets that are not listed here. For explanations of acronyms, please see "Abbreviations, Acronyms, and Chemical Symbols" in the front of this report. Abbreviations are as follows: $\mathrm{CH}_{4}$, methane; $\mathrm{CO}_{2}$, carbon dioxide; hr, hour; $\mathrm{km}$, kilometer, $\mathrm{m}$, meter; $\mathrm{N}_{2} \mathrm{O}$, nitrous oxide; yr, year]

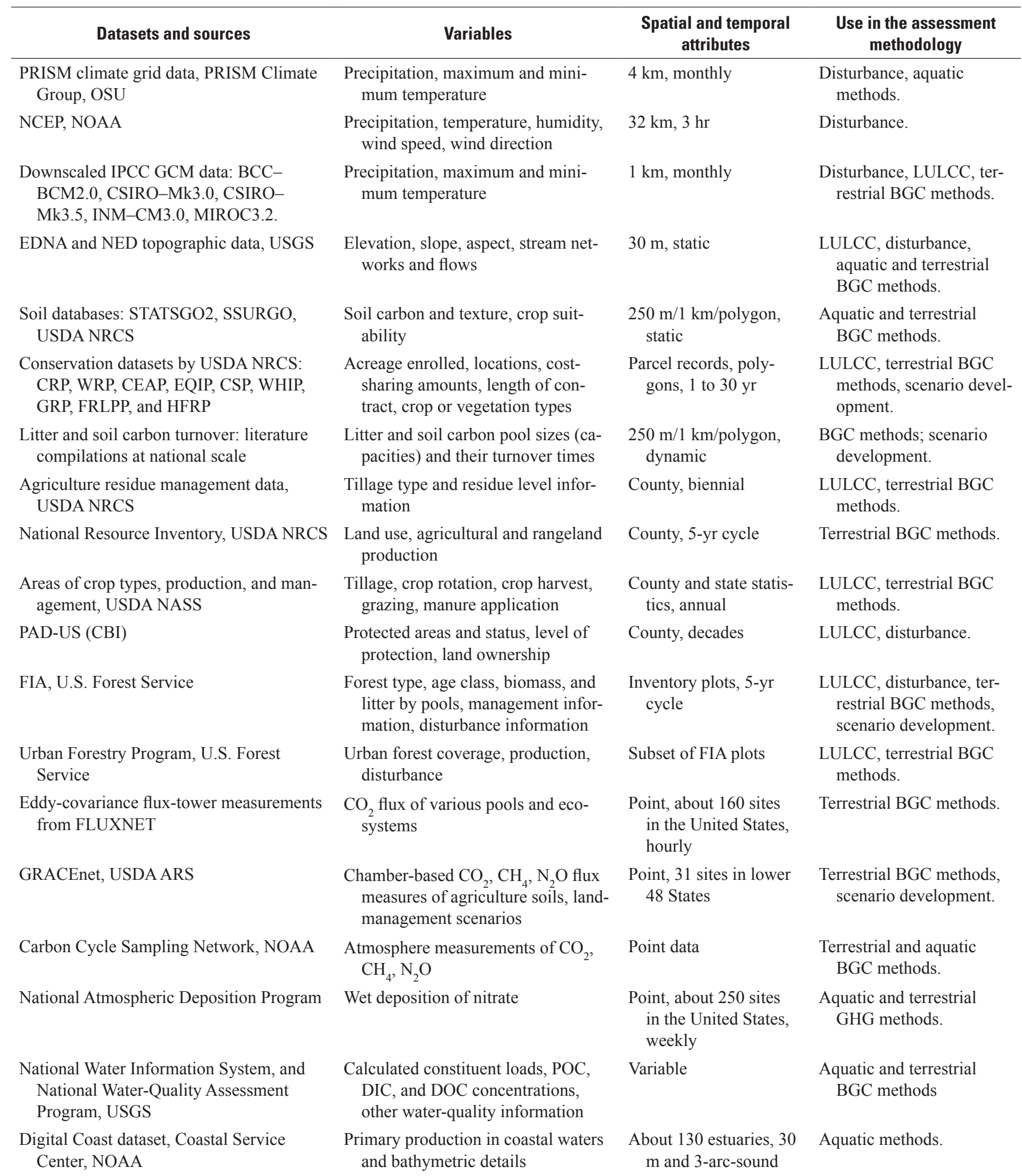


Table 3.7. Data needs, sources, variables, spatial and temporal resolution, and uses in the assessment methodology.-Continued

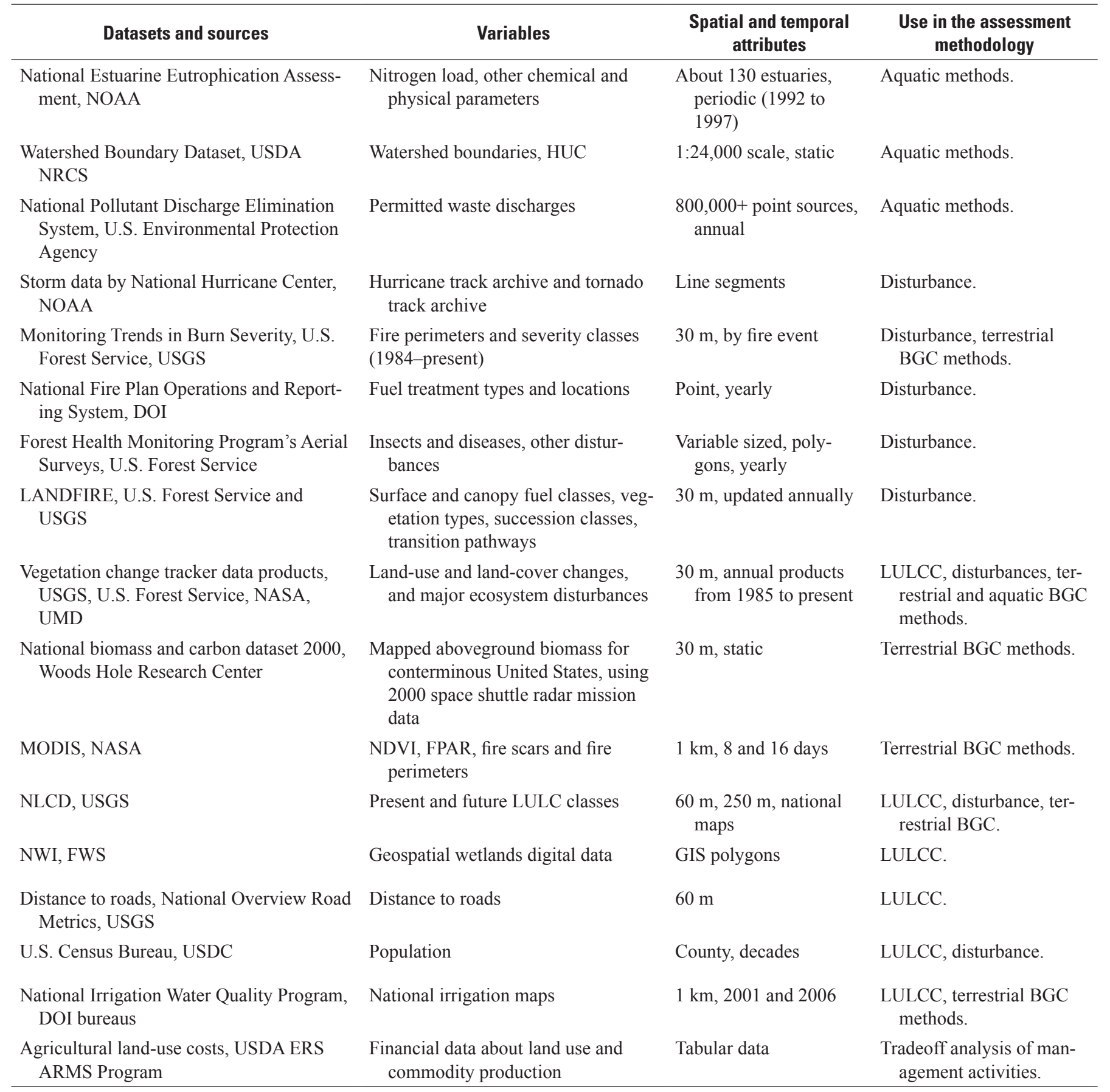


tion structure, such as biomass, do not exist. Although this methodology will rely on surrogate data (for land cover, vegetation types, and fire data) and on limited data for soils and permafrost, the strategy for collecting data on vegetation, permafrost, and biomass will rely primarily on (1) increasing the spatial extent of LIDAR data and (2) conducting strategic sampling campaigns in areas where carbon-sequestration capacity and (or) GHG emissions are deemed most likely to change (see chapter 4 for a discussion of science needs).

- Assessment of carbon sequestration and GHG emissions in aquatic habitats will be based on existing data on streamflow, water chemistry, suspended sediment, coastal production, and sedimentation rates, which are stored in national databases such as the National Water Information System (NWIS) and the Reservoir Sedimentation Database (RESSED). Existing GHG data related to aquatic habitats also will be used, but the data are scattered (and are not in a central repository) and availability is limited. Additional data collection will be needed to improve the accuracy of the assessment; the following areas specifically will need to be addressed: (1) gaps in the spatial coverage of surfacewater and groundwater chemistry (carbon and nutrient species); (2) a lack of fine-resolution temporal data for stream chemistry; and (3) poor spatial and temporal coverage for coastal, estuarine, lake, and impoundment sedimentation rates, sediment carbon concentrations, and GHG fluxes. It is recommended that additional chemical data be collected at sites along transects from mountains into coastal waters and at a temporal resolution sufficient to accurately estimate carbon, nitrogen, and suspended-sediment fluxes. The transport of carbon, nitrogen, and suspended sediments during storms can be particularly important, and estimating this transport will require a combination of manual sampling, automated sampling, and the use of in situ sensors. It is also recommended that measurements of sedimentation rate, organic carbon in sediment, and GHG fluxes in these aquatic habitats be substantially expanded, particularly in small impoundments, estuaries, and nearshore environments, where carbon cycling and burial can be quite rapid.

- Although the Soil Survey Geographic (SSURGO) database (http://soils.usda.gov/survey/geography/ssurgo) contains the most spatially detailed soil information available for the Nation (1:24,000- or 1:12,000-scale), it is not a periodic soil inventory and does not offer information on changes in soil carbon stocks. In addition, the SSURGO data are complete for approximately 86 percent of the land area of the conterminous United States and 7 percent of Alaska. Complete coverage for the conterminous United States and Alaska is available from the U.S. General Soil Map (STATSGO2, formerly STATSGO, http://soils.usda.gov/survey/geography/statsgo/), but it has a reduced spatial detail $(1: 250,000$-scale for the conterminous United States and 1:1,000,000-scale for Alaska). The scale for Alaska is a concern because the region is undergoing warming trends (Chapin and others, 2008). Warming trends have lead to an increase in wildfires in Alaska that have the potential to release more $\mathrm{CO}_{2}$ than all of the terrestrial net primary productivity (NPP) in the United States (Wiedinmyer and Neff, 2007; Chapin and others, 2008). Efforts are underway by the USDA NRCS to fill gaps in the SSURGO data, but workshops and studies that are targeted to address soil carbon dynamics are needed. An enhanced soil survey effort focused on soil carbon dynamics will make use of multiple data sources (for example databases with contributions by multiple investigators, satellite images, radar, LIDAR, digital elevation models, published soil maps and pedon datasets, targeted soil sampling, and opportunistic soil sampling in conjunction with trace-gas measurements) in order to improve the hydrologic, thermal, and landscape assessments of soil carbon and its potential for GHG release. The USGS has initiated the North American Carbon Network (Johnson and Harden, 2009), a database for Alaska with contributions from multiple investigators, and has begun to identify areas that are undersampled (Bliss and Maursetter, 2010). Soil carbon dynamics will be the topic for one or two targeted workshops with other relevant agencies and science programs. The results of the workshops can then be used to identify large and (or) vulnerable soil carbon stocks. A targeted soil-sampling campaign that links soil carbon stocks, soil carbon pools, and trace-gas characterization most likely will be recommended.

- Future potential climate scenarios associated with IPCC SRES storylines (Nakicenovic and others, 2000) are needed. Forecasts of future climate conditions have been produced using GCMs for each scenario and are available from the IPCC's and various other Web sites; however, downscaling the GCM datasets for use with the individual IPCC scenarios is a necessary step that will provide the spatial resolution required for the national assessment. Although downscaled datasets exist (for example, Maurer and others, 2007), they do not meet the data criteria of fine temporal resolution (monthly) for simulations, appropriate parameters (maximum and minimum temperature and precipitation), and fine spatial resolution (one to a few kilometers) for the three IPCC SRES emission scenarios of interest (A1B, $\mathrm{A} 2$, and B1). To generate these data, "change factors" (percent changes in precipitation and temperature between baseline and projected conditions; Arnell and Reynard, 1996; Pilling and Jones, 1999; Hay and Sem, 2000; Prudhomme and others, 2002; Arnell, 2003a,b; Eckhardt and Ulbrich, 2003; Diaz-Nieto and Wilby, 2004) will be computed by comparing the output from IPCC's Scenario $20 \mathrm{C} 3 \mathrm{M}$ simulations for the $20^{\text {th }}$ century (IPCC, 2007), which uses GCM baseline conditions, with output for the three IPCC SRES emission sce- 
narios (Nakicenovic and others, 2000). Five GCMs (see models in table 3.8.) from the World Climate Research Programme's Coupled Model Intercomparison Project (phase 3) (CMIP3) multimodel dataset archive will be processed; an ensemble means will be calculated and an assessment of ensemble ranges also will be performed for the three emission scenarios. These five models are the only ones in this collection that will provide data for both the current and future conditions needed for these scenarios. Ensembles of GCM output have been found to provide a more reliable representation of potential regional changes and uncertainties than the results from single models that cover large geographic extents (for example, Murphy and others, 2004; IPCC, 2007). Climate-projection output will be downscaled based on the geospatial relation of the change fields to historical PRISM data, which has 4-km spatial resolution (see PRISM Web site at http://www.prism.oregonstate. edu). Procedures for the estimating change fields and downscaling geospatial data are from an implementation developed by Lauren E. Hay and Steven L. Markstrom (U.S. Geological Survey, unpub. data, 2010). The resulting 4-km-resolution climate-projection data for monthly maximum and minimum temperatures and precipitation will be further downscaled to $1-\mathrm{km}$ resolution through GIS interpolation to yield spatially smoothed climate data layers for use in conjunction with other fine-spatialscale data layers for national assessment models (note that this second downscaling step provides no increase in quality over the input baseline PRISM data).

\subsubsection{Land-Use and Land-Cover Change}

Current Land Use and Land Cover--The examination of carbon sequestration and emissions will require an analysis of changes in both land use (for example, a conversion of agricultural land to urban land) and land cover (for example, harvesting trees on forested land). To analyze both requires techniques that will use spatial and nonspatial data. The LULC method (this section) and the ecosystem disturbance method (section 3.3.3) will provide spatially explicit representations of both land-use and land-cover components, and will require spatially explicit input data. Given the need for a spatially explicit assessment for all areas of the Nation, remote-sensing data will be extensively used, from which we will determine land cover and will indirectly infer some land-use information. Data will be included on the broad land-use and land-cover categories that are readily available from remotely sensed data (land-use classes, such as "agriculture" and "development," or land-cover classes, such as "deciduous forest" and "barren"). Specific land-management activities associated with land use that aren't available as spatially explicit data will be handled through a statistical scaling approach that is related to the biogeochemical modeling framework. The integration of the LULC, ecosystem-disturbance, and biogeochemical models will provide the ability to examine the effects of both landuse and land-cover change on carbon sequestration and GHG emissions.

This section describes the procedures used to model spatially explicit LULC change. The NLCD 2001 database (Homer and others, 2004) will be used as the primary spatialdata source for land-cover information for the "current" time frame (2001), the year in which model simulations begin. The NLCD classification scheme has been modified to include not only NLCD land-cover classes, but also a limited number of land-use classes that could be handled easily by the LULC modeling framework (table 3.4). Augmentation of the NLCD dataset will be accomplished by incorporating (1) vegetation change tracker (VCT) data products (Huang and others, 2010) produced from the LANDFIRE program in order to map forested areas that have been disturbed by clearcutting, and (2) irrigated lands data (U.S. Geological Survey, 2010) to distinguish dry land from irrigated land. Given the complexity of modeling multiple urban-development classes at a national scale, we also have condensed the 2001 NLCD developed classes into one comprehensive developed class. See table 3.4 for the final modified thematic land-cover classes.

Future Potential Land-Use and Land-Cover Changes.For each of the scenarios outlined in figure 3.4 and table 3.6, an LULC model will be used to provide spatially explicit thematic maps that cover each year from 2001 through 2050.

Table 3.8. General circulation models used to project future climate scenarios.

[Output from the five GCM models will be downscaled for this assessment. From Nakicenovic and others (2000). GCM, general circulation model]

GCM dataset name and abbreviation

Bergen Climate Model 2.0 (BCC-BCM2.0)

Commonwealth Scientific and Industrial Research Organisation Mark 3 (CSIRO-Mk3.0)

Commonwealth Scientific and Industrial Research Organisation Mark 3 (CSIRO-Mk3.5)

Institute for Numerical Mathematics CM3 (INM-CM3.0)

\section{Responsible agency}

Bjerknes Centre for Climate Research, University of Bergen, Norway.

Commonwealth Scientific and Industrial Research Organisation, Australia.

Commonwealth Scientific and Industrial Research Organisation, Australia.

Institute for Numerical Mathematics, Russian Academy of Science, Russia.

National Institute for Environmental Studies, Japan. 
Between 2001 and 2010, LULC trajectories will be the same across all scenarios because they are considered collectively to be "current." The 2001 to 2010 time frame will be based on empirically measured LULC change as mapped by the 2006 NLCD change product (Xian and others, 2009) and the VCT data products (Huang and others, 2010) produced from LANDFIRE program. These data will serve as reference data to both calibrate the 2001 to 2010 "projections," and to validate model results. The LULC model will be used next to project LULC from 2011 to 2050 for each scenario.

The spatially explicit simulation model, "forecasting scenarios of land cover change" (FORE-SCE) (Sohl and others, 2007; Sohl and Sayler, 2008) will be used for projected LULC change. FORE-SCE uses two distinct, but linked, components called "Demand" and "Spatial Allocation," a structure that will allow for both linkages with external models and the inclusion of input data on driving-force variables derived from data at different scales. The complete LULC modeling framework will include an ability to ingest scenario-based assessments (LULC demand) to produce spatially explicit LULC maps that are compatible for assessing carbon sequestration and GHG fluxes.

The "Demand" component will provide overall proportions of LULC classes at a regional scale, and will be expressed as annual "prescriptions" for future LULC change. The annual prescriptions will be typically in the form of a simple table that will provide annual proportions of all mapped LULC classes. The "Demand" component will be constructed through extrapolation of historical trends, econometric modeling, integrated modeling, or scenarios based on expert knowledge. For this assessment, the LULC "Demand" component for the R scenario (see section 3.2.2) will be provided by the IPCC SRES scenario construction described in section 3.2.2 ("Framework for Assessing Future Potential Carbon Stocks, Carbon Sequestration, and Greenhouse-Gas Fluxes") and in appendix A ("Reference and Alternative Mitigation Scenarios"). The "Demand" component for the scenarios where LULC is enhanced for carbon sequestration (the M, L, and ML scenarios defined in section 3.2.2) will be done by combining the spreadsheet results (detailed in section 3.2.2 and appendix A) for enhancing LULC for carbon sequestration with the reference IPCC SRES scenario LULC proportions.

The "Spatial Allocation" component will use the LULC prescriptions from the "Demand" component to produce spatially explicit thematic LULC maps on an annual basis. The "Spatial Allocation" component of FORE-SCE was designed to take advantage of both historical and contemporary LULC research and data from the USGS. For this methodology, data from the USGS Land Cover Trends project (Loveland and others, 2002) and the NLCD (Homer and others, 2004) will be used to parameterize a unique, patch-based spatial-allocation procedure, one which can mimic realistic configurations and placement of individual patches of LULC change on an annual basis. The placement of patches will be guided by probability surfaces for each LULC type that are constructed through the analyses of empirical relationships between existing LULC patterns and a wide array of spatially explicit biophysical and socioeconomic data. The "Spatial Allocation" component places patches of LULC "change" on the landscape, one by one, until the annual prescription from the "Demand" component is met. The model then proceeds to the next yearly iteration, producing annual LULC maps from 2001 to 2050.

FORE-SCE also tracks the ages of forest stands. The initial (2001) age will be established by using the VCT data products (Huang and others, 2010) produced from the LANDFIRE program, which tracks natural and anthropogenic disturbances by analyzing historical layers of Landsat Thematic Mapper (TM) data and Forest Inventory and Analysis (FIA) sample points. A composite image will be constructed from these two sources that will identify the initial age of the forest stand for each 250-m pixel. The forest-stand age will be increased for each annual FORE-SCE scenario run; the age will be reestablished at " 0 " if forests are clearcut or if previously nonforested land is newly established (afforested) (for example, if a new pine plantation is established on previously nonforested land). Forest-stand age also will be used to more realistically mimic typical regional forest-cutting cycles and to inform biogeochemical modeling.

For the national assessment, each of the scenario runs outlined in figure 3.4 and table 3.6 will be run for each of the three IPCC SRES storylines (Nakicenovic and others 2000). The ecosystem-disturbance method (discussed in the next section) will be integrated directly with annual ecosystem disturbance data and with LULC data passed between FORE-SCE and the disturbance model in order to ensure that the projected LULC change results will be integrated with the annual ecosystem disturbance results (introduced in the next section). The direct integration of FORE-SCE, the disturbance model, and the biogeochemical modeling framework (the General Ensemble Modeling System, or GEMS) also will allow for the examination of land-use, land-cover, and landmanagement components that cannot be handled by any one individual model. Although FORE-SCE models all thematic LULC change for all terrestrial ecosystems, the model is not well equipped to handle coastal processes that affect thematic LULC change along coasts (for example, changes in coastal wetlands or other ecosystems due to sea-level rise or other coastal processes). An external coastal wetland model (discussed in appendix B, "Mapping and Modeling of Land-Use and Land-Cover Changes") will be used to map thematic LULC change for coastal wetland areas for each of the three IPCC SRES storylines (Nakicenovic and others, 2000). These data will be integrated with the FORE-SCE and disturbance model results when modeling is completed for a scenario. The final data products will be annual, 250-m-resolution, thematic LULC maps and transition statistics from 2001 to 2050 for each scenario. A much more detailed description of the LULC modeling framework can be found in appendix B.

Test Results Using the Land-Use and Land-Cover Model.-A test using the LULC modeling methodology was created for two EPA Level III ecoregions (modified from Omernik, 1987), the Mississippi Alluvial Plain (ecoregion 73) and the Mississippi Valley Loess Plains (ecoregion 74). Of the 
scenarios listed in table 3.6, LULC modeling was completed for the $\mathrm{R}$ and $\mathrm{L}$ scenarios (see section 3.2.2). Using a simplified protocol for regional scenario construction, annual prescriptions of LULC change that are consistent with the A1B scenario were produced for each ecoregion, thus providing the "Demand" component for the R scenario. The "Demand" component for A1B was fed to the FORE-SCE "Spatial Allocation" component, which was then parameterized independently for each ecoregion (using methods described in appendix B). Spatially explicit LULC maps from 2001 to 2050 then were produced for the $\mathrm{R}$ scenario.

The L scenario also was modeled. The spreadsheet approach for assessing land-use mitigation actions was used to independently identify optimal land-use changes that would increase carbon sequestration and mitigate other GHG fluxes in each ecoregion. Some selected land-use changes that resulted from running the $\mathrm{L}$ scenario were as follows:

- Restore forested wetlands (bottomland hardwood) where previously they have been used for agriculture in the Mississippi Alluvial Plain.

- Increase afforestation by converting marginal agricultural land to forests in the Mississippi Valley Loess Plains.

- Eliminate deforestation caused by processes other than forest harvesting and replanting.

- Eliminate the loss of wetlands (other than coastal wetlands) caused by conversion to other land uses.

- Increase the time between forest harvests from 25 to 45 years.

- Reduce the rates of clearcutting forests by 50 percent.

Annual LULC change prescriptions were constructed for the $\mathrm{L}$ scenario on the basis of the spreadsheet analysis and the land-use-mitigation actions identified above, thereby providing a "Demand" component. This "Demand" component was then fed into the FORE-SCE "Spatial Allocation" components, which was used to produce spatially explicit LULC maps from 2001 to 2050 for the L scenario.

Figure 3.6 shows the net LULC change between 2010 and 2050 for both the R and L scenarios, for the entirety of both EPA Level III ecoregions 73 and 74. Ecoregion 73 (the Mississippi Alluvial Plain) was characterized by very little LULC change in the R scenario, but it changed significantly in the L scenario (primarily due to restoration of croplands to woody wetlands). Ecoregion 74 (the Mississippi Valley Loess Plains) showed active LULC change in the R scenario due to significant urban development and afforestation (primarily by converting agricultural land to pine forests). In the L scenario, significantly more afforestation occurred, where more agricultural land was converted to natural forest types rather than pine forests. The L scenario also was characterized by much less forest cutting (the "anthropogenic" class in figure 3.6)

Figure 3.7 shows the initial 2010 LULC, and the projected LULC changes for the period 2010 through 2050 for a portion of the two ecoregions. The reference $(\mathrm{R})$ scenario is used in parts $C$ and $E$ and the enhanced LULC (L) scenario is used in parts $D$ and $F$. Very significant changes in LULC are evident between part $D$ (the result of running the R scenario) and part $F$ (the result of running the $\mathrm{L}$ scenario); the results project lower forest-cutting rates in the Mississippi Valley Loess Plains (Claiborne County, Miss.) and large increases in forested wetland restoration in the Mississippi Alluvial Plain (Tensas Parish, La.). The projected land-cover maps from 2010 to 2050 for both the R and L scenarios will be used to model carbon stocks, carbon sequestration, and GHG fluxes, as described in section 3.3.4.

\subsubsection{Ecosystem Disturbances}

As discussed in chapter 2, ecosystem disturbances are defined as episodic events that may affect the composition, structure, or function of an ecosystem (Pickett and White, 1985; E.A. Johnson and Miyanishi, 2001; M.G. Turner and others, 2001). Ecosystem disturbances are treated distinctly from global environmental change effects, which include sustained alterations in climate that may arise from increasing $\mathrm{CO}_{2}$ in the atmosphere or nitrogen deposition (B.L. Turner and others, 1990). The definition of ecosystem disturbances is also separate from events related to LULC, such as forest converted to cropland. Major ecosystem disturbances are one of the primary mechanisms that have potential to reset carbon sequestration pathways and change ecosystems from carbon sinks to sources (Baldocchi, 2008; Running, 2008).

\section{Disturbances Included in the Assessment.-Ecosystem} disturbances are discrete events that affect the composition, structure, and (or) function of an ecosystem or landscape (Pickett and White, 1985; M.G. Turner and others, 2001; Johnson and Miyanishi, 2001). Ecosystem disturbances are important because they result in a transfer of carbon between live and dead pools; in the case of fires, the disturbance causes the immediate release of carbon and GHGs to the atmosphere (Campbell and others, 2007; Meigs and others, 2009). Carbon stocks, carbon sequestration, and GHG fluxes may be altered further in the years immediately following a disturbance because of patterns of mortality, regeneration, and productivity (Hicke and others, 2003; M.G. Turner and others, 2004). Currently, fuel treatments and controlled burning are used in many fire-prone ecosystems to reduce wildfire hazard and risk (Agee and Skinner, 2005). Recent studies also have demonstrated the potential reductions in carbon loss from fires in fire-prone ecosystems through the use of fuel treatments and controlled burning (Hurteau and North, 2009; Stephens and others 2009; Wiedinmyer and Hurteau, 2010); however, in ecosystems with long fire-return intervals, treatments may result in a reduction of long-term carbon-sequestration capacity (Harmon and others, 2009; Mitchell and others, 2009). Therefore, both ecosystem disturbances and disturbance-management activities must be incorporated in the assessment in order to evaluate their potential effects on carbon stock, carbon sequestration, and GHG fluxes.

The following ecosystem disturbance types (both natural and anthropogenic) should be considered in the national 


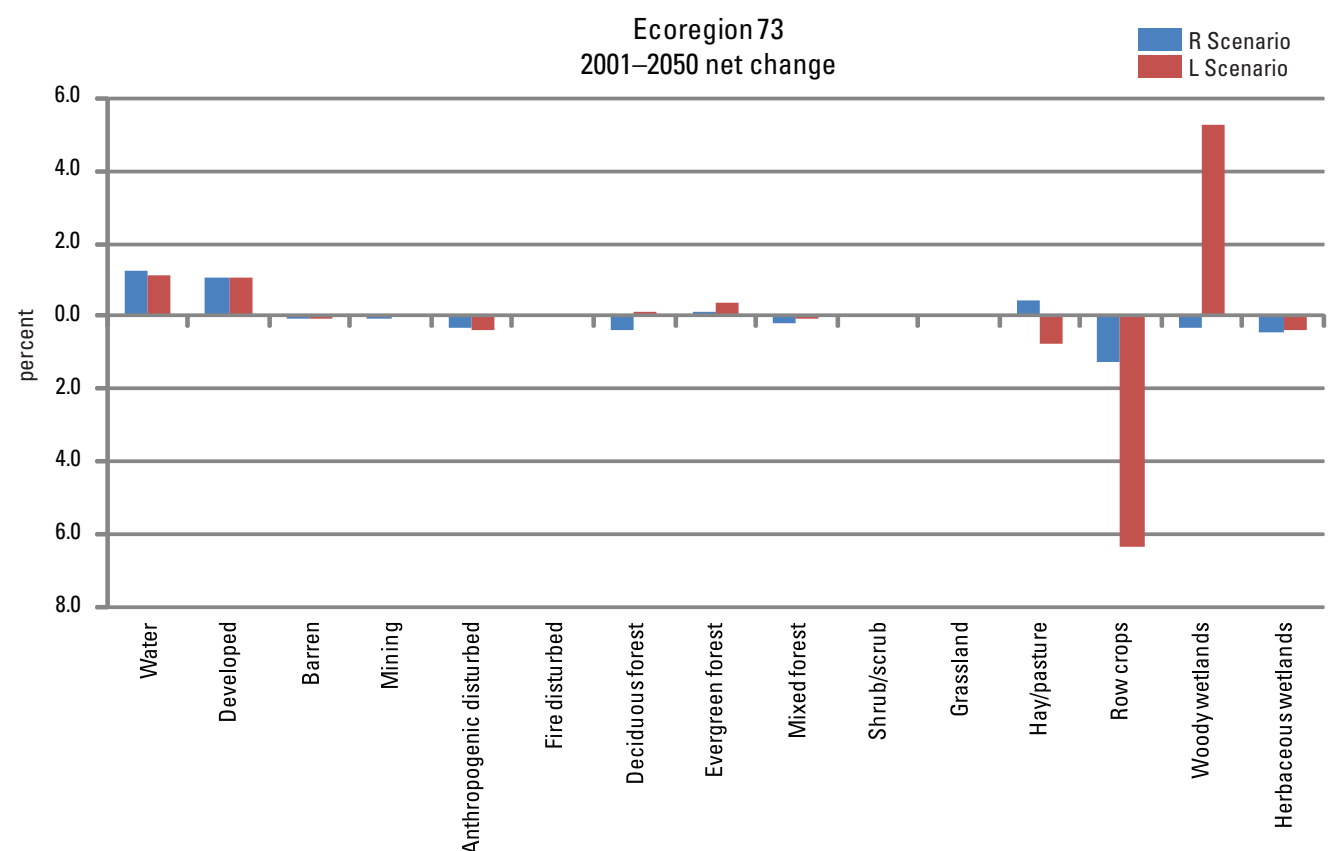

Land use/land cover

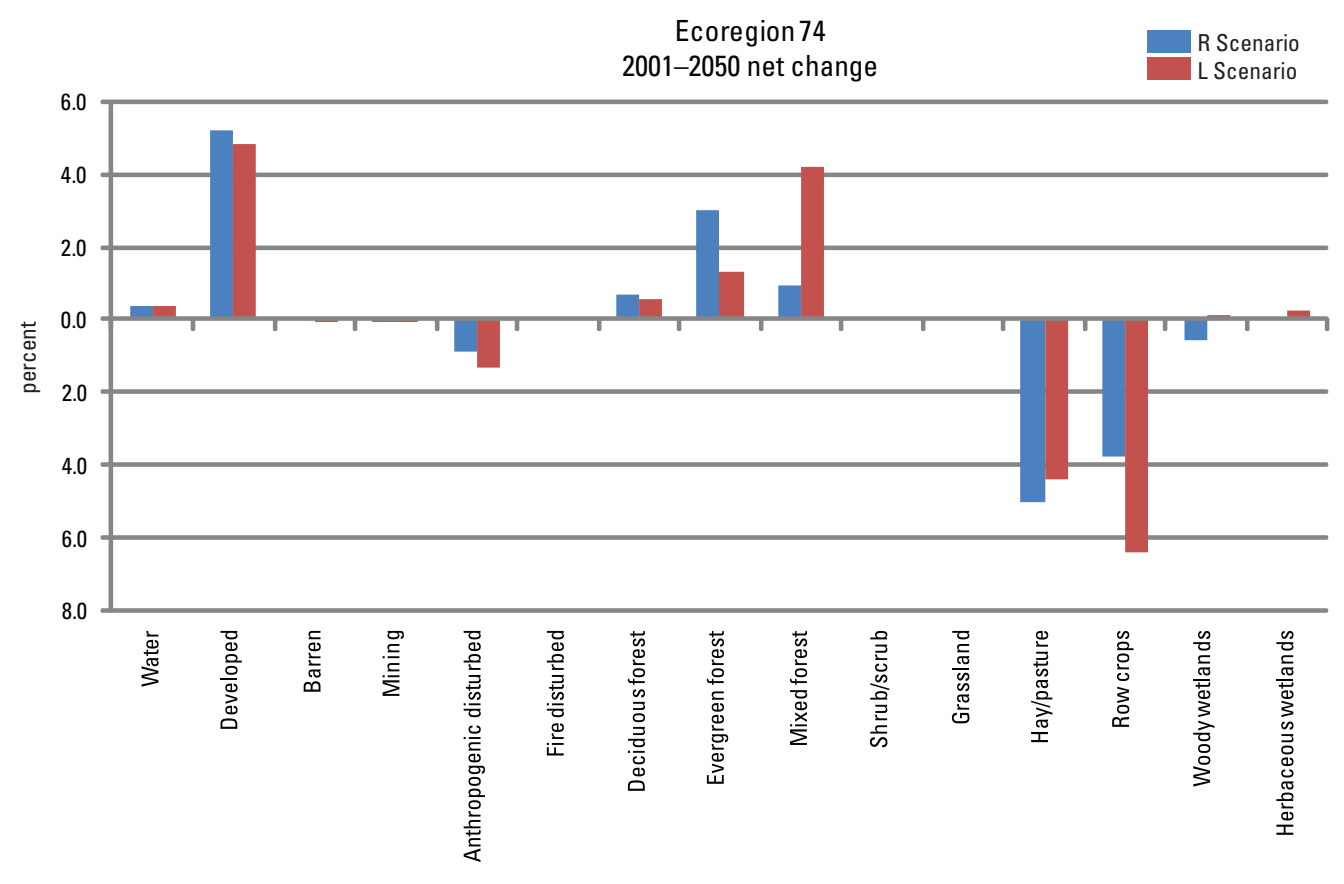

Land use/land cover
Figure 3.6. Graphs showing the net change for the modeled land-use and land-cover types in the two U.S. Environmental Protection Agency Level III ecoregions (modified from Omernik, 1987) used in the test study, using the prototype methodology and running both the $\mathrm{R}$ (reference land use, land cover, and land management) and $L$ (enhanced land use and land cover with reference land management) scenarios. Ecosystem 73, Mississippi Alluvial Plain; Ecosystem 74, Mississippi Valley Loess Plains. 

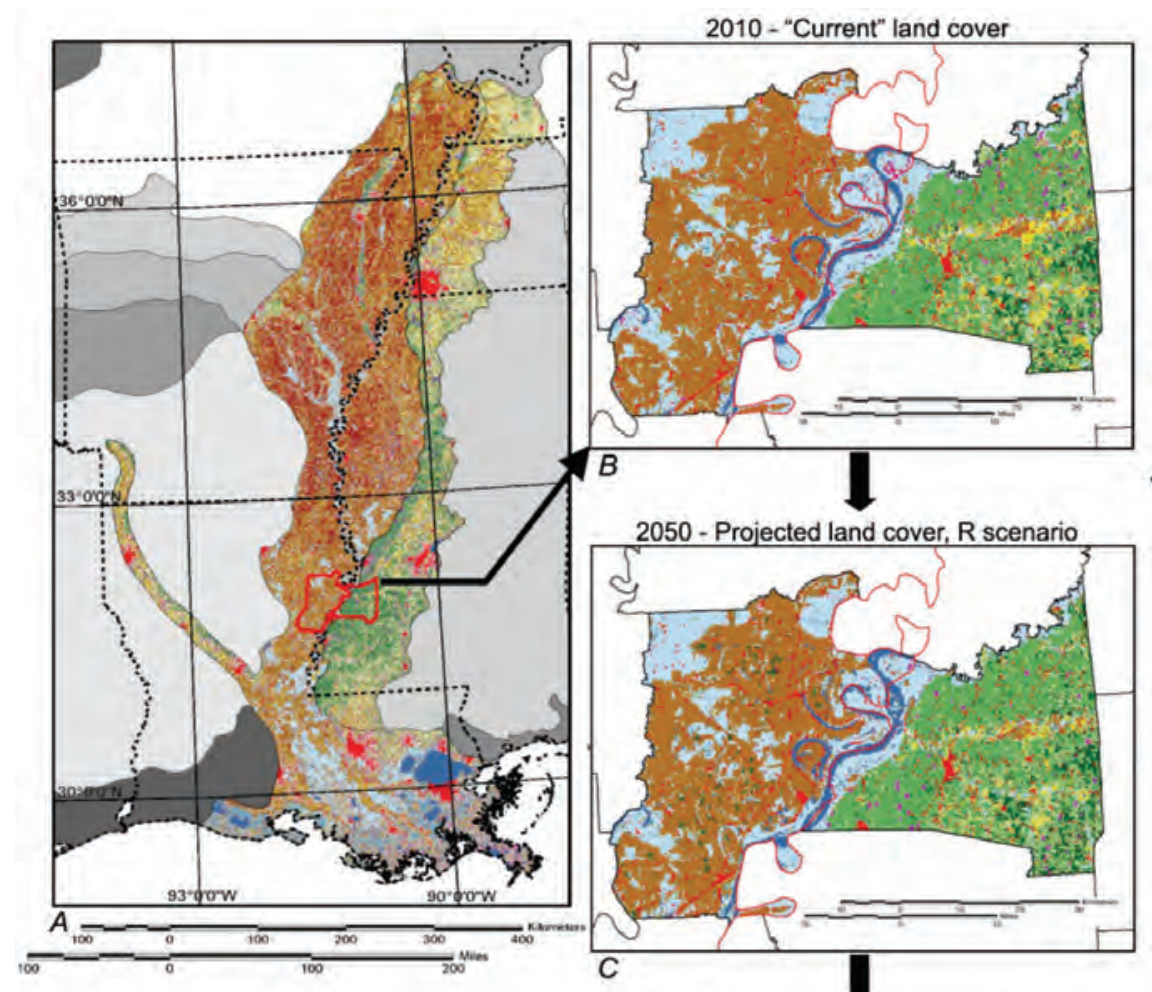

2050 - Projected land cover, R scenario

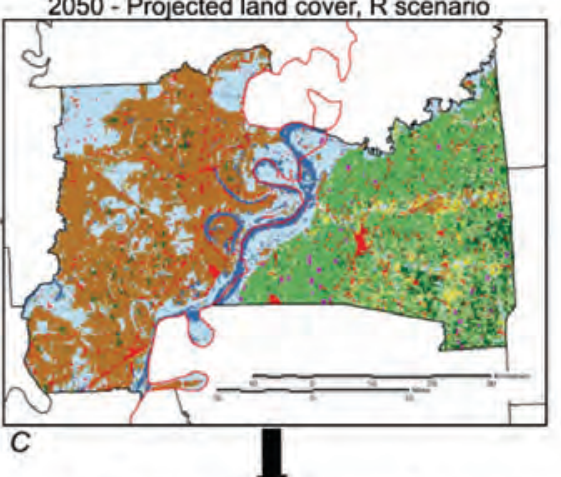

Explanation

Land-cover change

(for parts $\mathrm{E}$ and $\mathrm{F}$ )

No change

$\square$ Urban/developed

$\square$ Clearcut

Afforestation

Woody wetland restoration

Other change

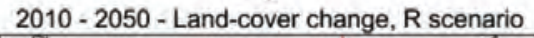

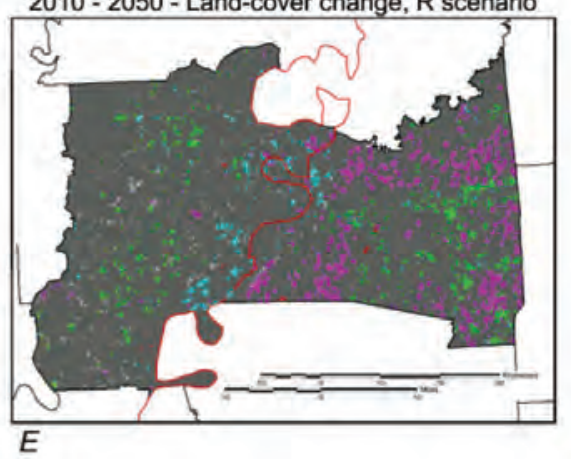

Explanation

Land cover (for parts A - D)

Open water $\square$ Evergreen forest

$\square$ Urban/developed $\square$ Hay/pasture

Clearcut

Barren

Deciduous forest

Mixed forest

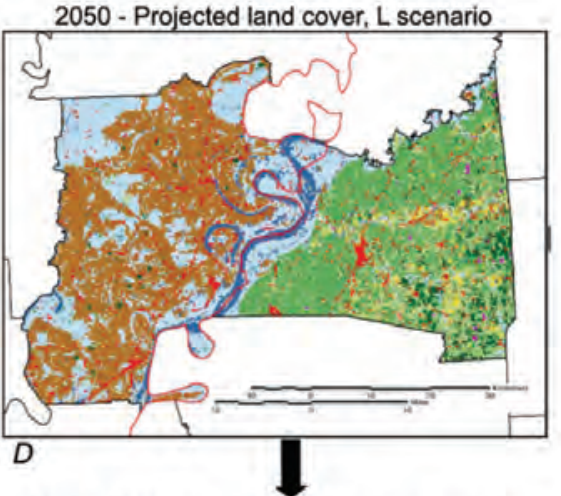

2010 - 2050 - Land-cover change, L scenario

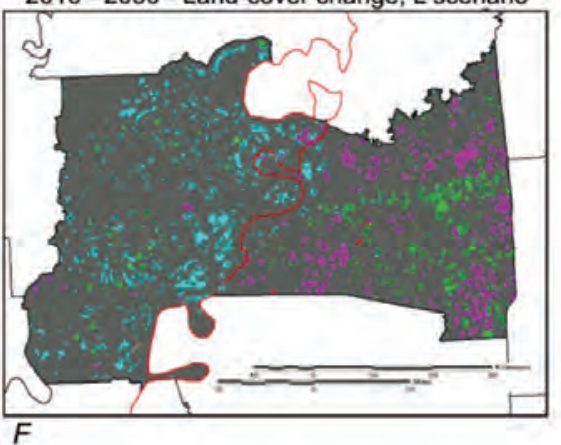

Figure 3.7. Maps showing the results of a land-use-modeling test for the A1B scenario (Nakicenovic and others, 2000). A, Area of study showing land-cover classes for two EPA Level III ecoregions (modified from Omernik (1987)) as follows: 1, Mississippi Alluvial Plain; 2, Mississippi Valley Loess Plains. Tensas Parish, La., and Claiborne County, Miss. (outlined on the map), were selected to run the scenarios that are shown in the enlargements (parts $B-F$. $B$, “Current" land cover (2010). $C$,
Projected land cover in 2050 using the "reference land use, land cover, and land management" (R) scenario. D, Projected land cover in 2050 using the "enhanced land use and land cover with reference land management" (L) scenario. $E$, Land-cover change from 2010 through 2050 using the $\mathrm{R}$ scenario. F, Land-cover change using the $L$ scenario. Obvious differences in land cover are evident in parts $E$ and $F$. 
assessment: wildfires, hurricanes, tornados and other damaging winds, insect- and disease-related forest mortality, and land-management activities such as fuel treatments and forest cuts (table 3.9). The impacts of disturbances and land-management activities on carbon stocks, carbon sequestration, and GHG fluxes will be considered for the following ecosystems: forests, grassland/shrublands, and wetlands.

Current Ecosystem Disturbances.-The task of capturing current ecosystem disturbances will start by creating annual summaries of past disturbances using records of recent wildfires, storms, and insect and disease outbreaks, by ecoregion. These annual summaries will include disturbance type, cause, number of events, and total area affected. Fire summaries also will include ecoregion-level estimates for emissions, which will be created by totaling individual estimates for each fire using the Consume model (Prichard and others, 2006) and the First Order Fire Effects Model (FOFEM) (Reinhardt and others 1997) with the fuel-loading model (FLM) and fuel-characteristic classification system (FCCS) data produced for the LANDFIRE project (Rollins, 2009). The annual disturbance summaries will be provided as tables and further summarized as probability distributions for each U.S. Environmental Protection Agency (EPA) Level II ecoregion.

Future Ecosystem Disturbances.-The occurrence and spread of disturbances are influenced by a variety of processes and patterns operating at different scales (Peters and others, 2004; Falk and others, 2007; Raffa and others, 2008). Therefore, the methodology to simulate future disturbances incorporates a series of components operating at different spatial and temporal scales to characterize and forecast regional patterns as well as the footprints and impacts of individual disturbance events. Relations between past disturbances (frequencies and extents) and climate, vegetation, and socioeconomic drivers will be identified at ecoregion scales using empirical relations, which also will be used to forecast potential future disturbance occurrence patterns. Future disturbance footprints will be simulated using a variety of approaches, described in more detail below and in appendix $\mathrm{C}$.

Fire-related disturbances and fire-management activities will include wildfires, prescribed fires, and fuel treatments. The methods for forecasting wildfires will incorporate the four basic processes: ignition, spread, effects, and succession
(Keane and others, 2004). The projections of ecoregion wildfire activity will be made using climate-driven predictions of the number of wildfires each year (Westerling and others, 2006; Preisler and Westerling, 2007). The individual ignition locations will be determined from empirical probability surfaces using climate, vegetation, land cover, and topography as predictor variables (Syphard and others, 2008). The predicted probability surfaces will be updated each year by incorporating changes made by the LULC (section 3.3.2) and BCG (section 3.3.4) methods. The spread of individual fires will be simulated each year using the minimum-travel time (MTT) algorithm (Finney, 2002), the LANDFIRE fuels and topography layers (Rollins, 2009), and National Oceanic and Atmospheric Administration (NOAA) North American Regional Reanalysis (NARR) weather data. Fuel-treatment projections (including prescribed fires) will be made from historical distributions (the number of treatments per year and the size of individual treatments). The treatment locations will be placed randomly within wildland vegetation types (forest, shrub, grass, depending on the type of treatment) in public lands and allowed to spread (using the MTT algorithm for prescribed fire and a "patch-grow" algorithm for other treatments; Finney, 2002) until a predetermined treatment area is reached or an entire patch of contiguous wildland vegetation has been treated.

Disturbances that are not related to fire (nonfire disturbances) will include insects and disease outbreaks, hurricanes, tornadoes, and damaging winds. The location and spread of insect and disease outbreaks will be based on empirical probability surfaces developed using epidemiology and speciesdistribution modeling techniques with vegetation, climate, topography, and previous outbreak locations as predictors (Elith and others, 2006; Phillips and others, 2006; Elith and Leathwick, 2009). Hurricane, tornado, and damaging wind activity (number of storms per year) will be based on a random selection of data from historical storm-occurrence summaries (for tornados and damaging winds) and national summaries (for hurricanes). An empirical storm-track generator (Vickery and others, 2000) will establish the storm path. For tornados and damaging winds, the footprint of the storm disturbances will be determined using remote sensing of landscape change (RSLC) techniques and historical storm locations. A similar

Table 3.9. Major natural and anthropogenic ecosystem disturbances, selected attributes, and data sources.

[MTBS, Monitoring Trends in Burn Severity project; LANDFIRE, Landscape Fire and Resource Management Planning Tools Project; RSLC, remote sensing of landscape change activities at U.S. Geological Survey; NFPORS, National Fire Plan Operations and Reporting Systems; USFS, U.S. Forest Service]

\begin{tabular}{lll}
\hline \multicolumn{1}{c}{ Disturbance type } & Characteristic attributes of data sources & \multicolumn{1}{c}{ Data sources } \\
\hline Wildland fires & Fire size, severity, and emissions & MTBS, LANDFIRE. \\
$\begin{array}{l}\text { Hurricanes, tornados, damaging winds } \\
\text { Insect and diseases }\end{array}$ & $\begin{array}{l}\text { Storm tracks, severity, and areas of mortality } \\
\text { Areas of defoliation and mortality }\end{array}$ & $\begin{array}{l}\text { RSLC. } \\
\text { Uorest cuts (clearcuts and thinning) }\end{array}$ \\
$\begin{array}{l}\text { Fuel treatments (including prescribed fires) } \\
\text { aerial surveys, RSLC. }\end{array}$ & Areas of cuts, cutting types & RSLC. \\
\hline
\end{tabular}


approach will be used for hurricanes, but a surface-wind-field and exposure model will also be incorporated to determine where damage to vegetation occurs (Boose and others 1994).

The redistribution of biomass among the different pools following both fire and nonfire disturbances will be quantified using a look-up table approach containing information on changes in biomass pools by ecosystem type, for each type of disturbance or management activity. The look-up table (example given in table D2 in appendix D) will be derived from published estimates and field inventories (for example, FIA) and will be used by the BGC modeling methods (discussed later in this chapter) to distribute biomass among different pools following disturbances. For fires, emissions will be estimated for each fire using data layers from the LANDFIRE fuel-loading model (FLM) and fuel-characteristic classification system (FCCS) with the Consume and First Order Fire Effects Model (FOFEM) fuel-consumption and emission models (Reinhardt and others, 1997; Prichard and others, 2006). The post-disturbance influence on vegetation productivity will be accounted for by the BGC methods.

During the disturbance simulations for the national assessment, a critical step will be to update the LULC and fuels data (fire behavior fuel model, canopy height, canopy cover, canopy bulk density, canopy base height, FLM and FCCS) that will be used to simulate disturbance locations and spread. During each annual time step in the simulation, in places where disturbances and management activities occurred, the LULC and fuels layers will be updated by using the existing vegetation state and transition models developed for LANDFIRE and "look-up" tables that link vegetation state to fuel layers and NLCD categories. Appendix C contains a detailed technical discussion of the data sources, the methods that will be used to characterize and model the ecosystem disturbances and management activities, and the data products that will be produced.

Disturbance modeling components are linked with the scenario framework (fig. 3.4). Climate changes associated with each of the IPCC SRES scenarios (Nakicenovic and others, 2000) will increase or decrease the frequency of the disturbances and will influence the spread and severity of individual disturbance events. LULC-change projections will interact with disturbance modeling by influencing the extent and arrangement of land-cover types within ecoregions, therefore constraining the spread of individual disturbance events. Additionally, the influence of disturbance-related land-management activities will be incorporated through fuel-treatment and fire-suppression modules. This integrated modeling framework will allow for a comparison of how changes in land cover, land use, and land management under different scenarios might influence disturbances and their impacts on carbon storage and GHG emissions in various ecosystems. See appendix $\mathrm{C}$ for more details on modeling major ecosystem disturbances.

Expected Outputs for Ecosystem Disturbances.-For the references and mitigation scenarios associated with the IPCC storylines (table 3.6), the final data products from the ecosystem disturbance modeling will include regional summaries and maps of current and future potential annual disturbances, levels of severity, and GHG emissions (carbon monoxide, carbon dioxide, methane, and nonmethane hydrocarbons). The data products will be presented as probability distributions that will summarize the range of results produced across replicated simulation runs.

Test Results Using the Ecosystem Disturbance Model.The wildfire component of the ecosystem disturbance model was tested in the same two EPA level III ecoregions that were used in the test that used the land-use and land-cover model (section 3.3.2): the Mississippi Alluvial Plain and the Mississippi Valley Loess Plains. For the test, wildfire histories for the two selected ecoregions were constructed by using the Monitoring Trends in Burn Severity (MTBS) project database (Eidenshink and others, 2007). In order to show the relation between fire occurrences and the land cover (which is based on the nominal year 2001) in each ecoregion, only the data for wildfires that occurred before 2001 were used. This search resulted in data on 12 fires that occurred in the Mississippi Alluvial Plain ecoregion and 22 fires that occurred in the Mississippi Valley Loess Plains ecoregion. The small sample sizes prevented the construction of a predictive model that might demonstrate a statistically significant relation between wildfires and climate and LULC. Therefore, the number of wildfires simulated for each month was determined by drawing randomly from the historical distribution of monthly fire occurrences. A random distribution of ignition was used (with ignition points limited to natural vegetation types, such as is found in forests, grassland/shrublands, and wetlands) in order to estimate the probability of ignition locations.

Overall, the test showed that wildfires in the two ecoregions burned a small area; between 2001 and 2008, the observed (MTBS data) annual number of wildfires and area burned were 2 wildfires and 1,471 ha per year in the Mississippi Alluvial Plain and 0.5 wildfire and 166 ha per year in the Mississippi Valley Loess Plains. Simulation results for the same time period using the IPCC SRES A1B storyline (Nakicenovic and others, 2000) produced annual results of 0.6 wildfires and 2,450 ha burned in the Mississippi Alluvial Plain and 0.8 wildfires and 500 ha burned in the Mississippi Valley Loess Plains (figs. 3.8 and 3.9). The simulation results do not exactly match the observed results because of the stochastic nature of fire occurrence in the model; however, the simulated results were within the range of variability of observed values for number of fires and area burned each year. Because the wildfire simulation runs did not result in a large area burned each year in the test area, the fires' effects were not incorporated into the BGC modeling methods discussed later in this chapter.

The initial results suggest that wildfires will not have a substantial impact on GHG emissions in the test region. The results indicate that there would be few fires and most of the fires would be small; less than 3,000 ha were burned each year in the simulations. Fuel consumption and emissions were not estimated using the FOFEM and Consume models because the input data (FCCS and FLM) were not yet available for the Southern United States (they are available now for Western United States). Predicting fire occurrence and spread is an 

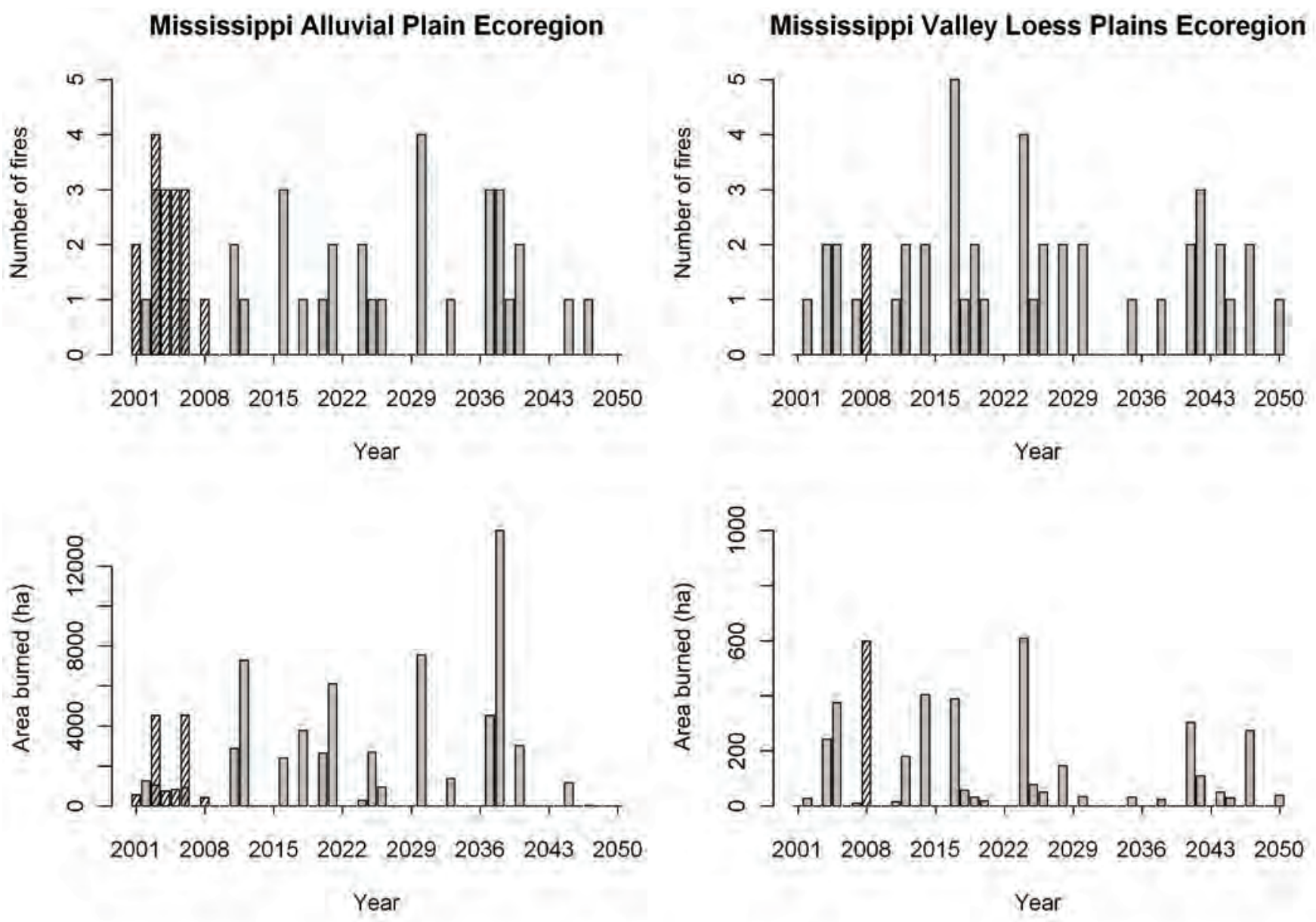

\section{Explanation \\ $\square$ Predicted \\ U Observed}

Figure 3.8. Graphs showing the observed and simulated number of wildfires per year, and the observed and simulated number of hectares of area burned by wildfire per year, using the IPCC SRES A1B storyline from the Intergovernmental Panel on Climate Change's Special Report on Emissions Scenarios (Nakicenovic and others, 2000) for the two EPA Level III ecoregions used in the test. Note that the horizontal axes for graphs showing number of hectares burned have different scales, and that some years had no observed or simulated fires.

inherently difficult process to simulate well. With this in mind, the differences between the observed and simulated number of fires and the area burned were not large; they were on a similar order of magnitude and reflected the inherently random nature of annual fire occurrence patterns and the spread of individual fires in the region.

\subsubsection{Carbon Stocks, Carbon Sequestration, and Greenhouse-Gas Fluxes in Terrestrial Ecosystems}

The 2006 IPCC Guidelines for National Greenhouse Gas Inventories (IPCC, 2006) recognized two major approaches for estimating GHG fluxes in ecosystems: an inventory approach and a process-based modeling approach. The inventory approach (also referred to as the "bookkeeping" or "spreadsheet" approach) relies on direct measurements of carbon pools over a specific time period and applies empirically derived algorithms (such as carbon-response curves and emission factors) to estimate net carbon sequestration (Houghton and others, 1999). In contrast, the modeling approach uses process-based BGC models to estimate carbon stocks, carbon sequestration, and GHG fluxes over time in response to controlling factors such as climate, LULC change, and ecosystem disturbance. The carbon stocks, carbon sequestration, and GHG fluxes are estimated at each modeled time step. For this assessment, the current (2001-2010) and future (2011-2050) 


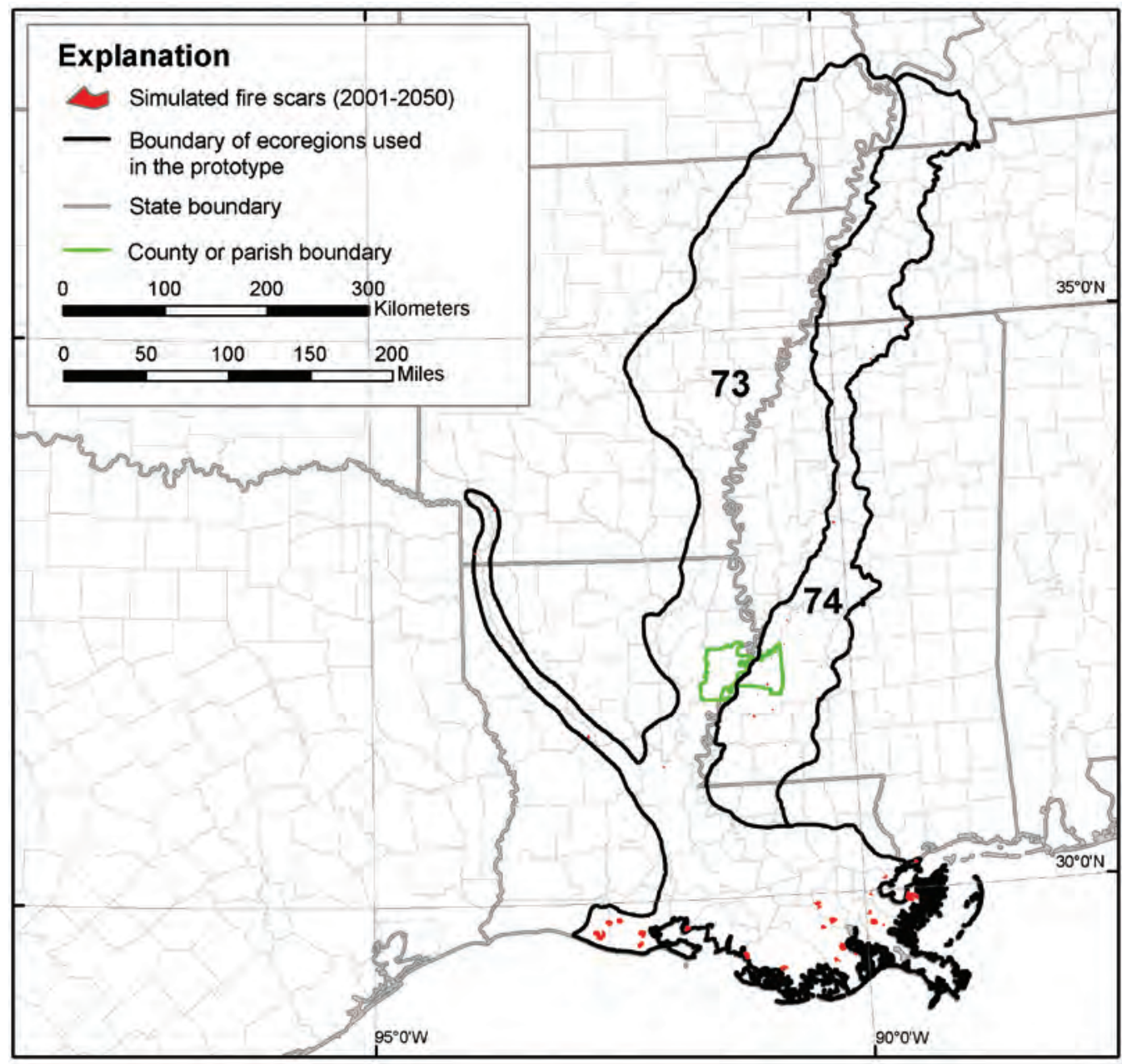

Figure 3.9 Map of the test area showing locations of simulated wildfires in two EPA Level III ecoregions for 2001 through 2050, using the A1B storyline from the Intergovernmental Panel on Climate Change's Special Report on Emissions Scenarios (IPCC SRES; Nakicenovic and others, 2000. Ecoregions are as follows: 73, Mississippi Alluvial Plain; 74, Mississippi Valley Loess Plains. carbon stocks, carbon sequestration, and GHG fluxes will be evaluated. For current estimates, the approaches will use field observations, published data, and other published information to calibrate model inputs and to evaluate model results. For future projections, the two general approaches will diverge on the basis of various LULC- and climate-change scenarios. In addition, the process-based modeling approach will incorporate several BGC simulation models for various ecosystems, as discussed below.

Accounting approach.-A spreadsheet model will be used to simulate carbon dynamics and GHG emissions. The spreadsheet approach generally will be limited to nonspatial or coarse-spatial-resolution simulations; the number of formulas used in a spreadsheet usually will be small, which will prevent the inclusion of a simulation of a complex ecosystem, GHG fluxes, LULC, or land-management interactions. The Guidelines for National Greenhouse Gas Inventories (IPCC, 2006) provide equations and factors for building the spreadsheets. For this assessment, the spreadsheet will be developed in a parallel manner with the BGC modeling approach in order to compare and verify outputs (for example, there will be only a cursory check for sizes, distributions, patterns, or trends of estimates in order to capture and correct obvious errors).
Process-based modeling approach.-For this assessment, process-based BGC modeling will be conducted using the general ensemble modeling system (GEMS) developed by the USGS (S. Liu, Loveland, and Kurtz, 2004). The GEMS is designed to provide spatially explicit biogeochemical model simulations over large areas. The system uses both agent and direct implementation approaches to interact with encapsulated biogeochemical models, such as Century (Parton and others, 1987), Erosion-Deposition-Carbon Model (EDCM) (S. Liu and others, 2003), and Integrated Biosphere Simulator (IBIS) (Foley and others, 1996).

The agent implementation model interface is used with GEMS to conduct model runs of existing encapsulated BGC models. This approach requires minimum modifications to encapsulated models and can be useful for reusing models that are difficult to modify. Regional-scale BGC models, such as Century, EDCM, and IBIS, can be encapsulated or linked in GEMS (S. Liu, Kaire, and others, 2004; S. Liu, Loveland, and Kurtz, 2004; Tan and others, 2005; J. Liu and others, 2006). Because GEMS is designed to encapsulate multiple models and to parameterize and implement these models using the same data, it provides an ideal platform for using "model ensembles" to identify and address issues and uncertainty that 
are related to model structure and to mathematical representations of biophysical processes.

The direct implementation approach is used to merge BGC models directly with GEMS to allow more efficient, spatially explicit simulations. Many regional-scale model applications adopt a time-space sequence simulation approach, which implements a complete simulation for an individual pixel from beginning to end before moving to the next pixel. In an example linking GEMS with EDCM, a space-time sequence is used instead (each time step is simulated for the whole region before moving to the next step). This approach can be exploited to quantify lateral movements of water, soil, carbon, and nitrogen and can interface with other modeling systems such as FORE-SCE and ecosystem disturbance maps. BGC modeling will be a dynamic process, and national experts will be consulted during the assessment to provide comments on the overall modeling approach and to consider other potentially suitable BGC models for use on the GEMS platform.

As discussed above, there are two primary reasons to use both the spreadsheet approach and the process-based modeling approach for this assessment: First, the different methods each have their unique applications. The spreadsheet approach is relatively straightforward and transparent, but it is limited in spatial deployment and in linking with environmental changes and mitigation activities. In contrast, the process-based modeling approach is spatially explicit and dynamic, but it can be too complex for users to follow all of the processes considered and internal calculations. Second, applying both approaches provides the opportunity to crosscheck a model's performance and results and enhances overall confidence in assessment results.

Different input data will be used for the two different, yet complementary approaches because of the varying model structures and data-format requirements. For example, the combination of the GEMS spreadsheet and the EDCM uses joint frequency distribution (JFD) tables and Monte Carlo simulations for forest ages in order to generate the initial biomass in a forest; however, GEMS combined with Century uses remote-sensing data (showing tree-canopy cover types and height) to estimate biomass without considering the forest's age. The data-model integration will be improved to allow the same datasets to be used by different BGC methods during the assessment.

Table 3.10 lists examples of the methods or models, deliverables, technical processes, target ecosystems, and data needs or sources that will be used in the assessment. Details of the spreadsheet and process-based modeling methods are described in appendix D.

Assessment of Carbon Stocks and Carbon Sequestration.The primary input data for the assessment of carbon stocks and sequestration will come from in situ measurements of aboveground biomass (inventory data), in situ soil measurements (for example, from GRACEnet), soil maps, carbon-flux measurements from eddy-covariance flux towers, remote sensing of vegetation, LULC maps, ecosystem-disturbance datasets, and land-management datasets available from various sources. See table 3.7 for the datasets and sources for this data. The assessment of carbon stocks and sequestration will be conducted by using both the spreadsheet and the processbased model simulation approaches. The net ecosystem carbon change will be calculated as the difference in the carbon stock between two time steps. As indicated in table 3.10, parameterization for current carbon stocks and sequestration will be based on observational data from different sources, as well as on current biophysical data such as soil, climate, LULC, and ecosystem disturbances. Parameterization for future potential carbon stocks and sequestration will require projected future potential climate, LULC changes, and disturbances along the scenario trajectories. The spreadsheet approach will compute carbon stocks, carbon sequestration, and GHG fluxes averaged at the level of assessment units, using predefined algorithms and the input data. For the process-based model simulation approach, carbon fluxes will be modeled using the technical processes listed in table 3.10. For both approaches, the primary drivers of carbon stocks and carbon sequestration will be climate change, LULC changes, ecosystem disturbances, and possible changes in land-management practices.

Assessment of Greenhouse-Gas Fluxes.-Modeling and assessing methane $\left(\mathrm{CH}_{4}\right)$ and nitrous oxide $\left(\mathrm{N}_{2} \mathrm{O}\right)$ fluxes will be more complicated than modeling and assessing carbon dioxide $\left(\mathrm{CO}_{2}\right)$ fluxes because direct observational data for $\mathrm{CH}_{4}$ and $\mathrm{N}_{2} \mathrm{O}$ are scarce. Available data include eddy-covariance flux-tower data, field measurements from various sources and published literature, and soil-flux measurements that are compiled in sources such as GRACEnet. A general strategy for assessing GHG flux, in light of the shortage of measured flux data, will be to focus on ecological conditions such as soil moisture and temperature that control GHG fluxes, which are more prevalent and available.

The emission of $\mathrm{CH}_{4}$ will be estimated through the simulation of soil biogeochemical processes, including methane production by methanogenic bacteria under anaerobic conditions, oxidation by methanotrophic bacteria under aerobic conditions, and transport to the atmosphere (Conrad, 1989). The principal controls on these processes are soil moisture, water-table position, soil temperature, the availability and quality of suitable substrates, and physical pathways for $\mathrm{CH}_{4}$ to be released into the atmosphere. Many models have been developed to simulate site-scale processes of $\mathrm{CH}_{4}$ generation, consumption, and transport (C. Li and others, 1992; Cao and others, 1996; Potter, 1997; Walter and others, 2001; Zhuang and others, 2006). Some of these models yield a detailed representation of the site-scale vertical soil processes; however, the deployment of these models over large areas has been challenging because of the difficulties in parameterizing these models and in simulating some of the critical driving variables, such as water-table position.

The denitrification-decomposition (DNDC) model (Li and others, 1992) has been applied to estimate $\mathrm{CH}_{4}$ and $\mathrm{N}_{2} \mathrm{O}$ fluxes for a range of ecosystems, including prairie potholes. Although DNDC is one option for estimating $\mathrm{CH}_{4}$ and $\mathrm{N}_{2} \mathrm{O}$ in this assessment, finding supporting data will be very difficult. A potential solution is to implement an approach that is 
Table 3.10. Preliminary methods or models, quantifying parameters, technical processes, target ecosystems, and data needs or sources that will be used to assess parameters of carbon stocks, carbon sequestration, and greenhouse-gas flux.

[The methods or models listed have been tested and prototyped, but additional models may be added, depending on unique ecosystem conditions or technical needs encountered during the assessment. Input data requirements for each ecosystem also are listed. For an explanation of acronyms, please see "Abbreviations, Acronyms, and Chemical Symbols" in the front of this report. Abbreviations are as follows: $\mathrm{C}_{\mathrm{s}}$, carbon stock; $\mathrm{C}_{\mathrm{sr}}$, carbon sequestration; GHG, greenhouse gas (greenhouse gas is carbon dioxide $\left(\mathrm{CO}_{2}\right)$, nitrous oxide $\left(\mathrm{N}_{2} \mathrm{O}\right)$, and methane $\left(\mathrm{CH}_{4}\right)$ ); $\mathrm{C}_{\text {ed }}$, carbon erosion and deposition]

\begin{tabular}{|c|c|c|c|c|}
\hline Method or model & $\begin{array}{l}\text { Quantifying } \\
\text { parameters }\end{array}$ & Technical process & Target ecosystem & Data needs or sources \\
\hline $\begin{array}{l}\text { Spreadsheet } \\
\text { (Houghton and others, } \\
\text { 1999) }\end{array}$ & $\mathrm{C}_{\mathrm{s}}, \mathrm{C}_{\mathrm{sr}}, \mathrm{GHG}$ flux & $\begin{array}{l}\text { Algorithms based on } \\
\text { storage-age growth } \\
\text { curves }\end{array}$ & $\begin{array}{l}\text { Forests } \\
\text { Urban forests } \\
\text { Grassland/shrublands } \\
\text { Croplands } \\
\text { Wetlands }\end{array}$ & $\begin{array}{l}\text { Growth curve from FIA, crop pro- } \\
\text { duction data from NRCS, NWI, } \\
\text { local and IPCC standard GHG } \\
\text { emission factors, GRACEnet } \\
\text { data. }\end{array}$ \\
\hline $\begin{array}{l}\text { EDCM } \\
\text { (S. Liu and others, 2003) }\end{array}$ & $\begin{array}{c}\mathrm{C}_{\mathrm{s}}, \mathrm{C}_{\mathrm{sr}}, \mathrm{GHG} \text { flux } \\
\mathrm{C}_{\text {ed, }} \text { carbon and } \\
\text { nitrogen leaching }\end{array}$ & $\begin{array}{l}\text { Maximum potential } \\
\text { productivity, monthly } \\
\text { time step, spatial sam- } \\
\text { pling, and ensemble } \\
\text { simulation } \\
\text { Parameterizations (Cao } \\
\text { and others, 1995; S. } \\
\text { Liu, 1999; Parton and } \\
\text { others, 2001) }\end{array}$ & $\begin{array}{l}\text { Forests } \\
\text { Urban forests } \\
\text { Grasslands/shrublands } \\
\text { Croplands } \\
\text { Wetlands }\end{array}$ & $\begin{array}{l}\text { LULCC data, current climate data, } \\
\text { IPCC GCM projections, USDA } \\
\text { agriculture production data, } \\
\text { disturbance data (fire, drought), } \\
\text { hydrological model inputs (soil } \\
\text { erosion, deposition), land-man- } \\
\text { agement data (grazing intensity, } \\
\text { fertilizer application), SSURGO } \\
\text { soil data, GRACEnet data. }\end{array}$ \\
\hline $\begin{array}{l}\text { Century } \\
\text { (Parton and others, 1987) }\end{array}$ & $\begin{array}{l}\mathrm{C}_{\mathrm{s}}, \mathrm{C}_{\mathrm{sr}}, \mathrm{GHG} \text { flux, } \\
\text { carbon and nitrogen } \\
\text { leaching }\end{array}$ & $\begin{array}{l}\text { Maximum potential } \\
\text { productivity, monthly } \\
\text { time step, spatial sam- } \\
\text { pling, and ensemble } \\
\text { simulation }\end{array}$ & $\begin{array}{l}\text { Forests } \\
\text { Urban forests } \\
\text { Grassland/shrublands } \\
\text { Croplands }\end{array}$ & $\begin{array}{l}\text { LULCC data, topography (DEM), } \\
\text { current climate data, IPCC GCM } \\
\text { projections, USDA agriculture } \\
\text { production data, disturbance } \\
\text { data (fire, drought), hydrologi- } \\
\text { cal model inputs (soil erosion, } \\
\text { deposition), GRACEnet data. }\end{array}$ \\
\hline $\begin{array}{l}\text { IBIS } \\
\text { (Foley and others, 1996) }\end{array}$ & $\begin{array}{l}\mathrm{C}_{\mathrm{s}}, \mathrm{C}_{\mathrm{sr}}, \mathrm{CO}_{2}, \\
\text { carbon and nitrogen } \\
\quad \text { leaching }\end{array}$ & $\begin{array}{l}\text { Farquhar-type leaf level } \\
\text { model, hourly time } \\
\text { step, use of subpixel } \\
\text { information. }\end{array}$ & $\begin{array}{l}\text { Forests } \\
\text { Urban forests } \\
\text { Grassland/shrublands } \\
\text { Croplands }\end{array}$ & $\begin{array}{l}\text { LULCC data, topography (DEM), } \\
\text { current climate data, IPCC GCM } \\
\text { projections, USDA census data, } \\
\text { disturbance data (fire, drought), } \\
\text { hydrological model inputs (soil } \\
\text { erosion, deposition). }\end{array}$ \\
\hline $\begin{array}{l}\text { USPED } \\
\text { (Mitas and Mitasova, } \\
\text { 1998) }\end{array}$ & $\mathrm{C}_{\mathrm{ed}}$ & $\begin{array}{l}\text { Empirical two-dimen- } \\
\text { sional algorithm }\end{array}$ & $\begin{array}{l}\text { Forests } \\
\text { Scrub/shrub and grass- } \\
\quad \text { land } \\
\text { Croplands }\end{array}$ & $\begin{array}{l}\text { Link with EDCM } \\
\text { Soil erodibility factor (K) from } \\
\text { SSURGO, SRTM data, LULCC } \\
\text { data, precipitation data derived } \\
\text { from climate data (current and } \\
\text { future projections). }\end{array}$ \\
\hline Zero-dimensional model & GHG flux & $\begin{array}{l}\text { Process-based, simple } \\
\text { framework, compat- } \\
\text { ible with large scales } \\
\text { Parameterizations (C. Li } \\
\text { and others, 1992; Cao } \\
\text { and others, 1996; Pot- } \\
\text { ter, 1997; Walter and } \\
\text { others 2001; Hénault } \\
\text { and others, 2005; } \\
\text { Zhuang and others, } \\
\text { 2006) }\end{array}$ & Wetlands & $\begin{array}{l}\text { Link with EDCM } \\
\text { NWI, SSURGO, NCDC, NLCD, } \\
\text { regional wetland databases, } \\
\text { GRACEnet data. }\end{array}$ \\
\hline
\end{tabular}


similar to an empirical approach developed by Cao and others (1996), which balances the needs of considering the site-scale processes with the feasibility of deploying the site-scale model over large areas in order to address spatial heterogeneity

Other methods also exist for simulating $\mathrm{N}_{2} \mathrm{O}$ emissions (for example, C. Li and others, 1992; S. Liu and others, 1999; Parton and others, 2001; Hénault and others, 2005). Methods for estimating $\mathrm{N}_{2} \mathrm{O}$ emissions from ecosystems will parallel those used by a study of $\mathrm{N}_{2} \mathrm{O}$ emissions in the Atlantic zone of Costa Rica using GEMS and EDCM (S. Liu and others, 1999; Reiners and others, 2002). Nitrification and denitrification are the major processes that lead to the emission of $\mathrm{N}_{2} \mathrm{O}$ from soils. Atmospheric and terrestrial deposition, plant uptake, mineralization, soil sorption, and soil leaching act as major controls on the nitrogen balance. For the assessment, the GEMS and EDCM algorithms will be enhanced in order to simulate the $\mathrm{N}_{2} \mathrm{O}$ flux. The results of the simulation will be compared with observational data (for example, from GRACEnet).

Land Use and Land Cover Changes._-LULC change (such as a conversion of agricultural land to forest) is a significant driver of changes in carbon stocks, carbon sequestration, and GHG fluxes. For this assessment, the BGC modeling process using the GEMS platform will be directly coupled with LULC-change modeling results (section 3.2.2) to account for the effects of past and (or) current LULC changes and for projected future land-use changes on carbon-nitrogen dynamics in ecosystems. LULC-change maps generated by FORESCE model will be used to produce spatial simulation units. For an individual simulation unit, a LULC-change file, called the "event schedule file," will be created. This file specifies the type and timing of any LULC-change event, as well as the type and timing of land-management practices, such as cultivation and fertilization.

Ecosystem Disturbance.-The extent and severity of natural or anthropogenic disturbances will be determined using combined outputs from LULC-change and ecosystemdisturbance methods. For example, maps showing fire perimeters and burn severity (Landscape Succession Model (LANDSUM) and MTBS maps (Keane and others, 2007; Eidenshink and others, 2007)) will be used in combination with the new fire modeling effort in simulation model runs to indicate the timing, location, and severity level of fires. The effects of fires will be expressed as biomass consumption loss and mortality loss (see table D2 in appendix D). On the basis of the loss rates, simulation model runs will reallocate the aboveground-biomass and soil-carbon pools for each individual land pixel. Consumption loss results in direct carbon emission to the atmosphere, but mortality loss converts live biomass carbon to dead carbon pools. The disturbed ecosystem will start to regrow (through the vegetation recovery process) based on the new soil-nutrient pool and new leaf-area index calculated by the models. The calculation of other disturbance effects will follow a similar approach, but with different carbon transition coefficients among various pools. The regrowth processes that follow the disturbances will be calculated based on light and water availability, temperature, nutrient availability, plant competition, and other environmental conditions. Tree planting will be assumed to follow a clearcutting or a stand-replacement fire event if a forest plantation is indicated in the resulting land-cover map; otherwise, natural vegetation recovery will be assumed to occur.

Assessment of Land-Management Activities. - In addition to natural disturbances (for example, geological disasters, wildfires), human land-management activities play a critical role in carbon stocks, carbon sequestration, and GHG fluxes. For example, implementing conservation residue management can significantly mitigate carbon emissions from soils and can make a bigger difference than conventional tillage management. For the assessment, the following land-management activities will be evaluated:

- Conversions between LULC classes and crop rotation

- Land management practices, including-

- Logging or forest thinning

- Forest fertilization

- Fuel treatment of forest and rangeland, including thinning, prescribed burns, and so on

- Grazing intensity

- Tillage practices coupled with residue input (such as conventional tillage, reduced tillage, and no-till practices)

- Fertilization rate for and manure application on croplands

- Irrigation of croplands and forests

The key algorithms that account for land-management activities (such as irrigation, fertilization, and residue return) will be embedded in the GEMS. Relevant data and other parameter inputs will be compiled from existing databases, as noted in table 3.7.

Assessment of Erosion and Deposition.-Soil erosion and deposition affect soil-profile evolution, the spatial redistribution of carbon and nutrients, and the dynamics of carbon and nitrogen in ecosystems (S. Liu and others, 2003; Lal and others, 2004). Soil erosion and deposition will be assessed using the Unit Stream Power Erosion and Deposition (USPED) model (Mitas and Mitasova, 1998) to quantify the impacts of soil erosion and deposition on soil-carbon loss, soil-profile evolution, onsite dynamics of carbon and nitrogen, and offsite transport of carbon and nitrogen on the landscape and into wetland environments and aquatic systems. Quantitative estimates of soil carbon erosion and deposition estimates will be compared with assessments of aquatic carbon stocks and sequestration described in following sections.

Wood-Product Carbon Pool.-Carbon sequestration in wood products, landfills, and other offsite storage areas can be significant in the accounting of terrestrial carbon sequestration 
capacity (Skog and Nicholson, 1998). The fate of harvested wood can be tracked by using a simple offline spreadsheetaccounting approach (for example, S. Liu and others, 2003), but it requires forest-based assessments of harvest rates (Manies and others, 2005). The USFS maintains accurate data and methods for tracking and estimating carbon in wood products (for example, see W.B. Smith and others, 2009). For the assessment, the USFS, the EPA, and others will be consulted to develop the appropriate algorithms to estimate wood-product carbon.

Data Assimilation.-A major source of uncertainty in the assessment is the scarcity of in situ and other observational data obtained at appropriate spatial and temporal scales. Data assimilation refers to techniques that constrain simulations with reference conditions using limited observational data. For example, the Markov Chain Monte Carlo (MCMC) method (an algorithm used to simulate probability distributions) relies heavily on computation and is, therefore, difficult to apply over a region where the number of simulation units is large; however, the method can be an effective and ideal way to derive representative values and their uncertainties for the model parameters from limited point observations, such as data from FLUXNET. Other data-assimilation techniques include model inversion; for example, PEST (EPA's modelindependent parameter estimation application; http://www.epa. gov/ceampubl/tools/pest/) (S. Liu and others, 2008), Ensemble Kalman Filter (EnKF) (Evensen, 1994, 2003), and Smoothed Ensemble Kalman Filter (SEnKF) (Chen and others, 2006, 2008). These methods have been implemented in the GEMS to derive parameter information for the model from plot measurements of carbon and nitrogen stocks (for example, S. Liu and others, 2008) and from eddy-covariance flux-tower observations (for example, Chen and others, 2008). For the assessment, a combination of data-assimilation techniques will be used to ensure that the model simulations agree well with various observations from different sources and scales.

Integration With Other Methods or Models for the Assessment.-Model integration will be a critical step for the assessment because of the time- and space-dependent relations among the different technical components. For example, modeling LULC requires information about site-scale soil fertility or soil organic carbon from BGC modeling to inform the allocations of crops in space and time. On the other hand, the ecosystem-disturbance information will affect land-use behaviors, such as timber harvesting. Without stepwise coupling between FORE-SCE and the ecosystem-disturbance model, timber-harvesting activities might still be prescribed in areas where biomass will have been completely consumed by fire in the ecosystem-disturbances model. Carbon or biomass stock (fuel load) will strongly affect the probability of fire occurrence and the level of severity of those fires, which requires coupling the ecosystem-disturbance model with carbon-stock information from the GEMS.

One goal of the GEMS modeling is to link the terrestrial and aquatic components of both the biogeochemical cycling and the transport of carbon. This linkage will constrain terrestrial simulations of carbon loss with calculations of lateral carbon flux, aquatic carbon stocks, and aquatic GHG emissions determined from water flow, water chemistry, and lake- and reservoir-sedimentation data, as described in section 3.3.5.

Uncertainty in the Assessment.-All models are simplified representations of the real world; therefore, biases and uncertainties in model results are common phenomena. The overall approach for estimating uncertainty for the assessment is discussed in section 3.3.8. To reduce biases in modeling, the BGC models will be calibrated with in situ data. Uncertainties (random errors) related to assessment results, parameters, and model structure will be handled following the general IPCC (2006) guidance. Influencing factors considered in uncertainty evaluation (such as forest age and soil-carbon content) should have an uncertainty range, expressed as a probability distribution function (PDF) curve or stated in a probability look-up table, so that the IPCC error propagation equations can be applied to evaluate regional level uncertainty. In modeling carbon stocks, carbon sequestration, and GHG fluxes, uncertainty factors also may include forest and crop species, soil type, canopy density, logging location, burn severity, and agricultural management. The PDFs of model parameters will be derived by using data-assimilation techniques at eddycovariance flux tower sites across the country. Opportunities for biogeochemical model comparisons will be sought.

Test Using Terrestrial Methods to Assess Carbon Stocks, Carbon Sequestration and Greenhouse-Gas Fluxes.-The test area for the LULC modeling effort included Tensas Parish, La., and Claiborne County, Miss., in the Mississippi Alluvial Plain and the Mississippi Valley Loess Plains (EPA Level III ecoregions 73 and 74, modified from Omernik, 1987), respectively (fig. 3.10). The reason for selecting these two jurisdictions was to cover three major ecosystem types (forests, croplands, and wetlands). As of 2001, Claiborne County was dominated by forests ( 73 percent, consisting of 47 percent deciduous, 6 percent evergreen, 9 percent mixed, and 11 percent anthropogenic disturbances), followed by wetlands (10 percent) and croplands (10 percent, including hay/pasture). Tensas Parish was mainly classified into croplands (54 percent), wetlands (33 percent), forests ( 3 percent), and other (10 percent).

Three methods (GEMS-spreadsheet, GEMS-Century, and GEMS-EDCM) were used for the test. As noted above, different input data were used by the methods. GEMS-Century used STATSGO and GEMS-EDCM used SSURGO for the initial soil data. To initialize the biomass carbon data and to show the general relation between vegetation height and biomass carbon, GEMS-Century used vegetation-height maps from the interagency LANDFIRE database, whereas GEMS-EDCM used forest-age maps from FORE-SCE (which were derived from the FIA) and a correlation between age and biomass (that is, forest growth curves). The percentage of area of specific crop types (found by running a Monte Carlo simulation) was initialized as follows: corn, 34 percent; cotton, 30 percent; soybeans, 12 percent; wheat, 10 percent; and others, 14 percent. GHG fluxes in wetlands were estimated by using the GEMS-EDCM method, based on the technical processes described in table 


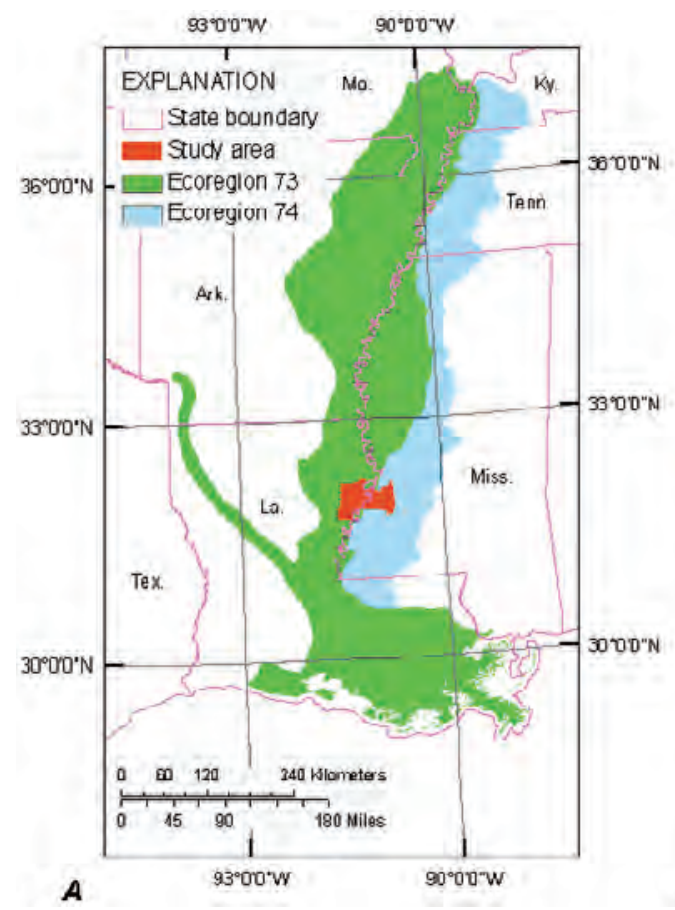

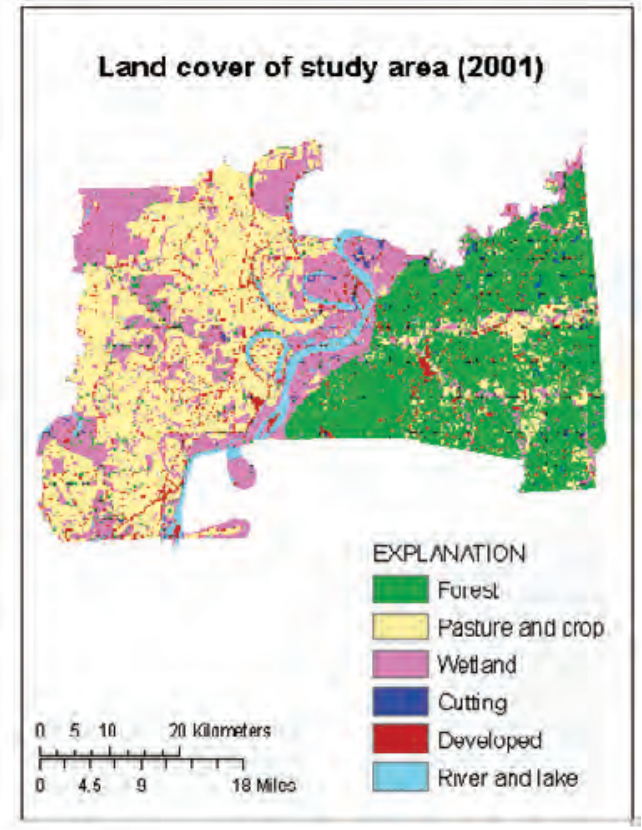

B
Figure 3.10. Map showing results of a test using terrestrial methods to assess carbon stocks, carbon sequestration and greenhousegas fluxes. $A$, Location of test area. $B$, Distribution of landcover classes in 2001. The test area includes Tensas Parish, La., and Claiborne County, Miss., in the Mississippi Alluvial Plain and the Mississippi Valley Loess Plains (EPA Level III ecoregions 73 and 74 modified from Omernik (1987)), respectively.
3.10. USPED was used to estimate soil erosion and deposition. Monte Carlo simulation was applied to the initial forest ages, types of crops, and soil organic carbon. A complete ecoregion simulation was performed at a $250-\mathrm{m}$ spatial resolution; every pixel was simulated only once instead of selecting sample pixels and performing ensemble simulations.

All simulations for the test were performed under the $\mathrm{R}$ and L scenarios (see definition above in section 3.2.2) generated by FORE-SCE for the period from 2001 through 2050 (see appendix B, "Mapping and Modeling of Land-Use and Land-Cover Changes" for a detailed discussion on mapping and modeling LULC changes). The model simulations were constrained by grain yields for crops and forest age growth curves. The major output variables included biomass carbon stock, total ecosystems carbon stock, carbon sequestration, and $\mathrm{N}_{2} \mathrm{O}$ and $\mathrm{CH}_{4}$ emissions. Additional output data, such as carbon stock and sequestration by pools, also were produced. No validation or uncertainty assessments (for both input data and data products) were performed for the test because of time constraints and because the validation and uncertainty assessments were designed to be conducted using the EPA Level II ecoregions (discussed below in this chapter), not the Level III regions used for the test.

Table 3.11 shows that estimates of the total carbon stocks at the beginning of the model simulations (2001) were 40.91, 34.22, and 43.30 Tg, and estimates for the end (2050) were 49.36, 51.89, and 48.07 Tg, respectively, for the GEMSSpreadsheet, GEMS-Century, and GEMS-EDCM methods. For the initial carbon stock in 2001, the GEMS-Spreadsheet and GEMS-EDCM methods showed little difference, but the GEMS-Century method began with a much lower estimate (data not shown). The difference was caused by their different initialization approaches in biomass and soil organic carbon (SOC). Although the GEMS-Century method began with a lower carbon stock value in 2001, it reached a higher carbon stock value in 2050 than the other because of the higher carbon-sequestration rate during the study period.

Although there were differences in how the biomass carbon was initialized among these methods, some conclusions may be drawn from the test results (table 3.11, fig. 3.11). First, the annual rates of carbon sequestration were consistent, varying only within a range of $0.2 \mathrm{TgC} / \mathrm{yr}$. Second, the GEMSCentury and GEMS-EDCM method runs demonstrated a synchronized temporal-change pattern, and the pattern was different from that of GEMS-spreadsheet method. This difference in temporal patterns may suggest that the two biogeochemical methods (GEMS-Century and GEMS-EDCM) captured the impacts of climate variability and change on carbon dynamics and the GCM-spreadsheet method did not. Third, carbon sequestration in biomass decreased over time primarily because of the aging of forests in the region.

The total carbon sequestration (the change in carbon stocks) using the GEMS-Century method was $17.67 \mathrm{Tg}$ from 2001 to 2050 , which was much higher than that calculated by using the GEMS-spreadsheet model (8.45 Tg) or the GEMSEDCM method (4.76 Tg) (table 3.11). The corresponding annual carbon-sequestration rates for the test area were $0.17,0.35$, and $0.14 \mathrm{Tg} \mathrm{C} / \mathrm{yr}$ from the GEMS-spreadsheet, GEMS-Century, and GEMS-EDCM methods, respectively. The differences shown here might be attributed to the differences in the input data sources, initial parameter values, and simulation algorithms of each model, especially between the GEMS-Century and GEMS-EDCM methods. For example, higher rate of carbon sequestration from the GEMS-Century 
Table 3.11. Total carbon stocks and cumulative and additional carbon sequestration within the test area (Tensas Parish, La., and Claiborne County, Miss.), calculated using the specified method, and using the "reference land use, land cover, and land management" (R) and "enhanced land use and land cover with reference land management" (L) scenarios.

[Values represent the amount at the end of the given year. Abbreviations and acronyms are as follows: EDCM, Erosion-Deposition-Carbon Model; GEMS, general ensemble modeling system; Tg, teragrams]

\begin{tabular}{|c|c|c|c|c|c|c|c|c|c|}
\hline \multirow{2}{*}{ Year } & \multicolumn{3}{|c|}{ Total carbon stocks, by method, in $\mathrm{Tg}^{1}$} & \multicolumn{3}{|c|}{$\begin{array}{l}\text { Cumulative carbon sequestration, by } \\
\text { method, in } \mathrm{Tg}^{1}\end{array}$} & \multicolumn{3}{|c|}{$\begin{array}{l}\text { Additional carbon sequestration, by } \\
\text { method, in } \mathrm{Tg}^{2}\end{array}$} \\
\hline & $\begin{array}{c}\text { GEMS- } \\
\text { spreadsheet }\end{array}$ & $\begin{array}{l}\text { GEMS- } \\
\text { Century }\end{array}$ & $\begin{array}{l}\text { GEMS- } \\
\text { EDCM }\end{array}$ & $\begin{array}{l}\text { GEMS- } \\
\text { spreadsheet }\end{array}$ & $\begin{array}{l}\text { GEMS- } \\
\text { Century }\end{array}$ & $\begin{array}{l}\text { GEMS- } \\
\text { EDCM }\end{array}$ & $\begin{array}{l}\text { GEMS- } \\
\text { spreadsheet }\end{array}$ & $\begin{array}{l}\text { GEMS- } \\
\text { Century }\end{array}$ & $\begin{array}{l}\text { GEMS- } \\
\text { EDCM }\end{array}$ \\
\hline 2001 & 40.91 & 34.22 & 43.30 & & & & & & \\
\hline 2010 & 43.45 & 38.37 & 42.56 & 2.54 & 4.15 & -0.74 & 0.30 & 0.47 & 0.02 \\
\hline 2040 & 48.48 & 49.14 & 46.70 & 7.58 & 14.92 & 3.39 & 1.27 & 1.43 & 0.82 \\
\hline 2050 & 49.36 & 51.89 & 48.07 & 8.45 & 17.67 & 4.76 & 1.64 & 1.75 & 1.08 \\
\hline
\end{tabular}

${ }^{1}$ Values were calculated using the "enhanced land use and land cover with reference land management" (L) scenario.

${ }^{2}$ Values represent the difference between the L scenario and the "reference land use, land cover, and land management" (R) scenarios.

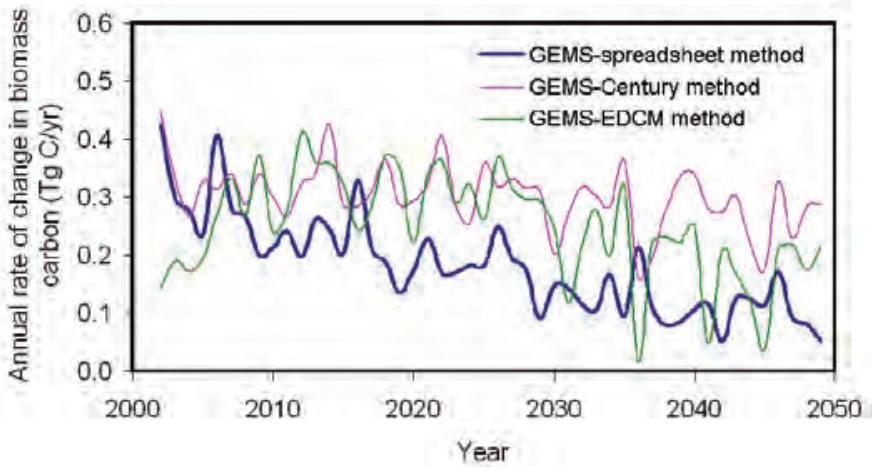

Figure 3.11. Graph showing comparisons of annual carbonsequestration rates of biomass carbon stock among the three methods (GEMS-spreadsheet, GEMS-Century, and GEMS-EDCM) using the "enhanced land use and land cover with reference land management" (L) scenario for the whole test area from 2001 to 2050. The same comparison made using the same methods and the "reference land use, land cover, and land management" (R) scenario yielded similar results. Abbreviations and acronyms are as follows: EDCM, Erosion-Deposition-Carbon Model, GEMS, general ensemble modeling system; $\mathrm{TgC} / \mathrm{yr}$, teragrams of carbon per year.

method might have been caused by the lower initial biomass carbon values, faster biomass accumulation (compared to the GEMS-spreadsheet method's result), and SOC accumulation. In contrast, the lower carbon-sequestration estimate from the GEMS-EDCM method can be attributed to lower biomass accumulation (compared to the GEMS-spreadsheet method's result) and SOC loss.

All three methods estimated significantly higher ecosystem carbon stocks (table 3.11) for the L scenario, indicating additional carbon sequestration of $1.64,1.75$, and $1.08 \mathrm{Tg}$ from the GEMS-spreadsheet, GEMS-Century, and
GEMS-EDCM methods, respectively, relative to the $\mathrm{R}$ scenario. These amounts represented about an additional 20 percent, 10 percent, and 23 percent increase, respectively, above the carbon-sequestration values calculated using the $\mathrm{R}$ scenario. The result suggests that these models, rather consistently, are capable of quantifying additional carbon sequestration from enhanced changes in land-use and land-cover activities such as the Wetland Reserve Program.

Table 3.12 lists major differences in $\mathrm{CH}_{4}$ and $\mathrm{N}_{2} \mathrm{O}$ emissions between the GEMS-spreadsheet and GEMS-EDCM methods (no results are currently available from the GEMSCentury method). The major conclusions of this comparison of methods were as follows: (1) the GEMS-spreadsheet method estimated an annual $\mathrm{CH}_{4}$-emission rate on wetlands that is more than double that of the GEMS-EDCM method; (2) estimates of $\mathrm{N}_{2} \mathrm{O}$ emissions demonstrated opposite temporal trends, although both methods produced similar $\mathrm{N}_{2} \mathrm{O}$-emission rates; and (3) the GEMS-spreadsheet method showed small increases in annual emission rates of $\mathrm{CH}_{4}$ and $\mathrm{N}_{2} \mathrm{O}$, whereas the GEMS-EDCM method showed decreasing trends. Both $\mathrm{CH}_{4}$ - and $\mathrm{N}_{2} \mathrm{O}$-emission rates were greatly affected by soil moisture, temperature, and substrate availability, and thus varied considerably depending on site conditions. For example, $\mathrm{CH}_{4}$ emissions from rice paddies ranged from 2 to $1,642 \mathrm{kgC} / \mathrm{ha} / \mathrm{yr}$ (Lindau and others, 1990). After reviewing many field studies, we found that the uncertainty of the $\mathrm{CH}_{4}$ and $\mathrm{N}_{2} \mathrm{O}$ emission factors using the GEMS-spreadsheet method was very high. The predicted emission rates of $\mathrm{CH}_{4}$ and $\mathrm{N}_{2} \mathrm{O}$ from the GEMS-EDCM method were within the uncertainty range of local field observations. Using the L scenario, the GEMS-spreadsheet method resulted in greater $\mathrm{CH}_{4}-$ and $\mathrm{N}_{2} \mathrm{O}$-emission rates than the GEMS-EDCM method (fig. 3.12) relative to the $\mathrm{R}$ scenario.

The preliminary results from the test highlighted several issues. First, the differences between the models (specifically the biases and errors in the individual models) were a major 
Table 3.12. Annual emission rates of methane and nitrous oxide and their total differences (between 2001 and 2050), for the "reference land use, land cover, and land management" (R) and the "enhanced land use and land cover with reference land management" (L) scenarios.

[Abbreviations and acronyms are as follows: $\mathrm{CH}_{4}$, methane; EDCM, Erosion-Deposition-Carbon Model; GEMS, general ensemble modeling system; L, "enhanced land use and land cover with reference land management" scenario; $\mathrm{N}_{2} \mathrm{O}$, nitrous oxide; R, "reference land use, land cover, and land management" scenario]

\begin{tabular}{|c|c|c|c|c|c|c|c|c|}
\hline \multirow{3}{*}{ Year } & \multicolumn{4}{|c|}{$\begin{array}{c}\mathrm{CH}_{4} \text { from wetlands (billion grams of } \\
\text { carbon per year) }\end{array}$} & \multicolumn{4}{|c|}{$\begin{array}{c}\mathrm{N}_{2} \mathrm{O} \text { from all land (billion grams of } \\
\text { carbon per year) }\end{array}$} \\
\hline & \multicolumn{2}{|c|}{$\begin{array}{c}\text { GEMS- } \\
\text { spreadsheet } \\
\text { method }\end{array}$} & \multicolumn{2}{|c|}{$\begin{array}{l}\text { GEMS-EDCM } \\
\text { method }\end{array}$} & \multicolumn{2}{|c|}{$\begin{array}{l}\text { GEMS- } \\
\text { spreadsheet } \\
\text { method }\end{array}$} & \multicolumn{2}{|c|}{$\begin{array}{l}\text { GEMS-EDCM } \\
\text { method }\end{array}$} \\
\hline & $\mathbf{L}$ & $\mathbf{R}$ & $\mathbf{L}$ & $\mathbf{R}$ & $\mathbf{L}$ & $\mathbf{R}$ & $\mathbf{L}$ & $\mathbf{R}$ \\
\hline 2001 & 28.47 & 28.42 & 15.50 & 15.47 & 2.74 & 2.74 & 2.77 & 2.76 \\
\hline 2010 & 28.88 & 28.53 & 13.32 & 13.20 & 2.78 & 2.77 & 1.98 & 1.99 \\
\hline 2020 & 29.26 & 28.36 & 12.66 & 12.45 & 2.82 & 2.76 & 1.91 & 1.92 \\
\hline 2030 & 29.80 & 28.24 & 13.57 & 13.24 & 2.87 & 2.77 & 1.86 & 1.89 \\
\hline 2040 & 30.43 & 28.10 & 13.04 & 13.65 & 2.92 & 2.77 & 1.74 & 1.77 \\
\hline 2050 & 31.01 & 27.94 & 12.92 & 12.42 & 2.96 & 2.76 & 1.73 & 1.77 \\
\hline Difference between 2050 and 2001 & 2.54 & -0.48 & -2.59 & -3.05 & 0.22 & 0.02 & -1.04 & -1.00 \\
\hline Average & 29.64 & 28.27 & 13.50 & 13.41 & 2.85 & 2.76 & 2.00 & 2.02 \\
\hline Standard deviation & 0.96 & 0.23 & 1.03 & 1.12 & 0.08 & 0.01 & 0.39 & 0.37 \\
\hline
\end{tabular}

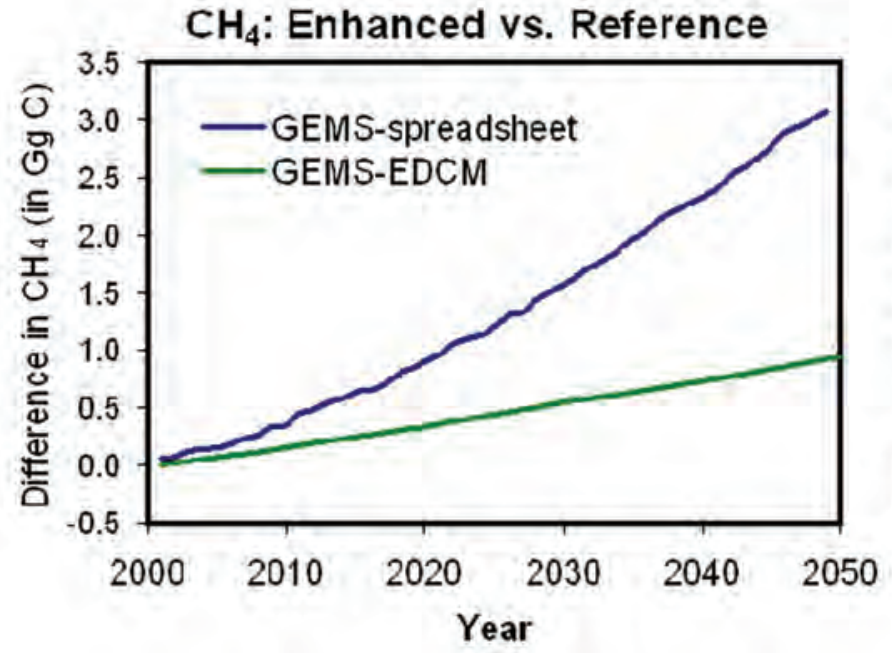

Figure 3.12. Graphs showing comparisons of annual methane emission from wetlands and the total nitrous-oxide emission from all land between the GEMS-spreadsheet model and the GEMSEDCM model, showing the difference between the "reference land use, land cover, and land management" (R) scenario and the "enhanced land use and land cover with reference land

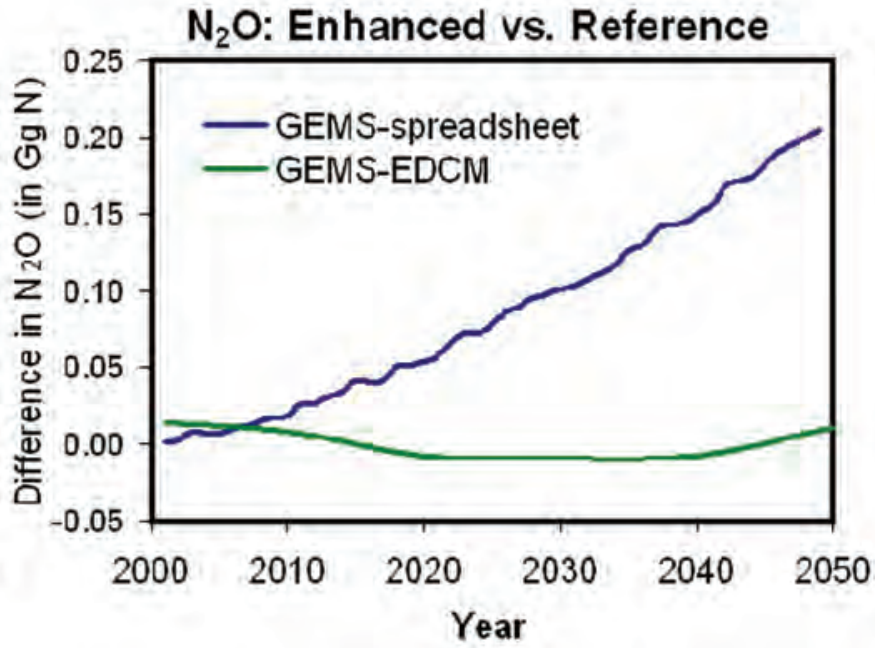

management" (L) scenario, from 2001 to 2050. The emission rate from the GEMS-EDCM model is the 10-year average. Abbreviations and acronyms are as follows: $\mathrm{CH}_{4}$, methane; $\mathrm{EDCM}$, Erosion-Deposition-Carbon Model; $\mathrm{Gg}$ C, gigagrams of carbon; ; $\mathrm{Gg} \mathrm{N}$, gigagrams of nitrogen; GEMS, general ensemble modeling system; $\mathrm{N}_{2} \mathrm{O}$, nitrous oxide. 
contribution to the overall uncertainty. Using model ensembles within the GEMS framework, some of the model uncertainty can be reduced and model's structure errors can be corrected. Second, the input data process (for example, using different forest biomass initialization data and processes in the models) might significantly affect the model's output and, therefore, the assessment of carbon stocks, carbon sequestration, and GHG fluxes. As new and improved data and modeling results become available, they will be incorporated into this methodology. Third, future efforts should emphasis literature review and metadata analysis in order to quantify the uncertainty of field observations at the regional scale.

\subsubsection{Carbon Sequestration and Greenhouse- Gas Fluxes of Aquatic Ecosystems}

Aquatic ecosystems in this assessment are defined to include streams, rivers, estuaries, coastal waters, and perennial ponds, lakes, and impoundments. Coastal and freshwater wetlands and ephemeral wet depressions that temporarily retain water following precipitation or flooding events will be assessed using the methods described for terrestrial ecosystems.

Inland aquatic ecosystems are important components of terrestrial landscapes and commonly are locations of intense carbon sequestration, biogeochemical cycling, and greenhousegas emissions (Cole and others, 2007). Similarly, coastal aquatic ecosystems are important because they receive, sequester, and biogeochemically process riverine and groundwater inputs of terrestrial carbon and nutrients. Coastal primary production is enhanced by inputs of terrestrially derived nutrients and coastal sequestration is enhanced by the co-transported sediments.

Aquatic ecosystems are not fully integrated into current terrestrial ecosystem models; therefore, their role in a national assessment of carbon sequestration and GHG fluxes must be quantified independently, relying more on empirical and statistically based assessment methods instead of the BGC modeling used for terrestrial ecosystems. This quantification requires the tracking of the carbon's sources and sinks from headwater areas, along stream and river courses, to and through inland water bodies, to and through estuaries, to its delivery and fate in coastal waters. Water is the principal carrier of dissolved and particulate carbon, and aquatic carbon flux is dependent on streamflow; therefore, a quantitative understanding of the relation between precipitation and runoff for ecoregions, and an accurate accounting of stream and river flow will be required. The assessment of the BGC cycling of aquatic carbon (including the production, consumption, and emission of GHGs) also will require additional knowledge of water chemistry and water's physical conditions, such as temperature, light penetration, and water-level fluctuations. The assessment of aquatic ecosystems will rely on empirical methods that use available national and regional datasets (current and forecasted) of streamflow, water chemistry, size and distribution of water bodies, watershed characteristics, sediment transport and deposition, and other environmental variables to estimate and predict amounts and rates of carbon sequestration and GHG fluxes. Appendix E provides detailed discussion of methods for assessing aquatic ecosystems.

Lateral Fluxes.-The initial assessment of lateral fluxes of dissolved and particulate carbon will be based on available streamflow and water-chemistry data, including data from the National Water Information System (NWIS; http://waterdata.usgs.gov/nwis). Long-term changes in lateral fluxes may be more closely linked to a change in water quantity than to a change in the relation between water and carbon yield (Striegl and others, 2007). Additionally, streamflow data are much more prevalent than water-chemistry data that specifically characterizes carbon yield, and predicting streamflow is much more reliable than predicting the change in carbon yield; therefore, the primary emphasis will be placed on developing an ecoregion-level understanding of the relation between water and carbon yield in water using existing data. Projecting the changes in water discharge based on climate-change and landuse change scenarios can then be accomplished using the USGS Precipitation-Runoff Modeling System ${ }^{1}$ or similar programs.

These projections will be used together with empirically derived relations between water and carbon yield to project changes in lateral carbon export. Alternative methods for estimating lateral flux using data that characterize LULC in watersheds also will be explored, including the application of a carbon module (currently under development) of the "spatially referenced regressions on watershed attributes" (SPARROW) water-quality model. ${ }^{2}$. Existing SPARROW modules will be used to model nutrient and sediment fluxes (Alexander and others, 2008; Schwarz, 2008). A related goal of the assessment is to move towards fully coupling the GEMS and other terrestrial ecosystem models with a lateral export model. Additional information on the methodology for calculating carbon stocks, carbon sequestration, and GHG fluxes from inland waters, estuaries, and coastal waters is provided in appendix E.

Lakes and Impoundments.-The net storage of carbon in lakes and impoundments reflects a balance between carbon burial in sediments and GHG emissions from the surfaces and outlets of the water bodies. Carbon burial in lakes is driven mainly by autochthonous production, which has been quantified in a variety of settings (Cole and others, 2007). For the assessment, carbon-burial estimates will be compiled and analyzed statistically to derive a probability distribution function (PDF) of sedimentation rates in lakes. Carbon burial in impoundments (reservoirs and farm ponds) depends primarily on sedimentation rates and the concentration of the organic carbon in the buried sediments (S.V. Smith and others, 2005). Sedimentationrate data are sparse, but include data for approximately 1,800 reservoirs in the Reservoir Sedimentation Database (RESSED); ${ }^{3}$ these data will be used to develop a PDF of sedimentation rates in reservoirs. The concentration of organic carbon in the buried

\footnotetext{
${ }^{1}$ http://wwwbrr.cr.usgs.gov/projects/SW_MoWS/software/oui_and_mms_s/ prms.shtml.

${ }^{2}$ http://water.usgs.gov/nawqa/sparrow.

${ }^{3}$ http://ida.water.usgs.gov/ressed.
} 
sediments often reflects the carbon content of the upland soils from which they were eroded (Ritchie 1989; S.V. Smith and others, 2005). For the assessment, the concentration of organic carbon in lake and impoundment sediments will be approximated on the basis of a new map showing soil carbon that was developed by the USGS using SSURGO data (Bliss and others, 2009). The surface areas of lakes and impoundments within each assessment unit will be mapped using data in the National Land Cover Database (NLCD). Carbon for each assessment unit will be calculated as the product of sedimentation rates, concentrations of organic carbon in the sediments, and the surface areas of lakes and impoundments.

Data on GHG emissions from lakes and impoundments are very sparse, particularly for $\mathrm{CH}_{4}$ and $\mathrm{N}_{2} \mathrm{O}$; available data will be compiled from published literature, and the statistical distribution of GHG fluxes will be analyzed. The resulting PDFs will be combined with lake and impoundment surfacearea data to estimate GHG fluxes from lakes and impoundments within each EPA Level II ecoregion. Region-specific data collection on sedimentation rates and GHG fluxes from lakes and impoundments will be necessary in order to further refine the model estimates; these data will enable the development of new regression models that will be used to estimate carbon sequestration in inland water bodies, using watershed characteristics and nutrient loads as explanatory variables.

Coastal Waters.-Coastal and estuarine biogeochemical processes related to fixation and burial of carbon are intimately tied to coastal autochthonous production through the process of terrestrial riverine transport of nutrients and sediments to estuarine and coastal environments. Nutrients transported from inland regions may stimulate the primary production in coastal waters (da Cunha and others, 2007; Seitzinger and Mayorga, 2008), and sediments may act to increase the flux of this material to the deep ocean, where the carbon would be buried and effectively sequestered from the atmosphere for millions of years (Hedges and Keil, 1995; Armstrong and others, 2002; Sarmiento and Gruber, 2002). The assessment of carbon sequestration in coastal waters thus will include a model of the primary production that is sensitive to the changing nutrient content of the water and a process model that explicitly incorporates both the primary production and the controlling processes in carbon remineralization, such as degradation during sinking, ballasting, bioturbation, and burial (Dunne and others, 2005). Because the method used here is a sensitivity analysis approach as a function of changes in terrestrial GHG transport, there is no need to spatially define the seaward boundaries of the coastal waters; however, because local conditions such as the water-column depth and the depositional environment are important controlling factors, the estimates of carbon sequestration and associated BGC processes will be produced on an individual basis for coastal waters that have a large terrestrial source and on a regional basis for coastal waters that have smaller sources. The changes in production and release of methane and nitrous oxide in sediments in intertidal, estuarine, and coastal waters will be estimated by using regression models to generate projected water-column depths, sediment production, and the contribution of groundwater to coastal waters, which can be significant (Bange, 2006; Hirota and others, 2007).

\subsubsection{Analyses of Assessment Results- Mitigation Activities, Ecosystem Services, Costs, and Benefits}

The primary data products of the assessment will contribute to an understanding of how carbon and GHG move in and out of natural and managed ecosystems under current and future potential conditions. The potentially broad range of users most likely will need data products that are synthesized to highlight (1) the potential effects (such as LULC change) and effectiveness of mitigation activities (such as land-management activities), (2) the direct and ancillary effects on ecosystem services, and (3) the associated economic and social costs for carbon sequestration and the reduction of GHG emissions. Quantifying the direct and ancillary effects on ecosystem services will increase the relevance to and impact of the assessment results on mitigation strategies and management actions. This section summarizes the proposed methods for analyzing the effects of mitigation activities, the effects on ecosystem services, and the relevant economic and social costs of mitigation activities. See appendixes $\mathrm{D}$ and $\mathrm{F}$ for details about the methods.

Analysis of the Effects of Mitigation Activities.-Converting nonforested land to forested land sequesters more carbon per unit of area (expressed as "carbon density") than other landmanagement activities that are focused only on increasing the soil organic carbon (SOC) (Thomson and others, 2008). The actual amount of carbon stored in forest is a function of the forest type (for instance, deciduous or evergreen), its location, and the time required for the trees to grow. If the land use remains in agriculture, then increases in SOC will vary by management activity and the effects of crop cultivation are usually minimal after 15 to 20 years (West and Post, 2003). In addition, future climate conditions may dramatically alter key controls, such as temperature or moisture availability, thus causing the historic rates of carbon accumulation to be inaccurate. These variable effects of deliberate LULC changes or land-management changes on carbon sequestration can be evaluated quantitatively and displayed in formats such as table 3.13. For the assessment results, it is important to understand not only the total amount of potential carbon sequestration, but also the relations between the changes in carbon and the cost of gaining additional sequestration capacity. The cost may be expressed in terms of the time taken to reach the goal, resources that are spent, acres of lands used, and combinations of these. The effects of LULC changes and (or) land-management changes over a period of years can be easily analyzed using tools such as statistical software, GIS, or spreadsheets, and the results can be summarized using tables such as the example shown in table 3.13.

Analysis of the Effects of Mitigation Activities on Ecosystem Services.-Ecosystem services are the benefits that people and societies derive from the natural processes that sustain ecosystems (Daily, 1997). A mitigation strategy may have ancillary 
effects on ecosystem goods and services. Ancillary effects are defined as those effects that are subordinate to the primary goal or intended impact of a strategy, policy, or mitigation activity, including unintended consequences. Any change, either anthropogenic or naturally occurring, that affects structural components (such as the composition of a plant community) or processes (such as nutrient cycling) will impact the quality, quantity, and types of services produced from that ecosystem. Although it is beyond the scope of the assessment to quantify all ecosystem services, some of the important services that are likely to be affected by mitigation activities for ecological carbon sequestration are listed in table 3.14.

Estimating and forecasting the changes in carbon stocks, carbon sequestration, and GHG fluxes resulting from mitigation strategies will be based on the spreadsheet and the GEMS modeling approaches described in section 3.3.4 and appendix D. Many of these primary assessment data products can also be categorized as ecosystem services (table 3.14) including carbon stocks in soils and vegetation, carbon sequestration, $\mathrm{CH}_{4}$ and $\mathrm{N}_{2} \mathrm{O}$ emissions, net

Table 3.13. Example of a table format for reporting the effectiveness of mitigation activities for sequestering carbon, by the duration (years) of the implementation.

[Mitigation activities include land-use and land-cover changes and land-management activities. The values in the cells would be given as $\mathrm{MgC/}$ ha/yr (millions of grams of carbon per hectare per year). LULCC, land-use and land-cover change]

\begin{tabular}{|c|c|c|c|c|c|c|c|c|}
\hline \multirow[b]{2}{*}{ Mitigation activity } & \multicolumn{8}{|c|}{ Duration, in $\mathrm{MgC} / \mathrm{ha} / \mathrm{yr}$} \\
\hline & $\begin{array}{c}0-5 \\
\text { years }\end{array}$ & $\begin{array}{c}6-10 \\
\text { years }\end{array}$ & $\begin{array}{l}11-15 \\
\text { years }\end{array}$ & $\begin{array}{l}\text { 16-20 } \\
\text { years }\end{array}$ & $\begin{array}{l}21-25 \\
\text { years }\end{array}$ & $\begin{array}{l}26-30 \\
\text { years }\end{array}$ & $\begin{array}{l}31-35 \\
\text { years }\end{array}$ & $\begin{array}{l}36-40 \\
\text { years }\end{array}$ \\
\hline \multicolumn{9}{|c|}{ LULCC } \\
\hline \multicolumn{9}{|l|}{ Conversion of pasture to evergreen forest } \\
\hline \multicolumn{9}{|l|}{ Conversion of croplands to woody wetland } \\
\hline \multicolumn{9}{|c|}{ Land-management change } \\
\hline \multicolumn{9}{|l|}{ Increased harvest rotation } \\
\hline \multicolumn{9}{|l|}{ Increased conservation tillage } \\
\hline \multicolumn{9}{|c|}{ LULCC and land-management change } \\
\hline Conversion of pasture to managed evergreen forest & & & & & & & & \\
\hline
\end{tabular}

Table 3.14. Ecosystem services that are likely to be affected by mitigation activities and will be analyzed, their functions, and the assessment data products that will be used to analyze the effects of mitigation activities.

[Abbreviations are as follows: $\mathrm{CH}_{4}$, methane; $\mathrm{GHG}$, greenhouses gas; $\mathrm{N}_{2} \mathrm{O}$, nitrous oxide]

\begin{tabular}{lll}
\hline Ecosystem service & Function of the ecosystem services & \multicolumn{1}{c}{$\begin{array}{c}\text { Assessment data products to be used in analyzing } \\
\text { effects of mitigation activities }\end{array}$} \\
\hline Soil formation & Supporting & Soil organic carbon. \\
Primary production & Supporting & Net ecosystem productivity. \\
GHG mitigation & Regulating & Soil organic carbon. \\
& & Carbon sequestration. \\
Water quality & Regulating & $\mathrm{N}_{2} \mathrm{O}, \mathrm{CH}_{4}$ emissions. \\
& & Soil erosion. \\
Food & Provisioning & Nitrate retention. \\
Wildlife habitat & Provisioning & Grain production. \\
& & Species richness. \\
& & Occupancy and connectivity models. \\
& & Species climate vulnerability. \\
Fiber & Metapopulation dynamics. \\
Recreation & Cultural & Timber production. \\
& & Species richness. \\
\hline
\end{tabular}


ecosystem productivity, timber production, grain production, and soil erosion. The estimates of how changes in carbon stocks, carbon sequestration, and GHG fluxes will affect ecosystem services will be produced for each ecoregion because they will be based on the primary assessment data products.

In addition to data already produced as the result of the analysis of mitigation effects for carbon stocks, carbon sequestration, and GHG fluxes, further analysis will be necessary. As an example, biophysical production functions and habitat suitability indices will need to be constructed based on the known relations between the LULC classes in an ecosystem (generated by FORE-SCE and GEMS modeling) and the relevant ecosystem services (Nelson and others, 2008; Tirpak and others, 2009). For example, suitable habitat for specific wildlife species will vary as a function of forest composition and will be different for evergreen and deciduous forests. These data will be combined with existing models such as SWAT (Soil and Water Assessment Tool of the USDA), GEMS-Century, GEMSEDCM, and the Landscape Disturbance and Succession model (LANDIS-II, a forest landscape model created by a consortium of the USFS, University of Wisconsin, and Portland State University). A distributed geospatial model-sharing platform will be used to facilitate sharing and integrating these models, which will quantify ecosystem services and provide decision support. Additional details are provided in appendix F.

Given the need to have regionally specific information and our limited understanding of the complex relationships among ecosystem processes, land-management actions, climate change, and ecosystem services, this part of the assessment will be limited to case studies within selected ecoregions where data and models already have been developed and can be readily incorporated into the assessment framework. The most likely regions include the Mississippi Alluvial Valley, Prairie Pothole Region, southern Florida, and the Chesapeake Bay watershed.

Different ecosystem services have different definitions, ranges, and meanings, so an ecosystem services change indicator (ESCI) has been defined in this report in order to compare them simultaneously:

$$
\mathrm{ESCI}=\frac{\mathrm{ES}-\mathrm{ES}_{0}}{\mathrm{ES}_{0}}
$$

where ES refers to the output value of a selected ecosystem service, and

$\mathrm{ES}_{0}$ is the corresponding baseline value.

A test that compared the ESCI values for selected ecosystem services was conducted for Tensas Parish, La. (in EPA Level III Ecoregion 73, Mississippi Alluvial Plain), and Clairborne County, Miss. (Ecoregion 74, Mississippi Valley Loess Plains). The changes in selected ecosystem services as they relate to carbon sequestration were considered by using the IPCC SRES A1B storyline (Nakicenovic and others, 2000), the land-cover classes for the two jurisdictions (see figure 3.7), and the "reference land use, land cover, and land management" $(\mathrm{R})$ and the "enhanced land use and land cover with reference land management" (L) scenarios (see section 3.2.2). The results in table 3.15 and figure 3.13 are an example of the model outputs and one method (using ESCI) of comparing changes over time using the IPCC SRES A1B storyline and the $\mathrm{R}$ and $\mathrm{L}$ scenarios. In practice, ecosystem services will be quantified using multiple models for the assessment and for providing uncertainty estimates. In the table, the modeled timber production as an ecosystem service for the 2041 through 2050 time period for the $\mathrm{R}$ and $\mathrm{L}$ scenarios is 9.70 and 3.61 grams of carbon per square meter per year $\left(\mathrm{gC} / \mathrm{m}^{2} / \mathrm{yr}\right)$, respectively, although the baseline value for 2001 through 2010 is $4.89 \mathrm{gC} / \mathrm{m}^{2} / \mathrm{yr}$. An ESCI value of greater than zero indicates

Table 3.15. Preliminary ecosystem service estimates for a test in Tensas Parish, La., and Claiborne County, Miss., using the A1B storyline.

[Abbreviations and acronyms are as follows: $\mathrm{CH}_{4}$, methane; ESCI, ecosystem services change indicator; L, "enhanced land use and land cover with reference land management" scenario; $\mathrm{N}_{2} \mathrm{O}$; nitrous oxide; R, "reference land use, land cover, and land management" scenario]

\begin{tabular}{|c|c|c|c|c|c|c|}
\hline \multirow[b]{2}{*}{ Assessment data products } & \multirow[b]{2}{*}{ Unit of measurement } & \multirow{2}{*}{$\begin{array}{c}\text { Baseline } \\
\text { value } \\
\text { (2001-2010) }\end{array}$} & \multicolumn{2}{|c|}{ R (2041-2050) } & \multicolumn{2}{|c|}{ L (2041-2050) } \\
\hline & & & $\begin{array}{l}\text { Output } \\
\text { value }\end{array}$ & ESCI & $\begin{array}{l}\text { Output } \\
\text { value }\end{array}$ & ESCI \\
\hline Soil organic carbon & Grams of carbon per square meter & 5,433 & 6,153 & 0.133 & 6,155 & 0.133 \\
\hline Carbon sequestration & Grams of carbon per square meter & 6,193 & 9,872 & 0.594 & 10,207 & 0.648 \\
\hline Carbon storage & Grams of carbon per square meter & 12,377 & 16,810 & 0.358 & 17,146 & 0.385 \\
\hline Carbon sequestration & Grams of carbon per square meter & 148 & 91 & -0.384 & 105 & -0.292 \\
\hline $\mathrm{N}_{2} \mathrm{O}$ emission & Gigagrams of nitrogen & 24.3 & 21.6 & 0.112 & 21.7 & 0.110 \\
\hline $\mathrm{CH}_{4}$ emission & Teragrams of carbon & 0.163 & 0.133 & 0.183 & 0.143 & 0.125 \\
\hline
\end{tabular}




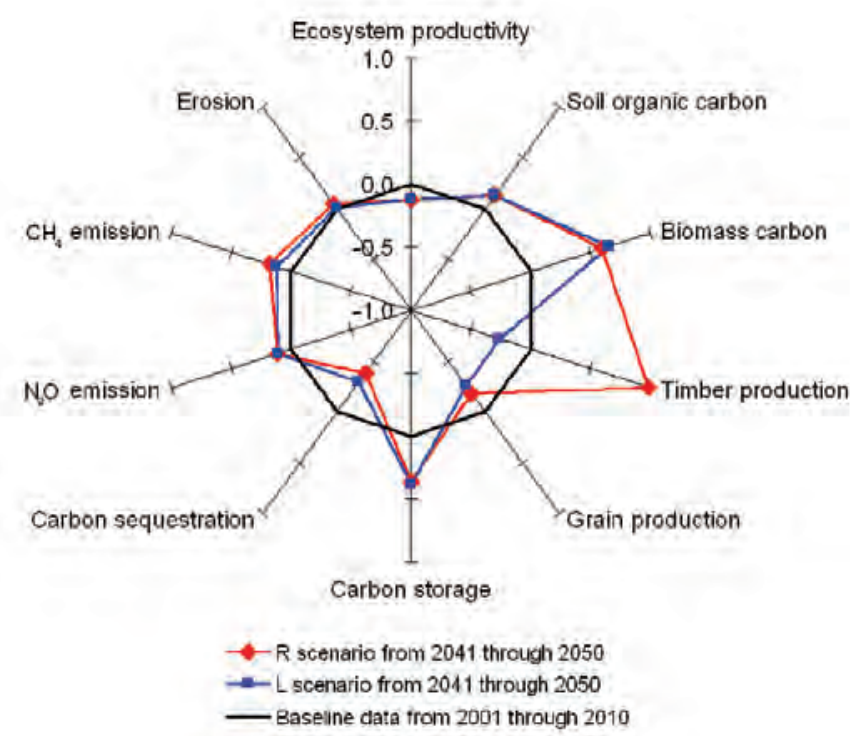

Figure 3.13. Chart showing a comparison of ecosystem service changes using the ecosystem service change indicator (ESCI). Baseline data for 2001 through 2010 are shown along with projected changes from 2041 through 2050 using the "reference land use, land cover, and land management" (R) and the "enhanced land use and land cover" with reference land management" (L) scenarios. Values shown apply to the whole chart.

a positive increase in ecosystem service change compared to baseline (2001-2010); an ESCI value of less than zero indicates a negative change. The ESCI absolute value reflects the magnitude of the ecosystem change.

Analysis of Mitigation Costs and Benefits.-The implementation of mitigation activities to enhance carbon sequestration can result in societal benefits associated with reducing impacts of climate change and can also provide benefits from marketable commodities, such as harvested timber and other ecosystem services. Depending on the activity, the net societal values for carbon sequestration can be positive (societal benefits) or negative (societal costs). Carbon-sequestration activities also have costs, such as the opportunity cost of the land on which to enact a mitigation activity, as well as any associated capital or maintenance costs. This section will explain a simple accounting approach that can be used to estimate the potential benefits and costs of a management activity so that a user will get a "first-cut" approximation of an activity's possible payoff. Both current and potential market and societal benefits and management-activity costs will be included in a discounted cash flow (DCF) analysis (Schaltegger and Burritt, 2000; Wrisberg and de Haes, 2002). A DCF analysis is a widely used valuation tool that will (1) account for both the benefits (the societal benefits of carbon sequestration and any other benefits) and the capital and operating costs of a potential project, and (2) assume the value of money changes over time (discount rate). All future flows of benefits and costs will be estimated and discounted to yield a present value. Assuming that all other relevant market conditions are constant, if the value of the investment is greater than the cost of the investment, the activity will have a positive net present value. An example of the application of this method in Tensas Parish, La., using one potential mitigation activity, is given later in this section.

The assessment methodology will use the DCF analysis to estimate (1) the carbon sequestration and other ecosystemservice benefits as well as any income from a marketed commodity (for example, sawtimber), if applicable; and (2) the economic costs of acquiring the land and implementing a mitigation activity. The benefits and costs will be estimated in terms of the present value of the benefits (PVB) and the present value of the costs (PVC) of a mitigation activity. In addition, the DCF method will be used to associate the benefit and cost information of mitigation activities in one ecoregion with others. Furthermore, the analysis of the benefits and costs of a management activity will not be quantified as constraints for the scenario construction, which are ramifications of landmanagement activities.

Two types of ecosystem services benefits will be included in the methodology (Jenkins and others, 2010). The first benefit is the market value of a commodity that is sold in traditional markets. The second benefit is the economic value to society in terms of the flow of ecosystem services. Both should be used in societal-benefit and cost analyses of public policies or programs. The present value of the market benefits will be entered into the numerator of equation $\mathrm{F} 1$ in appendix $F$ to calculate the present value of benefits (PVB).

Market benefits.-The market value for services provided by a particular ecosystem is based on the commodities that are currently bought and sold in traditional markets. Market values for the economically valuable outputs of certain ecosystems, such as timber (stumpage value), will be estimated using a market price of the output harvested in the year it is sold, which will be assumed to be the final year in which the assessment was conducted; the estimated market value is entered into the DCF. These direct-use services are typically consumptive (for example, commercial fishing, and pharmaceuticals).

Nonmarket benefits. - Some ecosystem services, such as recreational fishing and birdwatching, are not valued in traditional markets (nonmarket values). Although the price of a marketable commodity is determined by willing buyers and sellers in the marketplace, ecosystem services that currently are not traded in a market require alternative ways to estimate their value to society (Merlo and Croitoru, 2005; Richardson and Loomis, 2009).

The measurement and estimation of societal values in the assessment will link ecosystem services to existing valuation methods in order to facilitate the analysis of these externalities by users. For example, economic studies that elicit the willingness to pay either by using economic surveys (Hanemann and others, 1991; Stevens and others, 2000) or by market-based factors (Bernknopf and others, in press) can provide monetary benefit estimates of ecosystem services (Loomis and Helfand, 
2001). These types of analyses will be used to estimate the willingness of society to pay for environmental improvements. Brookshire and others (2010) used the stated preference approach to estimate the value of vegetation composition, water availability, bird breeding, and migratory bird abundance in a watershed in the southwestern United States; however, when the resources for conducting an economic analysis in certain places like this one are limited, one approach to economic valuation is to use benefit transfer studies. Benefit transfer studies are a means to adapt a study from one location or region to another. This approach is a way to harness the benefits of existing economic studies while minimizing the need for costly new site-specific analyses (Brookshire and Neill, 1992; Devosouges and others, 1998; Brookshire and Chermak, 2007; Brookshire and others, 2007). The benefit transfer method will be applied in the test described below and will apply the specific results from a preexisting study for valuing several ecosystem services for the Mississippi Alluvial Valley to Tensas Parish, La. (Jenkins and others, 2010). For example, ecosystem societal value estimates will be based on the number of hectares converted from agricultural use to managed forest plantations. The nonmarket benefit estimates will be entered into equation $\mathrm{F} 1$ in appendix $\mathrm{F}$ to calculate the PVB of these ecosystem services.

Because few markets exist for ecosystem services, the assessment methodology will incorporate the possibility of potential markets for specific ecosystem services such as nitrogen mitigation (Jenkins and others, 2010). Potential markets will be included because of the possibility that, while the assessment is being planned, the markets for ecosystem services will expand and new policies associated with those markets will be implemented. Potential market values can be entered into the numerator of equation F1 in appendix F.

Economic costs. - Land and the cost to implement a mitigation activity will vary over time and space because of the type, size, and design criteria of the mitigation activity; its geographic location; the cost of labor and materials for it; the alternative uses of the targeted land; and the biophysical site characteristics. In the methodology, economic costs will be estimated as a present value (PVC equation F2 in appendix F) and an equivalent annual cost (EAC, which is calculated using equation $\mathrm{F} 3$ in appendix $\mathrm{F}$ and is derived from the PVC).

The components of cost are: (1) the cost of obtaining the land, and (2) the direct engineering costs ${ }^{4}$ involved in the ecological carbon-mitigation activity that has been chosen. The second component includes the following factors: (1) up-front or one-time capital-investment costs for establishment and installation of the mitigation activity, including site preparation, planting, and any initial chemical treatments (and documentation of the environmental impacts of all of the preceding); (2) recurring capital expenses of the activity, such as the expenses related to boundary maintenance; and (3) annual operating, maintenance, and management costs (including performance

\footnotetext{
${ }^{4}$ Investment and operating costs are incurred for economic production and its environmental impacts and improvements.
}

monitoring, administration, insurance, and other transaction costs). See appendix F for details on these cost categories.

For the test, the economic costs were estimated using methods found in Brown and Kadyszewski (2005), Huang and others (2004), and Atkinson and others (2004). They are shown in table F1 and are computed using equations F2 and F3 in appendix F. These cost estimates were used in the test below for Tensas Parish, La. Other estimates have been developed to assess the engineering costs for afforestation projects (Adams and others, 1996); reviews and summaries of the studies that employ them are found in (Stavins and Richards, 2005).

Test for Estimating the Costs and Benefits of a Mitigation

Activity.-In this test, the benefits and costs of a mitigation activity were calculated. The theoretical mitigation activity for the test was the conversion of 10,475 ha of agricultural land to forest in Tensas Parish, La. Specifically, this study compares the cost and benefits of the mitigation activity (foresting the land) with the costs and benefits of the current (or reference) unmitigated agricultural land. The benefits of the marketable sawtimber (timber suitable for sawing) products mentioned below were estimated using equations F4 through F9 in appendix F.

Benefits. - In 2009, if the intent of the mitigation activity included harvesting the timber, the market value for the timber was based on stumpage values of $\$ 31.01$ per ton for sawtimber (Louisiana Department of Agriculture and Forestry, 2010). By applying equation $\mathrm{F} 1$ in appendix $\mathrm{F}$, the present value of the benefits for harvesting the timber for a 40 -year period, discounted at 4 percent, for the mitigation activity was calculated to be $\$ 303,700$ (assuming that all the harvested timber was of sawtimber quality). The timber would be harvested in year 40 of the mitigation activity, which is 2050 for this test.

The test links biophysical outcomes with economic values. The benefits estimate of the ecosystem services is based on the benefit transfer method for the Mississippi Alluvial Valley (EPA Level III ecoregion modified from Omernik (1987)) in Tensas Parish, as estimated by Jenkins and others (2010). The benefits estimate is entered into the numerator of equation F2 in appendix F. The estimates for the mitigation activity are calculated using the same 4 percent discount rate as for the costs and market values calculation described above. The current $(\$ 1$ per hectare per year) and potential (\$396 per hectare per year) market values for carbon sequestration are less than $\$ 1$ million per year and \$4.1 million per year, respectively, although the societal value could range from $\$ 1.8$ million to $\$ 2.3$ million per year (a societal value range of $\$ 171$ to $\$ 222$ per hectare per year). Two examples of societal benefits would be (1) avoiding loss of wildlife habitat caused by rising temperatures by sequestrating carbon dioxide and other GHG, and (2) wetland preservation to improve water quality. The potential economic value of this service that could be realized is as high as $\$ 6.4$ million per year; the present value benefits at a 4 percent discount rate would be $\$ 61.1$ million (calculated using equation F1 in appendix F). Nitrogen mitigation could have potential market $(\$ 624$ per hectare per year) and social $(\$ 1,248$ per hectare per year) values of $\$ 6.5$ million per year and $\$ 13.1$ million per year, respectively. The potential economic value of this ecosystem service could 
be as great as $\$ 19.6$ million per year; the present value benefits at a 4 percent discount rate would be $\$ 387.9$ million (calculated using equation $\mathrm{F} 1$ in appendix F).

Costs.-The PVC and EAC were estimated using equations F2 and F3 in appendix F with cost data indexed to 2009 dollars (Council of Economic Advisers, 2008, table B-101) (Huang and others, 2004; Brown and Kadyszewski, 2005). The cost estimates are for the analysis of the mitigation activity that converts 10,475 hectares of agricultural land to woody wetlands over a 40-year period in Tensas Parish, under the "enhanced land use and land cover with reference land management" (L) scenario; the assumption is that converting the land from agricultural use to woody wetlands improves the carbon sequestration capacity of that acreage. The potential land and implementation costs would be about $\$ 18.5$ million ( $\mathrm{PVC}$ using a cost of $\$ 1,766$ per hectare discounted at a rate of 4 percent) and $\$ 1.4$ million per year (EAC at $\$ 130$ per hectare per year) using the data in table F1 in appendix F.

Net benefits. - The net present value of the mitigation activity (the difference between present values of benefits

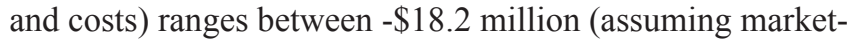
able timber value only) and $\$ 436.9$ million (assuming that all potential and societal values for the ecosystem services are realized). Although the mitigation-activity costs may be significant at $\$ 18.5$ million, the values of the marketable commodities along with the potential values of ecosystem services could be even greater. Thus, depending on the assumptions of the benefits to be included, the return on investment in the mitigation activity could be significant.

\subsubsection{Validation Methods}

The validation strategy for the national assessment is designed to achieve two overarching objectives: to identify, quantify, and document sources of error that underlie the assessment results, and to guide efforts to increase accuracy through improvements in data collection, model design, sampling design, and other elements of the methodology. The validation effort will focus primarily on the assessment data products; the quality of the input data will be documented by reference to existing reports. (The methodology for validation is found in appendix G.)

Because the assessment deliverables will be produced and reported at the scale of assessment units (EPA Level II ecoregions of Omernik (1987)), validation exercises also will be conducted at that scale. Validation will be conducted for assessment results of the "current" (2001-2010) carbon stocks, carbon sequestration, and GHG fluxes in ecosystem. Because the same methods and model runs will be used to produce results for 2001 through 2050, the validation results for target data products can be considered indicative of future potential assessment.

A set of output data products (estimates) from the assessment of terrestrial and aquatic systems will be the initial

Table 3.16. Partial list of deliverable and intermediate data products targeted for validation, and the corresponding reference data sources and needs.

[For explanations of acronyms, please see "Abbreviations, Acronyms, and Chemical Symbols" in the front of the report. Abbreviations are as follows: GHG, greenhouse gas; km, kilometers; m, meter]

\begin{tabular}{|c|c|c|}
\hline Data products for validation & Reference data sources & Reference data needs \\
\hline Land-cover and land-use change & LANDFIRE VCT & None. \\
\hline Wildland fires, and carbon emissions by fires & $\begin{array}{l}\text { LANDFIRE MTBS, Consume outputs, } \\
\text { NOAA Carbon Tracker }\end{array}$ & $\begin{array}{l}\text { Field plots of changes in aboveground } \\
\text { biomass. }\end{array}$ \\
\hline Delivery of water to coastal area & USGS streamgage network & None. \\
\hline $\begin{array}{l}\text { Net ecosystem productivity (NEP) by pools } \\
\text { and ecosystems }\end{array}$ & AmeriFlux, NEON, NOAA Carbon Tracker & Additional flux data points. \\
\hline Modeled Leaf Area Index (LAI) & MODIS LAI (1-km resolution) & $\begin{array}{l}\text { LAI at less than or equal to } 250-\mathrm{m} \text { resolution } \\
\text { (30-m from Landsat). }\end{array}$ \\
\hline Grain yields & USDA NASS and ARS & 30-m from Landsat. \\
\hline Carbon stocks by pools and ecosystems & FIA, LTER, NEON, ARS, GRACEnet & Aboveground biomass data from LIDAR. \\
\hline Nitrous oxide emissions by ecosystems & $\begin{array}{l}\text { AmeriFlux, NEON, NOAA Carbon Tracker, } \\
\text { ad-hoc reports }\end{array}$ & $\begin{array}{l}\text { GHG flux data for aquatic and wetland } \\
\text { systems. }\end{array}$ \\
\hline Carbon delivery by rivers to coastal areas & NWIS, SPARROW, NEWS & None. \\
\hline
\end{tabular}


targets for validation (table 3.16). The target data products will be selected based on their relative importance to the assessment results and the availability of suitable, existing reference data. As a general rule, the validation approach will compare the data products to the best available (most suitable) reference data sets that were produced independently of the national assessment. The validation strategy is adaptable to changes in data availability and information requirements. Depending on the assessment data products and the availability of reference data, probability sampling will be considered as a statistical framework for validation (Stehman and other 2003). Individual assessment data products may be added or removed from the list of validation targets in response to model performance or specific issues that may arise. Additional or improved reference datasets will be incorporated as they become available and when deemed effective in support of validation objectives.

\subsubsection{Methods for Assessing and Reporting Uncertainty}

Gaps in data, current modeling capabilities, interactions between ecological phenomena, and scientific understanding of the mechanics of these complex interactions can produce large uncertainties in the assessment. The treatment of uncertainties is related to the validation assessment, discussed above. Although validation methods will be used for assessing of current carbon stocks, carbon sequestration, and GHG fluxes, uncertainty in the assessment will be focused mainly on scenarios, data, and methods related to future potential conditions. There are two general sources of uncertainty for the assessment: uncertainty related to the IPCC storyline framework, which is unquantifiable (unpredictable); and uncertainty related to data and methods, which may be quantified and reported. The methods for treating uncertainties in the assessment are designed based on IPCC guidelines on uncertainties (IPCC, 2006). Appendix G provides more detailed discussion.

Uncertainty From the Use of the Storylines and Scenarios.-As noted in the previous discussion of storylines (sections 2.5.1 and 3.2.2), the use of three IPCC SRES storyline (Nakicenovic and others, 2000) will effectively bound the size of the overall uncertainty. In addition, the scenarios for alternative land-use and land-management options (section 3.2.2) will be assessed for their potential effects on enhancing carbon sequestration and reducing GHG fluxes. These scenarios also will produce uncertainty in assessment results. For this methodology, the strategy for treating storyline- or scenario-related uncertainties will involve the following steps:

- Communicating the sources of uncertainty.-Potential sources of uncertainty (see appendix G) include choices of storylines or scenarios and the downscaling process.

- Reducing the unknown uncertainties.-Measures to reduce unknown uncertainties will include (1) downscaling the IPCC SRES storylines based on data and studies rather than on global-scale model outputs; (2) standardizing the downscaling methods, which will be accomplished through consultation sessions with regional experts; and (3) increasing the consistency of the scenario framework by using the same design criteria for each alternative scenario and aligning it with the IPCC SRES storylines.

Uncertainty Related to Data and Assessment Methods.Although uncertainties related to input data and methods are bound by the storyline and scenario uncertainties discussed above, it is still important to assess and quantify uncertainties related to the data and assessment methods under each of the storylines used. Providing information on quantifiable uncertainties will allow users to evaluate assessment results and the methodology for a given scenario. The sources of uncertainty related to the assessment data and methods include the following: input data; the scarcity of data (such as GHG flux data for different ecosystems) that pertains to the assessment methods and deliverables; the process-model structure and associated parameters that are used to estimate carbon stocks, carbon sequestration, and GHG fluxes; and the interactions between components of the assessment (for example, projecting LULC change and evaluating the effects).

The basic approach for estimating uncertainties related to the data and assessment methods will follow IPCC (2006) recommendations. The input data (including the derived intermediate data products that are produced during the assessment) will be processed to produce joint frequency distributions, which in turn are used in Monte Carlo resampling and simulation runs to estimate uncertainty in the resulting output products. For uncertainties introduced by using different methods or models, multiple model runs and statistical analysis will be used to summarize the relative contributions of the technical components to the final uncertainties. All of the data resulting from the assessment also will be evaluated by experts in consultation sessions. Expert opinions then can be used to assess uncertainties.

The focus of assessing and communicating uncertainties is on quantifying the variability of end results, which will be carbon storage, carbon sequestration, and GHG fluxes; therefore, some uncertainties that may arise during the many parts of the modeling process may have very little effect on the final outcome, which will be summarized and delivered at the scale of assessment units. For example, specific locations of land-cover changes across a homogeneous landscape may be highly uncertain, but they may make very little difference in the overall long-term carbon-sequestration measurement at the scale of the assessment-units.

\subsubsection{Requirements of Section 712 of the Energy Independence and Security Act for Measuring and Monitoring}

As discussed in chapter 1, section 712 of the EISA (U.S. Congress, 2007) requires that the methodology address the 
measuring, quantifying, and monitoring of carbon stocks, carbon sequestration, and GHG fluxes across the Nation, including coastal waters and estuaries. These three required tasks are closely related: measurements collected directly or remotely provide the necessary data for quantifying the carbon stocks, carbon sequestration, and GHG fluxes, and the continual, systematic repetition of such measurements constitutes monitoring. The methods that are designed to fulfill the EISA requirement for measuring and monitoring carbon stocks, carbon sequestration, and GHG fluxes include the identification of objectives and data source, and a plan for filling data gaps are summarized below. Detailed information on the method is in appendix $\mathrm{H}$.

Objectives for Measuring and Monitoring.-The principal objectives for measuring and monitoring carbon stocks, carbon sequestration, and GHG fluxes are as follows:

- Periodically quantify carbon stocks, carbon sequestration, GHG fluxes, and related ecosystem properties and processes in the United States for the purpose of evaluating their status and trends.

- Aggregate and update observational monitoring data for the purpose of validation; that is, for assessing the accuracy of model results.

- Provide a basis for evaluating the effectiveness of applied mitigation activities and strategies undertaken to reduce GHG emissions from ecosystems and promote carbon sequestration.

The methodology for measuring and monitoring is designed to support the scope of the national assessment and to be adaptive to changing data resources, improved methodologies, and evolving requirements for data and information, while maintaining consistency, scientific credibility, and transparency.

Methodology for Measuring and Monitoring.-Achieving the above objectives requires the continual coordination and implementation of two major activities:

- Quantification of the relevant data products through the spatial aggregation of measurements and (or) model results

- Provision of the data and information that is required for such quantification and for validation and evaluation of mitigation effectiveness

The methodology for measuring and monitoring for the assessment (appendix H) focuses on the provision of the required data and information. The methodology builds on existing data resources that are created, managed, or supported by various agencies and programs across the Federal Government (such as DOI, USDA, NASA, NOAA, and the National Science Foundation (NSF)) and is designed to be adaptive to changing data resources, improved techniques, and evolving requirements for data and information, while maintaining consistency, scientific credibility, and transparency.

Availablity of Data .- The effectiveness of the methodology for measuring and monitoring will be constrained by the availability of required in situ and other observational data, which often are not uniformly distributed in space or among major ecosystems and pools. Known data gaps or deficiencies are identified in appendix $\mathrm{H}$, along with a strategy for developing new or enhanced measurement capabilities. The strategy for ensuring that adequate data is available for measuring, quantifying, and monitoring focuses on critical data shortages and monitoring needs and includes the following:

- Expanded airborne and ground-based measurements of GHG fluxes in terrestrial and aquatic ecosystems

- Expanded measurements of dissolved and particulate forms of carbon (DOC, DIC, and POC) and nutrients (nitrogen and phosphorus), sedimentation rates, and concentration of organic carbon in sediments of aquatic ecosystems

- Improved remote-sensing capabilities for quantifying and mapping terrestrial biomass and small inland water bodies by developing and applying high-resolution satellite imagery and such promising technologies as small- and large-footprint LIDAR

The successful implementation of this strategy requires partnerships and coordination among government agencies and other organizations.

\subsection{Data Products, Deliverables, and Reports}

The assessment will generate a large quantity of data products in tabular and map formats; for example, carbon stocks, carbon sequestration, and GHG-flux parameters by ecosystem, pool, scenario, and time period will result from the assessment, as will the associated validation and uncertainty estimates (where appropriate). Assessment results will be reported as the final deliverables. In this section, various data products that will be generated by the methodology are introduced, followed by a discussion of assessment reporting mechanisms.

\subsubsection{Data Products}

The methodology uses a set of integrated methods to assess carbon stocks, carbon sequestration, and GHG fluxes in relation to major controlling processes (such as LULC change and ecosystem disturbances) and potential mitigation strategies (such as LULC change and land-management change). As a result, both the intermediate data products (such as LULC, wildland fire, and river discharge datasets) and final data products (such as carbon stocks, net biome productivity and ecosystem carbon balance, or $\mathrm{CH}_{4}$ and $\mathrm{N}_{2} \mathrm{O}$ flux derived either as digital maps or tabular data) will be generated by various methods. Table 3.17 lists examples of the data products. For the maps, a common spatial resolution of $250 \mathrm{~m}$ is listed as a pixel size used by spatially explicit models; however, the map resolution does not designate the scale of the methodology. The scale of the methodology is set as assessment units, as discussed in section 3.1.2. 
Table 3.17. A subset of primary deliverables for the national assessment, by deliverable type.

[For an explanation of acronyms, please see "Abbreviations, Acronyms, and Chemical Symbols" in the front of this report. Abbreviations are as follows: $\mathrm{CH}_{4}$, methane; $\mathrm{kg}$, kilogram; $\mathrm{kgC} / \mathrm{ha} / \mathrm{yr}$, kilograms of carbon per hectare per year; $\mathrm{kgN} / \mathrm{ha} / \mathrm{yr}$, kilograms of nitrogen per hectare per year; $\mathrm{MgC}$, megagrams of carbon; $\mathrm{MgC} / \mathrm{ha}$, megagrams of carbon per hectare; $\mathrm{MgC} / \mathrm{ha} / \mathrm{yr}$; megagrams of carbon per hectare per year; $\mathrm{MgCH}_{4} / \mathrm{km}^{2}$, megagrams of methane per square kilometer; $\mathrm{MgCO}_{2 \text {-eq }} / \mathrm{ha} / \mathrm{yr}$, megagrams of carbon dioxide equivalent per hectare per year; $\mathrm{MgDOC} / \mathrm{km}^{2}$, megagrams of dissolved organic carbon per square kilometer; $\mathrm{N}_{2} \mathrm{O}$, nitrous oxide; $\mathrm{TgC}$, teragrams of carbon; $\mathrm{TgC} / \mathrm{yr}$, teragrams of carbon per year]

\begin{tabular}{|c|c|c|c|}
\hline Product name & Data type & Unit of measurement & Time interval \\
\hline Net primary productivity (NPP) & Map series and statistics & $\mathrm{MgC} / \mathrm{ha} / \mathrm{yr}$ & Annual for 2001-2050. \\
\hline Net ecosystem productivity (NEP) & Map series and statistics & $\mathrm{MgC} / \mathrm{ha} / \mathrm{yr}$ & Annual for $2001-2050$. \\
\hline Net ecosystem carbon balance (NECB) & Map series and statistics & $\mathrm{MgC} / \mathrm{ha} / \mathrm{yr}$ & Annual for 2001-2050. \\
\hline Soil carbon stock & Map series and statistics & $\mathrm{MgC} / \mathrm{ha}$ & Annual for 2001-2050. \\
\hline Grain yields & Map series and statistics & $\mathrm{MgC} / \mathrm{ha} / \mathrm{yr}$ & Annual for 2001-2050. \\
\hline Carbon stock/flux trends & Statistics & $\mathrm{TgC} / \mathrm{yr}, \mathrm{TgC}$ & Annual for 2001-2050. \\
\hline Carbon accumulation in lake and reservoir sediments & Statistics & $\mathrm{MgC}$ & Annual for $2001-2050$. \\
\hline Carbon accumulation in coastal waters & Statistics & $\mathrm{MgC}$ & Annual for 2001-2050 \\
\hline Delivery of organic carbon by rivers to coastal areas & Statistics & $\mathrm{MgDOC} / \mathrm{km}^{2}$ & Annual. \\
\hline Delivery of inorganic carbon by rivers to coastal areas & Statistics & $\mathrm{MgDOC} / \mathrm{km}^{2}$ & Annual. \\
\hline $\mathrm{CH}_{4}$ and $\mathrm{N}_{2} \mathrm{O}$ flux from estuaries and coastal waters & Statistics & $\mathrm{MgCO}_{2-\mathrm{eq}} / \mathrm{ha} / \mathrm{yr}$ & Annual. \\
\hline $\begin{array}{l}\text { Land suitability for REDD by NPP, fire disturbance catego- } \\
\text { ries, and scenario storylines }\end{array}$ & Map series and statistics & Thematic classes & Annualized average. \\
\hline $\begin{array}{l}\text { Future soil erosion and surface runoff potential by major } \\
\text { ecosystem types and management scenarios }\end{array}$ & Map series and statistics & Thematic classes & Annualized average. \\
\hline $\begin{array}{l}\text { Greenhouse-gas reduction }\left(\mathrm{N}_{2} \mathrm{O}, \mathrm{CH}_{4}\right) \text { by ecosystem type and } \\
\text { LULC and land-management scenario }\end{array}$ & Map series and statistics & $\begin{array}{l}\mathrm{MgC} / \mathrm{ha} / \mathrm{yr} \\
\mathrm{MgCO}_{2}-\mathrm{eq} / \mathrm{ha} / \mathrm{yr}\end{array}$ & Annualized average. \\
\hline Wildland fire perimeters and severity & Map series & Thematic classes & Annual for 2011-2050. \\
\hline Sediment and nutrient flux to estuaries and coastal waters & Statistics & $\mathrm{kg}$ & Monthly and annual. \\
\hline
\end{tabular}




\subsubsection{Assessment Reporting}

The methods and format for reporting the results of the assessment will follow the guidelines in IPCC (2006) for reporting carbon stocks, carbon sequestration, and GHG fluxes. For each assessment unit, the types of deliverables to be reported are listed below:

- Estimates of present and future carbon stocks and sequestration by pool, ecosystem, and assessment scenario, and by 10 -year intervals

- Estimates of present and future GHG fluxes by pool, ecosystem, and assessment scenario, and by 10 -year intervals

- Analyses of biophysical effects (for example, climate, land-cover patterns, or ecosystem disturbances, such as fire) on carbon stocks, carbon sequestration, and GHG fluxes
- Analyses of the effectiveness of potential LULC changes and land-management activities for enhanced carbon sequestration and reduced net GHG emissions

- Analyses of the potential ramifications of mitigation strategies (including analyses of the effects and effectiveness of potential mitigation activities and their effects on other ecosystem services

- Validation and uncertainty estimates and associated analyses for appropriate deliverables and data products

Examples that illustrate the methods by which these assessment results will be reported are presented here for a subset of results and associated estimated uncertainties (table 3.18), for reporting emissions and effects of wildfires and manmade fires (table 3.19), and for validation results (table 3.20). The method, timing, format, and content of reporting the assessment results will be determined early in the assessment process and will be based on actual results.

Table 3.18. Example of a table format for reporting the results of the assessment of carbon stocks, carbon sequestration, and greenhouse gases, including uncertainties, for current or future scenarios depicted in table 3.6.

[The table will be used as part of assessment-unit reports to present results for years encompassed by the assessment (2001-2050). Acronyms are as follows: DIC, dissolved inorganic carbon; DOC, dissolved organic carbon; GHG, greenhouse gases; NBP, net biome productivity; NECB, net ecosystem carbon balance; POC, particulate organic carbon]

\begin{tabular}{|c|c|c|c|c|c|}
\hline \multirow{2}{*}{ Carbon and GHG measurements } & \multicolumn{5}{|c|}{ Ecosystems } \\
\hline & Forest & Cropland & Grassland/shrublands & Wetlands & Aquatic habitat \\
\hline \multicolumn{6}{|l|}{ Carbon stocks } \\
\hline \multicolumn{6}{|l|}{ NBP/NECB } \\
\hline \multicolumn{6}{|l|}{ Carbon flux } \\
\hline \multicolumn{6}{|l|}{$\mathrm{N}_{2} \mathrm{O}$ flux } \\
\hline \multicolumn{6}{|l|}{$\mathrm{CH}_{4}$ flux } \\
\hline \multicolumn{6}{|l|}{ Lateral carbon flux (DOC, DIC, POC) } \\
\hline Global warming potential (GWP) & & & & & \\
\hline
\end{tabular}


Table 3.19. Example of a table format for reporting the effects of wildfires and manmade fires on carbon stocks for a given assessment unit, for all ecosystems.

$\left[\mathrm{kgC} / \mathrm{m}^{2} / \mathrm{yr}\right.$, kilograms of carbon per square meter per year]

\begin{tabular}{|c|c|c|c|c|c|}
\hline Wildfire types & \multicolumn{5}{|c|}{ Years of the assessment } \\
\hline \multicolumn{6}{|l|}{ Low-severity wildland fire } \\
\hline High-severity wildland fire & & & & & \\
\hline
\end{tabular}

Table 3.20. Example of a table format for reporting validation results of comparing the reference data with the 2010 assessment estimates (present conditions) for selected assessment parameters, for a given assessment unit.

\begin{tabular}{|c|c|c|c|c|c|}
\hline Validation target & Measurement units & Estimated value & Mean deviation & $\begin{array}{l}\text { Mean absolute } \\
\text { deviation }\end{array}$ & $\begin{array}{l}\text { Root mean } \\
\text { square error }\end{array}$ \\
\hline \multicolumn{6}{|l|}{ Forest carbon stock } \\
\hline \multicolumn{6}{|l|}{ Forest carbon emission by fire } \\
\hline \multicolumn{6}{|l|}{ Forest net ecosystem productivity } \\
\hline Carbon export to coastal waters & & & & & \\
\hline
\end{tabular}




\section{Conducting the National Assessment}

With the proposed methodology framework and specific methods and models outlined in chapter 3 , the focus of this chapter is on implementing the national assessment. This chapter also includes a discussion of science needs, as well as a brief examination of potential applications.

\subsection{Operational Issues}

In order to implement the EISA-mandated national assessment (U.S. Congress, 2007), several operational and logistical issues, including interagency cooperation, access to required data, assessment prioritization and scheduling, and project management, will need to be addressed. These issues are outlined below.

Interagency cooperation and coordination.-The methodology is the result of a multidisciplinary approach that required cooperation and collaborations with more than one organization. Shared activities included development of the mitigation scenarios, remote sensing, in situ data access, and field validation of assessment results. For the assessment, close coordination with agencies and organizations that conduct relevant resource assessments and research will continue to be necessary. Close cooperation and coordination can be facilitated by organizing an interagency assessment team established for this purpose, with scientists from appropriate organizations coordinating technical exchanges, developing interagency agreements about data sharing, overseeing production of data products, and forming an executive oversight committee to provide high-level support to the assessment.

Engagement of the national and international science community.-The active engagement of the national and international science community throughout the assessment will be necessary to ensure that the results are timely, useful, accessible, and relevant. This engagement will facilitate internal benefits (such as possible advances in scientific areas such as climate change, biogeochemical modeling, or ecosystem disturbances) and external benefits (such as assistance in comparing various models, synthesis workshops, and comparing the assessment results derived using the various models.

Enhancement of data access and management.-The national assessment will require access to numerous datasets from a variety of sources to ensure the quality of the assessment and to minimize the uncertainty of assessment results. Access to some types of data may present varying degrees of difficulty. For example, some datasets are proprietary, some must be acquired through formal acquisition processes (for example, remotely sensed wildfire perimeters and severities), and some will require formal agreements that precisely dictate how to acknowledge credit for providing the data. There also may be difficulty in organizing and managing the data (including the metadata).

Prioritization and scheduling assessment activities.-The methodology uses U.S. Environmental Protection Agency
(EPA) Level II ecoregions (Omernik, 1987) as the primary assessment unit so that carbon stocks, carbon sequestration, and GHG fluxes can be assessed one ecoregion at a time, in the context of mitigation scenarios that will be developed specifically for that ecoregion. Federal agencies and other stakeholders will be consulted to prioritize the order in which ecoregions will be assessed. For instance, ecoregions with the greatest potential for increased carbon sequestration, regions that are predicted to experience the most profound impacts from climate-change or land-use and land-cover changes, and regions where established collaborative opportunities already exist may receive the highest priorities. Prioritization also should be based on data quality and availability. For example, Alaska may be assessed at a later time to allow for additional data collection (in situ and remote sensing) and processing.

Active project management.-A well-defined, structured, and scalable project-management process should be established and followed for the assessment. The project-management plan should be developed, organized in structured phases and tasks, and submitted for review by the interagency assessment oversight team. The plan should establish metrics and include all linked dependencies. The project plan will ensure that activities are executed effectively and efficiently, with progress measured against established metrics in order to complete the assessment within the allotted time frame.

\subsection{Major Scientific Research and Development Needs}

The methodology is based on balanced considerations of the established scientific knowledge, the operational efficiency of methods and models, and the availability of datasets that meet the assessment needs. The gaps in required input data are addressed in chapter 3 , which also contains plans for reducing the effects of the data gaps; however, as noted throughout chapter 3 and in the various appendixes, it is crucial to address scientific needs and data gaps to further improve and enhance the ability to accurately assess carbon stocks, carbon sequestration, and GHG fluxes of the Nation's ecosystems. Key areas of research and developemnt are as follows:

Permafrost.-Assessments of permafrost and GHG responses to changes in permafrost would benefit greatly from targeted studies linking permafrost degradation to changes in surface water and GHG fluxes. Although some such studies are underway and their results may be available for the assessment, in situ measurements and model development should be designed to establish probability assessments for hotspots of GHG release; such assessments should be based on field studies in stratified sampling designs by landscape (based on slope and permafrost information), ecosystem (vegetation type, disturbance age), and geohydrologic unit (surficial geology and substrate).

Ecosystem disturbances.-Spatially explicit mapping and modeling of ecosystem disturbances are challenging. Mapping and modeling of wildland fires and anthropogenic disturbances 
(such as forest cuts) are technically more advanced than modeling other ecosystem disturbances (such as storm damage, and forest defoliation and mortality caused by insect outbreaks). There are national programs that produce spatially explicit datasets of various major ecosystem disturbances, but there is a lack of consensus about their technical standards and readiness for operational applications. Although this methodology documents an approach for spatially mapping, characterizing, and forecasting wildland fires and other disturbances, there is a strong need for continued vetting of the proposed methods by comparing results with other methods and models and by conducting validation exercises using in situ and other fire data.

Wetlands.-Accurate mapping of wetlands and aquatic habitats is a key step in the assessment of different ecosystems; however, despite the availability of national datasets, such as the National Land Cover Database and the National Wetland Inventory, determining the spatial boundaries of wetlands and aquatic habitats will be an early research and development priority in the assessment. Practical methods will be devised to spatially separate upland systems, inland-freshwater systems, inland-wetland systems, coastal-salt-marsh systems, and coastal-aquatic systems. Certain satellites that collect high-resolution data (for example, GeoEye1 and Worldview2) could provide extensive coverage that would aid in mapping these systems. An eight-band sensor on the Worldview 2 satellite provides imagery with a bathymetric wavelength that could be used for measuring and monitoring terrestrial vegetation with the additional benefit of detecting sediment beds of reservoirs, impoundments, and coastal estuaries. These mapping efforts would provide data enabling a better understanding of patch- and landscape-scale controls on carbon stocks, carbon sequestration, and GHG fluxes, including the potential effects of sea-level rise, and would enhance the assessment results for wetlands.

Inland basins, reservoirs, estuaries, and coastal areas.Few data are available to construct models for determining GHG fluxes and accumulation rates of carbon in sediments in inland basins, reservoirs, estuaries, and coastal areas. Additional data are needed to accurately model fluxes and carbon sequestration as a function of surface-water and groundwater flow of nutrients and sediment into these systems.

Biogeochemical models.-Biogeochemical modeling of carbon stocks, carbon sequestration, and GHG fluxes will be a core capability of the assessment and will incorporate both bookkeeping and process-based modeling methods in order to improve consistency in and enhance the transparency of the overall methodology. The crosscheck and the use of data assimilation techniques, as discussed above, are helpful, but more research and development needs exist, such as the identification and use of other appropriate BGC models based on their unique suitability for different ecosystems, pools, and flux types. Techniques need to be improved for model comparison, result validation or accuracy of the assessment, and implementation of uncertainty assessment.
Integration of the assessments for terrestrial and aquatic ecosystems.-Terrestrial and aquatic ecosystems have different ecological processes that determine GHG fluxes. The assessment of aquatic ecosystems should be dynamically integrated with that of the terrestrial systems so that the relevant terrestrial estimates (for example, rates of surface runoff and erosion) may be used as input data for estimating carbon sequestration in and GHG fluxes from aquatic ecosystems. Research needs to be conducted to link and integrate methods for assessing the interplay between these two types of ecosystems. An application of the research would include the consideration of the tradeoffs between decisionmaking related to the management of water resources versus carbon sequestration and GHG fluxes, as well as inland and coastal sediment management and supply.

Sequestration planning.-One approach to evaluating potential mitigation strategies may be a constrained optimization analysis that combines biophysical feasibility with economic, ecosystem-service, political, and other constraints. To develop a constrained optimization approach, research is needed to develop a mechanism that would provide feedback on the interactions between applying the mitigation scenarios (including the evaluation of costs and the impact on ecosystem services) and modeling the future land-use transitions that might affect carbon sequestration and GHG fluxes. Currently there is no feedback between the models and the mitigation scenarios, which means that the effects and effectiveness of mitigation scenarios are not interactively modeled. The oneway flow from mitigation scenarios to LULC transitions and to changes in carbon sequestration and GHG fluxes limits the range of outcomes for decisions. Sequestration planning will be most useful when a constrained optimization framework is adopted and the sensitivity of planning to the constraints is incorporated to achieve the most sequestration per dollar of cost.

Ecosystem services.-Carbon sequestration and GHG mitigation are just two of the many services provided by ecosystems. Additional research is needed in the following broad areas to improve the ability to evaluate the direct and ancillary effects of carbon-management activities and mitigation strategies on the suite of ecosystem services that are relevant to programs in the U.S. Department of the Interior and other agencies:

- Empirical data and models (statistical, mechanical, driver-stressor-response) that quantify how changes in ecosystem structure and processes affect the quality and quantity of ecosystem services

- Effects of spatial and temporal scales on ecosystem service measurements

- Development of a nationally consistent carbon suitability index for implementing prospective management actions, mitigation strategies, and scenario development 
- Integration of socioeconomic, ecological, and naturalscience components for measuring and evaluating ecosystem services including valuation, decisionmaking, stakeholders, ecological endpoints, resilience, and sustainability

- Spatially explicit decision-support tools to simultaneously evaluate ecological tradeoffs of multiple services

Uncertainty.-Consistent methods need to be developed and applied for assessing all major sources of uncertainty. The identification of major factors that contribute to uncertainty in estimates of carbon stocks, carbon sequestration, and GHG fluxes will result from a series of sensitivity analyses. These results will help guide the focus of future monitoring efforts. Documentation of levels of uncertainty must be completed, and recommendations for approaches to reducing uncertainty will be developed, where feasible. A comprehensive review of input data uncertainty (for example, variability in forestinventory data, classification accuracy of land-cover data, and assessment of spatial autocorrelation in input layers) will be conducted to derive distribution functions that can be used in the simulation modeling process. Experiments will be conducted to determine the impact of uncertainty on certain modeling assumptions and decisions (for example, aggregating land-cover categories, choosing the spatial resolution at which modeling is conducted, and comparing results with relevant published literature).

\subsection{Intended Applications}

Given the legislative requirements of the EISA (discussed in chapter 1), the assessment results are intended to assist in the development of carbon- and GHG-mitigation opportunities and strategies, promote understanding of adaptation needs under different climate-change scenarios, and estimate potential ancillary effects of mitigation actions on other ecosystem services, as well as many other activities. Users of the assessment results are likely to include public policymakers and analysts, Federal, State, and local government officials, nongovernmental organizations, individuals and community stakeholders, and the scientific community.

The methodology is designed to conduct an assessment and improve the understanding of the spatiotemporal distribution of GHG fluxes and carbon-sequestration capacities in ecosystems, as well as effects and effectiveness of a range of future potential climate-change and mitigation scenarios. The assessment will provide information regarding the benefits and possible tradeoffs between policies and land-use activities that enhance carbon sequestration and reduce net GHG emissions. To help inform these choices and permit comparison, the assessment will proceed by ecoregion, providing maps, statistics, and tabular data of existing and potential carbon stocks, carbon sequestration capacity, and GHG reduction. Specific applications include the following:

1. Estimation of the economic payoffs of mitigation activities and the impacts to the landscape and other ecosystem services caused by mitigation activities. The datasets and maps will be compatible for analysis by others who employ econometric models and economic sector models for benefit and cost studies of policies and regulations

2. Measurement of ecosystem-service flows in terms of physical and economic production and impacts that reflect physical, economic, and institutional constraints (for example, services provided by protected lands versus potential carbon-sequestration actions in surrounding lands)

3. Monitoring for resource management by landowners, developers, verifiers, and regulators. To track and forecast changing conditions, the methodology uses remote sensing to assess land-area changes at the resolution of 250 $\mathrm{m}$ that can be aggregated first to EPA Level II ecoregions and then to a national scale

4. Identification of potential disturbance regimes (for example, wildfires) and the effects of land-management actions (such as fuel treatments) to help inform decisions about the risks and opportunities of land-management activities related to natural and human hazards

These applications are consistent with other evaluation measurements and decision frameworks used by resource managers to achieve the maximum increase in carbon-sequestration capacity and GHG reduction. The results of the assessment should be a complement to economic policy models already in use by the EPA and the USDA to analyze the impact of policies related to climate change. This assessment does not, however, include macroeconomic policy analysis with the objective to allocate resources among economic sectors, nor will it contain a microeconomic model of individual investment opportunities and behavior. Rather, the assessment will be an estimate of carbon sequestration capacity and mitigation costs in ecosystems, as determined by land cover, land use, land management, and climate projections, but not determined by the influence of the market economy and individual behavioral decisions. 
This page intentionally left blank. 


\section{References Cited}

[Reports that are only available online may require a subscription for access.]

Adams, D.M., Alig, R.J., Callaway, J.M., McCarl, B.A., and Winnett, S.M., 1996, The forest and agricultural sector optimization model (FASOM); Model structure and policy applications: U.S. Department of Agriculture, Forest Service, Pacific Northwest Research Station, Research Paper PNW-RP-495, 60 p.

Agee, J.K., and Skinner, C.N., 2005, Basic principles of forest fuel reduction treatments: Forest Ecology and Management, v. 211, no. 1-2, p. 83-96, doi:10.1016/j.foreco.2005.01.034.

Alcamo, J., Henrichs, T., and Rosch, T., 2000, World water in 2025-Global modeling and scenario analysis for the World Water Commission on water for the 21st century: University of Kassel, Center for Environmental Systems Research Report A0002, 48 p.

Alexander, R.B., Smith, R.A., Schwarz, G.E., Boyer, E.W., Nolan, J.V., and Brakebill, J.W., 2008, Differences in phosphorus and nitrogen delivery to the Gulf of Mexico from the Mississippi River Basin: Environmental Science and Technology, v. 42, no. 3, p. 822-830, doi:10.1021/es0716103.

Alig, R.J., Plantinga, A.J., Ahn, SoEun, and Kline, J.D., 2003, Land use changes involving forestry in the United States; 1952 to 1997 , with projections to 2050: U.S. Department of Agriculture, Forest Service, Pacific Northwest Research Station, General Technical Report PNW-GTR-587, 92 p., accessed June 10, 2010, at http://www.treesearch.fs.fed.us/ pubs/5596.

Allen, L.H., Jr., Baker, J.T. and Boote, K.J., 1996, The $\mathrm{CO}_{2}$ fertilization effect-Higher carbohydrate production and retention as biomass and seed yield, in Bazzaz, Fakhri, and Sombroek, Wim, eds., Global climate change and agricultural production-Direct and indirect effects of changing hydrological, pedological and plant physiological processes: Chichester, United Kingdom, Food and Agriculture Organization of the United Nation and John Wiley and Sons, accessed May 30, 2010, at http://www.fao.org/docrep/ w5183e/w5183e00.HTM.

Armstrong, R.A., Lee, C., Hedges, J.I., Honjo, S., and Wakeham, S.G., 2002, A new, mechanistic model for organic carbon fluxes in the ocean based on the quantitative association of POC with ballast minerals: Deep-Sea Research Part 2-Topical Studies in Oceanography, v. 49, no. 1-3, p. 219-236.

Arnell, N.W., 2003a, Effects of IPCCSRES emissions scenarios on river runoff-A global perspective: Hydrology and Earth System Sciences, v. 7, p. 619-641.
Arnell, N.W., 2003b, Relative effects of multi-decadal climatic variability and changes in the mean and variability of climate due to global warming-Future streamflows in Britain: Journal of Hydrology, v. 270, p. 195-213.

Arnell, N.W., and Reynard, N.S., 1996, The effects of climate change due to global warming on river flows in Great Britain: Journal of Hydrology, v. 183, p. 397-424.

Atkinson, A.J., Trenham, P.C., Fisher, R.N., Hathaway, S.A., Johnson, B.S., Torres, S.G., and Moore, Y.C., 2004, Designing monitoring programs in an adaptive management context for regional multiple species conservation plans: U.S. Geological Survey Technical Report, 69 p.

Australian Government, Department of Climate Change, 2009, Australia's national greenhouse accounts; National greenhouse gas inventory; Accounting for the Kyoto target, May 2009: Australian Government, Department of Climate Change, 24 p., accessed June 10, 2010, at http://www.climatechange.gov.au/climate-change/ /media/ publications/greenhouse-report/national-greenhouse-gasinventory-pdf.ashx.

Baldocchi, Dennis, 2008, "Breathing" of the terrestrial biosphere; Lessons learned from a global network of carbon dioxide flux measurement systems: Australian Journal of Botany, v. 56, p. 1-26, doi:10.1071/bt07151.

Baldocchi, Dennis, Falge, Eva, Gu, Lianhong, Olson, Richard, Hollinger, David, Running, Steve, Anthoni, Peter, Bernhofer, C., Davis, Kenneth, Evans, Robert, Fuentes, Jose, Goldstein, Allen, Katul, Gabriel, Law, Beverly, Lee, Xuhui, Malhi, Yavinder, Meyers, Tilden, Munger, William, Oechel, Walt, Paw U, K.T., Pilegaard, Kim, Schmid, H.P., Valentini, Riccardo, Verma, Shashi, Vesala, Timo, Wilson, Kell, and Wolfsy, Steve, 2001, FLUXNET-A new tool to study the temporal and spatial variability of ecosystem-scale carbon dioxide, water vapor, and energy flux densities: Bulletin of the American Meteorological Society, v. 82, no. 11, p. 2415-2434.

Bange, H.W., 2006, Nitrous oxide and methane in European coastal waters: Estuarine Coastal and Shelf Science, v. 70, no. 3, p. 361-374, doi:10.1016/j.ecss.2006.05.042.

Baron, V.S., Mapfumo, E., Dick, A.C., Naeth, M.A., Okine, E.K., and Chanasyk, D.S., 2002, Grazing intensity impacts on pasture carbon and nitrogen flow: Journal of Range Management, v. 55, no. 6, p. 535-541.

Battin, T.J., Luyssaert, Sebastiaan, Kaplan, L.A., Aufdenkampe, A.K., Richter, Andreas, Tranvik, L.J., 2009, The boundless carbon cycle: Nature Geoscience, v. 2, p. 598-600, doi:10.1038/ngeo618.

Bernknopf, Richard, Gillen, Kevin, Wachter, Susan, and Wein, Anne, in press, A spatial hedonic pricing model: Using econometrics and geographic information systems 
for property valuation, in Linné, M.R., Cirincione, John, and Thompson, M.M., eds., Visual valuation-Practical applications in property analysis and valuation: Ithaca, N.Y., Cornell University Press.

Birdsey, Richard, 2004, Data gaps for monitoring forest carbon in the United States; An inventory perspective: Environmental Management, v. 33, supplement 1, p. S1-S8, doi:10.1007/s00267-003-9113-6.

Birdsey, R.A., and Heath, L.S., 1995, Carbon changes in U.S. forests, in Joyce, L.A., ed., Productivity of America's forests and climate change: U.S. Department of Agriculture, Forest Service, Rocky Mountain Forest and Range Experiment Station, General Technical Report RM-GTR-271, p. 56-70.

Blackard, J.A., Finco, M.V., Helmer, E.H., Holden, G.R., Hoppus, M.L., Jacobs, D.M., Lister, A.J., Moisen, G.G., Nelson, M.D., Riemann, R., Ruefenacht, B., Salajanu, D., Weyermann, D.L., Winterberger, K.C., Brandeis, T.J., Czaplewski, R.L., McRoberts, R.E., Patterson, P.L., and Tymcio, R.P., 2008, Mapping U.S. forest biomass using nationwide forest inventory data and moderate resolution information: Remote Sensing of Environment, v. 112, p. 1658-1677.

Bliss, N.B., 2003, Soil organic carbon on lands of the Department of the Interior: U.S. Geological Survey Open-File Report 2003-304, 52 p., accessed June 22, 2010, at http://egsc.usgs.gov/isb/pubs/openfile/OFR03-304.pdf..

Bliss, N.B., and Maursetter, John, 2010, Soil organic carbon stocks in Alaska estimated with spatial and pedon data: Soil Science Society of America Journal, v. 74, p. 565-579.

Bliss, N.B., Waltman, S.W., and West, L., 2009, Detailed mapping of soil organic carbon stocks in the United States using SSURGO: Eos, v. 90, no. 52, Abstract B51F-0367.

Bond-Lamberty, Ben, and Thomson, Allison, 2010, Temperature-associated increases in the global soil respiration record: Nature, v. 464, p. 579-U132, doi:10.1038/ nature 08930 .

Boose, E.R., Foster, D.R., and Fluet, Marcheterre, 1994, Hurricane impacts to tropical and temperate forest landscapes: Ecological Monographs, v. 64, no. 4, p. 369-400.

Boudreau, B.P., and Ruddick, B.R., 1991, On a reactive continuum representation of organic-matter diagenesis: American Journal of Science, v. 291, p. 507-538.

Boyd, J.W., and Krupnick, A.J., 2009, The definition and choice of environmental commodities for nonmarket valuation: Washington, D.C., Resources for the Future Discussion Paper 09-35, 60 p., accessed June 14, 2010, at http://www.rff.org/Publications/Pages/ PublicationDetails.aspx?PublicationID=20911.
Bridgham, S.D., Megonigal, J.P., Keller, J.K., Bliss, N.B., and Trettin, C., 2006, The carbon balance of North American wetlands: Wetlands, v. 26, p. 889-916.

Brookshire, D., and Chermak, J., 2007, Benefit and informational transfers, in Navrud, Ståle, and Ready, Richard, eds., Environmental value transfer; Issues and methods: Dordrecht, Netherlands, Springer, p. 11-22, doi:10.1007/1-40205405-X_2.

Brookshire, D., Chermak, J., and DeSimone, R., 2007, Uncertainty, benefit transfers and physical models; A middle Rio Grande Valley focus, in Navrud, Ståle, and Ready, Richard, eds., Environmental value transfer; Issues and methods: Dordrecht, The Netherlands, Springer, p. 89-109, doi:10.1007/1-4020-5405-X.

Brookshire, D.S., Goodrich, David, Dixon, M.D., Brand, L.A., Benedict, Karl, Lansey, Kevin, Thacher, Jennifer, Broadbent, C.D., Stewart, Steve, McIntosh, Molly, and Kang, Doosun, 2010, Ecosystem services and reallocation choices: A framework for preserving semi-arid regions in the southwest: Journal of Contemporary Water Research \& Education, v. 144, no. 1, p. 60-74, doi:10.1111/j.1936704X.2010.00075.x.

Brookshire, D., and Neill, H., eds., 1992, Benefit transfers' conceptual and empirical issues: Water Resources Research, v. 28 , no. 3 , p. $651-655$.

Brown, Sandra, and Kadyszewski, John, 2005, Carbon supply for the pilot region-Arkansas, Louisiana, and Mississippi: Arlington, Va., Winrock International, $71 \mathrm{p}$.

Bruce, J.P., Frome, Michele, Haites, Eric, Janzen, Henry, Lal, Rattan, and Paustian, Keith, 1999, Carbon sequestration in soils: Journal of Soil and Water Conservation, v. 54, p. 382-389.

Camill, Peter, 2005, Permafrost thaw accelerates in boreal peatlands during late-20th century climate warming: Climatic Change, v. 68, p. 135-152.

Campbell, J., Donato, D., Azuma, D., and Law, B., 2007, Pyrogenic carbon emission from a large wildfire in Oregon, United States: Journal of Geophysical Research-Biogeosciences, v. 112, no. G4, p. 11.

Canadell, J.G., Le Quéré, Corinne, Raupach, M.R., Field, C.B., Buitenhuis, E.T., Ciais, Philippe, Conway, T.J., Gillett, N.P., Houghton, R.A., and Marland, Gregg, 2007, Contributions to accelerating atmospheric $\mathrm{CO}_{2}$ growth from economic activity, carbon intensity, and efficiency of natural sinks: Proceedings of the National Academy of Sciences, v. 104 , no. 47 , p. $18,866-18,870$, doi:10.1073/ pnas. 0702737104 . 
Canadell, J.G., and Raupach, M.R., 2008, Managing forests for climate change mitigation: Science, v. 320, n. 5882, p. 1456-1457, doi:10.1126/science.1155458.

Cao, Mingkui, Dent, J.B., and Heal, O.W., 1995, Methane emissions from China's paddyland: Agriculture, Ecosystems \& Environment, v. 55, p. 129-137.

Cao, Mingkui, Marshall, Stewart, and Gregson, Keith, 1996, Global carbon exchange and methane emissions from natural wetlands; Application of a process-based model: Journal of Geophysical Research, v. 101, no. D9, p. 14399-14414.

Carpenter, S.R., Pingali, P.L., Bennett, E.M., and Zurek, M.B., eds., Millennium Ecosystem Assessment; Ecosystems and human well-being; Scenarios, volume 2: Washington, D.C, Island Press, $17 \mathrm{p}$.

Causarano, H.J., Franzluebbers, A.J., Reeves, D.W., and Shaw, J.N., 2006, Soil organic carbon sequestration in cotton production systems of the Southeastern United States-A review: Journal of Environmental Quality, v. 35, p. 13741383.

Chapin, F.S., III, Trainor, S.F., Huntington, Orville, Lovecraft, A.L., Zavaleta, Erika, Natcher, D.C., McGuire, A.D., Nelson, J.L., Ray, Lily, Calef, Monika, Fresco, N.L., Huntington, Henry, Rupp, T.S., DeWilde, La'ona, and Naylor, R.L., 2008, Increasing wildfire in the boreal forest; Causes, consequences, and pathways to potential solutions of a wicked problem: BioScience, v. 58, no. 6, p. 531-540.

Chapin, F.S., Woodwell, G.M., Randerson, J.T., Rastetter, E.B., Lovett, G.M., Baldocchi, D.D., Clark, D.A., Harmon, M.E., Schimel, D.S., Valentini, R., Wirth, C., Aber, J.D., Cole, J.J., Goulden, M.L., Harden, J.W., Heimann, M., Howarth, R.W., Matson, P.A., McGuire, A.D., Melillo, J.M., Mooney, H.A., Neff, J.C., Houghton, R.A., Pace, M.L., Ryan, M.G., Running, S.W., Sala, O.E., Schlesinger, W.H., and Schulze, E.D., 2006, Reconciling carbon-cycle concepts, terminology, and methods: Ecosystems, v. 9, p. 1041-1050, doi:10.1007/s10021-005-0105-7.

Chen, M., Liu, S., and Tieszen, L., 2006, State-parameter estimation of ecosystem models using a Smoothed Ensemble Kalman Filter, in Voinov, A., Jakeman, A.J., and Rizzoli, A.E., eds., Proceedings of the iEMSs third biennial meeting-Summit on environmental modeling and software: Burlington, Vt., International Environmental Modelling and Software Society, 7 p. on one CD-ROM., accessed June 18, 2010, at http:/www.iemss.org/iemss2006/papers/ w16/334_Chen_1.pdf.

Chen, M., Liu, S., Tieszen, L.L., and Hollinger, D.Y., 2008, An improved state-parameter analysis of ecosystem models using data assimilation: Ecological Modelling, v. 219, no. 3-4, p. 317-326, accessed June 14, 2010, at http://dx.doi.org/10.1016/j.ecolmodel.2008.07.013.
Ciais, P., Wattenbach, M., Vuichard, N., Smith, P., Piao, S.L., Don, A., Luyssaert, S., Janssens, I.A., Bondeau, A., Dechow, R., Leip, A., Smith, P.C., Beer, C., Van der Werf, G.R., Gervois, S., Van Oost, K., Tomelleri, E., Freibauer, A., Schulze, E.D., and Carboeurope Synthesis Team, 2010, The European carbon balance. Part 2, Croplands: Global Change Biology, v. 16, p. 1409-1428, doi:10.1111/j.13652486.2009.02055.x.

Cleland, D.T., Crow, T.R., Saunders, S.C., Dickmann, D.I., Maclean, A.L., Jordan, J.K., Watson, R.L., Sloan, A.M., and Brosofske, K.D., 2004, Characterizing historical and modern fire regimes in Michigan (USA) - A landscape ecosystem approach: Landscape Ecology, v. 19, no. 3, p. 311-325.

Cole, J.J., Prairie, Y.T., Caraco, N.F., McDowell, W.H., Tranvik, L.J., Striegl, R., Duarte, C.M., Kortelainen, P., Downing, J.A., Middleburg, J.J., and Melack, J.M., 2007, Plumbing the global carbon cycle; Integrating inland waters into the terrestrial carbon budget: Ecosystems, v. 10, p. 171-184, doi:10.1007/s10021-006-9013-8.

Committee on Assessing and Valuing the Services of Aquatic and Related Terrestrial Ecosystems and National Research Council, 2005, Valuing ecosystem services-Toward better environmental decision-making: Washington, D.C., The National Academies Press, 278 p.

Conrad, R., 1989, Control of methane production in terrestrial ecosystems, in Andreae, M.O., and Schimel, D.S., eds., Exchange of trace gases between terrestrial ecosystems and the atmosphere: New York, John Wiley and Sons.

Cosgrove, W.J., and Rijsberman, F.R., 2000, World water vision-Making water everybody's business: London, Earthscan Publications, Ltd., 108 p.

Costanza, Robert, Fisher, Brendan, Mulder, Kenneth, Liu, Shuang, and Christopher, Treg, 2007, Biodiversity and ecosystem services - A multi-scale empirical study of the relationship between species richness and net primary production: Ecological Economics, v. 61, p. 478-491.

Council of Economic Advisers, 2008, Economic report of the President, transmitted to the [U.S.] Congress February 2008, together with the annual report of the Council of Economic Advisers: Washington, D.C., Council of Economic Advisers, 354 p., accessed June 24, 2010, at http://fraser.stlouisfed.org/publications/ERP/issue/3056/ download/48677/ERP_2008.pdf.

Cowardin, L.M., Carter, Virginia, Golet, F.C., and LaRoe, E.T., 1979, Classification of wetlands and deepwater habitats of the United States: U.S. Fish and Wildlife Service FWS/OBS-79-31, 131 p., accessed June 14, 2010, at http://www.fws.gov/wetlands/_documents/ gNSDI/ClassificationWetlandsDeepwaterHabitatsUS.pdf. (Reprinted 1992.) 
Creyts, Jon, Derkach, Anton, Nyquist, Scott, Ostrowski, Ken, and Stephenson, Jack, 2007, Reducing U.S. greenhouse gas emissions- How much at what cost?: McKinsey and Company, U.S. Greenhouse Gas Abatement Mapping Initiative Executive Report, December, 83 p., accessed April 7, 2010, at http://www.mckinsey.com/clientservice/ccsi/pdf/ US_ghg_final_report.pdf.

da Cunha, L.C., Buitenhuis, E.T., Le Quéré, Corinne, Giraud, Xavier, and Ludwig, Wolfgang, 2007, Potential impact of changes in river nutrient supply on global ocean biogeochemistry: Global Biogeochemical Cycles, v. 21, GB4007, doi:10.1029/2006GB002718.

Dagg, M., Benner, R., Lohrenz, S., and Lawrence, D., 2004, Transformation of dissolved and particulate materials on continental shelves influenced by large rivers; Plume processes: Continental Shelf Research, v. 24, p. 833-858.

Daily, G.C., 1997, The potential impacts of global warming on managed and natural ecosystem: Implications for human well-being [abs.]: Papers of the American Chemical Society, v. 213, p. 12-ENVR.

Daily, G.C., and Matson, P.A., 2008, Ecosystem servicesFrom theory to implementation: Proceedings of the National Academy of Sciences, v. 105 , no. 28, p. 9455-9456, doi:10.1073/pnas.0804960105.

Del Grosso, S.J., Mosier, A.R., Parton, W.J., and Ojima, D.S., 2005, Daycent model analysis of past and contemporary soil $\mathrm{N}_{2} \mathrm{O}$ and net greenhouse gas flux for major crops in the USA: Soil and Tillage Research, v. 83, p. 9-24.

Dentener, F., Drevet, J., Lamarque, J.F., Bey, I., Eickhout, B., Fiore, A.M., Hauglustaine, D., Horowitz, L.W., Krol, M., Kulshrestha, U.C., Lawrence, M., Galy-Lacaux, C., Rast, S., Shindell, D., Stevenson, D., Van Noije, T., Atherton, C., Bell, N., Bergman, D., Butler, T., Cofala, J., Collins, B., Doherty, R., Ellingsen, K., Galloway, J., Gauss, M., Montanaro, V., Müller, J.F., Pitari, G., Rodriguez, J., Sanderson, M., Solmon, F., Strahan, S., Schultz, M., Sudo, K., Szopa, S., and Wild, O., 2006, Nitrogen and sulfur deposition on regional and global scales; A multimodel evaluation: Global Biogeochemical Cycles, v. 20, GB4003, doi:10.1029/2005GB002672.

Devosouges, W.H., Johnson, F.R., and Banzhaf, H.S., 1998, Environmental policy analysis with limited informationPrinciples and applications of the transfer method: Cheltenham, U.K., American International Distribution Corporation.

de Vries, W., 2009, Assessment of the relative importance of nitrogen deposition and climate change on the sequestration of carbon by forests in Europe-An overview: Forest Ecology and Management, v. 258, p. VII-X, doi:10.1016/ s0378-1127(09)00590-8.
Diaz-Nieto, Jacqueline, and Wilby, R.L., 2005, A comparison of statistical downscaling and climate change factor methods-Impacts on low flows in the River Thames, United Kingdom: Climatic Change, v. 69, p. 245-268, doi:10.1007/ s10584-005-1157-6.

Dillon, G.K., Knight, D.H., and Meyer, C.B., 2005, Historic range of variability for upland vegetation in the Medicine Box National Forest, Wyoming: U.S. Department of Agriculture, U.S. Forest Service, Rocky Mountain Research Station, RMRS-GTR-139, 96 p.

Downing, J.A., Prairie, Y.T., Cole, J.J., Duarte, C.M., Tranvik, L.J., Striegl, R.G., McDowell, W.H., Kortelainen, P., Caraco, N.F., Melack, J.M., and Middleburg, J.J., 2006, The global abundance and size distribution of lakes, ponds, and impoundments: Limnology and Oceanography, v. 51, no. 5, p. 2388-2397.

Drummond, M.A., 2007, Regional dynamics of the grassland change in the western Great Plains: Great Plains Research, v. 17 , p. $133-144$.

Drummond, M.A., and Loveland, T.R., 2010, Land-use pressure and a transition to forest-cover loss in the Eastern United States: BioScience, v. 60, p. 286-298.

Dunne, J.P., Armstrong, R.A., Gnanadesikan, Anand, and Sarmiento, J.L., 2005, Empirical and mechanistic models for the particle export ratio: Global Biogeochemical Cycles, v. 19, no. 4. GB4026, doi:10.1029/2004GB002390.

Dwyer, J.F., Novak, D.J., Noble, M.H., and Sisinni, S.M., 2000 , Connecting people with ecosystems in the 21st century; An assessment of our Nation's urban forests: U.S. Department of Agriculture, Forest Service, Pacific Northwest Research Station, General Technical Report PNW-GTR-490, 483 p., accessed June 14, 2010, at http://www.treesearch.fs.fed.us/pubs/12517.

Eckhardt, K., and Ulbrich, U., 2003, Potential impacts of climate change on groundwater recharge and streamflow in a central European low mountain range: Journal of Hydrology, v. 284, p. 244-252.

Eidenshink, J., Schwind, B., Brewer, K., Zhu, Z., Quayle, B., and Howard, S., 2007, A project for monitoring trends in burn severity: Fire Ecology, v. 3, no. 1, p. 3-20.

Einsele, Gerhard, Yan, Jianping, and Hinderer, Matthias, 2001, Atmospheric carbon burial in modern lake basins and its significance for the global carbon budget: Global and Planetary Change, v. 30, p. 167-196.

Elith, Jane, Graham, C.H., Anderson, R.P., Dudik, Miroslav, Ferrier, Simon, Guisan, Antoine, Hijmans, R.J., Huettmann, Falk, Leathwick, J.R., Lehmann, Anthony, Li, Jin, Lohmann, L.G., Loiselle, B.A., Manion, Glenn, Moritz, Craig, Nakamura, Miguel, Nakazawa, Yoshinori, Overton, J.M., 
Peterson, A.T., Phillips, S.J., Richardson, Karen, ScachettiPereira, Ricardo, Schapire, R.E., Soberon, Jorge, Williams, Stephen, Wisz, M.S., and Zimmermann, N.E., 2006, Novel methods improve prediction of species' distributions from occurrence data: Ecography, v. 29, no. 2, p. 129-151.

Elith, Jane, and Leathwick, J.R., 2009, Species distribution models - Ecological explanation and prediction across space and time: Annual Review of Ecology, Evolution, and Systematics, v. 40, p. 677-697.

Elmore, A.J., and Asner, G.P., 2006, Effects of grazing intensity on soil carbon stocks following deforestation of a Hawaiian dry tropical forest: Global Change Biology, v. 12, no. 9, p. 1761-1772.

Elser, J.J., Bracken, M.E.S., Cleland, E.E., Gruner, D.S., Harpole, W.S., Hillebrand, Helmut, Ngai, J.T., Seabloom, E.W., Shurin, J.B., and Smith, J.E., 2007, Global analysis of nitrogen and phophorus limitation of primary producers in freshwater, marine and terrestrial ecosystems: Ecology Letters, v. 10, no. 12, p. 1135-1142, doi:10.1111/j.14610248.2007.01113.x.

Eswaran, H., van den Berg, E., and Reich, P., 1993, Organic carbon in oils of the world: Soil Science Society of America Journal, v. 57, p. 192-194.Euskirchen, E.S., McGuire, A.D., Kicklighter, D.W., Zhuang, Q., Clein, J.S., Dargaville, R.J., Dye, D.G., Kimball, J.S., McDonald, K.C., Melillo, J.M., Romanovsky, V.E., and Smith, N.V., 2006, Importance of recent shifts in soil thermal dynamics on growing season length, productivity, and carbon sequestration in terrestrial high-latitude ecosystems: Global Change Biology, v. 12, p. 731-750.

Evensen, Geir, 1994, Sequential data assimilation with a nonlinear quasi-geostrophic model using Monte Carlo methods to forecast error statistics: Journal of Geophysical Research, v. 99, no. C5, p. 10,143-10,162, doi:10.1029/94JC00572.

Evensen, Geir, 2003, The ensemble Kalman filter-Theoretical formulation and practical implementation: Ocean Dynamics, v. 53, no. 4, p. 343-367, doi:10.1007/s10236003-0036-9.

Falk, D.A., Miller, Carol, McKenzie, Donald, and Black, A.E., 2007, Cross-scale analysis of fire regimes: Ecosystems, v. 10 , p. $810-823$.

Faulkner, S.P., 2004, Soils and sediment; Understanding wetland biogeochemistry, in Spray, S.L., and McGlothlin, K.L., eds., Wetlands: Lanham, Md., Rowman and Littlefield Publishers, Inc., p. 30-54.

Finney, M.A., 2002, Fire growth using minimum travel time methods: Canadian Journal of Forest Research, v. 32, no. 8, p. 1420-1424.
Fisher, Brendan, Turner, Kerry, Zylstra, Matthew, Brouwer, Roy, de Groot, Rudolf, Farber, Stephen, Ferraro, Paul, Green, Rhys, Hadley, David, Harlow, Julian, Jefferiss, Paul, Kirkby, Chris, Morling, Paul, Mowatt, Shaun, Naidoo, Robin, Paavola, Jouni, Strassburg, Bernardo, Yu, Doug, and Balmford, Andrew, 2008, Ecosystem services and economic theory; Integration for policy-relevant research: Ecological Applications, v. 18, no. 8, p. 2050-2067.

Foley, J.A., Prentice, I.C., Ramankutty, Navin, Levis, Samuel, Pollard, David, Sitch, Steven, and Haxeltine, Alex, 1996, An integrated biosphere model of land surface process, terrestrial carbon balance, and vegetation dynamics: Global Biogeochemical Cycles, v. 10, no. 4, p. 603-628.

Follett, R.F., 2010, Symposium-Soil carbon sequestration and greenhouse gas mitigation: Soil Science Society of America Journal, v. 74, p. 345-346, doi:10.2136/sssaj2009. cseqghgsymp.intro.

Galloway, J.N., Dentender, F.J., Capone, D.G., Boyer, E.W., Howarth, R.W., Seitzinger, S.P., Asner, G.P., Cleaveland, C.C., Green, P.A., Holland, E.A., Karl, D.M., Michael, A.F., Porter, J.H., Townsend, A.R., and Vorosmarty, C.J., 2004, Nitrogen cycles; Past present, and future: Biogeochemistry, v. 70, p. 153-226.

Gibbs, H.K., Brown, Sandra, Niles, J.O., and Foley, J.A., 2007, Monitoring and estimating tropical forest carbon stocks-Making REDD a reality: Environmental Research Letters 2, 045023, doi:10.1088/1748-9326/2/4/045023.

Global Carbon Project, 2009, Carbon budget and trends 2008: Global Carbon Project, available at http://www.globalcarbonproject.org/.

Goodale, C.L., Apps, M.J., Birdsey, R.A., Field, C.B., Heath, L.S., Houghton, R.A., Jenkins, J.C., Kohlmaier, G.H., Kurz, W., Liu, S.R., Nabuurs, G.J., Nilsson, S., and Shvidenko, A.Z., 2002, Forest carbon sinks in the Northern Hemisphere: Ecological Applications, v. 12, p. 891-899.

Grissino-Mayer, H.D., Romme, W.H., Floyd, M.L., and Hanna, D.D., 2004, Climatic and human influences on fire regimes of the southern San Juan Mountains, Colorado, USA: Ecology, v. 85, no. 6, p. 1708-1724.

Hales B., Takahashi, T., and Bandstra, L., 2005, Atmospheric $\mathrm{CO}_{2}$ uptake by a coastal upwelling system: Global Biogeochemical Cycles, v. 19, GB1009, doi:10.1029/2004GB002295.

Hamilton, R.B., Barrow, W.C., Jr., and Ouchley, K., 2005, Old-growth bottomland hardwood forests as bird habitat, implications for contemporary forest management, in Fredrickson, L.H., and others, eds., Ecology and management of bottomland hardwood systems - The state of our understanding: Puxico, Mo., University of Missouri-Columbia, Gaylord Memorial Laboratory Special Publication 10, p. 373-388. 
Hanemann, W.M., Loomis, John, and Kanninen, Barbara, 1991, Statistical efficiency of double-bounded dichotomous choice contingent valuation: American Journal of Agricultural Economics, v. 73, p. 1255-1263.

Hansen, M.C., DeFries, R.S., Townshend, J.R.G., Carroll, M., Dimiceli, C., and Sohlberg, R.A., 2003, Global percent tree cover at a spatial resolution of 500 meters-first results of the MODIS vegetation continuous fields algorithm: Earth Interactions, v. 7, p. 1-15.

Harmon, M.E., Moreno, A., and Domingo, J.B., 2009, Effects of partial harvest on the carbon stores in douglas-fir/western hemlock forests; A simulation study: Ecosystems, v. 12, no. 5 , p. 777.

Hay, J.E., and Sem, Graham, 2000, Vulnerability and adaptation-Evaluation and regional synthesis of national assessments of vulnerability and adaptation to climate change: South Pacific Regional Environment Programme, 28 p.

Hay, L.E., Wilby, R.L., and Leavesley, G.H., 2000, A comparison of delta change and downscaled GCM scenarios for three mountainous basins in the United States: Journal of American Water Resources, v. 36, p. 2.

Heath, L.S., and Smith, J.E., 2000, An assessment of uncertainty in forest carbon budget projections: Environmental Science and Policy, v. 3, no. 2-3, p. 73-82, doi:10.1016/ S1462-9011(00)00075-7.

Hedges, J.I., and Keil, R.G., 1995, Sedimentary organic-matter preservation-An assessment and speculative synthesis: Marine Chemistry, v. 49, p. 81-115.

Hénault, C., Bizouard, F., Laville, P., Gabrielle, B., Nicoullaud, B., Germon, J.C., and Cellier, P., 2005, Predicting in situ soil $\mathrm{N}_{2} \mathrm{O}$ emission using $\mathrm{NOE}$ algorithm and soil database: Global Change Biology, v. 11, no. 1, p. 115-127, doi:10.1111/j.1365-2486.2004.00879.x.

Hicke, J.A., Asner, G.P., Kasischke, E.S., French, N.H.F., Randerson, J.T., Collatz, G.J., Stocks, B.J., Tucker, C.J., Los, S.O., and Field, C.B., 2003, Postfire response of North American boreal forest net primary productivity analyzed with satellite observations: Global Change Biology, v. 9, no. 8 , p. $1145-1157$.

Hirota, Mitsuru, Senga, Yukiko, Seike, Yasushi, Nohara, Seiishi, and Kunii, Hidenobu, 2007, Fluxes of carbon dioxide, methane and nitrous oxide in two contrastive fringing zones of coastal lagoon, Lake Nakaumi, Japan: Chemosphere, v. 68 , no. 3, p. 597-603.

Homer, Collin, Huang, Chengquan, Yang, Limin, Wylie, Bruce, and Coan, Michael, 2004, Development of a 2001 national land-cover database for the United States: Photogrammetric Engineering and Remote Sensing, v. 70, no. 7 , p. 829-840.
Hooper, D.U., Chapin, F.S., Ewel, J.J., Hector, A., Inchausti, P., Lavorel, S., Lawton, J.H., Lodge, D.M., Loreau, M., Naeem, S., Schmid, B., Setala, H., Symstad, A.J., Vandermeer, J., and Wardle, D.A., 2005, Effects of biodiversity on ecosystem functioning - A consensus of current knowledge: Ecological Monographs, v. 75, p. 3-35.

Houghton, R.A., and Hackler, J.L., 2000, Changes in terrestrial carbon storage in the United States. 1. The roles of agriculture and forestry: Global Ecology and Biogeography, v. 9, p. 125-144.

Houghton, R.A., Hackler, J.L., and Lawrence, K.T., 1999, The U.S. carbon budget - Contributions from land-use change: Science, v. 285, p. 574-578.

Huang, Chengquan, Goward, S.N., Masek, J.G., Thomas, Nancy, Zhu, Zhiliang, and Vogelmann, J.E., 2010, An automated approach for reconstructing recent forest disturbance history using dense Landsat time series stacks: Remote Sensing of Environment, v. 114, p. 183-198.

Huang, Chengquan, Yang, Limin, Wylie, Bruce, and Homer, Collin, 2001, A strategy for estimating tree canopy density using LANDSAT 7 ETM+ and high resolution images over large areas: International Conference on Geospatial Information in Agriculture and Forestry, 3d, Denver, Colo., November 5-7, 2001, Proceedings, on one CD-ROM, accessed June 22, 2010, at http://permanent.access.gpo.gov/ lps11930/landcover.usgs.gov/pdf/canopy_density.pdf.

Huang, C.-H., Bates, Richard, Kronrad, G.D., and Cheng, Shiaolin, 2004, Economic analyses of sequestering carbon in loblolly pine, cherrybark oak, and northern red oak in the United States: Environmental Management, v. 33, supplement 1, p. S187-S199.

Hudiburg, T., Law, B., Turner, D.P., Campbell, J., Donato, D., and Duane, M., 2009, Carbon dynamics of Oregon and northern California forests and potential land-based carbon storage: Ecological Applications, v. 19, p. 163-180.

Hurteau, Matthew, and North, Malcolm, 2009, Fuel treatment effects on tree-based forest carbon storage and emissions under modeled wildfire scenarios: Frontiers in Ecology and the Environment, v. 7, no. 8, p. 409-414.

Intergovernmental Panel on Climate Change, 1990, Climate change [-First assessment report (FAR) of the IPCC]: Cambridge, UK, Cambridge University Press, overview and $3 \mathrm{v}$. (Climate change; The IPCC scientific assessment, by Working Group I; Climate change; The IPCC impacts assessment, by Working Group II; Climate change; The IPCC response strategies, by Working Group III), accessed June 14, 2010, at http://www.ipcc.ch/publications_and_data/ publications_and_data_reports.htm.

Intergovernmental Panel on Climate Change, 1996, Climate change 1995 [ - Second assessment report (SAR) of the 
IPCC]: Cambridge, UK, Cambridge University Press, synthesis and $3 \mathrm{v}$. (The science of climate change, by Working Group I; Impacts, adaptations and mitigation of climate change, by Working Group II; Economic and social dimensions of climate change, by Working Group III), accessed June 14, 2010, at http://www.ipcc.ch/publications_and_data/ publications_and_data_reports.htm.

Intergovernmental Panel on Climate Change, 2001, Climate change 2001 [-Third assessment report (TAR) of the IPCC]: Cambridge, UK, Cambridge University Press, synthesis report and $3 \mathrm{v}$. (The scientific basis, by Working Group I; Impacts, adaptation, and vulnerability, by Working Group II; Mitigation, by Working Group III), accessed June 14, 2010, at www.ipcc.ch/publications_and_data/ publications_and_data_reports.htm.

Intergovernmental Panel on Climate Change, 2006, 2006 IPCC guidelines for national greenhouse gas inventories. (Prepared by the IPCC National Greenhouse Gas Inventories Programme; edited by H.S. Eggleston, L. Buendia, K. Miwa, T. Ngara, and K. Tanabe): Hayama, Kanagawa, Japan, Institute for Global Environmental Strategies, $5 \mathrm{v}$., accessed June 14, 2010, at http://www.ipcc-nggip.iges.or.jp/ public/2006gl/index.html.

Intergovernmental Panel on Climate Change, 2007, Climate change 2007 [-Fourth assessment report (AR4) of the IPCC]: Cambridge, UK, Cambridge University Press, The AR4 synthesis report and $3 \mathrm{v}$. (The physical science basis, by Working Group I; Impacts, adaptation, and vulnerability, by Working Group II; Mitigation of climate change, by Working Group III), accessed June 14, 2010, at http://www. ipcc.ch/publications_and_data/publications_and_data reports.htm.)

Jaworski, N.A., Howarth, R.W., and Hetling, L.I., 1997, Atmospheric deposition of nitrogen oxides onto the landscape contributes to coastal eutrophication in the northeast United States: Environmental Science \& Technology, v. 31, p. 1995-2004.

Jenkins, W.A., Murray, B.C., Kramer, R.A., and Faulkner, S.P., 2010, Valuing ecosystem services from wetlands restoration in the Mississippi Alluvial Valley: Ecological Economics, v. 69, no. 5, p. 1051-1061, doi:10.1016/j.ecolecon.2009.11.022.

Johansson, Robert, Peters, Mark, and House, Robert, 2007, Regional environment and agriculture programming model: U.S. Department of Agriculture Economic Research Service Technical Bulletin 1816, 111 p., available at http://www.ers.usda.gov/publications/tb1916/tb1916fm.pdf.

Johnson, E.A., and Miyanishi, Kiyoko, eds., 2001, Forest fires-Behaviour and ecological effects: San Diego, Calif., Academic Press, 594 p.
Johnson, Kristofer, and Harden, Jennifer, 2009, An Alaskan soil carbon database: Eos, v. 90, no. 21, p. 184.

Joyce, L.A., 1989, An analysis of the range forage situation in the United States - 1989-2040: U.S. Department of Agriculture, Forest Service, Rocky Mountain Forest and Range Experiment Station, General Technical Report RM-180, p. 84 .

Joyce, L.A., ed., 1995, Productivity of America's forests and climate change: U.S. Department of Agriculture, Forest Service, Rocky Mountain Forest and Range Experiment Station, General Technical Report RM-GTR-271, 70 p.

Joyce, L.A., and Birdsey, Richard, tech. eds., 2000, The impact of climate change on America's forests; A technical document supporting the 2000 USDA Forest Service RPA assessment: U.S. Department of Agriculture, Forest Service, Rocky Mountain Research Station General Technical Report RMRS-GTR-59, 134 p., accessed June 14, 2010, at http://www.fs.fed.us/rm/pubs/rmrs_gtr059.html.)

Keane, R.E., Cary, G.J., Davies, I.D., Flannigan, M.D., Gardner, R.H., Lavorel, Sandra, Lenihan, J.M., Li, Chao, and Rupp, T.S., 2004, A classification of landscape fire succession models - Spatial simulations of fire and vegetation dynamics: Ecological Modelling, v. 179, no. 1, p. 3-27.

Keane, R.E., Rollins, M., and Zhu, 2007, Using simulated historical time series to prioritize fuel treatments on landcapes across the United States; the LANDFIRE prototype project: Ecological Modeling, v. 204, no. 3-4, p. 485-502.

Khalil, S.M., and Finkl, C.W., 2009, Regional sediment management strategies for coastal restoration in Louisiana, USA: Journal of Coastal Research, special issue 56, p. $1320-1324$.

Khan, I.A., and Spalding, R.F., 2003, Development of a procedure for sustainable in situ aquifer denitrification; Remediation: Journal of Environmental Cleanup Costs, Technologies, and Techniques, v. 13, no. 2, p. 53-69.

Kim, M.K., and McCarl, B.A., 2009, Uncertainty discounting for land-based carbon sequestration: Journal of Agricultural and Applied Economics, v. 41, no. 1, p. 1-11.

Kuchler, A.W., 1964, Potential natural vegetation of the conterminous United States: New York, American Geographical Society Special Publication 36, 116 p.

Lal, Rattan, Follett, Richard, Stewart, B.A., and Kimble, J.M., 2007, Soil carbon sequestration to mitigate climate change and advance food security: Soil Science, v. 172, p. 943-956, doi:10.1097/ss.0b013e31815cc498.

Lal, Rattan, Griffin, Michael, Apt, Jay, Lave, Lester, and Morgan, M.G., 2004, Managing soil carbon: Science, v. 304, no. 5669 , p. 393. 
Langner, L.L., and Flather, C.H., 1994, Biological diversity; Status and trends in the United States: U.S. Department of Agriculture, Forest Service, Rocky Mountain Forest and Range Experiment Station General Technical Report RMGTR-244, 24 p.

Larsen, John, 2009, Net emission reductions under cap-andtrade proposals in the 111th Congress, 2005-1050: Washington, D.C., World Resources Institute, accessed March 23, 2010, at http://www.wri.org/publication/usclimatetargets.

Latham, D.J., and Rothermel, R.C., 1993, Probability of fire-stopping precipitation events: U.S. Department of Agriculture, Forest Service, Intermountain Research Station Research Note INT-RN-410, 8 p.

Lawrence, D.M., and Slater, A.G., 2005, A projection of sever near-surface permafrost degradation during the 21 st century: Geophysical Research Letters, v. 32, p. 5, doi:10.1029/2005GL025080.

Le Quéré, Corinne, Raupach, M.R., Canadell, J.G., Marland, Gregg, Bopp, Laurent, Ciais, Philippe, Conway, T.J., Doney, S.C., Feely, R.A., Foster, Pru, Friedlingstein, Pierre, Gurney, Kevin, Houghton, R.A., House, J.I., Huntingford, Chris, Levy, P.E., Lomas, M.R., Majkut, Joseph, Metzl, Nicolas, Ometto, J.P., Peters, G.P., Prentice, I.C., Randerson, J.T., Running, S.W., Sarmiento, J.L., Schuster, Ute, Sitch, Stephen, Takahashi, Taro, Viovy, Nicolas, van der Werf, G.R., and Woodward, F.I., 2009, Trends in the sources and sinks of carbon dioxide: Nature Geoscience, v. 2, p. 831-836, doi:10.1038/ngeo689.

Lewandrowski, Jan, Peters, Mark, Jones, Carol, House, Robert, Sperow, Mark, Eve, Marlen, and Paustian Keith, 2004, Economics of sequestering carbon in the U.S. agricultural sector: U.S. Department of Agriculture, Economic Research Service Technical Bulletin TB-1909, 69 p., accessed June 14, 2010, at http://www.ers.usda.gov/Publications/TB1909/.

Li, Changsheng, Frolking, steve, and Frolking, T.A., 1992, A model of nitrous oxide evolution from soil driven by rainfall events-1. Model structure and sensitivity: Journal of Geophysical Research, v. 97, p. 9759-9776.

Lindau, C.W., Patrick, W.H., Jr., DeLaune, R.D., and Reddy, K.R., 1990, Rate of accumulation and emission of $\mathrm{N}_{2}, \mathrm{~N}_{2} \mathrm{O}$, and $\mathrm{CH}_{4}$ from flooded rice soil: Plant and Soil, v. 129, p. 269-276.Liu, Jinxun, Liu, Shuguang, and Loveland, T.R., 2006, Temporal evolution of carbon budgets of the Appalachian forests in the U.S. from 1972 to 2000: Forest Ecology and Management, v. 222, no. 1-3, p. 191-201, doi:10.1016/j.foreco.2005.09.028.

Liu, Jinxun, Liu, Shuguang, Loveland, T.R., and Tieszen, L.L., 2008, Integrating remotely sensed land cover observations and a biogeochemical model for estimating forest ecosystem carbon dynamics: Ecological Modelling, v. 219, p. 361-372.
Liu, S., Kaire, M., Wood, E., Diallo, O., and Tieszen, L.L., 2004, Impacts of land use and climate change on carbon dynamics in south-central Senegal: Journal of Arid Environments, v. 59, p. 583-604.

Liu, S., Liu, J., Li, Z., Loveland, T.R., and Tieszen, L.L., 2006, Upscaling terrestrial carbon dynamics from sites to regions with uncertainty measures; The GEMS experience, in Proceedings of the International Environmental Modelling and Software Society 3rd Biennial Meeting, Burlington,Vt., July 9-12, 2006.

Liu, Shuguang, 2009, Quantifying the spatial details of carbon sequestration potential and performance, in McPherson, B.J., and Sundquist, E.T., eds., Carbon sequestration and its role in the global carbon cycle: American Geophysical Union, Geophysical Monograph Series, v. 183.

Liu, Shuguang, Anderson, Pamela, Zhou, Guoyi, Kauffman, Boone, Hughes, Flint, Schimel, David, Watson, Vicente, and Tosi, Joseph, 2008, Resolving model parameter values from carbon and nitrogen stock measurements in a wide range of tropical mature forests using nonlinear inversion and regression trees: Ecological Modelling, v. 219, no. 3-4, p. $327-341$.

Liu, Shuguang, Bliss, Norman, Sundquist, Eric, and Huntington, T.G., 2003, Modeling carbon dynamics in vegetation and soil under the impacts of soil erosion and deposition: Global Biogeochemical Cycles, v. 17, no. 2, p. 1074, doi:10.1029/2002GB002010.

Liu, Shuguang, Loveland, T.R., and Kurtz, R.M., 2004, Contemporary carbon dynamics in terrestrial ecosystems in the southeastern plains of the United States: Environmental Management, v. 33, Supplement 1, p. S442-S456, doi:10.1007/s00267-003-9152-z.

Liu, Shuguang, Reiners, W.A., Keller, Michael, and Schimel, D.S., 1999, Model simulation of changes in $\mathrm{N}_{2} \mathrm{O}$ and $\mathrm{NO}$ emissions with conversion of tropical rain forests to pastures in the Costa Rican Atlantic zone: Global Biogeochemical Cycles, v. 13, p. 663-677.

Loomis, John, and Helfand, Gloria, 2001, Environmental policy analysis for decision making: Dordrecht, Netherlands, Kluwer Academic Publishers, 348 p.

Louisiana Department of Agriculture and Forestry, 2010, Timber stumpage values - Calendar year 2009: Louisiana Department of Agriculture and Forestry, accessed June 22, 2010, at http://www.ldaf.state.la.us/portal/Portals/0/FOR/ Reports/Timber\%20severance/sevtaxval09.pdf.

Loveland, T.R., and DeFries, R.S., 2004, Observing and monitoring land use and land cover change, in DeFries, R.S., Asner, G.P., and Houghton, R.A., eds., Ecosystems and land use change: American Geophysical Union, Geophysical Monograph Series, v. 153, p. 231-246. 
Loveland, T.R., Sohl, T.L., Stehman, S.V., Gallant, A.L., Sayler, K.L., and Napton, D.E., 2002, A strategy for estimating the rates of recent United States land-cover changes: Photogrammetric Engineering and Remote Sensing, v. 68, p. 1091-1099.

Lubowski, R.N., Plantinga, A.J., and Stavins, R.N., 2006, Land-use change and carbon sinks; Econometric estimation of the carbon sequestration supply function: Journal of Environmental Economics and Management, v. 51, p. $135-152$.

Luyssaert, S., Ciais, P., Piao, S.L., Schulze, E.D., Jung, M., Zaehle, S., Schelhaas, M.J., Reichstein, M., Churkina, G., Papale, D., Abril, G., Beer, C., Grace, J., Loustau, D., Matteucci, G., Magnani, F., Nabuurs, G.J., Verbeeck, H., Sulkava, M., Van der Werf, G.R., Janssens, I.A., and members of the Carboeurope-IP Synthesis Team, 2010, The European carbon balance; Part 3, Forests: Global Change Biology, v. 16, p. 1429-1450, doi:10.1111/j.13652486.2009.02056.x.

Manies, K.L., Harden, J.W., Bond-Lamberty, B.P., and O'Neill, K.P., 2005, Woody debris along an upland chronosequence in boreal Manitoba and its impact on long-term carbon storage: Canadian Journal of Forest Research, v. 35, p. $472-482$.

Marland, G., Boden, T.A., and Andres, R.J., 2009, Global, regional, and national fossil fuel $\mathrm{CO}_{2}$ emissions: Oak Ridge, Tenn., U.S. Department of Energy, Carbon Dioxide Information Analysis Center, Oak Ridge National Laboratory, accessed June 10, 2010, at http://cdiac.ornl.gov/trends/emis/ overview.html.

Maurer, E.P., Brekke, L., Pruitt, T., and Duffy, P.B., 2007, Fine-resolution climate projections enhance regional climate change impact studies:, Eos, v. 88, no. 47, p. 504.

McKelvey, K.S., and Busse, K.K., 1996, Twentieth-century fire patterns on Forest Service lands, chap. 41 of Assessments and scientific basis for management options, v. 2 of Sierra Nevada Ecosystem Project, final report to Congress: Davis, Calif., University of California, Centers for Water and Wildland Resources, p. 1119-1138, accessed June 14, 2010, at http://ceres.ca.gov/snep/pubs/web/PDF/ VII_C41.PDF. (Also available as U.S. Geological Survey Digital Data Series DDS-43 at http://pubs.usgs.gov/dds/ dds-43/VOL_II/VII_C41.PDF.)

McLachlan, S.M., and Knispel, A.L., 2005, Assessment of long-term tallgrass prairie restoration in Manitoba, Canada: Biological Conservation, v. 124, p. 75-88.

McMahon, S.M., Parker, G.G., and Miller, D.R., 2010, Evidence for a recent increase in forest growth: Proceedings of the National Academy of Sciences, v. 107, no. 8, p. 3611-3615.
McNulty, S.G., 2002, Hurricane impacts on US forest carbon sequestration: Environmental Pollution, v. 116, p. S17-S24.

Meigs, G.W., Donato, D.C., Campbell, J.L., Martin, J.G., and Law, B.E., 2009, Forest fire impacts on carbon uptake, storage, and emission - The role of burn severity in the Eastern Cascades, Oregon: Ecosystems, p. 1-22.

Merlo, M., and Croitoru, L., eds., 2005, Valuing Mediterranean forests-Towards total economic value: CABI Publishing, $448 \mathrm{p}$.

Meyer, W.B., and Turner, B.L., II, 1992, Human population growth and global land-use/-cover change: Annual Review of Ecology and Systematics, v. 23, p. 39-61.

Millennium Ecosystem Assessment, 2003, Ecosystems and human well-being - A framework for assessment: Washington, D.C., Island Press.

Mitchell, S.R., Harmon, M.E., and O'Connell, K.E.B., 2009, Forest fuel reduction alters fire severity and long-term carbon storage in three Pacific Northwest ecosystems: Ecological Applications, v. 19, no. 3, p.643-655.

Moss, R.H., Edmonds, J.A., Hibbard, K.A., Manning, M.R., Rose, S.K., van Vuuren, D.P., Carter, T.R., Emori, Seita, Kainuma, Mikiko, Kram, Tom, Meehl, G.A., Mitchell, J.F.B., Nakicenovic, Nebojsa, Riahi, Keywan, Smith, S.J., Stouffer, R.J., Thomson, A.M., Weyant, J.P., and Wilbanks, T.J., 2010, The next generation of scenarios for climate change research and assessment: Nature, v. 463, no. 7282 , p. $747-756$.

Murphy, J.M., Sexton, D.M.H., Barnett, D.N., Jones, G.S., Webb, M.J., Collins, M., and Stainforth, D.A., 2004, Quantifications of modeling uncertainties in a large ensemble of climate change simulations: Nature, v. 430, no. 7001, p. $768-772$.

Murray, B.C., Sommer, A.J., Depro, B., Sohngen, B.L., McCarl, B.A., Gillig, D., de Angelo, Benjamin, and Andrasko, Kenneth, 2005, Greenhouse gas mitigation potential in US forestry and agriculture: U.S. Environmental Protection Agency Report 430-R-05-006, November, variously paged.

Nakicenovic, Nebojsa, Alcamo, Joseph, Davis, Gerald, de Vries, Bert, Fenhann, Joergen, Gaffin, Stuart, Gregory, Kenneth, Grübler, Arnulf, Jung, T.Y., Kram, Tom, La Rovere, E.L., Michaelis, Laurie, Mori, Shunsuke, Morita, Tsuneyuki, Pepper, William, Pitcher, Hugh, Price, Lynn, Riahi, Keywan, Roehrl, Alexander, Rogner, H.-H., Sankovski, Alexei, Schlesinger, Michael, Shukla, Priyararshi, Smith, Steven, Swart, Robert, van Rooijen, Sascha, Victor, Nadejda, and Dadi, Zhou, 2000, Special report on emissions scenarios; A special report of Working Group III of the Intergovernmental Panel on Climate Change [IPCC]: Cambridge, UK, Cambridge University Press, 599 p., accessed June 14, 2010, at 
http:/www.grida.no/publications/other/ipcc\%5Fsr/?src=/ climate/ipcc/emission/index.htm.

Neff, J.C., Harden, J.W., and Gleixner, G., 2005, Fire effects on soil organic matter content, composition, and nutrients in boreal interior Alaska: Canadian Journal of Forest Research, v. 35 , p. 2178-2187, doi:10.1139/x05-154.

Negra, Christine, Sweedo, C.C., Cavendar-Bares, Kent, and O'Malley, Robin, 2008, Indicators of carbon storage in US ecosystems - Baseline for terrestrial carbon accounting: Journal of Environmental Quality, v. 37, p. 1376-1382, doi:10.2134/jeq2007.0290.

Nelson, Erik, Mendoza, Guillermo, Regetz, James, Polasky, Stephen, Tallis, Heather, Cameron, D.R., Chan, K.M.A., Daily, G.C., Goldstein, Joshua, Kareiva, P.M., Lonsdorf, Eric, Naidoo, Robin, Rickett, T.H., and Shaw, M.R., 2009, Modeling multiple ecosystem services, biodiversity conservation, commodity production, and tradeoffs at landscape scales: Frontiers in Ecology and the Environment, v. 7, no. 1, p. 4-11, doi:10.1890/080023.

Nelson, Erik, Polasky, Stephen, Lewis, D.J., Plantinga, A.J., Lonsdorf, Eric, White, Denis, Bael, David, and Lawler, J.J., 2008, Efficiency of incentives to jointly increase carbon sequestration and species conservation on a landscape: Proceedings of the National Academy of Sciences, v. 105, no. 28, p. 9471-9476, doi:10.1073/pnas.0706178105.

Norby, R.J., DeLucia, E.H., Gielen, Birgit, Calfapietra, Carlo, Giardina, C.P., King, J.S., Ledford, Joanne, McCarthy, H.R., Moore, D.J.P., Ceulemans, Reinhart, De Angelis, Paolo, Finzi, A.C., Karnosky, D.F., Kubiske, M.E., Lukac, Martin, Pregitzer, K.S., Scarascia-Mugnozza, G.E., Schlesinger, W.H., and Oren, Ram, 2005, Forest response to elevated $\mathrm{CO}_{2}$ is conserved across a broad range of productivity: Proceedings of the National Academy of Sciences, v. 102, no. 50, p. 18052-18056, doi:10.1073/pnas.0509478102.

Omernik, J.M., 1987, Ecoregions of the conterminous United States: Annals of the Association of American Geographers, v. 77 , no. 1, p. $118-125$.

Omernik, J.M., 2004, Perspectives on the nature and definition of ecological regions: Environmental Management, v. 34, Supplement 1, p. S27-S38, doi:10.1007/ s00267-003-5197-2.

Pacala, S.W., Hurtt, G.C., Baker, D., Peylin, P., Houghton, R.A., Birdsey, R.A., Heath, L., Sundquist, E.T., Stallard, R.F., Ciais, P., Moorcroft, P., Caspersen, J.P., Shevliakova, E., Moore, B., Kohlmaier, G., Holland, E., Gloor, M., Harmon, M.E., Fan, S.-M., Sarmiento, J.L., Goodale, C.L., Schimel, D., and Field, C.B., 2001, Consistent land- and atmosphere-based U.S. carbon sink estimates: Science, v. 292, no. 5525, p. 2316-2320, doi:10.1126/ science. 1057320 .
Parton, W.J., Holland, E.A., Grosso, S.J.D., Hartman, M.D., Martin, R.E., Mosier, A.R., Ojima, D.S., and Schimel, D.S., 2001, Generalized model for $\mathrm{NO}_{x}$ and $\mathrm{N}_{2} \mathrm{O}$ emissions from soils: Journal of Geophysical Research, v. 106, no. D15, p. 17403-17419.

Parton, W.J., Hartman, M., Ojima, D., and Schimel, D., 1998, Daycent and its land surface submodel-Description and testing: Global and Planetary Change, v. 19, p. 35-48.

Parton, W.J., Schimel, D.S., Cole, C.V., and Ojima, D.S., 1987, Analysis of factors controlling soil organic-matter levels in Great-Plains grasslands: Soil Science Society of America Journal, v. 51, p. 1173-1179.

Parton, W.J., Scurlock, J.M.O., Ojima, D.S., Gilmanov, T.G., Scholes, R.J., Schimel, D.S., Kirchner, T., Menaut, J.C., Seastedt, T., Garcia Moya, E., Kamnalrut, A., and Kinyamario, J.I., 1993, Observations and modeling of biomass and soil organic matter dynamics for the grassland biome worldwide: Global Biogeochemical Cycles, v. 7, p. 785-809, doi:10.1029/93gb02042.

Paustian, Keith, Ravindranath, N.H., and van Amstel, Andre, coords., 2006, Agriculture, forestry, and other land uses, v. 4 of Intergovernmental Panel on Climate Change, 2006 IPCC guidelines for national greenhouse gas inventories (prepared by the IPCC National Greenhouse Gas Inventories Programme; edited by Eggleston, H.S., Buendia, Leandro, Miwa, Kyoko, Ngara, Todd, and Tanabe, Kiyoto): Hayama, Kanagawa, Japan, Institute for Global Environmental Strategies, accessed June 14, 2010, at http://www.ipcc-nggip.iges.or.jp/public/2006gl/vol4.html.

Penman, Jim, Gytarsky, Michael, Hiraishi, Taka, Krug, Thelma, Kruger, Dina, Pipatti, Riitta, Buendia, Leandro, Miwa, Kyoto, Ngara, Todd, Tanabe, Kiyoto, and Wagner, Fabian, eds., 2003, Good practice guidance for land use, land-use change and forestry: Hayama, Japan, Intergovernmental Panel on Climate Change.

Peters, D.P.C., Pielke, R.A., Bestelmyer, B.T., Allen, C.D., Munson-McGee, Stuart, and Havstad, K.M., 2004, Crossscale interactions, nonlinearities, and forecasting catastrophic events: Proceedings of the National Academy of Sciences, v. 101, no. 42, p. 15130-15135, doi:10.1073/ pnas.0403822101.

Phillips, S.J., Anderson, R.P., and Schapire, R.E., 2006, Maximum entropy modeling of species geographic distributions: Ecological Modelling, v. 190, no. 3-4, p. 231-259.

Piao, Shilong, Ciais, Phillippe, Friedlingstein, Pierre, Peylin, Phillippe, Reichstein, Markus, Luyssaert, Sebastiaan, Margolis, Hank, Fang, Jingyun, Barr, Alan, Chen, Anping, Grelle, Achim, Hollinger, D.Y., Laurila, Tuomas, Lindroth, Anders, Richardson, A.D., and Vesala, Timo, 2008, Net carbon dioxide losses of northern ecosystems in response 
to autumn warming: Nature, v. 451, p. 49-52, doi 10.1038/ nature 06444 .

Piao, Shilong, Fang, Jingyun, Ciais, Philippe, Peylin, Philippe, Huang, Yao, Sitch, Stephen, and Wang, Tao, 2009, The carbon balance of terrestrial ecosystems in China: Nature, v. 458, p. 1009-U82, doi:10.1038/nature07944.

Pickett, S.T.A., and White, P.S., 1985, Patch dynamics; A synthesis, in The ecology of natural disturbance and patch dynamics: New York, Academic Press, p. 371-384.

Pilling, C., and Jones, J.A.A., 1999, High resolution climate change scenarios-Implications for British runoff: Hydrological Processes, v. 13, no. 17, p. 2877-2895.

Post, W.M., Emanuel, W.R., Zinke, P.J., and Stangenberger, A.G., 1982, Soil carbon pools and world life zones: Nature, v. 298 , p. $156-159$.

Potter, C.S., 1997, An ecosystem simulation model for methane production and emission from wetlands: Global Biogeochemical Cycles, v. 11, no. 4, p. 495-506, doi:10.1029/97GB02302.

Potter, C.S., and Klooster, S.A., 1997, Global model estimates of carbon and nitrogen storage in litter and soil poolsResponse to changes in vegetation quality and biomass allocation: Tellus Series B-Chemical and Physical Meteorology, v. 49, p. 1-17.

Potter, Christopher, Klooster, Steven, Hiatt, Seth, Fladeland, Matthew, Genovese, Vanessa, and Gross, Peggy, 2007, Satellite-derived estimates of potential carbon sequestration through afforestation of agricultural lands in the United States: Climatic Change, v. 80, no. 3-4, doi:10.1007/ s10584-006-9109-3.

Powell, D.S., Faulkner, J.L., Darr, D.R., Zhu, Zhiliang, and MacCleery, D.W., 1993, Forest resources of the United States, 1992: U.S. Department of Agriculture, Rocky Mountain Forest and Range Experiment Station, General Technical Report RM-234, 132 p. plus one map, accessed June 14, 2010, at http://www.fs.fed.us/rm/pubs_rm/rm_gtr234.html.

Preisler, H.K., and Westerling, A.L., 2007, Statistical model for forecasting monthly large wildfire events in Western United States: Journal of Applied Meteorology and Climatology, v. 46, no. 7, p. 1020-1030, doi:10.1175/JAM2513.1.

Prichard, S.J., Ottmar, R.D., and Anderson, G.K., 2006, Consume 3.0 user's guide: Seattle, Wash., U.S. Department of Agriculture, Forest Service, Pacific Northwest Research Station. Pacific Wildland Fire Sciences Laboratory, 234 p., accessed June 14, 2010, at http://www.fs.fed.us/pnw/fera/ research/smoke/consume/consume30_users_guide.pdf.

Prisley, S.P., and Mortimer, M.J., 2004, A synthesis of literature on evaluation of models for policy applications, with implications for forest carbon accounting: Forest
Ecology and Management, v. 198, no. 1-3, p. 89-103, doi:10.1016/j.foreco.2004.03.038.

Prudhomme, Christel, Reynard, Nick, and Crooks, Sue, 2002, Downscaling of global climate models for flood frequency analysis: where are we now?: Hydrological Processes, v. 16, p. 1137-1150, doi:10.1002/hyp.1054.

Raffa, K.F., Aukema, B.H., Bentz, B.J., Carroll, A.L., Hicke, J.A., Turner, M.G., and Romme, W.H., 2008, Cross-scale drivers of natural disturbances prone to anthropogenic amplification; The dynamics of bark beetle eruptions: Bioscience, v. 58, no. 6, p. 501-517.

Raich, J.W., and Schlesinger, W.H., 1992, The global carbon-dioxide flux in soil respiration and its relationship to vegetation and climate: Tellus, v. 44, p. 81-99, doi:10.1034/j.1600-0889.1992.t01-1-00001.x.

Ramaswamy, V., Boucher, O., Haigh, D., Hauglustaine, D., Haywood, J., Myhre, T., Nakajima, T., Shi, G.Y., and Solomon, S., 2001, Radiative forcing of climate change, chap. 6 of Houghton, J.T., Ding, Y., Griggs, D.J., Noguer, M., van der Linden, P.J., Dai, X., Maskell, K., and Johnson, C.A., eds., Climate change 2001-The scientific basis; Contribution of Working Group I to the Third Assessment Report of the Intergovernmental Panel on Climate Change: Cambridge, United Kingdom, Cambridge University Press, p. 349-416.

Raskin, P.D., 2005, Global scenarios-Background review for the millennium ecosystem assessment: Ecosystems, v. 8, no. 2, p. 133-142, doi:10.1007/s10021-004-0074-2.

Raskin, Paul, Gallopin, Gilberto, Gutman, Pablo, Hammond, Al, and Swart, Rob, 1998, Bending the curve-Toward global sustainability: Stockholm, Stockholm Environment Institute Pole Star Series Report 8, 90 p. plus one annex, accessed June 14, 2010, at http://sei-international. org/mediamanager/documents/Publications/Future/bending_the_curve.pdf.

Reams, G.A., Smith, W.D., Hansen, M.H., Bechtold, W.A., Roesch, F.A., and Moisen, G.G., 2005, The forest inventory and analysis sampling frame, in Bechtold, W.A., and Patterson, P.L., eds., The enhanced forest inventory and analysis program - National sampling design and estimation procedures: U.S. Department of Agriculture, Forest Service, Southern Research Station General Technical Report SRS-80, p. 11-26., accessed June 14, 2010, at http://www.srs.fs.usda.gov/pubs/20371.

Reay, D.S., Dentener, Frank, Smith, Pete, Grace, John, and Feely, R.A., 2008, Global nitrogen deposition and carbon sinks: Nature Geoscience, v. 1, p. 430-437, doi:10.1038/ ngeo230.

Reddy, K.R., and Delaune, R.D., 2008, Biogeochemistry of wetlands: Boca Raton, Fla., CRC Press, 800 p. 
Reeder, J.D., Franks, C.D., and Milchunas, D.G., 2000, Root biomass and microbial processes, in Follett, R.F., and Kimble, J.M., eds., The potential of U.S. grazing lands to sequester carbon and mitigate the greenhouse effects: Boca Raton, Fla., Lewis Publisher, p. 139-166.

Rees, R.M., Bingham, I.J., Baddeley, J.A., and Watson, C.A., 2005, The role of plants and land management in sequestering soil carbon in temperate arable and grassland ecosystems: Geoderma, v. 128, nos. 1-2, p. 130-154, doi:10.1016/j.geoderma.2004.12.020.

Reiners, W.A., Liu, S., Gerow, K.G., Keller, M., and Schimel, D.S., 2002, Historical and future land use effects on $\mathrm{N}_{2} \mathrm{O}$ and $\mathrm{NO}$ emissions using an ensemble modelling approach; Costa Rica's Caribbean lowlands as an example: Global Biogeochemical Cycles, v. 16, p. 1068, doi:10.1029/2001GB001437.

Reinhardt, E.D., Keane, R.E., and Brown, J.K., 1997, First order fire effects model; FOFEM 4.0 user's guide: U.S. Department of Agriculture, Forest Service, Intermountain Research Station, General Technical Report INT-GTR-344, 65 p., accessed June 14, 2010, at http://www.fs.fed.us/rm/ pubs_int/int_gtr344.html.

Richards, G.P., and Brack, Chris, 2004, A continental biomass stock and stock change estimation approach for Australia: Australian Forestry, v. 67, p. 284-288, accessed June 14, 2010, at http://business.highbeam.com/436220/ article-1G1-196730178/continental-biomass-stock-andstock-change-estimation.

Richards, Gary, and Evans, David, 2000, Carbon accounting model for forests (CAMFor) user manual, version 3.35: Australian Greenhouse Office National Carbon Accounting System Technical Report 26, 47 p., accessed June 14, 2010, at http://pandora.nla.gov.au/tep/23322.

Richardson, Leslie, and Loomis, John, 2009, The total economics value of threatened, endangered and rare speciesAn updated meta-analysis: Ecological Economics, v. 68, no. 5, p. 1535-1548, doi:10.1016/j.ecolecon.2008.10.016.

Ritchie, J.C., 1989, Carbon content of sediments of small reservoirs: Water Resources Bulletin, v. 25, no. 2, p. 301-308, doi:10.1111/j.1752-1688.1989.tb03065.x.

Rollins, M.G., 2009, LANDFIRE; A nationally consistent vegetation, wildland fire, and fuel assessment: International Journal of Wildland Fire, v. 18, no. 3, p. 235-249, doi:10.1071/WF08088.

Rollins, M.G., Swetnam, T.W., and Morgan, Penelope, 2001, Evaluating a century of fire patterns in two Rocky Mountain wilderness areas using digital fire atlases: Canadian Journal of Forest Research, v. 31, no. 12, p. 2107-2123, doi:10.1139/cjfr-31-12-2107.
Ross, M.T., Fawcett, A.A., and Clapp, C.S., 2009, U.S. climate mitigation pathways post-2012 - Transition scenarios in ADAGE: Energy Economics, v. 31, supplement 2, p. S212S222, doi:10.1016/j.eneco.2009.06.002.

Running, S.W., 2008, Ecosystem disturbance, carbon, and climate: Science, v. 321, no. 5889, p. 652-653, doi:10.1126/ science. 1159607.

Running, S.W., Baldocchi, D.D., Turner, D.P., Gower, S.T., Bakwin, P.S., and Hibbard, K.A., 1999, A global terrestrial monitoring network integrating tower fluxes, flask sampling, ecosystem modeling and EOS satellite data: Remote Sensing of Environment, v. 70, no. 1, p. 108-127, doi:10.1016/S0034-4257(99)00061-9.

Ryan, M.G., Harmon, M.E., Birdsey, R.A., Giardina, C.P., Heath, L.S., Houghton, R.A., Jackson, R.B., McKinley, D.C., Morrison, J.F., Murray, B.C., Pataki, D.E., and Skog, K.E., 2010, A synthesis of the science on forests and carbon for US forests: Issues in Ecology, v. 13, p. 17.

Sarmiento, J.L., and Gruber, Nicolas, 2002, Sinks for anthropogenic carbon: Physics Today, v. 55, no. 8, p. 30-36, doi:10.1063/1.1510279.

Schaltegger, Stefan, and Burritt, Roger, 2000, Contemporary environmental accounting-Issues, concepts, and practice: Sheffield, UK, Greenleaf Publishing Limited, 462 p.

Scheraga, J.D., and Grambsch, A.E., 1998, Risks, opportunities, and adaptation to climate change: Climate Research, v. 10 , no. 1, p. $85-95$.

Schuman, G.E., Janzen, H.H., and Herrick, J.E., 2002, Soil carbon dynamics and potential carbon sequestration by rangelands: Environmental Pollution, v. 116, no. 3, p. 391-396, doi:10.1016/S0269-7491(01)00215-9.

Schwarz, G.E., 2008, A preliminary SPARROW model of suspended sediment for the conterminous United States: U.S. Geological Survey Open-File Report 2008-1205, 8 p., accessed June 23, 2010, at http://pubs.usgs.gov/ of/2008/1205.

Seitzinger, S.P., and Mayorga, Emilio, 2008, Linking watersheds to coastal systems; A global perspective on river inputs of $\mathrm{N}, \mathrm{P}$ and $\mathrm{C}$ : Ocean Carbon and Biogeochemistry News, v. 1, no. 1, p. 8-11, accessed June 14, 2010, at http:/www.us-ocb.org/publications/ OCB_NEWS_APR08.pdf.

Simpson, I.J., Rowland, F.S., Meinardi, Simone, and Blake, D.R., 2006, Influence of biomass burning during recent fluctuations in the slow growth of global tropospheric methane: Geophysical Research Letters, v. 33, L22808, doi:10.1029/2006GL027330.

Skog, K.E., and Nicholson, G.A., 1998, Carbon cycling through wood products; The role of wood and paper prod- 
ucts in carbon sequestration: Forest Products Journal, v. 48, no. $7-8$, p. $75-83$.

Sleeter, B.M., Wilson, T.S., Soulard, C.E., and Liu, Jinxun, 2010, Estimation of late twentieth century landcover change in California: Environmental Monitoring and Assessment, doi:10.10007/s10661-010-1385-8, accessed June 14, 2010, at http://www.springerlink.com/ content/17173232522221g5/.

Smith, J.E., and Heath, L.S., 2001, Identifying influences on model uncertainty - An application using a forest carbon budget model: Environmental Management, v. 27, no. 2, p. 253-267, doi:10.1007/s002670010147.

Smith, S.V., Sleezer, R.O., Renwick, W.H., and Buddemeier, R.W., 2005, Fates of eroded soil organic carbon-Mississippi basin case study: Ecological Applications, v. 15, no. 6, p. 1929-1940, doi:10.1890/05-0073.

Smith, W.B., 2002, Forest inventory and analysis; A national inventory and monitoring program: Environmental Pollution, v. 116, no. 1, p. S233-S242, doi:10.1016/S02697491(01)00255-X.

Smith, W.B., tech. coord.; Miles, P.D., data coord.; Perry, C.H., map coord.; Pugh, S.A., data CD coord., 2009, Forest resources of the United States, 2007: U.S. Department of Agriculture, Forest Service, Washington Office, General Technical Report WO-78, 336 p., accessed June 14, 2010, at http://www.nrs.fs.fed.us/pubs/7334.

Smith, W.B., Vissage, J.S., Darr, D.R., and Sheffield, R.M., 2001, Forest resources of the United States, 1997: U.S. Department of Agriculture, Forest Service, North Central Research Station, General Technical Report NC-219, 190 p., accessed June 14, 2010, at http://www.treesearch.fs.fed.us/pubs/10845.

Sohl, T.L., Loveland, T.R., Sleeter, B.M., Sayler, K.L., and Barnes, C.A., 2009, Addressing foundational elements of regional land-use change forecasting: Landscape Ecology, v. 25, no. 2, p. 233-247, doi:10.1007/s10980-009-9391-3.

Sohl, Terry, and Sayler, Kristi, 2008, Using the FORE-SCE model to project land-cover change in the southeastern United States: Ecological Modelling, v. 219, nos. 1-2, p. 49-65, doi:10.1016/j.ecolmodel.2008.08.003.

Sohl, T.L., Sayler, K.L., Drummond M.A., and Loveland, T.R., 2007, The FORE-SCE model-A practical approach for projecting land-use change using scenario-based modeling: Journal of Land Use Science, v. 2, no. 2, p. 102-126, doi:10.1080/17474230701218202.

Soulé, P.T., and Knapp, P.A., 2006, Radial growth rate increases in naturally occurring ponderosa pine trees-A late-20th century $\mathrm{CO}_{2}$ fertilization effect?: New Phy- tologist, v. 171, no. 2, p. 379-390, doi:10.1111/j.14698137.2006.01746.x.

Stavins, R.N., and Richards, K.R., 2005, The cost of U.S. forest-based carbon sequestration: Arlington, Va., Pew Center on Global Climate Change, 40 p., accessed June 14, 2010, at http:/www.pewclimate.org/publications/report/ cost-us-forest-based-carbon-sequestration.

Stehman, S.V., Sohl, T.L., and Loveland, T.R., 2003, Statistical sampling to characterize recent United States land-cover change: Remote Sensing of Environment, v. 86, p. 517-529.

Stephens, S.L., Moghaddas, J.J., Hartsough, B.R., Moghaddas, E.E.Y., and Clinton, N.E., 2009, Fuel treatment effects on stand-level carbon pools, treatment-related emissions, and fire risk in a Sierra Nevada mixed-conifer forest: Canadian Journal of Forest Research, v. 39, no. 8, p. 1538-1547, doi:10.1139/X09-081.

Stevens, T.H., Belkner, R., Dennis, D., Kittredge, D., and Willis, C., 2000, Comparison of contingent valuation and conjoint analysis for ecosystem management: Ecological Economics, v. 32, no. 1, p. 63-74, doi:10.1016/S09218009(99)00071-3.

Striegl, R.G., Dornblaser, M.M., Aiken, G.R., Wickland, K.P., and Raymond, P.A., 2007, Carbon export and cycling by the Yukon, Tanana, and Porcupine Rivers, Alaska, 20012005: Water Resources Research, v. 43, no. 2, W02411, doi:10.1029/2006WR005201.

Sundquist, E.T., Ackerman, K.V., Bliss, N.B., Kellndorfer, J.M., Reeves, M.C., and Rollins, M.G., 2009, Rapid assessment of U.S. forest and soil organic carbon storage and forest biomass carbon sequestration capacity: U.S. Geological Survey Open-File Report 2009-1283, 15 p., accessed June 14, 2010, at http://pubs.usgs.gov/ofr/2009/1283.

Syphard, A.D., Radeloff, V.C., Keuler, N.S., Taylor, R.S., Hawbaker, T.J., Stewart, S.I., and Clayton, M.K., 2008, Predicting spatial patterns of fire on a southern California landscape: International Journal of Wildland Fire, v. 17, no. 5, p. 602-613, doi:10.1071/WF07087.

Syvitski, J.P.M., Peckham, S.D., Hilberman, Rachael, and Mulder, Thierry, 2003, Predicting the terrestrial flux of sediment to the global ocean; A planetary perspective: Sedimentary Geology, v. 162, nos. 1-2, p. 5-24, doi:10.1016/ s0037-0738(03)00232-x.

Tan, Zhengxi, Lal, Rattan, and Liu, Shuguang, 2006, Using experimental and geospatial data to estimate regional carbon sequestration potential under no-till practice: Soil Science, v. 171, no. 12, p. 950-959, doi:10.1097/01. ss.0000235845.17826.f0.

Tan, Zhengxi, Liu, Shuguang, Johnston, C.A., Loveland, T.R., Tieszen, L.L., Liu, Jinxun, and Kurtz, Rachel, 2005, Soil 
organic carbon dynamics as related to land use history in the northwestern Great Plains: Global Biogeochemical Cycles, v. 19, GB3011, doi:10.1029/2005GB002536.

Tan, Zhengxi, Liu, Shuguang, Li, Zhengpeng, and Loveland, T.R., 2007, Simulated responses of soil organic carbon stock to tillage management scenarios in the northwest Great Plains: Carbon Balance and Management, v. 2, no. 7, doi:10.1186/1750-0680-2-7.

Thomson, A.M., Izaurralde, R.C., Smith, S.J., and Clarke, L.E., 2008, Integrated estimates of global terrestrial carbon sequestration: Global Environmental Change, v. 18, no. 1, p. 192-203, doi:10.1016/j.gloenvcha.2007.10.002.

Tirpak, J.M., Jones-Farrand, D.T., Thompson, F.R., III, Twedt, D.T., Baxter, C.K., Fitzgerald. J.A., and Uihlein, W.B., III, 2009, Assessing ecoregional-scale habitat suitability index models for priority landbirds: The Journal of Wildlife Management, v. 73, no. 8, p. 1307-1315, doi:10.2193/2008-125.

Tranvik, L.J., Downing, J.A., Cotner, J.B., Loiselle, S.A., Striegl, R.G., Ballatore, T.J., Dillon, Peter, Finlay, Kerri, Fortino, Kenneth, Knoll, L.B., Kortelainen, P.L., Kutser, Tiit, Larsen, Soren, Laurion, Isabelle, Leech, D.M., McCallister, S.L., McKnight, D.M., Melack, J.M., Overholt, Erin, Porter, J.A., Prairie, Yves, Renwick, W.H., Roland, Fabio, Sherman, B.S., Schindler, D.W., Sobek, Sebastian, Tremblay, Alain, Vanni, M.J., Verschoor, A.M., von Wachenfeldt, Eddie, and Weyhenmeyer, G.A., 2009, Lakes and reservoirs as regulators of carbon cycling and climate: Limnology and Oceanography, v. 54, no. 6, part 2, p. 2298-2314.

Turner, B.L., II, Kasperson, R.E., Meyer, W.B., Dow, K.M., Golding, Dominic, Kasperson, J.X., Mitchell, R.C., and Ratick, S.J., 1990, Two types of global environmental change - Definitional and spatial-scale issues in their human dimensions: Global Environmental Change, v. 1, no. 1, p. 14-24, doi:10.1016/0959-3780(90)90004-S.

Turner, B.L., II, Lambin, E.F., and Reenberg, Anette, 2007, The emergence of land change science for global environmental change and sustainability: Proceedings of the National Academy of Sciences, v. 104, no. 52, p. 2066620671, doi:10.1073/pnas.0704119104.

Turner, M.G., Gardner, R.H., and O’Neill, R.V., 2001, Landscape ecology in theory and practice-Pattern and process: New York, Springer-Verlag, 404 p.

Turner, M.G., Tinker, D.B., Romme, W.H., Kashian, D.M., and Litton, C.M., 2004, Landscape patterns of sapling density, leaf area, and aboveground net primary production in postfire lodgepole pine forests, Yellowstone National Park (USA): Ecosystems, v. 7, no. 7, p. 751-775, doi: 10.1007/ s10021-004-0011-4.

Twedt, D.J., Uihlein, W.B., III, and Elliott, A.B., 2006, A spatially explicit decision support model for restoration of forest bird habitat: Conservation Biology, v. 20, no. 1, p. 100-110, doi:10.1111/j.1523-1739.2006.00303.x.

United Nations Environment Programme, 2002, Global environment outlook 3 (GEO-3) - Past, present and future perspectives: United Nations Environment Programme, 446 p., accessed June 14, 2010, at http://www.unep.org/GEO/ geo3/.

U.S. Census Bureau, 2009, TIGER $^{\circledR}$, TIGER/Line ${ }^{\circledR}$ and TIGER $^{\circledR}$-related products: U.S. Census Bureau, accessed June 10, 2010, at http://www.census.gov/geo/www/tiger/.

U.S. Climate Change Science Program, 2007, The first state of the carbon cycle report (SOCCR)-The North American carbon budget and implications for the global carbon cycle (King, A.W., Dilling, Lisa, Zimmerman, G.P., Fairman, D.M., Houghton, R.A., Marland, Gregg, Rose, A.Z., and Wilbanks, T.J., eds.): National Oceanic and Atmospheric Administration, National Climatic Data Center, 242 p., accessed June 14, 2010, at http://www.climatescience.gov/ Library/sap/sap2-2/final-report/default.htm.

U.S. Congress, 1970, National Environmental Policy ActPublic Law 91-190: U.S. Congress, available at http://ceq. hss.doe.gov/nepa/regs/nepa/nepaeqia.htm.

U.S. Congress, 1974, Forest and Rangeland Renewable Resources Planning Act: Washington, D.C., U.S. Congress, 17 p., accessed Jun 23, 2010 at http://www.fs.fed.us/emc/ nfma/includes/range74.pdf

U.S. Congress, 2007, Energy Independence and Security Act-Public Law 110-140: U.S. Congress, 311 p., available at http://frwebgate.access.gpo.gov/ cgi-bin/getdoc.cgi?dbname=110_cong_public_ laws\&docid=f:publ140.110.pdf.

U.S. Department of Agriculture, 2008, U.S. agriculture and forestry greenhouse gas inventory, 1990-2005: U.S. Department of Agriculture, Office of the Chief Economist, Global Change Program, Technical Bulletin 1921, 169 p., accessed June 14, 2010, at http://www.usda.gov/oce/climate_change/ AFGGInventory1990_2005.htm.

U.S. Department of Agriculture, Forest Service, 2000, 2000 RPA assessment of forest and range lands: U.S. Department of Agriculture, Forest Service, FS-687, 78 p., available only at http://www.fs.fed.us/research/rpa/2000rpa/rpaasses.pdf. [Errata sheet available at http://www.fs.fed.us/research/ rpa/2000rpa/ERRATA_sheet_for_2000_RPA_ Assessment_12March02.PDF.]

U.S. Department of Agriculture, Forest Service, 2007a, Forest inventory and analysis strategic plan; A history of success, a dynamic future: U.S. Department of Agriculture Forest Service FS-865, 17 p., accessed June 14, 2010, at http://fia.fs.fed.us/library/fact-sheets/overview/ FIA_Strategic_Plan2.pdf. 
U.S. Department of Agriculture, Forest Service, 2007b, Interim update of the 2000 Renewable Resources Planning Act assessment: U.S. Department of Agriculture Forest Service FS-874, 114 p., accessed June 14, 2010, at http://www.fs.fed.us/research/rpa/pubs-supporting-interimupdate-of-2000-rpa-assessment.shtml.

U.S. Department of Agriculture, Natural Resources Conservation Service, 2009, Summary report—2007 national resources inventory: U.S. Department of Agriculture, Natural Resources Conservation Service, and Ames, Iowa, Center for Survey Statistics and Methodology, Iowa State University, 123 p, accessed June 14, 2010, at http://www.nrcs.usda.gov/technical/ NRI/2007/2007_NRI_Summary.pdf.

U.S. Environmental Protection Agency, 2008, EPA analysis of the Lieberman-Warner Climate Security Act of 2008, S.2191 in the 110th Congress: U.S. Environmental Protection Agency, 192 p., accessed April 7, 2010, at http://www.epa.gov/climatechange/downloads/ s2191_EPA_Analysis.pdf.

U.S. Environmental Protection Agency, 2009, Inventory of U.S. greenhouse gas emissions and sink-1990-2007: U.S. Environmental Protection Agency EPA 430-R09-004, accessed June 10, 2010, at http://www.epa.gov/ climatechange/emissions/usgginv_archive.html.

U.S. Environmental Protection Agency, 2010, Inventory of U.S. greenhouse gas emissions and sinks-1990-2008: U.S. Environmental Protection Agency EPA 430-R10-006, accessed June 10, 2010, at http://www.epa.gov/ climatechange/emissions/usinventoryreport.html.

U.S. Geological Survey, 2010, U.S. irrigation data-MODIS irrigated agriculture dataset for the United States (MIrADUS): U.S. Geological Survey, accessed June 10, 2010, at http://earlywarning.usgs.gov/USirrigation/.

Van Geen, A., Takesue, R.K., Goddard, J., Takahashi, T., Barth J.A., and Smith, R.L., 2000, Carbon and nutrient dynamics during coastal upwelling off Cape Blanco, Oregon: Deep Sea Research Part II: Topical Studies in Oceanography, v. 47, nos. 5-6, p. 975-1002, doi:10.1016/S09670645(99)00133-2.

Vickery, P.J., Skerlj, P.F., and Twisdale, L.A., 2000, Simulation of hurricane risk in the U.S. using empirical track model: Journal of Structural Engineering, v. 126, no. 10, p. $1222-1237$.

Vitousek, P.M., and Howarth, R.W., 1991, Nitrogen limitation on land and in the sea-How can it occur?: Biogeochemistry, v. 13, no. 2, p. 87-115, doi:10.1007/BF00002772.
Walter, B.P., Heilmann, Martin, and Matthews, Elaine, 2001, Modeling modern methane emissions from natural wetlands, 1. Model description and results: Journal of Geophysical Research, v. 106, no. D24, p. 34189-34206, doi:10.1029/2001JD900165.

West, T.O., and Post, W.M., 2003, Soil organic carbon sequestration rates by tillage and crop rotation-A global data analysis: Soil Science Society of America Journal, v. 66, p. 1930-1946.

Westerling, A.L., Hidalgo, H.G., Cayan, D.R., and Swetnam, T.W., 2006, Warming and earlier spring increase western U.S. forest wildfire activity: Science, v. 313, no. 5789, p. 940-943, doi: 10.1126/science.1128834.

Wiedinmyer, Christine, and Hurteau, M.D., 2010, Prescribed fire as a means of reducing forest carbon emissions in the western United States: Environmental Science and Technology, v. 44, no. 6, p. 1926-1932, doi:10.1021/es902455e.

Wiedinmyer, Christine, and Neff, J.C., 2007, Estimates of $\mathrm{CO}_{2}$ from fires in the United States; Implications for carbon management: Carbon Balance and Management, v. 2, 12 p., doi:10.1186/1750-0680-2-10.Wise, Marshall, Calvin, Katherine, Thomson, Allison, Clarke, Leon, Bond-Lamberty, Benjamin, Sands, Ronald, Smith, S.J., Janetos, Anthony, and Edmonds, James, 2009, Implications of limiting $\mathrm{CO}_{2}$ concentrations for land use and energy: Science, v. 324, no. 5931, p. 1183-1186, doi:10.1126/science. 1168475 .

Wrisberg, Nicoline, and de Haes, H.A.U., eds., 2002, Analytical tools for environmental design and management in a systems perspective: Dordrecht, Netherlands, Kluwer Academic Publishers, $277 \mathrm{p}$.

Xian, George, Homer, Collin, and Fry, Joyce, 2009, Updating the 2001 National Land Cover Database land cover classification to 2006 by using Landsat imagery change detection methods: Remote Sensing of Environment, v. 113, no. 6, p. 1133-1147, doi:10.1016/j.rse.2009.02.004.

Zhuang, Qianli, Melillo, J.M., Sarofim, M.C., Kicklighter, D.W., McGuire, A.D., Felzer, B.S., Sokolov, Andrei, Prinn, R.G., Steudler, P.A., and $\mathrm{Hu}$, Shaomin, 2006, $\mathrm{CO}_{2}$ and $\mathrm{CH}_{4}$ exchanges between land ecosystems and the atmosphere in northern high latitudes over the 21st century: Geophysical Research Letters, v. 33, no. 17, p. L17403.1-L17403.5, doi:10.1029/2006GL026972. 
This page intentionally left blank. 


\section{Glossary}

afforestation The process of establishing trees on land that is not a forest, or has not been a forest for a long time, by planting trees or their seeds.

allochthonous From the outside, such as energy or nutrients that come from outside an ecosystem.

anaerobic An environment where atmospheric oxygen is absent, or an organism that doesn't require oxygen to function.

ancillary effect A positive or negative effect that is subordinate to the primary goal or the intended impact of a strategy, policy, or management action, including unintended consequences. For example, planting more trees to increase carbon sequestration may have the ancillary effect of increasing bird habitat.

assessment A quantitative evaluation of present and future. For this report, it is specifically an evaluation of carbon stocks, carbon sequestration, and greenhouse-gas fluxes in ecosystems.

assessment units Synonymous with the U.S. Environmental Protection Agency (EPA) Level II ecoregions (Omernik, 1987) and watersheds that are aligned, to the extent possible, with boundaries of the ecoregions. Coastal areas also are considered to be assessment units.

autochthonous From within, such as energy or nutrients that come from within an ecosystem.

baseline The reference for a measurable quantity against which an alternative outcome can be measured. A baseline can be static and can serve as an initial or starting condition. A baseline can also be dynamic and serve as a reference line for a defined set of conditions through time.

biome A general ecosystem classification, including forests, grasslands, and wetlands.

carbon burial In this report, refers to deposition of organic carbon and subsequent burial by inorganic sediments in lake, impoundment, stream, estuarine, and marine systems. Carbon also may be sequestered (sometime referred to as "buried") by injection of $\mathrm{CO}_{2}$ into suitable underground geologic formations.

carbon sequestration The removal of carbon dioxide from the atmosphere and its storage in ecological sinks (components of terrestrial or aquatic ecosystems).

conservation tillage Reduced tillage that is defined, in part, by limited cultivation and retention of plant residues on the soil surface.

contingent valuation A survey-based technique to collect information to determine the value of a nonmarket resource, such as protecting the environment or an ecosystem service.

crop rotation Sequentially growing different crops in the same field or area to (1) avoid the buildup of pests such as insects and pathogens, and (2) replenish nutrients and soil structure. denitrification The process of converting nitrate or nitrite to nitrogen containing gases like nitrous oxide by microbial processes.

deforestation The process of removing or clearing trees from forested land.

ecophysiology An area of plant ecology that investigates the relation between an organism's function and its surrounding environment.

ecosystem A natural system that is formed by the interaction of a group of organisms with their environment.

ecosystem disturbance An episodic event that may affect the composition, structure, and (or) function of an ecosystem.

ecosystem service The benefits that people and societies derive from the natural processes that sustain ecosystems.

emission A discharge or release, such as discharging greenhouse gases into the atmosphere through natural processes and human activity.

evapotranspiration A compound term used to describe the process of evaporation and plant transpiration. Evaporation accounts for the movement of water to the atmosphere from surfaces such as soils, plant canopies, and water bodies. Transpiration refers to the evaporation of water from plant leaves.

externality The economic impact on a party that is not directly involved in a transaction. In such a case, prices do not reflect the full costs or benefits in production or consumption of a product or service.

flux A flow of an entity, such as the flow of carbon from one pool to another.

flux tower A tower with instruments (for example, an anemometer that measures windspeed) that gives estimates of heat, water, and gas flux in the atmosphere.

gross primary productivity The sum of carbon fixation by plants. Photosynthesis is the process by which plants fix atmospheric carbon and assimilate it within the plant biomass.

inventory A sampling-based data collection and quantitative evaluation of recent natural resource conditions.

land cover The vegetative or other surface cover of a landscape, such as forests, grasslands, wetlands, or barren.

land use The use of land by humans, typically referring to the economic use of the land, such as for residential, agricultural, or manufacturing.

lateral flux The transport of particulate inorganic and organic carbon and dissolved organic and inorganic carbon by rivers. A portion of this carbon is deposited in inland basins, waterways, coastal areas, and oceans.

methanogensisis A form of anaerobic respiration by microbes that produces methane.

mitigation Human actions to reduce the sources of or enhance the sinks of greenhouse gases. 
monitoring The systematic collection and analysis of repeated measurements or observations through time.

net ecosystem exchange A value that reflects the net exchange of carbon between the land or ocean and the atmosphere, and equals the net ecosystem production minus the transport of carbon to groundwater or to deep ocean water.

net ecosystem carbon balance A value that reflects the overall carbon balance from all sources and sinks in an ecosystem, whether the sources are physical, biological, and human (including runoff and lateral transport by rivers).

net ecosystem production The net annual carbon accumulation by an ecosystem, which is calculated by subtracting ecosystem respiration from the gross primary productivity, and refers to the amount of organic carbon fixed in an ecosystem that is not respired there and is therefore available for accumulation, export, or oxidation.

net primary productivity The amount of new plant material produced annually, which is calculated by subtracting plant respiration from the gross primary productivity.

nitrification The process of converting ammonium to nitrate by microbial processes.

opportunity cost What must be given up in terms of the next best alternative in making a decision. Any decision that involves a choice between two or more options has an opportunity cost. It does not have to be measured in dollars.

pool A natural region or artificial holding area containing an accumulation of carbon or having the potential to accumulate carbon.

primary productivity The process of converting carbon dioxide, water, and solar energy into plant biomass.

reforestation The process of establishing a new forest by planting or seeding trees in an area where trees have previously grown.

reporting units Equivalent to assessment units. Synonymous with the U.S. Environmental Protection Agency (EPA) Level II ecoregions (Omernik, 1987) and watersheds that are aligned, to the extent possible, with boundaries of the ecoregions.

risk A chance for injury or loss. In this report, it refers to the range of potential values of certain carbon-sequestration capacities or greenhouse-gas fluxes given certain environmental, economic, and policy conditions. It also refers to the potential harm or benefit to the environment because of a particular mitigation action implemented to maximize carbon sequestration.

scenario A plausible description of how the future may develop based on a coherent and internally consistent set of assumptions about key driving forces (for example, land-use and land-cover changes) and relations.

sink A natural region or artificial holding area in which the amount of carbon is accumulating.

soil organic carbon The amount of organic carbon held in the soil.

source A natural region or artificial holding area in which the amount of carbon is decreasing.

stock The amount or quantity of carbon contained in a natural region or artificial holding area.

storyline Narratives developed by the Intergovernmental Panel on Climate Change (IPCC) to describe consistent relations between the driving forces that cause greenhousegas emissions and provide context for scenario quantification. Each storyline represents a different set of demographic, technological, and economic developments.

uncertainty The inability to precisely know properties (such as the magnitude or position) of a quantifiable parameter for estimating and projecting carbon-sequestration capacities and greenhouse-gas fluxes.

validation Quantitative evaluation of the quality of the input and (or) output data products of the assessment. 


\section{Appendix A. Reference and Alternative Mitigation Scenarios}

The reference and alternative mitigation scenarios will be designed to deliver results on the assessment components. (See chapter 1 for interpretation of the components and key concepts.) In essence, the components of the assessment required by section 712 of the Energy Independence and Security Act of 2007 (EISA) (U.S. Congress, 2007) will be satisfied by an evaluation of current carbon inventories, as well as potential carbon-sequestration capacity and greenhouse-gas (GHG) emission reductions from mitigation activities and strategies in ecosystems under a range of climate scenarios. The three overarching scenarios will be from the Intergovernmental Panel on Climate Change (IPCC) "Special Report on Emission Scenarios" (SRES) - A1B, A2, and B1 (Nakicenovic and others, 2000). The three IPCC scenarios are the socioeconomic storylines that will be used to guide the development of specific mitigation scenarios for this assessment. They are broad in scope and consistent with the IPCC SRES used in the U.S. Department of Agriculture (USDA) U.S. Forest Service's (USFS) 2010 Forest and Rangeland Renewable Resources Planning Act (RPA) assessment (U.S. Department of Agriculture, U.S. Forest Service, 2010). The IPCC SRES storylines are derived from assumptions on global-level driving forces and need to be downscaled to the national and regional level. The role of the storylines is to push experts to think beyond present conditions and the current range of thinking.

For this assessment, reference and alternative scenarios for mitigation will be developed within each of the IPCC storylines. Reference scenario (R) and alternative mitigation scenarios in each assessment unit are developed for various socioeconomic storylines and climate scenarios. Alternative mitigation scenarios are designed to enhance carbon sequestration and reduce GHG emissions from land-management change (scenario $\mathrm{M}$ ), land-use and land-cover change (scenario L), or both (scenario ML).

This appendix provides details on the national and regional processes to construct reference and alternative scenarios. At the national level, mitigation activities - such as land-use and land-cover (LULC) change and land-management changes - are selected for national assessment from a compilation of candidate mitigation activities. They are prioritized for national importance based on the existing knowledge of carbon-sequestration capacity, quantity of land suitable for the activity, and consulting agency priority. Ultimate inclusion of a mitigation activity in the assessment is determined by data availability and modeling capabilities. Also, national-level consultation will be used to develop a national set of storylines consistent with IPCC SRES and to establish guidelines for scenario construction to ensure consistency across ecoregion assessments. At the ecoregion level, reference scenarios (R) of LULC and land management are projected for each of the storylines within the confines of the national interpretation. For each ecoregion, mitigation activities will be evaluated for the potential to maximize carbon sequestration and minimize GHG emissions; evaluations will use published studies, regional expertise, and spreadsheet calculations. Mitigation scenarios are portfolios of management activities and LULC changes described in terms of amounts of change and timing of implementation. In accordance with national guidelines, alternative mitigation scenarios will be constructed to enhance carbon sequestration. Further elaboration of mitigation-activity selection, interpretation of the IPCC storylines for the reference and mitigation scenarios, and scenario construction follows. The last section provides a summary of the national and regional consultation process.

\section{A.1. National Selection of Mitigation Activities}

The selection of mitigation activities for the national assessment involves prioritization of mitigation activities and identification of the relevant national datasets. The assessment addresses two types of mitigation activities that ecologically sequester carbon or mitigate GHG emissions in ecosystems: LULC change and land-management change. LULC change is described in terms of changes between thematic LULC classes (section 3.2 of the main document), and land management occurs within the confines of a LULC class. LULC changes for increasing carbon sequestration include afforestation (conversions from pasture and croplands into forested land classes), mine-land reclamation, and wetland restoration or construction (transitions into the wetland classes). LULC changes to reduce GHG emissions may include the reduction of deforestation and the reduction of rice cultivation. Management activities on croplands may include conservation tillage, more efficient fertilization application, and crop rotations. On forest lands, management pertains to forest management and timber harvesting. All these mitigation activities affect GHG fluxes from aquatic systems via effects on erosion and nutrient loads.

Candidate mitigation activities have been compiled from the literature (for example, Lewandrowski and others, 2004; Murray and others, 2005; Eggleston and others, 2006) and underwent preliminary preparation and review at a policy workshop that was conducted by the Center for Climate Strategies and convened at the U.S. Geological Survey (USGS) headquarters in Reston, Va., December 1-2, 2009. A catalog of mitigation activities was distributed in advance and participants provided feedback. Criteria to prioritize mitigation activities for national assessment may include the primary considerations for ecological carbon-sequestration capacity:

- Sequestration capacity per hectare of mitigation activity

- Hectares of suitable lands for mitigation activity change to identify applicable upper bounds on mitigation activity change

- Time-effectiveness of sequestration to address how quickly the mitigation activity provides climate-change mitigation and duration of the effect of the mitigation activity on sequestration rate (for example, five decades for management activities affecting forest 
and soil pools, one decade for cropland management changes, and two decades for LULC conversion)

- Permanence of sequestration to address differences in how much carbon remains sequestered over time for each mitigation activity

The product of the first two measures recognizes activities that may result in smaller changes in rates of sequestration, but that are applicable to a vast quantity of lands (for example, rangelands). In addition, the priorities of consulting agencies will be considered in the selection of mitigation activities for the assessment.

Candidate mitigation activities listed in table 3.5 of this report are aligned with those incorporated into the Forest and Agriculture Sector Optimization Model with Greenhouse Gases (FASOM-GHG) (Murray and others, 2005) to provide perspective on the scope of the assessment and to indicate common areas where FASOM-GHG methods, data sources, and results for mitigation activities will be informative for the methodology (table A1). Not all FASOM-GHG mitigation strategies are within the scope of the assessment; for example, the category of fossil-fuel mitigation from crop and livestock production will not be used. Conversely, some mitigation activities not represented in FASOM-GHG are included as candidate mitigation activities in the assessment.

The mitigation activities will be researched before presentation to policy makers and the consulting agencies. The legislation requires the Secretary of the Interior to consult with the Secretary of Energy, the Secretary of Agriculture, the Administrator of the Environmental Protection Agency, the Secretary of Commerce (acting through the Under Secretary for Oceans and Atmosphere), and the heads of other relevant agencies. The candidate mitigation activities priorities will be discussed at a national workshop, but final selection will be subject to data availability, acceptance of assumptions, and model capabilities. Mitigation activities that currently (2010) are operational for the assessment are listed in table A2.

Land-use change is measured as the number of hectares of LULC class change. Within LULC classes, land-management activities are measured as the number of hectares of land-management change. Land management is complex because any one type of land management can be implemented with varying intensity. By way of example, Adams and others $(1996,2005)$ defined and used regional forest-management-intensity classes, ranging from passive to high-intensity management, for their analyses of carbon-sequestration supply. For the assessment, land management "carbon-sequestration intensity" relates to carbon-sequestration rate. For example, carbon optimal harvests that maximize sequestration in the forest ecosystem and wood products are of greater "carbon-sequestration intensity" than economically optimal harvest rotations (Huang and Kronrad, 2001). Analogies for croplands include crop rotation (versus monocultures) and tillage intensity (Choi and Sohngen, 2009). Carbon intensities of grazing-land management will be framed by recent (2010) rangeland and grassland research (Follett and others, 2001; Bremer and Ham, 2010; Brown and others, 2010).
Also specified at the national level are guidelines to construct alternative mitigation scenarios that are portfolios of mitigation activities, with details on the amounts of change and the timing of implementation. At the regional level, three alternative mitigation scenarios are constructed relative to a reference scenario. The storylines behind each set of reference and alternative scenarios need to be interpreted at the national level to ensure consistency across ecoregions.

\section{A.2. National Interpretation of Storylines}

The next step toward creating a set of regional LULC and land-management scenarios is to develop a set of national storylines consistent with the IPCC SRES. This step will be done primarily through a national workshop. Using existing LULC projections associated with the IPCC SRES scenarios and other supporting data as a guide, expert opinion will be solicited to describe plausible reference scenarios of LULC and land management based on the underlying assumptions of the SRES storylines. National storylines can be viewed as thematically enriched sets of SRES storylines with characteristics specific to United States land use and land management. Nakicenovic and others (2000) provided the following narratives and assumptions for each of the SRES scenario families (table A3). For more complete descriptions of SRES storylines, see Nakicenovic and others (2000).

The A1 storyline and scenario family describes a future world of rapid economic growth, minimal or decreasing population growth, and the introduction of new and more efficient technologies. The primary underlying themes are convergence among regions, capacity building, and increased cultural and social interactions, with a substantial reduction in regional differences in per-capita income. The A1 scenario family develops into four groups that describe alternative technological changes in the energy system.

The A2 storyline and scenario family describes a heterogeneous world. The underlying theme is self-reliance and preservation of local identities. Fertility patterns across regions converge slowly, which results in population growth. Economic development primarily is regionally oriented, and per-capita economic growth and technological changes are more fragmented and slower than in other storylines.

The B1 storyline and scenario family describes a convergent world with the same low population growth as in the A1 storyline, but with rapid changes in economic structures toward a service and information economy, with reductions in material intensity, and the introduction of clean and resourceefficient technologies. The emphasis is on global solutions to economic, social, and environmental sustainability, including improved equity, but without additional climate initiatives.

A primary deliverable of the national workshop will be expanded LULC narratives and national-scale LULC trajectories. Nested within the national narratives will be assumptions on the regional variability of LULC and management where available (fig. A1.) For example, a national-scale narrative 
Table A1. Candidate mitigation activities compared with strategies associated with the Forest and Agriculture Sector Optimization Model with Greenhouse Gases.

[Modified from Murray and others (2005). FASOM-GHG, Forest and Agriculture Sector Optimization Model with Greenhouse Gases; $\mathrm{CH}_{4}$, methane; $\mathrm{N}_{2} \mathrm{O}$, nitrous oxide; GHG, greenhouse gas]

\begin{tabular}{|c|c|c|}
\hline Strategy/activity & Candidate mitigation activities & Mitigation activities tracked in FASOM-GHG \\
\hline Afforestation carbon sequestration & Convert lands to forest ${ }^{1}$ & Convert agricultural lands to forest. \\
\hline $\begin{array}{l}\text { Forest management carbon seques- } \\
\text { tration }\end{array}$ & $\begin{array}{l}\text { Lengthen timber harvest-regeneration rotation } \\
\text { Increase forest management intensity (increasing forest } \\
\text { density, thinning, fire-fuel reduction, insect and disease } \\
\text { management) } \\
\text { Preserve forests }{ }^{1}\end{array}$ & $\begin{array}{l}\text { Lengthen timber harvest-regeneration rotation. } \\
\text { Increase forest management intensity. } \\
\text { Preserve forests. }\end{array}$ \\
\hline $\begin{array}{l}\text { Forest management } \mathrm{CH}_{4} \text { and } \mathrm{N}_{2} \mathrm{O} \\
\text { mitigation }\end{array}$ & Reduce deforestation ${ }^{1}$ & Reduce deforestation. \\
\hline $\begin{array}{l}\text { Agricultural soil carbon sequestra- } \\
\text { tion }\end{array}$ & $\begin{array}{l}\text { Reduce cropland tillage } \\
\text { Crop mix change to high-residue crops } \\
\text { Increase efficiency of crop fertilization } \\
\text { Convert grasslands and perennial crops } \\
{ }^{1} \\
\text { Increase winter cover crops } \\
\text { Reduce summer fallow } \\
\text { Restore agricultural land } \\
\text { Increase irrigation efficiency }\end{array}$ & $\begin{array}{l}\text { Change crop tillage. } \\
\text { Change crop mix. } \\
\text { Change crop fertilization. } \\
\text { Convert grassland. }\end{array}$ \\
\hline $\begin{array}{l}\text { Fossil-fuel mitigation from crop } \\
\text { production }\end{array}$ & & $\begin{array}{l}\text { Change crop tillage. } \\
\text { Change crop mix. } \\
\text { Change crop input. } \\
\text { Change irrigated/dry land mix. }\end{array}$ \\
\hline $\begin{array}{l}\text { Agricultural } \mathrm{CH}_{4} \text { and } \mathrm{N}_{2} \mathrm{O} \text { mitiga- } \\
\text { tion }\end{array}$ & $\begin{array}{l}\text { Reduce cropland tillage } \\
\text { Improve crop mix } \\
\text { Increase efficiency of crop fertilization } \\
\text { Reduce rice acreage }^{1}\end{array}$ & $\begin{array}{l}\text { Change crop tillage. } \\
\text { Change crop mix. } \\
\text { Change crop input. } \\
\text { Change rice acreage. } \\
\text { Change irrigated/dry land mix. } \\
\text { Control enteric fermentation. } \\
\text { Change livestock herd size. } \\
\text { Change livestock system. } \\
\text { Manage manure. }\end{array}$ \\
\hline $\begin{array}{l}\text { Grassland/rangeland soil carbon } \\
\text { sequestration }\end{array}$ & $\begin{array}{l}\text { Improve grazing management practices } \\
\text { Restore degraded rangelands } \\
\text { Improve use of fertilizer } \\
\text { Allow natural succession towards native shrub and forest }\end{array}$ & Not applicable. ${ }^{2}$ \\
\hline Rangeland GHG mitigation & Reduce severe rangeland fire & Not applicable. \\
\hline Grassland GHG mitigation & Avoid conversion to energy crops ${ }^{1}$ & Not applicable. \\
\hline $\begin{array}{l}\text { Wetland carbon sequestration } \\
\text { (negative impact on } \mathrm{CH}_{4} \text { ) }\end{array}$ & Preserve, construct, and restore wetlands ${ }^{1}$ & Not applicable. \\
\hline Wetland carbon mitigation & Preserve wetlands ${ }^{1}$ & Not applicable. \\
\hline Urban land carbon sequestration & Increase urban forests & Not applicable. \\
\hline Barren land carbon sequestration & Reclaim mined lands ${ }^{1}$ & Not applicable. \\
\hline Wood product sequestration & $\begin{array}{l}\text { Improve mill waste recovery } \\
\text { Extend life of wood products } \\
\text { Extend storage in landfills }\end{array}$ & Change wood product mix. \\
\hline Wood product GHG mitigation & Improve logging & Not applicable. \\
\hline Fossil-fuel mitigation & Not applicable & Produce crops for biofuel use. \\
\hline $\begin{array}{l}\text { Technological potential for carbon } \\
\text { sequestration }\end{array}$ & $\begin{array}{l}\text { Use biochar } \\
\text { Restore degraded rangelands }\end{array}$ & Use biochar (under investigation). \\
\hline Aquatic GHG mitigation & $\begin{array}{l}\text { Reduce nutrient export from urban and agricultural lands } \\
\text { Alter withdrawal from deep reservoirs }\end{array}$ & Not applicable. \\
\hline
\end{tabular}

\footnotetext{
${ }^{1}$ Indicates a land-use change in the assessment (as distinct from a land-management change).

${ }^{2}$ FASOM-GHG 2010 has expanded rangeland and grassland categories and therefore can track LULC changes in these categories, but no mitigation activities are currently implemented.
} 
might include assumptions on forest use while highlighting certain regions as likely places for changes in forestry.

In figure $\mathrm{A} 1$, the primary graph begins with the solid black line which denotes measured LULC change based on the USGS Land Cover Trends project (Loveland and others, 2002). In this figure, the trends data represent national estimates for a hypothetical LULC class from 1970 to 2000. The subsequent solid-red line represents LULC composition as modeled using the "forecasting scenarios of land cover change" (FORE-SCE) model based on actual LULC measurements from the 2006 National Land Cover Database (NLCD) change product and LANDFIRE vegetation change tracker (VCT) products as inputs for 2001 through 2010. The set of

Table A2. Mitigation activities included in 2001 dataset of landuse and land-cover starting points.

[These mitigation activities have been implemented in simulation models proposed for use in this methodology. A discussion can be found in section 3.2 of this report. USGS EROS, U.S. Geological Survey Center for Earth Resources Observation and Science; USDA NASS, U.S. Department of Agriculture National Agricultural Statistics Service; USDA FIA, U.S. Department of Agriculture Forest Service Forest Inventory and Analysis Program; LANDFIRE, Landscape Fire and Resource Management Planning Tools]

\begin{tabular}{ll}
\hline \multicolumn{1}{c}{ Mitigation activity } & \multicolumn{1}{c}{ Data source } \\
\hline Irrigation & USGS EROS National Irrigation Map. \\
Drainage & USGS EROS National Irrigation Map. \\
Fertilization & USDA NASS. \\
Residue management & Residue management county statistics. \\
Tillage & USDA NASS. \\
Crop rotation & USDA NASS. \\
Grazing & USDA NASS. \\
Manure application & USDA NASS. \\
Forest cutting & USDA FIA. \\
Forest thinning & USDA FIA. \\
Fuel treatments & LANDFIRE. \\
\hline
\end{tabular}

three dashed-green lines that follows represents hypothetical trajectories of the same LULC class for each of the scenarios in the IPCC SRES for the United States. The inset graph represents the spatial and temporal variability of LULC composition for the A1B SRES scenario across assessment units (U.S. Environmental Protection Agency's Level II ecoregions, modified from Omernik (1987). The different colors represent discrete geographic regions.

\section{A.3. Ecoregion Reference Scenario Construction}

Regional reference scenarios build from the national storylines discussed above. The foundations of regional scenarios are LULC and land-management histories developed through review of existing historical data sources, including the comprehensive analysis of recent historical LULC change from the USGS Land Cover Trends research project (Loveland and others, 2002). Regional expert consultations will be used to project recent historical LULC into the future based on the current (2010) understanding of the interaction of drivers of LULC change. Regional experts will link SRES and national LULC and management storylines with the biophysical and socioeconomic characteristics of ecoregions to provide a range of LULC and management futures consistent with historical observations.

The scenario construction process also may incorporate exogenous projections of particular LULC types or management. Examples include projections of population from the U.S. Census Bureau or the USFS's 2010 RPA land-use projections; however, maintaining fidelity with the SRES storylines is required, and the regional expert consultation process will determine the degree to which these exogenous projections are used, if at all. Other coarse-scale LULC modeling efforts, such as those provided by IPCC SRES modeling teams, can be empirically downscaled and combined with existing expertise in LULC science, LULC histories reported in existing studies, and regional expert knowledge to construct regional LULC scenarios for each ecoregion. Constraints on scenario construction primarily are the SRES storylines and existing

Table A3. Qualitative characteristics associated with three scenario families from the Intergovernmental Panel on Climate Change Special Report on Emission Scenarios.

[Modified from Nakicenovic and others (2000). GDP, gross domestic product]

\begin{tabular}{llll}
\hline \multirow{2}{*}{ Scenario characteristics } & \multicolumn{3}{c}{ Special Report on Emission Scenarios storyline } \\
\cline { 2 - 4 } & \multicolumn{1}{c}{ A1B } & A2 & B1 \\
\hline Population growth & Low & High & Low. \\
GDP growth & Very high & Medium & High. \\
Energy use & Very high & High & Low. \\
Land-use changes & Low & Medium high & High. \\
Resource availability & Medium & Low & Low. \\
Pace and direction of technological change & Rapid & Slow & Medium. \\
Technological change favoring & Balanced & Regional & Efficiency and dematerialization. \\
\hline
\end{tabular}


knowledge of regional LULC change. This flexible framework creates opportunities to explore a wide range of regional LULC scenarios, and remain consistent with overall SRES assumptions and characteristics.

\section{A.4. National Interpretation of Storylines for Alternative Mitigation Scenarios}

Interpretation of the national storyline is expanded to support construction of the alternative mitigation scenarios. A mitigation scenario is a combination of future potential LULC and land-management changes (activities) associated with vetted climate and socioeconomic conditions to illustrate possible GHG mitigation capacities with various assumptions. There is no precedent for constructing alternative mitigation scenarios for the IPCC SRES. The USFS RPA assessment has not embarked on this endeavor. Alteration of the reference scenario to explore mitigation activities to enhance carbon sequestration and reduce GHG emissions compromises the internal consistency of a reference scenario that is devoid of carbon-sequestration policy. Notably, carbon-sequestration policy that leads to reduced GHG emissions and increased carbon sequestration affects climate, but this effect cannot be captured without modeling policy changes at the global scale. Although the more recent representative concentration pathways (RCP) effort (Moss and others, 2010) avoids this problem by finding alternative scenarios for each radiative forcing target, it requires scenarios to meet carbon sequestration and GHG-emission reduction targets, rather than explore ecosystem capacity. The methodology accepts climate incongruity for alternative scenarios. Conceptually, it is easier to guard the storyline for changes in land management (M), although changes in land management have implications for yields and consumption patterns. Departure from the storyline is exaggerated by
LULC changes to enhance carbon sequestration ( $\mathrm{L}$ and ML) because of competing uses for land to produce food, fiber, and energy for the population. The IPCC SRES storylines are used to motivate a diverse set of alternative mitigation scenarios emphasizing mitigation activities, different change amounts, and different concerns for the temporal aspects of carbon sequestration, including time-effectiveness and permanence of sequestration.

The three storylines are differentiated by assumptions that will be related to emphases on mitigation activities, amounts of change, and importance of timing and permanence of carbon sequestration. Examples are described below:

- For IPCC SRES storyline A1B-

- The freeing of natural resources could enable afforestation

- The emphasis on management versus conservation is more likely to promote plantations rather than natural forest

- The pervasiveness of urban sprawl may restrict reductions in the rates of urban development

- The technological progressiveness of A1B may justify technological feasibility of biochar and rangeland restoration

- For IPCC SRES storyline A2-

- The increased or large population growth and focus on sustainable food production may limit conversion of agricultural lands to forest lands, but it may be compatible with agricultural practices that enhance carbon sequestration through conservation tillage, efficient fertilizer usage, crop rotations, and cover crops

- The concern for water quality for sustainable agriculture may prompt wetland restoration

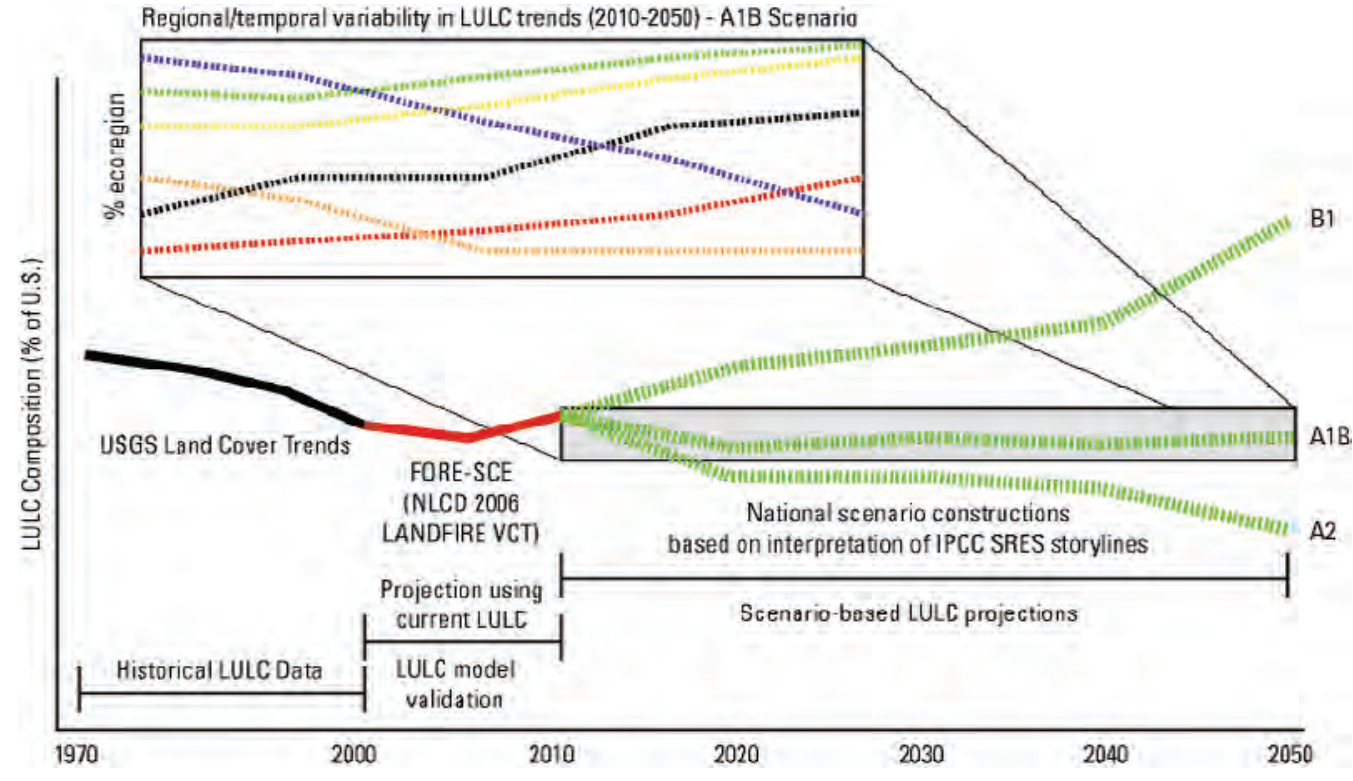

Figure A1. Diagram showing the national and regional scenario scaling concept, showing past, present, and projected land-use and land-cover change. LULC, land use and land cover; FORE-SCE, Forecasting Scenarios for Future Land Cover model; NLCD, National Land Cover Database; LANDFIRE, Landscape Fire and Resource Management Planning Tools; VCT, vegetation change tracker; IPCC, Intergovernmental Panel for Climate Change; SRES, Special Report on Emission Scenarios. 
- For IPCC SRES storyline B1-

- The focus on sustainable development may embrace sustainable food production and wetland protection within A2, but it also may include sustainable forestry practices including the following:

- Afforestation and avoidance of deforestation

- Expansion of urban forests

- Forest management for carbon sequestration

- Native species

- Resource efficiency may promote slower rates of development and increased urban density

- The sustainable development focus may value longand short-term carbon-sequestration activities

Alternatively, national initiatives, similar to Conservation Reserve Program (CRP), for ecological carbon sequestration will be invited from consulting agencies and applied to varying degrees (for example, high, medium, and low levels of national commitment) across the storylines. Either way, the national consultation process will be relied upon to provide national bounds on increases in mitigation activities. Similarly, bounds on mitigation activities in ecoregions also need to be evaluated.

\section{A.5. Ecoregion Evaluation of Mitigation Activities}

For each ecoregion, mitigation activities will be examined for relevance (for example, grazing-land management is more prevalent in some ecoregions than others) and evaluated for their potential to sequester carbon and reduce GHG emissions. Evaluating LULC conversions and land-management changes in the ecoregion will identify activities that maximize carbon sequestration to provide an efficient means to construct alternative mitigation scenarios that "optimize" sequestration in the ecoregion given a limited number of scenario simulation runs and no iteration. Furthermore, a transparent evaluation of mitigation activities complements the complex simulations of LULC change and biogeochemical modeling. Evaluating mitigation activities is accomplished by using results from regional studies of carbon-sequestration-mitigation activities, consulting with regional experts (for example, GRACEnet participants), and developing a spreadsheet tool. Two objectives of GRACEnet are to identify an agricultural system that most likely maximizes soil carbon sequestration and to identify an agricultural system that minimizes net global warming potential (Jawson and others, 2005; U.S. Department of Agriculture, Agricultural Research Service, 2010). As a result of carbonsequestration research, some regional studies of mitigation activities are readily available. For example, relevant studies about mitigation activities in the Mississippi Alluvial Plain and Mississippi Valley Loess Plains ecoregions include the following.
- Loblolly pine harvest rotations (Huang and Kronrad, 2006; Sohngen and Brown, 2008)

- Fertilization of loblolly pine plantations (Fox and others, 2007)

- Sequestration from softwood (evergreen) forest versus hardwood (deciduous) forest (Sohngen and Brown, 2006)

- Reforestation of poorly stocked pine plantation (Huang and others, 2004)

- Conservation tillage (Franzluebbers, 2005)

- Cotton rotations including pasture (versus monoculture) and with cover crops (Causarano and others, 2006)

- Restoration of bottomland forests (Wainger and King, 2001; Jenkins and others, 2009).

These studies provide details on potential land-management and LULC change for the ecoregion. State climatechange studies provide further indications of the potential to enhance sequestration. For example, the Arkansas Governor's Commission on Global Warming plan sets a target of 4 percent increase in urban trees by 2025 (Arkansas Governor's Commission on Global Warming, 2008). Consulting with regional experts will further develop a knowledge base for mitigationactivity potential to enhance sequestration capacity in the ecoregion.

A spreadsheet tool will be used to synthesize available study results and fill in details on carbon sequestration. The tool will present aggregated planning-level estimates of how annual rates of carbon sequestration and cumulative carbon sequestration will change with time as a result of changes in LULC and management from time of implementation. (This is in contrast to the reference and alternative scenarios that stage the implementation of the mitigation activities with time.) The spreadsheet tool will enable exploration of the sensitivity of carbon sequestration to forest management (thinning, harvest rotation, and sequestration in wood products) and agricultural crop rotations of importance to the ecoregion, as needed. A similar spreadsheet tool was developed for the U.S. Environmental Protection Agency (EPA) in the late 1990s and implemented for Omernik's (1987) ecoregions (Dennis King, University of Maryland, written commun., 2010). The Natural Capital Research Group at the University of Maryland Center for Environmental Science (UMCES) developed a spreadsheet approach during 1996 and 1997 for the EPA Office of Policy Analysis, in preparation for the 1997 Kyoto Conference. When the United States pulled out of the Kyoto negotiations in 1998, the project was suspended; the spreadsheet results for 22 management activities were not published, although they were used in 1999 and 2000 in a project for the EPA Office of Air to show how one might "score" domestic carbon trading that involved land-based carbon sequestration. Although this tool needs updating, further development, and refinement for the assessment, the effort provides a proof of concept. 
The mitigation-activity spreadsheet tool will be developed to report results for each of the assessment units with calculations made at the regional and subregional levels. Each spreadsheet will show the expected change (gains, losses, and net) in carbon sequestered resulting from a specific LULC or management activity to another during three periods: a transitional term of 15 years, the medium term of 16 to 40 years, and the longer term of 41 to 100 years, or to an endpoint deemed appropriate for the mitigation activity (as the capacity of some forest ecosystems to sequester carbon is not captured within the 40-year horizon of the assessment). The results will be backed up by detailed tables showing how aboveground, belowground, and on-ground carbon is expected to increase and decrease with time. The spreadsheets will refer to the models that generated them (for example, the Century model from Parton and others (1993)) so that users interested in moving beyond planning-level estimates to consider specific policies in specific jurisdictional boundaries will have access to more detailed and precise numbers.

A column for hectares of suitable or available land for each mitigation activity will be inserted to complete estimates of total carbon potential for the activity and to provide an upper bound on change amount. Designating and bounding suitability is not a well-defined task. The FASOM-GHG conversion (for example, pasture to forest) suitability was derived from Natural Resources Conservation Service (NRCS) land surveys and expert opinion (Adams and others, 1996). The FORE-SCE probability surfaces indicate relative suitability of land for LULC. There are limits on land-management suitability, as well. For example, the benefit of no-till methods in heavy clay soils is questionable (Rochette and others, 2008).

A concept related to suitability is availability, which is the supply of hectares of mitigation activities for a price (Brown and Kadyszewski, 2005); therefore, suitability also is indicated by the hectares of mitigation activities supplied at a high carbon price. In short, various data sources and model results provide indications of hectares of suitability and availability; for the prototype study region, the availability of bottomland forest was taken from the marginal land analysis of Wainger and King (2001). The percentage change in bottomland forest was noted to fall within the percentage change of national afforestation estimated by FASOM-GHG for the \$50-pertonne (megagram) price (Murray and others, 2005) and the USDA (Lewandrowski, 2004). Similarly, the national results from the latter two studies were used to indicate conservation tillage change bounds, but regional results from those studies could be accessed for the assessment. The increase in urban forests was adopted from the State climate-change plans. Regional consultation also will be used to indicate bounds on the suitability and availability of hectares for mitigation activities in the ecoregion.

The assessment unit spreadsheets for mitigation activities will be populated as follows:

1. Available studies and regional subject expertise will be used to specify the mitigation activities for each LULC class in the assessment unit.
2. The Carbon Online Estimator (COLE; U.S. Department of Agriculture, U.S. Forest Service, 2010a), the Voluntary Reporting of Greenhouse Gases-Carbon Management Evaluation Tool (COMET-VR; U.S. Department of Agriculture, Natural Resources Conservation Service, 2010), and the Century carbon model (which has a user-friendly interface) will be used to estimate annual rates of carbon sequestration for each LULC and management activity within each EPA Level II ecoregion from year 1 (for example, year of transition to the management activity intensity) to year 40 and beyond as appropriate.

3. The results of step 2 will be compared with results of earlier nationwide research (for example, Sperow and others, 2003).

4. The number of hectares in each LULC class and landmanagement carbon-intensity class for the starting conditions for each EPA Level II ecoregion (section 3.2 of this report) will be obtained.

5. The hectares of LULC class suitability will be estimated using FORE-SCE probability surfaces, estimates from other studies (for example, FASOM-GHG suitability estimates based on data from the National Resources Inventory (NRI) of the NRCS)), and regional consultation, as will land-management suitability limits.

6. A spreadsheet tool for each EPA Level II ecoregion will be prepared (see table A4 for a sample report).

7. Instructions and caveats about using the spreadsheet data, providing explanations about how spreadsheet numbers were generated, and links back to underlying simulations and models will be documented.

For users outside of the assessment, additional steps can be implemented to refine a spreadsheet tool to organize information for various spatial scales, such as counties and States, and to package spreadsheet tools in various ways to support the needs of users.

\section{A.6. Alternative Mitigation Scenario Construction for Ecoregions}

For an ecoregion, three alternative mitigation scenarios will be constructed to enhance carbon sequestration and reduce GHG emissions through land management (M), LULC change (L), and both (ML) for each storyline. Each set of storyline alternative mitigation scenarios will be built from national guidelines regarding mitigation activity emphases (for example, managed versus natural), commitments to change (for example, high, medium, low), and aggressiveness of carbon sequestration (for example, urgent, constant, delayed). The evaluation of the mitigation activities, described above, provides the means by which to specify mitigation activities that maximize carbon sequestration, to bound mitigation activity change within the ecoregion and storyline, and to indicate carbon sequestration with time. 
Table A4. Sample spreadsheet format adapted from earlier spreadsheets for the U.S. Environmental Protection Agency.

[GHG, greenhouse gas; LULC, land use and land cover; $\mathrm{Mg} / \mathrm{ha} / \mathrm{yr}$, megagram (metric ton) per hectare per year]

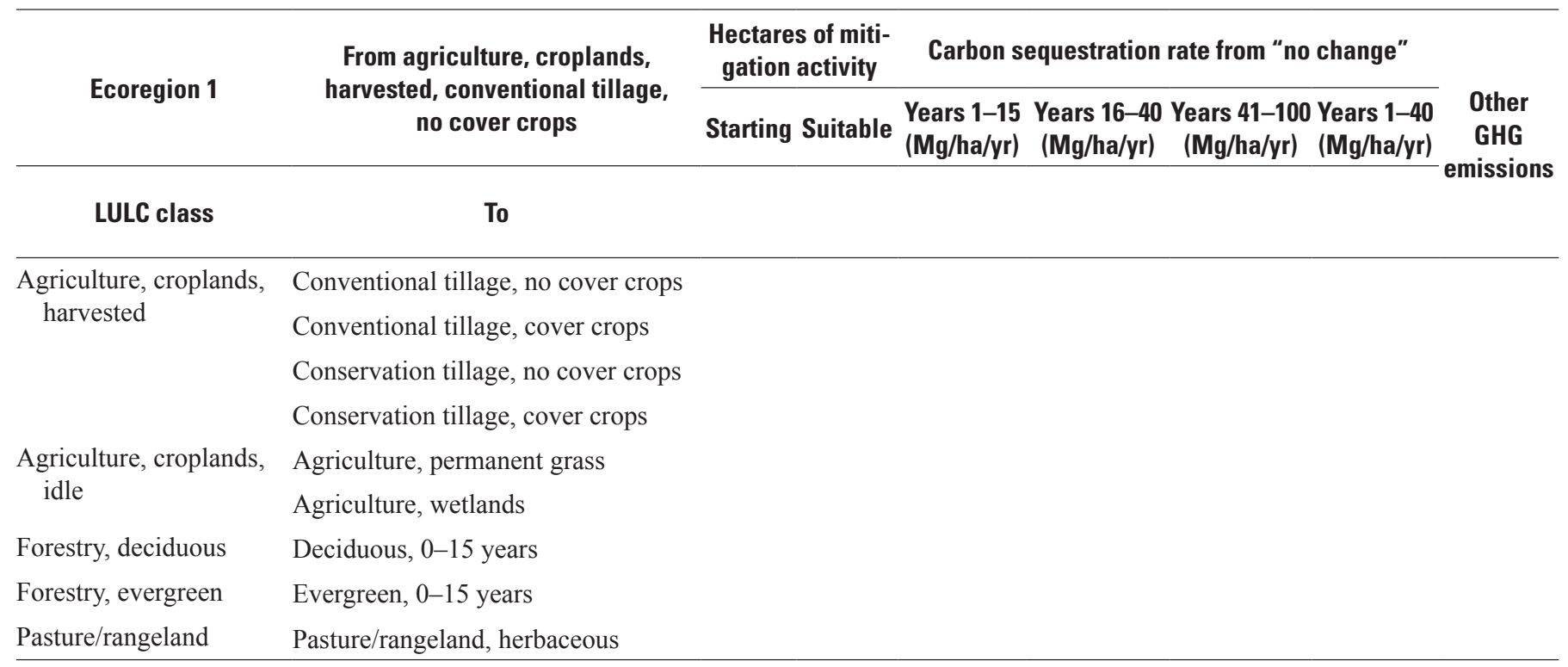

In the absence of national and regional consultation, a preliminary example of an alternative mitigation scenario for the sample region is provided for illustrative purposes in table A5. The features of an alternative enhanced scenario (for example, ML scenario for the A1B storyline (denoted as A1B_ML)) are:

- Net change from 2010 to 2050 of the alternative scenario reported against the net change of the reference case

- LULC change implemented at an annualized rate of the net change (constant implementation)

- Reasons for and amounts of LULC changes, and constraints on conversions

- Reasons for and amounts of land-management changes within LULC classes

Supporting references for each of the two types of mitigation activities in these ecoregions were noted in section A.2. Except for bottomland forest restoration in the Mississippi Alluvial Plain (where a study proposed acres of conversion), land-use percentages and management change are fabricated in the absence of a functioning regional consultation process.

There are many other factors that affect realized sequestration capacity including cost, technological feasibility, effects on ecosystem functions and services, energy usage, and policy implementation. The primary purpose of the scenario construction is to assess the ecological sequestration capacity of ecosystems. Demonstrating relations between carbon sequestration and other factors are provided in chapter 3 of this report and appendix F.

\section{A.7. National and Regional Consultation Processes}

\section{A.7.1. Framework for Engaging Expert Opinion to Calibrate Models}

An important conceptual component of the modeling process is consultation. The goal of this consultation process is to ensure that the constituents of the reference and alternative mitigation scenarios being modeled in the assessment are relevant at the scale of the assessment unit. Further, it is desirable, and indeed necessary, that the processes and assumptions used to construct scenarios (and constituents) are consistent across ecoregions so that comparisons are valid. The assessment will engage regional experts to ensure regional relevance operating within a national framework to ensure consistency.

The assessment requires the integration of somewhat disparate models and project components, and consequent fields of expertise, such as LULC change, land-management change, biogeochemical modeling, policy, and economics. As such, the approach to calibrating modeling components will be split into two branches (fig. A2). One branch of the calibration process will focus on reference scenario development; the other will focus on mitigation scenario development. The two calibration branches are not independent, but can proceed in parallel with careful scheduling. Each of the two branches will be led by a subgroup in the assessment; the subgroup members will maintain contact with the other subgroup through the project leadership group. To improve the efficiency and outcomes of the calibration process, 
external organizations with significant experience in working with experts may be retained and used to help develop protocols, materials, and tools where needed.

An important aspect to all scales of scenario construction is the use of historical LULC, rates of LULC change, landmanagement dynamics, and other related data, both spatial and nonspatial. Examples of such data are found in table A6. These data will first be used during national reference scenario construction and consultation to document the historical trajectories of variables affecting U.S. LULC change and management, inform experts about spatial variability of U.S. LULC change, and provide a historical baseline from which to project changes in LULC and management under alternative scenarios.

\section{A.7.2. National Reference Scenario Development (Box A in Figure A2)}

The foundation of the assessment process is a suite of SRES-based reference scenarios. The three SRES scenarios will be interpreted, and a narrative description will be developed. These three storylines comprise the national reference modeling scenarios. These national, initial "strawman" reference scenarios will be reviewed and refined by a wide array of relevant experts at a national workshop. Comments and suggestions from a geographically diverse set of workshop participants will be reviewed and incorporated where needed. The outcome of this process will be a set of national-level, reference storylines and scenarios. At this scale, focus is on developing qualitative storylines rather than quantitative scenarios. The storylines will be the primary product used to develop regional land-use scenarios.

\section{A.7.3. National Mitigation Scenario Development (Box B in Figure A2)}

One of the key questions to be addressed for the assessment is which of the mitigation activities have the greatest potential to increase carbon sequestration and GHG fluxes. Because land-change modeling and biogeochemical assessment models are a central part of the methodology, the list of candidate mitigation activities must be compared against the capabilities of the models and data availability to ensure that they are compatible. A national consultation with a diverse set of experts will be used to obtain additional external review of the list of mitigation activities, prioritize mitigation activities for the assessment, set national guidelines for plausible maximum mitigation activity change, and provide guidelines on the assignment of mitigation activities to the storylines. Supplemental small meetings with specific relevant experts also may be held to ensure that a variety of stakeholder interest groups are represented. The outcome of this process will be a national set of guidelines for implementing mitigation scenarios to increase carbon sequestration and reduce GHG emissions at the regional level.

\section{A.7.4. Regional Reference Scenario Development (Box C in Figure A2)}

To improve the relevance of assessment results at regional levels, the national reference scenarios will be downscaled to EPA Level II ecoregions (assessment units; modified from Omernik, 1987). To accomplish this important goal, a series of regional consultations will be conducted. Relevant assessment staff will identify and engage key experts in each ecoregion. Because many of the ecoregions are quite large, the team will explore using model input ranges based upon regional expert suggestions (for example, various data scales from the U.S. Census Bureau) with qualitative (for example, types of specific LULC transitions) and quantitative (for example, overall national rates of LULC change) constraints developed during the national scenario development stage to guide regional scenario construction. The results of this development process are a critical input to the next step in the process-developing regional-level mitigation scenarios.

\section{A.7.5. Regional Mitigation Scenario Development (Box D in Figure A2)}

Results from the national mitigation scenario workshop and regional reference scenario consultations are combined in this final step aimed at regionalizing mitigation scenarios. Regional experts will be engaged to work from a set of activities from the national list in the context of the reference scenarios developed for that region. Regional engagement may be organized through regional entities such as the U.S. Fish and Wildlife Service's Landscape Conservation Cooperatives (LCC) and the U.S. Department of Interior's initiative for Climate Science Centers. Regional experts will suggest changes to the selected mitigation activities to improve local and regional relevance, will review the synthesis of relevant research and spreadsheet results, and will review three

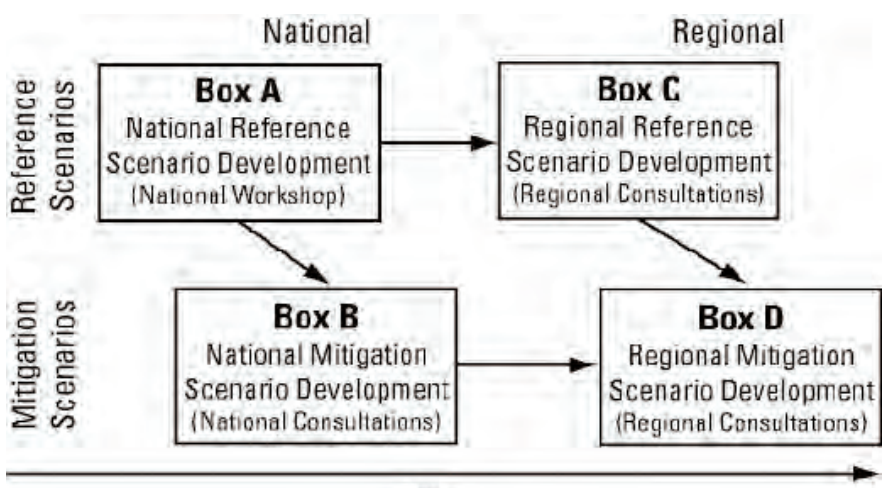

Time

Figure A2. Diagram showing the national and regional consultation process to obtain expert knowledge to calibrate scenarios for the assessment. 


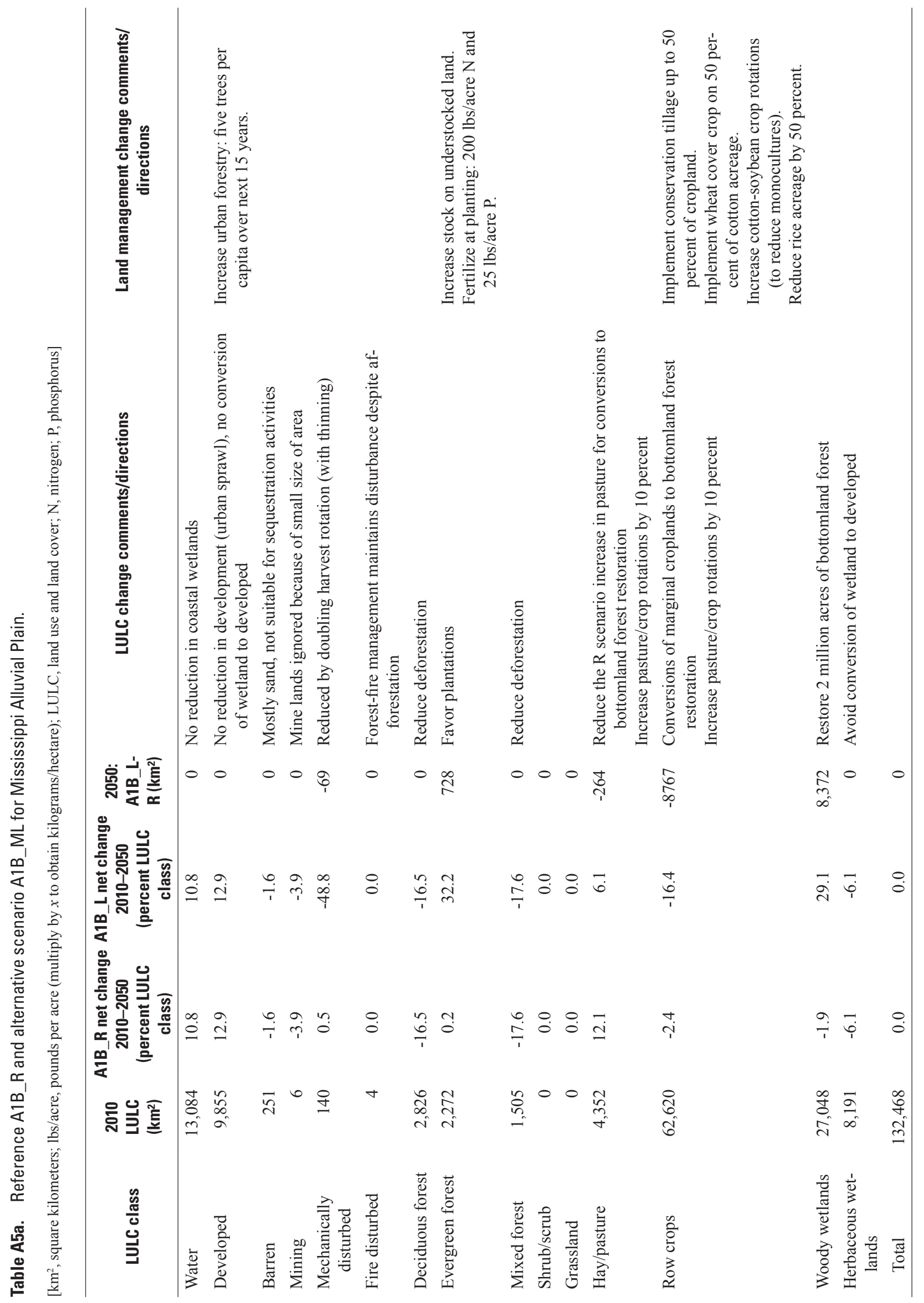




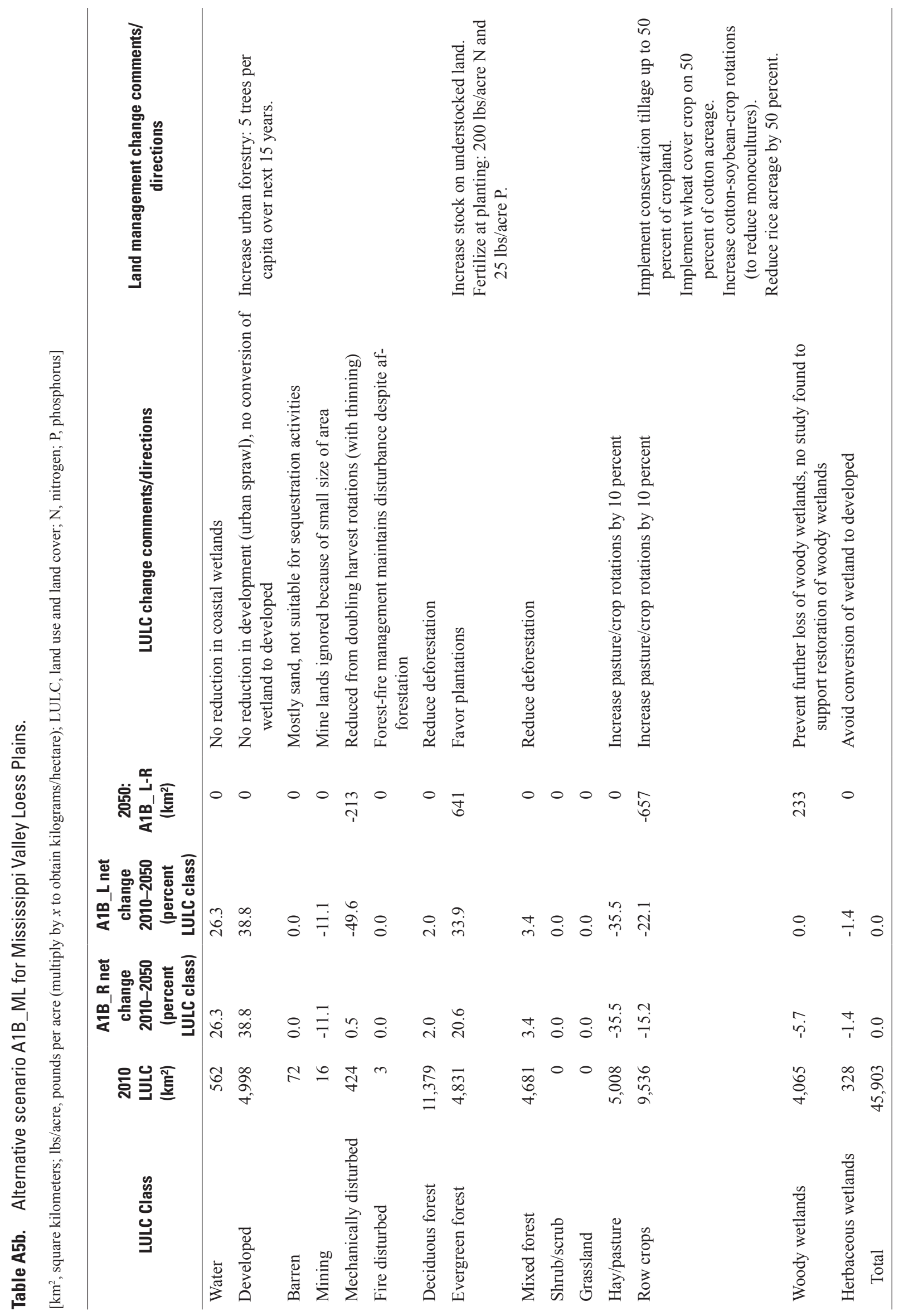


regional mitigation scenarios for each storyline. It is important to note that process consistency will be maintained throughout these steps by requiring that each successive scenario construction build upon previous stakeholder's or expert's calibration steps.

\section{A.7.6. Schedule Considerations}

The two branches of the calibration process interrelate, and careful scheduling of the workshops and consultations will be required to meet overall deadlines. It is important to remember that this calibration process is an early component of the overall production scheme, and delays in the calibration process will cascade down through the schedule and ultimately create delays in the final products. Adequate time for planning workshops and consultations, as well as compiling and interpreting the results, must be explicitly included in the calibration schedule.

The general process is as follows: national reference scenario development (box A in figure A2); national mitigation scenario development (box B in figure A2); regional reference scenario development (box C in figure A2); and regional mitigation scenario development (box D in figure A2); however, these steps are not necessarily sequential. Regional scenario calibrations must precede the corresponding regional mitigation strategy calibration, but the regional scenario calibrations can take place significantly earlier and do not need to proceed on a pace that matches the regional mitigation strategy calibrations.

\section{A.7.7. Approximate Schedule}

The approximate schedule is summarized below.

- The national reference scenario workshop likely will occur in the fall of 2010.

- National mitigation scenario workshop and consultations will follow as soon as the final results are available.

- Regional reference scenario consultations require products from the mitigation scenario workshop, therefore they cannot commence until the products are complete and the final results are available.

- Regional mitigation scenario consultations must follow the associated scenario consultation, and they should be completed for each ecoregion well before the products are needed by the modelers.

Table A6. Data sources and characteristics used to inform and develop reference and alternative scenarios.

[USDA, U.S. Department of Agriculture; USGS, U.S. Geological Survey; LULC, land use and land cover; EPA, U.S. Environmental Protection Agency; NRCS, Natural Resources Conservation Service]

\begin{tabular}{|c|c|c|c|}
\hline Data source & Description & Spatial resolution & Temporal resolution \\
\hline U.S. Population Census & $\begin{array}{l}\text { Decadal population estimates, } \\
\text { U.S. population projections }\end{array}$ & $\begin{array}{l}\text { Subcounty (block, block group), } \\
\text { county, State }\end{array}$ & $\begin{array}{l}10 \text { years, with annual population } \\
\text { projections. }\end{array}$ \\
\hline USDA Cropland Data Layer & State maps of crop type & $30-60 \mathrm{~m}$, States & $\begin{array}{l}\text { Annual; } 2000 \text { to present (not } \\
\text { national coverage). }\end{array}$ \\
\hline USGS Land Cover Trends & $\begin{array}{l}\text { Sample-based estimates of } \\
\text { LULC change for contermi- } \\
\text { nous United States; reports } \\
\text { documenting LULC dynamics }\end{array}$ & $\begin{array}{l}\text { EPA ecoregions (Levels I, II, and } \\
\text { III) and States }\end{array}$ & $\begin{array}{l}\text { Every } 6 \text { to } 8 \text { years between } 1973 \\
\text { and } 2000 .\end{array}$ \\
\hline $\begin{array}{l}\text { National Land Cover Dataset and } \\
\text { Database (NLCD) }\end{array}$ & $\begin{array}{l}\text { Land-cover map of the contermi- } \\
\text { nous United States }\end{array}$ & $30 \mathrm{~m}$ & 1992, 2000, 2006. \\
\hline $\begin{array}{l}\text { Forest Inventory and Analysis } \\
\text { (FIA) Program of the USDA } \\
\text { U.S. Forest Service }\end{array}$ & $\begin{array}{l}\text { Sample-based point locations; } \\
\text { characterizations of U.S. forest } \\
\text { dynamics }\end{array}$ & $\begin{array}{l}\text { Point-based observations on U.S. } \\
\text { forest lands }\end{array}$ & Annual. \\
\hline $\begin{array}{l}\text { National Resources Inventory } \\
\text { (NRI) of the USDA NRCS }\end{array}$ & $\begin{array}{l}\text { Sample-based estimates of land } \\
\text { use and other changes (non- } \\
\text { Federal lands) }\end{array}$ & $\begin{array}{l}\text { Point-based estimates for States } \\
\text { (some local and regional data/ } \\
\text { estimates also available) }\end{array}$ & 1977, 1982, 1987, 1992, 1997. \\
\hline $\begin{array}{l}\text { National Wetlands Inventory } \\
\text { (NWI) }\end{array}$ & Characterization of wetlands & Feature-based; local to national & $\begin{array}{l}\text { Based on source data from } 1980 \mathrm{~s} \\
\text { and 1990s. }\end{array}$ \\
\hline
\end{tabular}




\section{A.8. References Cited}

[Reports that are only available online may require a subscription for access.]

Adams, D.M., Alig, R.J., Callaway, J.M., McCarl, B.A., and Winnett, S.M., 1996, The forest and agricultural sector optimization model (FASOM)-Model structure and policy applications: U.S. Department of Agriculture, Forest Service, Pacific Northwest Research Station, Research Paper PNW-RP-495, 60 p., accessed March 31, 2010, at http://www.fs.fed.us/pnw/pubs/pnw_rp495.pdf.

Adams, Darius, Alig, Ralph, McCarl, B.A., and Murray, B.C., 2005, FASOMGHG conceptual structure, and specification_-Documentation: accessed June 22, 2010, at http://agecon2.tamu.edu/people/faculty/mccarl-bruce/ papers/1212FASOMGHG_doc.pdf.

Arkansas Governor's Commission on Global Warming, 2008, Final report-October 2008: Arkansas Governor's Commission on Global Warming [variously paged], accessed April 12, 2010, at http://www.arclimatechange.us/ewebeditpro/ items/O94F20338.pdf.

Bremer, D.J., and Ham, J.M., 2010, Net carbon fluxes over burned and unburned native tallgrass prairie: Rangeland Ecology \& Management, v. 63, no. 1, p. 72-81.

Brown, Joel, Angerer, Jay, Salley, S.W., Blaisdell, Robert, and Stuth, J.W., 2010, Improving estimates of rangeland carbon sequestration potential in the US Southwest: Rangeland Ecology and Management, v. 63, no. 1, p. 147-154.

Brown, Sandra, and Kadyszewski, John, 2005, Carbon supply for the pilot region-Arkansas, Louisiana, and Mississippi: Arlington, Va., Winrock International, 71 p.

Causarano, H.J., Franzluebbers, A.J., Reeves, D.W., and Shaw, J.N., 2006, Soil organic carbon sequestration in cotton production systems of the southeastern United States: Journal of Environmental Quality, v. 35, p. 1374-1383, accessed June 22, 2010, at http://jeq.scijournals.org/cgi/content/ full/35/4/1374.

Choi, S.W., and Sohngen, Brent, 2009, The optimal choice of residue management, crop rotations, and cost of carbon sequestration-Empirical results in the Midwest US: Climatic Change, v. 99, no. 1-2, p. 279-294, doi:10.1007/ s10584-009-9680-5.

Eggleston, Simon, Buendia, Leandro, Miwa, Kyoko, Ngara, Todd, and Tanabe, Kiyoto, eds., 2006, volume 4-Agriculture, forestry, and other land use, v. 4 of 2006 IPCC guidelines for national greenhouse gas inventories: Kanagawa, Japan, Intergovernmental Panel on Climate Change, variously paged, accessed June 22, 2010, at http://www.ipcc-nggip.iges.or.jp/public/2006gl/vol4.html.
Follett, R.F., Kimble, J.M., and Lal, R., eds., 2001, The potential of U.S. grazing lands to sequester carbon and mitigate the greenhouse effect: Boca Raton, Fla., CRC Press LLC, $442 \mathrm{p}$.

Fox, T.R., Allen, H.L., Albaugh, T.J., Rubilar, Rafael, and Carlson, C.A., 2007, Tree nutrition and forest fertilization of pine plantations in the southern United States: Southern Journal of Applied Forestry, v. 31, no. 1, p. 5-11.

Franzluebbers, A.J., 2005, Soil organic carbon sequestration and agricultural greenhouse gas emissions in the southeastern USA: Soil and Tillage Research, v. 83, no. 1, p. 120-147, accessed April 28, 2010, at http:/www.sciencedirect.com/science/article/B6TC64FPN9V6-2/2/91b6d022eabb3cbc960f37e3a9f3b00d.

Huang, C.-H., Bates, Richard, Kronrad, G.D., and Cheng, Shiaolin, 2004, Economic analyses of sequestering carbon in loblolly pine, cherrybark oak, and northern red oak in the United States: Environmental Management, v. 33, supplement 1, p. S187-S199. (Also available at http://www.springerlink.com/content/vcwpkaj0bx2lbge6/ fulltext.pdf.)

Huang, C.-H., and Kronrad, G.D., 2001, The cost of sequestering carbon on private forest lands: Forest Policy and Economics, v. 2, no. 2, p. 133-142, doi:10.1016/S13899341(01)00046-6.

Huang, C.-H., and Kronrad, G.D., 2006, Effects of carbon revenues on the rotation and profitability of loblolly pine plantations: Southern Journal of Applied Forestry, v. 30, no. 1, p. 1-9.

Jawson, M.D., Shafer, S.R., Franzluebbers, A.J., Parkin, T.B., and Follett, R.F., 2005, GRACEnet - Greenhouse gas reduction through agricultural carbon enhancement network: International Journal of Soil and Tillage Research, v. 83, p. 167-172, doi:10.1016/j.still.2005.02.015.

Jenkins, W.A., Murray, B.C., Kramer, R.A., and Faulkner, S.P., 2009, Valuing ecosystem services from wetlands restoration in the Mississippi alluvial valley: Ecological Economics, v. 69, no. 5, p. 1051-1061, doi:10.1016/j.ecolecon.2009.11.022.

Lewandrowski, Jan, Peters, Mark, Jones, Carol, House, Robert, Sperow, Mark, Eve, Marlen, and Paustian, Keith, 2004, Economics of sequestering carbon in the U.S. agricultural sector: U.S. Department of Agriculture, Economic Research Service Technical Bulletin TB-1909, 69 p. (Also available at http://www.ers.usda.gov/Publications/TB1909/.)

Loveland, T.R., Sohl, T.L., Stehman, S.V., Gallant, A.L., Sayler, K.L., and Napton, D.E., 2002, A strategy for estimating the rates of recent United States land-cover changes: Photogrammetric Engineering and Remote Sensing, v. 68, no. 10, p. 1091-1099. 
Moss, R.H., Edmonds, J.A., Hibbard, K.A., Manning, M.R., Rose, S.K., van Vuuren, D.P., Carter, T.R., Emori, Seita, Kainuma, Mikiko, Kram, Tom, Meehl, G.A., Mitchell, J.F.B., Nakicenovic, Nebojsa, Riahi, Keywan, Smith, S.J., Stouffer, R.J., Thomson, A.M., Weyant, J.P., and Wilbanks, T.J., 2010, The next generation of scenarios for climate change research and assessment: Nature, v. 463, no. 7282, p. 747-756, doi:10.1038/nature08823.

Murray, Brian, Jenkins, Aaron, Kramer, Randall, and Faulkner, S.P., 2009, Valuing ecosystem services from wetlands restoration in the Mississippi Alluvial Valley: Durham, N.C., Nicholas Institute for Environmental Policy Solutions, Duke University, $43 \mathrm{p}$.

Murray, B.C., Sommer, A.J., Depro, Brooks, Sohngen, Brent, McCarl, B.A., Gillig, D., de Angelo, B., and Andrasko, K., 2005, Greenhouse gas mitigation potential in U.S. forestry and agriculture: U.S. Environmental Protection Agency Report 430-R-05-006 (November 2005), variously paged [154 p.]. (Also available at http://www.epa.gov/ sequestration/greenhouse_gas.html.)

Nakicenovic, Nebojsa, Alcamo, Joseph, Davis, Gerald, de Vries, Bert, Fenhann, Joergen, Gaffin, Stuart, Gregory, Kenneth, Grübler, Arnulf, Jung, T.Y., Kram, Tom, La Rovere, E.L., Michaelis, Laurie, Mori, Shunsuke, Morita, Tsuneyuki, Pepper, William, Pitcher, Hugh, Price, Lynn, Riahi, Keywan, Roehrl, Alexander, Rogner, H.-H., Sankovski, Alexei, Schlesinger, Michael, Shukla, Priyararshi, Smith, Steven, Swart, Robert, van Rooijen, Sascha, Victor, Nadejda, and Dadi, Zhou, 2000, Special report on emissions scenarios; A special report of Working Group III of the Intergovernmental Panel on Climate Change [IPCC]: Cambridge, UK, Cambridge University Press, 599 p., accessed June 14, 2010, at http://www.grida.no/publications/other/ipcc $\% 5 \mathrm{Fsr} /$ ?src=/ climate/ipcc/emission/index.htm.

Omernik, J.M., 1987, Ecoregions of the conterminous United States: Annals of the Association of American Geographers, v. 77 , no. 1, p. 118-125.

Rochette, Philippe, Angers, D.A., Chantigny, M.H., and Bertrand, Normand, 2008, Nitrous oxide emissions respond differently to no-till in a loam and a heavy clay soil: Soil Science Society of America Journal, v. 72, p. 1363-1369, doi:10.2136/sssaj2007.0371.
Sohngen, Brent, and Brown, Sandra, 2006, The influence of conversion of forest types on carbon sequestration and other ecosystem services in the south central United States: Ecological Economics, v. 57, p. 698-708.

Sohngen, Brent, and Brown, Sandra, 2008, Extending timber rotations - Carbon and cost implications: Climate Policy, v. 8, no. 5, p. 435-451, doi:10.3763/cpol.2007.0396.

Sperow, M., Eve, M., and Paustian, K., 2003, Potential soil C sequestration on U.S. agricultural soils: Climatic Change, v. 57, no. 3, p. 319-339.

U.S. Congress, 2007, Energy Independence and Security Act_Public Law 110-140: U.S. Congress, 311 p., available at http://frwebgate.access.gpo.gov/ cgi-bin/getdoc.cgi?dbname $=110$ _cong_public_ laws\&docid=f:publ140.110.pdf.

U.S. Department of Agriculture, Agricultural Research Service, 2010, National program 204-Global change - GRACEnet: U.S. Department of Agriculture, Agricultural Research Service, accessed June 22, 2010, at http://www.ars.usda.gov/research/programs/ programs.htm?np_code $=204 \&$ docid $=17271$.

U.S. Department of Agriculture, U.S. Forest Service, 2010a, Carbon on line estimator, Version 2.0: U.S. Department of Agriculture, U.S. Forest Service, accessed June 22, 2010, at http://www.ncasi2.org/COLE/index.html.

U.S. Department of Agriculture, U.S. Forest Service, 2010b, The RPA assessment_-Past, present, and future: U.S. Department of Agriculture, U.S. Forest Service, accessed May 21, 2010, at http://www.fs.fed.us/research/rpa/ what.shtml\#2010RPA.

U.S. Department of Agriculture, Natural Resources Conservation Service, 2010, Voluntary reporting carbon management tool: U.S. Department of Agriculture, Natural Resources Conservation Service, accessed June 22, 2010, at http://www.cometvr.colostate.edu/.

Wainger, L.A., and King, D.M., 2001, The benefits and costs of reforesting economically marginal crop lands_-The case of Mississippi Delta: Jackson, Miss., Delta Land Trust, accessed March 31, 2010, at http://www.cbl.umces.edu/ eprice/. 


\section{Appendix B. Land-Use and Land-Cover Modeling}

This appendix describes details of the spatially explicit land-use and land-cover (LULC) modeling component of this methodology. The simulation model FORE-SCE (forecasting scenarios of land cover change) will be used, which is a spatially explicit modeling framework that produces scenariobased, thematic LULC maps at annual time steps. The model begins with a LULC map representing conditions at the beginning of the simulation period and places realistic patches of LULC "change" for each subsequent yearly iteration. The proportion and type of LULC change are determined by the scenario being simulated, whereas the location of change is driven by site-specific biophysical characteristics. The modeling framework is capable of producing scenario-based simulations of future LULC change at a variety of spatial and thematic resolutions.

FORE-SCE originally was developed in support of a sensitivity analysis of the effects of LULC change on climate variability (Sohl and others, 2007; Sohl and Sayler, 2008). Although the initial application had specific requirements that helped define the initial model structure, the U.S. Geological Survey (USGS) modeling team designing FORE-SCE wanted to develop a flexible modeling system that could be adapted for future applications covering a range of research interests. FORE-SCE development began by adopting some of the key characteristics of the Conversion of Land Use and its Effects (CLUE) series of models (Veldkamp and Fresco, 1996; Verburg and others, 2006, 2008). One of the primary components adopted from CLUE is the modular framework, with distinct but linked "Demand" and "Spatial Allocation" modules. This structure allows for both linkages with exogenous models, but also for direct or indirect incorporation of driving force factors operating at multiple scales. The flexibility offered by this framework greatly increases model utility for a variety of applications. What follows is an explanation of model design, potential data gaps, and primary outputs.

\section{B.1. FORE-SCE Structure}

\section{B.1.1. Demand Component}

The "Demand" component of FORE-SCE provides overall, regional proportions of LULC annual change (an annual regional "prescription" of LULC change). A wide variety of methodologies potentially can be used to construct demand, as long as the final products are simple tables of annual LULC change for each LULC class being mapped. Approaches used for construction of demand for past FORE-SCE applications consisted of extrapolations of historical trends (Sohl and others, 2007; Sohl and Sayler, 2008) and exploratory scenarios constructed through the use of expert knowledge (Sohl and others, 2007). CLUE modeling applications also have used trends extrapolations for demand (Verburg and others, 1999, 2006), scenarios constructed through the use of empirical data and expert knowledge (Kok and Winograd, 2002), and complex modeling of demand through the use of a global economic model and an integrated assessment model (Verburg and others, 2008).

Demand for this application is directly linked to the use of storylines from the Intergovernmental Panel on Climate Change (IPCC) "Special Report on Emission Scenarios" (SRES) (Nakicenovic and others, 2000). Reference scenario demand will be provided by the scenario downscaling processes discussed in section 3.2 of this report ("Methodology Framework") and appendix A of this report ("Reference and Alternative Mitigation Scenarios"). Demand for alternative management scenarios associated with policy and mitigation actions will be provided by the methodologies discussed in section 3.2 of this report. Scenario-specific demand for reference and alternative scenarios will be provided as regionally specific prescriptions for annual LULC change from 2001 to 2050 , with annual net change in individual LULC types. This information will be passed to the spatial allocation component of FORE-SCE, which will spatially distribute annual demand for change.

\section{B.1.2. Spatial Allocation Component}

The spatial allocation component of FORE-SCE ingests "demand" for a given region and spatially allocates prescribed LULC change on the landscape. The core drivers for identifying locations of LULC change are probability surfaces, constructed through the analysis of empirical relations between existing LULC patterns and a wide array of spatially explicit biophysical and socioeconomic data. Although the use of probability surfaces follows the primary methodology used by the CLUE series of models, the actual allocation of change is markedly different, with FORE-SCE utilizing a patch-based allocation methodology. The following provides a summary of the primary elements of the spatial allocation methodology.

\section{B.1.2.1. Construction of Probability Surfaces}

The spatial allocation component requires probability surfaces for each LULC class being modeled. Empirical analyses of the relation between spatial datasets representing drivers of LULC change and existing LULC patterns are used to construct the probability surfaces, using a stepwise logistic regression. The most stable and robust explanation for regional LULC patterns is obtained by analysis of endpoint (the most current) LULC (de Koning and others, 1998); therefore, the dependent variable for use in the logistic regression analysis is the presence or absence of a given LULC type as mapped by the 2001 starting land-cover product (section 3.2 of this report). Independent variables used in the logistic regression include any spatially explicit datasets representing LULC driving forces. 
Drivers of LULC change are unique and are based on geographic setting (Sohl and others, 2007). Given the unique characteristics of each region, probability surfaces will be independently modeled and constructed for each U.S. Environmental Protection Agency (EPA) Level II ecoregion (modified from Omernik, 1987). For each ecoregion, drivingforce variables linked to LULC change for that region will be identified, acquired, and formatted. Spatially and thematically stratified sample points are drawn from within an ecoregion, and values for land cover (dependent variable) and all ancillary datasets (independent variables) are extracted. Probability surfaces are then constructed for every thematic LULC class being modeled. For each LULC class, driving-force variables linked with the LULC class are identified, and an initial logistic regression run is performed. Initial results are examined for the presence of correlated independent variables. In cases where two highly correlated variables are selected by the stepwise regression, one of the two paired variables is discarded to mitigate the effects of multicollinearity. The regression is run again with the remaining variables. Output from the stepwise logistic regression is then used in the construction of probability-of-occurrence surfaces for that LULC class, as:

$$
\theta_{h}=\left\{1+\exp \left[-a-\sum_{k=1}^{i} b_{k} x_{h k}\right]\right\}^{-1},
$$

where $\theta_{h}$ is the probability for pixel $h$ being a member of the class (values range from 0 to 1 );

$\alpha \quad$ is the intercept parameter;

$b \quad$ is the regression coefficient for LULC class $k$; and

$x \quad$ is an explanatory variable.

The probability surfaces constructed from the logistic regression process are referred to as "baseline probability" and are a primary component of the remaining spatial allocation procedure as described below.

\section{B.1.2.2. Model Parameterization}

The FORE-SCE model relies on historical LULC data for parameterization of the spatial allocation component. Several key parameters governing FORE-SCE's patch-placement procedure use information from the USGS Land Cover Trends project (Loveland and others, 2002). As with the probability surface construction, model parameterization is done on an ecoregion-by-ecoregion basis. Before running the spatial allocation module, the following parameters are populated as follows: patch size, "clumpiness," probability modifier, and patch library.

Patch size.-Typical patches of LULC change differ in size and configuration, depending upon LULC type and region. For the patch-based spatial allocation procedure, patch-size distribution for every LULC type is required. Empirically measured patch sizes from the USGS Land Cover Trends project are analyzed for each LULC type. Mean patch size and standard deviation for every LULC type is used to populate tables for each ecoregion in the analysis area.
"Clumpiness."-Some forms of LULC change tend to occur as tightly collocated clumps, whereas other forms of LULC change tend to be more dispersed. A "clumpiness" parameter is used to control dispersion of LULC-change patches in the spatial allocation procedure. "Clumpiness" refers to the parts of the probability surface where change patches are allowed to be placed, and is expressed as a threshold value on the probability-surface histogram. For typically "clumped" LULC types such as urban and developed lands, the greatest probability values get preference for selection and placement of a change patch. For more dispersed LULC types, restrictions on the part of the probability histogram that can be used are more relaxed, resulting in more dispersed change patches. The "clumpiness" parameter for each LULC type is established through examining LULC change characteristics as mapped by the USGS Land Cover Trends project.

Probability modifier-A probability modifier for a given LULC transition is based on scenario specifications and the likelihood of a given transition based on empirical historical data. Contingency tables from the USGS Land Cover Trends project provide a complete descriptive matrix of historical land-cover change for a given Level II ecoregion, and thus provide historical context for the likelihood of a given LULC transition in that region. Scenario specifications also may have a strong effect on the potential likelihood of a given LULC transition. The USGS Land Cover Trends contingency tables and a scenario's unique specifications are used to construct probability-modifier tables for each ecoregion. Probabilitymodifier values range from 0 to 1 at 0.1 increments and simply are multipliers affecting the baseline probability surfaces (those constructed through the logistic regression procedure). For example, a probability modifier of " 0 " typically is assigned to all possible transitions of urban or developed land to another LULC type because these transitions are extremely unlikely given the relative permanence of development on the landscape once it has occurred. As a multiplier to baseline probability, existing urban lands are thus excluded from potential change to another LULC type. A similar application of probability-modifier values can be used to alter baseline probability surfaces, reducing probabilities for specific forms of transition. Using the probability modifier is a powerful methodology for controlling specific scenario-defined storylines.

Patch library.-Patch size and distribution (through patch size and "clumpiness" parameters) are only two components affecting aggregate landscape pattern. Patch configuration and shape are another component. FORE-SCE mimics actual historical patches of landscape change to better represent landscape pattern. For each ecoregion, patch "libraries" are populated for every LULC type by copying actual patch configurations (patches of a specific size, shape, and orientation) from the USGS Land Cover Trends database. The populated patch libraries are sorted by size, with multiple configurations for each patch size. The patch libraries are then used for the patch-by-patch spatial allocation procedure as discussed below. 


\section{B.1.2.3. Establishing Protected Areas}

Although the probability surfaces define the suitability of a location to support a given LULC type, they do not account for the protected status of each parcel of land. The Protected Areas Database of the United States (PAD-US Partnership, 2009; for this methodology, the version of the database maintained by the Conservation Biology Institute of Oregon is used (PAD-US (CBI)) provides attributed polygons of protected lands in the United States. The PAD-US Partnership is a public and private collaboration to provide a database of public and private protected lands and includes Federal, State, and local protected lands, as well as information from national nonprofit organizations, such as The Nature Conservancy and Ducks Unlimited. Although it does not cover some protected lands, such as private conservation easements, the database does cover most of the protected lands in the United States. These data are used to better represent LULC change that may occur on these lands, with decision rules used to either alter or eliminate probabilities of LULC change occurring, dependent on the type of protection identified with each polygon.

\section{B.1.2.4. Tracking Forest-Stand Age}

FORE-SCE utilizes a forest-stand-age layer to establish and track the age of a stand of forest. This layer is used to mimic actual forest-cutting cycles and to inform the biogeochemical modeling on not only LULC type, but also the age structure of forested lands. Two sources of information are being used to construct an initial forest-stand-age layer. The vegetation change tracker (VCT) product (Huang and others, 2010) tracks disturbance using stacks of Landsat Thematic Mapper (TM) data. These data are being used to populate a database that identifies forest pixels disturbed between 1984 and 2001 and the date of last disturbance. In areas that have not been disturbed since 1984, an interpolated stand age surface is constructed from Forest Inventory and Analysis (FIA) sampling points. The "composite stand age" image constructed from these two sources will be used to track forest age as the model iterates through 2050.

\section{B.1.2.5. Running the Spatial Allocation Component}

The core of the spatial allocation module consists of the placement of individual patches of LULC change, guided by the aforementioned model parameterization and the regional probability surfaces. The process begins with the baseline probability surface for one of the LULC types being modeled. Patch placement is dependent on the combined characteristics of baseline probability, LULC type in the current iteration, the probability modifier parameter, decision rules on protected areas, and in the case of forest pixels, a function of current stand age. A "total probability" value is calculated for each pixel in the study area:

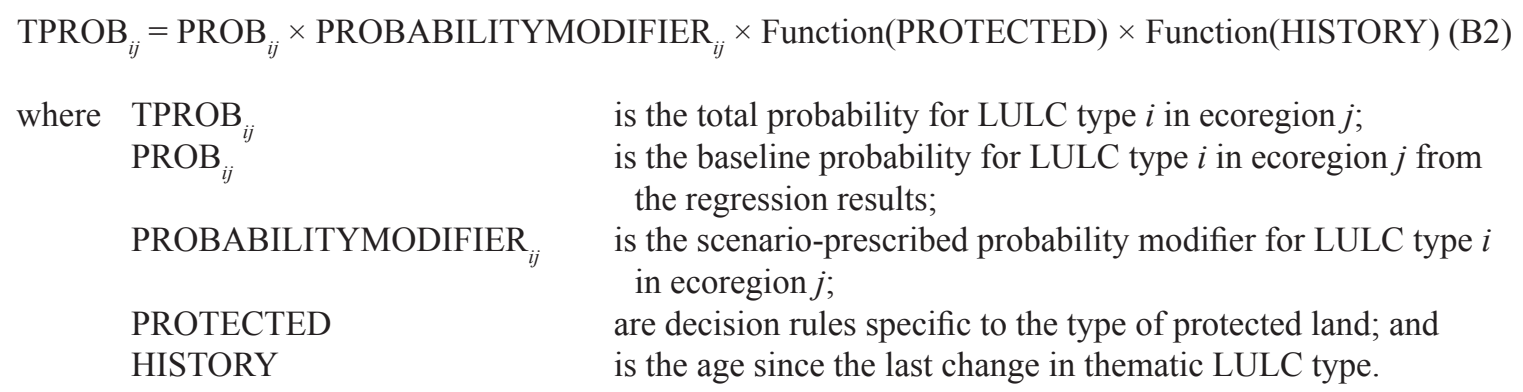

Once total probability is calculated for a given LULC type, the "clumpiness" parameter is used to segment the probability-surface histogram into an "allowable" part for patch placement. To begin the patch-placement procedure, a stochastic methodology is used to place a "seed" pixel on the probability surface. A patch size then is assigned to the seed pixel. In past applications, patch size distributions are represented as Gaussian, an assumption that greatly simplifies the patch development process. A number generator capable of producing a random value within the desired Gaussian distribution is used to 
select a patch size based on the mean and standard deviation of patch sizes measured by the USGS Land Cover Trends project for that LULC type. The patch library for that LULC type is then consulted, and a random patch configuration for the assigned patch size is selected. The patch then is placed on the landscape.

The process is repeated for each LULC type, with the requisite number of patches placed on the landscape to meet areal "demand" for each LULC type. When demand is met, an LULC map is produced for that yearly iteration. Forest-stand-age maps are updated, with all undisturbed pixels iterated upwards by "1," and all disturbed (cut) forest pixels assigned a stand age of " 0 ." The process then iterates forward to the next yearly iteration. At the start of each iteration, new probability surfaces are recalculated from updated, dynamic independent variables. For example, precipitation and temperature data will be used as independent variables in the logistic regressions, and if selected as predictor variables for a given LULC type, coefficients for the regression equation will be established. For future years, downscaled General Circulation Model (GCM) projections of precipitation and temperature will be used to update LULC probabilities, based on those changes in climate variables. Whereas some variables will remain static throughout the simulation period (for example, topographic variables), other variables associated with the changing landscape (for example, changes in urban development density) will be dynamic and will affect future probability surfaces.

Upon the completion of a modeling run, annual, thematic LULC maps from 2001 to 2050 will have been produced, consistent with the scenario-defined assumptions and resultant "demand" for each LULC type. Past applications of FORESCE have produced one set of maps for a scenario. For the national assessment, many model runs for each scenario will be produced. Given the stochastic components related to patch placement and configuration, using Monte Carlo simulations will allow for the examination of uncertainties associated with location of LULC change.

\section{B.2. Land-Use and Land-Cover Modeling Components External to FORE-SCE}

\section{B.2.1. Coastal Modeling}

The existing version of FORE-SCE is not equipped to deal with processes affecting coastal LULC change, especially coastal-wetland change in response to natural processes such as sea-level rise or erosion and deposition. Given the difficulties in specifically modeling all processes affecting LULC change, it is important that regional LULC models be able to use existing research and modeling activities where possible (Sohl and others, 2010). Rather than utilize FORE-SCE to loosely mimic coastal-change processes, an exogenous coastal-process model will be used with modeling results separately integrated with FORE-SCE results.
Assumptions of static landscapes inspire predictions that about one-half of the world's coastal wetlands will disappear in response to acceleration in the rate of sea-level rise during this century. These estimates, however, incorrectly rely on models where bed surfaces accrete at historical rates, where inundation occurs across static landscapes, or on comparisons between historical accretion and future sea-level rise (Kirwan and Guntenspergen, 2009).

Coastal ecosystems are dynamic environments that have significant capacity to adjust to changes in rates of sea-level rise through nonlinear feedback mechanisms. These types of ecogeomorphic feedbacks likely explain the persistence of wetlands within the intertidal zone for thousands of years, as indicated by the stratigraphic record, and observations of accretion rates that are highest in regions with historically high rates of sea-level rise.

An ecogeomorphic model that incorporates nonlinear feedbacks among inundation, plant growth, and substrate accretion (Kirwan and Guntenspergen, 2010) will be used to project coastal-wetland change for the United States under different sea-level-rise scenarios. In this model, the marsh surface accretes at a rate determined by its elevation relative to sea level. Increasing inundation leads to higher rates of sediment deposition, which helps coastal wetlands keep pace with sea-level rise. Vegetation also responds to increasing inundation and vegetation growth increases at low elevations, enhancing sediment trapping and organic matter accretion and limiting erosion; however, the model also recognizes that there are limits to the conditions under which feedbacks between inundation and sediment accretion can maintain a stable intertidal system.

This model has been used in the first comprehensive attempt to model coastal-wetland resilience to accelerating sea-level rise. Our experiments indicate that a threshold rate of sea-level rise exists above which inundation leads to rapid and irreversible conversion of intertidal marshland into unvegetated subtidal surfaces. The specific site conditions (tidal range and suspended-sediment concentration) that respond to maximum rates of sea-level rise also were identified. The results indicate that the amount of sediment available for accretion strongly affects the maximum rate of sea-level rise that coastal wetlands can survive, a positive relation exists between the threshold rate of sea-level rise and tidal range, and interactions occur between tidal range and suspended sediment in the water column.

The predictions of threshold sea-level-rise rates for a large range of sediment concentrations and tidal ranges agree with observations from estuaries worldwide that were not used to design or parameterize the model. The results indicate that regions with low tide ranges or suspended-sediment concentrations will submerge in the near future, even for conservative projections of sea-level rise, and that marshes in high-tiderange environments with abundant sediment are likely to remain stable under more rapid projections of sea-level rise. 


\section{B.2.2. Integration With Disturbance Modeling}

To better represent processes related to fire disturbance, insect damage, and other natural disturbances, an exogenous disturbance modeling effort will be used (section 3.3.3 in this report). Given the "competition" for land between the primarily anthropogenic change modeled by FORE-SCE and the primarily natural change modeled by the disturbance modeling, annual communication between the models is essential for the national assessment. At the start of a yearly iteration, the disturbance model will produce polygons of disturbance and pass those data to the FORE-SCE modeling environment. Those natural disturbance polygons will be directly used in that year's final LULC map and will be excluded for consideration for LULC change within the FORE-SCE modeling environment. The relation between natural disturbance and potential effects on probabilities for the anthropogenic LULC change tracked by the FORE-SCE model also will be examined.

\section{B.3. Potential Data Gaps}

LULC modelers must try to establish causality between LULC change and the biophysical and socioeconomic drivers of change; however, a primary difficulty in establishing those linkages is the availability of representative spatial data for those driving-force variables (Parker and others, 2002). Spatially explicit statistical models have been criticized for overreliance on datasets that happen to be available and underrepresentation of significant drivers of LULC change without easily obtained spatial data (Briassoulis, 2000). This uneven availability of the data remains an issue for spatial models that rely on logistic regression and the use of probability surfaces. Simply put, adequate data to represent all pertinent driving forces of LULC change often are not available. Although the outlined methodology and available data should successfully meet the goals of the assessment, LULC modeling potentially could be improved if land-ownership information, water-availability information, updated wetlands information, FIA access, national VCT data, local zoning and regultory data, and data about dynamic independent variables were available. These data needs are summarized below.

Land ownership.-Individual land owners and resource managers make land-use decisions based on the constraints or opportunities afforded to them within their unique geographic and ecological setting (Sohl and others, 2010). Detailed landownership information at the national level would undoubtedly improve the ability to represent differences in land-use decisions between primary ownership groups. For example, shifts in ownership patterns in the southeastern United States have the potential to dramatically alter forest structure in the region (Sohl and others, 2010). Both private industrial forestry and private nonindustrial forestry are altering the landscape significantly in the southeastern United States, but there are major differences between the groups in land use and management. The capability is lacking to explicitly map and track land-management changes, as spatially explicit data on ownership at that level of thematic detail also are lacking. Because of the lack of ownership data, regional assumptions regarding land management across all ownership types are made.

Water availability.-Availability of groundwater or surface water has a tremendous affect on agricultural land use. Downscaled, projected climate data consistent with IPCC SRES storylines will be available for use by the land-cover modeling team, and projected precipitation changes will affect characteristics of probability surfaces used in the spatial allocation module; however, projected changes in surface water or groundwater that can be used as irrigation sources are not obtained. Ideally, FORE-SCE would link with a comprehensive hydrologic model that is tied to water use and projected climate change for each IPCC scenario; however, the complexity and site-specific nature of hydrologic models that potentially could provide information on groundwater or surface-water changes prohibits their utilization at the national scale. There is no mechanism, therefore, by which to model changes in irrigated agriculture as a direct response to changes in water availability. The primary option in lieu of this information is to make informed estimates of projected future affects of future water availability at the regional scale, and to handle changes in irrigated agriculture through the topdown, "demand" component of the LULC modeling (define future proportions of irrigated agriculture through the scenario construction process).

Updated wetlands information.-Wetland land covers are difficult to map through standard mapping methodologies relying on remote-sensing data. Dedicated, intensive interpretation efforts such as the National Wetlands Inventory (NWI) program are extremely valuable for providing consistent, accurate, and thematically detailed wetlands mapping. Two issues that potentially affect the ability to represent wetland extent are digital availability of products such as NWI for the entire Nation, and the date of wetland information and the lack of updating. A national wetlands layer for the National Spatial Data Infrastructure (NSDI) is being constructed, but as of late 2007, coverage was limited to 60 percent of the conterminous United States (U.S. Fish and Wildlife Service, 2007). The U.S. Fish and Wildlife stated two primary goals for the NSDI: (1) complete wetlands mapping for the Nation, and (2) explore ways to keep the national wetlands database populated with updated (current) information, while simultaneously acknowledging the practical considerations with regard to funding. A consistently updated wetlands layer for the NSDI likely would satisfy current and future needs of the national assessment.

Forest Inventory and Analysis (FIA) data access.-As discussed above, FIA data currently are used in conjunction with VCT data to produce a starting "forest-stand-age" surface. FIA data are used much more extensively by the biogeochemical modeling team. Given the privacy and dissemination issues associated with FIA data, data access remains a primary challenge.

National vegetation change tracker (VCT) data.-VCT data are used to populate an initial "forest cutting" class in the 
2001 baseline land cover (section 3.2.1 of this report), as well as to produce an initial forest-stand-age surface. As of 2010, VCT data are not available at a national scale, as past VCT research has focused on prototype development, but plans are underway to produce these data at that scale. If timeline or other issues delay availability of VCT data for the national assessment, other data and methodologies will have to be used for mapping the initial forest-cutting class and the foreststand-age surface.

Local zoning and regulatory data.-Urban development is a relatively small land use at the national scale, but LULC transitions to urban development typically are "one-way" transitions, with the land permanently removed from the pool of pixels available for LULC change (and also subsequently limited in the potential options for carbon sequestration and mitigation). The basic FORE-SCE design should provide realistic regional patterns of urban change, but because local zoning or regulatory information that may restrict or encourage urban development is not being used (apart from the PAD-US data discussed in the previous section), local accuracy may suffer. Availability and incorporation of nationally consistent zoning and regulatory information at the local scale would improve local accuracy of urban development; however, this is a minor issue at the national scale in terms of carbon-sequestration potential. It could potentially affect the ability to accurately portray local effects of LULC change on carbon and other ecosystem services.

Dynamic independent variables. - As mentioned previously, future climate projections are consistent with IPCC reference scenarios, and as the model iterates, neighborhood variables (for example, urban density) also will be updated to be used as independent variables for the logistic regressions. Future projected changes in many independent variables cannot be tracked or modeled. Some independent variables are relatively static and likely would not require updating (for example, topographic variables), but there are independent variables that are inherently dynamic and for which projected values through 2050 are not readily available. This limited availability limits the ability to examine LULC response to changes in these driving-force variables; however, trying to model processes governing all input independent variables is difficult.

\section{B.4. FORE-SCE and Modeling Deliverables}

LULC modeling deliverables include information and data related to scenario-based LULC forecasts and the scenario framework and assumptions themselves. In summary, primary deliverables provided by the LULC modeling team will include the following:

- Initial (2001) land cover

- Initial (2001) land-use and land-management characteristics
- Narrative storylines for each of the "baseline" IPCC scenarios. Constructing national and regionally specific scenarios will include techniques for incorporating exogenous modeling results, historical LULC data, and the primary assumptions associated with each IPCC scenario. These data will be used to construct regionally specific scenarios consistent with IPCC assumptions. Narrative storylines will illustrate general expected effects of IPCC storylines on regional LULC change and can be used to communicate regionally specific driving forces of change

- Quantified scenarios ("Demand"), including LULC trends with time, land-management characteristics, and land-use histories

- Annual LULC for each "baseline" IPCC scenario through 2050, including maps of LULC and spatially explicit probability distributions resulting from Monte Carlo runs of the spatial allocation module

- Annual LULC for each "alternative" policy or mitigation scenario, including maps of LULC and spatially explicit probability distributions

- Land-use history information, including annual foreststand age, for each "baseline" and "alternative" scenario.

\section{B.5. References Cited}

[Reports that are only available online may require a subscription for access.]

Briassoulis, Helen, 2000, Analysis of land use changeTheoretical and modeling approaches, in Loveridge, Scott, ed., The Web book of regional science: Morgantown, W. Va., West Virginia University, Regional Research Institute, accessed March 31, 2010, at http://www.rri.wvu.edu/ regscweb.htm.

de Koning, G.H.J., Veldkamp, A., and Fresco, L.O., 1998, Land use in Ecuador-A statistical analysis at different aggregation levels: Agriculture, Ecosystems, and Environment, v. 70, p. 231-247.

Huang, Chengquan, Goward, S.N., Masek, J.G., Thomas, Nancy, Zhu, Zhiliang, and Vogelmann, J.E., 2010, An automated approach for reconstructing recent forest disturbance history using dense Landsat time series stacks: Remote Sensing of Environment, v. 114, p. 183-198.

Kirwan, M.L., and Guntenspergen, G.R., 2009, Accelerated sea-level rise-A response to Craft et al.: Frontiers in Ecology and the Environment, v. 7, no. 3, p. 126-127, doi:10.1890/09.WB.005.

Kirwan, M.L., and Guntenspergen, G.R., 2010, The influence of tidal range on the stability of coastal marshland: Journal of Geophysical Research, v. 115, F02009, doi:10.1029/2009JF001400. 
Kok, K., and Winograd, M., 2002, Modeling land-use change for Central America, with reference to the impact of Hurricane Mitch: Ecological Modelling, v. 149, p. 53-69.

Loveland, T.R., Sohl, T.L., Stehman, S.V., Gallant, A.L., Sayler, K.L., and Napton, D.E., 2002, A strategy for estimating the rates of recent United States land-cover changes: Photogrammetric Engineering and Remote Sensing, v. 68, p. 1091-1099.

Nakicenovic, Nebojsa, Alcamo, Joseph, Davis, Gerald, de Vries, Bert, Fenhann, Joergen, Gaffin, Stuart, Gregory, Kenneth, Grübler, Arnulf, Jung, T.Y., Kram, Tom, La Rovere, E.L., Michaelis, Laurie, Mori, Shunsuke, Morita, Tsuneyuki, Pepper, William, Pitcher, Hugh, Price, Lynn, Riahi, Keywan, Roehrl, Alexander, Rogner, H.-H., Sankovski, Alexei, Schlesinger, Michael, Shukla, Priyararshi, Smith, Steven, Swart, Robert, van Rooijen, Sascha, Victor, Nadejda, and Dadi, Zhou, 2000, Special report on emissions scenarios; A special report of Working Group III of the Intergovernmental Panel on Climate Change [IPCC]: Cambridge, UK, Cambridge University Press, 599 p., accessed June 14, 2010, at http://www.grida.no/publications/other/ipcc\%5Fsr/?src=/ climate/ipcc/emission/index.htm.

Omernik, J.M., 1987, Ecoregions of the conterminous United States: Annals of the Association of American Geographers, v. 77 , no. 1 , p. $118-125$.

Protected Areas Database of the United States (PADUS) Partnership, 2009, A map for the future-Creating the next generation of protected area inventories in the United States: Protected Areas Database of the United States Partnership, 20 p., accessed June 18, 2010, at http://www.protectedlands.net/images/ PADUS_FinalJuly2009LowRes.pdf.

Parker, D.C., Berger, Thomas, and Manson, S.M., eds., 2002, Agent-based models of land-use/land-cover changeReport and review of an International Workshop, October 4-7, 2001, Irvine, Calif.: Indiana University, LUCC Focus 1 Publication 6.
Sohl, T.L., Loveland, T.R., Sleeter, B.M., Sayler, K.L., and Barnes, C.A., 2010, Addressing foundational elements of regional land-use change forecasting: Landscape Ecology, v. 25, no. 2, p. 233-247, doi:10.1007/s10980-009-9391-3.

Sohl, T.L., and Sayler, K.L., 2008, Using the FORE-SCE model to project land-cover change in the southeastern United States: Ecological Modelling, v. 219, p. 49-65.

Sohl, T.L., Sayler, K.L., Drummond, M.A., and Loveland, T.R., 2007, The FORE-SCE model-A practical approach for projecting land-use change using scenario-based modeling: Journal of Land Use Science, v. 2, no. 2, p. 103-126.

U.S. Fish and Wildlife Service, 2007, Wetlands layerNational spatial data infrastructure-A phased approach to completion and modernization: U.S. Fish and Wildlife Service, 9 p., accessed June 18, 2010, at http://www.fws. gov/wetlands/documents/gNSDI/WetlandsLayerNSDIPhasedApproachtoCompletionModernization.pdf.

Veldkamp, A., and Fresco, L.O., 1996, CLUE-CR-An integrated multi-scale model to simulate land use change scenarios in Costa Rica: Ecological Modelling, v. 91, no. 1, p. 231-248, doi:10.1016/0304-3800(95)00158-1.

Verburg, P.H., Eickhout, Bas, and van Meijl, Hans, 2008, A multi-scale, multi-model approach for analyzing the future dynamics of European land use: Annals of Regional Science, v. 42, no. 1, p. 57-77, doi:10.1007/ s00168-007-0136-4.

Verburg, P.H., Overmars, K.P., Huigen, M.G.A., de Groot, W.T., and Veldkamp, A., 2006, Analysis of the effects of land-use change on protected areas in the Philippines: Applied Geography, v. 26, no. 2, p. 153-173.

Verburg, P.H., Rounsevell, M.D.A., and Veldkamp, A., 2006, Scenario-based studies of future land use in Europe: Agriculture, Ecosystems and Environment, v. 114, no. 1, p. 1-6.

Verburg, P.H., Veldkamp, A., and Fresco, L.O., 1999, Simulation of changes in the spatial pattern of land use in China: Applied Geography, v. 19, p. 211-233 
This page intentionally left blank. 


\section{Appendix C. Characterization and Modeling of Major Ecosystem Disturbances}

The assessment of the Nation's ecosystems for biological carbon sequestration will explicitly address disturbances such as wildfires (resulting from natural causes and human activity), as required by section 712 of the Energy Independence and Security Act (EISA; U.S. Congress, 2007). The national assessment disturbance methodology also will include tornadoes, damaging winds, hurricanes, and insect and disease outbreaks (table C1). Additionally, management activities, such as fuel treatments, designed to affect disturbances also will be considered by the disturbance methodology. For each disturbance type or management activity, the national assessment will follow a similar series of steps (fig. C1). First, recent disturbance patterns will be characterized as the number of events and area affected each year by ecoregion. The characterizations of recent trends will then be used to identify relations with climate, biophysical, and anthropogenic variables using statistical methods. When the resulting relations are statistically significant and ecologically relevant, they will be used to project future disturbance patterns.

The characterization of recent trends and statistical relations will capture broad-scale patterns, but additional methods are needed when projecting to locate and simulate the effects of each individual disturbance event; therefore, the national assessment will incorporate a second suite of methods to simulate the spread or placement of individual disturbance events at the pixel level when possible. These components of the disturbance model will include fire spread, empirical wind-fields, and habitat-suitability models for insects and disease. Some disturbances, especially insects and diseases, will lack the data or ecological understanding needed to build predictive relations at the 30 -meter $(\mathrm{m})$ pixel scale. In these cases, the summaries of recent disturbances and projections will be used to provide ecoregion-level disturbance probability distributions to the biogeochemical model (appendix D of this report), which will incorporate the spatial uncertainty inherent to the ecoregion-scale probabilities. The disturbance modeling will be adaptive and will incorporate new scientific understanding, data, and methods as they become available during the national assessment.

\section{C.1. Characterizing Past and Current Ecosystem Disturbances}

\section{C.1.1. Events Database}

The national assessment will leverage the fire-disturbance data compiled and used to maintain the Landscape Fire and Resource Management Planning Tools Project (LANDFIRE) data products. Additionally, several key datasets, not currently (2010) utilized by LANDFIRE, will be incorporated to characterize past and current nonfire disturbances. An events database will be constructed to hold data describing major ecosystem disturbances from the LANDFIRE refresh data call; burn perimeter and severity data from Monitoring Trends in Burn Severity (MTBS) (Eidenshink and others, 2007); data describing insects and diseases from the Forest Health Monitoring (FHM) program of the U.S. Forest Service (USFS); data from the National Oceanic and Atmospheric Administration (NOAA) National Hurricane Center's hurricane archive; and data from NOAA's National Weather Service Storm Prediction Center tornado track and damaging wind event archives (table C1). Data from the National Fire Plan Operations and Reporting System (NFPORS) also will be incorporated into the events database to characterize fuel treatments (table $\mathrm{C} 1$ ).

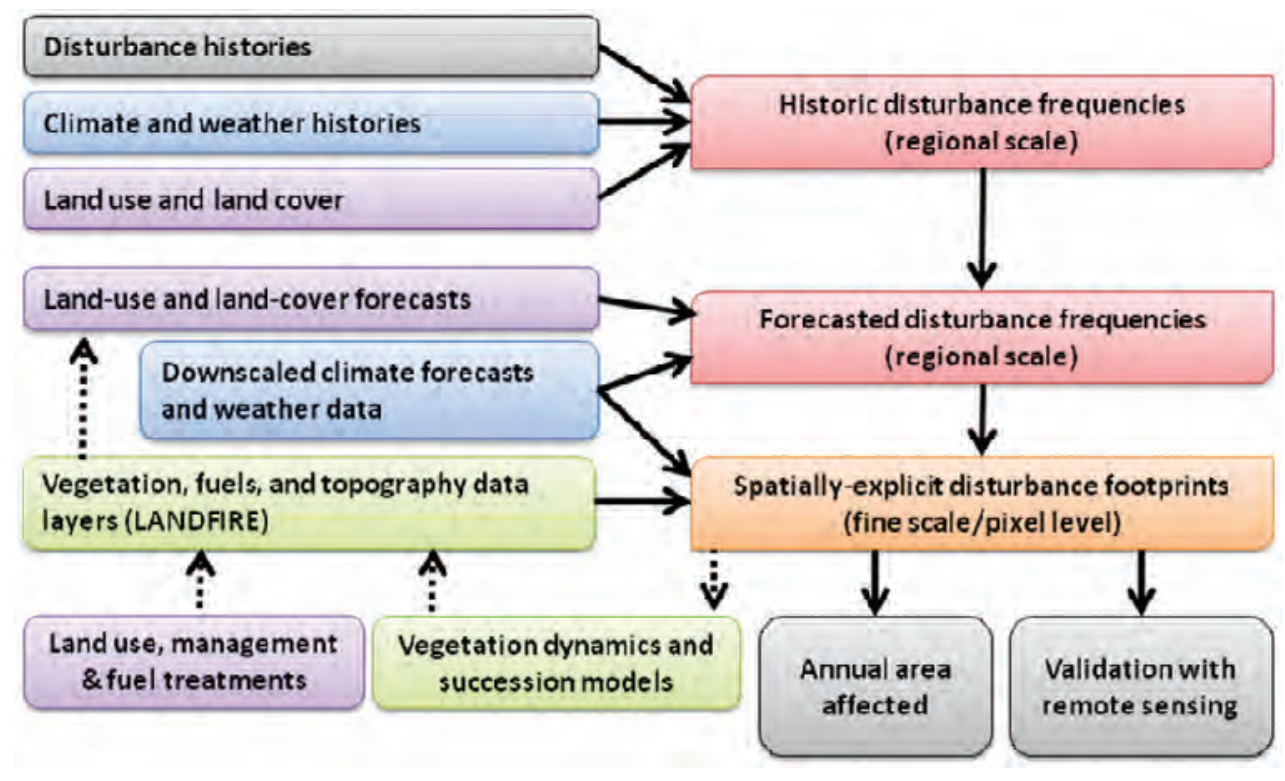

Figure C1. Generalized process and data flow chart showing disturbance modeling component tasks. Solid lines represent processes linking input datasets, models, and output datasets. Dashed lines indicate processes that update data sources required for disturbance modeling. Because each disturbance type differs in terms of the driving forces and the scales over which they operate, this streamlined modeling approach will be modified for each disturbance type. These distinctions will necessitate that the disturbance methodology be adaptive and include components that operate at different spatial and temporal scales. 


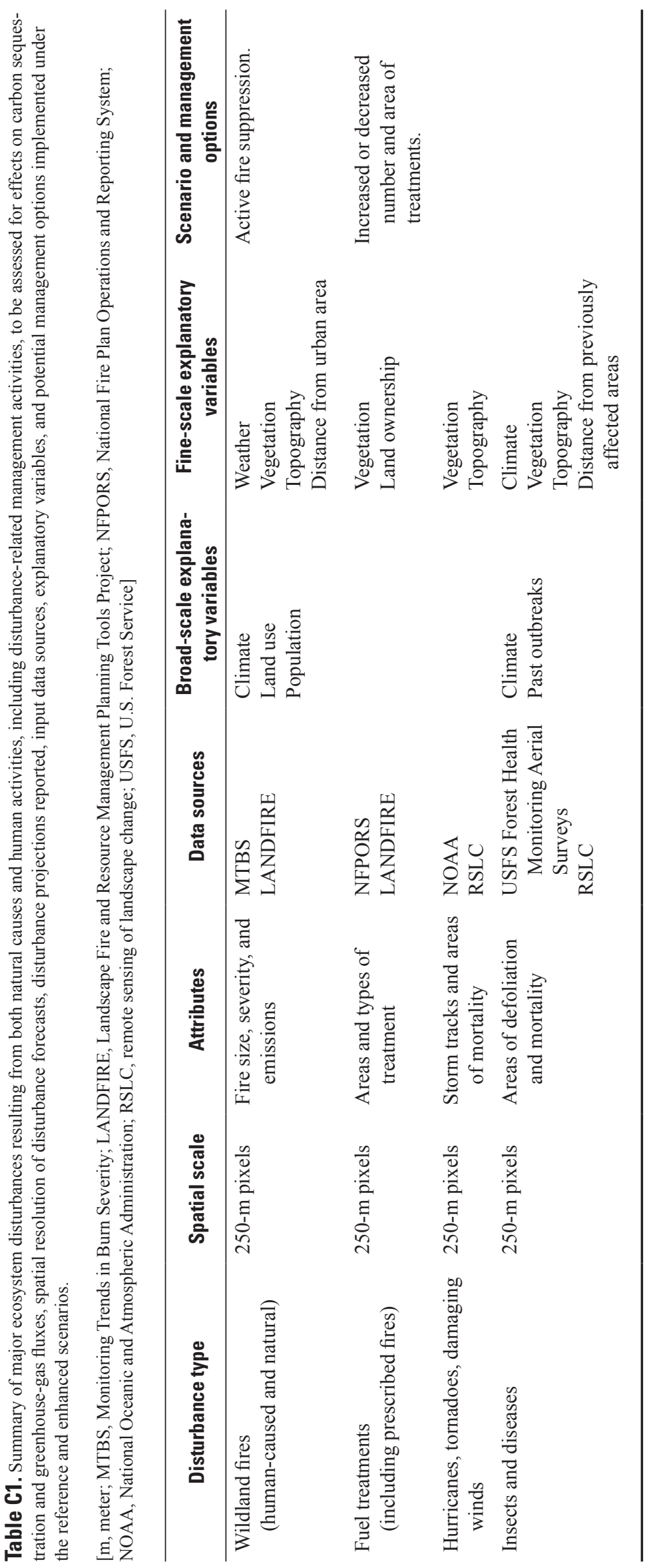


For many disturbance types, the existing data incorporated into the events database will contain only point and line vector information. For example, hurricane, tornado, and damaging wind data consist of lines and points of the approximate storm locations; additional information is needed to characterize the area affected. Remote sensing of landscape change can help fill these information gaps. Dramatic vegetation changes, such as stand-replacing fires and forest clearcuts, are easily identified in imagery; however, less severe types of disturbances, such as insect outbreaks and storm damage, are more difficult to distinguish (Ahren, 1988; Franklin and others, 2003; Skakun and others, 2003; Kennedy and others, 2007; Vogelmann and others, 2009). Therefore, disturbed areas will be identified by using vegetation change-detection algorithms that (1) take advantage of the rich temporal information in Landsat and Moderate Resolution Imaging Spectroradiometer (MODIS) time-series stacks, and (2) that search for anomalies in spectral reflectance and vegetation indices trends across all image dates (Huang and others, 2009, 2010).

The results of the vegetation change analysis will be used to augment the events database and provide additional data about the locations of fuel treatments, insect and disease outbreaks, and storm damage to vegetation. For instance, the FHM aerial-survey data are provided as polygons indicating disturbance cause; for example, the mountain pine beetle. There is heterogeneity in disturbance severity within the FHM polygons - healthy trees are interspersed among unhealthy trees. This heterogeneity will be captured by assigning attribute information about the disturbance cause provided by the FHM polygons to disturbed areas identified by the vegetation change analysis. Similarly, disturbed patches in the imagery that are spatially coincident with storm locations would be attributed as storm damage.

\section{C.1.2. Field-Reference Database}

The field-reference database will be a compilation of all existing georeferenced field data available for the United States in the Fire Effects Monitoring and Inventory Protocol (FIREMON) database structure compiled for LANDFIRE. It includes Forest Inventory and Analysis (FIA) data from the USFS, fire monitoring data from the National Park Service, and data from the U.S. Geological Survey's Gap Analysis Program (GAP). Data will be acquired and compiled as the assessment progresses geographically across the Nation. Data in the field-reference database will be used to validate the disturbance and management information in the events database (section C.1.1 of this report).

\section{C.1.3. Annual Summaries of Past and Current Disturbances}

Using the disturbance data described above, participants in the national assessment will start by characterizing past disturbances into annual summaries using records of recent wildfires, storms, and insect and disease outbreaks by ecoregion. These annual summaries will include disturbance type, cause, number of events, and total area affected. Fire summaries will include additional ecoregion-level estimates for emissions, and individual estimates for each fire calculated will be totaled using the Consume model (Prichard and others, 2006) and the First Order Fire Effects Model (FOFEM) (Reinhardt and others, 1997) with the fuel-loading model (FLM) and fuel-characteristic classification system (FCCS) data produced for the LANDFIRE project (Rollins, 2009). The annual disturbance summaries will be provided as tables and further summarized as probability distributions for each U.S. Environmental Protection Agency (EPA) Level II ecoregion (modified from Omernik, 1987) (table C2).

Table C2. Example of an output table showing recent disturbance summary data for the Mississippi Valley Loess Plains ecoregion.

[ $N$, number; MTBS, Monitoring Trends in Burn Severity]

\begin{tabular}{lcrrr}
\hline Disturbance type & Year & $\boldsymbol{N}$ & Hectares & Source \\
\hline Wildfire, human & 1984 & 0 & 0 & MTBS \\
Wildfire, human & 1985 & 0 & 0 & MTBS \\
Wildfire, human & 1986 & 1 & 239 & MTBS \\
Wildfire, human & 1987 & 0 & 0 & MTBS \\
Wildfire, human & 1988 & 2 & 518 & MTBS \\
Wildfire, human & 1989 & 0 & 0 & MTBS \\
Wildfire, human & 1990 & 2 & 529 & MTBS \\
Wildfire, human & 1991 & 0 & 0 & MTBS \\
Wildfire, human & 1992 & 1 & 223 & MTBS \\
Wildfire, human & 1993 & 3 & 705 & MTBS \\
Wildfire, human & 1994 & 4 & 2,666 & MTBS \\
Wildfire, human & 1995 & 0 & 0 & MTBS \\
Wildfire, human & 1996 & 6 & 4,367 & MTBS \\
Wildfire, human & 1997 & 0 & 0 & MTBS \\
Wildfire, human & 1998 & 2 & 383 & MTBS \\
Wildfire, human & 1999 & 1 & 202 & MTBS \\
Wildfire, human & 2000 & 2 & 731 & MTBS \\
Wildfire, human & 2001 & 0 & 0 & MTBS \\
Wildfire, human & 2002 & 0 & 0 & MTBS \\
Wildfire, human & 2003 & 0 & 0 & MTBS \\
Wildfire, human & 2004 & 0 & 0 & MTBS \\
Wildfire, human & 2005 & 0 & 0 & MTBS \\
Wildfire, human & 2006 & 0 & 0 & MTBS \\
Wildfire, human & 2007 & 0 & 0 & MTBS \\
Wildfire, human & 2008 & 2 & 599 & MTBS \\
\hline
\end{tabular}




\section{C.2. Identifying Drivers of Ecosystem Disturbances}

To project future disturbance events, the critical driving variables determining occurrence patterns need to be identified. Within the disturbance-modeling framework, these relations will be identified for ecoregions and for individual disturbance events. This two-scale approach will allow incorporation of broad-scale climatic drivers as well as fine-scale land-use, vegetation, and topographic patterns that affect individual disturbance events.

\section{C.2.1. Ecoregion-Level Relations}

The ecoregion annual disturbance summaries will be used to identify relations between disturbances and broad-scale climate, biophysical, and anthropogenic drivers using empirical methods. For example, inter-annual variability in fire occurrence has clear relations to extreme weather (Bessie and Johnson, 1995) and climate variables capturing drought and moisture availability and vegetation productivity in the preceding year (Swetnam and Betancourt, 1990; Westerling and others, 2006; Falk and others, 2007). Similarly, severe insect outbreaks often are related in part to climate conditions (Gan, 2004; Aukema and others, 2008). Broad-scale patterns of land use and land cover (LULC), topography, and population also may play significant roles in explaining disturbance patterns, especially for human-caused wildfire ignitions (Cardille and others, 2001; Syphard and others, 2007). By using previously identified relations, researchers will use statistical methods to test ecoregion-scale relations among recent disturbance occurrence, weather, climate, LULC trends, and population trends. General linear models will be used with negative binomial and Poisson responses for the number of disturbances and Gaussian responses for area affected; however, other statistical techniques may be used where appropriate. For certain disturbance types, such as hurricanes, where there is little evidence of a long-term trend, relations with climate and other broadscale predictors may not be identified. In such cases, the recent annual disturbance summaries will be used to simulate future disturbance occurrence patterns.

\section{C.2.2. Fine-Scale Relations}

Ecoregion-level relations will explain broad-scale patterns in terms of the number of disturbance events and total area disturbed each year; however, they provide minimal information about exactly where within ecoregions the individual disturbance events are most likely to occur. These patterns will be explained by using a second suite of empirical methods that predict the probability of disturbance at fine spatial resolutions (250-m pixels) and will incorporate fine-scale relations between disturbance-occurrence patterns and vegetation types, topography, and land use - especially from human pressures. For instance, abiotic and anthropogenic variables have been shown to be effective predictors of human-caused wildfire ignitions (Cardille and others, 2001; Syphard and others, 2008). Similarly, many of these same variables also have been shown to affect insects and disease because of preferential selection for certain hosts or vegetation types and transport by humans to previously unaffected areas (Prasad and others, 2010) in addition to topographic position, climate conditions, and previous outbreak locations (Dodds and others, 2006; Aukema and others, 2008; Santos and Whitham, 2010). In contrast, the likelihood of hurricane, tornado, and wind damage is largely dependent on vegetation type and topographic position (Boose and others, 2001; Kramer and others, 2001; Ramsey and others, 2001; Schulte and others, 2005). For each disturbance type, potential predictors will be identified from existing studies, and the relation between disturbance locations and predictors will be tested and quantified using statistical methods.

\section{C.3. Future Ecosystem Disturbance}

For the national assessment, projections of future disturbance events will be made for each of the reference and enhanced carbon-sequestration scenarios. The number of events and area affected by each disturbance will be projected using the previously identified ecoregion-scale and fine-scale methods (sections C.2.1 and C.2.2 above). To incorporate management activities, model parameters, probabilities, and predictions may be altered. For example, an increase in a prescribed fire-use scenario may simply double the number of prescribed fires simulated in any given year. Ecosystem disturbance modeling will be conducted and reported for EPA Level II ecoregions. The details of the modeling steps for each disturbance type and incorporation of mitigation and management actions are provided in the following sections.

\section{C.3.1. Wildfire (Human Caused and Natural)}

Simulations for wildfires will be made for each EPA Level III ecoregion for each reference and enhanced scenario. Predictions of annual ecoregion fire activity ( $n$ wildfires per year) will be based on previously developed empirical relations with broad-scale climate and LULC variables (section C.2.1 above). Ignition locations of individual fire events will be based on an additional set of probability surfaces based on empirical relations with weather, climate, vegetation, topography, and LULC (section C.2.2 above). Once ignition locations are determined, individual fire spread will be simulated using the minimum-travel-time (MTT) algorithm (Finney, 2002), the LANDFIRE fuels and topography layers (Rollins, 2009), and the fire-weather climatology derived from the NOAA North American Regional Reanalysis (NARR) weather data. Following fire spread, emission estimates will be summarized for each fire using the Consume and FOFEM models and the FCCS and FLM data produced by LANDFIRE (Rollins, 2009). 


\section{C.3.2. Fuel Treatment (Including Prescribed Fire)}

Simulations for fuel treatments will be run for EPA Level III ecoregions for each reference and enhanced scenario. Predictions of annual ecoregion treatment activities will be based on a random selection from the recent probability distribution of fuel-treatment activity ( $n$ treatments and area treated per year), but may be modified in terms of the number of treatments per year or area treated per year under the different enhanced scenarios. Individual fuel treatments will be restricted to public lands and randomly placed within wildland vegetation types depending on the type of treatments; for instance, forest-fuel thinning cannot occur in grasslands. Nonfire treatments will expand using a patch-grow algorithm until a final predicted treatment size is reached, or an entire contiguous wildland vegetation patch is treated. For prescribed fire-fuel treatments, the MTT fire-spread algorithm used by the wildfire modeling will be used (section C.3.1 above). The LANDFIRE fuel data layers will be updated after placement of fuel treatments, to account for treatment effects on fire behavior and spread.

\section{C.3.3. Insect and Disease Activity}

Simulations will be run for EPA Level III ecoregions for each reference and enhanced scenario. Predictions of annual ecoregion-level insect and disease activity (area affected per year) will be based on ecoregion empirical relations derived from epidemiological and species distribution modeling techniques (section C.2.1 above; Elith and others, 2006; Phillips and others, 2006; Elith and Leathwick, 2009) using climate, vegetation, topography, and previous outbreaks as predictors. Because of the potentially large number of unique insect species and diseases that could be simulated, spatially explicit species-occurrence modeling will be prioritized on the basis of the amount of area currently (2010) affected and the effect on standing biomass; example insects include the mountain pine beetle (Dendroctonous ponderoseae), the southern pine beetle (Dendroctonus frontalis), and the gypsy moth (Lymantria dispar; Krist and others, 2007). In cases where it is not possible to generate statistically and ecologically significant, spatially explicit probability surfaces, ecoregional probability distributions will be used instead.

\section{C.3.4. Tornado and Damaging Wind Events}

Tornado and damaging wind simulations also will be made for EPA Level III ecoregions under each reference and enhanced scenario. Ecoregion-level predictions of tornado activity ( $n$ storms per year) will be based on a random selection from regional summaries of recent occurrences. Then for each simulated tornado, an empirical storm-track generator (Vickery and others, 2000) will establish the tornado path. The width of the tornado-disturbance footprint will be determined from the recent distribution of storm track widths measured using remote sensing of landscape change (section C.1 above). If wind damage to vegetation can be effectively monitored from remote sensing of landscape change, then damaging wind models will be made similarly to tornado methods. Historic frequencies of the number of damaging wind events and area affected will be used to simulate future occurrence patterns.

\section{C.3.5. Hurricane Events}

Hurricane effects often occur over areas larger than the EPA Level III ecoregions used for other disturbance types; therefore, hurricane simulations will run annually, but for the entire United States for each reference and enhanced scenario. Predictions of hurricane activity ( $n$ storms per year) will be based on a random selection from regional summaries of recent occurrences. As with tornadoes, an empirical stormtrack generator will create a storm path and wind speeds along the path for each hurricane (Vickery and others, 2000). A surface wind-field and exposure probability surface based on topography and vegetation, calibrated with remote sensing of landscape change data, will determine areas where vegetation damage will occur (Boose and others, 1994).

\section{C.4. Disturbance Model Outputs}

Disturbance model outputs are listed in table $\mathrm{C} 1$ and will include tabular annual summaries of the number of events and area affected for each disturbance type or management activity for each assessment unit. Additionally, tabular summaries of annual greenhouse-gas emissions (methane, carbon monoxide, carbon dioxide, and nonmethane hydrocarbons) will be produced for wild and prescribed fires. Disturbance maps with 250-m spatial resolution also will be generated annually, with unique labeling for specific disturbance types. These outputs will be provided for recent disturbances (1984-2010) and future disturbances (2011-2050). Outputs for projections will be presented as probability distributions to represent the range of values observed under a number of simulation replicate runs.

\section{C.5. Vegetation Dynamics}

At the end of each year in the LULC-change model and disturbance-model simulations, updates will be made to vegetation-type and fuel data layers to incorporate the effects of disturbances, management actions, LULC, and vegetation succession. Initial vegetation conditions will be established from the existing vegetation-type and succession-class data layers in LANDFIRE (Rollins and Frame, 2006; Rollins, 2009). Each vegetation type has an existing vegetation-dynamics model that defines transitions among a number of succession classes. Transitions will be initiated using disturbance type, severity, and time since last disturbance. These succession trajectories are defined from historic disturbance regimes, and the vegetation dynamics are being updated to incorporate modern disturbance types; for instance, forest harvesting and 
invasive species. Furthermore, LANDFIRE fuel-model layers are defined using the vegetation types and succession classes, thereby allowing updates to account for vegetation change (Keane and others, 2001; Rollins and Frame, 2006). Thus, future vegetation-type, succession-class, and fuel models will be updated using the existing vegetation type and succession class and the outputs from the simulated disturbances and LULC changes.

\section{C.6. Scenarios and Management Options}

Management activities affecting fuel and ignition patterns potentially can have effects on carbon storage and greenhousegas emissions. The disturbance task will allow different management activities in future scenarios that incorporate a range of fire-management strategies. Specifically, fuel treatments (including fuel reduction and prescribed fire) will allow for increases or decreases in the area of different fuel treatments to be specified under alternative scenarios. The disturbance model also will incorporate fire suppression and its effect on limiting the size of wildfires using a wildfire containment probability algorithm developed by Finney and others (2009). Finally, the disturbance model's probability surfaces are sensitive to LULC changes and, therefore, may demonstrate unintended effects of land-management policies on disturbance regimes.

Management activities and the extent to which they affect disturbances will be simulated for each of the IPPC reference and enhanced scenarios. See section 3.3.1 of this report for details of the scenario development. Specifically, information will be gathered using questions such as "Within the A2 storyline, would it be feasible to double the area treated using prescribed fire in your region?" The results will be compiled into a management portfolio for each scenario and will be used to assess how different mitigation strategies might affect biological carbon storage and greenhouse-gas emissions.

\section{C.7. Relations to Existing Disturbance Models}

The modeling approach for future potential fires parallels other fire-modeling efforts in the United States, but there are some important differences. Desktop applications such as Fire Area Simulator (FARSITE) and FlamMap (a USFS fire-behavior mapping and analysis model) are used to examine individual fire events or landscape-level fire behavior. FARSITE simulates individual fire growth given an ignition point (Finney, 2004) and is considered to be "state of the art" in terms of fire-spread simulation, but the computation requirements are expensive and that prohibits its use for nationalscale assessments. The MTT algorithm, which is used for the national assessment, produces similar results with less of a computational burden (Finney, 2002). The MTT algorithm is integrated into FlamMap and relies on landscape-level fire behavior outputs produced by FlamMap to simulate fire growth in addition to other fire-behavior indices across a landscape
(Finney, 2006). The Fire Spread Probability model (FSPro) simulates fire spread using the MTT algorithm from thousands of randomly placed fire ignitions and stacks the results to produce burn probabilities. FSPro is integral to the wildland fire decision-support system (WFDSS) and fire program analysis (FPA). This approach is similar to FSPro in many ways because the same fire-spread algorithm is used; however, instead of generating burn probabilities like FSPro, this method generates individual burn perimeters and interacts with the LULC change model and the biogeochemical cycling model.

\section{C.8. Integrating Land-Use- and Land-Cover- Change Modeling and Biogeochemical Modeling}

There are reciprocal feedbacks among the primary modeling components, with the disturbance model, LULC-change model (appendix B of this report), and biogeochemical model (appendix E of this report) sharing data before and after each year in the simulations. At the end of each annual disturbancemodel simulation, the results will be communicated to the LULC-change model and the biogeochemical model. The biogeochemical and LULC-change models do not require the level of thematic and spatial detail provided by the LANDFIRE vegetation types; therefore, the LANDFIRE vegetationtype layer will be aggregated to $250-\mathrm{m}$ pixels and reclassified to National Land Cover Database (NLCD) categories using a look-up table at the end of each year in the disturbance-model simulations. The updated layer will then be transferred to the LULC-change model, and eventually to the biogeochemical model for calculating carbon stocks and greenhouse-gas fluxes for the current model-simulation year. In turn, the LULC-change modeling component will provide an updated land-cover layer to the disturbance-model component so that disturbance probability surfaces can be updated to reflect any changes that occurred. Additionally, the biogeochemicalmodel component will provide information on biomass-pool changes because of growth, mortality, and decomposition to recalibrate fuel-load data.

\section{C.9. Ecosystem-Disturbance Data Needs}

Representing the range of disturbances affecting ecosystem carbon stocks and greenhouse-gas fluxes depends largely on the availability of input data needed to parameterize and execute the various disturbance components. Fires and fuel treatments have the most complete existing datasets; however, even these datasets have limitations. Many fires are not mapped by the MTBS project, especially small fires and unreported fires occurring on public and private lands (Eidenshink and others, 2007). The NFPORS fuel-treatment database lacks the spatial detail and treatment-effects information needed for more sophisticated modeling. Other disturbance types, especially insect outbreaks and storms, lack data documenting the extent and effects of these disturbances with enough detail 
to use for the modeling efforts. Even though the capability to use remote-sensing data or aerial surveys to track storm and insect damage has been demonstrated, nationally consistent datasets currently (2010) are lacking. Consequently, these data gaps will limit the ability to account for the effects of all disturbances on ecosystem carbon storage and greenhouse-gas fluxes. Future research is needed to identify the most suitable algorithms and approach to generate a comprehensive land-disturbance and severity inventory for the Nation for use in carbon and greenhouse-gas assessments, and to develop models sensitive to climate and land change to project future disturbance-occurrence patterns.

\section{C.10. References Cited}

[Reports that are only available online may require a subscription for access.]

Ahren, F.J., 1988, The effects of bark beetle stress on the foliar spectral reflectance of lodgepole pine: International Journal of Remote Sensing, v. 9, p. 1451-1468.

Aukema, B.H., Carroll, A.L., Zheng, Yanbing, Zhu, Jun, Raffa, K.F., Moore, R.D., Stahl, Kerstin, and Taylor, S.W., 2008, Movement of outbreak populations of mountain pine beetle-Influences of spatiotemporal patterns and climate: Ecography, v. 31, no. 3, p. 348-358.

Bessie, W.C., and Johnson, E.A., 1995, The relative importance of fuels and weather on fire behavior in sub-alpine forests: Ecology, v. 76, no. 3, p. 747-762, doi: $10.2307 / 1939341$.

Boose, E.R., Chamberlin, K.E., and Foster, D.R., 2001, Landscape and regional impacts of hurricanes in New England: Ecological Monographs, v. 71, no. 1, p. 27-48, doi:10.1890/0012-9615(2001)071[0027:LARIOH]2.0.CO;2.

Boose, E.R., Foster, D.R., and Fluet, Marcheterre, 1994, Hurricane impacts to tropical and temperate forest landscapes: Ecological Monographs, v. 64, no. 4, p. 369-400, doi: $10.2307 / 2937142$.

Cardille, J.A., Ventura, S.J., and Turner, M.G., 2001, Environmental and social factors influencing wildfires in the upper Midwest, United States: Ecological Applications, v. 11, no. 1, p. 111-127, doi:10.1890/1051-0761(2001)011[0111:EAS FIW]2.0.CO;2.

Dodds, K.J., Garman, S.L., and Ross, D.W., 2006, Landscape analyses of Douglas-fir beetle populations in northern Idaho: Forest Ecology and Management, v. 231, no. 1-3, p. 119-130, doi:10.1016/j.foreco.2006.05.023.

Eidenshink, Jeff, Schwind, Brian, Brewer, Ken, Zhu, Z.L., Quayle, Brad, and Howard, Stephen, 2007, A project for monitoring trends in burn severity: Fire Ecology, v. 3, no. 1, p. $3-21$.
Elith, Jane, Graham, C.H., Anderson, R.P., Dudik, Miroslav, Ferrier, Simon, Guisan, Antoine, Hijmans, R.J., Huettmann, Falk, Leathwick, J.R., Lehmann, Anthony, Li, Jin, Lohmann, L.G., Loiselle, B.A., Manion, Glenn, Moritz, Craig, Nakamura, Miguel, Nakazawa, Yoshinori, Overton, J.M., Peterson, A.T., Phillips, S.J., Richardson, Karen, ScachettiPereira, Ricardo, Schapire, R.E., Soberon, Jorge, Williams, Stephen, Wisz, M.S., and Zimmermann, N.E., 2006, Novel methods improve prediction of species' distributions from occurrence data: Ecography, v. 29, no. 2, p. 129-151, doi:10.1111/j.2006.0906-7590.04596.x.

Elith, Jane, and Leathwick, J.R., 2009, Species distribution models-Ecological explanation and prediction across space and time: Annual Review of Ecology, Evolution, and Systematics, v. 40, p. 677-697, doi:10.1146/ annurev.ecolsys.110308.120159.

Falk, D.A., Miller, Carol, McKenzie, Donald, and Black, A.E., 2007, Cross-scale analysis of fire regimes: Ecosystems, v. 10 , p. $809-823$.

Finney, M.A., 2002, Fire growth using minimum travel time methods: Canadian Journal of Forest Research, v. 32, no. 8, p. 1420-1424.

Finney, M.A., 2004, FARSITE-Fire Area Simulator-Model development and evaluation (revised edition in 2004 of 1998 report): U.S. Department of Agriculture, Forest Service, Rocky Mountain Research Station, Research Paper RMRS-RP-4 (revised), 47 p., available at http://www.fs.fed.us/rm/pubs/rmrs_rp004.html.

Finney, M.A., 2006, An overview of FlamMap fire modeling capabilities, in Andrews, P.L., and Butler, B.W., comps., Fuels management-How to measure success - Conference proceedings, 28-30 March 2006, Portland, Oreg.: U.S. Department of Agriculture, Forest Service, Rocky Mountain Research Station, Proceedings RMRS-P-41, p. 213-220, accessed June 22, 2010, at http://www.fs.fed.us/rm/pubs/ rmrs_p041.html.

Finney, Mark, Grenfell, I.C., and McHugh, C.W., 2009, Modeling containment of large wildfires using generalized linear mixed-model analysis: Forest Science, v. 55, no. 3, p. 249-255.

Franklin, S.E., Wulder, M.A., Skakun, R.S., and Carroll, A.L., 2003, Mountain pine beetle red-attack forest damage classification using stratified Landsat TM data in British Columbia, Canada: Photogrammetric Engineering and Remote Sensing, v. 69, no. 3, p. 283-288.

Gan, Jianbang, 2004, Risk and damage of southern pine beetle outbreaks under global climate change: Forest Ecology and Management, v. 191, no. 1-3, p. 61-71.

Huang, Chengquan, Goward, S.N., Masek, J.G., Gao, Feng, Vermote, E.F., Thomas, Nancy, Schleeweis, Karen, Ken- 
nedy, R.E., Zhu, Zhiliang, Eidenshink, J.C., and Townshend, J.R.G., 2009, Development of time series stacks of Landsat images for reconstructing forest disturbance history: International Journal of Digital Earth, v. 2, no. 3, p. 195-218, doi:10.1080/17538940902801614.

Huang, Chengquan, Goward, S.N., Masek, J.G., Thomas, Nancy, Zhu, Zhiliang, and Vogelmann, J.E., 2010, An automated approach for reconstructing recent forest disturbance history using dense Landsat time series stacks: Remote Sensing of Environment, v. 114, no. 1, p. 183-198, doi:10.1016/j.rse.2009.08.017.

Keane, R.E., Burgan, Robert, and van Wagtendonk, Jan, 2001, Mapping wildland fuels for fire management across multiple scales - Integrating remote sensing, GIS, and biophysical modeling: International Journal of Wildland Fire, v. 10, no. 3-4, p. 301-319, doi:10.1071/WF01028.

Kennedy, R.E., Cohen, W.B., and Schroeder, T.A., 2007, Trajectory-based change detection for automated characterization of forest disturbance dynamics: Remote Sensing of Environment, v. 110, no. 3, p. 370-386, doi:10.1016/j.rse.2007.03.010.

Kramer, M.G., Hansen, A.J., Taper, M.L., and Kissinger, E.J., 2001, Abiotic controls on long-term windthrow disturbance and temperate rain forest dynamics in southeast Alaska: Ecology, v. 82, no. 10, p. 2749-2768.

Krist, F.J., Jr., Sapio, F.J., and Tkacz, B.M., 2007, Mapping risk from forest insects and diseases: U.S. Department of Agriculture, Forest Service, Forest Health Technology Enterprise Team, FHTET 2007-06, 115 p., accessed June 22, 2010, at http://www.fs.fed.us/foresthealth/technology/ pdfs/FHTET2007-06_RiskMap.pdf.

Omernik, J.M., 1987, Ecoregions of the conterminous United States: Annals of the Association of American Geographers, v. 77 , no. 1 , p. $118-125$.

Phillips, S.J., Anderson, R.P., and Schapire, R.E., 2006, Maximum entropy modeling of species geographic distributions: Ecological Modelling, v. 190, no. 3-4, p. 231-259.

Prasad, A.M., Iverson, L.R., Peters, M.P., Bossenbroek, J.M., Matthews, S.N., Sydnor, T.D., and Schwartz, M.W., 2010, Modeling the invasive emerald ash borer risk of spread using a spatially explicit cellular model: Landscape Ecology, v. 25, no. 3, p. 353-369, doi:10.1007/s10980-0099434-9.

Prichard, S.J., Ottmar, R.D., and Anderson, G.K., 2006, Consume 3.0 user's guide: Seattle, Wash., U.S. Department of Agriculture, Forest Service, Pacific Northwest Research Station, 234 p., accessed June 22, 2010, at http:/www.fs.fed.us/pnw/fera/research/smoke/consume/ consume30_users_guide.pdf.
Ramsey, E.W., Hodgson, M.E., Sapkota, S.K., and Nelson, G.A., 2001, Forest impact estimated with NOAA AVHRR and Landsat TM data related to an empirical hurricane wind-field distribution: Remote Sensing of Environment, v. 77 , no. 3, p. 279-292.

Reinhardt, E.D., Keane, R.E., and Brown, J.K., 1997, First Order Fire Effects Model-FOFEM 4.0 user's guide: U.S. Department of Agriculture, Forest Service, Intermountain Research Station, General Technical Report INT-GTR-344, 65 p., accessed June 22, 2010, at http:/www.fs.fed.us/rm/ pubs_int/int_gtr344.html.

Rollins, M.G., 2009, LANDFIRE-A nationally consistent vegetation, wildland fire, and fuel assessment: International Journal of Wildland Fire, v. 18, no. 3, p. 235-249, doi:10.1071/WF08088.

Rollins, M.G., and Frame, C.K., eds., 2006, The LANDFIRE prototype project-Nationally consistent and locally relevant geospatial data for wildland fire management: U.S. Department of Agriculture, Forest Service, Rocky Mountain Research Station, General Technical Report RMRS-GTR175, 416 p., accessed June 22, 2010, at http://www.fs.fed.us/ rm/pubs/rmrs_gtr175.html.

Santos, M.J., and Whitham, T.G., 2010, Predictors of Ips confusus outbreaks during a record drought in Southwestern USA - Implications for monitoring and management: Environmental Management, v. 45, no. 2, p. 239-249, doi:10.1007/s00267-009-9413-6.

Schulte, L.A., Mladenoff, D.J., Burrows, S.N., Sickley, T.A., and Nordheim, E.V., 2005, Spatial controls of pre-euroamerican wind and fire disturbance in northern Wisconsin (USA) forest landscapes: Landscape Ecology, v. 8, no. 1, p. 73-94, doi:10.1007/s10021-004-0052-8.

Skakun, R.S., Wulder, M.A., and Franklin, S.E., 2003, Sensitivity of the Thematic Mapper enhanced wetness difference index to detect mountain pine beetle red-attack damage: Remote Sensing of Environment, v. 86, no. 4, p. 433-443, doi:10.1016/S0034-4257(03)00112-3.

Swetnam, T.W., and Betancourt, J.L., 1990, Fire-southern oscillation relations in the Southwestern United States: Science, v. 249, no. 4972, p. 1017-1020.

Syphard, A.D., Radeloff, V.C., Keeley, J.E., Hawbaker, T.J., Clayton, M.K., Stewart, S.I., and Hammer, R.B., 2007, Human influence on California fire regimes: Ecological Applications, v. 17, no. 5, p. 1388-1402, doi:10.1890/061128.1.

Syphard, A.D., Radeloff, V.C., Keuler, N.S., Taylor, R.S., Hawbaker, T.J., Stewart, S.I., and Clayton, M.K., 2008, Predicting spatial patterns of fire on a southern California landscape: International Journal of Wildland Fire, v. 17, no. 5, p. 602-613, doi:10.1071/WF07087. 
U.S. Congress, 2007, Energy Independence and Security Act-Public Law 110-140: U.S. Congress, 311 p., available at http://frwebgate.access.gpo.gov/ cgi-bin/getdoc.cgi?dbname $=110$ cong public laws\&docid=f:publ140.110.pdf

Vickery, P.J., Skerlj, P.F., and Twisdale, L.A., 2000, Simulation of hurricane risk in the U.S. using empirical track model: Journal of Structural Engineering, v. 126, no. 10, p. $1222-1237$.
Vogelmann, J.E., Tolk, Brian, and Zhu, Zhiliang, 2009, Monitoring forest changes in the Southwestern United States using multitemporal Landsat data: Remote Sensing of Environment, v. 113, no. 8, p. 1739-1748.

Westerling, A.L., Hidalgo, H.G., Cayan, D.R., and Swetnam, T.W., 2006, Warming and earlier spring increase Western U.S. forest wildfire activity: Science, v. 313, no. 5789, p. 940-943, doi:10.1126/science.1128834. 
This page intentionally left blank. 


\section{Appendix D. Methods for Assessing Carbon Stocks, Carbon Sequestration, and Greenhouse-Gas Fluxes of Terrestrial Ecosystems}

Quantifying terrestrial carbon dynamics for large regions is a challenging task for scientists (Potter and others, 1993; Intergovernmental Panel on Climate Change, 1997; Houghton and others, 1999; McGuire and others, 2002; Liu, Loveland, and Kurtz, 2004; Parton and others, 2005; Sierra and others, 2009). Generally, two approaches are used to quantify terrestrial carbon dynamics for large regions. The first of these is the spreadsheet or bookkeeping approach (Intergovernmental Panel on Climate Change, 1997; Houghton and others, 1999) that relies on a set of predefined carbonresponse curves (for example, tree-growth curves) and uses regression equations or look-up tables; however, most carbonresponse curves are created locally on the basis of limited categories of site conditions. They may be insufficient for capturing the effects of the spatial and temporal variability of land use, soils, and climate on carbon dynamics. The second approach depends on process-based biogeochemical models (Schimel and others, 1994; Melillo and others, 1995; McGuire and others, 2002; Chen and others, 2003; Potter and others, 2005; Tan and others, 2005; Liu and others, 2006). Instead of predefining the carbon-response curves under typical conditions, as in the bookkeeping approach, this processbased approach simulates carbon dynamics under specific and changing environmental and management conditions. Although it is capable of capturing detailed responses to changes in the driving variables, it usually requires more complicated input data and parameters.

Many site-scale process-based biogeochemical models were developed during the past 20 years (Parton and others, 1987; Running and Coughlan, 1988; Li and others, 1992). They benefited from an improved understanding of biogeochemical processes resulting from controlled experiments and field observations. For regional studies, however, these models usually were directly applied to grid cells (for example, $0.5 \times$ 0.5 degrees longitude and latitude) that were larger than the site scale (Melillo and others, 1995; Pan and others, 1998; McGuire and others, 2001; Potter and others, 2005) without incorporating information on field-scale heterogeneities. This can result in significant biases in the estimations of important biogeochemical and biophysical processes (Avissar, 1992; Pierce and Running, 1995; Turner and others, 2000; Reiners and others, 2002). Therefore, deploying field-scale ecosystem models to generate regional carbon-sequestration estimates with measures of uncertainty is a challenge.

The General Ensemble Modeling System (GEMS) was designed to facilitate the application of classic site-scale models on a regional scale and to better integrate well-established ecosystem biogeochemical models by using a Monte Carlo-based ensemble approach to incorporate the probable occurrence of parameter values in simulations. Consequently, GEMS not only drives biogeochemical models to simulate the spatial and temporal trends of carbon and nitrogen dynamics, but it also determines uncertainty estimates of the predicted variables. GEMS previously has been applied in this way to simulate carbon dynamics for large areas in Africa (Liu, Kaire, and others, 2004) and the United States (Liu, Loveland, and Kurtz, 2004; Tan and others, 2005; Liu and others, 2006).

The spreadsheet and biogeochemical modeling approaches that will be used to quantify biological carbon sequestration and greenhouse-gas (GHG) emissions for the national assessment are described in detail in the following sections. In addition, model uncertainty, model integration with other model systems, and ecosystem-services modeling are described.

\section{D.1. Accounting and Modeling Simulations of Carbon Sequestration and Greenhouse-Gas Fluxes}

\section{D.1.1. GEMS Accounting Using the Spreadsheet Approach}

Spreadsheet approaches use a computer spreadsheet tool to simulate carbon dynamics and GHG emissions. The primary advantages of the spreadsheet approach are ease in model development and model transparency. The disadvantages of the spreadsheet approach include nonspatial or coarse spatial resolution of simulations and the relatively small number of formulas used in spreadsheet calculations. Nevertheless, although many processes have to be simplified or ignored, the spreadsheet approach provides reference results that are useful to compare with those from more process-based modeling systems.

In general, carbon accounting for almost all terrestrial sectors can be conducted using the spreadsheet approach. The 2006 Intergovernmental Panel on Climate Change (IPCC) Guidelines for National Greenhouse Gas Inventories (Intergovernmental Panel on Climate Change, 2006) provides equations and factors for building GHG spreadsheets. A spreadsheet approach will be implemented in parallel to GEMS to compare and verify GEMS outputs; this method is called "GEMS-spreadsheet."

The GEMS-spreadsheet method requires the following input data at the ecoregion level (or any geographic region):

- Land-cover transition tables during two periods (for example, 2001-2010 and 2011-2050)

- Vegetation-age distribution by land-cover type

- Carbon density by age and land-cover type

- GHG fluxes by vegetation age and land-cover type

- The severity of disturbances or management activities on live biomass carbon, expressed as the fraction of biomass killed or harvested 
- Carbon transfer coefficients among different pools, including the atmospheric carbon dioxide $\left(\mathrm{CO}_{2}\right)$ pool

- Carbon decomposition rates in various pools

The GEMS-spreadsheet method tracks the carbon stock of unchanged land units (that is, no land-cover transitions) in carbon pool $p_{1}$ in a given region using the following accounting procedure:

$$
C_{t, p_{w}}=\sum_{i}^{n} \sum_{j}^{m} A_{t, i} a_{t, i, j} c_{t, i, j, p_{i}},
$$

where $n$ and $m$

$$
\text { are the number of land-cover classes }
$$
and age classes, respectively,

$$
\begin{gathered}
A_{t, i} \quad \begin{array}{c}
\text { is the total unchanged area of land- } \\
\text { cover class } i \text { at time } t,
\end{array}
\end{gathered}
$$

$a_{t, i, j,}$ and $c_{t, i, j, p_{i}}$ are, respectively, area fraction and carbon density of land-cover class $i$, at time $t$, and in age class $j$.

Carbon-density values will be derived from the U.S. Forest Service's (USFS) Forest Inventory and Analysis (FIA) program data. Land-cover transitions and age distribution information will be from the "forecasting scenarios of landcover change" (FORE-SCE) model.

For those land units that experienced land-cover transitions, the following procedures are used to track carbon flow among different pools:

$$
C_{t, p_{i} \rightarrow p_{i}}=\sum_{i=1}^{n} \sum_{j=1}^{n} A_{t, i, j} c_{t, i, p 1} \alpha_{i, j, p_{i} \rightarrow p_{i}},
$$

where $A_{t, i, j}$

$$
\begin{aligned}
& A_{t, i, j} \\
& c_{t, i, p_{1}} \\
& \alpha_{i, j, p_{1} \rightarrow p_{2}}
\end{aligned}
$$

is the area changed from land-cover class $i$ to $j$ at time $t$;

is the average carbon density in pool $p_{1}$, and

is the fraction of carbon density in pool $p_{1}$ that is transferred to $p_{2}$ because of land-cover transition from $i$ to $j$.
In the GEMS-spreadsheet method, carbon is transferred among the live and dead, aboveground and belowground biomass pools and the wood-products pool (harvested materials). Carbon-transfer coefficients will be developed based on expert knowledge, remotely sensed data (for example, fire severity), and output from disturbances modeling.

The decomposition of carbon in a given pool (except the live biomass pool) is calculated as follows:

$$
C_{t, p_{1} \rightarrow C O}=-\beta_{p_{i} \rightarrow C_{2}} C_{t, p_{t}},
$$

where $\beta_{p_{1} \rightarrow C O}$ is the decomposition rate of carbon in pool $p_{1}$, defined as a fraction of the pool size.

In summary, the carbon stocks in live biomass, aboveground and belowground dead biomass, and wood products in a region at time $t$ are calculated as follows:

$$
C_{t, p_{i}}=C_{t, p_{t}}+\sum_{p_{i}=1}^{k} C_{t, p_{i} \rightarrow p_{i}}+C_{t, p_{i} \rightarrow C O_{2}},
$$

where $k$ is the number of carbon pools.

The total regional nitrous-oxide $\left(\mathrm{N}_{2} \mathrm{O}\right)$ and methane $\left(\mathrm{CH}_{4}\right)$ fluxes are calculated as follows using the GEMSspreadsheet method:

$$
F_{t}=\sum_{i}^{n} \sum_{j}^{m} A_{t, i} a_{t, i, j} \lambda_{t, i, j}
$$

where $\lambda_{t, i, j}$ is the flux of $\mathrm{N}_{2} \mathrm{O}$ or $\mathrm{CH}_{4}$ per area on land-cover class $i$, at time $t$, and in age class $j$.

Region-specific GHG fluxes for different ecosystems under various management practices will be compiled from extensive literature review and metadata analysis.

\section{D.1.2. GEMS Biogeochemical Modeling}

GEMS provides spatially explicit biogeochemical-model simulations for large areas. The overall GEMS input-data

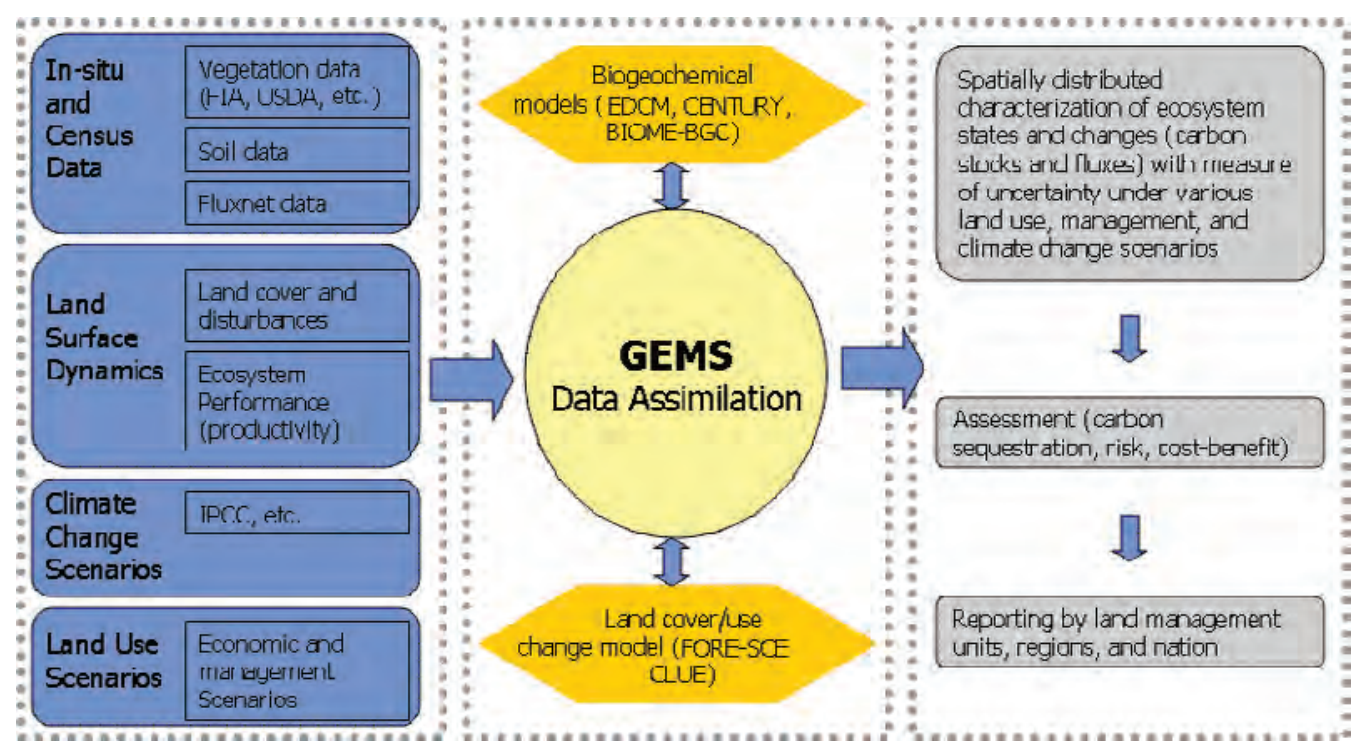

Figure D1. Diagram showing functionality and major types of input data for the General Ensemble Modeling System (GEMS). FIA, Forest Inventory and Analysis Program (U.S. Forest Service); USDA, U.S. Department of Agriculture; EDCM, Erosion-DepositionCarbon Model; BIOME-BGC, biome biogeochemical cycles; IPCC, Intergovernmental Panel on Climate Change; FORE-SCE, "forecasting scenarios of landcover change" model; CLUE, Conversion of Land Use and its Effects model. 
requirements and model functions are shown in figure D1, which indicates that GEMS, as an expandable framework, can process various land-use and disturbance data and link with existing models and tools. GEMS uses two approaches to interact with encapsulated biogeochemical models: agent and direct implementation.

\section{D.1.2.1. Ensemble Models or Agent Implementation}

A special model interface (that is, the agent) controls diverse plot- and regional-scale models in GEMS. This approach requires minimum or no modifications to the underlying biogeochemical models and can be useful for reusing models that are difficult to modify. Under the "agent implementation" mode, GEMS uses plot-scale ecosystem biogeochemical models to simulate carbon and nitrogen dynamics at the plot scale. It controls these site-scale models by automatically parameterizing them according to the biophysical conditions of any land parcel and deploying them across space without considering the interactions among land pixels. Plot- and regional-scale biogeochemical models, such as the Century model (Parton and others, 1987), the ErosionDeposition-Carbon Model (EDCM; Liu and others, 2003), and the Integrated Biosphere Simulator (IBIS; Foley and others, 1996), can serve as encapsulated ecosystem biogeochemical models in GEMS (Tan and others, 2005; Liu and others, 2006). Because GEMS is designed to encapsulate multiple models, and parameterize and execute these models using the same data, it provides an ideal platform to conduct "model ensemble" simulations to identify and address issues and uncertainty related to model structure and mathematical representations of biophysical processes.

To ensure a nationally consistent approach for selecting biogeochemical models for the assessment, a modeling workshop will be held in summer of 2010, and national ecosystem modeling experts will be invited to help identify additional suitable models. Model selection will address the ability to consider the effects of land-use and land-cover change, major disturbances, and climate change on carbon sequestration and GHG emissions. Predefined criteria are listed in table D1; this list does not mean that a single biogeochemical model must meet all these criteria.

\section{D.1.2.2. Direct Implementation}

Biogeochemical models, such as EDCM and Century, are merged directly with GEMS to allow more efficient, spatially explicit simulations. Many regional model applications adopt a time-space simulation paradigm, which runs a simulation for an individual pixel from beginning to end in time before moving to the next pixel. In the direct implementation (for example, GEMS-EDCM), the space-time sequence paradigm will be used instead (thus, GEMS simulates the whole region for a given time step first, then moves to next time step). The space-time sequence paradigm provides easy ways to integrate with other modeling systems such as FORE-SCE ("forecasting scenarios of land-cover change" model), USPED (Unit Stream Power-Based Erosion Deposition), and the disturbance models in a parallel computation fashion; lateral movements of carbon and nitrogen can be effectively quantified as well. Detailed descriptions of GEMS-EDCM, including its theoretical basis, general structure, simulation capability, and unique approach are provided in the following sections.

\section{D.1.2.3. GEMS Data Flow and Linkages With Other Modeling Products}

The overall GEMS flow chart of data and processes, including the spatial simulation unit setup, the Monte Carlo process, biogeochemical-model simulation, data assimilation, network Common Data Form (NetCDF) data processing and visualization, the post-simulation process, and uncertainty

Table D1. Tentative selection criteria and checklist for biogeochemical models to be included in the General Ensemble Modeling System (GEMS).

$\left[\mathrm{CO}_{2}\right.$, carbon dioxide $]$

\begin{tabular}{ll}
\hline \multicolumn{1}{c}{ Criteria } & \multicolumn{1}{c}{ Questionnaire checklist } \\
\hline Ecosystem processes & Include ecosystem carbon, nitrogen, and water cycles? \\
& Include ecophysiological processes (for example, photosynthesis)? \\
& Consider major ecosystem disturbances (fire, logging)? \\
& Consider major ecosystem management activities? \\
Ecosystem types and carbon pools & Include all major natural forest/shrub/grassland systems? \\
& Include agricultural ecosystems? \\
& Include wetland ecosystems? \\
& Include major vegetation and soil carbon/nitrogen pools? \\
& Allow for parallel model simulation? \\
Model structure and reuse & Well modularized and easy to be incorporated into GEMS? \\
& Coded in familiar programming language (C/C, Fortran)? \\
Scientific rigor & Model is well accepted and published? \\
& The team has some experience with the model? \\
& Allow sensitivity testing on key driving variables (for example, climate, $\left.\mathrm{CO}_{2}\right) ?$ \\
\hline
\end{tabular}




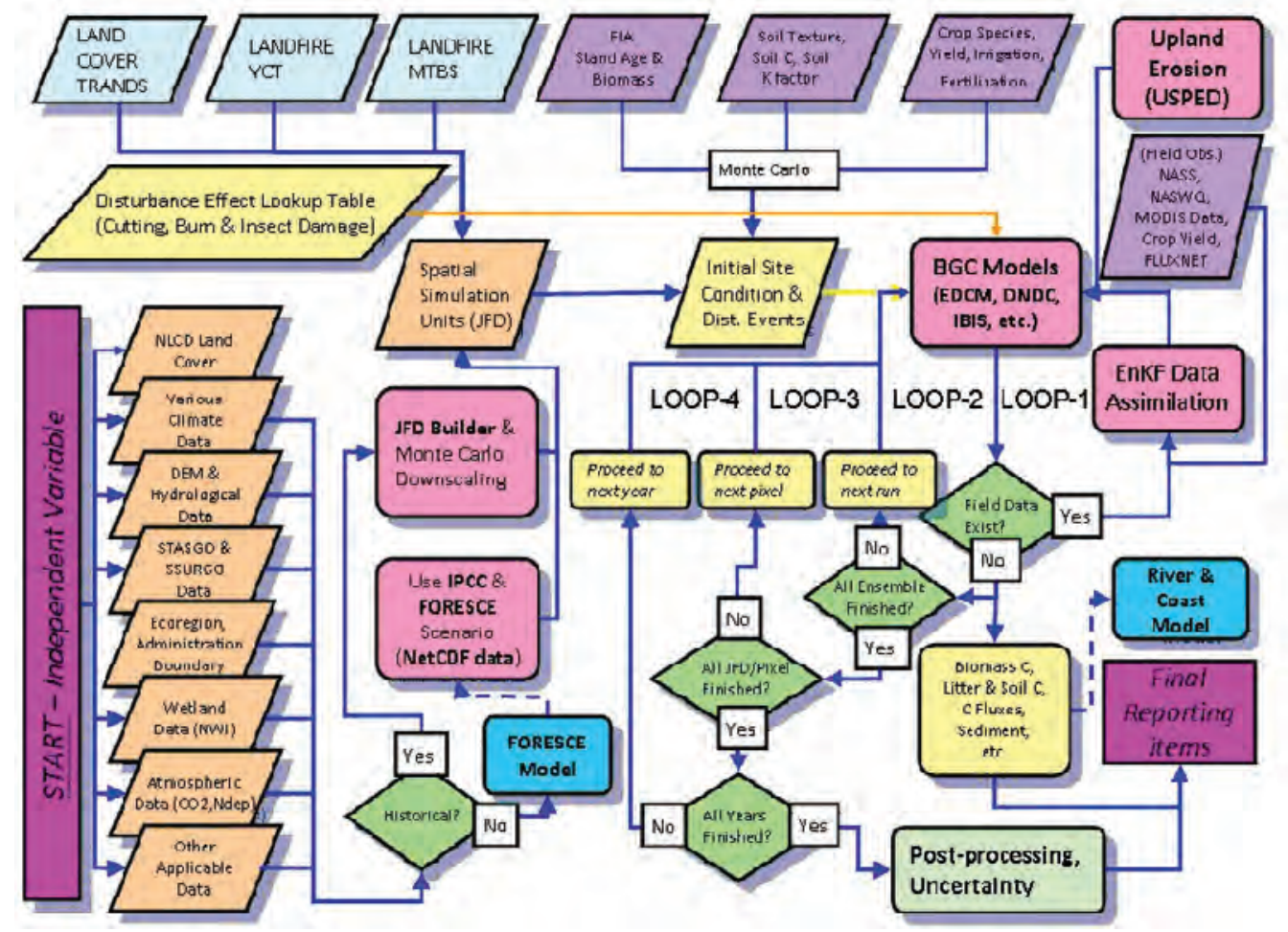

Figure D2. Flow chart of the General Ensemble Modeling System (GEMS) for biogeochemical simulations. Abbreviations are found in "Abbreviations, Acronyms, and Chemical Symbols" in the front of this report. assessment are shown in figure D2. The model also is capable of parallel simulations to estimate lateral carbon-nitrogen movements. These processes and data are described in detail in the following sections.

\section{D.2. GEMS Modeling}

\section{D.2.1. Major Processes Affecting Carbon Sequestration and Greenhouse-Gas Fluxes in GEMS}

The overall processes of land-atmosphere interactions (for example, vertical fluxes of carbon and nitrogen), lateral fluxes of carbon and nutrients, and the pertinent controlling mechanisms in GEMS are shown in figure D3. The simplified carbon cycle, which is the main biogeochemical cycle modeled with GEMS, includes gross primary productivity (GPP), net primary productivity (NPP), photosynthesis allocations (to leaf, root, stem), litter fall, mortality, debris accumulation, and decomposition of soil carbon. The carbon cycle is tightly coupled with nitrogen and water cycles. The water cycle includes algorithms to estimate rain interception, evaporation, transpiration, runoff, and soil water content. The water cycle is also linked with soil organic carbon decomposition and plant growth through soil water availability. The nitrogen cycle is coupled with the carbon cycle through nitrogen availability that controls plant growth and soil carbon decomposition. External driving forces are climate variation and change, human land-management activities, and natural disturbances. These forces and their effects are discussed in subsections below in this appendix. $\mathrm{CH}_{4}$ and $\mathrm{N}_{2} \mathrm{O}$ emissions will be quantified using available equations within biogeochemical models. If unavailable, other empirically derived approaches will be adopted (for example, the model of Cao and others (1996)).

\section{D.2.1.1. Ecosystem Production}

Quantification of ecosystem production starts with vegetation photosynthesis, which will be modeled using three different approaches in GEMS to overcome the disadvantages of any single algorithm. The three approaches include a lightuse-efficiency approach (Yuan and others, 2007), a biochemical-modeling approach (IBIS; Foley and others, 1996), and a scalar approach (Century; Parton and others, 1993). For example, the algorithm for leaf photosynthesis in IBIS is a modified Farquhar-type model (Farquhar and others, 1980). The gross photosynthesis rate through light-limited, rubisco-limited, and triosephosphate-utilization-limited mechanisms (Foley and others, 1996, equations 2, 4, and 5) is partly determined by intercellular $\mathrm{CO}_{2}$ concentration within the leaf, which in turn determines the water conductance and $\mathrm{CO}_{2}$ concentration at the leaf surface (Foley and others, 1996, equations 13, 14, and 15). The gross photosynthesis rate also is modified by leaf nitrogen level, which is determined by the soil nitrogen pool (Liu and others, 2005, equations 1, 8, and 9). At the canopy level, IBIS allows the leaf area index (LAI) to change dynamically depending on living leaf biomass.

The diagram of the carbon-nitrogen flow in IBIS is shown in figure D4. Foliar nitrogen concentration is 


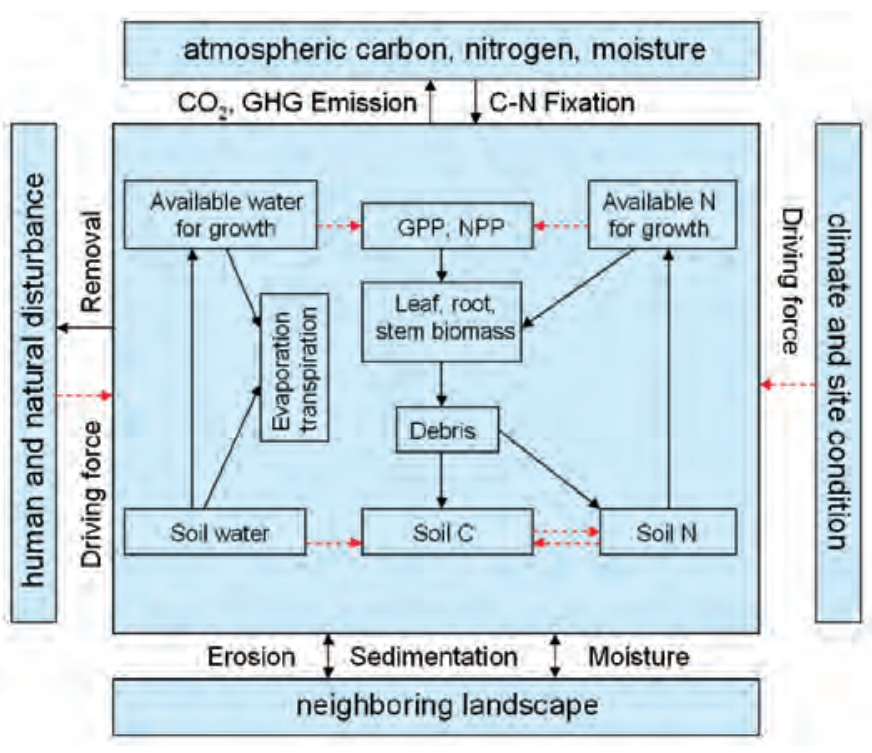

Figure D3. Diagram of the interactions of the biogeochemical processes in the General Ensemble Modeling System (GEMS). Black arrows indicate mass flow and red arrows indicate control modifiers. $\mathrm{CO}_{2}$, carbon dioxide; $\mathrm{GHG}$, greenhouse gas; $\mathrm{C}$, carbon; $\mathrm{N}$, nitrogen; GPP, gross primary productivity; NPP, net primary productivity.

represented by the leaf carbon-to-nitrogen ratio (and is denoted as leaf carbon-to-nitrogen), which is dynamically adjusted by a carbon-to-nitrogen modifier $\left(k_{c n}\right)$, which is determined by soil mineral nitrogen content $\left(N_{M}\right)$. The environmental conditions (radiation, water availability, temperature, and $\mathrm{CO}_{2}$ concentration), the LAI, and the maximum rubisco activity $\left(V_{m}\right)$ as limited by available leaf nitrogen determine the canopy-level gross primary productivity $\left(G P P_{c}\right)$. After deducting maintenance respiration (using the factor Maint resp), GPP ${ }_{c}$ gives canopy-level NPP $\left(N P P_{c}\right)$. At this point, $N P P_{c}$ represents the production of pure carbohydrate, rather than of new biomass carbon. A fraction of $N P P_{c}$ is consumed in growth respiration, with the remainder being converted to "stabilized" biomass $\left(N P P_{b}\right)$. The remaining biogeochemical processes, especially soil decomposition, are similar to those of the Century model.

\section{D.2.1.2. Soil Organic Carbon Cycle}

EDCM is an embedded ecosystem biogeochemical model in GEMS. It is based on the well-established ecosystem model Century (version IV) (Parton and others, 1993; Liu and others, 2003). Both models use empirical maximum potential vegetation productivity, together with limitations from temperature, water, and nutrients, to calculate production of trees and crops. The established algorithms of soil organic carbon (SOC) dynamics in Century form the basis of several other biogeochemical models, such as the Carnegie-Ames-Stanford Approach (CASA; Potter and others, 1993), the Integrated

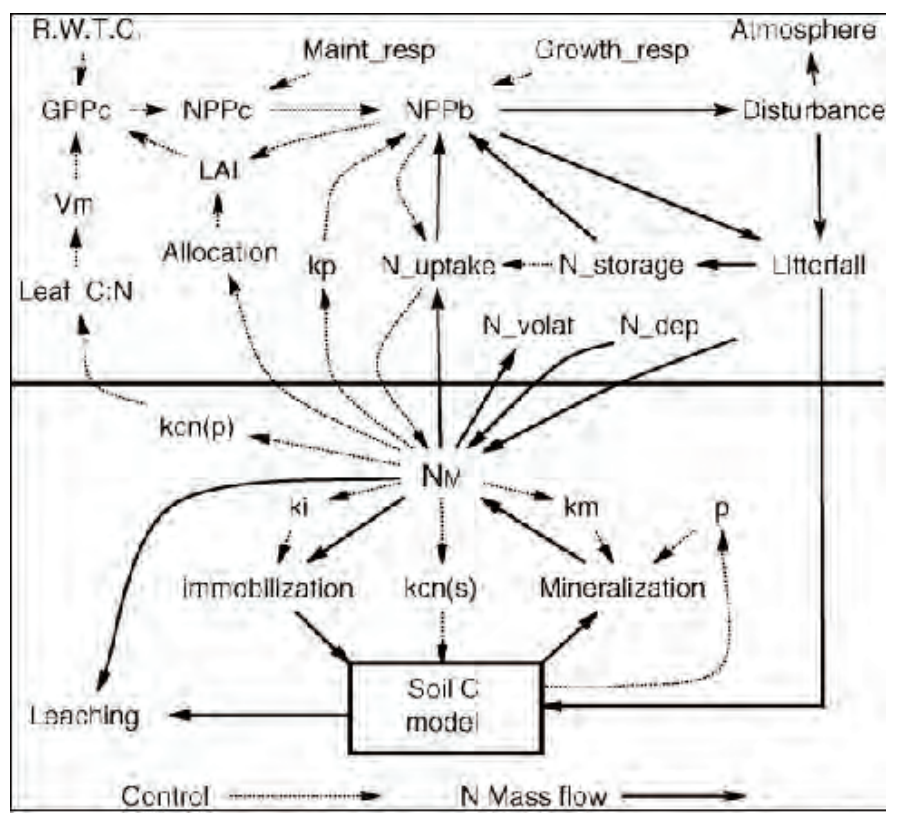

Figure D4. Diagram of carbon-nitrogen cycles and nitrogen controls in the Integrated Biosphere Simulator (IBIS); used with permission from Liu and others (2005). Dark solid arrows represent nitrogen mass flow, and light arrows indicate nitrogen control processes. Abbreviations are found in "Abbreviations, Acronyms, and Chemical Symbols" in the front of this report.

Terrestrial Ecosystem Carbon (InTEC) model (Chen and others, 2000), TRIPLEX (Peng and others, 2002), and IBIS (Foley and others, 1996). The soil nitrogen pools and fluxes in an agricultural system as simulated by Century and EDCM are shown in figure D5. All the nitrogen pools are tightly coupled with the carbon cycle.

Owing to its inheritance from its antecedent model (Century), EDCM is an advanced biogeochemical model that simulates the effects of various natural processes (for example, fires, hurricanes, atmospheric nitrogen deposition, atmospheric $\mathrm{CO}_{2}$ "fertilization," climate change and variability, and erosion and deposition) and management practices (for example, grain harvesting, timber harvesting, fertilization, land-cover and land-use change, cultivation, fertilization, manure addition) on carbon and nitrogen cycles at the ecosystem scale. EDCM can simulate the effect of soil erosion and deposition on carbon and nitrogen dynamics. More than 100 output variables are provided by EDCM, including NPP, net ecosystem productivity (NEP), carbon and nitrogen stocks in aboveground and belowground biomass, soil carbon dynamics, and so on. Century has a one-soil-layer structure for carbon and nutrients (nitrogen, phosphorus, and sulfur). In contrast, EDCM adopts a multiple-soil-layer structure to account for the stratification of the soil profile and SOC in each soil layer. It dynamically tracks the evolution of the soil profile (up to 10 soil layers) and carbon storage as affected by soil erosion and deposition. 


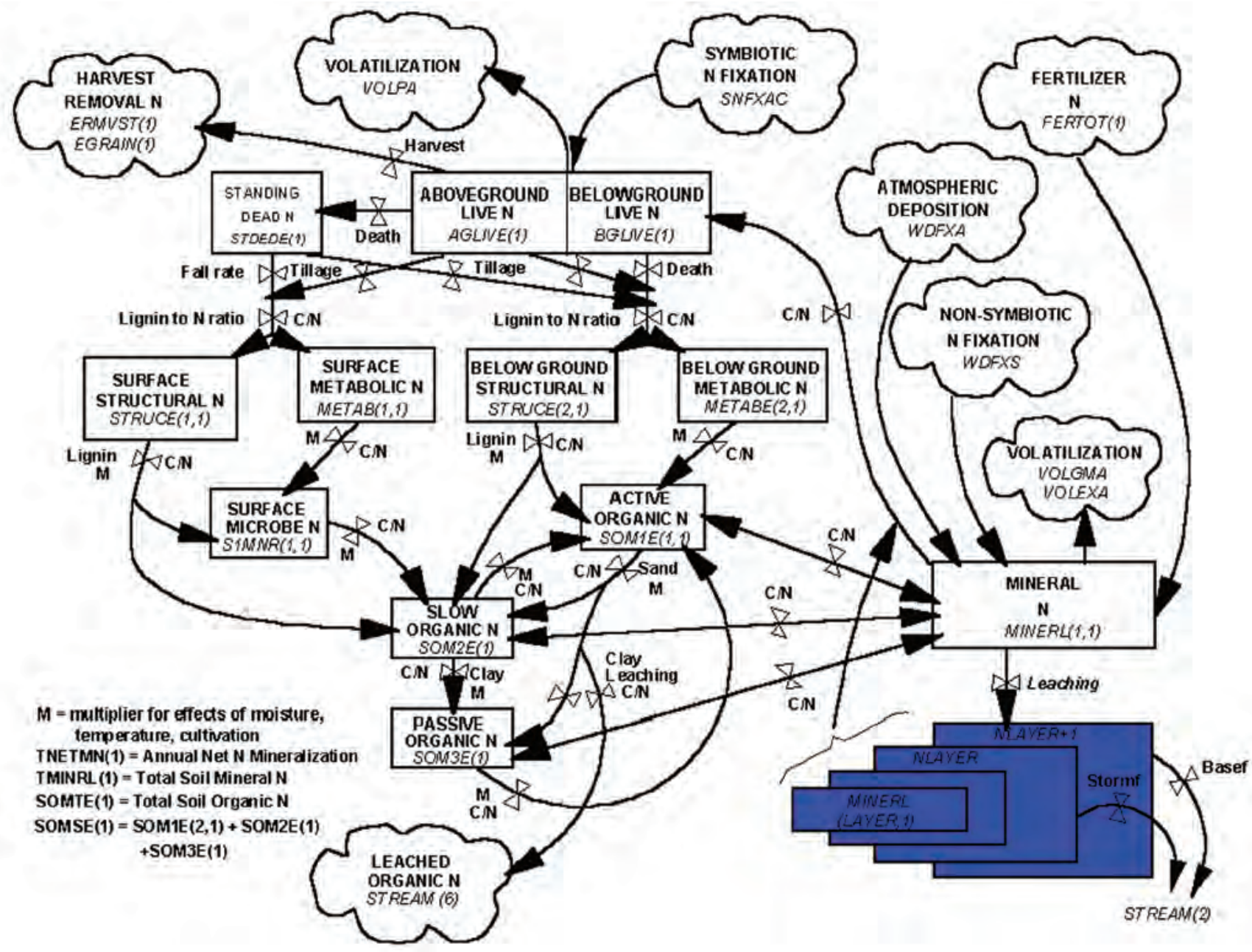

Figure D5. Diagram showing nitrogen cycling in a terrestrial ecosystem as simulated by the Century model and the ErosionDeposition-Carbon Model (EDCM). From Metherell and others (1993), used with permission. The nitrogen cycle is tightly coupled with the carbon cycle. $\mathrm{C} / \mathrm{N}$, carbon-to-nitrogen ratio. Abbreviations are found in "Abbreviations, Acronyms, and Chemical Symbols" in the front of this report.

\section{D.2.1.3. Effects of Disturbances}

Natural and anthropogenic disturbances (for example, fires, hurricanes, tornadoes, and forest cutting) are accounted for in the land-use- and land-cover-change (LULCC) model. Ecosystem disturbances will be parameterized in the model separately because the biogeochemical consequences of these types of disturbances can be vastly different; however, the basic procedures are similar.

Historical fire perimeters and burn-severity maps are used in GEMS to indicate the timing, location, and severity level of burns. The extent and severity of a disturbance event are usually captured by remote sensing or field monitoring and also can be estimated by models, such as the First Order Fire Effects Model (FOFEM) by Reinhardt and others (1997) and the Landscape Successional (LANDSUM) model by Keane and others (2006). The effects of burns are expressed as biomass consumption loss and mortality loss (table D2). Based on the loss rates, GEMS reallocates biomass and soil carbon pools for each individual land pixel. Consumption loss is a direct carbon emission to atmosphere, whereas motility loss converts live biomass carbon to dead carbon pools. The disturbed ecosystem will start regrowth with a new soil nutrient pool and a new LAI calculated in the model. Calculation of other disturbance effects will follow a similar approach to that used for fire effects, but with different carbon transition coefficients among various pools. The regrowth processes following disturbances are calculated based on light and water availability, temperature, nutrient availability, and other factors. GEMS assumes tree planting will follow the clearcutting event if a plantation is prescribed in the land-cover map, otherwise natural vegetation recovery will occur.

For the national assessment, simulated future-firedisturbance maps will be produced along with (or embedded in) the future land-use and land-cover (LULC) maps. These disturbance maps (including simulated severity levels) will 
Table D2. Fuel-consumption effects under different burn-severity levels, based on comparison of remotely sensed burn-severity and field observations.

[This table also is used in the fire-disturbance modeling tasks to calibrate fire-emission estimates. Source: Carl Key, U.S. Geological Survey, written commun., May 28, 2009]

\begin{tabular}{|c|c|c|c|c|c|c|}
\hline \multirow{2}{*}{ Components } & \multicolumn{3}{|c|}{ Consumption (percent) } & \multicolumn{3}{|c|}{ Mortality (percent) } \\
\hline & Low & Moderate & High & Low & Moderate & High \\
\hline \multicolumn{7}{|c|}{ Forest floor and soil } \\
\hline Litter/fine fuel & $15-60$ & $61-90$ & $91-100$ & - & - & - \\
\hline Duff & $5-30$ & $31-70$ & $71-100$ & - & - & - \\
\hline Medium fuel & $10-30$ & $31-50$ & $51-100$ & - & - & - \\
\hline Heavy & $5-15$ & $16-40$ & $41-100$ & - & - & - \\
\hline Soil & $5-20$ & $21-50$ & $51-100$ & - & - & - \\
\hline \multicolumn{7}{|c|}{ Understory layer } \\
\hline Herb & $16-60$ & $61-85$ & $86-100$ & - & - & - \\
\hline Shrub-leaf-wood & $10-40$ & $41-80$ & $81-100$ & - & - & - \\
\hline Shrub-leaf-wood & - & - & - & $1-20$ & $21-70$ & $71-100$ \\
\hline \multicolumn{7}{|c|}{ Premature trees } \\
\hline Leaf & $1-20$ & $21-70$ & $71-100$ & - & - & - \\
\hline Fine branch & $1-20$ & $21-70$ & $71-100$ & - & - & - \\
\hline Wood & - & - & - & $1-20$ & $21-75$ & $76-100$ \\
\hline \multicolumn{7}{|c|}{ Mature trees } \\
\hline Leaf & $1-20$ & $21-70$ & $71-100$ & - & - & - \\
\hline Branch & $1-20$ & $21-70$ & $71-100$ & - & - & - \\
\hline Wood & - & - & - & $1-20$ & $21-70$ & $71-100$ \\
\hline
\end{tabular}

be linked with GEMS the same way as the LULCC maps are linked. Annual fluxes of disturbance-induced carbon loss and the legacy multiyear cumulative effects will be reported.

\section{D.2.1.4. Effects of Management Activities}

In addition to natural disturbances (for example, climate variation, geological disasters, wildfires), human management activities also play a critical role in annual ecosystem carbon fluxes and soil carbon budgets. For example, implementing conservation residue management can significantly mitigate carbon emissions from soils in comparison to conventional tillage management. The conceptual carbon-change scenarios based on explicit simulations of management effects and feedback are shown in figure D6.

Management activities considered in the current GEMS include (but are not limited to) the following:

- Land-use changes, including conversions between land-use classes and crop rotation

- Land-management practices, consisting of -

- Logging event

- Forest fertilization

- Fire-fuel management, including prescribed burns

- Grazing (specified into various intensity classes)

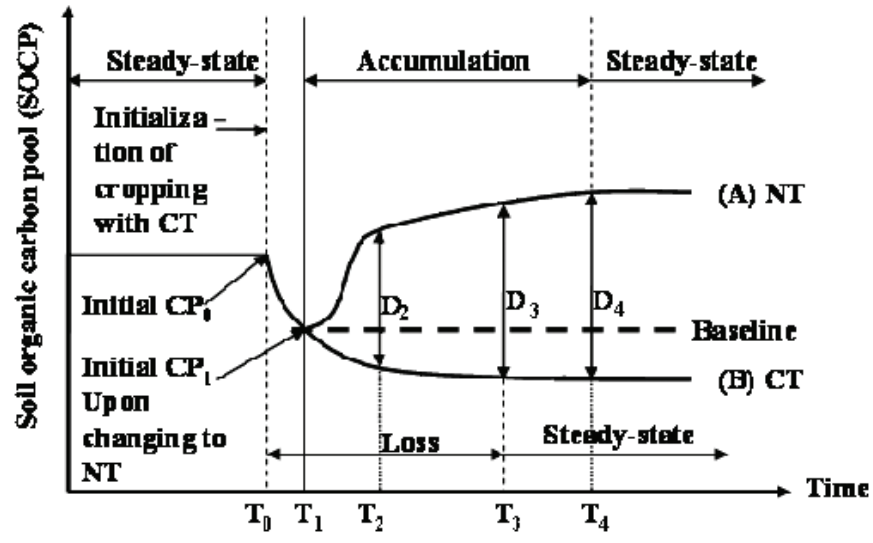

Figure D6. Conceptual model of soil organic carbon (SOC) dynamics under a paired treatment of conventional tillage (CT) and no-till (NT) after initialization of cultivation from natural status. $A$, SOC gain upon converting from CT to NT following $\mathrm{CT}$ for a period of $\left(\mathrm{T}_{1}-\mathrm{T}_{0}\right)$. $B$, SOC loss caused by cropping with CT since $T_{0}$. Difference (D) in SOC stock between NT and CT varies with time. SOC reaches a new equilibrium at $\mathrm{T}_{3}$ under $\mathrm{CT}$ and $\mathrm{T}_{4}$ under NT. The rates of SOC gain and SOC loss do not coincide but are a function of the initial SOC stock level and time scale. 
- Tillage practices coupled with residue input

- Fertilization rate and manure application

- Irrigation

Key algorithms, such as irrigation, fertilization, and residue return, are embedded in GEMS. Data and parameter sets will be collected and compiled from existing databases and literature.

\section{D.2.1.5. Effects of Erosion and Deposition}

Soil erosion and deposition affect soil profile evolution, spatial redistribution of carbon and nutrients, and ecosystem carbon-nitrogen dynamics (Liu and others, 2003; Lal and others, 2004). Soil erosion and deposition will be simulated by using the USPED model (Mitas and Mitasova, 1998). The effects of soil erosion and deposition on soil carbon erosion will be quantified; the processes to be modeled include soil-profile evolution, onsite ecosystem-carbon dynamics, and offsite transport of carbon and nitrogen onto the landscape and into wetland environments and aquatic systems.

USPED is a simple two-dimensional hydrological model that is comparable to the more broadly used Universal Soil Loss Equation (USLE) and Revised Universal Soil Loss Equation (RUSLE); however, unlike the USLE/RUSLE models that can predict only soil erosion, USPED also can simulate deposition on landscape and requires four major inputs only:

- Rainfall intensity, which is to be adjusted by the actual rainfall each year

- Soil erodibility factor ( $\mathrm{K}$ factor), which is available in the U.S. General Soil Map (also called the State Soil Geographic (STATSGO2) database) and the Soil Survey Geographic (SSURGO) databases

- Field carbon factor, which is directly converted from land-cover type

- Digital elevation model (DEM) data

Most of the input requirements are the same as those of USLE/ RUSLE.

USPED is suitable for GEMS because of its appropriate time step, level of complexity, capability of simulating erosion and deposition, and robustness. For linking soil carbon with erosion and deposition, EDCM adopts a multiple-soil-layer structure to account for the stratification of the soil profile and SOC in each soil layer. It dynamically keeps track of the evolution of the soil profile (up to 10 soil layers) and carbon storage as affected by soil erosion and deposition.

In EDCM, each soil-carbon pool in the top layer will lose a certain amount of carbon, if erosion happens. The carbon eroded is calculated as the product of the fraction of the top soil layer experiencing erosion, the total amount of SOC in the top 20 centimeters of the layer, and an enrichment factor for the eroded SOC to account for the uneven vertical distribution of SOC in the top layer. EDCM can dynamically update the soil layers affected by erosion and deposition.

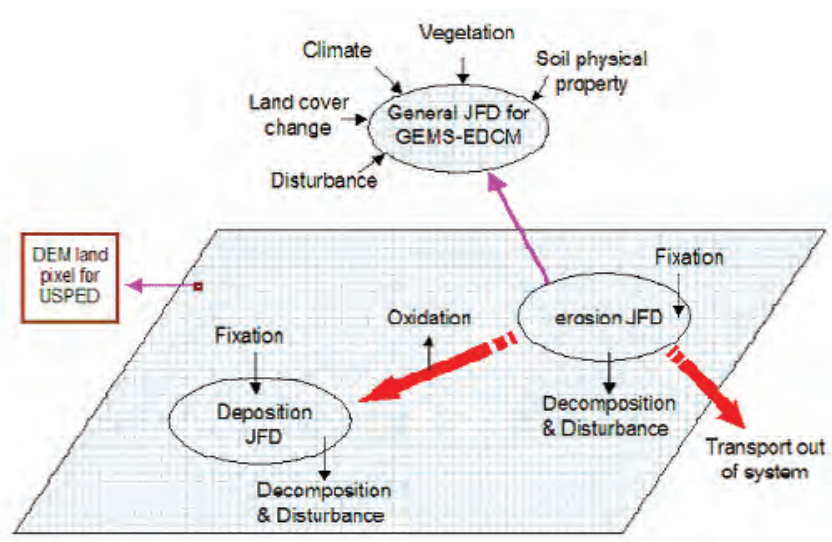

Figure D7. Diagram linking the erosion-deposition model (USPED; Unit Stream Power-Based Erosion Deposition) with the terrestrial biogeochemical model (EDCM; Erosion-DepositionCarbon Model) in GEMS (General Ensemble Modeling System). A JFD (joint frequency distribution) case indicates one or more pixels with the same site condition. DEM, digital elevation model.

One approach for linking USPED with GEMS is shown in figure D7. Simulated erosion and deposition are grouped into discrete classes, which will be included in the GEMS spatial simulation unit (joint frequency distribution (JFD) cases; see later explanations), to represent the land and water surfaces of the study area. Losses of carbon and nitrogen during lateral sediment transportation are accounted for using an oxidation factor.

\section{D.2.1.6. Fate of Wood Products}

Carbon in wood products, landfills, and other offsite storage can be significant in the accounting of terrestrial carbon-sequestration capacity (Skog and Nicholson, 1998). Currently (2010), GEMS does not track the fate of carbon in wood products. Because GEMS is linked directly to the data-management system for the purposes of reporting and dissemination of assessment results, a spreadsheet summarizing sequestration and GHG fluxes across ecosystems and carbon pools will be created. Most of the carbon pools will be simulated at a pixel level. For wood products, average values will be provided. The U.S. Environmental Protection Agency (EPA) and the USFS will be consulted about the proper way to estimate forest-product carbon and potential collaboration opportunities. Existing factors and equations about harvestedwood-product carbon pools (Smith and others, 2006; Skog, 2008) will be adopted and modified to link with GEMS to track the fate of harvested wood.

\section{D.2.1.7. Methane and Nitrous-0xide Fluxes}

The emission of $\mathrm{CH}_{4}$ at wetland sites will be simulated in terms of soil biogeochemical processes, including $\mathrm{CH}_{4}$ production by methanogenic bacteria under anaerobic conditions, oxidation by methanotrophic bacteria under aerobic 
conditions, and transport to the atmosphere (Conrad, 1989). The principal controls of these processes are soil moisture, water table position, soil temperature, availability and quality of suitable substrates, and pathways of $\mathrm{CH}_{4}$ transport to the atmosphere. A wide range of models have been developed to simulate the plot-scale processes of $\mathrm{CH}_{4}$ generation, consumption, and transport ( $\mathrm{Li}$ and others, 1992; Cao and others, 1996; Potter, 1997; Walter and others, 2001; Zhuang and others, 2006). A simple compartmental (zero-dimensional) model was developed by Cao and others (1996) to simulate wetland carbon dynamics for large areas. Another model by Potter (1997) simulated $\mathrm{CH}_{4}$ production rates from a microbial production ratio of $\mathrm{CO}_{2}$ and $\mathrm{CH}_{4}$, which changed as a function of the water-table depth. Slightly more complex one-dimensional models (Walter and others, 2001; Zhuang and others, 2006) also are available to tailor more detailed process descriptions. Some of these models have a detailed representation of plot-scale vertical soil processes. The deployment of these models for large areas, however, has been challenging because of the difficulties in defining parameters for these models and in simulating some of the critical driving variables, such as water-table position in individual wetlands for large areas.

The GEMS modeling team has applied the denitrification-decomposition (DNDC) model to simulate $\mathrm{CH}_{4}$ and $\mathrm{N}_{2} \mathrm{O}$ fluxes in the Prairie Pothole Region. A process-based model for $\mathrm{CH}_{4}$ that is similar to the Cao and others (1996) and DNDC approaches has been implemented in GEMS that will balance the needs of considering the plot-scale processes and the feasibility of deploying the plot-scale model for large areas to address spatial heterogeneity. Estimates of $\mathrm{CH}_{4}$ production by the model depend on the substrate availability (soil carbon and vegetation root carbon) and soil condition (soil temperature, redox), whereas $\mathrm{CH}_{4}$ oxidation is calculated based on the soil redox condition or water table.

In a zero-dimensional modeling approach, the $\mathrm{CH}_{4}$ emission from wetlands to the atmosphere is calculated as the difference between the $\mathrm{CH}_{4}$ production and oxidation:

$$
M E R_{t}=M P R_{t}-M O R_{t},
$$

where $M E R_{t}$ is the emission mass of $\mathrm{CH}_{4}$ per unit surface area of a wetland at time $t$,

$M P R_{t}$ is the production mass of $\mathrm{CH}_{4}$ per unit surface area of a wetland at time $t$, and

$M O R_{t}$ is the oxidation mass of $\mathrm{CH}_{4}$ per unit surface area of a wetland at time $t$.

$M P R_{t}$ and $M O R_{t}$ are estimated on the basis of such controlling factors as decomposed organic carbon, water-table position, soil temperature, and primary production of existing plants. These controlling factors are parameterized by applying or synthesizing techniques described in Cao and others (1996), Potter (1997), Walter and others (2001), and Zhuang and others (2006). A reasonably accurate prediction of the water-table position, in particular, is a challenging aspect. Further details are given below in section D.3.2 as part of a discussion on modeling lateral fluxes in and out of wetland systems.
Various models exist for simulating $\mathrm{N}_{2} \mathrm{O}$ emissions (for example, Li and others, 1992; Liu and others, 1999; Parton and others, 2001; Hénault and others, 2005). Procedures for estimating $\mathrm{N}_{2} \mathrm{O}$ emissions from ecosystems were developed in the prototype of the GEMS-EDCM method and applied to simulate and project $\mathrm{N}_{2} \mathrm{O}$ emissions in the Atlantic zone of Costa Rica (Liu and others, 1999; Reiners and others, 2002). Nitrification and denitrification processes are the primary processes that lead to the emission of $\mathrm{N}_{2} \mathrm{O}$ from soils. Atmospheric and terrestrial (for example, fertilizer, litter) depositions of nitrogen, plant uptake, mineralization, and leaching can act as the major controls. The existing GEMS algorithms for $\mathrm{N}_{2} \mathrm{O}$ flux simulations will be used to compare simulation results with observations (for example, GRACEnet) and to improve the model when necessary. A zero-dimensional model is also applicable for estimating $\mathrm{N}_{2} \mathrm{O}$ emissions from wetlands:

$$
N O E_{t}=N O E_{\text {denit }, t}+N O E_{\text {nit, }},
$$

where $N O E_{t} \quad$ is the $\mathrm{N}_{2} \mathrm{O}$ emission mass per unit surface area of a wetland at time $t$,

$N O E_{\text {denit, } t}$ is the production mass by denitrification per unit surface area of a wetland at time $t$, and

$N O E_{n i t, t} \quad$ is the production mass by nitrification per unit surface area of a wetland at time $t$.

$N O E_{\text {denit, }}$ and $N O E_{n i t, t}$ are quantified by applying or synthesizing techniques described in $\mathrm{Li}$ and others (1992), Liu and others (1999), Parton and others (2001), and Hénault and others (2005).

Subject to the availability of observation data, empirical regression models also can be developed for emissions of $\mathrm{CO}_{2}, \mathrm{CH}_{4}$, and $\mathrm{N}_{2} \mathrm{O}$ from wetlands with different land-cover types, as well as hydrologic and meteorological regimes. Much of the variations of $\mathrm{CO}_{2}$ and $\mathrm{CH}_{4}$ may be explained by considering wetland soil temperature and water-table elevation as predictor variables. Variations of $\mathrm{N}_{2} \mathrm{O}$ flux also could be captured by regressing with soil temperature and waterfilled pore space as the predictor variables; however, such regression models likely are highly site-specific and require large datasets given their purely statistical nature. Because such datasets rarely exist in current literature, deployment of such models in large spatial, as well as temporal, scales can hardly be justified as reliable given the uncertainty of estimated regression coefficients.

The IPCC tier 1 approach (Intergovernmental Panel on Climate Change, 2006) is a simple way of obtaining crude estimations of $\mathrm{CO}_{2}, \mathrm{CH}_{4}$, and $\mathrm{N}_{2} \mathrm{O}$ emissions from wetlands. The approach is based on some aggregate measures of emissions of specific GHG per unit of time and wetland area. Although IPCC (2006) provided global estimates of these emission factors based on existing literature, regional estimates for the wetlands in the United States also may be obtained from a comprehensive literature survey. Emission estimates obtained through the tier 1 approach would complement the evaluations of results of the simple biogeochemical models described previously. 


\section{D.2.2. GEMS Spatial Simulation Unit}

The spatial heterogeneities of the biophysical variables (such as land cover, soil texture, and DEM) often are represented on thematic maps and stored in georeferenced geographic information system (GIS) databases. The simulation unit in GEMS is a cluster of land pixels sharing a unique combination of values of environmental driving variables. Combining multiple input raster layers (maps) on a cellby-cell basis in a GIS, a JFD table can be created to list all unique combinations of the values of the overlay variables and their associated frequencies (areas or number of pixels). Each unique combination forms a GEMS simulation unit. The geographic locations of all the JFD cases are uniquely determined by the JFD map, thereby providing the spatial framework to visualize and analyze the spatial and temporal patterns of biogeochemical properties and processes.

Two examples of the JFD map are shown in figure D8. The first example (fig. D8A) overlays the soil and land-cover maps; the resulting JFD map shows the unique combinations of soil and land-cover conditions. An important feature of this JFD approach is the elimination of the need to perform model simulations pixel by pixel. One pixel represents all the pixels of a JFD case. The second example (fig. D8B) shows the land pixel sampling at certain spatial intervals (for example, 5 kilometers) on a stack of relatively higher resolution (for example, 30- to 250-m) maps. This sampling approach is used when there are too many land pixels and map layers. It also creates a JFD table where each JFD case contains one land pixel only.

\section{D.2.3. Using Ensemble Simulations to Reconcile Nonlinearity and Heterogeneity}

Studies indicate that averaging across the spatial and temporal heterogeneity of the input data could have significant effects on the carbon simulations (Avissar, 1992; Pierce and Running, 1995; Turner and others, 1996; Kimball and others, 1999). This indicates that incorporating ecosystem heterogeneity is necessary to accurately upscale carbon dynamics from site to regional scales. The direct approach of incorporating variance and covariance of input variables in the simulation process can be expressed as the following:

$$
E(p)=\sum_{i=1}^{n} E\left[p\left(X_{i}\right)\right] F\left(X_{i}\right)
$$

where $E$ is the operator of expectation,

$p \quad$ is the nonlinear model,

$X$ is a vector of model variables,

$n \quad$ is the number of strata or total JFD, and

$F \quad$ is the frequency of cells or the total area of strata $i$ as defined by the vector of $X_{i}$.

Any difference between the model scale and the spatial resolution of the data may introduce biases caused by model nonlinearity. An ensemble approach can assimilate the fine-scale heterogeneities in the databases to reduce potential biases. The mean value of a variable (for example, carbon stock and flux) of simulation unit $i$ in equation $\mathrm{D} 8$ can be estimated by using multiple stochastic model simulations:

$$
E\left[p\left(X_{i}\right)\right]=\frac{1}{m} \sum_{j=1}^{m} p\left(X_{i j}\right),
$$

where $m$ is the number of stochastic fine-scale model runs for simulation unit $i$, and
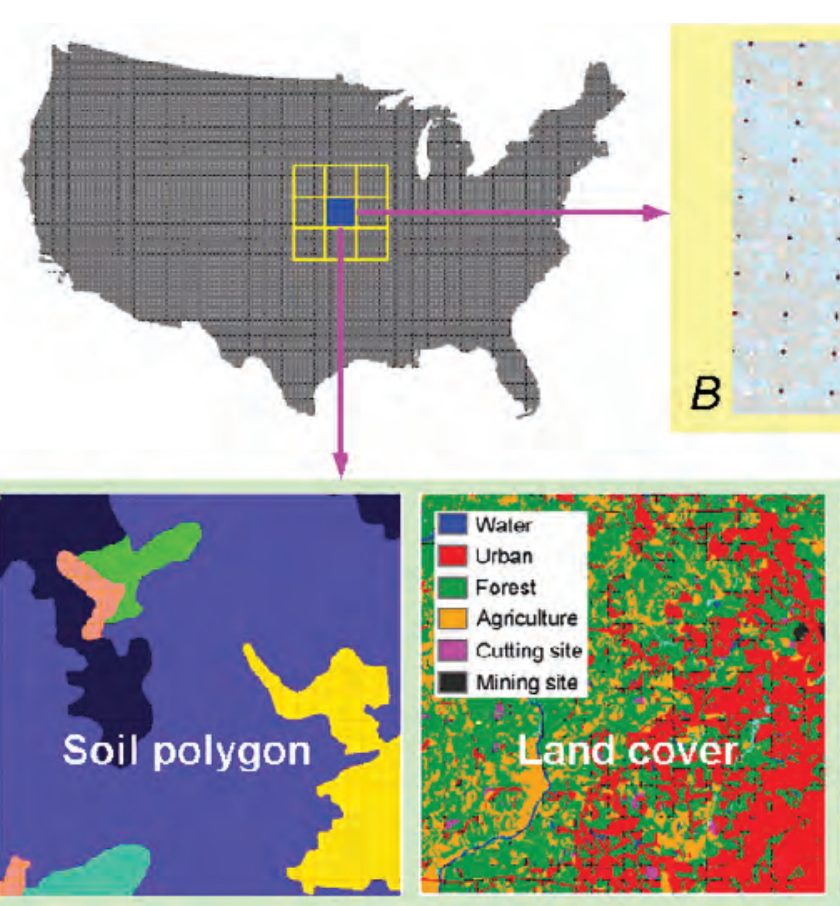

Figure D8. Diagram showing approaches to produce a jointfrequency distribution (JFD) map. A, Overlaying multiple map layers to create unique JFD cases from all land pixels. $B$, Spatial sampling at certain intervals. 
$X_{i j} \quad$ is the vector of model input values at the fine scale generated using a Monte Carlo approach within the space defined by $X_{i}$.

As a result, input values for each stochastic model run are sampled from their corresponding potential value domains $\left(X_{i}\right)$ that usually are described by their statistical information, such as moments and distribution types. The variance of the model simulations on regional scale can be quantified as follows:

$\sigma^{2}[p]=\sum_{i=1}^{n} \sigma^{2}\left[p\left(X_{i}\right)\right] F^{2}\left(X_{i}\right)+2 \sum_{i=1}^{n-1} \sum_{j=i+1}^{n} \operatorname{Cov}\left[p\left(X_{i}\right), p\left(X_{j}\right)\right] F\left(X_{i}\right) F\left(X_{j}\right)$,

where the variance and covariance of the model simulations on unit $i$ can be expressed as follows:

$$
\begin{gathered}
\sigma^{2}\left[p\left(X_{i}\right)\right]=\frac{1}{m-1} \sum_{j=1}^{m}\left[p\left(X_{i j}\right)-E\left[p\left(X_{i}\right)\right]\right]^{2} \text { and } \\
\operatorname{Cov}\left[p\left(X_{i}\right), p\left(X_{j}\right)\right]=E\left[p\left(X_{i}\right) p\left(X_{j}\right)\right]-E\left[p\left(X_{i}\right)\right] E\left[p\left(X_{j}\right)\right] .
\end{gathered}
$$

Other descriptive statistics, such as skewness, also can be calculated from the ensemble simulations. These moments characterize not only the spatial and temporal trends and patterns of simulated variables, but also their uncertainties in space and time.

Solving equation D10 will require excessive computational effort if the number of strata $n$ is quite large; however, if $p(X)$ and $p(X)$ are independent among a great number of strata, computations will be dramatically reduced because covariance defined in equation D12 will be zero. Hence, actual applications should sufficiently identify the independence among strata. For example, suppose $p(X)$ and $p(X)$ represent soil organic carbon within strata $i$ and strata $j$, respectively, and their random properties result from the randomness of soil texture and precipitation. If there is no lateral flow between strata $i$ and strata $j$, then $p(X)$ and $p(X)$ can be regarded as independent.

\section{D.2.4. Automated Model Parameterization (Monte Carlo Downscaling)}

Models developed for site-scale applications need linkages with georeferenced data to be deployed across a region. Most information in spatial databases is aggregated to the map-unit level as the mean or median values, making the direct injection of georeferenced data into the modeling processes problematic and potentially biased (Pierce and Running, 1995; Kimball and others, 1999; Reiners and others, 2002). Consequently, an automated model parameterization process usually is needed to incorporate field-scale spatial heterogeneities of state and driving variables into simulations. A Monte Carlo approach is built into GEMS to downscale aggregated information from map-unit level to field scale. Examples of data variables to be downscaled for parameterization include soil property, tree age, crop rotation, and forest cutting. The following describes the automated stochastic soil and forest-age initializations.

Soil polygons on the STATSGO2 and SSURGO maps are represented by map units; each has a unique map-unit identifier (ID), size, and location. Each map unit contains from 1 to 20 soil components, representing distinct soils types. Each soil component has a soil attributes table; however, the locations of the soil components within a map unit are not known. In GEMS, for any specific stochastic simulation, a soil component was randomly picked from all components within a soil map unit according to the probability defined by the areal fractions of the components. Once the component was determined, soil characteristics were retrieved from the corresponding soil component and layer attribute databases. For the variables with increased $\left(V_{\text {high }}\right)$ and decreased $\left(V_{\text {low }}\right)$ values, the following equation was used to assign a value $(V)$ to minimize potential biases from model nonlinearity (Pierce and Running, 1995; Reiners and others, 2002):

$$
V=\frac{V_{\text {low }}+V_{\text {high }}}{2}+\frac{p \times\left(V_{\text {high }}-V_{\text {low }}\right)}{3.92}
$$

where $p$ is a random value that follows standard normal distribution $N(0,1)$.

The above equation assumes that the possible values of the soil characteristics follow a normal distribution with 95 percent of the values varying between $V_{\text {high }}$ and $V_{\text {low }}$. 
The Monte Carlo approach also is used to downscale regional initial forest age. The currently available forest-age data come from State- or county-level forest-inventory statistics. The forest-age class distribution (area weight) is a feature on the regional scale. To assign a forest age for a specific location, a cumulative probability curve must be created on the basis of the forest-age class distribution (fig. D9). The next step is to generate a random $p$ value between 0 and 1 . The $p$ value will point to a specific level on the cumulative probability curve and match it to a corresponding age class. GEMS then uses a look-up table to retrieve initial forest biomass based on the age (Liu, Liu, and others, 2008).

\section{D.2.5. Data Assimilation}

Data assimilation techniques can be activated to constrain GEMS simulations with various observations at different spatial and temporal scales. Different data-assimilation techniques are implemented in GEMS to leverage the advantages and disadvantages of each method. For example, the Markov Chain Monte Carlo (MCMC) method is computation intensive and, therefore, difficult to apply to a region where the number of simulation units is large. It can be effective and ideal, however, to derive representative values and their uncertainties of model parameters from limited point observations, such as flux-tower measurements.

Other data assimilation techniques used by GEMS include model inversion using PEST (EPA's model-independent parameter estimation application; http://www.epa.gov/ ceampubl/tools/pest/) (Liu, Anderson, and others, 2008), Ensemble Kalman Filter (EnKF) (Evensen, 1994, 2003), and Smoothed Ensemble Kalman Filter (SEnKF) (Chen and others, 2006, 2008). Model inversion with the PEST package is based on optimal theory and thus requires that the model have a smooth response to model parameters. Both EnKF and SEnKF are based on statistical Bayesian theory and joint technology of Monte Carlo sampling with a Kalman filter.

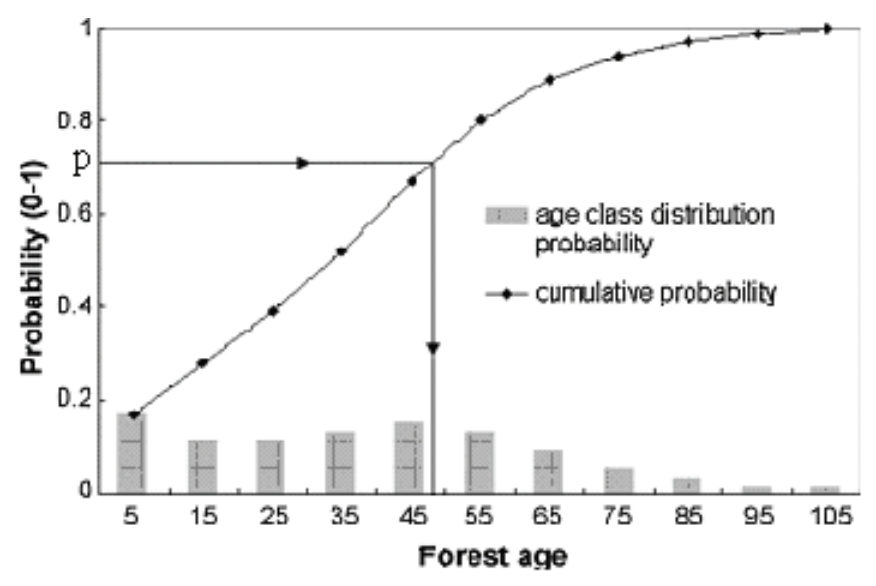

Figure D9. Monte Carlo downscaling of State- and county-level forest-age data to pixel level. From Liu, Liu, and others (2008), used with permission.
EnKF has many successful applications in weather forecasting and hydrology through incorporating various data into the model simulation process to improve estimation of model state variables. The GEMS team has used some of the approaches to derive model parameter information from plot measurements of carbon and nitrogen stocks (Liu, Anderson, and others, 2008) and from eddy-covariance flux-tower observations (Chen and others, 2008). A combination of data-assimilation techniques will be used to ensure that model simulations agree well with observations from different sources and scales.

Plot-scale.-FLUXNET (the flux network) and FIA data (plot-scale repetitive measurements of biomass stocks and vegetation dynamics) will be used to derive information on modelparameter values and their uncertainty. The derived modelparameter information at the plot scale will then be extrapolated to regional and national scales (Liu and others, 2008).

Regional to national scales. - EnKF, SEnKF, or other data-assimilation techniques will be used to assimilate remotely sensed and ground-based observations. For example, Zhao and others (2010) successfully assimilated the gross primary productivity (GPP) data of the Moderate Resolution Imaging Spectroradiometer (MODIS) products to support regional model simulations of carbon sequestration in a southeastern region

The SEnKF (Chen and others, 2006, 2008) will be used at the plot and regional scales. By combining EnKF with a kernel smoothing technique, SEnKF has the following characteristics:

- Simultaneously estimates the model states and parameters through concatenating unknown parameters and state variables into a joint state vector

- Mitigates dramatic, sudden changes of parameter values in the parameter-sampling and parameter-evolution process, and controls the narrowing of the parameter variance

- Recursively assimilates data into the model, and thus detects the possible time variations of parameters

- Properly addresses various sources of uncertainty stemming from input, output, and parameter uncertainties

In GEMS, the SEnKF procedure becomes regular Monte Carlo analysis at the time steps when no observation data are available for assimilation.

The SEnKF method was tested by assimilating observed fluxes of $\mathrm{CO}_{2}$ and environmental driving-factor data from an AmeriFlux forest station (located near Howland, Me.) into a model for partitioning eddy-covariance fluxes (Chen and others, 2008). Analysis demonstrated that model parameters, such as light-use efficiency, respiration coefficients, and the minimum and optimum temperatures for photosynthetic activity, are greatly constrained by eddy-covariance flux data at daily to seasonal time scales.

The SEnKF stabilizes parameter values quickly regardless of the initial values of the parameters. Predictions made by SEnKF with data assimilation matched observations substantially better than predictions made without data 
assimilation (fig. D10). Additionally, this approach also is efficient in finding the optimum parameters (fig. D11).

\section{D.2.6. Input and Output Processor and NetCDF Interface}

A GIS program (JFD Builder) was developed for generating a JFD table from primary input data layers. A NetCDF program (called NCWin) for processing and visualizing NetCDF data also was developed. All mapped data (for example, climate, soil, vegetation cover, disturbance events) are saved in NetCDF format in GEMS. The NCWin graphical user interface (GUI) provides the capability to convert and visualize input and output maps as well as temporal data trends (fig. D12).

\section{D.3. Integrating With Other Models}

\section{D.3.1. Linkages With Land-Use- and Land-Cover- Change Data and Projections}

For the national assessment, GEMS will be directly coupled with the land-use-change model FORE-SCE (appendix $\mathrm{B}$ of this report) to account for the effects of past land-cover and land-use changes and simulated future land-use changes on ecosystem carbon-nitrogen dynamics. LULCC maps generated by the model will be used to produce spatial simulation units either by the JFD approach or a land pixel sampling approach. For an individual plot, an LULCC file, called the "event schedule file," will be created. This file specifies the type and timing of any LULCC events, as well as the type and timing of management practices, such as cultivation and fertilization.

The LULCC information from the land-change model and other information (for example, the USDA Natural Resources Inventory (NRI) database) will be assimilated using the following procedures:

- Events such as forest clearcutting, deforestation, urbanization, and reforestation will be directly incorporated. A biomass removal or restoration algorithm will be applied to land pixels with these land-use-change events.

- Although annual clearcutting events will be provided by the land-change model, selective cutting events (for example, group-selection harvesting and fuel treatment) are not available. The selective cutting activities can be scheduled based on selective cutting rates derived from other sources, such as FIA databases, the new vegetation change tracker (VCT) product derived from LANDFIRE (Huang and others, 2009), and forest fuel-treatment data. GEMS can aggregate the total selective cutting area to an equivalent amount of clearcutting area and randomly assign the derived clearcutting to the forest landscape.
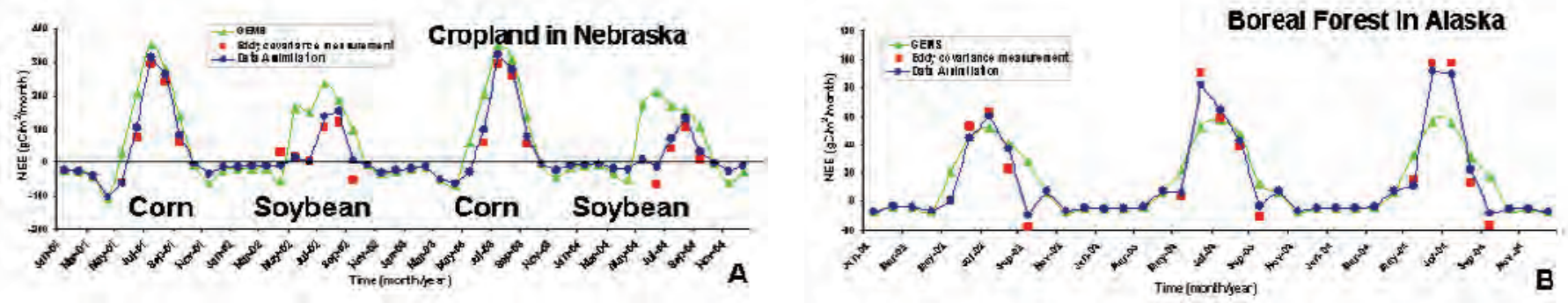

Figure D10. Graphs showing an example of Smoothed Ensemble Kalman Filter (SEnKF) data assimilation on state variables. The "GEMS" curve represents the GEMS model without data assimilation. The "Data Assimilation" curve represents the GEMS model with data assimilation. Field observations (red squares) are from the online data archive of American Flux Network (AmeriFlux) sites.
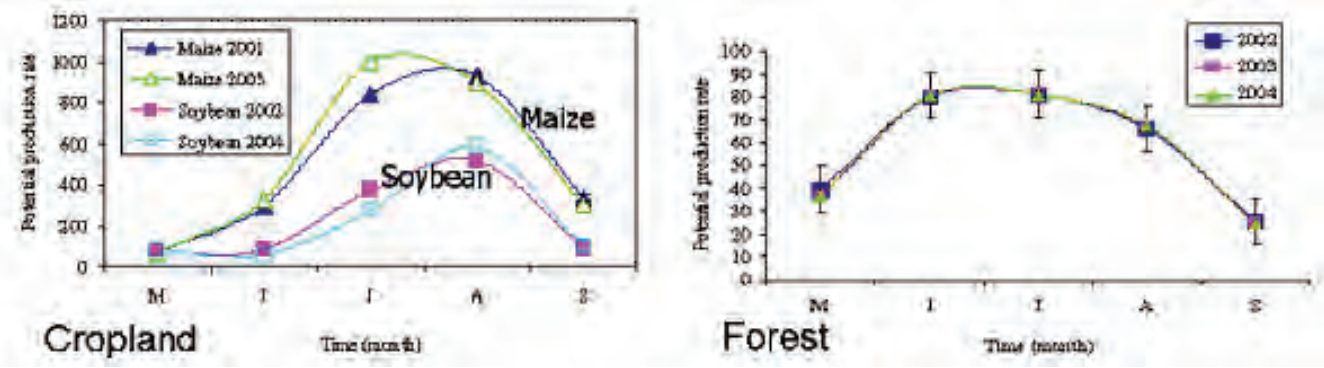

Figure D11. Graphs showing the results of parameter estimation for the plant-production submodel using the Smoothed Ensemble Kalman Filter (SEnKF) in the biogeochemical General Ensemble Modeling System (GEMS). The graphs show seasonal variations of the potential plant-production rate in croplands (left) and in forests (right). The seasonal variations imply that the structure of the plant-production model might not be adequate to represent the seasonality of crop growth. 


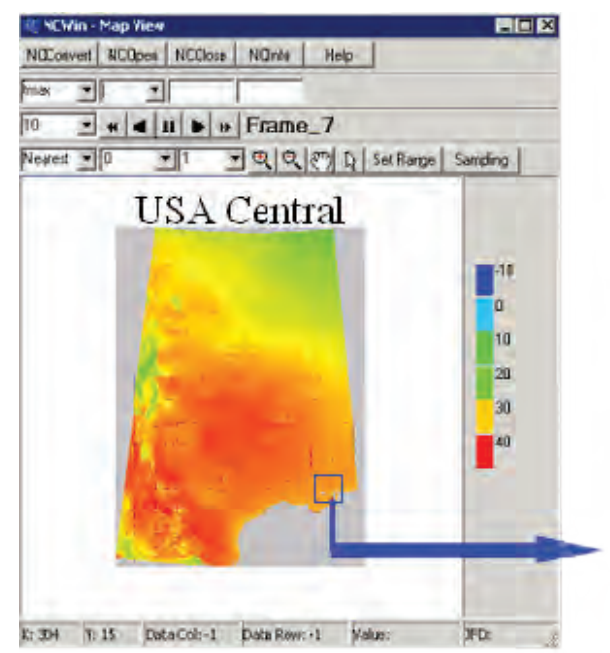

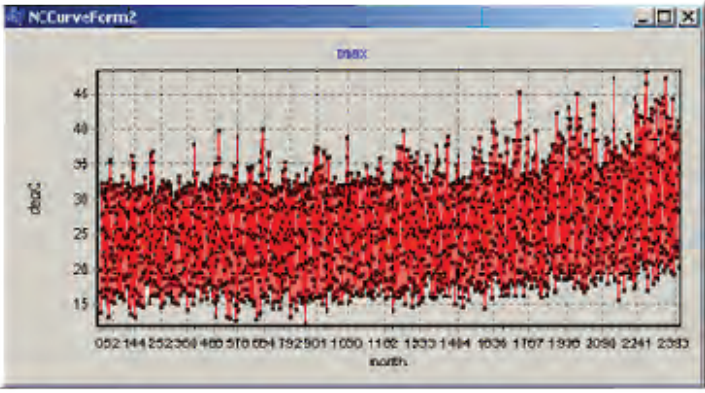

Figure D12. Screen capture showing an example of the NCWin map and data trends graphical user interface.
GEMS also will calculate specific thinning effects on biomass and soil carbon change when related publications and field data are synthesized.

- Mapping crop species distribution and rotations for large areas is still a primary challenge for national land-cover database development. Crops are aggregated into broad categories (for example, row crops, and other agricultural land). It is necessary to downscale aggregated classes into specific crops for biogeochemical modeling because different crops have different biological characteristics and management practices, likely resulting in different effects on carbon dynamics in vegetation and soils. Disaggregation of the agricultural land data is done stochastically in GEMS based on crop composition statistics at a district or county level. For example, in the U.S. Carbon Trends Project (Liu, Loveland, and Kurtz, 2004; Tan and others, 2005; Liu and others, 2006), schedules of cropping practices, including shares of various crops and rotation probabilities, were derived from the NRI database developed by the USDA Natural Resources Conservation Service. The NRI database is a statistically based sample of land-use and natural-resource conditions and trends on non-Federal lands in the United States. The inventory, covering about 800,000 sample points across the country, is done once every 5 years. Management practices, such as cultivation and fertilization, are incorporated into the LULCC sequences generated for the site according to crop or forest types and geographic region.

\section{D.3.2. Linkages With Aquatic and Wetland Systems}

The carbon and nitrogen fluxes within the aquatic ecosystems of wetlands, lakes, rivers, and streams, as well as their lateral interactions with the terrestrial ecosystems and vertical exchanges with the atmosphere, will be quantified within the integrated framework of GEMS through an encapsulated aquatic biogeochemical model. A general framework for the aquatic model, which is primarily developed at the site scale, is presented in figure D13.

The primary methodology related to aquatic and wetland systems is described in section D.2.1.7 and appendix E of this report. This subsection focuses on the geospatial aspects and heterogeneity of wetland conditions and processes for large areas. Wetlands are important systems that likely play a pivotal role in the sequestration or release of GHG gases. Physical processes such as the hydrology of flooding (which often is intermittent) and associated soil saturation can be considered as some of the common, principal drivers of wetland biogeochemistry. A functional wetland ecosystem can be conceptualized by interactions among the four major components of water, nutrients, habitat (plants and soils), and animals. A schematic diagram of these functional components and interactions is shown in figure D14.

Given the wide variety of coastal and inland wetlands and the wide range of biophysical and climate conditions across the country, it is very difficult to simulate the hydrological dynamics (for example, water table position) for individual wetlands for large areas using a purely process-based approach. The major challenges for testing and implementing these models include the limited availability of reliable datasets and proper parameterizations of important driving forces and boundary conditions. To address this challenge, a hybrid modeling approach, combining the process modeling and empirical modeling, is being developed to simulate water storage and water-table dynamics in wetlands. Model simulations will be used to derive relatively robust representations of water storage and water-table dynamics for different types of wetlands, such as permanent to semi-permanent and ephemeral to transitional. A frame-based state-transition approach will then be used along with prior knowledge to describe hydrological regimes for different wetlands under various meteorological conditions across the country.

The wetland approach (described in section D.2.1.7 of this report, as well as the river-stream-lake-impoundment 


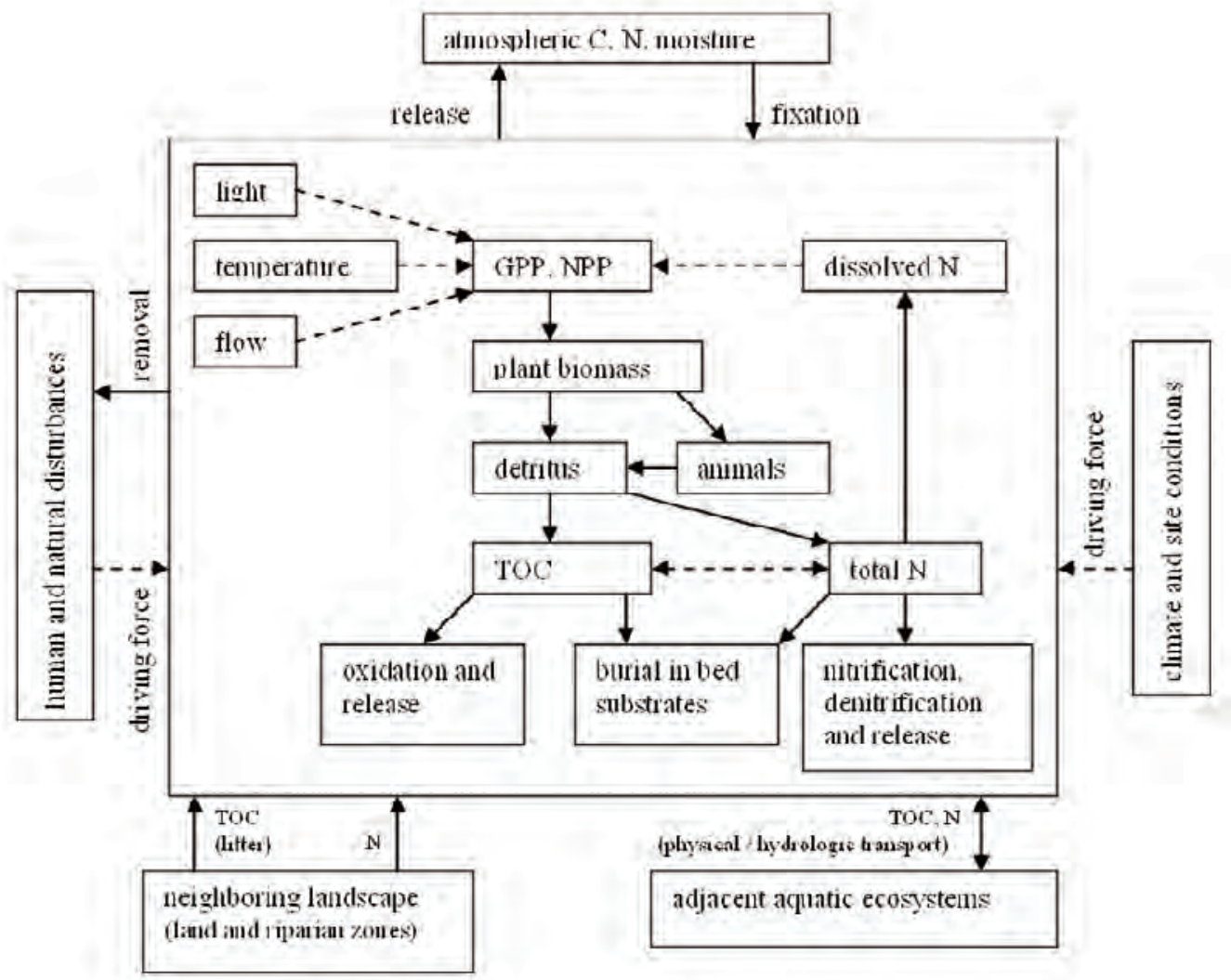

Figure D13. Diagram showing a simplified conceptualization of carbon (C) and nitrogen (N) fluxes, as well as their controls and driving forces, for an encapsulated aquatic biogeochemical model in GEMS. Solid arrows indicate mass flow and dashed arrows indicate controls or driving forces. Abbreviations are found in "Abbreviations, Acronyms, and Chemical Symbols" in the front of this report.

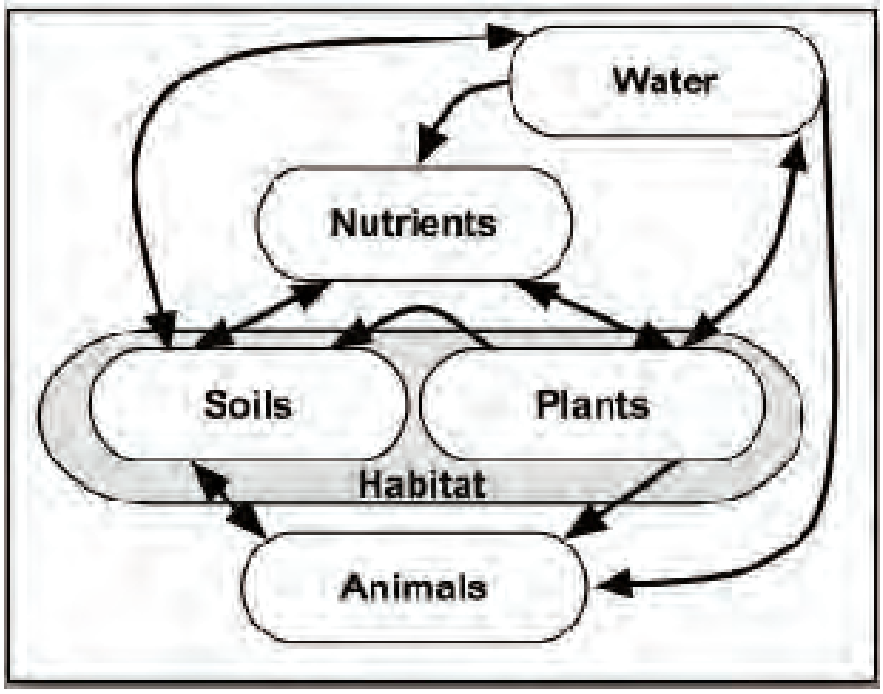

Figure D14. Diagram of conceptual wetland ecosystems and interactions among the functional groups. (Modified from Fitz and Hughes (2008), used with permission.)

methodology in appendix $\mathrm{E}$ of this report, will ingest the uplanderosion and organic-carbon data from GEMS as inputs of lateral fluxes from the terrestrial systems. Statistical analyses and findings of the aquatic team can contribute to the calibration, validation, and improvements of the wetland models for realistically simulating the greenhouse-gas fluxes to the atmosphere and evaluating the carbon sequestration of wetland ecosystems.

\section{D.3.3. Feedback Among the Models}

Model integration is a critical step in the project because there are time- and space-dependent feedbacks among the different modeling components. For example, FORE-SCE requires information about the site fertility or the SOC level from GEMS to optimize the allocations of crops in space and time. On the other hand, land-disturbance information will affect the land-use behaviors, such as timber harvesting. Without stepwise coupling between FORE-SCE and the disturbances model, timber harvesting activities might still be prescribed in areas where biomass has been completely consumed by fire in the disturbances model. Carbon or biomass stock (fuel load) will strongly affect the probability of fire occurrence and the severity of fires, which requires the coupling between the disturbances model and GEMS, with the latter providing carbon-stock information. Model integration will be accomplished on a parallel-processing computer system.

\section{D.4. Relations With Evaluation of Ecosystem Services}

Mitigation opportunities that are considered as management scenarios are evaluated with a spreadsheet approach. These opportunities will be modeled using GEMS. Examples of GEMS data products supporting mitigation opportunities (including ecosystem-services evaluation) are carbon stocks, $\mathrm{CH}_{4}, \mathrm{~N}_{2} \mathrm{O}$ fluxes, soil erosion, NPP, wood harvests, surface 
runoff, and crop yields. In addition, linkages to ecosystemservice evaluation methods (section 3.3.6) will be built based on GEMS output.

The Energy Independence and Security Act of 2007 (EISA) (U.S. Congress, 2007) requires that "short- and long-term mitigation or adaptation strategies" be developed as an outcome of the assessment. In chapter 1 of this report, this was interpreted as a requirement to develop relevant data products and information packages that can be used conveniently by land managers and other stakeholders to develop specific strategies; however, what is "good" from the perspective of one user may be "bad" to another. Landuse change and climate change affect a myriad of ecosystem services simultaneously; some identified specific ecosystem services may be misleading because the overall effect on the ecosystem is not evaluated. Hence, a broader perspective and context is needed to evaluate and understand concurrent effects on multiple ecosystem services. To solve this problem, a platform will be established to project changes in ecosystem services to support adaptive land-management practices. This provides a spatially explicit platform that can accommodate a diversity of land uses and climate change for simultaneous evaluations to better understand biophysical response and tradeoff analyses, highlighting relative effectiveness and efficiency of management activities.

A distributed geospatial model-sharing platform (fig. D15) will be used to model ecosystem services and provide decision support. This platform is necessary to facilitate sharing and integrating geospatial disciplinary models. A platform based on Java Platform Enterprise Edition (J2EE) and open-source geospatial libraries (Feng and others, 2009) is in development. Shared models on the platform are accessible to applications through the Internet using the Open Geospatial
Consortium (OGC) Web Processing Service (WPS) standard (fig. D16).

Assessment results related to the evaluation of ecosystem services, such as soil erosion and deposition, biomass production, $\mathrm{CO}_{2}$ emission, and GHG flux, will be evaluated and distributed using the model-sharing platform (fig. D15). For a specific region and specific interest, however, numerous submodels can be added to reflect the relative effectiveness and efficiency of management activities. For example, water quantity and water quality, which are important indices of ecosystem services, are increasingly affected by natural and anthropogenic activities. The widely used Soil and Water Assessment Tool (SWAT) can be used to estimate the landphase processes (for example, surface runoff, soil erosion, nonpoint-source nutrient loss, groundwater recharge, and baseflow) and water-phase processes (for example, water routing, sediment transport, and nutrient transport and its fate in the aquatic systems). GEMS will link with SWAT to assess the climate-change effects on water availability, and sediment and nutrient transport for the landscape. A pilot platform, named EcoServ (ecosystems services model), was developed in the Prairie Pothole region (PPR) to simulate the diversity of ecosystem services simultaneously at landscape scale.

\section{D.5. Estimating Uncertainties}

Uncertainty estimates can be in the form of estimated percent errors, standard deviations, confidence intervals, or any other relevant coefficient (Larocque and others, in press). For the assessment, an overall approach to assessing uncertainties is presented in appendix $\mathrm{G}$ of this report. Here, a brief

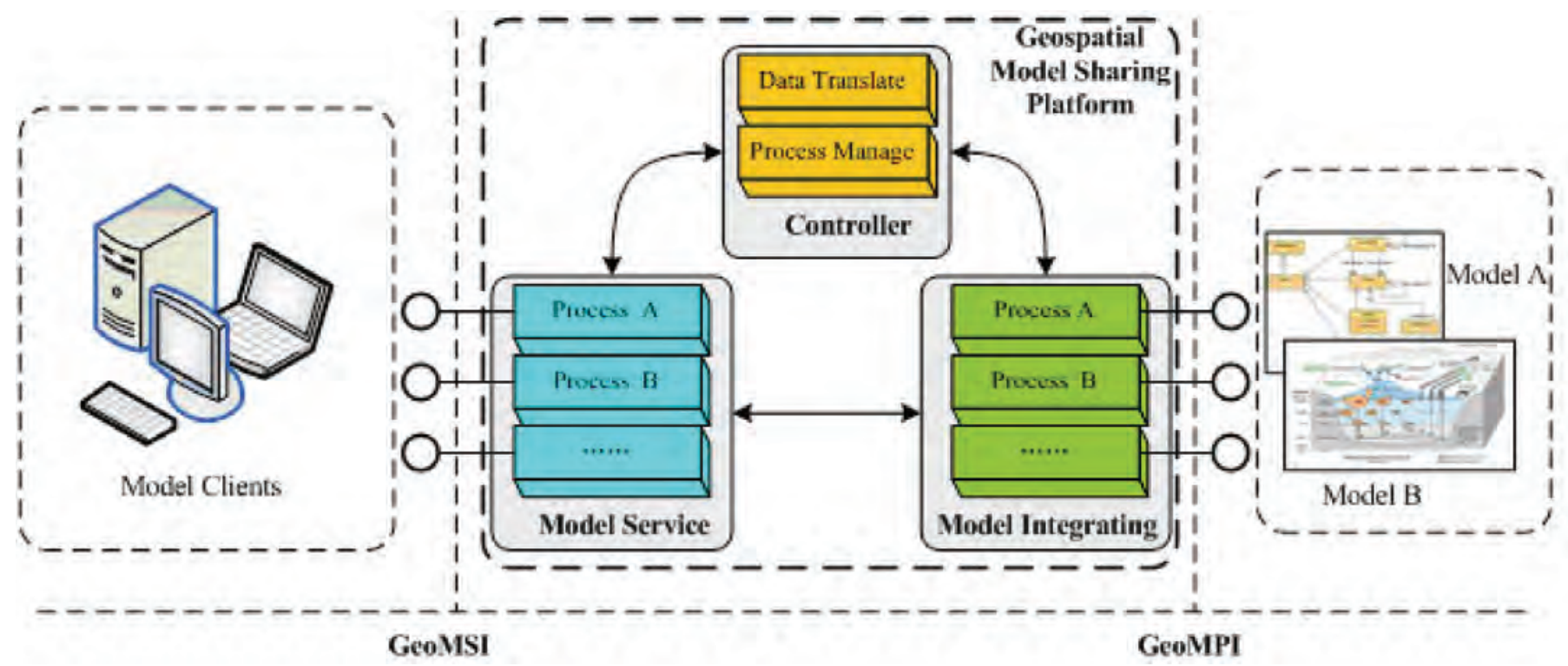

Figure D15. Diagram showing the system structure of the Geospatial Model Sharing Platform. From Feng and others (2009), used with permission. Abbreviations are found in the Abbreviations, Acronyms, and Chemical Symbols listing in the front of this report. 


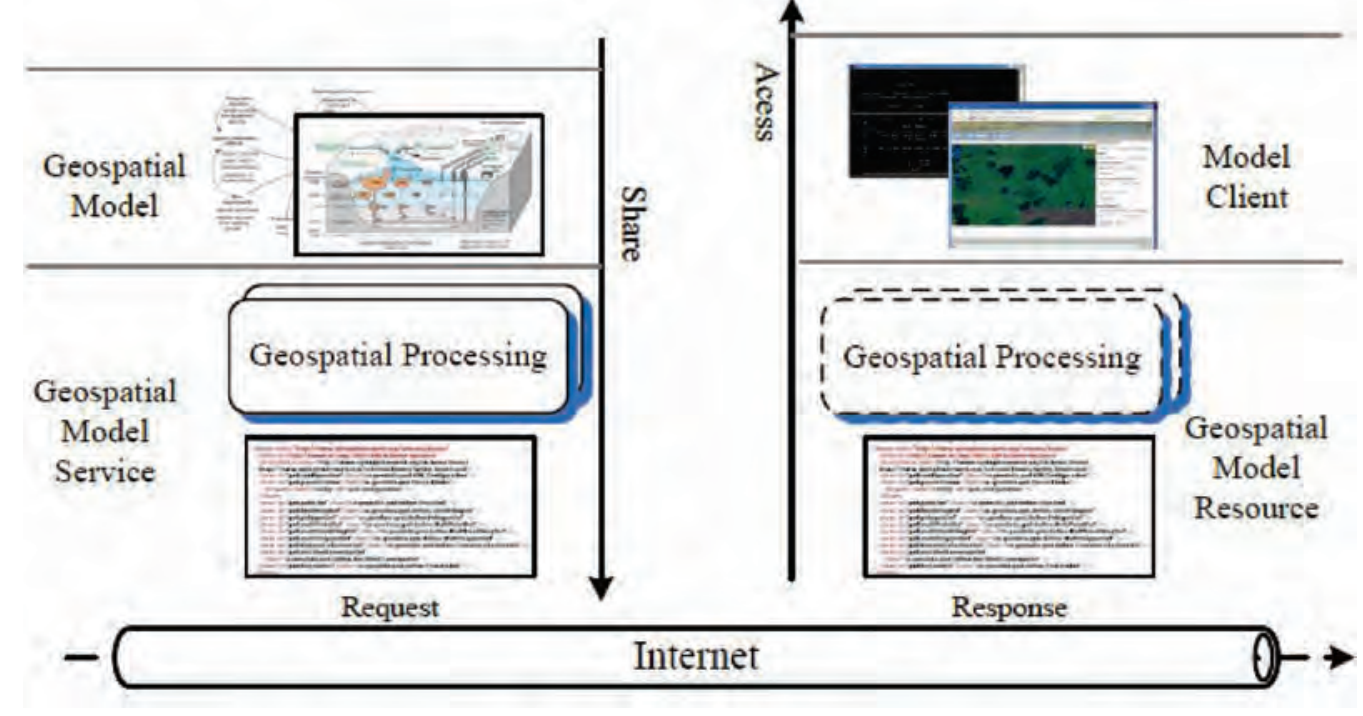

Figure D16. Conceptual flow diagram illustrating access to the shared geospatial model. From Feng and others (2009), used with permission. discussion is presented about how uncertainties related to GEMS data, parameters, and model structure will be handled.

Following the IPCC (2006) guidance, uncertainty analysis mainly focuses on random errors. Model bias removal will be based on model calibration with in situ data.

The factors to be considered in the uncertainty evaluation should have an uncertainty range, either expressed as a probability distribution function (PDF) curve or a probability lookup table. Typical PDFs described by IPCC (2006) are shown in figure D17. In GEMS, uncertainty factors may include forest age, crop species, soil type, canopy density, logging location, burn severity, and agricultural management.

If a model parameter has a PDF, it can be evaluated using error propagation. When a parameter PDF is not available, it is possible to derive the PDF using a data-assimilation technique. Some parameters may be obtained from expert judgment, which also has uncertainties.

The IPCC error propagation equation(s) will be used to aggregate the uncertainty from different vegetation types (such as forest or crop) to the JFD level, and aggregate uncertainty from the JFD level to a region:

$$
U_{\text {total }}=\frac{\sqrt{\left(U_{1} \times x_{1}\right)^{2}+\left(U_{2} \times x_{2}\right)^{2}+\ldots+\left(U_{1} \times x_{1}\right)^{2}}}{\left|x_{1}+x_{2}+\ldots+x_{n}\right|},
$$

where $x$ is area weight, and

$U$ is uncertainty.

Beyond error propagation, another effective approach to quantify modeling uncertainty is model comparison. Because GEMS can encapsulate multiple models, and parameterize and drive these models with the same data, it provides an ideal environment or platform to identify and address issues and uncertainty related to model structure and mathematical representations of biophysical processes. GEMS eventually will include 5 to 10 BGC models in the national assessment.

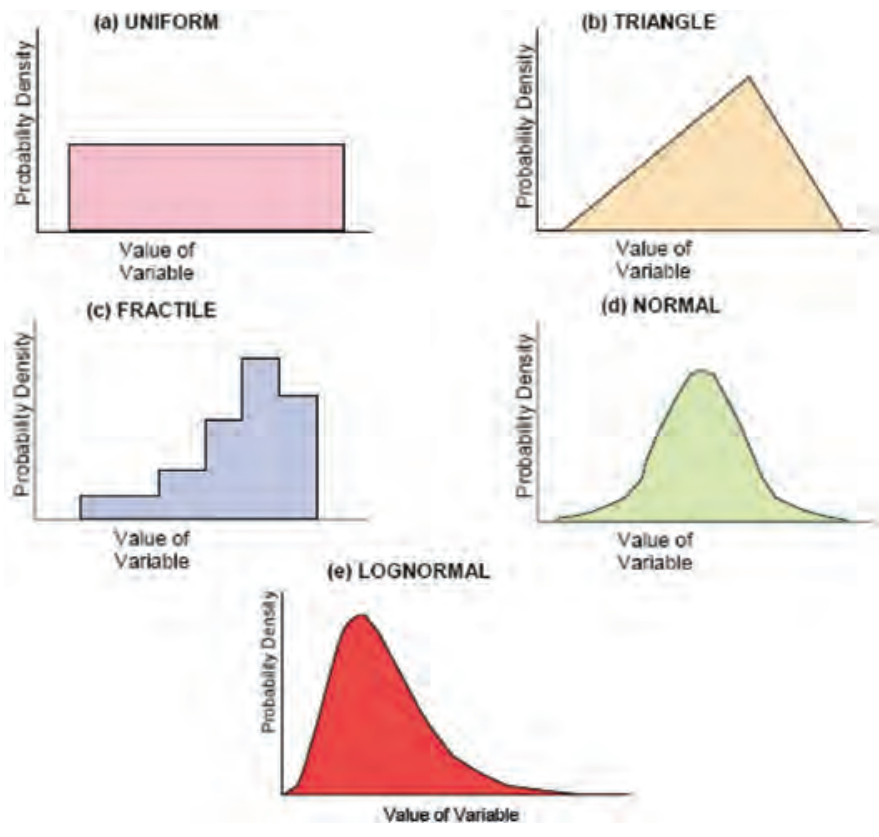

Figure D17. Typical probability distribution (density) function (PDF) curves. From Intergovernmental Panel on Climate Change (2006, p. 3.25), used with permission.

\section{D.6. Biogeochemical Deliverables}

Major GEMS deliverables generated from various models or approaches are listed in table D3. Most of the outputs can be summarized in tables and displayed in map series. 
Table D3. Preliminary methods or models to be used to assess parameters of carbon stocks, carbon sequestration, and greenhousegas fluxes by ecosystems defined for the assessment.

[The methods or models listed have been tested and prototyped, but additional models may be added depending on unique ecosystem conditions or technical needs encountered in the assessment. Input data requirements for each ecosystem are also listed. An explanation of abbreviations and acronyms is found in "Abbreviations, Acronyms, and Chemical Symbols" in the front of this report]

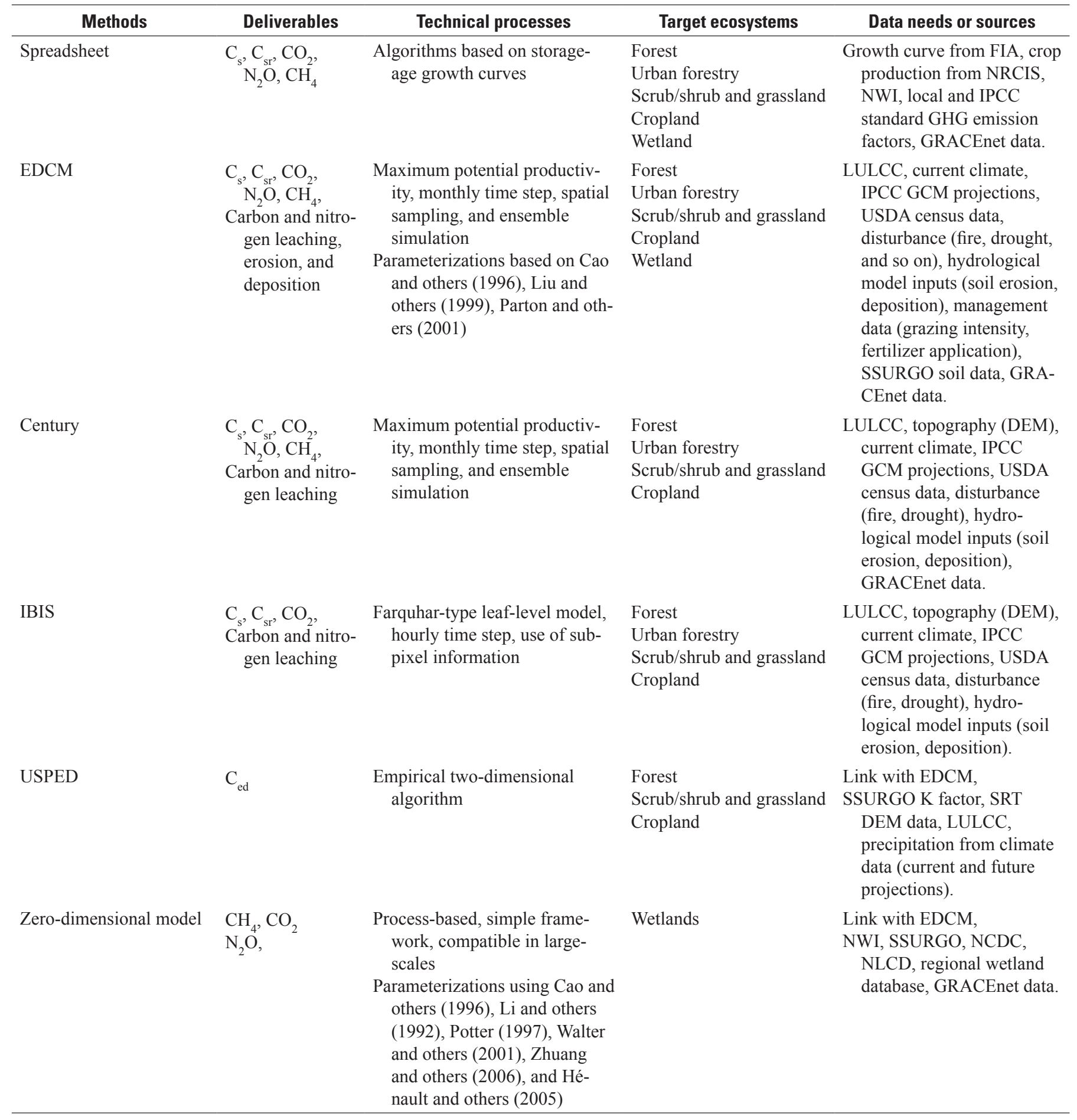




\section{D.7. References Cited}

[Reports that are only available online may require a subscription for access.]

Avissar, Roni, 1992, Conceptual aspects of a statisticaldynamical approach to represent landscape subgridscale heterogeneities in atmospheric models: Journal of Geophysical Research, v. 97, no. D3, p. 2729-2742, doi:10.1029/91JD01751.

Cao, Mingkui, Marshall, Stewart, and Gregson, Keith, 1996, Global carbon exchange and methane emissions from natural wetlands-Application of a process-based model: Journal of Geophysical Research, v. 101, no. D9, p. 14399-14414, doi:10.1029/96JD00219.

Chen, J.M., Ju, Weimin, Cihlar, Josef, Price, David, Liu, Jane, Chen, Wenjun, Pan, Jianjun, Black, Andy, and Barr, Alan, 2003, Spatial distribution of carbon sources and sinks in Canada's forests: Tellus B, v. 55, no. 2, p. 622-641, doi:10.1034/j.1600-0889.2003.00036.x.

Chen, M., Liu, S., and Tieszen, L., 2006, State-parameter estimation of ecosystem models using a Smoothed Ensemble Kalman Filter, in Voinov, A., Jakeman, A.J., and Rizzoli, A.E., eds., Proceedings of the iEMSs third biennial meeting-Summit on environmental modeling and software: Burlington, Vt., International Environmental Modelling and Software Society, 7 p. on one CD-ROM., accessed June 18, 2010, at http://www.iemss.org/iemss2006/papers/ w16/334_Chen_1.pdf.

Chen, M., Liu, S., Tieszen, L.L., and Hollinger, D.Y., 2008, An improved state-parameter analysis of ecosystem models using data assimilation: Ecological Modelling, v. 219, no. 3-4, p. 317-326, accessed June 18, 2010, at http://dx.doi.org/10.1016/j.ecolmodel.2008.07.013.

Chen, Wenjun, Chen, Jing, and Cihlar, Josef, 2000, An integrated terrestrial ecosystem carbon-budget model based on changes in disturbance, climate, and atmospheric chemistry: Ecological Modelling, v. 135, no. 1, p. 55-79, doi:10.1016/ S0304-3800(00)00371-9.

Conrad, R., 1989, Control of methane production in terrestrial ecosystems, in Andreae, M.O., and Schimel, D.S., eds., Exchange of trace gases between terrestrial ecosystems and the atmosphere: New York, John Wiley and Sons, p. 39-58.

Evensen, Geir, 1994, Sequential data assimilation with a nonlinear quasi-geostrophic model using Monte Carlo methods to forecast error statistics: Journal of Geophysical Research, v. 99, no. C5, p. 10143-10162, doi:10.1029/94JC00572.

Evensen, Geir, 2003, The ensemble Kalman filter-Theoretical formulation and practical implementation: Ocean Dynamics, v. 53, no. 4, p. 343-367, doi:10.1007/s10236003-0036-9.
Farquhar, G.D., von Caemmerer, Susanne, and Berry, J.A., 1980, A biochemical model of photosynthetic $\mathrm{CO}_{2}$ assimilation in leaves of C3 species: Planta, v. 149, p. 78-90, doi:10.1007/BF00386231.

Feng, Min, Liu, Shuguang, Ned, H.E., Jr., and Yin, Fang, 2009, Distributed geospatial model sharing based on open interoperability standards: Journal of Remote Sensing, v. 13, no. 6, p. 1060-1066.

Fitz, H.C., and Hughes, N., 2008, Wetland ecological models: Gainesville, Fla., University of Florida, Institute of Food and Agricultural Sciences Extension SL257, 6 p., accessed June 18, 2010, at http://edis.ifas.ufl.edu/pdffiles/ SS/SS48100.pdf.

Foley, J.A., Prentice, I.C., Ramankutty, Navin, Levis, Samuel, Pollard, David, Sitch, Steven, and Haxeltine, Alex, 1996, An integrated biosphere model of land surface process, terrestrial carbon balance, and vegetation dynamics: Global Biogeochemical Cycles, v. 10, no. 4, p. 603-628.

Hénault, C., Bizouard, F., Laville, P., Gabrielle, B., Nicoullaud, B., Germon, J.C., and Cellier, P., 2005, Predicting in situ soil $\mathrm{N}_{2} \mathrm{O}$ emission using $\mathrm{NOE}$ algorithm and soil database: Global Change Biology, v. 11, no. 1, p. 115-127, doi:10.1111/j.1365-2486.2004.00879.x.

Houghton, R.A., Hackler, J.L., and Lawrence, K.T., 1999, The U.S. carbon budget - Contributions from land-use change: Science, v. 285, no. 5427, p. 574-578, doi:10.1126/science.285.5.

Huang, Chengquan, Goward, S.N., Masek, J.G., Gao, Feng, Vermote, E.F., Thomas, Nancy, Schleeweis, Karen, Kennedy, R.E., Zhu, Zhiliang, Eidenshink, J.C., and Townshend, J.R.G., 2009, Development of time series stacks of Landsat images for reconstructing forest disturbance history: International Journal of Digital Earth, v. 2, no. 3, p. 195-218, doi:10.1080/17538940902801614.

Intergovernmental Panel on Climate Change, 1997, Revised 1996 IPCC guidelines for national greenhouse gas inventories: Paris, International Panel on Climate Change, 3 v., accessed June 18, 2010, at http://www.ipcc-nggip.iges.or.jp/ public/gl/invs1.html.)

Intergovernmental Panel on Climate Change, 2006, 2006 IPCC guidelines for national greenhouse gas inventories (Prepared by the IPCC National Greenhouse Gas Inventories Programme; edited by H.S. Eggleston, L. Buendia, K. Miwa, T. Ngara, and K. Tanabe): Hayama, Kanagawa, Japan, Institute for Global Environmental Strategies, 5 v., accessed June 14, 2010, at http://www.ipcc-nggip.iges.or.jp/ public/2006gl/index.html.

Kimball, J.S., Running, S.W., and Saatchi, S.S., 1999, Sensitivity of boreal forest regional water flux and net primary production simulations to sub-grid scale land cover com- 
plexity: Journal of Geophysical Research, v. 104, no. D22, p. 27789-27801.

Lal, Rattan, Griffin, Michael, Apt, Jay, Lave, Lester, and Morgan, M.G., 2004, Managing soil carbon: Science, v. 304, no. 5669 , p. 393.

Larocque, G.R., Bhatti, J.S., Ascough, J.C., II, Liu, J., Luckai, N., Mailly, D., Archambault, L., and Gordon, A.M., in press, An analytical framework to assist decision makers in the use of forest ecosystem model predictions: Environmental Modelling \& Software, doi:10.1016/j.envsoft.2010.03.009, corrected proof accessed June 18, 2010, at http://dx.doi.org/10.1016/j.envsoft.2010.03.009.

Li, Changsheng, Frolking, Steve, and Frolking, T.A., 1992, A model of nitrous oxide evolution from soil driven by rainfall events-1. Model structure and sensitivity: Journal of Geophysical Research, v. 97, no. D9, p. 9759-9776.

Liu, Jinxun, Liu, Shuguang, and Loveland, T.R., 2006, Temporal evolution of carbon budgets of the Appalachian forests in the U.S. from 1972 to 2000: Forest Ecology and Management, v. 222, no. 1-3, p. 191-201, doi:10.1016/j.foreco.2005.09.028.

Liu, Jinxun, Liu, Shuguang, Loveland, T.R., and Tieszen, L.L., 2008, Integrating remotely sensed land cover observations and a biogeochemical model for estimating forest ecosystem carbon dynamics: Ecological Modelling, v. 219, no. 3-4, p. 361-372.

Liu, Jinxun, Price, D.T., and Chen, J.M., 2005, Nitrogen controls on ecosystem carbon sequestration-A model implementation and application to Saskatchewan, Canada: Ecological Modelling, v. 186, no. 2, p. 178-195, doi:10.1016/ jecolmodel.2005.01.036.

Liu, S., Kaire, M., Wood, E., Diallo, O., and Tieszen, L.L., 2004, Impacts of land use and climate change on carbon dynamics in south-central Senegal: Journal of Arid Environments, v. 59, no. 3, p. 583-604, doi:10.1016/ jaridenv.2004.03.023.

Liu, Shuguang, Anderson, Pamela, Zhou, Guoyi, Kauffman, Boone, Hughes, Flint, Schimel, David, Watson, Vicente, and Tosi, Joseph, 2008, Resolving model parameter values from carbon and nitrogen stock measurements in a wide range of tropical mature forests using nonlinear inversion and regression trees: Ecological Modelling, v. 219 , no. 3-4, p. 327-341, accessed June 18, 2010, at http://dx.doi.org/10.1016/j.ecolmodel.2008.07.025.

Liu, Shuguang, Bliss, Norman, Sundquist, Eric, and Huntington, T.G., 2003, Modeling carbon dynamics in vegetation and soil under the impact of soil erosion and deposition: Global Biogeochemical Cycles, v. 17, no. 2, p. 1074, doi:10.1029/2002GB002010.
Liu, Shuguang, Loveland, T.R., and Kurtz, R.M., 2004, Contemporary carbon dynamics in terrestrial ecosystems in the southeastern plains of the United States: Environmental Management, v. 33, Supplement 1, p. S442-S456, doi:10.1007/s00267-003-9152-z.

Liu, Shuguang, Reiners, W.A., Keller, Michael, and Schimel, D.S., 1999, Model simulation of changes in $\mathrm{N}_{2} \mathrm{O}$ and $\mathrm{NO}$ emissions with conversion of tropical rain forests to pastures in the Costa Rican Atlantic zone: Global Biogeochemical Cycles, v. 13, p. 663-677.

McGuire, A.D., Sitch, S., Clein, J.S., Dargaville, R., Esser, G., Foley, J., Heimann, M., Joos, F., Kaplan, J., Kicklighter, D.W., Meier, R.A., Melillo, J.M., Moore, B., Prentice, I.C., Ramankutty, N., Reichenau, T., Schloss, A., Tian, H., Williams, L.J., and Wittenberg, U., 2001, Carbon balance of the terrestrial biosphere in the twentieth century; Analyses of $\mathrm{CO}_{2}$, climate and land use effects with four process-based ecosystem models: Global Biogeochemical Cycles, v. 15, no. 1, p. 183-206, doi:10.1029/2000GB001298.

McGuire, A.D., Wirth, C., Apps, M., Beringer, J., Clein, J., Epstein, H., Kicklighter, D.W., Bhatti, J., Chapin, F.S.I., de Groot, B., Efremov, D., Eugster, W., Fukuda, M., Gower, T., Hinzman, L., Huntley, B., Jia, G.J., Kasischke, E., Melillo, J., Romanovsky, V., Shvidenko, A., Vaganov, E., and Walker, D., 2002, Environmental variation, vegetation distribution, carbon dynamics and water/energy exchange at high latitudes: Journal of Vegetation Science, v. 13, no. 3, p. 301-314.

Melillo, J.M., Borchers, J., Chaney, J., Fisher, H., Fox, S., Haxeltine, A., Janetos, A., Kicklighter, D.W., Kittel, T.G.F., Mcguire, A.D., McKeown, R., Neilson, R., Nemani, R., Ojima, D.S., Painter, T., Pan, Y., Parton, W.J., Pierce, L., Pitelka, L., Prentice, C., Rizzo, B., Rosenbloom, N.A., Running, S., Schimel, D.S., Sitch, S., Smith, T., and Woodward, I., 1995, Vegetation ecosystem modelling and analysis project - Comparing biogeography and biogeochemistry models in a continental-scale study of terrestrial ecosystem responses to climate-change and $\mathrm{CO}_{2}$ doubling: Global Biogeochemical Cycles, v. 9, no. 4, p. 407-437.

Metherell, A.K., Harding, L.A., Cole, C.V., and Parton, W.J., 1993, Century soil organic matter model environment; Technical documentation; Agroecosystem version 4.0: U.S. Department of Agriculture, Agricultural Research Service, Great Plains System Research Unit Technical Report 4, accessed June 18, 2010, at http://daac.ornl.gov/ data/model_archive/CENTURY/century_vemap_m4/comp/ Century_Users_Manual_V4.pdf.

Mitas, Lubos, and Mitasova, Helena, 1998, Distributed soil erosion simulation for effective erosion prevention: Water Resources Research, v. 34, no. 3, p. 505-516, doi:10.1029/97WR03347. 
Pan, Yude, Melillo, J.M., McGuire, A.D., Kicklighter, D.W., Pitelka, L.F., Hibbard, Kathy, Pierce, L.L., Running, S.W., Ojima, D.S., Parton, W.J., and Schimel, D.S., 1998, Modelled responses of terrestrial ecosystems to elevated atmospheric $\mathrm{CO}_{2}$ - A comparison of simulations by the biogeochemistry models of the Vegetation/Ecosystem Modelling and Analysis Project (Vemap): Oecologia, v. 114, p. 389-404.

Parton, W.J., Gutmann, M.P., Williams, S.A., Easter, Mark, and Ojima, Dennis, 2005, Ecological impact of historical land-use patterns in the Great Plains; A methodological assessment: Ecological Applications, v. 15, no. 6, p. 1915-1928, doi:10.1890/04-1392.

Parton, W.J., Holland, E.A., Del Grosso, S.J., Hartman, M.D., Martin, R.E., Mosier, A.R., Ojima, D.S., and Schimel, D.S., 2001, Generalized model for $\mathrm{NO}_{\mathrm{x}}$ and $\mathrm{N}_{2} \mathrm{O}$ emissions from soils: Journal of Geophysical Research, v. 106, no. D15, p. 17403-17419, doi:10.1029/2001JD900101.

Parton, W.J., Schimel, D.S., Cole, C.V., and Ojima, D.S., 1987, Analysis of factors controlling soil organic-matter levels in Great-Plains grasslands: Soil Science Society of America Journal, v. 51, p. 1173-1179.

Parton, W.J., Scurlock, J.M.O., Ojima, D.S., Gilmanov, T.G., Scholes, R.J., Schimel, D.S., Kirchner, T., Menaut, J.-C., Seastedt, T., Garcia Moya, E., Kamnalrut, A., and Kinyamario, J.I., 1993, Observations and modeling of biomass and soil organic matter dynamics for the grassland biome worldwide: Global Biogeochemical Cycles, v. 7, no. 4, p. 785-809.

Peng, Changhui, Liu, Jinxun, Dang, Qinglai, Zhou, Xiaolu, and Apps, Mike, 2002, Developing carbon-based ecological indicators to monitor sustainability of Ontario's forests: Ecological Indicators, v. 1, no. 4, p. 235-246, doi:10.1016/ S1470-160X(02)00010-9.

Pierce, L.L., and Running, S.W., 1995, The effects of aggregating sub-grid land surface variation on large-scale estimates of net primary production: Landscape Ecology, v. 10, no. 4, p. 239-253.

Potter, C.S., 1997, An ecosystem simulation model for methane production and emission from wetlands: Global Biogeochemical Cycles, v. 11, no. 4, p. 495-506, doi:10.1029/97GB02302.

Potter, C., Klooster, S., Tan, P., Steinbach, M., Kumar, V., and Genovese, V., 2005, Variability in terrestrial carbon sinks over two decades; Part 2, Eurasia: Global and Planetary Change, v. 49, p. 177-186.

Potter, C.S., Randerson, J.T., Field, C.B., Matson, P.A., Vitousek, P.M., Mooney, H.A., and Klooster, S.A., 1993, Terrestrial ecosystem production-A process model based on global satellite and surface data: Global Biogeochemical Cycles, v. 7, no. 4, p. 811-841, doi:10.1029/93GB02725.
Reiners, W.A., Liu, S., Gerow, K.G., Keller, M., and Schimel, D.S., 2002, Historical and future land use effects on $\mathrm{N}_{2} \mathrm{O}$ and $\mathrm{NO}$ emissions using an ensemble modelling approach; Costa Rica's Caribbean lowlands as an example: Global Biogeochemical Cycles, v. 16, no. 4, doi:10.1029/2001GB001437.

Reinhardt, E.D., Keane, R.E., and Brown, J.K., 1997, First order fire effects model; FOFEM 4.0 user's guide: U.S. Department of Agriculture, Forest Service, Intermountain Research Station General Technical Report INT-GTR-344, 65 p., accessed June 14, 2010, at http://www.fs.fed.us/rm/ pubs_int/int_gtr344.html.

Running, S.W., and Coughlan, J.C., 1988, General model of forest ecosystem processes for regional applications, I. Hydrologic balance, canopy gas exchange and primary production processes: Ecological Modelling, v. 42, p. 125-154.

Schimel, D.S., Braswell, B.H., Holland, E.A., McKeown, Rebecca, Ojima, D.S., Painter, T.H., Parton, W.J., and Townsend, A.R., 1994, Climatic, edaphic, and biotic controls over storage and turnover of carbon in soils: Global Biogeochemical Cycles, v. 8, no. 3, p. 279-293, doi:10.1029/94GB00993.

Sierra, C.A., Loescher, H.W., Harmon, M.E., Richardson, A.D., Hollinger, D.Y., and Perakis, S.S., 2009, Interannual variation of carbon fluxes from three contrasting evergreen forests - The role of forest dynamics and climate: Ecology, v. 90, no. 10, p. 2711-2723, doi:10.1890/08-0073.1.

Skog, K.E., 2008, Sequestration of carbon in harvested wood products for the United States: Forest Products Journal, v. 58 , no. 6 , p. $56-72$.

Skog, K.E., and Nicholson, G.A., 1998, Carbon cycling through wood products - The role of wood and paper products in carbon sequestration: Forest Products Journal, v. 48, p. $75-8$

Smith, J.E., Heath, L.S., Skog, K.E., and Birdsey, R.A., 2006, Methods for calculating forest ecosystem and harvested carbon with standard estimates for forest types of the United States: U.S. Department of Agriculture, Forest Service, Northeastern Research Station General Technical Report NE-343, 216 p.

Tan, Zhengxi, Liu, Shuguang, Johnston, C.A., Loveland, T.R., Tieszen, L.L., Liu, Jinxun, and Kurtz, Rachel, 2005, Soil organic carbon dynamics as related to land use history in the Northwestern Great Plains: Global Biogeochemical Cycles, v. 19, doi:10.1029/2005GB002536.

Turner, D.P., Cohen, W.B., and Kennedy, R.E., 2000, Alternative spatial resolutions and estimation of carbon flux over a managed forest landscape in western Oregon: Landscape Ecology, v. 15, p. 441-452. 
Turner, D.P., Dodson, Rusty, and Marks, Danny, 1996, Comparison of alternative spatial resolutions in the application of a spatially distributed biogeochemical model over complex terrain: Ecological Modelling, v. 90, no. 1, p. 53-67, doi:10.1016/0304-3800(95)00143-3.

U.S. Congress, 2007, Energy Independence and Security Act-Public Law 110-140: U.S. Congress, 311 p., available at http://frwebgate.access.gpo.gov/ cgi-bin/getdoc.cgi?dbname $=110$ cong_public laws\&docid=f:publ140.110.pdf.

Walter, B.P., Heilmann, Martin, and Matthews, Elaine, 2001, Modeling modern methane emissions from natural wetlands, 1. Model description and results: Journal of Geophysical Research, v. 106, no. D24, p. 34189-34206, doi:10.1029/2001JD900165.

Yuan, Wenping, Liu, Shuguang, Zhou, Guangsheng, Zhou, Guoyl, Tieszen, L.L., Baldocchi, Dennis, Bernhofer, Christian, Gholz, Henry, Goldstein, A.H., Goulden, M.L.,
Hollinger, D.Y., Hu, Yueming, Law, B.E., Stoy, P.C., Vesala, Timo, and Wofsy, S.C., 2007, Deriving a light use efficiency model from eddy covariance flux data for predicting daily gross primary production across biomes: Agricultural and Forest Meteorology, v. 143, no. 3-4, p. 189-207, doi:10.1016/j.agrformet.2006.12.001.

Zhao, Shuqing, Liu, Shuguang, Li, Zhengpeng, and Sohl, T.L., 2010, Federal land management, carbon sequestration, and climate change in the southeastern U.S.-A case study with Fort Benning: Environmental Science and Technology, v. 44, no. 3, p. 992-997, doi:10.1021/es9009019.

Zhuang, Qianli, Melillo, J.M., Sarofim, M.C., Kicklighter, D.W., McGuire, A.D., Felzer, B.S., Sokolov, Andrei, Prinn, R.G., Steudler, P.A., and $\mathrm{Hu}$, Shaomin, 2006, $\mathrm{CO}_{2}$ and $\mathrm{CH}_{4}$ exchanges between land ecosystems and the atmosphere in northern high latitudes over the 21 st century: Geophysical Research Letters, v. 33, p. L17403.1- L17403.5, doi:10.1029/2006GL026972. 


\section{Appendix E. Methods for Assessing Carbon Stocks, Carbon Sequestration, and Greenhouse-Gas Fluxes of Aquatic Ecosystems}

\section{E.1. Introduction}

Inland and coastal waters are globally important locations of biogeochemical carbon cycling, carbon sequestration and carbon dioxide $\left(\mathrm{CO}_{2}\right)$, methane $\left(\mathrm{CH}_{4}\right)$, and nitrous oxide $\left(\mathrm{N}_{2} \mathrm{O}\right)$ exchange with the atmosphere. Although inland aquatic ecosystems represent less than 3 percent of the total land area of the United States, they have greatly accelerated areal rates of carbon cycling relative to terrestrial ecosystems and may dominate greenhouse-gas (GHG) fluxes and carbon sequestration locally and regionally. Globally, the mass of carbon exported by inland waters to oceans annually rivals terrestrial net ecosystem exchange (NEE; Sarmiento and Gruber, 2006), and annual carbon burial in inland water sediments is comparable to that of annual carbon burial in coastal ocean sediments (Cole and others, 2007). When evaluating the importance of coastal, estuarine, and inland waters in the carbon cycle, three major factors should be considered:

8. Stream and river delivery of inorganic carbon (IC) and organic carbon (OC) from terrestrial uplands; through lowlands, ponds, lakes, and reservoirs; and to coastal areas and oceans (termed "lateral transport")

9. Biogeochemical production, consumption, sequestration, and pass-through of dissolved, particulate, and gaseous carbon by ponds, lakes, and reservoirs

10. Biogeochemical production, consumption, sequestration, and pass-through of dissolved, particulate, and gaseous carbon by coastal waters and estuaries

The importance of inland waters in the carbon cycle tends to be overlooked in terrestrial ecosystem models and global climate models, partly because of their size. Most water bodies are much smaller than the individual grid cells used as accounting units for regional-scale models. This problem is compounded by the fact that the numbers of water bodies increase exponentially as water-body size decreases (Downing and others, 2006) and that rates of carbon sequestration (Downing and others, 2008) and carbon-gas exchange, particularly methane emission (Michmerhuizen and others, 1996), are thought to increase as water-body size decreases. Consequently, if a water body is large enough to be detected at the pixel scale for terrestrial ecosystem modeling, the rates of carbon sequestration and carbon-gas exchange associated with that water body are likely to be smaller than global or regional averages. For these reasons, accurate regional modeling of carbon sequestration and gas exchange currently (2010) requires independent assessment of lateral transport to and from those regions, accurate accounting of the areal extent and size distribution of water bodies within regions, and assignment of regionally explicit biogeochemical rates of carbon sequestration and gas exchange that encompass the size distribution of streams, rivers, ponds, lakes, and reservoirs within those regions.

The carbon mass balance of estuaries and coastal areas of the Nation also is poorly quantified. Estuaries and coastal areas are some of the most biologically productive areas of the world, and the delivery of terrestrial carbon and nutrients to them by lateral transport and coastal erosion substantially enhances that production. In addition, local currents, temperature, bottom slope, and biogeochemical reactions all affect the quantity and form of particulate and dissolved carbon that will be sequestered in coastal areas, pass through to oceans, or be converted to greenhouse gases and emitted to the atmosphere. These and many other physical, chemical and biological factors controlling carbon cycling in near-shore areas vary substantially with space and time, complicating a national assessment of carbon sequestration and flux. Processes in coastal areas often are overlooked or underestimated in ocean carbon-cycling models because ocean models normally are operated at relatively coarse spatial resolution, and inclusion of coastal pixels confounds remotely sensed data and model execution (Dunne and others, 2005, 2007). Because coastal areas represent the confluence of terrestrial and oceanic processes, most ocean carbon sequestration occurs in the coastal zone, and terrestrial processes may dramatically alter coastal and estuarine processes, impacts of terrestrial management actions and carbon processes in the coastal ocean should be carefully examined (Hedges and Keil, 1995; Seitzinger and others, 2005). Owing to coastal groundwater discharge, carbon fluxes also have received relatively little attention, but Cole and others (2007) estimated that, globally, groundwater conveys dissolved organic carbon (DOC) and dissolved inorganic carbon (DIC) loads making up about 25 percent of the total carbon flux from land to sea.

In the sections that follow, a methodology for national assessment is presented for lateral transport of carbon, carbon sequestration, and greenhouse-gas exchange associated with inland and coastal waters. Methods are proposed for projection of the assessment into the future to account for ongoing and anticipated land-cover and climate change. In this report, aquatic carbon is grouped into four general categories:

- DOC, which is composed of all the dissolved fraction of organic carbon molecules that result from the production and decomposition of living matter (dissolved is operationally defined as the fraction that passes a 0.45 or 0.2 micrometer filter)

- DIC, which is composed of the aqueous carbon anions bicarbonate $\left(\mathrm{HCO}_{3}^{-}\right)$and carbonate $\left(\mathrm{CO}_{3}^{-2}\right)$, carbonic acid, and dissolved $\mathrm{CO}_{2}$ 
- Particulate organic carbon (POC), which is composed mostly of plant and animal debris, but also includes organic colloids, precipitates, and DOC adsorbed to particle surfaces

- Particulate inorganic carbon (PIC), which is composed of mechanically eroded sediments derived from carbonate rocks and carbonate precipitates

DOC and DIC represent most of the total carbon mass in lateral transport, whereas POC and PIC represent most of the carbon stored in inland waters and coastal sediments. Except in areas where old DOC is released from the terrestrial environment (such as from petroleum hydrocarbons, glacial melt, or permafrost thaw), most DOC tends to be modern in age and represents recently produced photosynthate that is leached from decomposing plant debris and soil organic matter. DIC is produced primarily by weathering of carbonate and silicate rocks and fine particles, where onehalf of the carbon in DIC produced by carbonate weathering and all of the carbon in DIC produced by silicate weathering is derived from ecosystem respiration or atmospheric $\mathrm{CO}_{2}$, and is therefore modern. The DOC and DIC exported from terrestrial landscapes are largely unaccounted for in terrestrial NEE or net ecosystem production (NEP) measurements, but regionally they may represent more than 5 percent of total ecosystem production (Striegl and others, 2007). POC includes recently produced plant and animal debris and some older organic carbon debris that has eroded from landscapes and is carried by water. POC that settles to streambeds or lake bottoms may serve as a food source for grazing organisms and microbes or be sequestered. Except for lakes and ponds having recent precipitation of carbonates, PIC plays a relatively unimportant role in the sequestration of modern carbon, as it mostly comprises carbon from old marine carbonates.

\section{E.2. Transport of Carbon by Streams and Rivers}

\section{E.2.1. Lateral Transport}

Lateral or hydrologic transport of carbon includes the delivery of dissolved and particulate carbon by streams and rivers from terrestrial landscapes to inland water bodies, coastal waters, and oceans. It also includes delivery of dissolved carbon by groundwater discharge to inland water bodies and coasts. Water is the carrier of all lateral carbon transport; therefore, direct calculation of lateral carbon fluxes requires quantitative understanding of water discharge and of the seasonal relations between water discharge and the concentrations of the aqueous carbon species (DOC, DIC, POC, PIC) being transported. Inferential methods for estimating carbon flux based on land-cover characteristics and hydrologic systems modeling of flow based on geomorphic and climatic conditions are promising, but currently (2010) are not fully coupled with carbon chemistry. The most accurate way to assess lateral transport, therefore, is to develop statistical relations between historical flow and chemistry data, and then empirically derive daily loads (mass carbon per time) for each carbon species (Striegl and others, 2007). There are multivariate statistical programs, such as the U.S. Geological Survey (USGS) Load Estimator (LOADEST) program, which are designed to do this for streams and rivers (Runkel and others, 2004). Estimates of groundwater flux are less accurate because groundwater-flow rates and chemistry generally are not measured; however, groundwater contributions to total carbon flux for large areas, such as the coastal United States, can be assumed to be small relative to surfacewater flux.

\section{E.2.2. Estimation of Lateral Transport}

The LOADEST program (U.S. Geological Survey, 2010b) associates daily water-discharge values with constituent concentrations measured for a range of discharge conditions and develops statistical concentration-to-discharge relations for the constituent of concern. Based on these relations, it simulates concentrations for days without measurements, and then integrates discharge and concentration to estimate the total constituent load for the flow period analyzed. The accuracy of the estimates depends on the accuracy of the water discharge and constituent concentration measurements, adequate coverage of concentration measurements for a full range of flow conditions and seasons, and stability in concentration-to-discharge relations. Generally, at least 13 concentration measurements are required for LOADEST to produce accurate estimates; more are better, especially where concentration discharge relations vary seasonally. Sample collection during storm events is particularly important because most suspended sediment is transported during storms (Cohn and others, 1989; Hicks and others, 2000). If the LOADEST program is applied for estimation of lateral transport from streams and rivers that have not been streamgaged or sampled for concentrations of carbon species, the accuracy will be degraded based on additional uncertainties associated with the regression techniques for estimation of discharge and carbon concentration in those rivers.

The "spatially referenced regressions on watershed attributes" (SPARROW) model (U.S. Geological Survey, 2010e) uses these same techniques to estimate constituent loads (Schwarz and others, 2006, 2008). This model has the additional advantage of generating flow and concentrations based on land-use and land-cover characteristics and climatic data. It has been extensively applied for estimation of nitrogen and phosphorus loads and currently (2010) is under development for carbon species, particularly DOC. Additional detail on the SPARROW modeling approach is described in section E.4.3 of this report. 


\section{E.2.3. Data Needs and Availability}

Estimating carbon loads requires flow and water-chemistry data collected at identical or close locations during identical periods. These data are archived in the National Water Information System (NWIS; U.S. Geological Survey, 2010f). Nationally, the USGS has collected data on daily streamflow at more than 25,000 sites and periodic flow information at more than 45,000 sites. Water-chemistry data are much more sparse, such that the total number of stations having more than 10 years of record of flow, DIC, and DOC concentration data is about 200 sites. There are many more sites having shorter or partial records.

A first step in the assessment of lateral carbon flux is to extract data from NWIS at locations where streamflow, and DIC, DOC, POC, or PIC data have been collected. These data will be assembled into a working database for further analysis. Carbon-concentration data are most prevalent for carbonate alkalinity, from which DIC can be calculated, followed by DOC, POC, and PIC. For organic carbon, older datasets commonly have only total organic carbon concentration (TOC), which by definition is DOC + POC, but operationally is commonly closer to DOC. Where concentration data are missing for a particular carbon species, it will be necessary to statistically estimate concentrations from other available water-chemistry data.

\section{E.2.4. Approach: Nationwide Assessment of Lateral Flux}

A first goal of the data analysis will be to identify key streamgaging stations from throughout the United States where carbon loads can be calculated and carbon concentration-to-discharge relations can be established. These key stations will represent large aggregated basins that drain directly to coastal areas, such as the Mississippi and Columbia River Basins (fig. E1), and smaller basins that represent specific land-use or land-cover types and (or) ecoregions. Basins of the conterminous United States are mapped in four orders of hydrologic units, including 18 regions, 204 subregions, 324 accounting units, and 2,111 cataloging units (U.S. Geological Survey, 2010a). Alaska, Hawaii, and Puerto Rico are similarly divided. Approximately 308 hydrologic units drain directly to coastal areas of the United States, ranging from a few tens of square kilometers to the Mississippi River Basin. The assessment eventually will assign carbon lateral flux values to all of these units.

Seasonal and annual loads (mass of carbon over time) and yields (mass of carbon over basin area over time) will be determined for the key streamgaging stations using LOADEST and SPARROW. The mass flux of carbon is primarily determined by water discharge, so concentration-to-discharge and

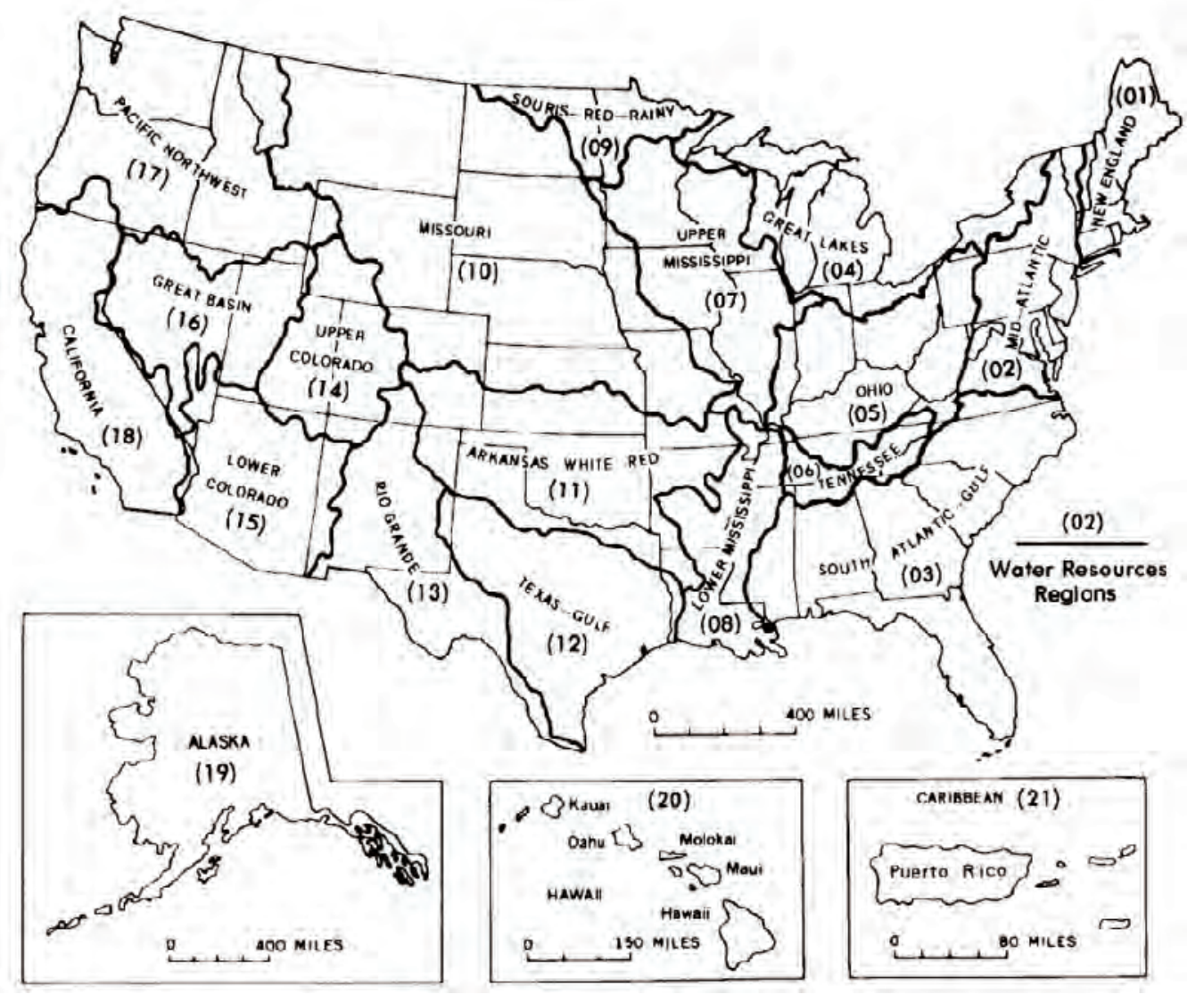

Figure E1. Map showing the water-resource regions of the United States that will be used as units for aquatic assessment (rivers, lakes, coastal regions). From Seaber and others, 1987, figure 2 . 
carbon yield-to-water yield relations also will be determined. These relations will be used for gap analysis to estimate fluxes from adjacent basins that are missing carbon-concentration data. Regression techniques will be used to estimate discharge for ungaged basins that are likely to transport substantial carbon to the coast, as in Hirsch and others (1982).

\section{E.2.5. Coupling of Lateral Flux With Terrestrial Models}

Currently (2010), the General Ensemble Modeling System (GEMS) and other terrestrial ecosystem models solve carbon mass balance in one-dimensional grid cells; they do not solve for lateral flow of water and carbon between cells. One goal of this assessment is to eventually couple hydrologic and terrestrial models so that water discharge and carbon flux can be estimated based on land use, land cover, physiography, and climate. The NWIS, LOADEST, and SPARROW analysis of lateral carbon flux will provide empirical validation for the development of these model attributes.

\section{E.2.6. Projections of Lateral Flux}

Water discharge is the primary determinant of lateral carbon transport from basins, and therefore needs to be accurately projected for estimation of future carbon flux. This will require projection of water discharge from downscaled climate predictions and application of flow-generation models, such as the Precipitation-Runoff Modeling System (PRMS) (Leavesley and others, 1983; U.S. Geological Survey, 2010d). Developing relations between lateral carbon flux and land use and land cover (LULC) and the coupling of these relations with GEMS or models such as SPARROW will further refine these projections. Developing such modeling capabilities should be a goal for future assessments.

\section{E.2.7. GHG Fluxes From Rivers}

In addition to the downstream transport of dissolved and particulate carbon, streams and rivers commonly are supersaturated with $\mathrm{CO}_{2}$ and $\mathrm{CH}_{4}$ relative to the atmosphere and emit greenhouse gases to the atmosphere along their entire courses (Cole and others, 2007). This can be attributed to withinstream biological cycling of carbon (Ritchie, 1989) and also to supersaturated groundwater and surface runoff contributing to streamflow.

\section{E.3. Lakes and Impoundments}

Inland waters are an important component of the global carbon cycle, but often are ignored in global climate models because they make up only a small part of the surface of continents, about 3 percent (Downing and others, 2006). Recent studies have shown, however, that fluxes of carbon from terrestrial to aquatic systems are substantial; for comparison, they are similar in magnitude to net ecosystem production of the terrestrial biosphere (about 2 petagrams per year $(\mathrm{Pg} / \mathrm{yr})$ of carbon), and thus, should not be ignored in global carbon budgets (Randerson and others, 2002; Cole and others, 2007). Although inland waters make up only a small fraction of total continental area, they are extremely active in the transport and storage of carbon received from the terrestrial environment (Cole and others, 2007; Tranvik and others, 2009). Pools of carbon stored in freshwater sediments also are large; approximately 820 petagrams (Pg) of carbon were stored in lake sediments during the Holocene (Einsele and others, 2001), which is comparable to the amount of carbon currently (2010) stored in the surface meter of soils (approximately 1,395 to $1,576 \mathrm{Pg}$ ) and terrestrial biomass (460

Pg) (Post and others, 1982; Raich and Schlesinger, 1992; Eswaran and others, 1993).

Humans have had a profound effect on hydrologic systems and sediment transport during the last several hundred years. Two of the main human affects are increased erosion, primarily related to deforestation and tilled agriculture, and construction of dams to form impoundments (Mann, 1985, 1986; Davidson and others, 1993; Paul and others, 1997; Renwick and others, 2005). Impoundments serve many functions; reservoirs commonly are used for hydroelectric power generation, recreation, flood control, and to store water for drinking and irrigation; ponds are smaller impoundments (usually less than or equal to 1 square kilometer) that typically are used for sediment retention, urban stormwater control, or to provide water for livestock. Impoundments have caused increased storage of sediment on the continents by creating pools of slow-moving water, where sediment that previously was carried in suspension by streams and rivers instead settles out and accumulates (Meade, 1982; Stallard, 1998). This alteration of the hydrologic system represents a substantial diversion of sediment that previously was exported to the ocean; it is estimated that sediment delivery to the oceans has been reduced approximately 50 percent by impoundments (Smith and others, 2005).

Organic matter makes up a small, but important, fraction of material that is eroded from upland areas and redeposited in colluvium or alluvium, or downstream in lakes or impoundments; in the Mississippi River Basin, for example, organic carbon averages 1.5 percent in erosional and depositional areas (Smith and others, 2005). Most organic carbon that is deposited in impoundments remains there for the life of the impoundment (tens to hundreds of years) because impoundment sediments usually are anoxic, which prevents oxidation of the organic matter (Tranvik and others, 2009); thus, burial of organic carbon in impoundment sediments can represent an important mechanism for carbon sequestration. Lakes can sequester organic carbon by burial as well; however, most of the carbon that is buried in lakes is autochthonous material that is produced by phytoplankton and aquatic macrophytes in the lake (Dean and Gorham, 1998). Tranvik and others (2009) estimated global burial of organic carbon in lakes and 
impoundments may account for $0.6 \mathrm{Pg} / \mathrm{yr}$ of carbon. This compares with organic carbon burial in oceans of $0.1 \mathrm{Pg} / \mathrm{yr}$ of carbon (Dean and Gorham, 1998) and net uptake of carbon by the terrestrial biosphere of 1 to $3 \mathrm{Pg} / \mathrm{yr}$ of carbon (Sundquist, 1993).

Organic-carbon-burial rates in lakes and impoundments are inversely related to water-body size (Smith and others, 2002; Downing and others, 2008); this is because of increased productivity in shallow eutrophic ponds and high rates of erosion and sedimentation in agricultural areas, where small farm ponds are common. Although ponds are small, they are extremely numerous, so their cumulative effect on the global carbon budget could be substantial. Renwick and others (2005) estimated that there may be up to 8 to 9 million ponds in the conterminous United States alone, and their number has been increasing by 1 to 2 percent annually in agricultural parts of the United States (Downing and others, 2006).

Lakes and impoundments emit substantial amounts of $\mathrm{CO}_{2}$ and $\mathrm{CH}_{4}$, and small amounts of $\mathrm{N}_{2} \mathrm{O}$ to the atmosphere, which contribute to greenhouse-gas warming. Global $\mathrm{CO}_{2}$ and $\mathrm{CH}_{4}$ fluxes from reservoirs account for 4 percent of total anthropogenic $\mathrm{CO}_{2}$ emissions and 20 percent of total anthropogenic $\mathrm{CH}_{4}$ emissions, respectively (St. Louis and others, 2000). The balance between carbon burial and GHG emissions determines whether or not lakes and impoundments are net sinks or net sources to global warming (Hanson and others, 2004). Global emissions of $\mathrm{CO}_{2}$ from lakes and reservoirs have been estimated at approximately $0.8 \mathrm{Pg} / \mathrm{yr}$ of carbon (Tranvik and others, 2009); for comparison, deforestation releases 1.6 to $2 \mathrm{Pg} / \mathrm{yr}$ (Sundquist, 1993; DeFries and others, 2002; Houghton, 2003; Sundquist and others, 2008). Methane emissions from lakes and impoundments could be even more important than $\mathrm{CO}_{2}$ in terms of greenhouse-gas potential. Methane is a powerful greenhouse gas, with 25 times the warming potential of $\mathrm{CO}_{2}$, and accounting for 20 percent of the anthropogenic greenhouse-gas effect (Cicerone and Oremland, 1988; Wuebbles and Hayhoe, 2002). Global emissions of methane from reservoirs have been estimated to be 70 teragrams per year $(\mathrm{Tg} / \mathrm{yr})$ of $\mathrm{CH}_{4}$, accounting for 7 percent of anthropogenic warming (St. Louis and others, 2000). Methane emissions from lakes add another 8 to $48 \mathrm{Tg} / \mathrm{yr} \mathrm{CH}_{4}$ to the atmosphere (Bastviken and others, 2004). Together, methane emissions from lakes and reservoirs are similar in magnitude to those from other anthropogenic sources, including fossilfuel combustion $\left(100 \mathrm{Tg} / \mathrm{yr} \mathrm{CH} \mathrm{CH}_{4}\right)$, waste management $(90 \mathrm{Tg} /$ yr $\mathrm{CH}_{4}$ ), enteric fermentation ( $\left.85 \mathrm{Tg} / \mathrm{yr} \mathrm{CH}_{4}\right)$, rice paddies (60 $\left.\mathrm{Tg} / \mathrm{yr} \mathrm{CH}_{4}\right)$, and biomass burning $\left(40 \mathrm{Tg} / \mathrm{yr} \mathrm{CH}_{4}\right)$ (St. Louis and others, 2000, and references therein).

The following section of this appendix describes the methodology for assessment of carbon sequestration in and greenhouse-gas fluxes from lakes and impoundments in the United States.

\section{E.3.1. Carbon Burial in Lakes and Impoundments}

Net storage of carbon in lakes and impoundments reflects a balance between carbon burial in sediments and GHG emissions from the surfaces and outlets of the water bodies. Estimation of carbon burial in lakes and impoundments requires several steps using a combination of geographic information systems (GIS), remote sensing, and statistical analyses, which are outlined in figure E2. To determine carbon burial in lakes and impoundments, it is necessary to quantify the total area of lakes and impoundments within specified size classes, sedimentation rates, and organic carbon concentrations in sediments.

The statistical distribution of water bodies within assessment units (U.S. Environmental Protection Agency (EPA) Level II ecoregions modified from Omernik (1987)) will be analyzed in a GIS framework to quantify their number and cumulative area within each of ten size classes (fig. E2). Input datasets will include the National Land Cover Dataset (NLCD) and the National Hydrography Dataset (NHD+). The NLCD is a nationally consistent land-cover
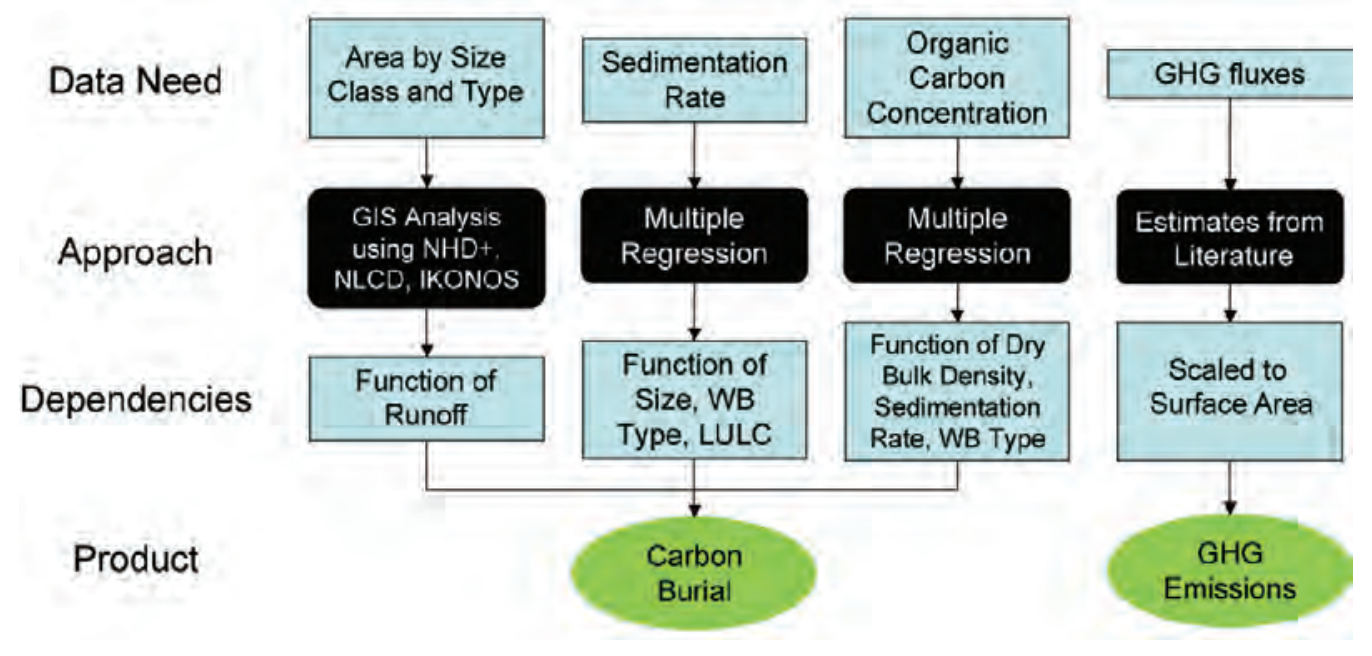

Figure E2. Schematic diagram showing key components of the methodology for assessing carbon sequestration in and greenhouse-gas fluxes from lakes and impoundments. Examples of key dependencies are given. GHG, greenhouse gas; IKONOS, Earth-observing satellite; LULC, land use and land cover; NHD+, National Hydrography Dataset Plus; NLCD, National Land Cover Database; WB, water body. 
classification scheme derived from Landsat Thematic Mapper satellite data. It is one of the primary datasets used by other components of the assessment, and thus, will be the primary dataset used to determine the statistical distribution and surface area of water bodies. The NHD+ is a GIS layer developed by the USGS that depicts the Nation's interconnected network of rivers, streams, lakes, impoundments, and canals. The NHD+ will be used to validate the information on water bodies in the NLCD. The NLCD and NHD+ layers display information at 30 -meter $(\mathrm{m})$ resolution, which is useful for identifying water bodies larger than approximately 0.001 square kilometers $\left(\mathrm{km}^{2}\right)$. Because of the potential importance of carbon cycling in smaller water bodies, the feasibility of mapping those as small as $0.0001 \mathrm{~km}^{2}$ will be investigated using a variety of techniques and datasets. It may be possible to map small water bodies using a combination of 10-m-resolution digital elevation models (DEMs) and 15-m panchromatic Landsat imagery, which cover most of the Nation. GeoEye and IKONOS are Earth observing satellites providing multispectral images at 2- to 4-m resolution, which can be used to identify water bodies, but the images are not available for the entire United States. Light detection and ranging (LIDAR) data collected using airborne surveys and synthetic aperture radar data collected using the Japanese Earth Resources Satellite 1 (JERS-1) have shown substantial promise in the identification and mapping of small water bodies (Telmer and Costa, 2007), but coverage is sparse in the United States.

The ratio of lakes to impoundments in each assessment unit will be determined by manually classifying a randomly selected subset of 200 water bodies based on visual inspection of high-resolution satellite imagery overlain on NLCD layers. The lake-to-impoundment ratio will be combined with waterbody-area information to estimate the cumulative area of lakes and impoundments within each assessment unit. This information is needed because lakes and impoundments tend to have different sedimentation rates and sediment organic carbon concentrations, reflecting differences in land use, autochthonous production, and other processes.

The second primary task when estimating carbon burial in lakes and impoundments is to quantify sedimentation rates (fig. E2). Relatively few direct measurements of sedimentation rates in lakes and impoundments are available; this is an important data gap that will limit the accuracy of carbon-burial estimates. Initial estimates of sedimentation rates will be derived from data compiled from published sources and databases; these data will be used to estimate probability distribution functions (PDFs) representing the statistical distribution of measured sedimentation rates, which will be scaled to lake and impoundment surface areas. Most lake-sedimentation data are from dated lake-sediment cores (Dean and Gorham, 1998; Cole and others, 2007); most impoundment sedimentation-rate data are from repeat bathymetric surveys. Although there is no central repository for lake-sediment core data, impoundment sediment-rate data are stored in the national Reservoir Sedimentation (RESSED) database (Advisory Committee on
Water Information, Subcommittee on Sedimentation, undated). The RESSED database includes data from approximately 1,800 reservoirs; however, this is less than 0.2 percent of the total number of impoundments in the United States (Ackerman and others, 2009). Additional data collection on lake and reservoir sedimentation rates could improve the accuracy of this assessment.

It may be possible to improve on the initial sedimentation rate estimates by using statistical relations between sedimentation rates and water-body size, water-body type (lake versus impoundment), and land use (Wetzel, 1990, 2001; Smith and others, 2001, 2002). Smith and others $(2001,2002)$, for example, reported that sedimentation rates vary inversely with water-body size and tend to be greater in impoundments than in lakes. Lakes and impoundments in basins with substantial tilled agriculture may be expected to have greater sedimentation rates than those in basins that are largely undisturbed (McIntyre, 1993). Correlations between sedimentation rates, water-body characteristics, and land use will be analyzed for lakes and impoundments in each assessment unit, and if significant relations are identified, multiple regression models will be developed to estimate sedimentation rates at unsampled water bodies throughout the assessment unit. Development of statistical relations in some assessment units may be limited by the scarcity of available sedimentation-rate data. Additional data collection could improve the reliability of statistical models used to estimate sedimentation and carbon-burial rates in unsampled water bodies.

OC concentrations in lake and impoundment sediments reflect the OC concentrations in upland sediments from which they are derived, plus particulate carbon derived from primary production in the water bodies (Smith and others, 2005). OC concentrations tend to be greater in lake sediments - where autochthonous production is relatively important - than in impoundment sediments (Mulholland and Elwood, 1982; Ritchie, 1989; Dean and Gorham, 1998). OC concentrations in lake sediments will be estimated from data in the literature. If sufficient data exist, then a PDF will be developed for OC in lake sediments; otherwise, a simple median concentration will be used. OC concentrations in impoundment sediments will be approximated by estimating median OC concentrations of soil in areas upslope and within a specified distance from each water body. Soil organic carbon (SOC) concentrations will be derived from a GIS layer of soil carbon provided by USGS (Bliss and others, 2009). Although it would be preferable to define a basin boundary and estimate SOC concentrations within that area, identifying and mapping basin boundaries for the large number of water bodies in the United States (on the order of 2.6 to 9 million; Renwick and others, 2005) is not operationally feasible. The simplification of the upland area providing sediment to downstream lakes and impoundments is likely to reduce the explanatory power of the predictive equations.

Burial of OC in lakes and impoundments (OC burial) will be calculated for each size class and type of water body using the following equation: 
$O C$ burial $=$ Total water body area $\times$ sedimentation rate $\times O C$ concentration

Sedimentation rate and OC concentrations will be represented by PDFs in the initial analysis. If valid statistical models can be developed for estimating sedimentation rates and OC concentrations based on water-body size and type, they will be used as input to equation E1.

Results will be aggregated by EPA Level II ecoregion for consistency with other components of the assessment.

\section{E.3.2. Alternate Method for Calculating Carbon Burial in Freshwater Aquatic Systems}

As a check on results from the carbon-burial estimates for lakes and impoundments outlined above, carbon burial also will be estimated using an independent mass-balance method, as in Smith and others (2005). The method begins with calculating a sediment budget for a river basin and solving for sediment storage $(S)$ :

$$
E-T=S
$$

where $E$ is sediment erosion determined for the basin in GEMS from the twodimensional Unit Stream Power Erosion and Deposition (USPED) model (Mitas and Mitasova, 1998);

$T \quad$ is sediment transported to the ocean, calculated in LOADEST from river discharge and suspended-sediment concentrations (Runkel and others, 2004); and

$S \quad$ is sediment storage, which includes redeposition of eroded sediments, primarily in alluvium, colluvium, and impoundments.

Sediment export to oceans is a relatively small component of the equation; Smith and others (2005) estimated that about 90 percent of eroded sediment is redeposited in depositional environments, and about 10 percent is exported to the ocean.

The equation for erosion, transport, and redeposition of $\mathrm{OC}$ is similar, but requires multiplying each of the terms in the sediment budget equation by the OC concentration (OC percent) of each sediment pool, and includes a residual term to account for oxidation of OC during transport and storage and replacement of eroded SOC in soil:

$$
E \times O C \text { percent }-T \times O C \text { percent }=S \times O C \text { percent } \pm \text { residual }
$$

The right side of equation E. 3 represents total carbon burial in inland water sediments \pm residual. The OC percent of eroded sediment is assumed to be the same as the OC percent of redeposited sediment, whereas the OC percent of sediment transported to the ocean is approximately twice as high, based on analyses by Ritchie (1989) and Smith and others (2005). Oxidation of OC usually is relatively minor, accounting for about 5 percent of the eroded OC budget (Smith and others, 2005). Replacement of eroded organic matter accounts for approximately 10 percent of the OC budget for the Mississippi River Basin (Smith and others, 2005).

These mass-balance calculations provide bounds on the amount of OC that may be stored in inland water sediments; it is recognized that these sediments include lakes and impoundments, as well as fluvial and colluvial systems.

\section{E.3.3. GHG Fluxes From Lakes and Impoundments}

Fluxes of greenhouse gases $\left(\mathrm{CO}_{2}, \mathrm{CH}_{4}, \mathrm{~N}_{2} \mathrm{O}\right)$ from lakes and impoundments will be estimated based on GHG fluxes reported in the literature. Because of the paucity of available data on $\mathrm{CH}_{4}$ and $\mathrm{N}_{2} \mathrm{O}$ fluxes from lakes and impoundments, a PDF approach will be used and emissions will be scaled to lake and impoundment surface areas. This necessarily simplistic approach will have large uncertainties associated with results, but could be refined in the future if sufficient data become available to build empirical models of GHG fluxes, as in Bastviken and others (2004) and in St. Louis and others (2000). These studies indicate that GHG emissions from lakes and impoundments are positively related to lake area, which is used as a surrogate for lake depth (Michmerhuizen and others, 1996; St. Louis and others, 2000; Bastviken 
and others, 2004). GHG emissions also appear to vary with temperature, based on observations of GHG emissions in the tropics, which were an order of magnitude greater than GHG emissions from temperate reservoirs (St. Louis and others, 2000).

\section{E.3.4. Error Estimation}

It is anticipated that uncertainties in carbon burial in and GHG fluxes from lakes and impoundments will be large because of spatial variability in processes and rates controlling carbon cycling; accounting for this variability using a variety of explanatory variables (for example, basin characteristics or nutrient loads) is difficult in empirical models built on sparse data. In some cases, two independent approaches will be used to estimate fluxes, which can serve as a check on results. The mass-balance calculations, for example, will provide an upper bound on OC burial in lakes and impoundments.

PDFs will be used to represent the statistical distribution of input data, such as sedimentation rates, OC concentrations in sediments, and GHG fluxes from lakes and impoundments. The spread, or variability, of the input data affects the range of possible outcomes; this range is quantifiable using the PDF approach, and will provide information about the uncertainty of estimated carbon burial and GHG emissions rates.

Uncertainty in the empirical models will be evaluated based on the standard errors of the model slopes and intercepts. Bootstrapping or Monte Carlo approaches could be used to evaluate the importance of variations in input datasets on model results; however, these approaches require a minimum number of observations (for example, 20) to provide meaningful results (Efron, 1981; Efron and Tibshirani, 1993), and it is anticipated that relatively few assessment units will have sufficient data. Additional data collection could allow the use of bootstrapping or Monte Carlo approaches in the future, which would improve the uncertainty analysis.

Uncertainty in sediment and OC mass-balance calculations stems from errors in calculation of sediment and OC fluxes in rivers and errors in calculated erosion rates (Smith and others, 2005). To estimate river fluxes of sediment and OC accurately, samples must be collected for a range of hydrologic conditions using appropriate sampling methods. Collecting some samples during storm events is particularly important because most suspended sediment is transported during storms (Cohn and others, 1989; Hicks and others, 2000). Errors in estimated erosion rates are difficult to quantify, but it is assumed the mean standard error of the estimates is near zero (Smith and others, 2001).

\section{E.3.5. Data Needs, Availability, and Gaps}

Sedimentation rates and $\mathrm{OC}$ concentrations in sediments are key variables for calculating carbon-burial rates in lakes and impoundments, but data are sparse. Measurements of sedimentation rates in lakes are not coordinated at the national level; measurements of sedimentation rates in impoundments are stored in the national RESSED database, but are not collected at sufficient temporal and spatial resolution to support accurate estimation of OC burial for the assessment. It is recommended that these measurements be expanded, a routine monitoring plan developed, and the RESSED database be used by the U.S. Department of Interior (DOI) and other government agencies as the primary repository for these data.

Despite the importance of GHG fluxes from lakes and impoundments in the global carbon and GHG budgets, measurements are sparse and uncoordinated, and there is no centralized database for these data. Methane emissions from the outlets of reservoirs may be particularly important, but cannot be quantified at regional or national scale with current (2010) information. It is recommended that a Federal monitoring program be initiated to coordinate and conduct GHG flux measurements from lakes and impoundments in support of future carbon assessments.

\section{E.3.6. Projections of Future Fluxes To and From Lakes and Impoundments}

Future changes in streamflow, land use, and other management actions have the potential to alter carbon burial in or GHG fluxes from aquatic systems, including lakes and impoundments. Streamflow is a major driver of carbon and nutrient fluxes in rivers, as discussed in section E.2.6 in this report, and efforts are underway to develop models for projecting streamflow and carbon fluxes under various climatechange scenarios.

Management actions can have complex effects, sometimes creating offsetting benefits in terms of carbon sequestration. Land-use conversion from tilled agriculture to no-till or forest, for example, is likely to cause an increase in carbon sequestration on land, but will reduce the amount of carbon buried in lakes and impoundments because of decreased erosion (table E1). Reducing nutrient runoff from agricultural lands through best management practices (BMPs) will reduce eutrophication and $\mathrm{CH}_{4}$ and $\mathrm{N}_{2} \mathrm{O}$ emissions from inland and coastal waters, but also might cause a decrease in carbon burial because of reduced POC loads in rivers. Understanding the complex effects of these management actions is an area of active research by USGS and other researchers. Adding the capability of simulating the effects of these management actions to existing models is a goal of the assessment.

\section{E.4. Coastal and Estuarine Systems}

\section{E.4.1. Carbon Sequestration in Coastal and Estuarine Systems}

Coastal and estuarine systems are sites where terrestrial and deep-ocean fluxes of nutrients to the surface ocean combine to fuel intense primary productivity. More than 90 
percent of global algal productivity occurs in coastal zones (including estuaries), with sufficient amounts of algal carbon sequestered to make coastal areas important sinks in the global carbon cycle (Dunne and others, 2007). Coastal areas also are sites that receive riverborne terrestrial exports of particulate and dissolved organic material, a fraction of which also is preserved in coastal marine sediments or is transported into the deep ocean. Globally, the magnitude of carbon sequestration in coastal oceans is on the same scale as net terrestrial ecosystem exchange and lateral flux of carbon to the oceans (fig. E3). Because only a small fraction of algal production and terrestrial inputs are preserved, and because coastal upwelling contributes $\mathrm{CO}_{2}$ from the deep oceans, carbon-preservation processes in coastal oceans may be obscured and difficult to quantify (Hales and others, 2006).

There are two major processes acting to sequester carbon in coastal and estuarine sediments and coastal-ocean watersdirect burial of OC in sediments, and particulate transport of OC from the surface to deep oceans (Sarmiento and Gruber, 2002). The latter commonly is referred to as the biological pump. Both processes are strongly related to phytoplankton productivity in the coastal surface oceans, both are coupled to sediment supply from the terrestrial system, and both result in sequestration of $\mathrm{CO}_{2}$ from the atmosphere for decadal to millennial time scales.
Carbon preserved by coastal ocean processes is from autochthonous primary production and from terrestrial inputs. Coastal primary production is fueled by nutrients supplied in terrestrial export, regeneration of nutrients in sediments and the water column, and by upwelling of nutrient-rich deep waters. The plankton production supported by externally supplied nutrients - the "new" production-represents potential net removal of $\mathrm{CO}_{2}$ from the atmosphere. The export of this production into the deep ocean and into coastal sediments is strongly tied to total production, with higher productivity increasing export (Wassman, 1990). Other factors such as water depth and phytoplankton size also have been linked with export (Dunne and others, 2005) with larger exports observed for populations of large phytoplankton, such as those produced in nutrient-rich coastal areas.

Primary production export from the surface ocean to below the mixed layer - the biological pump — is a major mechanism for sequestration of carbon in coastal oceans (Sarmiento and Gruber, 2002; Hales and others, 2006). Primary production in the surface ocean is transported from the mixed layer into the deep ocean as settling particles, with the transported carbon sequestered from free exchange with the atmosphere for periods of decades to centuries, depending on ocean circulation (Sarmiento and Gruber, 2002; Gnanadesikan and Marinov, 2008). Particle flux has been estimated to range from 0.7 to $1.5 \mathrm{Pg} / \mathrm{yr}$ (Dunne and others, 2007;

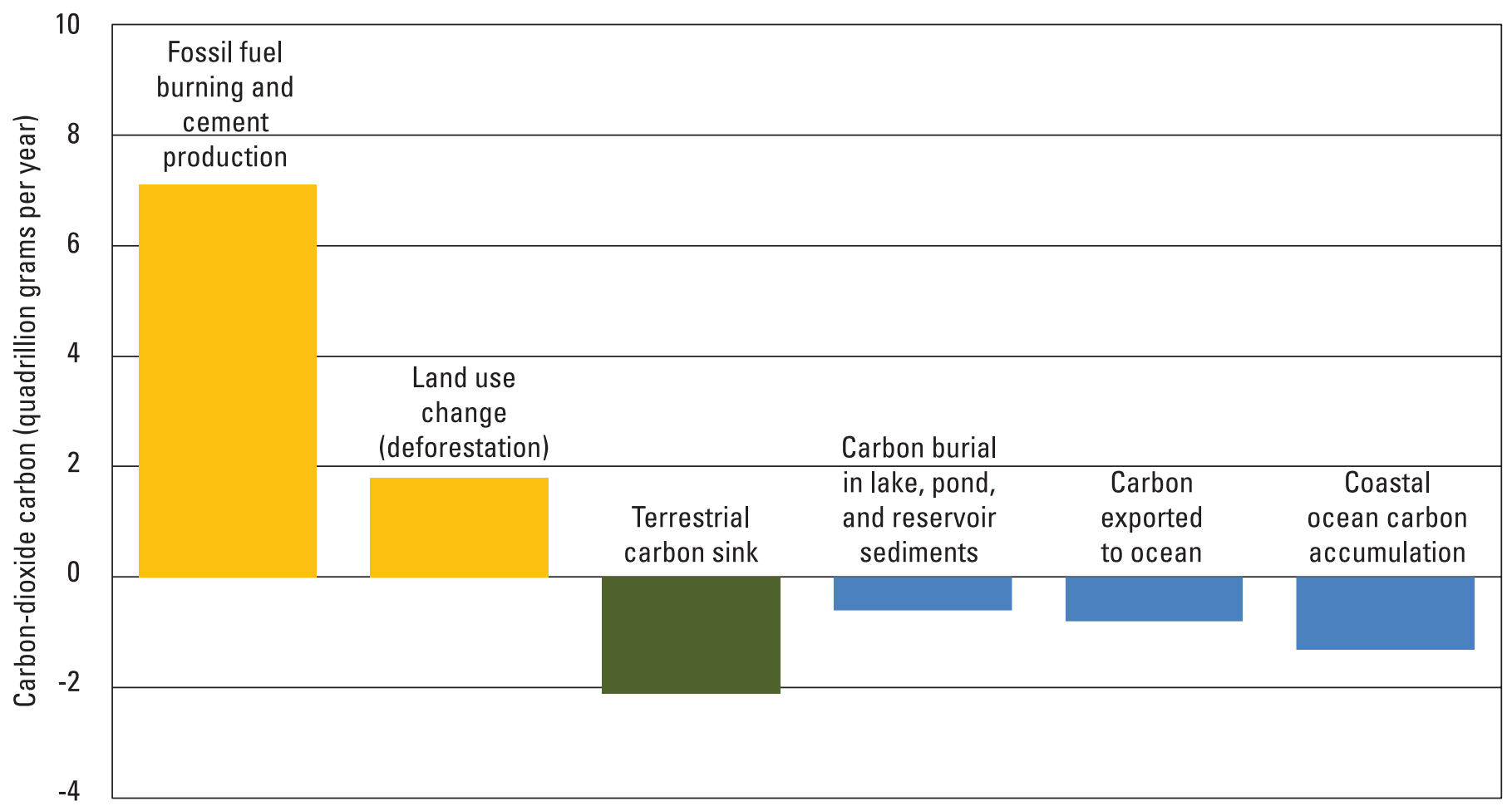

Figure E3. Chart showing the comparison of coastal carbon-sequestration processes to other important sources and sinks. Data from Hedges and Keil (1995), Muller-Karger and others (2005), Dunne and others (2007), Intergovernmental Panel on Climate Change (2007), and Tranvik and others (2009). 
Muller-Karger and others, 2005). Coastal carbon preservation in large measure is, therefore, directly and immediately affected by changes in nutrient export from terrestrial systems.

Historical changes in the nutrient supply to coastal oceans related to changes in land use and land cover - such as fertilizer use, increased urbanization, and wetland restoration-likely have altered coastal carbon preservation and will continue to affect coastal carbon preservation to a greater degree in the future (Billen and Garnier, 2007; Seitzinger and Mayorga, 2008). There also is abundant evidence suggesting that submarine groundwater discharge conveys significant amounts of nutrients to coastal systems (Slomp and Van Cappellen, 2004), comparable to the nutrient loads delivered by surface water in some watersheds with large nitrogen-loading rates and permeable soils (for example, Valiela and others, 1997, 2000; Kroeger, Swarzenski, Crusius, and others, 2007; Kroeger, Swarzenski, Greenwood, and others, 2007). It is important to note that much of this groundwater is quite young (less than 20 years old), and may represent source areas amenable to management.

As for nutrients, changes in sediment supply also can affect carbon preservation in coastal and estuarine systems. Rivers in the conterminous United States export an estimated 5 to $7 \mathrm{Tg} / \mathrm{yr}$ of carbon to the oceans in the form of POC (Pacala and others, 2001), some of which is directly preserved through burial (Hedges and others, 1997; Blair and others, 2004). More importantly, however, is the flux of sediment, which is estimated to be more than $1 \mathrm{Pg} / \mathrm{yr}$ (Aulenbach and others, 2007). Sediment supply is a significant control on estuarine and coastal carbon sequestration because the lithogenic minerals in sediments increase the particle floc densities and settling rate, thereby increasing the efficiency of the biological pump (Armstrong and others, 2002). Benthic carbon preservation also is affected because higher rates of burial result in the preservation of a greater fraction of the associated organic material (Boudreau and Ruddick, 1991; Hedges and Keil, 1995; Dagg and others, 2004). Significant changes in the sediment delivery to the coastal oceans have occurred during the past several decades, altering patterns of burial (for example, Vorosmarty and others, 2003; Leithold and others, 2005; Syvitski and others, 2005). Pressures from increasing population, changes in land use, and changes in patterns of precipitation also will result in changes in sediment discharge (Wilkinson and McElroy, 2007).

Burial of POC - largely derived from phytoplankton - in marine sediments is a major sink in the global carbon budget. Historically, estimates for ocean sediment burial have been approximately 0.15 Pg/yr (Hedges and Keil, 1995; Sarmiento and Gruber, 2002; Muller-Karger and others, 2005). More recent estimates, which explicitly include biogeochemical processes occurring in coastal systems, suggest that this flux may be twice as great (0.32 pg/yr) (Dunne and others, 2007). Coastal sedimentation accounts for 85 percent of global sediment POC burial (Hedges and Keil, 1995; Dunne and others, 2007), with two-thirds of this burial (one-half of the global oceanic carbon burial) occurring in deltaic sediments of large rivers with high productivity and rapid sediment-accumulation rates (Blair and others, 2004). Much of the remaining burial in coastal oceans occurs as the result of episodic inputs from small, mountainous river systems that often occur in tectonically active zones where rates of geologic uplift are high (Milliman and Syvitski, 1992; Blair and others, 2003; Leithold and others, 2005; Wheatcroft and others, 2010). For example, the Eel River in California accounts for 15 percent of the sediment flux from the conterminous United States.

In summary, carbon burial in coastal sediments or accumulation in the deep ocean is directly related to the riverborne flux of nutrients (increases coastal primary production) and sediment (increases the efficiency of benthic burial and the biological pump of carbon into the deep ocean). The coastal carbon-sequestration methodology thus includes a terrestrialflux component related to land use, a model of coastal primary production that is sensitive to changing nutrient inputs, and a process model that explicitly accounts for controlling processes in carbon remineralization such as degradation during sinking, ballasting, bioturbation, and burial (Dunne and others, 2005). The modeling approach used here is similar to a sensitivity analysis responding to changes in terrestrial inputs, and thus no seaward boundary is defined; however, because local conditions such as water-column depth and depositional environment are important elements that control sequestration, the estimates will be conducted individually for large terrestrial inputs, and regionally for smaller ones.

\section{E.4.2. Methane and Nitrous-0xide Fluxes in Coastal and Estuarine Systems}

Changes in production, uptake, and release of methane and nitrous oxide in intertidal sediments and estuarine or coastal waters and sediments also can be substantially affected by changes in nutrient fluxes from the terrestrial system (Seitzinger and Nixon; 1985; Seitzinger and Kroeze, 1998), as can groundwater inputs (Bange, 2006; Hirota and others, 2007).

Surface waters of estuaries and coastal waters are typically supersaturated with respect to GHG, and are thus sources to the atmosphere. These rates and controlling processes, however, are understudied on a national scale, and are likely underestimated. At present (2010), there is insufficient knowledge of $\mathrm{CH}_{4}$ and $\mathrm{N}_{2} \mathrm{O}$ fluxes in estuaries and coastal waters in the United States to make satisfactory estimates, or to develop mechanistic models of the fluxes. There is ample evidence, however, that the fluxes are likely to be of substantial size in terms of global warming potential (GWP) relative to carbon and GHG fluxes in other ecosystems, and the fluxes are likely to change in response to human actions, including intentional management to reduce GHG fluxes, and unintended environmental changes that may alter the rates of flux, such as changes in nitrogen loads, sediment-carbon loads, wetland coverage, and the occurrence of hypoxia associated with eutrophication and climate change. 
Nitrous oxide.-Owing to increasing nitrogen loading from fertilizer applications to watersheds, wastewater disposal, and atmospheric deposition, estuaries are among the most intensely fertilized ecosystems on earth. Typical fertilizer application rates to turf (about 110 kilograms of nitrogen per hectare per year; Valiela and others, 1997) and to crops (a wide range, but a reasonable average is about 140 kilograms of nitrogen per hectare per year; Valiela and others, 1997) are commonly exceeded by the rates of nitrogen loading to estuaries (for example, Chesapeake Bay main stem, 141 kilograms of nitrogen per hectare per year; Hudson River and Raritan Bay, 900 kilograms of nitrogen per hectare per year; Connecticut River, 3,705 kilograms of nitrogen per hectare per year; Bricker and others, 2007). Because of nearby terrestrial nitrogen sources, global estuarine $\mathrm{N}_{2} \mathrm{O}$ fluxes are estimated to be about 7 to 61 percent of total marine fluxes (Capone, 1991; Bange, 1996; Seitzinger and Kroeze, 1998; Nevison, 2004). At the same time, recent studies suggest that agricultural and soil $\mathrm{N}_{2} \mathrm{O}$ fluxes may be overestimated (Bange, 2006), in part because soil $\mathrm{N}_{2} \mathrm{O}$ consumption has not been appropriately considered (Chapuis-Lardy and others, 2007; Neftel and others, 2007). Thus, values reported by Bange (2006) indicate that estuarine $\mathrm{N}_{2} \mathrm{O}$ fluxes may be in the range of 4 to 25 percent of the total global flux from all sources. Further, as argued by Nevison (2000), measurements of $\mathrm{N}_{2} \mathrm{O}$ fluxes from estuaries and from groundwater are critical needs for improvement of Intergovernmental Panel on Climate Change (IPCC) methodology for $\mathrm{N}_{2} \mathrm{O}$ fluxes from agriculture. Recent literature (Nevison, 2000 , and references therein) reports that estimates of the groundwater contribution to $\mathrm{N}_{2} \mathrm{O}$ fluxes owing to leaching of nitrogen from agriculture may need to be revised downward, and that estuarine $\mathrm{N}_{2} \mathrm{O}$ fluxes may need to be revised upward to perhaps 25 percent of the $\mathrm{N}_{2} \mathrm{O}$ flux because of leaching loss of agricultural nitrogen.

In addition to fluxes from estuaries, it is likely that coastal waters outside of estuaries contribute significantly to fluxes, and furthermore that those fluxes will change in response to changes in anthropogenic nitrogen pollution and possibly to climate change. Part of the nitrogen loaded to landscapes ultimately transits to continental-shelf waters in discharges from rivers, groundwater, and estuaries, and there it fuels denitrification and production of new organic matter (Sietzinger and Giblin, 1996; Seitzinger and Kroeze, 1998; Seitzinger and others, 2006). The increasing anthropogenic nitrogen and associated new organic matter can be expected to fuel production of $\mathrm{N}_{2} \mathrm{O}$ (Bange, 2006). In an increasing number of locations (fewer than 400 documented global locations), eutrophication owing to increasing nitrogen loads is severe enough to produce low-oxygen "dead zones" in estuaries and on continental shelves (Diaz and Rosenberg, 2008), and that process may substantially enhance $\mathrm{N}_{2} \mathrm{O}$ fluxes on continental shelves (Naqvi and others, 2000). Bange (2006) compiled published data on $\mathrm{N}_{2} \mathrm{O}$ fluxes to the atmosphere from European estuaries and coastal waters and found that much greater flux densities existed within estuaries, but that the larger surface areas of the non-estuary coastal waters resulted in about 40 percent of the total coastal flux.

Methane.-A global estimate of estuarine $\mathrm{CH}_{4}$ flux has been attempted (Middelburg and others, 2002). The conclusions based on a compilation of existing data suggested that estuaries are consistently a source of $\mathrm{CH}_{4}$ to the atmosphere, amounting to about 9 percent of the global marine source. It is likely, however, that estuarine $\mathrm{CH}_{4}$ fluxes are severely underestimated and are significant to global fluxes (Bange, 2006). It is clear that important sources of $\mathrm{CH}_{4}$ fluxes from estuaries are direct inputs from rivers (Middelburg and others, 2002) and groundwater (Bugna and others, 1996; Crusius and others, 2008; Santos and others, 2009); tidal exchanges with salt marshes, mangroves, and intertidal sand and mud flats (Middelburg and others, 2002; Savvichev and others, 2004; Barnes and others, 2006; Ferron and others, 2007); and production in estuarine sediments (Abril and Iversen, 2002; Kitidis and others, 2007). There are two reasons to conclude that estuarine $\mathrm{CH}_{4}$ fluxes are underestimated:

- The majority of research attempts to measure dissolved $\mathrm{CH}_{4}$ concentrations in estuarine surface water focused primarily on the open waters of estuaries, farthest from the nearshore sources listed above, and likely after much of the flux to the atmosphere has already occurred.

- Most of the studies considered in the global flux estimate did not include fluxes from sediments to the atmosphere caused by ebullition of biogenic gas bubbles commonly composed primarily of $\mathrm{CH}_{4}$.

Neglect of fluxes caused by ebullitions (bubbles) is likely to dramatically underestimate fluxes because, in the few cases where such fluxes have been measured, they typically comprised 50 to more than 90 percent of fluxes from sediment (Hammond and others, 1975; Martens and Klump, 1980; Chanton and others, 1989; Hovland, 1993; Shalini and others, 2006; Rajkumar and others, 2008). Further, the importance of ebullitive fluxes is magnified by the fact that such fluxes largely escape oxidation in the sediment and water column (for instance, Martens and Klump (1980) estimated that 85 percent of $\mathrm{CH}_{4}$ in bubbles survived transit through $7.5 \mathrm{~m}$ of water), whereas much of the diffusive flux from sediments is consumed by oxidation before flux to the atmosphere. Fluxes owing to the release of bubbles are likely to be particularly important in shallow (less than $5 \mathrm{~m}$ ) waters (Joyce and Jewell, 2003), and releases are episodic on tidal and seasonal time scales (Chanton and others, 1989), making them difficult to measure and likely to be missed by oceanographic cruises (Hovland, 1993).

Rajkumar and others (2008) provide an example of a study where diffusive and ebullitive fluxes were measured and scaled to an entire estuary. In a 42-kilometer-long mangrovefringed estuary with a water-surface area of 690 hectares (ha), ebullitive fluxes comprised more than 90 percent of the $\mathrm{CH}_{4}$ flux. In terms of GWP, the $\mathrm{CH}_{4}$ flux was 453 moles $\mathrm{CO}_{2}-$ equivalents per square meter per year. Comparing this to the 
rates of carbon sequestration in U.S. forests and nonpermafrost peatlands, which are -2.9 and -1.0 moles carbon per square meter per year, respectively (U.S. Climate Change Science Program, 2007), this single estuary has a $\mathrm{CH}_{4}$ flux equivalent to the GWP of carbon sequestration in about 107,000 ha of forest, or 313,000 ha of peatland.

As discussed with regard to coastal $\mathrm{N}_{2} \mathrm{O}$ fluxes, it is likely that coastal waters outside of estuaries contribute significantly to $\mathrm{CH}_{4}$ fluxes as well. For example, Bange (2006) also compiled published data on $\mathrm{CH}_{4}$ fluxes from European estuaries and coastal waters, and similarly found much higher flux densities within estuaries. Still, fluxes from nonestuary coastal waters once again were responsible for about 40 percent of the total coastal flux.

Potential for change. - GHG fluxes from estuaries and coasts are likely evolving in response to environmental changes and human actions, including changes in nitrogen and phosphorus loading; inputs of GHG from rivers, groundwater, and wetlands; delivery of sediment; wetland coverage because of removal, restoration, or sea-level rise; and sediment carbon inventory because of dredging. Climate change can be expected to alter estuarine and coastal GHG fluxes in as yet unquantified ways because of sea-level rise and temperature increases. In recent decades, the areal coverage and intensity of coastal dead zones (hypoxic and anoxic zones) has increased dramatically in the United States and worldwide because of increasing nutrient loading (Diaz and Rosenburg, 2008), and climate change is expected to exacerbate that process (Justic and others, 2003; Boesch and others, 2007). Eutrophication and associated increases in OC production and low dissolved oxygen conditions both are likely to increase $\mathrm{CH}_{4}$ production (Giani and Ahrensfeld, 2002) and decrease $\mathrm{CH}_{4}$ oxidation (consumption) in estuaries. $\mathrm{N}_{2} \mathrm{O}$ fluxes are expected to increase in response to increasing nitrogen supply: Seitzinger and Kroeze (1998) suggest that the proportion of the nitrogen released to aquatic environments that is converted to atmospheric $\mathrm{N}_{2} \mathrm{O}$ depends on the nitrogen loading rate- from about 0.3 percent under conditions of low nitrogen loading, to 3 to 6 percent with higher nitrogen loading. Hypoxic and anoxic zones may be particularly important sources of $\mathrm{N}_{2} \mathrm{O}$ (Naqvi and others, 2000). Because $\mathrm{CH}_{4}$ fluxes from some estuaries and coasts may be large, and the assessment is focused on changes during the next four decades, it is worth noting that on a 20 -year time horizon, the GWP of $\mathrm{CH}_{4}$ in $\mathrm{CO}_{2}$ equivalents is estimated at 72 rather than the 25 equivalents typically considered on a 100-year time horizon (Intergovernmental Panel on Climate Change, 2007).

Coastal groundwater as a source.-GHG fluxes from coastal groundwater also have received little attention, but data do exist indicating that concentrations of $\mathrm{N}_{2} \mathrm{O}$ and $\mathrm{CH}_{4}$ are at times quite elevated in coastal groundwater (Butler and others, 1987; LaMontagne and others, 2003; Santos and others, 2009). Further, the global inventory of $\mathrm{N}_{2} \mathrm{O}$ in groundwater is a large term, comprising perhaps 10 to 20 percent of biogenic $\mathrm{N}_{2} \mathrm{O}$ (Ronen and others, 1988; Haag and Kaupenjohann, 2001). Correlations between radon activity in estuaries as a tracer of groundwater discharge and concentrations of dissolved $\mathrm{CH}_{4}$ (Bugna and others, 1996; Santos and others, 2009) and $\mathrm{N}_{2} \mathrm{O}$ (Crusius and others, 2008) suggest that groundwater is a dominant source for those dissolved gases in some estuaries. Finally, coastal groundwater may interact in important ways with $\mathrm{CH}_{4}$ production in estuarine sediments. Several authors have noted associations between the presence of discharging fresh groundwater in pore waters and elevated $\mathrm{CH}_{4}$ concentrations in shallow sediments, suggesting reduced sulfate inhibition of methanogenesis at low-salinity water or, in some cases, delivery to the estuary of terrestrial groundwater that is enriched in dissolved methane owing to onshore aquifer properties and the influence of freshwater wetlands and hydric soils (Hill and others, 1992; Bratton and others, 2004; Kogan and Paull, 2005). The assessment will, therefore, explicitly consider groundwater as a source for coastal GHG.

\section{E.4.3. Methodology for Assessing and Projecting Carbon Sequestration and Greenhouse-Gas Fluxes From Coastal and Estuarine Systems}

There are three subsections to the coastal and estuarine assessment methodology. The first subsection describes the methods used to assess the terrestrial supply of dissolved and particulate organic carbon, nutrients, and sediments to the coastal oceans. The second subsection describes the methods used to assess the role of estuaries and coastal processes in carbon storage. The third subsection describes a method for estimating the GHG fluxes from coastal and estuarine waters, intertidal sediments, and tidal systems not covered in the wetland assessment.

It is explicitly recognized that wetland restoration and destruction as well as changes caused by sea level rise will substantially affect carbon storage, carbon sequestration, and GHG production along coastal margins in the terrestrial to aquatic transition zone. Because the methods used to assess wetlands and sea-level rise are contained within the models used to assess terrestrial processes (as discussed in appendixes $\mathrm{C}$ and $\mathrm{D}$ in this report), these methods are not described here. Nevertheless, the effects of changes to coastal and estuarine wetlands and changes because of sea-level rise are represented in the coastal and estuarine methodology as it affects nutrient, carbon, and sediment fluxes.

The goal of the coastal and estuarine assessment is to assess the magnitude of linkages between terrestrial land use, coastal carbon sequestration, and GHG production, as driven by changes in flux of water, nutrients, sediment, and carbon from the continent. The coastal and estuarine assessment focuses exclusively on the carbon-sequestration and GHG production functions of estuaries and coastal systems that are presently (2010) affected or may be affected by changes in terrestrial processes responding to changing management, land use, population, or climate. Given that the modeled processes differ by coastal geomorphology and continental flux, the 
assessment will be segmented into physiographic regions, but the seaward spatial boundary will remain undefined.

The methods for assessment of coastal and estuarine processes are broken down into four parts, according to the methods used - surface-water fluxes of carbon, nutrients and sediments to estuaries and coasts; groundwater fluxes to estuaries and coasts; carbon preservation in coastal waters; and, greenhouse-gas (methane and nitrous oxide) release or uptake.

\section{E.4.3.1. Surface-Water Fluxes of Carbon, Nutrients, and Sediments}

The methods used to assess the carbon sequestration and GHG productions in coastal and estuarine systems require determination of the terrestrial fluxes that affect these processes. Current (2010) fluxes and future potential fluxes under different climate and land-use scenarios will be assessed using a hybrid modeling approach (SPARROW) that combines process-based and statistical models to calculate constituent fluxes from rivers (head of tide) to estuaries and the coastal zone across the United States. Datasets that drive the SPARROW model will include the LULC data generated as part of the assessment effort described in chapter 3 and appendix B of this report. Modeled data will be produced for all coastal and inland hydrologic units (HUC) that produce runoff to estuaries in the United States, and will be developed for DOC, POC, total suspended sediments (TSS), nitrogen (organic and inorganic) and phosphorus (organic and inorganic). The assessment also will incorporate estimates of the submarine groundwater flux to estuaries from coastal basins via modeled or literature values where available. This broader methodology will not consider inorganic carbon (dissolved $\mathrm{CO}_{2}$ or particulate) or micronutrients (silica, iron) at this time.

The goals of this part of the assessment are to estimate the mean annual flux of POC, TSS, and nutrients from hydrologic unit (HUC) basins across the United States to the head of tide; estimate the mean annual flux of particulate carbon, TSS, and nutrients from coastal landscapes below the head of tide; and develop new SPARROW models for key constituents that affect coastal carbon cycling, including organic nutrients, POC, and carbon degradation. The lateral-flux estimates described earlier will be conducted in coordination with these assessments.

A variety of modeling approaches have been used to estimate constituent contaminant sources and loads in basins including process-based and statistical models with a range of complexities (Alexander, Elliot, and others, 2002; Schwarz and others, 2006). Process-based (mechanistic) models, such as the Hydrological Simulation Program-Fortran (HSPF) (Bicknell and others, 2001) and the Soil and Water Assessment Tool (SWAT) (Srinivasan and others, 1993), use a detailed set of equations that attempt to describe relevant processes affecting water and constituent transport. These models typically have a complex mass-balance structure that requires a large number of input parameters and a priori assumptions about the dominant processes and reactions rates (Schwarz and others,
2006). In addition, these models often lack robust measures of uncertainty in model coefficients and predictions and suffer from challenges in extrapolating the results of small catchment models and field-scale measurements to larger spatial scales; however, these models are based on physical processes occurring in basins and drainage networks and theoretically would be applicable across a broad range of sites with detailed input data.

In comparison, statistical models have a simple correlative mathematical structure and use empirical relations, such as linear regression between stream measurements (load, concentration) and source or landscape drivers. Examples of purely statistical models include regressions of nitrogen export from large basins on population density (Peierls and others, 1991), net anthropogenic sources (Howarth and others, 1996), and atmospheric deposition (Howarth and others, 1996; Jaworski and others, 1997). Although these models can be applied in basins of various sizes and can incorporate uncertainty estimates, they typically use a "black box" approach that lacks a mechanistic explanation of the processes affecting contaminant transport (Schwartz and others, 2006). In addition, these models also lack spatial detail on the distribution of sources and sinks within basins and do not allow for assessing the relative importance of terrestrial versus aquatic processes.

Hybrid modeling approaches (SPARROW: Smith and others, 1997; Global NEWS: Seitzinger and others, 2005; PolFlow: de Wit, 2001) expand on simple statistical models by adding process-based model structure to develop relations with spatially referenced properties. For example, SPARROW has process-based mass-transport components for water flow paths, in-stream processing, and mass-balance constraints on model inputs, losses, and outputs (Schwarz and others, 2006). Parameters are estimated for monitoring stations with sufficient records for discharge and water-quality parameters (including capturing the dynamic range) by spatially correlating stream data with georeferenced data on constituent sources (atmospheric deposition, fertilizers, human and animal wastes) and delivery factors (precipitation, topography, vegetation, soils, water routing). Parameter estimation ensures that the calibrated model will not be more complex than can be supported by the data.

SPARROW has been included in several model comparison studies with process-based and statistical models. These include comparisons of total nitrogen (TN) loading with the models at the national scale and for the Chesapeake Bay Basin (Alexander and others, 2001). Alexander, Johnes, and others (2002) and Seitzinger and others (2002) also compared statistical and hybrid models for the northeastern United States, with results typically showing general agreement between models and literature estimates, but lower estimates of uncertainty with SPARROW in comparison to many other models (Alexander, Johnes, and others, 2002).

In this part of the assessment, SPARROW will be used to model the delivery of terrestrial carbon and other constituents in rivers to the coastal zone. Understanding carbon transport requires models that cover the conterminous United States 
and estimate the loading of key constituents to estuaries and coastal systems. A number of previous studies have used the SPARROW model for national-scale assessments of TN and total phosphorus (TP) sources and loads throughout the conterminous United States (Smith and others, 2003; Alexander and others, 2001). Separate regional studies of TN and TP loads also have been conducted in the Chesapeake Bay Basin (Preston and Brakebill, 1999; Brakebill and Preston, 2003; Roberts and Prince, 2010), the Mississippi River and tributaries (Alexander and others, 2008; Robertson and others, 2009) and New England (Moore and others, 2004). Although most studies to date have focused on TN and TP, SPARROW models also have also been developed for a range of parameters including E. coli (Puri and others, 2009), suspended sediment (Schwarz and others, 2006), and national estimates of total organic carbon, and dissolved solids (Anning and others, 2007).

SPARROW model parameters are estimated with nonlinear regression techniques by spatially correlating constituent flux estimates at monitoring stations with geospatial datasets on constituent sources and factors affecting constituent fate and transport. The calibrated models are used to predict flux and estimate source contributions for stream reaches throughout a river network (Schwarz and others, 2006). Data for in-stream nutrient loads at monitoring sites, nutrient sources, and land-surface characteristics are assigned to each stream reach in a digital stream-reach network that provides continuity between upstream and downstream loads. Mean annual loads typically are used from a large number of sites according to site-selection criteria, including the minimum number of observations at each station, maximum prediction accuracy of plus or minus 50 percent of mean annual load, and sufficient coverage of basin-attribute data (Schwarz and others, 2006; Alexander and others, 2008). Statistical approaches such as LOADEST (Runkel and others, 2004) and Fluxmaster (Schwarz and others, 2006) then are used to develop a time-series flow model and estimate the water-quality model (Schwarz and others, 2006).

Geospatial datasets are required as explanatory data in the SPARROW model as described in Schwarz and others (2006). The stream reach (and its incremental contributing drainage basin) is the basic spatial unit used to estimate and apply SPARROW models, and data collected at different spatial scales (for example, census block data, county fertilizer application) are converted to the stream-reach scale using GIS techniques (Schwarz and others, 2006).

To accomplish this assessment, monitoring data and geospatial datasets will be collected and evaluated for use in SPARROW models of constituent transport to the head of tide. Potential data sources are included in tables 3.7. and 3.10. in this report. The assessment will use land-use and land-cover data generated from the "forecasting scenarios of future land-cover" (FORE-SCE) model described in appendix B of this report to 2050 at 250 -m grid-cell resolution, will evaluate existing data, test assumptions, and develop correlations between parameters such as fertilizer-application rates and atmospheric deposition over time. The assessment also will include uncertainty estimates for parameters that have significant assumptions or are difficult to evaluate. Given that most SPARROW models are developed for studies of TN and TP, additional data types or sources may be required for models of other constituents affecting terrestrial-carbon contributions to estuaries and coastal systems.

SPARROW output contains prediction results paired with measures of accuracy in stream reaches. Constituent transport is predicted as fluxes (mass over time) at the reach and incremental basin scale with statistics on the prediction results (standard errors, prediction intervals). Fluxes then are used to derive constituent yields (mass over area over time), flow weighted concentrations (mass over volume) and contribution by sources (Schwarz and others, 2006). The temporal scale for data output in the current (2010) SPARROW structure is longterm mean-annual or mean-seasonal flux (mass per unit time) of constituents, the response variable of the model.

In the assessment, the transport of constituents to the head of tide will focus on an annual time scale and will be referenced to a specific year as described in Schwarz and others (2006); however, the development of parameter-estimation methods for applying the SPARROW model at shorter time steps (for example, seasonal or monthly; Schwarz and others, 2006) will be evaluated early in the study with existing TN and TP to develop a more mechanistic understanding of processes, fluxes, and temporal variability that will inform future model development and interpretation of annual-scale results. A number of terrestrially derived constituents affect carbon cycling in estuaries, and therefore need to be included in model output. Critical constituents currently (2010) modeled by SPARROW or in development include DOC, TSS, TN, and TP. The current (2010) methodology also will use SPARROW modeling to predict the form of dissolved nitrogen (inorganic versus organic) and POC transport since both are critical to carbon cycling in estuaries and coastal systems.

\section{E.4.3.2. Groundwater Fluxes of Carbon and Nutrients}

The SPARROW model and streamgage data do not estimate coastal groundwater loads. To adequately estimate nutrient loads to coastal waters, the assessment must explicitly estimate and model those inputs using a land use and geological typology approach. Nitrogen loads to estuaries and coasts from coastal groundwater discharge will be estimated using existing information on discharges and loads, and a typological approach to scale site-specific rates to larger sections of the United States coast. A number of published USGS reports include hydrological modeling estimates of groundwater discharge rates from specific basins, commonly using various versions of USGS's groundwater-flow model (MODFLOW) or related groundwater models (U.S. Geological Survey, 2010c) (for example, Scorca and Monti (2001)] for the north shore of Long Island; Monti and Scorca (2003) for the south shore of Long Island; Sanford and others (2008) for the Chesapeake Bay; and Masterson and others (2006) for Rhode Island). Discharge results of those studies will be applied, as a proportion 
of total rainfall to the catchment, to neighboring locations of similar climate and geology. Where available, results will be compared to estimates of fresh groundwater discharge at particular locations published in journal articles. Concentrations of nitrogen, carbon, and GHG in discharging groundwater will be estimated based on published and unpublished data, including Kroeger and others (1999), Bratton and others (2004, 2009), Crusius and others (2005), Cole and others (2006), Kroeger, Cole, and Valiela (2006), Kroeger, Cole, York, and Valiela (2006), Kroeger, Swarzenski, Crusius, and others (2007), Swarzenski and others (2007), and Kroeger and Charette (2008), at selected east coast sites and with USGS monitoring data for several thousand wells available through the USGS's National Water Information System (NWIS). The NWIS data will be selected based on well depth and proximity to the coast, and their suitability as an indication of concentrations in discharging groundwater will be assessed based on comparisons to USGS data on concentrations measured at the coast. Nitrogen concentrations and loads in groundwater will be further estimated based on application of a modified version of Nitrogen Loading Model (NLM) (Valiela and others, 1997, 2000). NLM is an empirical, land-use-based model of groundwater nitrogen loads to estuaries. The model will be applied to nearshore parts of basins not accounted for in SPARROW and streamgage estimates of river discharge and nitrogen loads.

\section{E.4.3.3. Carbon Preservation in Coastal Systems}

Carbon preservation in carbon systems also will use a hybrid modeling approach, and will be conducted in two tiers. The goals of this part of the assessment are (1) to quantify the mean annual burial flux of carbon to the sediments in coastal and estuarine environments, (2) to estimate the mean annual net flux of terrestrially supported, phytoplankton-derived, "new" production into the sediments and across the thermocline into the deep ocean; and (3) to develop a new modeling structure for coastal carbon cycling that incorporates variations in terrestrial inputs, POC degradation, burial, and transport to the deep ocean.

The conceptual modeling structure for this effort (fig. E4) starts with the effects of changing nutrient flux from terrestrial systems on productivity (and hypoxia) in coastal waters. Sediment POC inputs from rivers will contribute to the flux of carbon to the sediments, but will also act to ballast algal production, increasing transport through the mixed layer. Depending on the water depth and local currents, the particles are transported to the sediment surface or to below the thermocline, where the carbon is essentially sequestered (Hales and others, 2006). Particles arriving at the sediment surface are subject to continued degradation and resuspension until they are buried below the penetration of oxygen in the sediments, after which the carbon is presumed to be sequestered (Hedges and Keil, 1995; Hartnett and others, 1998).

The first major process to be modeled is carbon accumulation in coastal sediments, which, as discussed above, is a function of coastal productivity and sediment-accumulation rate. The vast majority of carbon preserved in the ocean is marine derived and occurs in coastal sediments, mainly in deltas (Hedges and Keil, 1995). The initial assessment of carbon sequestration occurring in these systems will be based on the sediment-flux values provided by section E.2 ("Transport of Carbon by Streams and Rivers") of this report, using values for carbon content provided in Hedges and Keil (1995) and other relevant publications with data on carbon content and grain-size distribution in major deltas of the

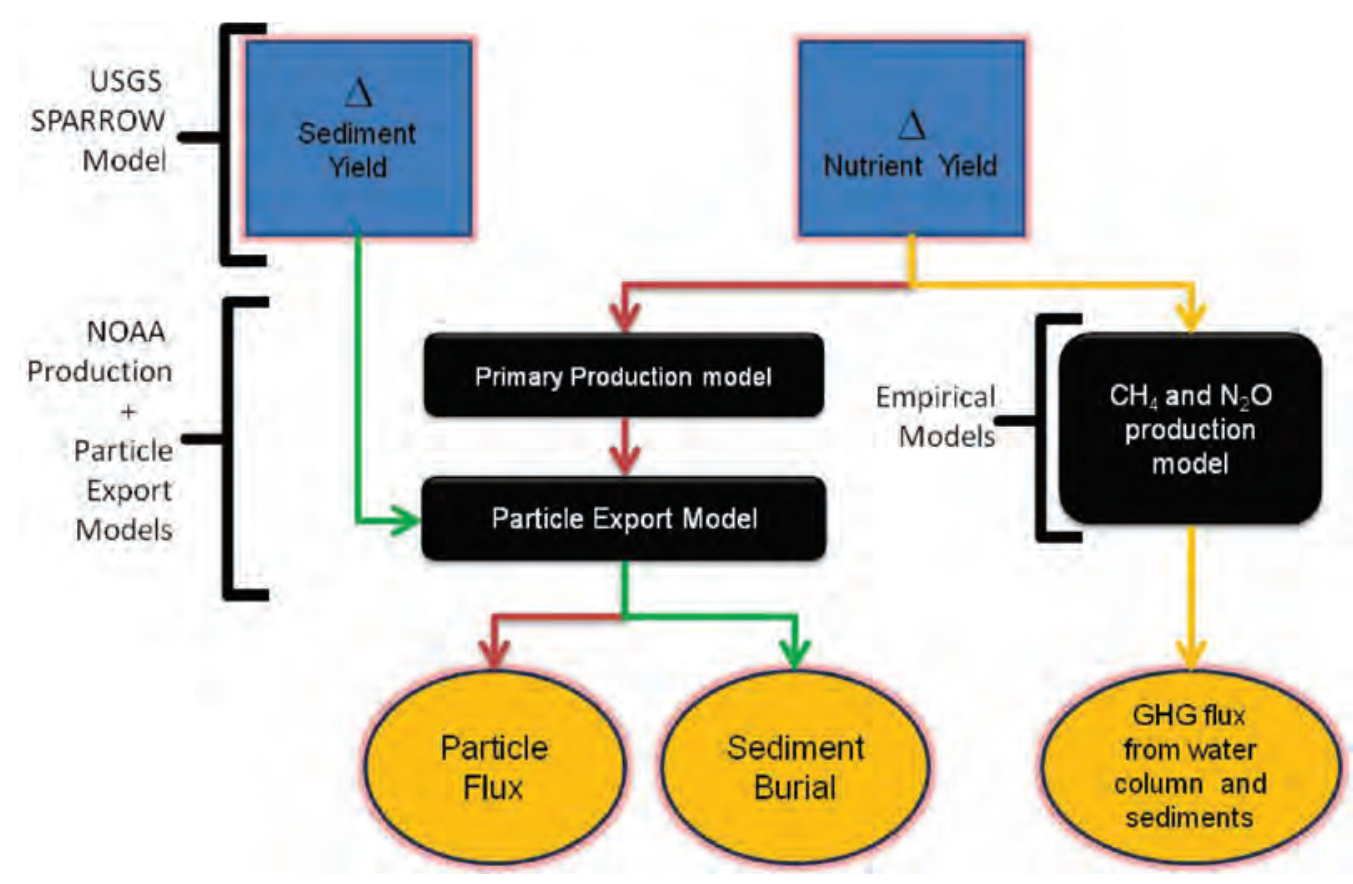

Figure E4. Diagram showing the modeling structure for coastal carbon-sequestration processes. 
United States. The previously published estimates of carbon accumulation are based on an assumed partitioning between deltaic and coastal sediments, with the correspondingly different carbon content in the depositional sites.

The same assumptions as presented in Hedges and Keil (1995) initially will be used until a diffusional model is implemented in conjunction with a sedimentation model (discussed below). It is anticipated that under some IPCC SRES scenarios (Nakicenovic and others, 2000), ocean warming will increase stratification and induce additional hypoxia (Levin and others, 2009). Our estimates will be adjusted based on the anticipated extent of hypoxic areas in many major river deltas (Howarth, 2008; Rabouille and others, 2008), whereby sediments underlying these suboxic zones will exhibit elevated levels of carbon preservation because of matrix protection and reduced microbial activity (Bergamaschi and others, 1997).

The second process to be modeled is phytoplankton biomass flux across the thermocline based on models developed in the National Oceanic and Atmospheric Administration (NOAA) Geophysical Fluid Dynamics Laboratory (Dunne and others, 2005) and conducted in collaboration with the NOAA team. They have developed a combined statistical-mechanistic model using global data that estimates phytoplankton size distribution and grazing from primary productivity, temperature, and a variety of other ecosystem variables. Ballasting, sinking rate, remineralization rate, and other relevant mechanistic variables also are included to assess the export of carbon from the photic zone. The model will be adapted for application in coastal areas and for the purpose of determining carbon flux to the sediments in shallow zones and below the thermocline in deeper zones.

This modeling approach divides the processes into productivity sediment preservation and biological pump contributions to carbon preservation. The first model component assesses the amount of coastal productivity supported by nutrient supply from rivers. Changes in nutrient supply can be caused by changes in population, discharge, agricultural practice, reforestation, and many other similar landuse-related or climate-related variables (Billen and Garnier, 2007), and will affect the primary productivity in adjacent coastal areas.

At present (2010), the assessment will calculate sediment, nutrient, and POC into coastal segments at monthly time increments. A discharge intensity factor will be used to assess dispersion, and an energetic factor to assess resuspension cycles - estimated as a function of bathymetry and wind energy - that affect the processing of organic carbon associated with particles (Burdige, 2005; Thunell and others, 2007). Resuspension owing to large events, such as hurricanes (Chen and others, 2009), is not taken into account.

The model will use monthly time increments to incorporate seasonality as well as river-ocean coherence, which can have a large effect on the fate of POC in coastal ocean systems (Wheatcroft and others, 2010). Dunne and others $(2005,2007)$ include a complete model description, model parameters, and equations. Data needs and sources are listed in table E1.

\section{E.4.3.4. Net Production of Methane and Nitrous Oxide in Estuaries and Coastal Waters}

$\mathrm{N}_{2} \mathrm{O}$ and $\mathrm{CH}_{4}$ fluxes from estuaries and coastal waters will be assessed based on empirical data on flux rates and will involve a geospatial approach to quantify coverage of key sources including salt marshes, mangroves, and intertidal areas. Where data are available, a regression approach will be taken to estimate flux rates based on spatial or temporal variations in controlling variables. In cases where insufficient data are available for a simple regression approach, information gaps initially will be filled with estimated unit values. For example, all fringing salt marsh initially will be estimated to contribute $\mathrm{CH}_{4}$ to adjacent estuaries at the same (albeit poorly constrained) rate.

Terrestrial inputs of $\mathrm{N}_{2} \mathrm{O}$ and $\mathrm{CH}_{4}$ will be estimated through linkages to measured and modeled discharges and chemical composition of rivers and groundwater. Methanogenic aquifers will be identified based on proposed geological controls, with thin vadose zones resulting in methanogenesis. $\mathrm{N}_{2} \mathrm{O}$ and $\mathrm{CH}_{4}$ content of coastal groundwater and rivers will be estimated based on LULC regressions (appendix B of this report), geological setting, biogeochemical conditions, chemical data synthesized from published literature, USGS monitoring data for groundwater and rivers available through NWIS, and other data sources, as available. Future changes in terrestrial $\mathrm{N}_{2} \mathrm{O}$ flux will be estimated based on modeled changes in nitrogen loads (SPARROW; NLM; Valiela and others, 1997, 2000), projected land-use changes, and an assumed proportion exported as $\mathrm{N}_{2} \mathrm{O}$ (for example, Seitzinger and Kroeze, 1998). Where data are available, variables to be considered will include eutrophication status, nitrogen load, hypoxia and anoxia, wetland coverage and type, latitude, climate, terrestrial-sediment load, sediment carbon content, water depth, salinity, and temperature or season. The assessment will require limited new data collections and monitoring to fill knowledge and data gaps, and will require uncertainty estimates given the limited data availability on $\mathrm{N}_{2} \mathrm{O}$ and $\mathrm{CH}_{4}$ in rivers and groundwater.

$\mathrm{N}_{2} \mathrm{O}$ flux to the atmosphere from the water column will be calculated as the sum of nitrification and denitrification rates, multiplied by the emission factor (EF), which is the proportion of the production rate of $\mathrm{N}_{2} \mathrm{O}$ versus other products (nitrate or $\mathrm{N}_{2}$ ) in those transformation processes (Seitzinger and Nixon, 1985; Seitzinger and Kroeze, 1998). The EF is calculated based on experiments showing that $\mathrm{N}_{2} \mathrm{O} / \mathrm{N}_{2}$ as a product of sediment denitrification increased linearly with nitrogen load $\left(r^{2}=0.97\right)$ and the EF for nitrification has been observed to vary from 0.3 to 30 percent (Goreau and others, 1980; Priscu and others, 1996). Thus, in the methodology, EF will be calculated as a fraction of total $\mathrm{N}$ transformation by denitrification and nitrification, and that fraction will increase with $\mathrm{N}$ load per unit area of estuary. The denitrification rate is assumed to be 50 percent of the nitrogen-loading rate, supported by a regression between those variables $\left(\mathrm{r}^{2}=0.81\right.$ versus inorganic nitrogen load; $r^{2}=0.7$ versus total nitrogen 


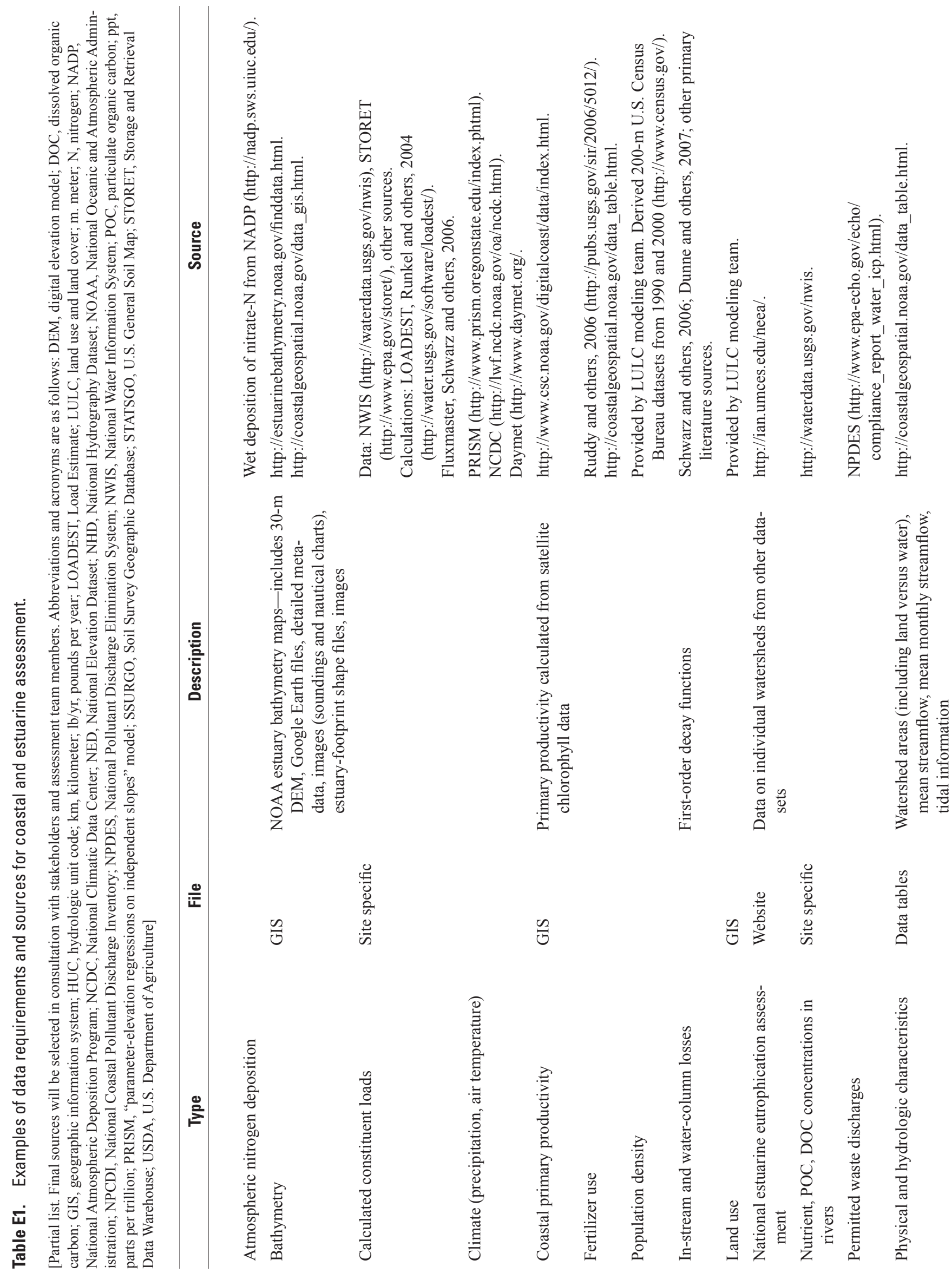




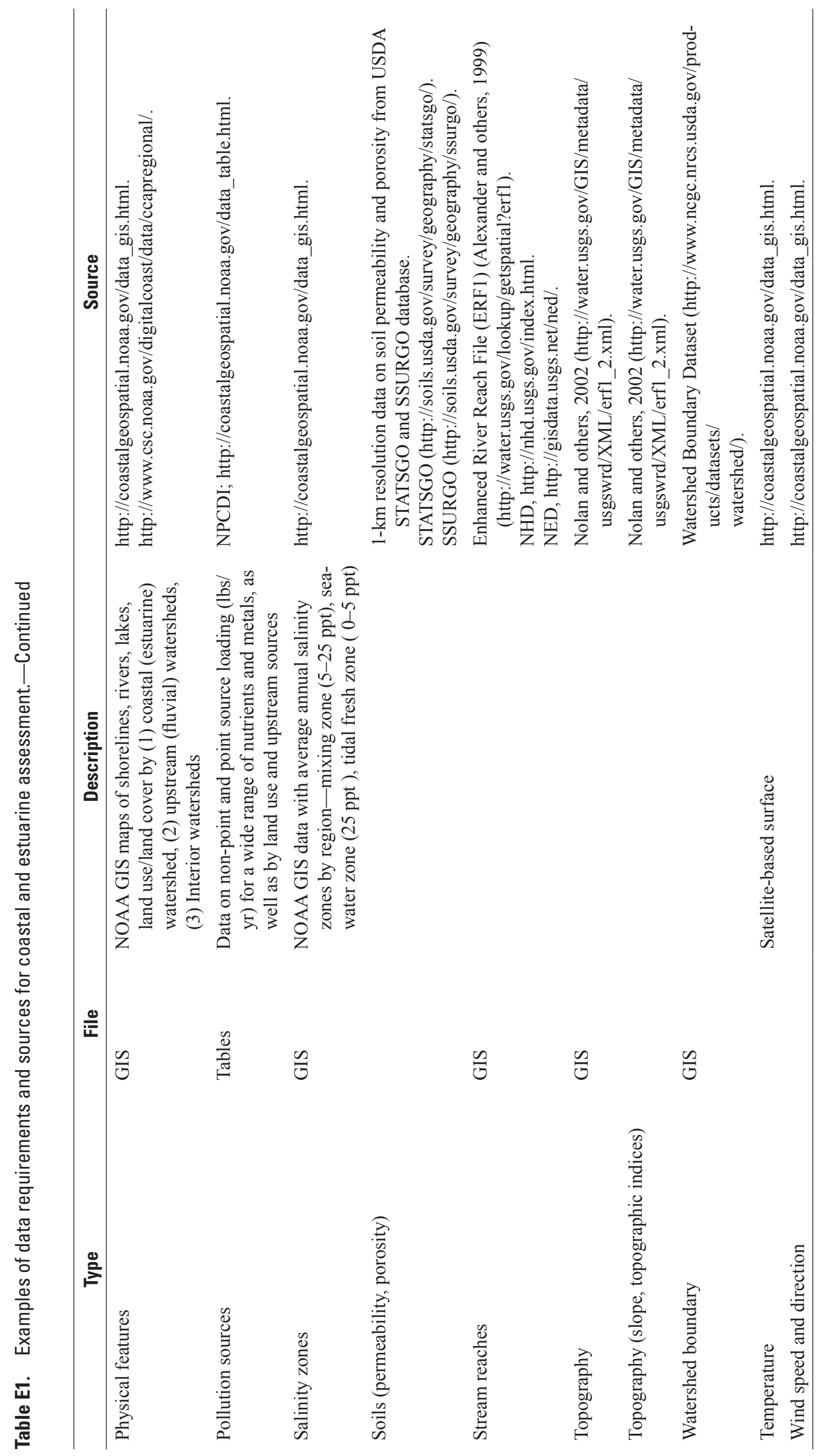


load) (Seitzinger and Kroeze, 1998). The modeled pelagic nitrification rate is less constrained, and is assumed to be 1.2 times the denitrification rate based on observations in Narragansett Bay (Seitzinger and others, 1984). Benthic nitrification is not included, although the rate has been observed to be approximately equivalent to pelagic nitrification (Berounski and Nixon, 1993). For the methodology, the total dissolved nitrogen (TDN) loads will be estimated based on the sum of loads from rivers (from the SPARROW model), direct groundwater discharge (NLM groundwater nitrogen model), and atmospheric deposition (derived from National Atmospheric Deposition Program (NADP) data). Modeled $\mathrm{N}_{2} \mathrm{O}$ flux rates from estuaries will be calculated as follows:

\begin{tabular}{|c|c|c|}
\hline & & $=\mathrm{EF} \times(\mathrm{NIT}+\mathrm{DENIT})$ \\
\hline \multicolumn{2}{|c|}{ calculated as } & $=1.2 \times$ DENIT \\
\hline & & $\mathrm{JIT}=0.5 \times$ TDNinput \\
\hline & $\mathrm{N}_{2} \mathrm{C}$ & $=\mathrm{EF} \times 1.1 \times \mathrm{TDNinput}$ \\
\hline \multirow[t]{5}{*}{ where } & $\mathrm{N}_{2} \mathrm{O}$ & $\mathrm{N}_{2} \mathrm{O}$ flux (grams of nitrogen per year) \\
\hline & $\mathrm{EF}$ & $\begin{array}{l}\text { emission factor }=\mathrm{N}_{2} \mathrm{O} / \mathrm{N}_{2}=(1.12 \times \\
\left.10^{-7}\right) \times \text { kilograms of nitrogen per square }\end{array}$ \\
\hline & NIT & $\begin{array}{l}\text { kilometer of estuary per year } \\
\text { pelagic nitrification rate (grams of } \\
\text { nitrogen per year) }\end{array}$ \\
\hline & DENIT & $\begin{array}{l}\text { sediment denitrification rate (grams of } \\
\text { nitrogen per year) }\end{array}$ \\
\hline & TDNinput & $\begin{array}{l}\text { external total dissolved nitrogen load } \\
\text { from rivers plus groundwater plus } \\
\text { atmospheric deposition (grams of } \\
\text { nitrogen per year) }\end{array}$ \\
\hline
\end{tabular}

This simple empirical model is intended to produce coarse estimates of fluxes, and the availability of data to construct and validate the model is extremely limited. The model will therefore be updated continuously as additional validation data become available. Field research and monitoring will be required to further develop, test, validate, and calibrate the model.

\section{E.4.4. Validation and Error Estimation}

Bootstrap methods will be used in the SPARROW model to address uncertainties in parameters and correct for potential bias (Schwarz and others, 2006; Robertson and others, 2009). The model will provide statistics to evaluate model results for SPARROW assumptions (variance, spatial bias, and outliers) and measures of model fit (Schwartz and others, 2006). Monte Carlo methods will be used to estimate uncertainty in models of coastal productivity and carbon accumulation (Dunne and others, 2005). Models will be validated using continuous monitoring data such as that produced by the USGS National Stream Quality Accounting Network (NASQAN) and other programs. Parameter data will be validated by comparison to existing scientific literature. Modeled accumulation rates will be validated using existing and proposed core data.

\section{E.5. References Cited}

[Reports that are only available online may require a subscription for access.]

Abril, Gwenaël, and Iversen, Niels, 2002, Methane dynamics in a shallow non-tidal estuary (Randers Fjord, Denmark): Marine Ecology, Progress Series, v. 230, p. 171-181.

Ackerman, K.V., Mixon, D.M., Sundquist, E.T., Stallard, R.F., Schwarz, G.E., and Stewart, D.W., 2009, RESISII-An updated version of the original reservoir sedimentation survey information system (RESIS) database: U.S. Geological Survey Data Series 434, available only at http://pubs.usgs.gov/ds/ds434/.

Advisory Committee on Water Information, Subcommittee on Sedimentation, undated, The reservoir sedimentation database (RESSED): U.S. Geological Survey, accessed June 16, 2010, at http://ida.water.usgs.gov/ressed/.

Alexander, R.B., Brakebill, J.W., Brew, R.E., and Smith, R.A., 1999, ERF1—Enhanced river reach file 1.2: U.S. Geological Survey, accessed June 10, 2010, at http://water.usgs.gov/ GIS/metadata/usgswrd/XML/erf1.xml.

Alexander, R.B., Elliott, A.H., Shankar, Ude, and McBride, G.B., 2002, Estimating the sources and transport of nutrients in the Waikato River Basin, New Zealand: Water Resources Research, v. 38, p. 1268-1290, doi:10.1029/2001WR000878.

Alexander, R.B., Johnes, P.J., Boyer, E.W., and Smith, R.A., 2002, A comparison of models for estimating the riverine export of nitrogen from large watersheds: Biogeochemistry, v. $57 / 58$, p. $295-339$.

Alexander, R.B., Smith, R.A., Schwarz, G.E., Boyer, E.W., Nolan, J.V., and Brakebill, J.W., 2008, Differences in phosphorus and nitrogen delivery to the Gulf of Mexico from the Mississippi River Basin: Environmental Science and Technology, v. 42, no. 3, p. 822-830, doi:10.1021/es0716103.

Alexander, R.B., Smith, R.A., Schwarz, G.E., Preston, S.D., Brakebill, J.W., Srinivasan, Raghavan, and Pacheco, P.A., 2001, Atmospheric nitrogen flux from the watersheds of major estuaries of the United States-An application of the SPARROW watershed model, in Valigura, Richard, Alexander, Richard, Castro, Mark, Meyers, Tilden, Paerl, Hans, Stacey, Paul, and Turner, R.E., eds., Nitrogen loading in coastal water bodies-An atmospheric perspective: American Geophysical Union Monograph 57, p. 119-170.

Anning, D.W., Bauch, N.J., Gerner, S.J., Flynn, M.E., Hamlin, S.N., Moore, S.J., Schaefer, D.H., Anderholm, S.K., and Spangler, L.E., 2007, Dissolved solids in basin-fill aquifers and streams in the southwestern United States: U.S. Geological Survey Scientific Investigations Report 2006-5315, 168 p. (Superseded in 2010 by version 1.1; 
187-p. text, 11 appendixes, and interactive map available at http://pubs.usgs.gov/sir/2006/5315/.)

Armstrong, R.A., Lee, Cindy, Hedges, J.I., Honjo, Susumu, and Wakeham, S.G., 2002, A new, mechanistic model for organic carbon fluxes in the ocean based on the quantitative association of POC with ballast minerals: Deep-Sea Research, Part 2. Topical Studies in Oceanography, v. 49, p. 219-236.

Aulenbach, B.T., Buxton, H.T., Battaglin, W.A., and Coupe, R.H., 2007, Streamflow and nutrient fluxes of the Mississippi-Atchafalaya River Basin and subbasins for the period of record through 2005: U.S. Geological Survey Open-File Report 2007-1080, available only at http://pubs.usgs.gov/ of $/ 2007 / 1080 /$.

Bange, H.W., 2006, Nitrous oxide and methane in European coastal waters: Estuarine Coastal and Shelf Science, v. 70, no. 3, p. 361-374, doi:10.1016/j.ecss.2006.05.042.

Bange, H.W., Rapsomanikis, S., and Andreae, M.O., 1996, The Aegean Sea as a source of atmospheric nitrous oxide and methane: Marine Chemistry, v. 53, p. 41-49.

Barnes, J., Ramesh, R., Purvaja, R., Nirmal Rajkumar, A., Senthil Kumar, B., Krithika, K., Ravichandran, K., Uher, G., and Upstill-Goddard, R., 2006, Tidal dynamics and rainfall control $\mathrm{N}_{2} \mathrm{O}$ and $\mathrm{CH}_{4}$ emissions from a pristine mangrove creek: Geophysical Research Letters, v. 33, L15405, doi:10.1029/2006GL026829.

Bastviken, David, Cole, Jonathan, Pace, Michael, and Tranvik, Lars, 2004, Methane emissions from lakes-Dependence of lake characteristics, two regional assessments, and a global estimate: Global Biogeochemical Cycles, v. 18, GB4009, doi:10.1029/2004GB002238.

Bergamaschi, B.A., Tsamakis, E., Keil, R.G., Eglinton, T.I., Montlucon, D.B., and Hedges, J.I., 1997, The effect of grain size and surface area on organic matter, lignin and carbohydrate concentration, and molecular compositions in Peru Margin sediments: Geochimica et Cosmochimica Acta, v. 61 , no. 6 , p. $1247-1260$.

Billen, Gilles, and Garnier, Josette, 2007, River basin nutrient delivery to the coastal sea-Assessing its potential to sustain new production of non-siliceous algae: Marine Chemistry, v. 106, no. 1-2, p. 148-160, doi:10.1016/j. marchem.2006.12.017.

Blair, N.E., Leithold, E.L., and Aller, R.C., 2004, From bedrock to burial-The evolution of particulate organic carbon across coupled watershed-continental margin systems: Marine Chemistry, v. 92, no. 1-4, p. 141-156, doi:10.1016/j.marchem.2004.06.023.

Blair, N.E., Leithold, E.L., Ford, S.T., Peeler, K.A., Holmes, J.C., and Perkey, D.W., 2003, The persistence of memory-
The fate of ancient sedimentary organic carbon in a modern sedimentary system: Geochimica et Cosmochimica Acta, v. 67 , no. 1, p. 63-73, doi:10.1016/S0016-7037(02)01043-8.

Bliss, N.B., Waltman, S.W., and West, L., 2009, Detailed mapping of soil organic carbon stocks in the United States using SSURGO: EOS Transactions, v. 90, no. 52, abstract B51F-0367.

Boesch, D.F., Coles, V.J., Kimmel, D.G., and Miller, W.D., 2007, Coastal dead zones and global climate change-Ramifications of climate change for Chesapeake Bay hypoxia: Arlington, Va., Pew Center on Global Climate Change, 14 p., accessed June 16, 2010, at http://www.pewclimate.org/ docUploads/Regional-Impacts-Chesapeake.pdf.

Brakebill, J.W., and Preston, S.E., 2003, A hydrologic network supporting spatially referenced regression modeling in the Chesapeake Bay watershed: Environmental Monitoring and Assessment, v. 81, no. 1-3, p. 73-84, doi:10.1023/A:1021356420864.

Bratton, J.F., Böhlke, J.K., Krantz, D.E., and Tobias, C.R., 2009, Flow and geochemistry of groundwater beneath a back-barrier lagoon - The subterranean estuary at Chincoteague Bay, Maryland, USA: Marine Chemistry, v. 113, no. 1-2, p. 78-92, doi:10.1016/j.marchem.2009.01.004.

Bratton, J.F., Böhlke, J.K., Manheim, F.T., and Krantz, D.E., 2004, Ground water beneath coastal bays of the Delmarva Peninsula-Ages and nutrients: Ground Water, v. 42, no. 7, p. 1021-1034.

Bricker, S., Longstaff, B., Dennison, W., Jones, A., Boicourt, K., Wicks, C., and Woerner, J., 2007, Effects of nutrient enrichment in the nation's estuaries-A decade of change: National Centers for Coastal Ocean Science, Silver Spring, Md., National Oceanic and Atmospheric Administration Coastal Ocean Program Decision Analysis Series No. 26, $328 \mathrm{p}$.

Bugna, G.C., Chanton, J.P., Cable, J.E., Burnett, W.C., and Cable, P.H., 1996, The importance of groundwater discharge to the methane budgets of nearshore and continental shelf waters of the northeastern Gulf of Mexico: Geochimica et Cosmochimica Acta, v. 60, no. 23, p. 4735-4746, doi:10.1016/S0016-7037(96)00290-6.

Burdige, D.J., 2005, Burial of terrestrial organic matter in marine sediments-A re-assessment: Global Biogeochemical Cycles, v. 19, GB4011, doi:10.1029/2004GB002368.

Butler, J.H., Jones, R.D., Garber, J.H., and Gordon, L.I., 1987, Seasonal distributions and turnover of reduced trace gases and hydroxylamine in Yaquina Bay, Oregon: Geochimica et Cosmochimica Acta, v. 51, no. 3, p. 697-706, doi:10.1016/0016-7037(87)90080-9. 
Capone, D.G., 1991, Aspects of the marine nitrogen cycle with relevance to the dynamics of nitrous and nitric oxide, in Rogers, J.E., and Whitman, W.B., eds., Microbial production and consumption of greenhouse gases-Methane, nitrogen oxides, and halomethanes: Washington, D.C., American Society for Microbiology, p. 255-275.

Chanton, J.P., Martens, C.S., and Kelley, C.A., 1989, Gas transport from methane-saturated, tidal freshwater and wetland sediments: Limnology and Oceanography, v. 34, no. 5, p. 807-819.

Chapuis-Lardy, L., Wrage, N., Metay, A., Chotte, J-L., and Bernoux, M., 2007, Soils, a sink for $\mathrm{N}_{2} \mathrm{O}$ ? A review: Global Change Biology, v. 13, p. 1-17.

Chen, Shuisen, Huang, Wenrui, Wang, Hongqing, and Li, Dan, 2009, Remote sensing assessment of sediment resuspension during Hurricane Frances in Apalachicola Bay, USA: Remote Sensing of Environment, v. 113, no. 12, p. 2670-2681, doi:10.1016/j.rse.2009.08.005.

Cicerone, R.J., and Oremland, R.S., 1988, Biogeochemical aspects of atmospheric methane: Global Biogeochemical Cycles, v. 2, no. 4, p. 299-327, doi:10.1029/ GB002i004p00299.

Cohn, T.A., DeLong, L.L., Gilroy, E.J., Hirsch, R.M., and Wells, D.K., 1989, Estimating constituent loads: Water Resources Research, v. 25, no. 5, p. 937-942.

Cole, J.J., Prairie, Y.T., Caraco, N.F., McDowell, W.H., Tranvik, L.J., Striegl, R.G., Duarte, C.M., Kortelainen, R., Downing, J.A., Middelburg, J.J., and Melack, J., 2007, Plumbing the global carbon cycle-Integrating inland waters into the terrestrial carbon budget: Ecosystems, v. 10, p. 171-184, doi:10.1007/s10021-006-9013-8.

Cole, M.L., Kroeger, K.D., McClelland, J.W., and Valiela, I., 2006, Effects of watershed land use on nitrogen concentrations and $\delta^{15}$ nitrogen in groundwater: Biogeochemistry, v. 77, p. 199-215, doi:10.1007/s10533-005-1036-2.

Crusius, John, Berg, Peter, Koopmans, D.J., and Erban, Laura, 2008, Eddy correlation measurements of submarine groundwater discharge: Marine Chemistry, v. 109, no. 1-2, p. 77-85, doi:10.1016/j.marchem.2007.12.004.

Crusius, J., Koopmans, D., Bratton, J.F., Charette, M.A., Kroeger, K., Henderson, P., Ryckman, L., Halloran, K., and Colman, J.A., 2005, Submarine groundwater discharge to a small estuary estimated from radon and salinity measurements and a box model: Biogeosciences, v. 2, p. 141-157, doi:10.5194/bg-2-141-2005.

Crusius, J., Kroeger, K.D., Bratton, J.F., Erban, L., Green, A., Baldwin, S., and Sundquist, E., 2008, $\mathrm{N}_{2} \mathrm{O}$ fluxes from coastal waters due to submarine groundwater discharge: Geochimica et Cosmochimica Acta, v. 72, p. A191.
Davidson, E.A., and Ackerman, I.L., 1993, Changes in soil carbon inventories following cultivation of previously untilled soils: Biogeochemistry, v. 20, p. 161-193, doi:10.1007/BF00000786.

Dean, W.E., and Gorham, Eville, 1998, Magnitude and significance of carbon burial in lakes, reservoirs, and peatlands: Geology, v. 26, no. 6, p. 535-538.

DeFries, R.S., Houghton, R.A., Hansen, M.C., Field, C.B., Skole, David, and Townshend, John, 2002, Carbon emissions from tropical deforestation and regrowth based on satellite observations for the 1980s and 1990s: Proceedings of the National Academy of Sciences, v. 99, no. 22, p. 14256-14261, doi:10.1073/pnas.182560099.

de Wit, M.J.M., 2001, Nutrient fluxes at the river basin scale. I-The PolFlow model: Hydrological Processes, v. 15, no. 5, p. 743-759, doi:10.1002/hyp.175.abs.

Diaz, R.J., and Rosenberg, Rutger, 2008, Spreading dead zones and consequences for marine ecosystems: Science, v. 321, no., 5891, p. 926-929, doi:10.1126/science.1156401.

Downing, J.A., Cole, J.J., Middelburg, J.J., Striegl, R.G., Duarte, C.M., Kortelainen, P., Prairie, Y.T., and Laube, K.A., 2008, Sediment organic carbon burial in agriculturally eutrophic impoundments over the last century: Global Biogeochemical Cycles, v. 22, GB1018, doi:10.1029/2006GB002854.

Downing, J.A., Prairie, Y.T., Cole, J.J., Duarte, C.M., Tranvik, L.J., Striegl, R.G., McDowell, W.H., Kortelainen, P., Caraco, N.F., Melack, J.M., and Middelburg, J.J., 2006, The global abundance and size distribution of lakes, ponds, and impoundments: Limnology and Oceanography, v. 51, no. 5, p. 2388-2397.

Dunne, J.P., Armstrong, R.A., Gnanadesikan, Anand, and Sarmiento, J.L., 2005, Empirical and mechanistic models for the particle export ratio: Global Biogeochemical Cycles, v. 19, GB4026, doi:10.1029/2004GB002390.

Dunne, J.P., Sarmiento, J.L., and Gnanadesikan, Anand, 2007, A synthesis of global particle export from the surface ocean and cycling through the ocean interior and on the seafloor: Global Biogeochemical Cycles, v. 21, GB4006, doi:10.1029/2006GB002907.

Efron, Bradley, 1981, Nonparametric standard errors and confidence intervals: Canadian Journal of Statistics, v. 9, no. 2, p. 139-172.

Efron, Bradley, and Tibshirani, R.J., 1993, An introduction to the bootstrap: New York, Chapman and Hall/CRC, Monographs on Statistics and Applied Probability 57, 436 p.

Einsele, Gerhard, Yan, Jianping, and Hinderer, Matthias, 2001, Atmospheric carbon burial in modern lake basins and its significance for the global carbon budget: Global and 
Planetary Change, v. 30, no. 3-4, p. 167-196, doi:10.1016/ S0921-8181(01)00105-9.

Eswaran, Hari, Van Den Berg, Evert, and Reich, Paul, 1993, Organic carbon in soils of the world: Soil Science Society of America Journal, v. 57, p. 192-194.

Giani, Luise, and Ahrensfeld, Elke, 2002, Pedobiochemical indicators for eutrophication and the development of "black spots" in tidal flat soils on the North Sea coast: Journal of Plant Nutrition and Soil Science, v. 165, no. 4, p. 537-543.

Gnanadesikan, Anand, and Marinov, Irina, 2008, Export is not enough -Nutrient cycling and carbon sequestration: Marine Ecology Progress Series, v. 364, p. 289-294, doi:10.3354/ meps07550.

Goreau, T.J., Kaplan, W.A., Wofsy, S.C., McElroy, M.B., Valois, F.W., and Watson, S.W., 1980, Production of $\mathrm{NO}_{2}$ and $\mathrm{N}_{2} \mathrm{O}$ by nitrifying bacteria at reduced concentrations of oxygen: Applied and Environmental Microbiology, v. 40, no. 3 , p. 526-532.

Haag, Daniel, and Kaupenjohann, Martin, 2001, Landscape fate of nitrate fluxes and emissions in Central Europe-A critical review of concepts, data, and models for transport and retention: Agriculture, Ecosystems and Environment, v. 86, no. 1, p. 1-21, doi:10.1016/S0167-8809(00)00266-8.

Hales, Burke, Karp-Boss, Lee, Perlin, Alexander, and Wheeler, P.A., 2006, Oxygen production and carbon sequestration in an upwelling coastal margin: Global Biogeochemical Cycles, v. 20, GB3001, doi:10.1029/2005GB002517.

Hammond, D.E., Simpson, H.J., and Mathieu, G., 1975, Methane and radon-222 as tracers for mechanisms of exchange across the sediment-water interface in the Hudson River estuary: Marine Chemistry in the Coastal Environment, chap. 7, p. 119-132, doi:10.1021/bk-1975-0018.ch007.

Hanson, P.C., Pollard, A.I., Bade, D.L., Predick, Katie, Carpenter, S.R., and Foley, J.A., 2004, A model of carbon evasion and sedimentation in temperate lakes: Global Change Biology, v. 10, p. 1285-1298, doi:10.1111/j.13652486.2004.00805.x.

Hartnett, H.E., Keil, R.G., Hedges, J.I., and Devol, A.H., 1998, Influence of oxygen exposure time on organic carbon preservation in continental margin sediments: Nature, v. 391, p. 572-574, doi:10.1038/35351.

Hedges, J.I., and Keil, R.G., 1995, Sedimentary organicmatter preservation-An assessment and speculative synthesis: Marine Chemistry, v. 49, no. 2-3, p. 81-115, doi:10.1016/0304-4203(95)00008-F.

Hedges, J.I., Keil, R.G., and Benner, R., 1997, What happens to terrestrial organic matter in the ocean?: Organic Geochemistry, v. 27, no. 5-6, p. 195-212, doi:10.1016/S01466380(97)00066-1.
Hill, J.M., Halka, J.P., Conkwright, R., Koczot, K., and Coleman, S., 1992, Distribution and effects of shallow gas on bulk estuarine sediment properties: Continental Shelf Research, v. 12, no. 10, p. 1219-1229, doi:10.1016/02784343(92)90081-T.

Hirsch, R.M., Slack, J.R., and Smith, R.A., 1982, Techniques of trend analysis for monthly water quality data: Water Resources Research, v. 18, no. 1, p. 107-121, doi:10.1029/ WR018i001p00107.

Houghton, R.A., 2003, Revised estimates of the annual net flux of carbon to the atmosphere from changes in land use and land management: Tellus, v. 55B, no. 2, p. 378-390.

Hovland, M., Judd, A.G., and Burke, R.A., Jr., 1993, The global flux of methane from shallow marine sediments: Chemosphere, v. 26 , no. $1-4$, p. 559-578, doi:10.1016/0045-6535(93)90442-8.

Howarth, R.W., 2008, Coastal nitrogen pollution-A review of sources and trends globally and regionally: Harmful Algae, v. 8, p. 14-20.

Howarth, R.W., Billen, G., Swaney, D., Townsend, A., Jaworski, N., Lajtha, K., Downing, J.A., Elmgren, R., Caraco, N., Jordan, T., Berendse, F., Freney, J., Kudeyarov, V., Murdoch, P., and Zhu, Zhao-Liang, 1996, Regional nitrogen budgets and riverine $\mathrm{N} \& \mathrm{P}$ fluxes for the drainages to the North Atlantic Ocean-Natural and human influences: Biogeochemistry, v. 35, no. 1, p. 75-139, doi:10.1007/ BF02179825.

Intergovernmental Panel on Climate Change, 2007, Climate change 2007-The physical science basis: Cambridge, United Kingdom, and New York, Cambridge University Press, 996 p. (Also available at http://www.ipcc.ch/publications_and_data/publications_and_data_reports.htm.)

Jaworski, N.A., Howarth, R.W., and Hetling, L.I., 1997, Atmospheric deposition of nitrogen oxides onto the landscape contributes to coastal eutrophication in the northeast United States: Environmental Science and Technology, v. 31, no. 7, p. 1995-2004.

Joyce, Jennifer, and Jewell, P.W., 2003, Physical controls on methane ebullition from reservoirs and lakes: Environmental and Engineering Geoscience, v. 9, no. 2, p. 167-178, doi:10.2113/9.2.167.

Justiç, D., Rabalais, N.N., and Turner, R.E., 2003, Simulated responses of the Gulf of Mexico hypoxia to variations in climate and anthropogenic nutrient loading: Journal of Marine Systems, v. 42, no. 3, p. 115-126.

Kellogg, R.L., Lander, C.H., Moffitt, D.C., and Gollehon, Noel, 2000, Manure nutrients relative to the capacity of cropland and pastureland to assimilate nutrients-Spatial and temporal trends for the United States: U.S. Department 
of Agriculture, Natural Resources Conservation Service, Economic Research Service Publication nps00-0579, 93 p. plus appendixes, accessed June 10, 2010, at http://www. nrcs.usda.gov/technical/NRI/pubs/manntr.html.

Kitidis, Vassilis, Tizzard, Louise, Uher, Günther, Judd, Alan, Upstill-Goddard, R.C., Head, I.M., Gray, N.D., Taylor, Gillian, Durán, Ruth, Diez, Raquel, Iglesias, Jorge, García-Gil, Soledad, 2007, The biogeochemical cycling of methane in Ria de Vigo, NW Spain-Sediment processing and sea air exchange: Journal of Marine Systems, v. 66, p. 258-271.

Kogan, Irina, and Paull, C.K., 2005, Coastal seismic wipe-outs-Distribution controlled by pore water salinity: Marine Geology, v. 217, no. 1-2, p. 161-175, doi:10.1016/j.margeo.2005.02.018.

Kroeger, K.D., Bowen, J.L., Corcoran, D., Moorman, J., Michalowski, J., Rose, C., and Valiela, I., 1999, Nitrogen loading to Green Pond, Massachusetts - Sources and evaluation of management options: Environment Cape Cod, v. 2, p. 15-26.

Kroeger, K.D., and Charette, M.A., 2008, Nitrogen biogeochemistry of submarine groundwater discharge: Limnology and Oceanography, v. 53, no. 3, p. 1025-1039.

Kroeger, K.D., Cole, M.L., and Valiela, I., 2006, Groundwatertransported dissolved organic nitrogen exports from coastal watersheds: Limnology and Oceanography, v. 51, no. 5, p. $2248-2261$.

Kroeger, K.D., Cole, M.L., York, J.K., and Valiela, I., 2006, Nitrogen loads to estuaries from waste water plumesModeling and isotopic approaches: Ground Water, v. 44, no. 2, p. 188-200.

Kroeger, K.D., Swarzenski, P.W., Crusius, J., Bratton, J.F., and Charette, M.A., 2007, Submarine ground-water dischargeNutrient loading and nitrogen transformations: U.S. Geological Survey Fact Sheet 2006-3110, 4 p. (Also available at http://pubs.usgs.gov/fs/2006/3110/.)

Kroeger, K.D., Swarzenski, P.W., Greenwood, Jason, and Reich, Christopher, 2007, Submarine groundwater discharge to Tampa Bay-Nutrient fluxes and biogeochemistry of the coastal aquifer: Marine Chemistry, v. 104, p. 85-97.

LaMontagne, M.G., Duran, Robert, and Valiela, Ivan, 2003, Nitrous oxide sources and sinks in coastal aquifers and coupled estuarine receiving waters: The Science of the Total Environment, v. 309, no. 1-3, p. 139-149, doi:10.1016/ S0048-9697(02)00614-9.

Leavesley, G.H., Lichty, R.W., Troutman, B.M., and Saindon, L.G., 1983, Precipitation-runoff modeling system: U.S. Geological Survey Water-Resources Investigations Report 83-4238, 207 p.
Leithold, E.L., Perkey, D.W., Blair, N.E., and Creamer, T.N., 2005, Sedimentation and carbon burial on the northern California continental shelf-The signatures of land-use change: Continental Shelf Research, v. 25, no. 3, p. 349371, doi:101016/j.csr.2004.09.015.

Levin, L.A., Ekau, W., Gooday, A.J., Jorissen, F., Middelburg, J.J., Naqvi, W., Neira, C., Rabalais, N.N., and Zhang, J., 2009 , Effects of natural and human-induced hypoxia on coastal benthos: Biogeosciences, v. 6, p. 2063-2098.

Mann, L.K., 1985, A regional comparison of carbon in cultivated and uncultivated alfisols and millisols in the Central United States: Geoderma, v. 36, p. 241-253.

Mann, L.K., 1986, Changes in soil carbon storage after cultivation: Soil Science, v. 142, no. 5, p. 279-288, doi:10.3334/ CDIAC/tcm.007.

Martens, C.S., and Klump, J.V., 1980, Biogeochemical cycling in an organic-rich coastal marine basin-I. Methane sediment-water exchange processes: Geochimica et Cosmochimica Acta, v. 44, p. 471-490.

Masterson, J.P., Sorenson, J.R., Stone, J.R., Moran, S.B., and Hougham, Andrea, 2006, Hydrogeology and simulated ground-water flow in the Salt Pond Region of southern Rhode Island: U.S. Geological Survey Scientific Investigations Report 2006-5271, $57 \mathrm{p}$.

McIntyre, S.C., 1993, Reservoir sedimentation rates linked to long-term changes in agricultural land use: Water Resources Bulletin, v. 29, no. 3, p. 487-495.

Meade, R.H., 1982, Sources, storages and sinks of river sediment in the Atlantic drainage of the United States: Journal of Geology, v. 90, no. 3, p. 235-252.

Michmerhuizen, C.M., Striegl, R.G., and McDonald, M.E., 1996, Potential methane emission from north-temperate lakes following ice melt: Limnology and Oceanography, v. 41 , no. 5 , p. $985-991$.

Middelburg, J.J., Nieuwenhuize, J., Iversen, N., Hogh, N., de Wilde, H., Helder, W., Seifert, R., and Christof, O., 2002, Methane distribution in European tidal estuaries: Biogeochemistry, v. 59, no. 1-2, p. 95-119.

Milliman, J.D., and Syvitski, J.P.M., 1992, Geomorphic/ tectonic control of sediment discharge to the ocean-The importance of small mountainous rivers: Journal of Geology, v. 100 , p. 525-544.

Mitas, Lubos, and Mitasova, Helena, 1998, Distributed soil erosion simulation for effective erosion prevention: Water Resources Research, v. 34, p. 505-516, doi:10.1029/97WR03347.

Monti, Jack, Jr., and Scorca, M.P., 2003, Trends in nitrogen concentration and nitrogen loads entering the South Shore 
Estuary Reserve from streams and ground-water discharge in Nassau and Suffolk Counties, Long Island, New York, 1952-97: U.S. Geological Survey Water-Resources Investigations Report 02-4255, 36 p.

Moore, R.B., Johnston, C.M., Robinson, K.W., and Deacon, J.R., 2004, Estimation of total nitrogen and phosphorus in New England streams using spatially referenced regression models: U.S. Geological Survey Scientific Investigations Report 2004-5012, 42 p., accessed June 22, 2010, at http://pubs.usgs.gov/sir/2004/5012/.

Mulholland, P.J., and Elwood, J.W., 1982, The role of lake and reservoir sediments as sinks in the perturbed global carbon cycle: Tellus, v. 24, p. 490-499.

Muller-Karger, F.E., Varela, Ramon, Thunell, Robert, Luerssen, Remy, Hu, Chuanmin, and Walsh, J.J., 2005, The importance of continental margins in the global carbon cycle: Geophysical Research Letters, v. 32, L01602, doi:10.1029/2004GL021346.

Nakicenovic, Nebojsa, Alcamo, Joseph, Davis, Gerald, de Vries, Bert, Fenhann, Joergen, Gaffin, Stuart, Gregory, Kenneth, Grübler, Arnulf, Jung, T.Y., Kram, Tom, La Rovere, E.L., Michaelis, Laurie, Mori, Shunsuke, Morita, Tsuneyuki, Pepper, William, Pitcher, Hugh, Price, Lynn, Riahi, Keywan, Roehrl, Alexander, Rogner, H.-H., Sankovski, Alexei, Schlesinger, Michael, Shukla, Priyararshi, Smith, Steven, Swart, Robert, van Rooijen, Sascha, Victor, Nadejda, and Dadi, Zhou, 2000, Special report on emissions scenarios; A special report of Working Group III of the Intergovernmental Panel on Climate Change [IPCC]: Cambridge, UK, Cambridge University Press, 599 p., accessed June 14, 2010, at http://www.grida.no/publications/other/ipcc $\% 5 \mathrm{Fsr} /$ ?src=/ climate/ipcc/emission/index.htm.

Naqvi, S.W.A., Jayakumar, D.A., Narvekar., P.V., Naik, H., Sarma, V.V.S.S., D’Souza, W., Joseph, S., and George, M.D., 2000, Increased marine production of $\mathrm{N}_{2} \mathrm{O}$ due to intensifying anoxia on the Indian continental shelf: Nature, v. 408, p. 346-349, doi:10.1038/35042551.

Neftel, Albrecht, Flechard, Chris, Ammann, Christof, Conen, Franz, Emmenegger, Lukas, and Zeyer, Kerstin, 2007, Experimental assessment of $\mathrm{N}_{2} \mathrm{O}$ background fluxes in grassland systems: Tellus B, v. 59, no. 4, p. 470-482, doi:10.1111/j.1600-0889.2007.00273.x.

Nevison, C., 2000, Review of the IPCC methodology for estimating nitrous oxide emissions associated with agricultural leaching and runoff: Chemosphere - Global Change Science, v. 2, no. 3, p. 493-500, doi:10.1016/S14659972(00)00013-1.

Nevison, C.D., Lueker, T.J., and Weiss, R.F., 2004, Quantifying the nitrous oxide source from coastal upwelling: Global Biogeochemical Cycles, v. 18, GB1018, doi:10.1029/ 2003 GB002110.
Nolan, J.V., Brakebill, J.W., Alexander, R.B., and Schwarz, G.E., 2002, ERF1_2-Enhanced river reach file 2.0: U.S. Geological Survey, accessed June 10, 2010, at http://water.usgs.gov/GIS/metadata/usgswrd/XML/ erf1_2.xml.

Pacala, S.W., Hurtt, G.C., Baker, D., Peylin, P., Houghton, R.A., Birdsey, R.A., Heath, L., Sundquist, E.T., Stallard, R.F., Ciais, P., Moorcroft, P., Caspersen, J.P., Shevliakova, E., Moore, B., Kohlmaier, G., Holland, E., Gloor, M., Harmon, M.E., Fan, S.-M., Sarmiento, J.L., Goodale, C.L., Schimel, D., and Field, C.B., 2001, Consistent land- and atmosphere-based U.S. carbon sink estimates: Science, v. 292, no. 5525, p. 2316-2320, doi:10.1126/science. 1057320 .

Paul, E.A., Paustian, K.A., Elliott, E.T., and Cole, C.V., 1997, Soil organic matter in temperate agroecosystems - Longterm experiments in North America: Boca Raton, Fla., CRC Press, $432 \mathrm{p}$.

Peierls, B.L., Caraco, N.F., Pace, M.L., and Cole, J.J., 1991, Human influence on river nitrogen: Nature, v. 350, p. 386-387, doi:10.1038/350386b0.

Post, W.M., Emanuel, W.R., Zinke, P.J., and Stangenberger, A.G., 1982, Soil carbon pools and world life zones: Nature, v. 298, p. 156-159.

Preston, S.D., and Brakebill, J.W., 1999, Application of spatially referenced regression modeling for the evaluation of total nitrogen loading in the Chesapeake Bay Watershed: U.S. Geological Survey Water-Resources Investigations Report 99-4054, 12 p., accessed June 22, 2010, at http://md.water.usgs.gov/publications/wrir-99-4054/.

Priscu, J.C., Downes, M.T., and McKay, C.P., 1996, Extreme supersaturation of nitrous oxide in a non-ventilated Antarctic lake: Limnology and Oceanography, v. 41, no. 7, p. 1544-1551.

Puri, Deepti, Karthikeyan, R., and Babbar-Sebens, M., 2009, Predicting the fate and transport of E.coli in two Texas river basins using a spatially referenced regression model: Journal of the American Water Resources Association, v. 45, no. 4, p. 928-944, doi:10.1111/j.1752-1688.2009.00337.x.

Rabouille, C., Conley, D.J., Dai, M.H., Cai, W.-J., Chen, C.T.A., Lansard, B., Green, R., Yin, K., Harrison, P.J., Dagg, M., and McKee, B., 2008, Comparison of hypoxia among four river-dominated ocean margins - The Changjiang (Yangtze), Mississippi, Pearl, and Rhône rivers: Continental Shelf Research, v. 28, no. 12, p. 1527-1537, doi:10.1016/j.csr.2008.01.020.

Raich, J.W., and Schlesinger, W.H., 1992, The global carbon-dioxide flux in soil respiration and its relationship to vegetation and climate: Tellus, Series B-Chemi- 
cal and Physical Meteorology, v. 44B, no. 2, p. 81-99, doi:10.1034/j.1600-0889.1992.t01-1-00001.x

Rajkumar A.N., Barnes, J., Ramesh, R., Purvaja, R., and Upstill-Goddard, R.C., 2008, Methane and nitrous oxide fluxes in the polluted Adyar River and estuary, SE India: Marine Pollution Bulletin, v. 56, no. 12, p. 2043-2051, doi:10.1016/j.marpolbul.2008.08.005.

Randerson, J.T., Chapin, F.S., III, Harden, J.W., Neff, J.C., and Harmon, M.E., 2002, Net ecosystem production-A comprehensive measure of net carbon accumulation by ecosystems: Ecological Applications, v. 12, no. 4, p. 937-947, doi:10.1890/1051-0761(2002)012[0937:NEPACM]2.0.CO;2.

Renwick, W.H., Smith, S.V., Bartley, J.D., and Buddemeier, R.W., 2005, The role of impoundments in the sediment budget of the conterminous United States: Geomorphology, v. 71, no. 1-2, p. 99-111.

Ritchie, J.C., 1989, Carbon content of sediments of small reservoirs: Water Resources Bulletin, v. 25, p. 301-308.

Roberts, A.D., and Prince, S.D., 2010, Effects of urban and non-urban land cover on nitrogen and phosphorus runoff to Chesapeake Bay: Ecological Indicators, v. 10, no. 2, p. 459-474, doi:10.1016/j.ecolind.2009-07-017.

Roberts, A.D., Prince, S.D., Jantz, C.A., and Goetz, S.J., 2009, Effects of projected future urban land cover on nitrogen and phosphorus runoff to Chesapeake Bay: Ecological Engineering, v. 35, no. 12, p. 1758-1772, doi:10.1016/j. ecolong.2009.09.001.

Robertson, D.M., Schwarz, G.E., Saad, D.A., and Alexander, R.B., 2009, Incorporating uncertainty into the ranking of SPARROW model nutrient yields from Mississippi/Atchafalaya River Basin Watersheds: Journal of the American Water Resources Association, v. 45, no. 2, p. 534-549.

Ronen, Daniel, Magaritz, Mordeckai, and Almon, Ehud, 1988, Contaminated aquifers are a forgotten component of the global $\mathrm{N}_{2} \mathrm{O}$ budget: Nature, v. 335, no. 6185, p. 57-59.

Ruddy, B.C., Lorenz, D.L., and Mueller, D.K., 2006, Countylevel estimates of nutrient inputs to the land surface of the conterminous United States, 1982-2001: U.S. Geological Survey Scientific Investigations Report 2006-5012, 17 p., accessed June 10, 2010, at http://pubs.usgs.gov/ $\operatorname{sir} / 2006 / 5012 /$.

Runkel, R.L., Crawford, C.G., and Cohn, T.A., 2004, LOAD ESTimator (LOADEST) - A FORTRAN program for estimating constituent loads in streams and rivers: U.S. Geological Survey Techniques and Methods, book 4, chap. A5, 69 p., accessed June 16, 2010, at http://pubs.water.usgs.gov/tm4a5.

Sanford, W.E., Pope, J.P., and Nelms, D.L., 2008, Simulation of groundwater-level and salinity changes in the Eastern
Shore, Virginia: U. S. Geological Survey Scientific Investigations Report 2009-5066, 125 p.

Santos, I.R., Dimova, Natasha, Peterson, R.N., Mwashote, Benjamin, Chanton, Jeffrey, and Burnett, W.C., 2009, Extended time series measurements of submarine groundwater discharge tracers $\left({ }^{222} \mathrm{Rn}\right.$ and $\left.\mathrm{CH}_{4}\right)$ at a coastal site in Florida: Marine Chemistry, v. 113, no. 1-2, p. 137-147, doi:10.1016/j.marchem.2009.01.009.

Sarmiento, J.L., and Gruber, Nicolas, 2002, Sinks for anthropogenic carbon: Physics Today, v. 55, no. 8, p. 30-36.

Sarmiento, J.L., and Gruber, Nicolas, 2006, Ocean biogeochemical dynamics: Princeton University Press, 503 p.

Savvichev, A.S., Rusanov, I.I., Yusupov, S.K., Pimenov, N.V., Lein, A.Y., and Ivanov, M.V., 2004, The biogeochemical cycle of methane in the coastal zone and littoral of the Kandalaksha Bay of the White Sea: Microbiology, v. 73, no. 4, p. $457-468$.

Schwarz, G.E., 2008, A preliminary SPARROW model of suspended sediment for the conterminous United States: U.S. Geological Survey Open-File Report 2008-1205, 8 p., available only online at http://pubs.usgs.gov/of/2008/1205.

Schwarz, G.E., Hoos, A.B., Alexander, R.B., and Smith, R.A., 2006, The SPARROW surface water-quality model-Theory, application, and user documentation: U.S. Geological Survey Techniques and Methods, book 6, chap. B3, 248 p., available only at http://pubs.usgs.gov/tm/2006/tm6b3/.

Scorca, M.P., and Monti, Jack, Jr., 2001, Estimates of nitrogen loads entering Long Island Sound from ground water and streams on Long Island, New York, 1985-96: U.S. Geological Survey Water-Resources Investigations Report 00-4196, $29 \mathrm{p}$.

Seaber, P.R., Kapinos, F.P., and Knapp, G.L., 1987, Hydrologic unit maps: U.S. Geological Survey Water-Supply Paper 2294, 63 p., 1 oversize plate. (All but the plate also available at http://pubs.usgs.gov/wsp/wsp2294/.)

Seitzinger, S.P., and Giblin, A.E., 1996, Estimating denitrification in North Atlantic continental shelf sediments: Biogeochemistry, v. 35, no. 1, p. 235-260.

Seitzinger, S.P., Harrison, J.A., Dumont, Egon, Beusen, A.H.W., and Bouwman, A.F., 2005, Sources and delivery of carbon, nitrogen, and phosphorus to the coastal zone: An overview of Global Nutrient Export from Watersheds (NEWS) models and their applications: Global Biogeochemical Cycles, v. 19, GB4S01, doi:10.1029/2005GB002606.

Seitzinger, S.P., and Kroeze, Carolien, 1998, Global distribution of nitrous oxide production and $\mathrm{N}$ inputs in freshwater and coastal marine ecosystems: Global Biogeochemical Cycles, v. 12, no. 1, p. 93-113, doi:10.1029/97GB03657. 
Seitzinger, S.P., and Mayorga, Emilio, 2008, Linking watersheds to coastal systems - A global perspective on river inputs of N, P and C: Ocean Carbon and Biogeochemistry News, v. 1, no. 1, p. 8-11. (Also available at http://www. us-ocb.org/publications/OCB_NEWS_APR08.pdf.)

Seitzinger, S.P., and Nixon, S.W., 1985, Eutrophication and the rate of denitrification and $\mathrm{N}_{2} \mathrm{O}$ production in coastal marine sediments: Limnology and Oceanography, v. 30, no. 6, p. 1332-1339.

Seitzinger, S.P., Nixon, S.W., and Pilson, M.E.Q., 1984, Denitrification and nitrous oxide production in a coastal marine ecosystem: Limnology and Oceanography, v. 29, p. 73-83.

Seitzinger, S.P., Styles, R.V., Boyer, E.W., Alexander, R.B., Billen, Gilles, Howarth, R.W., Mayer, Bernhard, and van Breemen, Nico, 2002, Nitrogen retention in rivers-Model development and application to watersheds in the eastern United States: Biogeochemistry, v. 57-58, no. 1, p. 199237, doi:10.1023/A:101574569794.

Shalini, A., Ramesh, R., Purvaja, R., and Barnes, J., 2006, Spatial and temporal distribution of methane in an extensive shallow estuary, south India: Journal of Earth System Science, v. 115, no. 4, p. 451-460.

Slomp, C.P., and Van Capellen, Philippe, 2004, Nutrient inputs to the coastal ocean through submarine groundwater discharge - Controls and potential impact: Journal of Hydrology, v. 295, no. 1-4, p. 64-86.

Smith, R.A., Alexander, R.B., and Schwarz, G.E., 2003, Estimating the natural background concentrations of nutrients in streams and rivers of the conterminous United States: Environmental Science and Technology, v. 37, no. 14, p. 3039-3047, doi:10.1021/es020663b.

Smith, S.V., Renwick, W.H., Bartley, J.D., and Buddemeier, R.W., 2002, Distribution and significance of small, artificial water bodies across the United States landscape: The Science of the Total Environment, v. 299, no. 1-3, p. 21-36.

Smith, S.V., Renwick, W.H., Buddemeier, R.W., and Crossland, C.J., 2001, Budgets of soil erosion and deposition for sediments and sedimentary organic carbon across the conterminous United States: Global Biogeochemical Cycles, v. 15 , no. 3, p. 697-707.

Smith, S.V., Sleezer, R.O., Renwick, W.H., and Buddemeier, R.W., 2005, Fates of eroded soil organic carbon-Mississippi basin case study: Ecological Applications, v. 15, no. 6, p. 1929-1940, doi:10.1890/05-0073.

St. Louis, V.L., Kelley, C.A., Duchemin, E., Rudd, J.W.M., and Rosenberg, D.M., 2000, Reservoir surfaces as sources of greenhouse gases to the atmosphere-A global estimate: BioScience, v. 50, p. 766-775.
Stallard, R.F., 1998, Terrestrial sedimentation and the C cycle-Coupling weathering and erosion to carbon storage: Global Biogeochemical Cycles, v. 12, p. 231-257.

Striegl, R.G., Dornblaser, M.M., Aiken, G.R., Wickland, K.P., and Raymond, P.A., 2007, Carbon export and cycling by the Yukon, Tanana, and Porcupine Rivers, Alaska, 20012005: Water Resources Research, v. 43, no. 2, W02411, doi:10.1029/2006WR005201.

Sundquist, E.T., 1993, The global carbon dioxide budget: Science, v. 259, no. 5097, p. 934-941.

Sundquist, Eric, Burruss, Robert, Faulkner, Stephen, Gleason, Robert, Harden, Jennifer, Kharaka, Yousif, Tieszen, Larry, and Waldrop, Mark, 2008, Carbon sequestration to mitigate climate change: U.S. Geological Survey Fact Sheet 2008-3097, 4 p. (Also available at http://pubs.usgs.gov/ fs/2008/3097/.)

Swarzenski, P.W., Reich, Chris, Kroeger, K.D., and Baskaran, Mark, 2007, Ra and Rn isotopes as natural tracers of submarine groundwater discharge in Tampa Bay, Florida: Marine Chemistry, v. 104, no. 1-2, p. 69-84, doi:10.1016/j. marchem.2006.08.001.

Syvitski, J.P.M., Vörösmarty, C.J., Kettner, A.J., and Green, Pamela, 2005, Impact of humans on the flux of terrestrial sediment to the global coastal ocean: Science, v. 308, no. 5720, p. 376-380, doi:10.1126/science.1109454.

Telmer, K.H., and Costa, M.P.F., 2007, SAR-based estimates of the size distribution of lakes in Brazil and Canada-A tool for investigating carbon in lakes: Aquatic Conservation, v. 17 , no. 3 , p. 289-304.

Thunell, Robert, Benitez-Nelson, Claudia, Varela, Ramon, Astor, Yrene, and Muller-Karger, Frank, 2007, Particulate organic carbon fluxes along upwelling-dominated continental margins - Rates and mechanisms: Global Biogeochemical Cycles, v. 21, GB1022, 12 p., doi:10.1029/2006GB002793.

Tranvik, L.J., Downing, J.A., Cotner, J.B., Loiselle, S.A., Striegl, R.G., Ballatore, T.J., Dillon, Peter, Finlay, Kerri, Fortino, Kenneth, Knoll, L.B., Kortelainen, P.L., Kuster, Tiit, Larsen, Soren, Laurion, Isabelle, Leech, D.M., McCallister, S.L., McKnight, D.M., Melack, J.M., Overholt, Erin, Porter, J.A., Prairie, Yves, Renwick, W.H., Roland, Fabio, Sherman, B.S., Schindler, D.W., Sobek, Sebastian, Tremblay, Alain, Vanni, M.J., Verschoor, A.M., von Wachenfeldt, Eddie, and Weyhenmeyer, G.A., 2009, Lakes and reservoirs as regulators of carbon cycling and climate: Limnology and Oceanography, v. 54, no. 6, part 2, p. 2298-2314.

Trefry, J.H., Metz, Simone, Nelson, T.A., Trocine, R.P., and Eadie, B.J., 1994, Transport of particulate organic carbon by the Mississippi River and its fate in the Gulf of Mexico: Estuaries, v. 17, no. 4, p. 839-849. 
U.S. Climate Change Science Program, 2007, The first state of the carbon cycle report (SOCCR)-The North American carbon budget and implications for the global carbon cycle (King, A.W., Dilling, Lisa, Zimmerman, G.P., Fairman, D.M., Houghton, R.A., Marland, Gregg, Rose, A.Z., and Wilbanks, T.J., eds.): National Oceanic and Atmospheric Administration, National Climatic Data Center, 242 p., accessed June 14, 2010, at http://www.climatescience.gov/ Library/sap/sap2-2/final-report/default.htm.

U.S. Geological Survey, 2010a, Hydrologic unit maps: U.S. Geological Survey, accessed June 16, 2010, at http://water.usgs.gov/GIS/huc.html.

U.S. Geological Survey, 2010b, Load estimator (LOADEST) - A program for estimating constituent loads in streams and rivers: U.S. Geological Survey, accessed June 16, 2010, at http://water.usgs.gov/software/loadest/.

U.S. Geological Survey, 2010c, MODFLOW and related programs: U.S. Geological Survey, accessed June 16, 2010, at http://water.usgs.gov/nrp/gwsoftware/modflow.html.

U.S. Geological Survey, 2010d, PRMS—Precipitation-runoff modeling system: U.S. Geological Survey, accessed June 16, 2010, at http://water.usgs.gov/software/PRMS/.

U.S. Geological Survey, 2010e, SPARROW surface waterquality modeling: U.S. Geological Survey, accessed June 16, 2010, at http://water.usgs.gov/nawqa/sparrow/.

U.S. Geological Survey, 2010f, USGS water data for the nation: U.S. Geological Survey, accessed June 16, 2010, at http://waterdata.usgs.gov/nwis.
Valiela, I., Collins, G., Kremer, J., Lajtha, K., Geist, M., Seely, M., Brawley, J., and Sham, C.H., 1997, Nitrogen loading from coastal watersheds to receiving estuaries-New method and application: Ecological Applications, v. 7, no. 2, p. $358-380$.

Valiela, Ivan, Geist, Margaret, McClelland, James, and Tomasky, Gabrielle, 2000, Nitrogen loading from watersheds to estuaries - Verification of the Waquoit Bay nitrogen loading model: Biogeochemistry, v. 49, no. 3, p. 277-293.

Vörösmarty, C.J., Meybeck, Michael, Fekete, Balázs, Sharma, Keshav, Green, Pamela, and Syvitski, J.P.M., 2003, Anthropogenic sediment retention-Major global impact from registered river impoundments: Global and Planetary Change, v. 39, p. 169-190.

Wetzel, R.G., 1990, Land-water interfaces-Metabolic and limnological regulators: Verhandlungen der Internationalen Vereinigung für Theoretische und Angewandte Limnologie, v. 24, p. 6-24.

Wetzel, R.G., 2001, Limnology_Lake and river ecosystems: Academic Press, 1006 p.

Wuebbles, D.J., and Hayhoe, K., 2002, Atmospheric methane and global change: Earth-Science Reviews, v. 57, no. 3-4, p. 177-210, doi:10.1016/S0012-8252(01)00062-9. 
This page intentionally left blank. 


\section{Appendix F. Methods for Analyzing Ecosystem Services and Benefits and Costs of Mitigation Activities}

The assessment results will be important to a broad range of users to help quantify potential effects and effectiveness of mitigation strategies (land-use and land-cover change, land-management activities), ancillary effects on ecosystem services, and associated economic and social costs for carbon sequestration and reduction of greenhouse-gas emissions. This appendix includes additional material on quantifying ecosystem services and estimating the present value of the benefits of those services and costs of a management activity.

\section{F.1. Ecosystem Services}

Quantifying and projecting changes in carbon stocks and greenhouse-gas (GHG) emissions resulting from climate change, management actions, and mitigation strategies will be based on the spreadsheet and the General Ensemble Modeling System (GEMS) approaches described in section 3.3.4 and appendix D of this report. Many of these primary assessment data products also can be categorized as ecosystem services, including carbon stocks in soils and vegetation, carbon sequestration, methane and nitrous-oxide emissions, net ecosystem production (NEP), timber production, grain production, and soil erosion. These ecosystem service estimates can be produced for each ecoregion reporting unit because they will be based on the primary assessment data products.

For other services not produced within the GEMS biogeochemical models or spreadsheets, the assessment will use an integrated ecosystem modeling approach (Starfield and Chapin, 1996) to quantify the ancillary effects of management activities and mitigation strategies on important ecosystem services. This approach builds on the state-transition model concept by linking conceptual, statistical, and mechanistic models in a spatially explicit framework. The modeling and data components contained within the framework of the integrated ecosystem services model use "forcasting scenarios of land cover change" (FORE-SCE) outputs as the initial basis for the spatial distribution of land use and land cover (LULC) in a given landscape. Biophysical production functions are constructed from known relations between the LULC class ecosystem attributes and the relevant ecosystem services (Nelson and others, 2008, 2009). For wildlife habitat, habitat-suitability index methods will be used wherein the composition and structure at the site and landscape scales control the amount and quality of suitable habitat for a given species or guild (Wakely and Roberts, 1996; Villard and others, 1998; Tirpak and others, 2009). Because forest-stand composition and structure is correlated with habitat suitability, growth and yield models such as the Forest Vegetation Simulator (FVS) (Crookston and Dixon 2005, Chivoiu and others, 2006) and the Forest Landscape Disturbance and Succession Model (LANDIS-II) model (He and others, 2005) are two that will be used. Site-occupancy modeling (MacKenzie and others, 2006) accounts for variation in detection probability and produces robust estimates of the proportion of area occupied (PAO) for specific species. For a service like waterfowl habitat, values can be computed as a function of the energy values of different crops (mapped according to U.S. Department of Agriculture's (USDA) National Agricultural Statistical Service (NASS) program) and vegetation types and converted into duck energy days (DEDs, the amount of energy required by one mallard-size duck for one day) (Kross and others, 2006).

Other services, such as sediment and nutrient retention, require data on relevant driver-stressor relations, which can be derived from current research, primary scientific literature, and expert workshops. The widely used Soil and Water Assessment Tool (SWAT) can be used to estimate the land-phase processes (for example, surface runoff, soil erosion, nonpointsource nutrient loss, groundwater recharge, and base flow) and water-phase processes (for example, water routing, sediment transport, and nutrient transport and its fate in the aquatic systems). GEMS will link with SWAT to assess the climatechange effects on water availability, and sediment and nutrient transport over landscape.

A distributed geospatial-model-sharing platform will be used to model ecosystem services and provide decision support (fig. F1). This platform is necessary to facilitate sharing and integrating geospatial disciplinary models. A platform based on Java Platform Enterprise Edition (J2EE) and opensource geospatial libraries (Feng and others, 2009) is in development. Shared models on the platform can be accessible to applications through the Internet using the Open Geospatial Consortium (OGC) Web Processing Service (WPS) standard (fig. F2). A pilot platform, EcoServ, was developed in the Prairie Pothole Region (PPR) to simulate diverse ecosystem services simultaneously at the landscape scale.

Given the need to have regionally specific information and the limited understanding of the complex relations among ecosystem processes, management actions, climate change, and ecosystem services, this part of the assessment will be limited to case studies within selected ecoregional assessment units where data and models have been developed and can be readily incorporated into the assessment framework. Likely areas include the Mississippi Alluvial Valley, Prairie Pothole Region, southern Florida, and the Chesapeake Bay Basin.

\section{F.2. Costs and Benefits}

The present value of the benefits (PVB) of a management activity are entered into the formula for calculating the present value of benefits in equation F1. Carbon sequestration is assumed to start accruing in the $10^{\text {th }}$ year of the activity. All 

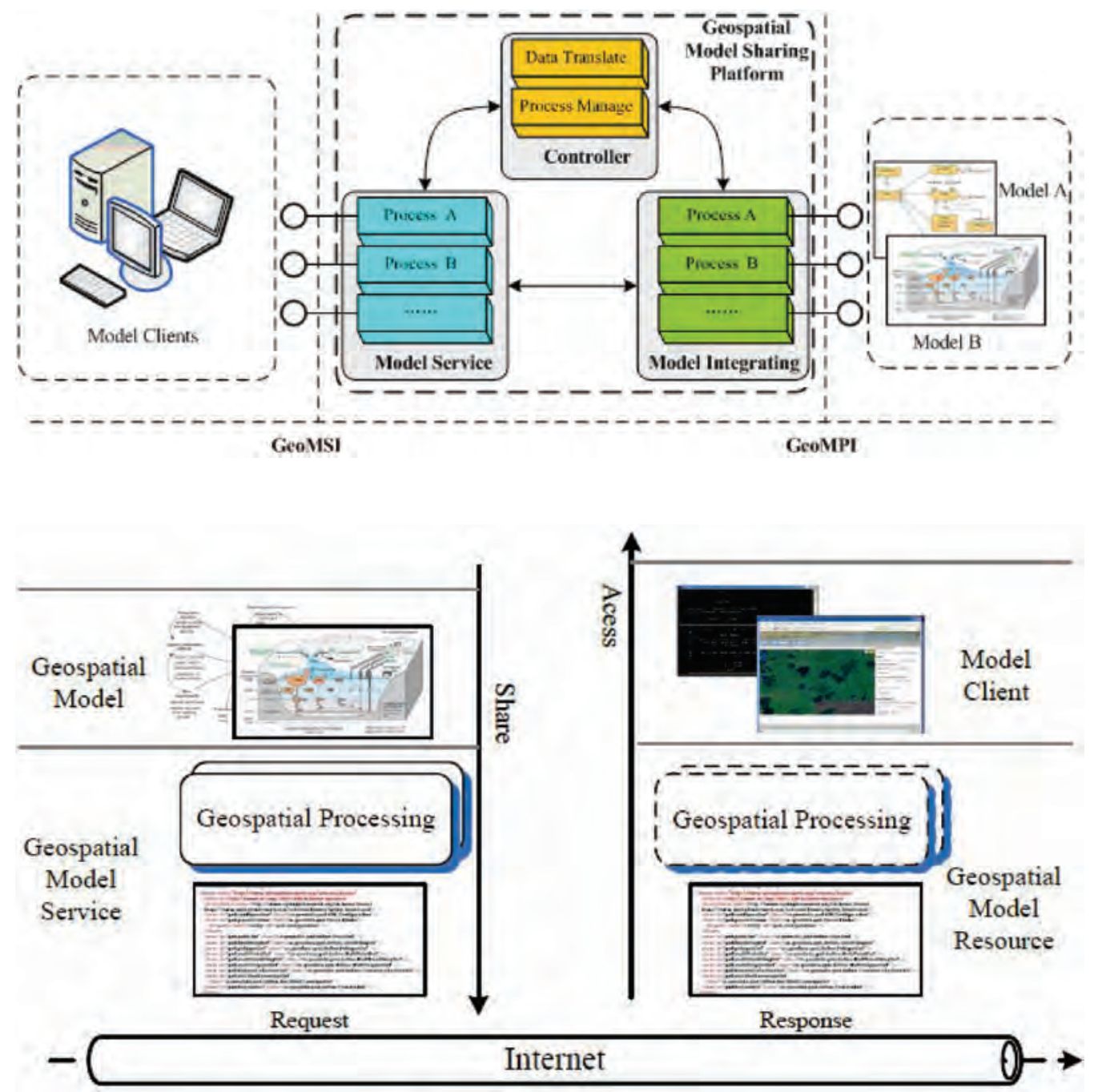

Figure F1. Diagram showing the system structure of the geospatial-model-sharing platform. GeoMSI, geospatial model service interface; GeoMPI, geospatial model processing interface.
Figure F2. Conceptual flow diagram of accessing shared geospatial model. other benefits begin in year 1 of the activity or 1 year after the initial investment in establishing the activity.

$$
P V B=\sum_{t=1}^{T} \frac{B_{t}}{(1+r)^{t}}
$$

where

$$
\begin{array}{cl}
t & \text { is time, } \\
T & \text { is the terminal year for the mitigation activity, } \\
r & \text { is a discount rate, and } \\
B & \text { is the gross ecosystem service benefits } \\
& \text { associated with a management activity. }
\end{array}
$$

Present value cost (PVC, equation F2) of management activities is the discounted sum of land value, variable costs of production (McKenney and others, 2004), and the equivalent annual cost (EAC, equation F3) values for the time horizon of the analysis (Stavins and Richards, 2005). Estimation of the PVC and EAC use the following equations. PVC in equation F2 represents the formulation of the present value of the economic costs of a sequestration mitigation activity:

$$
P V C=\sum_{t=0}^{T} \frac{P C_{t}}{(1+r)^{t}},
$$

where PC is $C_{E s t}+C_{O \& M}+C_{M G M T}$,

$t \quad$ is time,

$T \quad$ is the terminal year for the mitigation activity,

$r$ is a discount rate,

$C_{E s t} \quad$ are periodically recurring capital costs, including annual land rental payments and other initial investment costs required in establishing the management activity,

$C_{\text {O\&M }}$ are annual operating and maintenance costs of the activity with time, and

$C_{M G M T}$ are annual and periodic management costs including administration, insurance, and other transaction costs.

Possible local combinations of soil quality and other land characteristics (nutrients, moisture, composition), access from roads, slope, aspect, water availability (precipitation, irrigation), plants (type, density, composition) can affect the costs of specific management activities. The data used in estimating the present value of costs are listed in table F1. These establishment and continuing costs occur at different times during the lifetime of a management activity. 
The $\mathrm{EAC}$ in equation $\mathrm{F} 3$ is a conversion of the PVC into an annual value (Stavins and Richards, 2005):

$$
E A C=P V C \times\left[\frac{r}{1-(1+r)^{-T}}\right],
$$

The stumpage value is estimated as follows:

$$
\begin{gathered}
W_{M g(\text { timber }) / h a}=W_{C / h a} \times 2, \\
W_{M g(\text { timber }) / h a}^{\text {Change }}=W_{M g(\text { timber }) / h a}^{E N H}-W_{M g(\text { timber }) / h a}^{R E F} \\
W_{M g \text { (timber })}^{\text {Change }}=W_{M g(\text { timber }) / h a}^{\text {Change }} \times \text { hectares, } \\
W_{\text {Tons(timber })}^{\text {Chane }}=W_{M g(\text { timber })}^{\text {Change }} \times 0.907, \\
V_{\text {timber }}=W_{\text {Tons (timber })}^{\text {Chane }} \times \$ / \text { ton }, \text { and }
\end{gathered}
$$

where $W_{C h a}$

$W_{\text {Mg(timber) } / h a}$ is the weight of timber in megagrams $W_{\text {REF }}^{R E F} \quad$ per hectare,

$W_{M g(t i m b e r) / h a}$ is the weight of timber in megagrams $W^{E N H} \quad$ per hectare for the reference case, $W_{M g(t i m b e r) / h a}$ is the weight of timber in megagrams ${ }_{W}$ Change per hectare for the enhanced case, $W_{M g(t i m b e r) / h a}$ is the change in weight of timber in megagrams per hectare from the $W_{\text {Change }}$ reference case to the enhanced case, $W_{M g(t i m b e r)}$ is the total weight change for the areal $W_{\text {Change unit, }}$ Tons(timber) is the total tons of the change for the areal unit,

\$/ton is the price of the timber commodity,

\begin{tabular}{|c|c|c|c|}
\hline $\begin{array}{l}\text { Mitigation } \\
\text { activity }\end{array}$ & Establishment (one-time costs) & Periodic & Annual \\
\hline $\begin{array}{l}\text { Afforestation, } \\
\text { hardwood }\end{array}$ & $\begin{array}{l}\text { Land }^{\mathrm{a}}(\text { fee simple if purchased) } \\
\text { Saplings and planting }=\$ 209 / \mathrm{ha} \\
\text { Site preparation }=\$ 145 / \mathrm{ha} \\
\text { Supervision }=\$ 109 / \mathrm{ha}\end{array}$ & $\begin{array}{l}\text { Herbicide application one time per year for } \\
5 \text { years }=\$ 72 / \text { ha } \\
\text { Management update every } 10 \text { years }=\$ 38 / \mathrm{ha} \\
\text { Boundary maintenance every } 10 \text { years }=\$ 8 / \mathrm{ha}\end{array}$ & $\begin{array}{l}\text { Land rental price }=\$ 77 \mathrm{per} \text { ha/yr } \\
\text { Measuring, monitoring and } \\
\text { administration (for example, } \\
\text { insurance) } \\
\quad=\$ 4 \text { per ha/yr. }\end{array}$ \\
\hline Grazing & & & $\begin{array}{l}\text { Land rental price (or mortgage } \\
\text { payments) }=\$ 77 \text { per ha/yr. } \\
\text { Management and administration } \\
\quad=\$ 37 \text { per ha/yr. }\end{array}$ \\
\hline $\begin{array}{l}\text { No-till agricul- } \\
\quad \text { ture }\end{array}$ & & & $\begin{array}{l}\text { Annuity payment }=\$ 22 \text { per ha/ } \\
\text { yr }-\$ 48 \text { per ha/yr. }\end{array}$ \\
\hline
\end{tabular}
and

$V_{\text {timber }} \quad$ is the economic value of the timber.

Table F1. Establishment and other capital and operating costs for management activities in U.S. Environmental Protection Agency Level III ecoregions 73 (Mississippi Alluvial Plain) and 74 (Mississippi Valley Loess Plains) (modified from Omernik, 1987; Omernik, 2004).

[Source: Huang and others, 2004; Brown and others, 2005; U.S. Department of Agriculture, 2010. ha, hectares; ha/yr, hectares per year]

${ }^{a}$ Land could be purchased through annual mortgage payments. 


\section{F.3. References Cited}

[Reports that are only available online may require a subscription for access.]

Brown, Sandra, Delaney, M., Dushku, A., Howley, B., Moore, N., Pearson, T., Qi, Y., Shoch, D., Slaymaker, D., and Vancurova, I., 2005, Carbon supply for the pilot regionArkansas, Louisiana, and Mississippi: Arlington, Va., Winrock International, $71 \mathrm{p}$.

Chivoiu, Bogdan, Shao, Guofan, Moser, John, and Mills, W.L., 2006, ArcFVS - An integration of a geographic information system and forest vegetation simulator: Science in China Series E, Technological Sciences, v. 49, no. 1, p. 35-44, doi:10.1007/s11431-006-8105-1.

Crookston, N.L., and Dixon, G.E., 2005, The forest vegetation simulator-A review of its structure, content, and applications: Computers Electronics Agriculture, v. 49, no. 1, p. 60-80.

He, H.S., Li, Wei, Sturtevant, B.R., Yang, Jian, Shang, B.Z., Gustafson, E.J., and Mladenoff, D.J., 2005, LANDIS 4.0 users guide. LANDIS - A spatially explicit model of forest landscape disturbance, management, and succession: U.S. Department of Agriculture, Forest Service, North Central Research Station, General Technical Report NC-263, 93 p., accessed June 21, 2010, at http://nrs.fs.fed.us/pubs/3603.

Huang, C.-H., Bates, Richard, Kronrad, G.D., and Cheng, Shiaolin, 2004, Economic analyses of sequestering carbon in loblolly pine, cherrybark oak, and northern red oak in the United States: Environmental Management, v. 33, supplement 1, p. S187-S199, accessed June 21, 2010, at http:/www.springerlink.com/content/vcwpkaj0bx2lbge6/ fulltext.pdf.

Kross, Jennifer, Kaminski, R.M., Reinecke, K.J., Penny, E.J., and Pearse, A.T., 2006, Moist-soil seed abundance in managed wetlands in the Mississippi Alluvial Valley: Journal of Wildlife Management, v. 72, no. 3, p. 707-714.

MacKenzie, Darryl, Nichols, James, Royle, J., Pollock, Kenneth, Bailey, Larissa, and Hines, James, 2006, Occupancy estimation and modeling-Inferring patterns and dynamics of species occurrence: Burlington, Mass., Academic Press, $344 \mathrm{p}$.

McKenney, D.W., Yemshanov, Denys, Fox, Glenn, and Ramlal, Elizabeth, 2004, Cost estimates for carbon sequestration from fast growing poplar plantations in Canada: Forest Policy and Economics, v. 6, no. 3-4, p. 345-358, doi:10.1016/j.forpol.2004.03.010.
Nelson, Erik, Mendoza, Guillermo, Regetz, James, Polasky, Stephen, Tallis, Heather, Cameron, D.R., Chan, K.M., Daily, G.C., Goldstein, Joshua, Kareiva, P.M., Lonsdorf, Eric, Naidoo, Robin, Ricketts, T.H., and Shaw, M.R., 2009, Modeling multiple ecosystem services, biodiversity conservation, commodity production, and tradeoffs at landscape scales: Frontiers in Ecology and the Environment, v. 7, no. 1, p. 4-11, doi:10.1890/080023.

Nelson, Erik, Polasky, Stephen, Lewis, D.J., Plantinga, A.J., Lonsdorf, Eric, White, Denis, Bail, David, and Lawler, J.J., 2008, Efficiency of incentives to jointly increase carbon sequestration and species conservation on a landscape: Proceedings of the National Academy of Sciences, v. 105, no. 28, p. 9471-9476, doi:10.1073/pnas.0706178105.

Omernik, J.M., 1987, Ecoregions of the conterminous United States: Annals of the Association of American Geographers, v. 77 , no. 1, p. 118-125.

Omernik, J.M., 2004, Perspectives on the nature and definition of ecological regions: Environmental Management, v. 34, Supplement 1, p. S27-S38, doi:10.1007/ s00267-003-5197-2.

Starfield, A.M., and Chapin, F.S., III, 1996, Model of transient changes in arctic and boreal vegetation in response to climate and land use change: Ecological Applications, v. 6, no. 3, p. 842-864, doi:10.2307/2269489.

Tirpak, J.M., Jones-Farrand, D.T., Thompson, F.R., III, Twedt, D.J., Baxter, C.K., Fitzgerald. J.A., and Uihlein, W.B., III, 2009, Assessing ecoregional-scale habitat suitability index models for priority landbirds: Journal of Wildlife Management, v. 73, no. 8, p. 1307-1315, accessed June 21, 2010, at http://hdl.handle.net/10113/36183.

Stavins, Robert, and Richards, Kenneth, 2005, The cost of forest-based carbon sequestration: Arlington, Va., Pew Center on Global Climate Change, $52 \mathrm{p}$.

U.S. Department of Agriculture, 2010, Quick Stats - 2007 census of agriculture: U.S. Department of Agriculture, accessed June 9, 2010, at http://151.121.3.59/?source desc=CCROP\&commodity_desc=RENT.

Villard, M.A., Schmidt, E.V., and Maurer, B.A., 1998, Contribution of spatial modeling to avian conservation, in Marzluff, J.M., and Sallabanks, Rex, eds., Avian conservation-Research and management: Washington, D.C., Island Press, $563 \mathrm{p}$. 


\section{Appendix G. Methods for Validation and Uncertainty Assessment}

\section{G.1. Validation for the National Assessment}

Within the context of the national assessment methodology, validation is defined as a quantitative evaluation of the quality of the input and (or) output data products upon which the assessment will be based. The validation strategy is designed to achieve two principal objectives: to identify, quantify, and document sources of error that underlie the assessment results; and to guide efforts to increase accuracy through improvements in data collection, model design, sampling design, and other elements of the methodology.

In terms of conducting validation for the assessment, potential errors underlying the assessment results can be attributed either to the input data products that are independent of the models or to model performance. The known accuracy of independent input data products, such as the National LandCover Datasets (NLCD), will be documented by referencing published reports - no new efforts are planned for validation of these existing data products. Instead, the validation strategy is focused on new data products generated from assessment models.

\section{G.1.1. General Approach}

The methods employed in the national assessment involve numerous input and output variables, each of which represents a potential target for validation. The validation strategy described herein is premised on recognition that individual variables are not equally effective as validation targets, and each target must be selected with consideration to its relative importance for the assessment results and the availability and quality of reference data. These considerations led to the selection of 14 variables as both appropriate and feasible targets for validation. The selected target variables and their characteristics (measurement units, spatial and temporal attributes) are listed in table G1. The set consists predominately of end-point data products from the modeling of terrestrial and aquatic systems, but also includes key, intermediate data products (land-use and land-cover change, ecosystem disturbance by fire).

Opportunities for validation fundamentally are constrained by the availability of suitable, existing reference datasets, and resources to support new dataset development and implementation of validation tasks. The key factors that affect the suitability of a reference dataset are its inherent data quality and the correspondence with the spatial and temporal attributes of the target variable. As a general rule, the validation will draw upon the best available (most suitable) existing datasets produced independently of the national assessment activity itself and additional monitoring data as they become available. The reference datasets to be employed for initial validation are listed in table G1. The reference data sources are identified as existing or prospective. The prospective data sources address data gaps or deficiencies and have strong potential to be realized in a timeframe that is sufficiently short to be considered feasible for application in the national assessment.

\section{G.1.2. Sampling Strategy for Validation}

A sampling approach to validation will be constructed to create a practical alternative to the time consuming and expensive option of a full coverage national validation using all potentially available validation data. The sampling approach will focus on a much smaller total area within which validation data can be selected, evaluated for quality, and processed for analyses. The probability sampling design underlying the validation will allow for rigorous inference to validate the full national assessment.

The rationale of the sampling approach is to spatially constrain the collection and processing of validation data. The candidate validation data from all carbon pools will be collected and the spatial co-location of these data will allow for analysis of associations among pools as well as within pools. The collection of validation data will not be restricted to the sample locations. For example, extremely valuable but sparse datasets, such as those available from FLUXNET, will be used in their entirety. Data of known quality that are available across a broad spatial extent (for example, Forest Inventory and Analysis (FIA) and National Resources Inventory (NRI)) also may be used in their entirety for certain validation analyses. The sampling approach primarily is targeted for potential validation data that require thorough scrutiny to establish fitness for use.

The sampling design for validation will be stratified with each of the assessment units serving as a stratum. This will allow validation results to be reported by these assessment units (U.S. Environmental Protection Agency Level II ecoregions, modified from Omernik, 1987). The sampling unit within each ecoregion will be a county, and a sample of counties will be selected within an ecoregion. A further stratification within each region will be constructed using criteria defining a priority of interest. That is, counties exhibiting large model uncertainties, high quantities of land-cover change, or containing rare conditions (for example, estuaries, wetlands, or impoundments) may be sampled with greater probability to increase the sample of validation data appropriate to address key questions. Potential validation data from any carbon pool then would be collected within the selected sample counties. In some cases, the validation data will have originated from a probability sampling design (for example, FIA and NRI reference data), and the desired probability-sampling feature of these validation data will be maintained. In other cases, the validation data will not have a rigorous sampling basis (for example, existing light detection and ranging (LIDAR) coverage), and the representation of the sample will be limited to the area of existing coverage. 

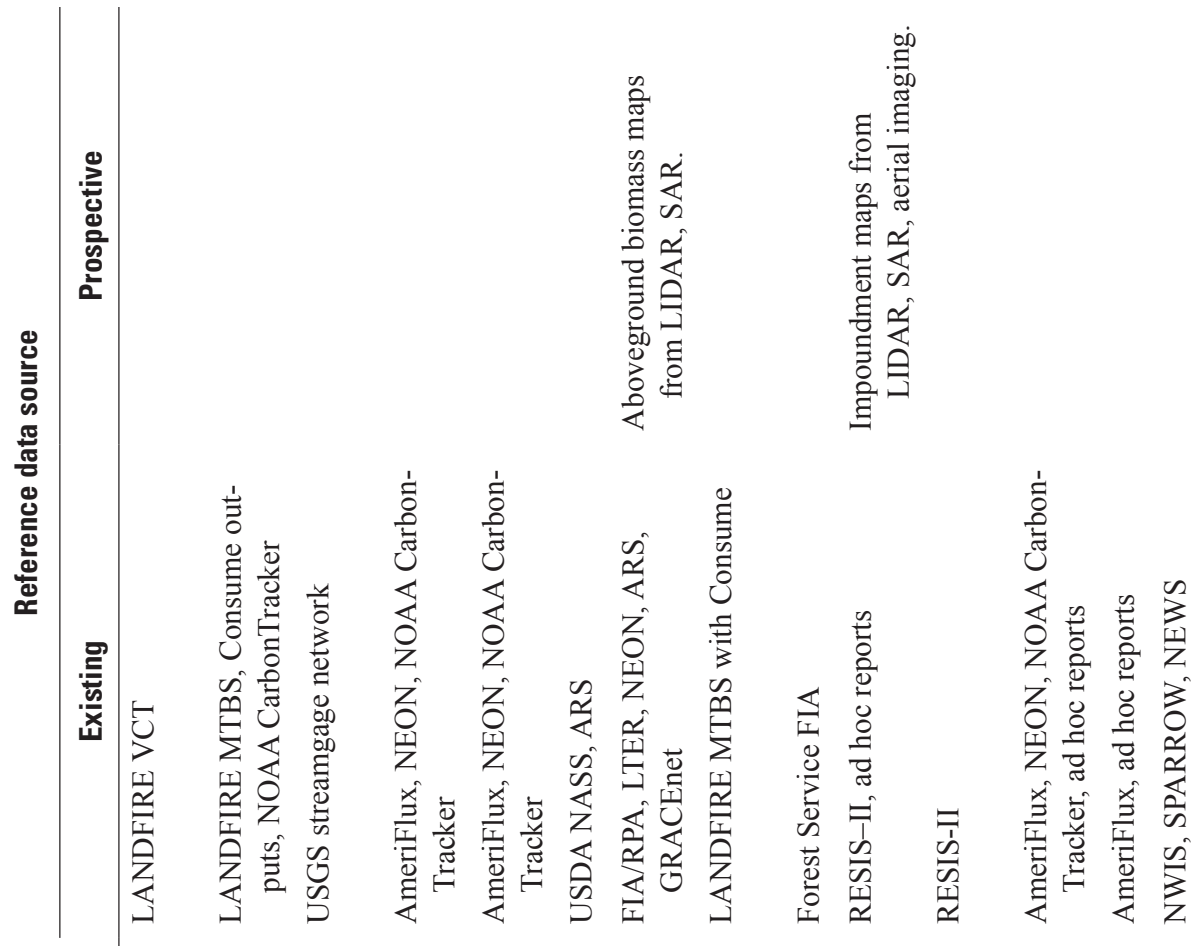

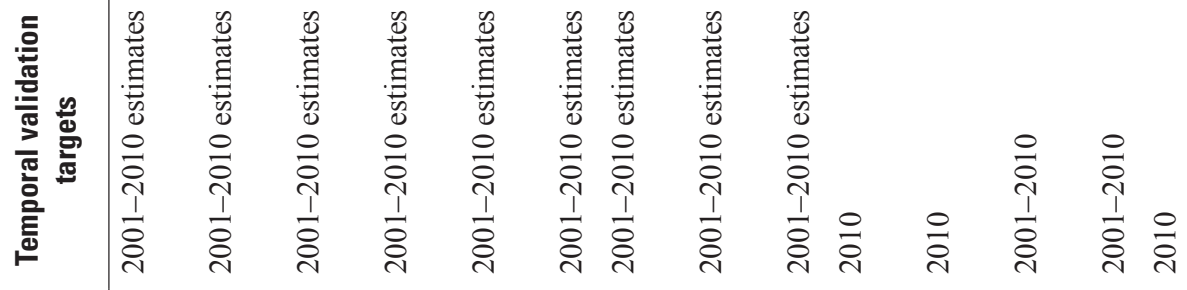

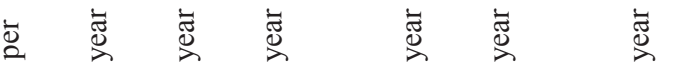

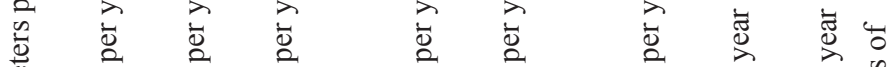

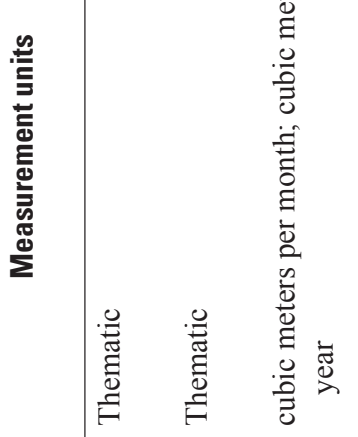

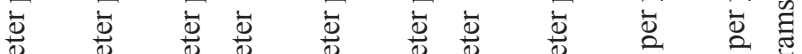

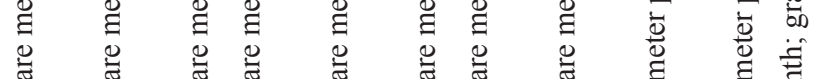

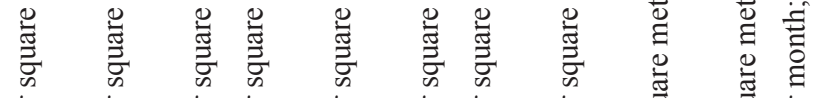

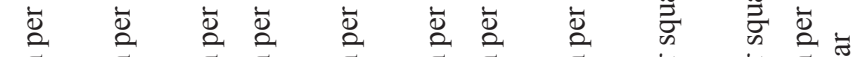

ธี हี

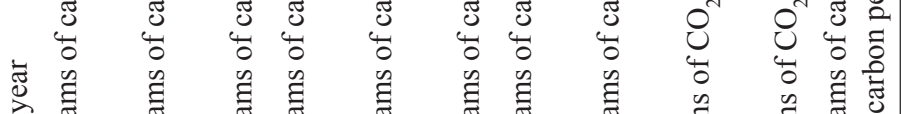

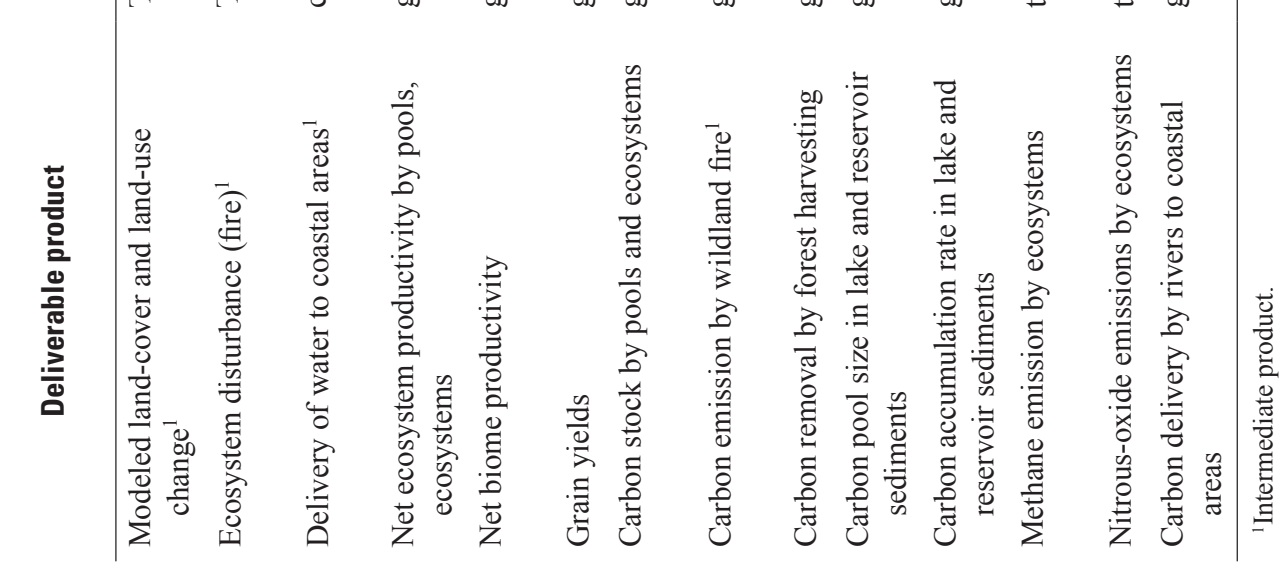


The validation sampling design will be constructed to allow continuous augmentation of the sample to build the validation database as resources become available; however, the sampling design will ensure that defensible estimates can be obtained from the sample at any stage during the procurement of the validation database.

\section{G.1.3. Quality Control and Quality Assurance}

Validation is the cornerstone for quality control and quality assurance (QC/QA) in the national assessment and subsequent monitoring. The validation and modeling teams will coordinate a continual review of information from the validation activity to identify problems or deficiencies in model results. Inconsistencies in model results and reference data that are deemed significant or anomalous in space or time will be flagged for further investigation. The modeling teams will seek to identify and understand the factors that underlie such inconsistencies, define explicit strategies to reduce or resolve them, and whenever feasible, promptly implement those strategies. Thus, the QC/QA process is realized through a dynamic feedback loop in which the validation leads to improved understanding of the methodology performance, which in turn leads to improvements in the methodology design and implementation (data, models, sampling).

\section{G.1.4. Relation Between Validation and Monitoring}

The strategies for validation and monitoring in the national assessment methodology are closely coupled. The data requirements addressed by the monitoring strategy encompass those for validation. Thus, validation and QC/QA will be sustained in parallel with monitoring subsequent to the initial national assessment.

\section{G.1.5. Adaptability of Validation Strategy}

The validation strategy will be adaptable to changes in data availability and information requirements. Individual data products from the assessment (including intermediate ones) may be added or removed from the list of validation targets in response to changes in model performance or specific issues that may arise. Additional or improved datasets will be incorporated as they become available and when deemed effective in support of validation objectives. The potential data sources identified in table $\mathrm{G} 1$ are recognized to have particularly strong potential for improving the reliability of the assessment results. In particular, implementation of LIDARbased techniques for estimating aboveground biomass can be readily achieved through coordination of the growing set of planned and potential LIDAR-related activities of the U.S. Geological Survey (USGS) and other governmental or private organizations. The benefits and opportunities for incorporating
LIDAR-derived biomass data in the national assessment are addressed below.

\section{G.1.6. Addressing Data Gaps and Deficiencies: The Case of LIDAR}

LIDAR technology of various configurations has been well demonstrated in the literature, beginning as early as the 1980s, to be effective in quantifying forest and nonforest structure (Lefsky and others, 2002; Lim and others, 2003). Current (2010) systems collect extremely accurate three-dimensional information at the meter level from airborne systems and at the centimeter level from ground-based systems. The wealth of commercial and research sensors are providing three-dimensional data of vegetation structure at an unprecedented rate; however, there is not yet a capability that can provide the spatial and temporal coverage that space-based optical and radar systems offer. Whereas LIDAR has been used successfully on disparate projects across the country to quantify vegetation structure and biomass (Nelson and others, 2003), there is not a coordinated, concerted effort to collect systematic, standardized LIDAR-derived structural information for a national-scale biomass estimation, validation, and quantification of change.

\section{G.2. Uncertainty Assessment}

Although the validation process evaluates the quality of output products based on comparison with existing data, uncertainty assessment builds on this by estimating confidence bounds on estimates that cannot be validated; for example, projections into the future or estimates for which there are no existing validation data. Assessing complex socioenvironmental systems generally contains some uncertainty resulting from data gaps, modeling capabilities, interactions between ecological phenomena, and our scientific understanding of the mechanics of these complex systems. It is essential for users of the national assessment to be aware of the many uncertainties inherent in methods and assumptions used. It is useful to distinguish between quantifiable uncertainties where some form of statistical information is available and nonquantifiable uncertainties where such information is not available. Because the latter are more difficult to analyze explicitly, the basic strategy will be to treat these uncertainties separately in terms of a two-level approach, based roughly on the Intergovernmental Panel on Climate Change (IPCC) guidelines (Intergovernmental Panel on Climate Change, 2006).

\section{G.2.1. Communication About Unquantifiable Uncertainties}

The first-level uncertainty assessment is designed to incorporate unquantifiable uncertainties (designated as 
"unpredictabilities" by the IPCC) in terms of a representative set of scenarios to be modeled. These scenarios will be constructed to capture the relevant variability range in those factors deemed most important for carbon sequestration (including climate changes and population growth). There is no attempt to assign probabilities to different scenarios or storylines; they simply serve as examples of potential future conditions that might reasonably be expected to occur under different sets of assumptions about future environments and behavior; however, by adopting these different sets of assumptions, it is possible to model the carbon and greenhouse-gas (GHG) outcomes with measurable levels of uncertainty. Thus, these scenarios represent a set of uncertainty bounds on our assumptions about future conditions.

For this assessment, three of the major storylines proposed by the IPCC (Nakicenovic and others, 2000) will be followed, within which alternative management and mitigation scenarios are proposed (section 3.2 of this report). Uncertainty related to scenarios is considered unpredictable; hence, a strategy for communicating such uncertainty is needed. The communication effort will focus on sources of uncertainties and their potential effect.

\section{G.2.2. Uncertainty Sources of Reference Scenarios and Potential Reduction Measures}

Scenarios are useful tools to provide a range of potential future alternatives. This assessment will develop national and regional reference scenarios (section 3.2 of this report) that are consistent with IPCC storylines. The Special Report on Emission Scenarios (SRES) identified six primary sources of uncertainty within the scenarios framework (Nakicenovic and others, 2000). The same sources of uncertainty also are contained in the use of reference as well as alternative management scenarios developed for the assessment. The six sources identified are listed below.

Choice of storylines. - This category describes the uncertainty associated with the characteristics of the storylines and mostly is related to the combination of quantitative assumptions, such as increased population growth and decreased economic growth, used for each storyline.

Authors' interpretation of storylines. - Differences in the translation of qualitative storylines into quantitative drivers can introduce uncertainty into the storylines. Uncertainty may be reduced for harmonized drivers (population, gross domestic product) if parameters for drivers are chosen consistently with the storylines.

Translation of understanding of linkages between driving forces into quantitative inputs for scenario analysis.- Scientific understanding between the linkages of drivers and quantifiable input parameters for models is limited and often results in an inconsistent application across modeling efforts.

Methodological differences. - These uncertainties arise from the modeling structure as well as the underlying uncertainties between drivers and their resulting effects.
Different sources of data.- Source data, such as land-use histories and baseline conditions, often are inconsistent in their availability (both spatially and temporally).

Inherent uncertainties.-Events considered "rare" are not included in modeling efforts because of their inherent unpredictability. Nonetheless, rare events have the ability to affect future trajectories and produce considerably different outcomes.

\section{G.2.3. Uncertainties of Alternative Mitigation Scenarios and Potential Reduction Measures}

As noted above, uncertainties around the IPCC SRES storylines and interpretation of them also apply to the alternative management scenarios for the same storylines. Here, a key uncertainty involves the design and implementation of future policies. Policy will affect eligibility for incentives, and policy instruments will motivate change to various degrees. Because of these concerns, direct prediction of future potential policies is not considered for the methodology to avoid increasing uncertainty. Instead, alternative management scenarios are linked with interpretation of plausible land-management activities. Sources of uncertainty and potential reduction measures relevant to alternative scenario development are given below.

Estimates of rates, suitable lands, and timing.-Uncertainties in the spreadsheet estimates can be improved by broadly incorporating expert knowledge at the regional and subregional level. Improving the spatial footprint by incorporating region-specific expert knowledge in the scenarios should (at least in theory) help improve uncertainties. Additionally, the estimates also can be improved by increasing the thematic precision of the land-use, land-cover, and landmanagement information (for example, managed loblolly pine forest versus softwood forest in the southeast). Increased thematic precision has ramifications for data requirements and availability and increases the cost of the analysis.

The evaluation of management activities for the criteria of cost, ecosystem effects, energy usage, and technological progress. - The uncertainties of a management activity's performance are constrained by the use of relative, rather than absolute, estimates. Again, extensive consultation at the regional and subregional level will help.

Uncertainties related to behavioral responses assumed in developing the scenarios. - Such uncertainties may be captured or reduced by comparing the results of a scenario development with the results of a biogeochemical simulation, and more effectively, by monitoring or repeating assessments that revisit behavioral responses.

\section{G.2.4. Estimation for Quantifiable Uncertainties}

The second type of uncertainty treatment involves the explicit modeling of potential carbon sequestration for different scenarios. From a spatial perspective, the key objective of these models will be to scale down the parameters of each 
scenario (such as overall climatic conditions and population pressures) to grid cells that are small enough to allow explicit carbon-sequestration modeling. At this level of modeling, it is deemed that all uncertainties should be treated in a quantifiable way. It is important to distinguish between "value" uncertainty of input data and model parameters, uncertainty of model structure and mathematical processes, and uncertainty affected by other technical components of the methodology such as land-use and land-cover change and disturbance modeling. All value uncertainties will be treated as probability distributions that can serve as inputs to model simulations. Where statistical data are available, such distributions will be estimated by standard statistical procedures based on IPCC recommendations (Intergovernmental Panel on Climate Change, 2006). Otherwise, such distributions will be elicited through expert judgments (typically triangular distributions based on elicited value ranges and most likely values).

\section{G.2.5. Uncertainty of Input Data and Model Parameters}

Following the IPCC (2006) guidance, uncertainty analysis will focus on random errors associated with input data and model parameters. The following steps will be followed during the assessment to evaluate and report this type of uncertainty.

Input data used for modeling-Such as biophysical data (climate, soil), modeled data (wildland fire, land-use change), and expert-knowledge-related data (mitigation activities) will be assigned an uncertainty range, either expressed as a probability distribution function (PDF) curve or a probability look-up table. Example approaches include the following.

Land-cover data.- Uncertainty in initial land-use and land-cover data may be expressed as a contingency table, which can be used to develop empirical distributions of possible land-cover types for individual pixels, based on misclassification rates (Prisley and Smith, 1987; Fang and others, 2006). These empirical distributions can be translated into initial carbon-density distributions (Quaife and others, 2008).

Forest age and biomass. - Parameters used for initializing the biogeochemical modeling are based on the FIA program. Plot-level data can be aggregated based on location to the level of the Joint Frequency Distribution (JFD) unit used in biogeochemical methods. Aggregation can provide distributions for parameters such as forest age, biomass, species groups, site quality, canopy density, and so on.

Soil parameters.-Using the tables associated with the Soil Survey Geographic (SSURGO) database, it is possible to obtain ranges and distributions for important soil parameters based on the present soil components and their relative frequency.

Using approaches such as those outlined above or an empirical distribution (probability look-up table), similar to the fractile distribution shown in figure G1, input data distributions can be fit to mathematically defined statistical distributions, such as those described by IPCC (2006).

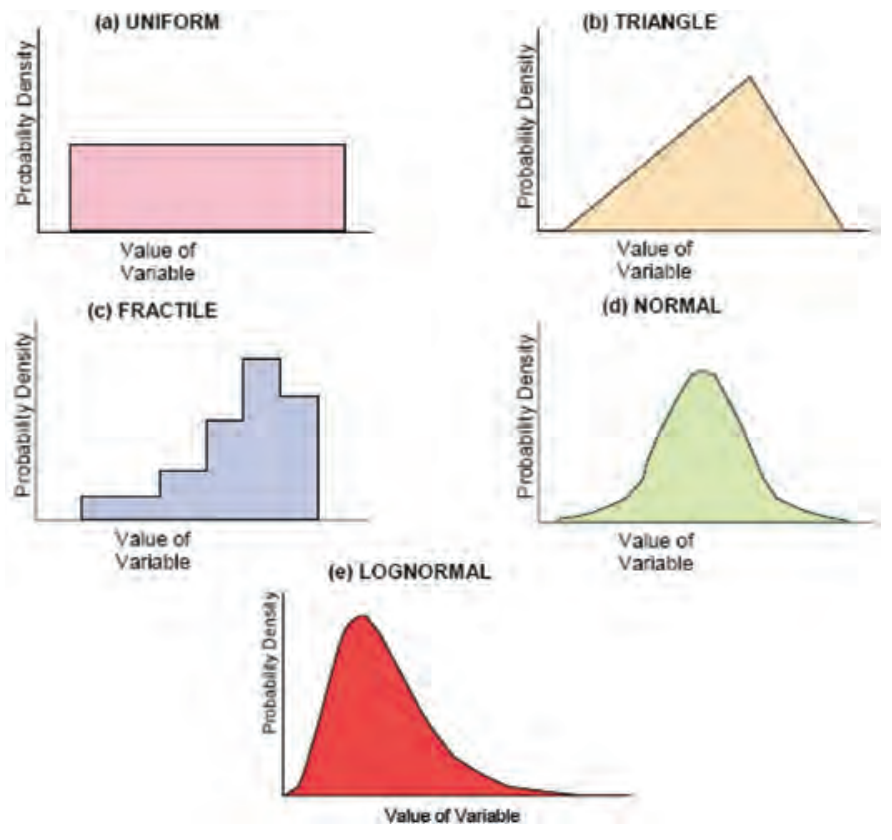

Figure G1. Typical probability distribution (density) function (PDF) curves. From Intergovernmental Panel on Climate Change (2006, p. 3.25), used with permission.

If a model parameter has a PDF, it can be evaluated using error propagation. When a parameter PDF is not available, it is possible to derive one using data-assimilation techniques. Some parameters may be obtained from expert judgment. For example, PDF parameters for remote-sensing-based fire-severity modeling may be obtained from table D2 in appendix D.

As input data are processed by models, additional opportunities arise to evaluate uncertainty. For example, the "forecasting scenarios of land-cover change" model (FORE-SCE) (appendix B of this report) uses logistic regression to predict probabilities of individual types of land-cover transitions. The result is a suite of probability surfaces representing the most likely locations for different types of changes to occur. Landcover changes are then allocated across a landscape. During this process, information on uncertainty is available from fit statistics for the regression models (Hosmer and Lemeshow, 2000), as well as from the probability surfaces (Dendoncker and others, 2008). For example, comparing the probabilities for different types of change at a given pixel can indicate how much more likely one type of change is than another. When probabilities for several types of change are similar, there is greater uncertainty and ambiguity as to the type of change that will occur.

It should be noted, however, that the focus will be on quantifying the variability of end results, which will be carbon storage and GHG fluxes. Uncertainties may arise during many parts of the modeling process that may have little effect on the final outcome. For example, the specific location of land-cover changes across a homogeneous landscape may be extremely uncertain, but also may make a minimal difference in overall long-term carbon sequestration at the reporting-unit level. 


\section{G.2.6. Uncertainty of Model Structure and Component Interactions}

Structural and other conceptual uncertainties will be treated using model-run evaluation and expert judgment. One issue that the assessment should address is which biogeochemical models to use for which ecosystems, and which key carbon-, nutrient-, and water-cycle elements will be treated by the models. This will be determined based on a criteria evaluation process outlined in chapter 3 of this report. Although it is possible to use alternative modeling forms in principle, it is deemed most practical from an operational perspective to consistently use the biogeochemical (BGC) models most recommended by experts. In doing so, it is vital that all assumptions be made explicit to model users. In addition, model sensitivities to key assumptions will be evaluated by simulations, and results made available to users. Both of these analyses can be tracked using a spreadsheet, which will be adopted for the entire assessment to track results and enhance user transparency.

For other conceptual uncertainties - such as the effects of climate change on disturbances and land-use and land-cover changes, or the interactions between the carbon, nutrient, and water cycles - statistical techniques such as the use of the IPCC-recommended PDF and Monte Carlo resampling methods may be used to understand the size of their uncertainties and relations between different ecosystem processes.

Because the General Ensemble Modeling System (GEMS) can encapsulate multiple models, and parameterize and drive these models with the same data, it provides an ideal environment or platform to identify and address issues of uncertainty related to model structure and mathematical representations of biophysical processes. For this assessment, model comparisons will be used within the GEMS structure and with other modeling groups via a national workshop. Additionally, to reduce biases in modeling, the models will be calibrated with in situ data (for example, flux-tower data, FIA data).

\section{G.2.7. Uncertainty Related to Specific Methods}

The assessment is required by the Energy Independence and Security Act (EISA) (U.S. Congress, 2007) to consider ecosystem-controlling processes, such as wildland fire, landuse change, lateral transport, and agricultural practices. The use of explicitly mapped and modeled ecosystem-controlling processes on a national basis for carbon sequestration and GHG fluxes should improve upon uncertainties in assessment results (Running, 2008), but it also is possible that incorporation of such information can introduce new uncertainties into the methodology. Uncertainties related to the ecosystem-controlling processes will be quantified and reported. The basic approach for assessing such uncertainties is related to developing synthesis information and data products in support of formulating mitigation strategies. This approach is discussed in chapter 3 and appendix F of this report.

\section{G.2.8. Increasing User Confidence by Delivering and Comparing Results}

This two-level approach focuses primarily on model inputs and model construction, but from the user's perspective, uncertainties generally are most easily communicated in terms

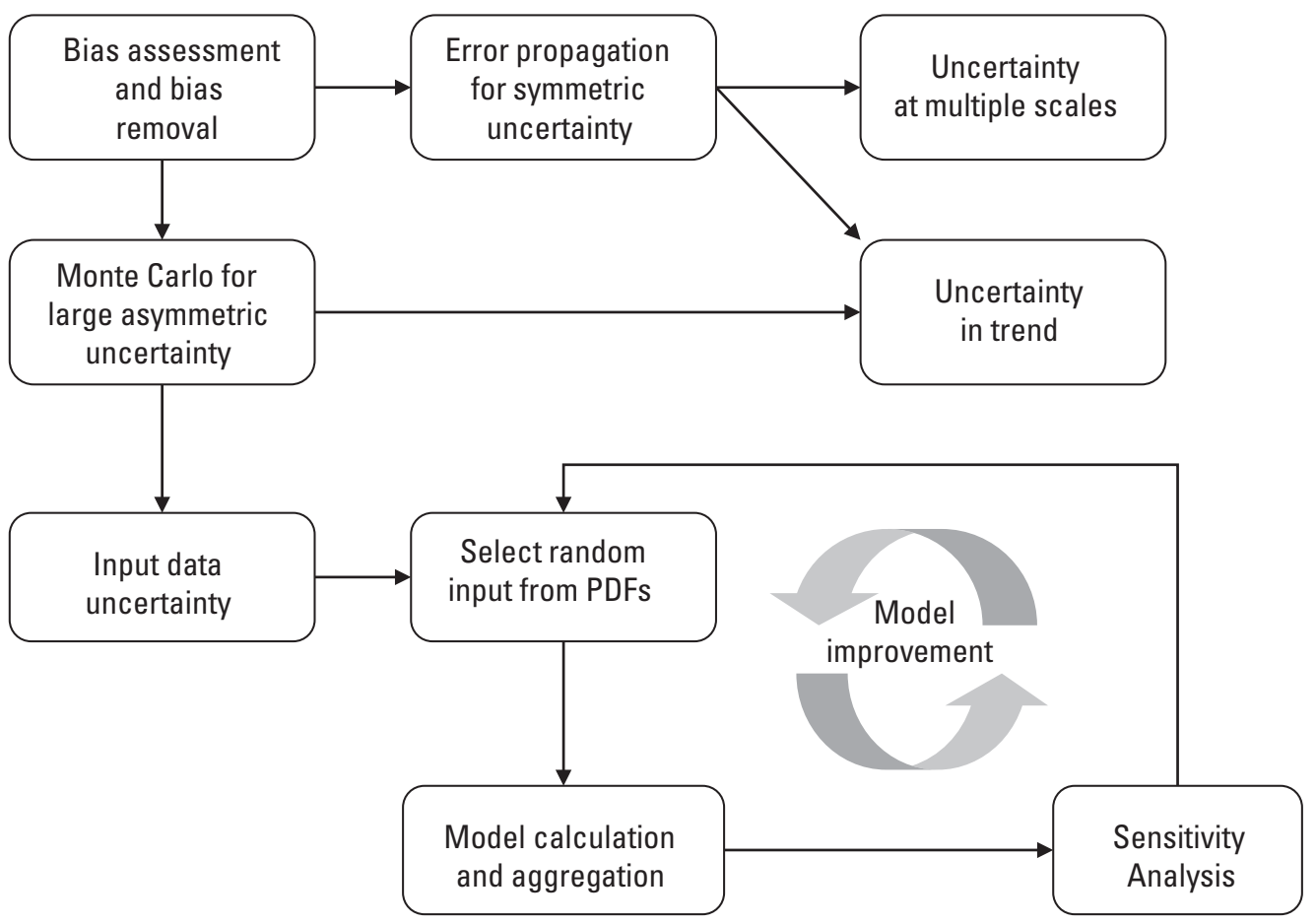

Figure G2. Diagram illustrating the recommended process for combining uncertainty from various sources in a carbonsequestration assessment. PDF, probability distribution function. 
of model outputs. The validation process described previously, when communicated together with uncertainty analysis, will help enhance user confidence about the input scenarios and data or model uncertainties. An important aspect of communicating the results and their uncertainties will be the ability to draw comparisons between the results of this assessment and other published projections of terrestrial carbon sequestration. For example, the validation plan includes a comparison of assessment results with the spatial and temporal distribution of terrestrial sources and sinks of atmospheric carbon estimated by the biosphere and fire modules of the National Oceanic and Atmospheric Administration's (NOAA) CarbonTracker system (table G1; Peters and others, 2007; additional information at URL http://www.esrl.noaa.gov/gmd/ccgg/carbontracker/). Highlighting differences between approaches, assumptions, data sources, and modeling techniques used in this assessment and other published works will help place the assessment results in perspective.

An additional means for communicating results to users is the delivery of assessment products in digital map format. The distribution of the maps through an online user interface (described in appendix I of this report) will allow users to obtain frequency distributions of the deliverables and an opportunity to explore these uncertainties in more depth (albeit, at different scales). It also is possible to provide summary measures of uncertainty based on all scenarios, such as overall value ranges (Intergovernmental Panel on Climate Change, 2006; fig. G2).

\section{G.3. References Cited}

[Reports that are only available online may require a subscription for access.]

Dendoncker, N., Schmit, C., and Rounsevell, M., 2008, Exploring spatial data uncertainties in land-use change scenarios: International Journal of Geographic Information Science, v. 22, no. 9, p. 1013-1030.

Fang, Shoufan, Gertner, George, Wang, Guangxing, and Anderson, Alan, 2006, The impact of misclassification in land use maps in the prediction of landscape dynamics: Landscape Ecology, v. 21, no. 2, p. 233-242, doi:10.1007/ s10980-005-1051-7.

Hosmer, D.W., and Lemeshow, Stanley, 2000, Applied logistic regression ( $2 \mathrm{~d}$ ed.): New York, Wiley, 375 p.

Intergovernmental Panel on Climate Change, 2006, 2006 IPCC guidelines for national greenhouse gas inventories: Hayama, Kanagawa, Japan, Institute for Global Environmental Strategies, 5 v., accessed June 22, 2010, at http://www.ipcc-nggip.iges.or.jp/public/2006gl/index.html.

Lefsky, M.A., Cohen, W.B., Parker, G.G., and Harding, D.J., 2002, Lidar remote sensing for ecosystem studies: BioScience, v. 52, no. 1, p. 19-30.
Lim, Kevin, Treitz, Paul, Wulder, Michael, St-Onge, Benoît, and Flood, Martin, 2003, LiDAR remote sensing of forest structure: Progress in Physical Geography, v. 27, no. 1, p. 88-106, doi:10.1191/0309133303pp360ra.

Nakicenovic, Nebojsa, Alcamo, Joseph, Davis, Gerald, de Vries, Bert, Fenhann, Joergen, Gaffin, Stuart, Gregory, Kenneth, Grübler, Arnulf, Jung, T.Y., Kram, Tom, La Rovere, E.L., Michaelis, Laurie, Mori, Shunsuke, Morita, Tsuneyuki, Pepper, William, Pitcher, Hugh, Price, Lynn, Riahl, Keywan, Roehrl, Alexander, Rogner, H.-H., Sankovski, Alexei, Schlesinger, Michael, Shukla, Priyadarshi, Smith, Steven, Swart, Robert, van Rooyen, Sascha, Victor, Nadejda, and Dadi, Zhou, 2000, Special report on emissions scenarios: Cambridge, Cambridge University Press, Intergovernmental Panel on Climate Change Special Report, 599 p., accessed June 22, 2010, at http:/www.grida.no/publications/other/ ipcc_sr/?src=/climate/ipcc/emission/.

Nelson, Ross, Valenti, M.A., Short, Austin, and Keller, Cherry, 2003, A multiple resource inventory of Delaware using airborne laser data: Bioscience, v. 53, no. 10, p. 981-992, doi:10.1641/0006-3568(2003)053[0981:AMRIOD]2.0.CO;2.

Omernik, J.M., 1987, Ecoregions of the conterminous United States: Annals of the Association of American Geographers, v. 77 , no. 1 , p. $118-125$.

Peters, W., Jacobson, A.R., Sweeney, C., Andrews, A.E., Conway, T.J., Masarie, K., Miller, J.B., Bruhwiler, L.M., Pétron, G., Hirsch, A.I., Worthy, D.E., van der Werf, G.R., Randerson, J.T., Wennberg, P.O., Krol, M.C., and Tans, P.P., 2007, An atmospheric perspective on North American carbon dioxide exchange - CarbonTracker: Proceedings of the National Academy of Sciences, v. 104, no. 48, p. $18,925-18,930$.

Prisley, S.P., and Smith, J.L., 1987, Using classification error matrices to improve the accuracy of weighted land-cover models: Photogrammetric Engineering and Remote Sensing, v. 53, no. 9, p. 1259-1263.

Quaife, T., Quegan, S., Disney, M., Lewis, P., Lomas, M., and Woodward, F.I., 2008, Impact of land cover uncertainties on estimates of biospheric carbon fluxes: Global Biogeochemical Cycles, v. 22, GB 4016, doi:10.1029/2007GB003097.

Running, S.W., 2008, Ecosystem disturbance, carbon, and climate: Science, v. 321, p. 652-653, doi:10.1126/science. 1158736 .

U.S. Congress, 2007, Energy Independence and Security Act-Public Law 110-140: U.S. Congress, 311 p., available at http://frwebgate.access.gpo.gov/ cgi-bin/getdoc.cgi?dbname=110_cong_public_ laws\&docid=f:pub1140.110.pdf. 
This page intentionally left blank. 


\section{Appendix H. Methods for Energy Independence and Security Act Measuring and Monitoring Requirements}

The Energy Independence and Security Act (EISA) (U.S. Congress, 2007) prescribes that the national assessment methodology include a comprehensive strategy for "measuring, monitoring, and quantifying covered greenhouse gas emissions and reductions" from ecosystems - a monitoring plan. Appropriately, the EISA also indicates that the assessment methodology should be used to carry out this mandate. In the context of the EISA and the methodology, therefore, monitoring has two distinct functions. The first is to comprehensively monitor changes in carbon sequestration in and greenhousegas (GHG) flux from ecosystems on a national scale. Monitoring at the national scale involves spatial and temporal extrapolation of data collected at specific locations over broad areas using complex biogeochemical models. The second function of monitoring is more classical: measuring change with time at specific locations. This type of monitoring is used to develop and validate the models used for extrapolation.

\section{H.1. Monitoring Objectives and Scope}

To fulfill the EISA requirement for monitoring, the principal objectives and their respective scopes are as listed below:

- Provide ongoing, systematic quantification of carbon stocks, sequestration, GHG emissions, and related ecosystem properties and processes in the United States for the purpose of evaluating their status and trends.

- Aggregate and update observational monitoring data for the purpose of validation; for example, assessing the accuracy of model results.

- Provide a basis for evaluating the effectiveness of applied mitigation activities and strategies undertaken to reduce GHG emissions from ecosystems and promote carbon sequestration.

It is intended that the monitoring plan for the national assessment be adaptive to changing data resources, improved methodologies, and evolving requirements for data and information, while maintaining consistency, scientific credibility, and transparency. The monitoring plan also is designed to be closely coordinated with the science-implementation strategy of the North American Carbon Program's (Denning, 2005) other U.S. carbon-cycle research activities.

\section{H.2. Definitions}

It is useful to clearly define and differentiate among the three closely related tasks of measuring, quantifying, and monitoring that are prescribed in the EISA. Measurement is defined here as the application of effective tools and techniques for collecting primary data that address data requirements of the national assessment. Two types of measurements are recognized: direct observations (for example, flux towers) and remotely sensed observations (for example, Landsat).

Quantification is defined here as the determination of numerical values for the data products addressed in the national assessment, including current and projected carbon stocks, carbon sequestration, GHG emissions, and reductions in those emissions because of mitigation actions. Quantification in the national assessment is achieved primarily through the spatial aggregation of measurements and model results described in the preceding sections.

Monitoring is defined here as periodic measurement, which enables quantification and validation of GHG fluxes, carbon sequestration, and related ecosystem properties and processes. Another purpose of monitoring is for evaluating the effectiveness of applied mitigation strategies or management actions for increasing carbon sequestration, reducing GHG emission, and related goals.

\section{H.3. Types of Resource Monitoring}

Successful large-scale monitoring programs typically incorporate data collected at several spatiotemporal scales, each providing a unique and valuable contribution to the monitoring effort (fig. H1). Plot- and local-scale research and monitoring provide detailed information not observable at larger scales. Long-term monitoring provides trends information not observable by other means. Spatially extensive surveys provide a means to assess variability across ecosystems and provide estimates of population parameters for regions of interest. Remotely sensed data permit observation and assessment at regional to global scales. These data must be synthe-

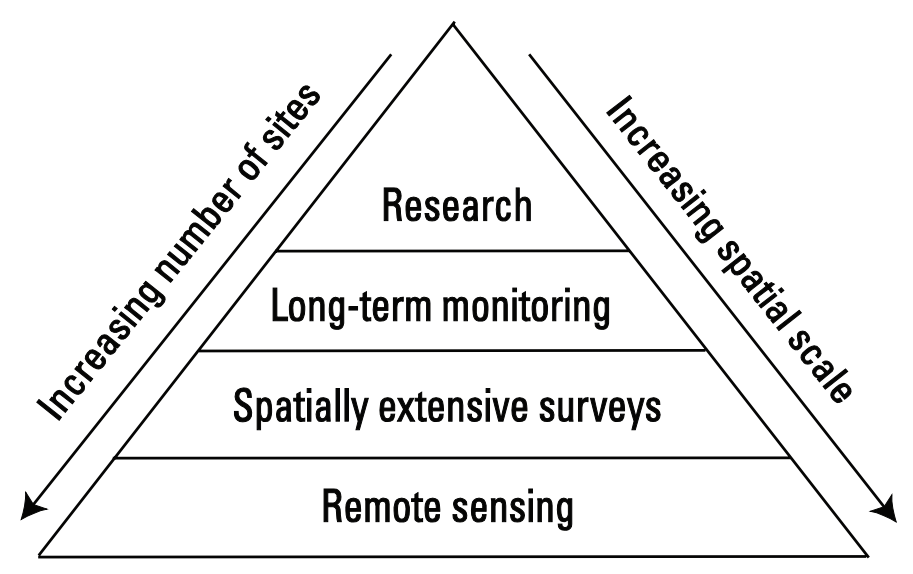

Figure H1. Diagram illustrating types of monitoring needed for assessing carbon sequestration and greenhouse-gas fluxes. 
sized into a form that permits quantification over the spatial extent of the monitored area and analysis of change with time.

Although these four types of monitoring represent different spatial scales, they practically and logistically overlap. At the plot and local scale, intensive data collection provides information that is essential for developing a better understanding of carbon-cycling processes. This understanding enables the continued improvement of ecosystem models used to calculate carbon sequestration and GHG fluxes.

Long-term monitoring performed at fixed, georeferenced locations is needed to assess temporal trends in direct measurements of GHG flux and carbon sequestration, as well as to quantify important variables used in flux calculations, such as streamflow, water quality, soil chemistry, and biomass. These types of data provide the ability to assess and distinguish among short-term, seasonal, annual, interannual, and long-term trends. Some examples of programs that could provide key data for the national assessment include the U.S. Geological Survey's (USGS) streamflow and water-quality monitoring programs, the National Oceanic and Atmospheric Administration (NOAA) climate-monitoring program, and the U.S. Forest Service's (USFS) Forest Inventory and Analysis (FIA) Program; additional examples of datasets and programs that could provide data for the assessment are listed in the individual appendixes of this report.

Spatially extensive surveys provide data at regional to national scales that can be used to evaluate how variables change in response to natural or human-related stressors. A key benefit of spatially extensive surveys is that the data can be merged with spatially continuous national land-use and land-cover data, and statistical relations can be developed that permit model estimates of GHG fluxes at sites not directly measured. Surveys of dissolved and particulate carbon in rivers from headwaters to oceans, for example, can be used to examine how concentrations and fluxes of carbon vary in relation to basin size, elevation, land cover, soil properties, and geology. Multiple-regression models then can be created to estimate carbon concentrations and fluxes at unsampled sites. Survey data also can be used to evaluate GHG sources and carbon sinks; spatial patterns in GHG concentrations in the atmosphere and oceans, for example, can be used to identify site characteristics that are useful for flux or carbon sequestration.

Data collected through remote sensing are essential for regional efforts such as mapping and tracking changes in land cover and land use, assessing biomass, and evaluating ecosystem disturbances caused by storms, insects, or fire. For example, multispectral estimating data from the Landsat satellite program are used by the USGS and the U.S. Department of Agriculture (USDA) to create maps of land cover and land use, such the National Land Cover Database (NLCD); these data are updated periodically and are key inputs to modeling changes in carbon storage and GHG flux with time.

\section{H.4. Existing Monitoring Data Sources}

The bulk of the data needed to comprehensively monitor carbon sequestration and GHG fluxes are available from existing programs and efforts (U.S. Environmental Protection Agency (EPA), 2010). Monitoring data currently are collected by a wide variety of Federal agencies, including the USGS, NOAA, the National Aeronautics and Space Administration (NASA), the USDA, and the EPA, as well as State and local governments and academic and private monitoring and research efforts. Monitoring data produced by others and needed by the national assessment are derived from a broad range of disciplines, including climate, hydrology, biology, and soil science (table H1). The methods described in other appendixes to this report describe in detail the diverse datasets

Table H1. Example monitoring needs with key parameters and primary areas of application in the assessment.

[Abbreviations and acronyms are as follows: $\mathrm{GHG}$, greenhouse gas; $\mathrm{CO}_{2}$, carbon dioxide; $\mathrm{CH}_{4}$, methane; $\mathrm{N}_{2} \mathrm{O}$, nitrous oxide; LULC, land cover and land use; LAI, leaf area index; DOC, dissolved organic carbon; POC, particulate organic carbon; DIC, dissolved inorganic carbon]

\begin{tabular}{lll}
\multicolumn{1}{c}{$\begin{array}{c}\text { Monitoring categories } \\
\text { (examples) }\end{array}$} & \multicolumn{1}{c}{ Key parameters } & Primary application \\
\hline Climate & Precipitation, air temperature, radiation, wind speed & Estimate GHG gas flux and aquatic flux quantification. \\
GHG fluxes & $\mathrm{CO}_{2}, \mathrm{CH}_{4}, \mathrm{~N}_{2} \mathrm{O}$ & Direct GHG flux quantification and validation. \\
Land cover and land use & Percentage change in LULC classes & Estimate carbon inventory. \\
Disturbances & Fire, insect and disease, storms & Estimate carbon inventory and GHG flux quantification. \\
Vegetation properties & Biomass, LAI, fuels & Carbon inventory. \\
Soil properties & Organic and inorganic carbon, soil moisture, & Carbon inventory and GHG flux quantification. \\
& permafrost & \\
Water quality & Sediment, nutrients, DOC, POC, DIC & Aquatic GHG fluxes. \\
Hydrology & Streamflow, groundwater levels & GHG fluxes from terrestrial and aquatic systems. \\
Coastal primary production & Chlorophyll & Carbon burial in coastal systems. \\
Ecosystem services & Timber production, habitat condition & Ecosystem impacts. \\
\hline
\end{tabular}


needed for a national assessment, as well as their identification, assimilation, and evaluation.

There is a strong need for coordination among the existing monitoring programs and data aggregation efforts to support the needs of the national assessment while avoiding a duplication of efforts. Several efforts are proposed or under way to aggregate some of the many types of data needed for regional- and national-scale monitoring into a consistent format, and to make it available for general use, including the science-implementation strategy developed for the North American Carbon Carbon Program (Denning, 2005). In the absence of a robust and comprehensive data aggregation program housed within another Federal program, this role should be incorporated into the national assessment.

Further, it is suggested that the national assessment evaluate new and existing data sources and data aggregation programs for incorporation into the framework in conjunction with each monitoring cycle. This periodic evaluation would ensure that redundant data-collection and data-aggregation efforts are avoided in fulfilling the EISA requirement for monitoring. It also will ensure that all appropriate available data are assimilated, regardless of source.

\section{H.5. Major Monitoring Needs}

\section{H.5.1. Land Use and Land Cover}

Land use and land cover (LULC) continually evolves in response to changes in biophysical and socioeconomic driving forces. Providing updated LULC information through an active and sound LULC monitoring system would allow the evaluation of the effects of a changing landscape on carbon sequestration and GHG fluxes.

Land-use monitoring will focus on updating current (2000-2010) LULC information from the perspective of LULC and land management, using updated data on LULC, socioeconomic drivers, and climate to inform and revise scenarios used in periodically updated LULC forecasts and to provide updated 50-year LULC scenario-based forecasts.

The monitoring protocol will leverage existing USGS and agency LULC initiatives, relying on the Multi-Resolution Land Characteristics Consortium (MRLC), specifically, the NLCD and the proposed MRLC monitoring program (Yang, 2008). The goal of the MRLC monitoring strategy is continual updating and augmentation of a multitemporal (annual to 5-year) and multispatial resolution (1 to 250 meters) NLCD to support national-scale environmental and land-monitoring needs. This information, along with updated socioeconomic trends and climate data, will be used to update potential future scenarios and forecasting LULC.

The task of monitoring carbon sequestration and GHG fluxes from vegetated surfaces can be achieved by using a combination of remote sensing and georeferenced plot data. Relative to other ecosystems, forests have far more extensive data-monitoring programs that are suitable for evaluating carbon sequestration and GHG fluxes. The USFS's FIA Program provides a rich database; new programs tasked with improving flux-tower networks and the characterization of vegetation structure, composition, and biomass are critically needed for urban forests, rangelands, and other nonforested systems, which occupy nearly 325 million hectares in the United States. The National Resources Inventory (NRI), administered by the Natural Resources Conservation Service (NRCS), collects such information, but the resulting data have been practically inaccessible; however, they could represent a valuable asset to the monitoring endeavor. Some systems, such as the USDA's GRACEnet ("greenhouse gas reduction through agricultural carbon enhancement" network) and the American flux network (Ameriflux), offer significant promise for monitoring nonforest landscapes and calibrating biogeochemical models, yet they are hardly extensive enough to provide estimates of carbon-sequestration estimates independently for entire landscapes. Likewise, a paucity of data exists describing belowground carbon dynamics, and this deficiency is a clear impediment to reliable estimates of belowground carbon sequestration through time. A more extensive network focused on belowground carbon dynamics is critical. In addition to field-based networks, more remote-sensing data suitable for characterizing vegetation attributes in nonforest landscapes are needed. Some high-resolution LIDAR sensors are available, which will undoubtedly be used to monitor vegetation conditions such as biomass and carbon stocks. The success of the monitoring of vegetated surfaces depends upon leveraging existing networks while developing new datacollection programs, especially in areas lacking sufficient data or exhibiting uncertainty.

Much of the existing knowledge regarding carbon dynamics on vegetated surfaces, especially in nonforested landscapes, describes carbon flux but not sequestration. Thus, long-term studies focused on carbon sequestration, especially soil organic carbon, are needed. More fundamentally, basic research is needed to enable determination of carbon stocks in shrublands. Tens of millions of hectares of these lands exist in the United States alone and have not yet been sufficiently studied in this capacity. To this end, simple equations linking stand structure and cover to standing biomass (and thus standing carbon), which are suitable for regionally scaling standing carbon estimates when coupled with remote-sensing data (such as LIDAR for stand structure), need to be reformulated. Additionally, relatively simple variables, such as aboveground biomass, remain largely uncharacterized in a regional, operational manner. Finally, interagency data sharing is critical for determining other data gaps. Comprehensive evaluation of data sources and their temporal and spatial coverage and suitability for evaluating GHG and carbon-sequestration dynamics is needed to determine true gaps in data.

\section{H.5.2. Soil Carbon Stocks and Fluxes}

It is suggested that the assessment will include the quantification of soil carbon stocks and fluxes from organic sources 
(for example, soil organic carbon (SOC), whereas only stock estimates will be provided from inorganic soil carbon (SIC) pools). Relative to other pools, soil-carbon observations are spatially and temporally sparse. SOC-flux estimates for grasslands and agricultural systems can be obtained from efforts such as those by Ogle and others (2007), which provides quantification of SOC in support of the EPA's official GHG estimates (U.S. Environmental Protection Agency, 2010). Additionally, the GRACEnet program (Jawson and others, 2005) offers a limited number of soil-carbon measurements in primarily agricultural landscapes. In the forest sector, the FIA program provides the most comprehensive forest soil-carbonmonitoring database available (O'Neill and others, 2005). Agency programs and those at research institutions provide a suitable starting point for assimilating and aggregating SOC measures for monitoring purposes. Despite the paucity of programs offering measures of organic carbon components, those aimed at measuring inorganic components are even less numerous. Globally, SIC storage in arid and semiarid soils is approximately 2 to 10 times larger than SOC storage (Schlesinger, 1982; Eswaran and others, 2000). Annual fluxes from inorganic sources, however, are at least an order of magnitude smaller (U.S. Climate Change Science Program, 2007) than fluxes from organic sources. In addition, estimating fluxes from SIC are more difficult than estimating fluxes from SOC (Emmerich, 2003; Svejcar and others, 2008). Therefore, although SIC stocks will be estimated by using the Soil Survey Geographic Database of the NRCS (SSURGO) and the State Soil Geographic Database of the NRCS (STATSGO; replaced in 2006 by the U.S. General Soil Map (STATSGO2)), no estimates of annual flux from SIC will be considered.

Data describing belowground nutrient cycling and carbon sequestration are sparse. More scientific studies aimed at evaluating biophysical processes occurring in soils are necessary to produce more reliable estimates of GHG flux for the United States. To this end, Follett and others (2010) identified the need for a national soil-carbon measurement and modeling network. Such a system would improve the understanding of soil processes and enable better GHG and carbon-sequestration estimates. In addition, more data are needed that describe the annual flux of carbon from inorganic sources, particularly in arid regions where little is known about the primary drivers and magnitude of this phenomenon.

\section{H.5.3. Aquatic Data}

Monitoring the aquatic processes related to GHG emission and carbon sequestration presents a set of unique challenges. Inland waters store and transport considerable carbon; thus, quantification of inland processes is critical to the understanding of carbon and GHG processes (U.S. Climate Change Science Program, 2007). Rivers in the conterminous United States export an estimated 30 to 40 million metric tons of carbon per year to the oceans in the form of dissolved and particulate organic carbon and inorganic carbon derived from the atmosphere (Pacala and others, 2001). The fate and magnitude of riverine carbon exported to the coast are critical to accurately quantifying regional and national carbon sequestration (Liu and others, 2000; U.S. Climate Change Science Program, 2007). GHG fluxes also may be significant in estuaries and in the coastal ocean (Blair and others, 2004; Dagg and others, 2004; Punshon and Moore, 2004; Biswas and others, 2007). Given the importance in carbon-sequestration processes and GHG production, it is vital to accurately monitor the fluxes and alterations of carbon and GHG in aquatic systems. It is envisioned that the national assessment will use data primarily from existing USGS streamgaging networks and water-quality programs for monitoring in the terrestrial domain (Seitzinger and Mayorga, 2008) and existing NOAA productivitymonitoring efforts for monitoring in the coastal oceans.

To reduce the uncertainty in modeling carbon fluxes to lakes, impoundments, estuaries, and coastal zones, it is essential to continue and expand existing hydrologic monitoring of the Nation's rivers (streamflow and water quality). Sites should include a continuum from headwaters to the ocean, and better temporal coverage is needed for a range of hydrologic conditions. A large fraction of carbon transport occurs during short, intense events, many of which are driven by storms; thus, a combination of automated samplers and continuous, in-stream monitors are required to obtain improved flux estimates. A comprehensive set of constituents should be measured, including carbon, nitrogen, and phosphorus in all their major forms, as well as turbidity, suspended sediment, chlorophyll, temperature, and conductance. These data should be collected at a sufficient number of sites to allow regression model development within the USGS's "spatially referenced regression on watershed" (SPARROW) and Load Estimator (LOADEST) modeling frameworks; this approach will provide the best available estimates of carbon and nutrient fluxes in rivers and to estuaries.

Despite the importance of GHG fluxes from lakes and impoundments in global carbon and GHG budgets, measurements are sparse and uncoordinated, and there is no centralized database. Methane emissions from the outlets of reservoirs may be particularly important, but they cannot be quantified at regional or national scales with currently available (2010) information. A monitoring program is needed to estimate regional and national GHG fluxes from the surfaces of lakes and impoundments and from the outlets of reservoirs.

Estimates of carbon burial in lakes and impoundments have uncertainty because of the sparseness of sedimentationrate and carbon-content data used to parameterize statistical models. Existing reservoir-monitoring programs should be expanded to include lakes and small farm ponds.

\section{H.5.4. Priorities for New Data Collection}

The national assessment will rely on existing interagency programs for input data for the models that will be used to predict changes in carbon storage and GHG fluxes; however, the accuracy of some model predictions will be limited by sparse (or in some cases, nonexistent) datasets that are 
needed to parameterize model equations. New data-collection programs are needed to accurately quantify GHG fluxes and sequestration in various ecosystems, especially in nonforest and nonagricultural, terrestrial environments and aquatic habitats. The most critical data gaps in the availability of monitoring data are described in table H2. It is envisioned that the national assessment will coordinate with existing programs to ensure that these gaps are filled. It should be noted that two types of gaps are identified: gaps where ongoing monitoring is necessary to adequately constrain and calculate fluxes that will likely change under future climate regimes, and gaps where data should be collected for a limited time because insufficient data exist to accurately predict fluxes using parameters collected in current (2010) monitoring programs.

Table H2. Critical data gaps in the monitoring effort and recommended solutions.

[Abbreviations and acronyms are as follows: DOC, dissolved organic carbon; DIC, dissolved inorganic carbon; $\mathrm{NO}_{3}$, nitrate; DON, dissolved organic nitrogen; USGS, U.S. Geological Survey; SPARROW, "spatially referenced regression on watershed attributes" model; GHG, greenhouse gas; $\mathrm{CH}_{4}$, methane; $\mathrm{N}_{2} \mathrm{O}$, nitrous oxide; FLUXNET, flux network; m, meter; LIDAR, light detection and ranging]

\section{Monitoring target} Continuous DOC, DIC, $\mathrm{NO}_{3}$, DON, chlorophyll
suspended sediment concentrations

Temperature, conductivity at USGS surfacewater gaging stations

Small water bodies (primarily farm ponds)

Carbon-burial rates in lakes and impoundments

Groundwater levels and chemistry

GHG flux

Biomass (aboveground and belowground)

Changes in boreal vegetation and soil in Alaska

Ecosystem disturbances
Data gap and possible solutions

New sensors can be used to monitor these constituents' concentrations inexpensively (Downing and others, 2008; Saraceno and others, 2009). Existing data are exclusively from discrete sampling. Recommend installation at key locations, and paired at the river inflow and estuary mouth.

Existing USGS gaging network is largely lacking these data, which are critical for models used to predict dissolved and particulate fluxes of carbon and nutrients in rivers, such as SPARROW.

Sparsely available data suggest that GHG exchange between small water bodies and the atmosphere may dominate flux of $\mathrm{CH}_{4}$ and $\mathrm{N}_{2} \mathrm{O}$ from many landscapes. The distribution of small water bodies needs to be mapped at high resolution (less than $5 \mathrm{~m}$ ), and GHG fluxes need to be measured as a subset of them. This will allow creation of statistical models that can be used to estimate GHG fluxes from small water bodies in a given area.

There are insufficient data to create accurate statistical models for carbon burial in lakes and impoundments across the Nation. Collection and analysis of dated sediment cores from a small subset of lakes and impoundments would greatly improve national carbon-burial-rate estimates.

Fluctuations in groundwater levels drive carbon storage and GHG production in soils, and groundwater chemistry can influence nutrient fluxes in surface water and coastal systems. A national program for monitoring groundwater levels and chemistry is needed in order to accurately model GHG fluxes from soils and to estimate nutrient fluxes to surface water and coastal oceans.

Additional flux data are critically needed from a variety of domains, in particular for $\mathrm{CH}_{4}$ and $\mathrm{N}_{2} \mathrm{O}$. Data are especially needed for impoundments, grasslands, and wetlands nationwide. Existing FLUXNET tower sites should be expanded to include more sites and constituents (for example, $\mathrm{CH}_{4}$ and $\mathrm{N}_{2} \mathrm{O}$ ). Airborne programs should be implemented to characterize spatiotemporal variability in point fluxes.

Biomass monitoring should be expanded, especially in nonforested habitats, where longterm monitoring data are sparse. A combination of LIDAR, radar, and multispectral data might be suitable for this need, but additional research is needed to make these processes operational.

Because of the rapid rate of change in the Alaskan climate, it is critical to quickly develop an interagency, multidisciplinary monitoring program that would include establishment of long-term monitoring, spatial surveys, and remote-sensing capabilities.

New research is needed to enhance national capabilities to detect, map, model, and project defoliation and mortality of forests caused by insect outbreaks and storm damages. A first step toward such national capabilities is a healthy long-term Landsat program, and availability of all Landsat scenes acquired and processed at the highest processing level. 


\section{H.6. References Cited}

[Reports that are only available online may require a subscription for access.]

Biswas, H., Mukhopadhyay, S.K., Sen, S., and Jana, T.K., 2007, Spatial and temporal patterns of methane dynamics in the tropical mangrove dominated estuary, NE coast of Bay of Bengal, India: Journal of Marine Systems, v. 68, no. 1-2, p. 55-64, doiL10.1016/j.marsys.2006.11.001.

Blair, N.E., Leithold, E.L., and Aller, R.C., 2004, From bedrock to burial - The evolution of particulate organic carbon across coupled watershed-continental margin systems: Marine Chemistry, v. 92, no. 1-4, p. 141-156, doi:10.1016/j.marchem.2004.06.023.

Dagg, M., Benner, R., Lohrenz, S.E., and Lawrence, D., 2004, Transformation of dissolved and particulate materials on continental shelves influenced by large rivers-Plume processes: Continental Shelf Research, v. 24, p. 833-858.

Denning, A.S., ed., 2005, Science implementation strategy for the North American carbon program: U.S. Carbon Cycle Science Program, 67 p., accessed June 22, 2010, at http:/www.carboncyclescience.gov/documents/ nacp_sis_2005.pdf.

Downing, B.D., Bergamaschi, B.A., Evans, D.G., and Boss, Emmanuel, 2008, Assessing contribution of DOC from sediments to a drinking-water reservoir using optical profiling: Lake and Reservoir Management, v. 24, no. 4, p. 381-391.

Emmerich, W.E., 2003, Carbon dioxide fluxes in a semiarid environment with high carbonate soils: Agricultural and Forest Meteorology, v. 116, no. 1-2, p. 91-102.

Eswaran, H., Reich, P.F., Kimble, J.M., Beinroth, F.H., Padmanabhan, E., and Moncharoen, P., 2000, Global carbon stocks, in Lal, R., Kimble, J.M., Stewart, B.A., and Eswaran, H., eds., Global climate change and pedogenic carbonates: Boca Raton, Fla., Lewis Publishers, p. 15-25.

Follett, R.F., and Reed, D.A., 2010, Soil carbon sequestration in grazing lands - Societal benefits and policy implications: Rangeland Ecology and Management, v. 63, no. 1, p. 4-15, doi:10.2111/08-225.1.

Jawson, M.D., Shafer, S.R., Franzluebbers, A.J., Parkin, T.B., and Follett, R.F., 2005, GRACEnet-Greenhouse gas reduction through agricultural carbon enhancement network: International Journal of Soil and Tillage Research, v. 83, p. 167-172, doi:10.1016/j.still.2005.02.015.

Liu, J.T., Huang, J.S., Hsu, R.T., and Chyan, J.M., 2000, The coastal depositional system of a small mountainous riverA perspective from grain-size distributions: Marine Geology, v. 165, no. 1-4, p. 63-86.
Ogle, S.M., Breidt, F.J., Easter, Mark, Williams, Steve, and Paustian, Keith, 2007, An empirically based approach for estimating uncertainty associated with modeling carbon sequestration in soils: Ecological Modelling, v. 205, nos. 3-4, p. 453-463, doi:10.1016/j.ecolmodel.2007.03.007.

O’Neill, K.P., Amacher, M.C., and Perry, C.H., 2005, Soils as an indicator of forest health-A guide to the collection, analysis, and interpretation of soil indicator data in the Forest Inventory and Analysis program: U.S. Department of Agriculture, Forest Service, North Central Research Station, General Technical Report NC-25853, 53 p.

Pacala, S.W., Hurtt, G.C., Baker, D., Peylin, P., Houghton, R.A., Birdsey, R.A., Heath, L., Sundquist, E.T., Stallard, R.F., Ciais, P., Moorcroft, P., Caspersen, J.P., Shevliakova, E., Moore, B., Kohlmaier, G., Holland, E., Gloor, M., Harmon, M.E., Fan, S.-M., Sarmiento, J.L., Goodale, C.L., Schimel, D., and Field, C.B., 2001, Consistent land- and atmosphere-based U.S. carbon sink estimates: Science, v. 292, no. 5525, p. 2316-2320, doi:10.1126/science. 1057320 .

Punshon, Stephen, and Moore, R.M., 2004, Nitrous oxide production and consumption in a eutrophic coastal embayment: Marine Chemistry, v. 91, no. 1-4, p. 37-51, doi:10.1016/j. marchem.2004.01.003.

Saraceno, J.F., Pellerin, B.A., Downing, B.D., Boss, Emmanuel, Bachand, P.A.M., and Bergamaschi, B.A., 2009, High-frequency in situ optical measurements during a storm event-Assessing relationships between dissolved organic matter, sediment concentrations, and hydrologic processes: Journal of Geophysical Research, v. 114, G00F09, doi:10.1029/2009JG000989.

Schlesinger, W.H., 1982, Carbon storage in the caliche of arid soils-A case study from Arizona: Soil Science, v. 133, p. 247-255.

Seitzinger, S.P., and Mayorga, Emilio, 2008, Linking watersheds to coastal systems-A global perspective on river inputs of $\mathrm{N}, \mathrm{P}$ and $\mathrm{C}$ : Ocean Carbon and Biogeochemistry News, v. 1, no. 1, p. 8-11, accessed June 22, 2010, at http:/www.us-ocb.org/publications/ OCB_NEWS_APR08.pdf.

Svejcar, Tony, Angell, Raymond, Bradford, J.A., Dugas, William, Emmerich, William, Frank, A.B., Gilmanov, Tagir, Haferkamp, Marshall, Johnson, D.A., Mayeux, Herman, Mielnick, Pat, Morgan, Jack, Saliendra, N.Z., Schuman, G.E., Sims, P.L., and Snyder, Kereith, 2008, Carbon fluxes on North American rangelands: Rangeland Ecology and Management, v. 61, no. 5, p. 465-474.

U.S. Climate Change Science Program, 2007, The first state of the carbon cycle report (SOCCR) - The North Ameri- 
can carbon budget and implications for the global carbon cycle: National Oceanic and Atmospheric Administration, National Climatic Data Center, 242 p., accessed June 22, 2010, at http://www.climatescience.gov/Library/sap/sap2-2/ final-report/default.htm.

U.S. Congress, 2007, Energy Independence and Security Act-Public Law 110-140: U.S. Congress, 311 p., available at http://frwebgate.access.gpo.gov/ cgi-bin/getdoc.cgi?dbname=110_cong_public_ laws\&docid=f:publ140.110.pdf.

U.S. Environmental Protection Agency, 2010, Inventory of U.S. greenhouse gas emissions and sinks-1990-2008:
U.S. Environmental Protection Agency EPA 430-R10-006, accessed June 22, 2010, at http:/www.epa.gov/ climatechange/emissions/usgginv_archive.html.

Yang, Limin, 2008, Development of the United States national land cover database-Experience from 1992 and 2001 implementation, in Silk road for information from imagery, Beijing, China, July 3, 2008-July 11, 2008, The International Archives of the Photogrammetry, Remote Sensing, and Spatial Information Sciences, v. XXXVII, part B4: International Society for Photogrammetry and Remote Sensing, p. 1461-1465, accessed June 22, 2010, at http://www.mrlc.gov/index.php. 
This page intentionally left blank. 


\section{Appendix I. Data Management Technical Plan}

The national assessment of ecological carbon sequestration is based on a number of national capabilities including remote sensing, expert knowledge consultation, national inventory programs, land-use and land-cover maps, and simulation models. A data-processing, -management, and -serving system will be needed to provide the national assessment with data input, data output, information query and dissemination, and data-archive functionalities. The basic functions of the system should include the following:

- Remote-sensing data access

- Database building of expert knowledge of ecosystem processes and mitigation scenarios

- Database building of inventory and other in situ data (not the proprietary data held by national inventory programs such as the Forest Inventory and Analysis Program (FIA) of the U.S. Forest Service and the National Resources Inventory (NRI) of the Natural Resources Conservation Service)

- Climate, soil, and other biophysical data compilation required for the assessment

- Derived data storage, including geospatial data

- Table, chart, and report production

- Metadata production automation to the extent possible

This data-management system will consist of three subsystems: a data-storage subsystem; a data-conversion and integration subsystem; and a management, mapping, and reporting subsystem (fig. I1).

\section{I.1. Data Storage Subsystem}

The data-storage subsystem will be designed to support storage of data types with different spatial and temporal characteristics. Database software and hardware will be selected to provide the capability of handling large data volumes. An existing Sun Fire 4800 server running Oracle's Enterprise Edition Relational Database Management System (RDBMS) and the Environmental Systems Research Institute's (ESRI) Spatial Database Engine (ArcSDE) will be used for the prototype.

Storage of geospatial data and maps will be achieved by using geographic information system (GIS) database techniques. Spatial and nonspatial indexing will be used to enhance the performance on data searching and loading. The data-storage subsystem must be able to hold raster geospatial data, vector geospatial data, tabular data with no geospatial component, and text data.

The data-storage subsystem will be designed to handle the following datasets that will be collected from existing Federal programs:

- Remotely sensed images

- Vegetation, land-cover, land-use, and change maps

- Flux-tower data

- Climate, soil, and biophysical data

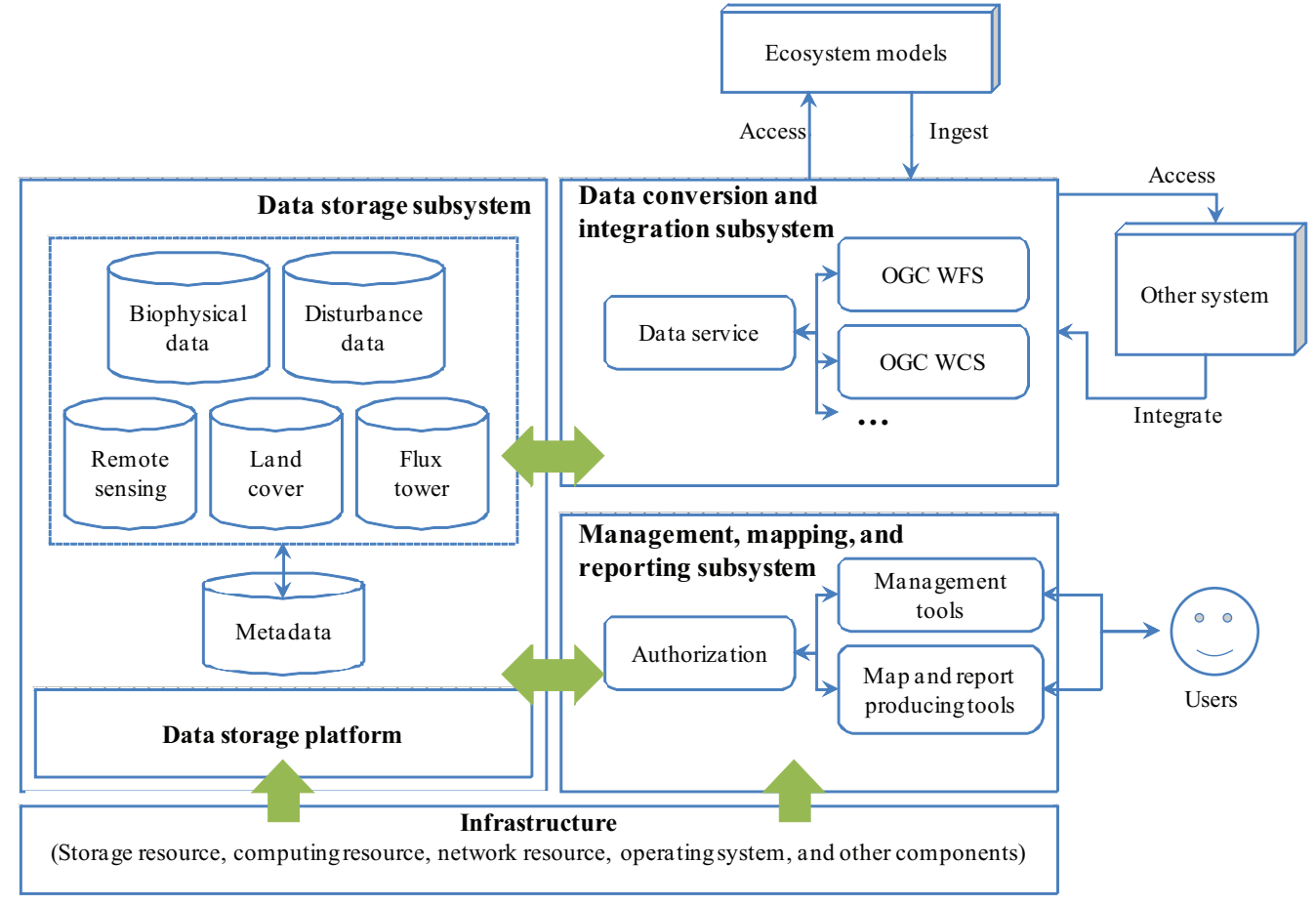

Figure I1. Diagram showing the overview of the proposed data-storage system for the national assessment of ecological carbon sequestration. $\mathrm{OGC}$, Open Geospatial Consortium, Inc.; WCS, Web Coverage Service; WFS, Web Feature Service. 
Other datasets will be added to the data-storage subsystem as they are identified as necessary components during the national carbon development assessment. Small to moderate data volumes will be ingested to demonstrate the abilities of this subsystem to handle complex ecosystem data. This subsystem also will provide storage for derived data from the model simulations, as well as maps and reports.

Metadata will be collected and stored in this subsystem. To ensure compatibility, the metadata structure will be designed following the standards of the International Organization for Standardization (ISO) and the Federal Geographic Data Committee (FGDC). This subsystem will be designed to synchronize metadata with associated data when new data are added or existing data are updated.

The Oracle database engine, coupled with ESRI's ArcSDE, will be able to store effectively all of the datasets and data types specified in this document. This data-storage solution is expandable to petabytes to accommodate the assessment requirements; a data-flow diagram is shown in figure I2.

\section{I.2. Data Conversion and Integration Subsystem}

The data-conversion and processing subsystem will be designed to provide key functions necessary for seamless integration of various datasets, including data and file-format conversion, reprojection, resampling, and other necessary geospatial transformations. These functions also will enable effective dissemination of results and data products derived through the national assessment. This subsystem will provide these functions via Web services for data access, exchange, and processing using standards-based interfaces. Open Geospatial Consortium, Inc. (OGC) and ISO data-service standards, such as Web Feature Service (WFS) and Web Coverage Service (WCS), will be adopted in the interface design. The interactive interfaces will allow other systems or clients to access the data through the Internet. In addition, this subsystem will provide capabilities for ingesting data from other remote data services and processing services. An overview of the processing subsystem is shown in figure I3.
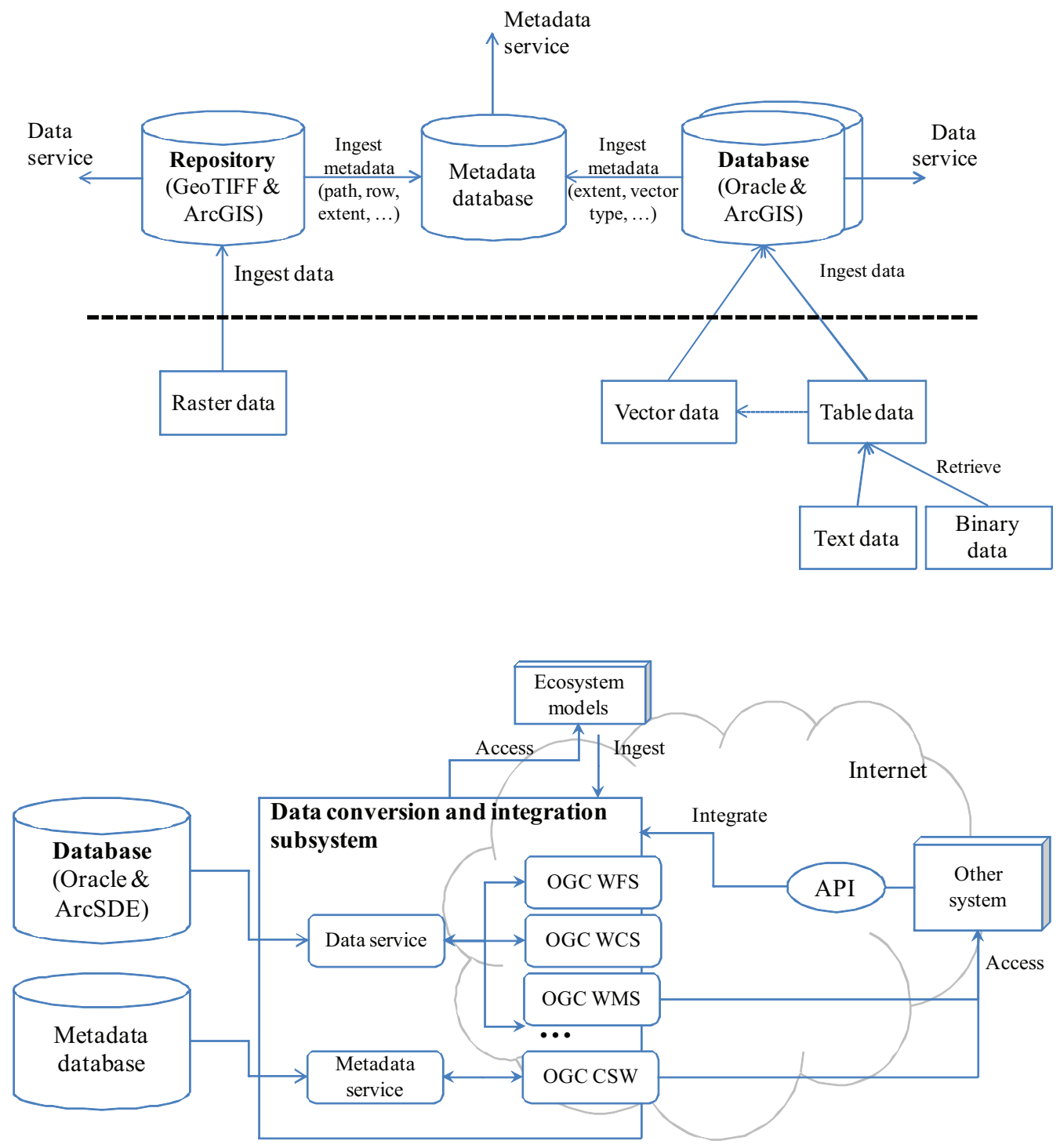

Figure 12. Data-flow diagram for the data-storage subsystem to be used for the national assessment of ecological carbon sequestration.

Figure 13. Diagram showing the data conversion and integration subsystem to be used for the national assessment of ecological carbon sequestration. ArcSDE, ESRI's Spatial Database Engine; OGC, Open Geospatial Consortium, Inc.; WFS, Web Feature Service; WCS, Web Coverage Service; WMS, Web Map Service; CSW, Catalogue Service for the Web; API, application programming interface. 
For the prototype, OGC services will be provided by using ESRI's ArcGIS Server. The ESRI software for OGC services integrates seamlessly with Oracle and ArcSDE, and allows for minimal development efforts.

\section{I.3. Management, Mapping, and Reporting Subsystem}

The managing, mapping, and reporting subsystem will provide Web-based tools for users to view, search, and update their database remotely. User authentication and access control will be implemented to enable secure data access and preserve data integrity. This subsystem also will provide functionalities for producing maps and reports using datasets collected by other Federal partners or produced through the national carbon assessment, or for extracting subsets of these data and saving them into a database or other desired formats. Web-based techniques will be used in developing this subsystem. The ESRI ArcGIS Server software product allows for Web-based delivery and custom tools to be developed.

\section{I.4. System Technology Components}

The planned system architecture is built on technology already in use at the Earth Resources Observation and Science (EROS) Center of the U.S. Geological Survey (USGS). The system architecture will use Oracle's Real Application Clusters (RAC) as its database, running ESRI's ArcSDE management software to add capacity for geospatial data. By leveraging Oracle RAC, the database subsystem can be spread across multiple systems and will provide increased availability and performance while using inexpensive commodity hardware. The diagram in figure I4 shows the anticipated system architecture.

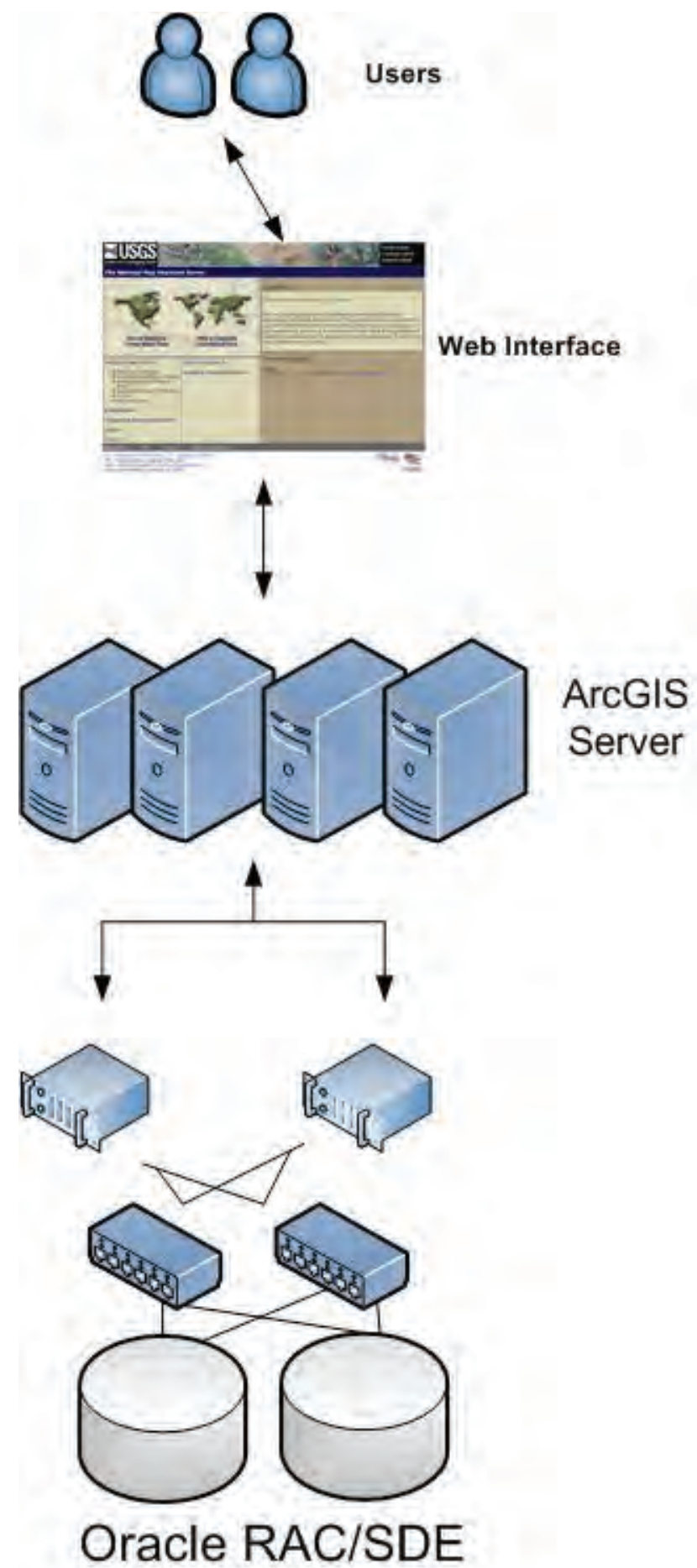

Figure 14. Diagram showing the system architecture to be used for the national assessment of ecological carbon sequestration. RAC, Real Application Clusters of Oracle; SDE, spatial database engine of ESRI. 